Universidade de São Paulo

Escola Politécnica da Universidade de São Paulo

Departamento de Engenharia Mecatrônica E

Sistemas MECÂNICOS

RAFAel Traldi Moura

\title{
Modelagem e ensaios mecânicos de polímeros termoplásticos sob carregamentos quase-estático e dinâmico
}

Tese apresentada à Escola Politécnica da Universidade de São Paulo para obtenção do Título de Doutor em Engenharia Mecânica. 

RAFAel Traldi Moura

\section{Modelagem e ensaios mecânicos de polímeros termoplásticos sob carregamentos quase-estático e dinâmico}

Tese apresentada à Escola Politécnica da Universidade de São Paulo para obtenção do Título de Doutor em Engenharia Mecânica.

Autor: Rafael Traldi Moura

Orientador: Marcilio Alves 
Este exemplar foi revisado e alterado em relação à versão original, sob responsabilidade única do autor e com a anuência de seu orientador.

São Paulo, 15 de janeiro de 2013.

Assinatura do autor

Assinatura do orientador

Moura, Rafael Traldi

Modelagem e ensaios mecânicos de polímeros termoplásticos sob carregamentos quase-estático e dinâmico / R.T. Moura. -- ed.rev. -- São Paulo, 2013.

$327 \mathrm{p}$.

Tese (Doutorado) - Escola Politécnica da Universidade de São Paulo. Departamento de Engenharia Mecatrônica e de Sistemas Mecânicos.

1. Polímeros (Materiais) 2. Termoplásticos 3. Dinâmica dos sólidos (Impacto) I. Universidade de São Paulo. Escola Politécnica. Departamento de Engenharia Mecatrônica e de Sistemas Mecânicos II. t. 
Aos meus pais, que me deram todo o suporte emocional, psicológico e financeiro para que eu alcançasse todos os desejos aspirados e à minha irmã que sempre me ofereceu o seu amparo, sua atenção e seu carinho. 



\section{Agradecimentos}

Aos meus pais, irmã e avós, que me apoiaram em todos os instantes.

À FAPESP, pelo suporte financeiro.

Ao Prof. Dr. Marcilio Alves, por ter me guiado desde o fim da graduação, sempre apoiando e fornecendo a liberdade suficiente para que eu pudesse amadurecer como pesquisador, permitindo desenvolver minhas próprias ideias, mesmo quando a resposta final era de seu conhecimento, apenas para que eu pudesse aprender com meus próprios erros e acertos. Agradeço também pela presença constante, incentivo a sempre melhorar não somente como doutorando, mas como ser humano, pela orientação e em especial pela amizade.

Ao Prof. Dr.Arild Holm Clausen, que me co-orientou no Structural Impact Laboratory (SIMLab), pertencente a Universidade Técnica Norueguesa (NTNU) na cidade de Trondheim, Noruega. Agradeço pelos momentos em que pacientemente ouviu minhas dúvidas, hipóteses e comentários, com extrema humildade e atenção, antes de expor seu conhecimento. Agradeço também pela companhia na sagrada pausa do café, nos passeios, eventos oficiais. Por fim, agradeço muito pela amizade, carinho e respeito a mim demonstrado.

A Paula T. Suehara, pela paciência nos momentos ausentes e pelo incentivo. Agradeço aos momentos de amizade, carinho, consolo, compreensão e alegrias.

Ao Grupo Mecânica dos Sólidos e Impacto em Estruturas, por colocar à disposição seu laboratório, equipamentos e recursos, e aos seus integrantes e ex-integrantes André Saikai Gomes, Caio Fukumori, Esdras, Daniel Martins, Giancarlo Barbosa Micheli, Leonardo Monteiro Mazzariol, Miguel Angel Calli, Rafael Celeghini Santiago, Renato Ramirez Neves, Renato Yamassaki e Roberto Oshiro, pelo constante apoio, amizade e inúmeros momentos de descontração.

Ao Laboratório SIMLab, por ter me disponibilizado toda sua estrutura e por ter me acolhido por oito meses e em especial aos seus integrantes Stephane, Trond e Egil, por terem me apresentado todas as periculosidades dos equipamentos e programas utilizados durante os experimentos. 

"Imagination is more important than knowledge. For knowledge is limited to all we now know and understand, while imagination embraces the entire world, and all there ever will be to know and understand."

Albert Einstein 



\section{Resumo}

Esta tese apresenta, primeiramente, revisões sobre polímeros, métodos para obtenção das propriedades mecânica de um material em uma ampla faixa de taxas de deformação além de uma revisão da mecânica do contínuo não linear, estruturas cinemáticas com divisão multiplicativa do gradiente de deformação e modelos de material para polímeros termoplásticos. Posteriormente são apresentados ensaios experimentais de relaxação, quase-estáticos e dinâmicos de tração e compressão em PEAD e PVC, seguidos por impactos em placas dos mesmos materiais. A grande quantidade de ensaios quase-estáticos objetivaram a análise da sensibilidade à taxa de deformação e ao tipo de carregamento, além do grau de anisotropia. Nestes e nos de relaxação, foi utilizada uma técnica de correlação de imagens digitais, DIC, mensurando as deformações longitudinais e transversais no plano, permitindo a obtenção de curvas tensão real deformação verdadeira em diversas secções transversais de um mesmo corpo de prova. Uma nova metodologia proposta para a obtenção de mapa de correções na análise da dispersão e atenuação na propagação de ondas em barras cilíndricas de materiais viscoelásticos permitiu uma maior confiabilidade e acurácia do comportamento viscoplástico obtido na Barra de Hopkinson dividida de pressão. Por fim, um modelo de material é proposto e tem seus parâmetros calibrados utilizando-se os ensaios de relaxação, quase-estáticos e de propagação de ondas em sua parte viscoelástica e a parte plástica dos ensaios quase-estáticos juntamente com os dados obtidos na Barra de Hopkinson em sua parte viscoplástica, na intenção de verificar seu funcionamento, simulando o impacto nas placas. 



\begin{abstract}
This thesis first presents a review on polymers, methods for measuring the material mechanical properties of in a wide range of strain rates and a review of nonlinear continuum mechanics, kinematic frameworks with multiplicative split of the deformation gradient altogether with models material for thermoplastic polymers. Later, This thesis presents results of relaxation, quasi-static and dynamic tests under tensile and compressive loads for HDPE and PVC, and subsequently impacts on plates of the same materials. The large number of quasi-static tests aimed to analyze the sensitivity to strain rate and to the type of loading, and also the degree of anisotropy. During these later tests and the relaxation ones, it was used a technique called digital image correlation, DIC, measuring the longitudinal and transverse strains in a plane and allowing the attainment of true stress true strain curves in various cross sections of the same specimen. A proposed new methodology for obtaining corrections map for the analysis of the dispersion and attenuation in wave propagation on cylindrical bars made of viscoelastic materials allowed greater reliability and accuracy of the viscoplastic behavior obtained in split Hopkinson bar pressure. Finally, a model material is proposed and has its parameters calibrated using relaxation, quasi-static and wave propagation tests in its viscoelastic part and plastic part of the quasi-static tests with the data obtained in bar Hopkinson in its viscoplastic part, in order to verify its behavior while simulating the plate impact tests.
\end{abstract}





\section{Lista de Figuras}

1.1 Exemplo de uso de termoplástico: (a) e (b) próteses de quadril e (c) prótese de ombro

1.2 Importância do conhecimento da resposta dinâmica dos polímeros: (a) e (b) influência da fadiga em uma prótese de joelho e (c) e (d) ensaios de impacto realizados em automóveis e dispositivos eletrônicos.

1.3 Simulação numérica em elementos finitos de uma prótese de joelho: modelagem em elementos finitos, (a), e resposta mecânica, (b) e (c). Retirados de $[52]$.

1.4 Formação do polímero polietileno a partir do monômero etileno.

1.5 Representação esquemática tridimensional de uma molécula polimérica. Adaptado de [22]

1.6 Tipos de estrutura de um molécula polimérica, no qual cada círculo representa uma mero, sendo (a) linear, (b) ramificada, (c) com ligações cruzadas e (d) em rede. Adaptado de [22]

1.7 Representação da cristalização em materiais semicristalinos. Retirado de $[22]$

1.8 Variação do módulo elástico em função da temperatura, retirado de [61].

1.9 Mecanismos de movimentação possíveis em uma cadeia polimérica, retirado de [61]. 
1.10 Evolução dos modelos de material para polímeros termoplásticos: (a) modelo de Haward e Tackray [41] de 1968 e (b) modelo de Boyce, Socrate e Llana [16].

1.11 Influência de ambas as resistências na tensão verdadeira, retirado de [24].

1.12 Modelo de material para polímeros termoplásticos semiceristalinos: (a) representação esquemática e (b) representação reológica. Retirados de [4]

1.13 Influência da taxa de deformação na temperatura de transição das fases: (a) exemplo do manual da Thermal Analysis DMA-Q800 e (b) influência de ambas as fases na relação entre tensão e taxa de deformação para o PMMA, adaptado [75]

2.1 Dispositivo para medição de deformação e evolução do deslocamento de cada secção transversal em função da posição atual da mesma em um corpo de prova de tração de aço. Medidas realizadas através do método de correlação de imagens digitais.

2.2 Evolução do de cada secção transversal em função da posição atual da mesma em um corpo de prova de tração de PEAD e corpo de prova com extensômetro.

2.3 Resultado de um ensaio de relaxação em PMMA.

2.4 Curva tensão deformação de um polímero termoplástico.

2.5 Resultado de um ensaio de relaxação em PMMA.

2.6 Ilustrações dos mecanismos de deformação nos polímeros e sua consequência no comportamento mecânico, retirados de [61].

2.7 Resultados comparativos de testes DTMA para duas frequências diferentes. 29

2.8 Barra de Hopkinson do laboratório do GMSIE, com configurações de compressão e de tração.

2.9 Esquemática para compreensão da Barra de Hopkinson. 
2.10 Resultado de um ensaio de relaxação em PMMA.

2.11 Design e conjunto montado da máquina TXM do laboratório GMSIE.

2.12 Espaço para visualização do corpo de prova e resultado do teste de um corpo de prova de alumínio.

2.13 Padrões de correlação gerados para análise comparativa de acurácia em deslocamento.

2.14 DIC aço teste $\mathrm{x}$ sim.

2.15 DIC aço teste $\mathrm{x}$ sim.

2.16 Comparação da distribuição da deformação verdadeira axial obtidos na simulação numérica e da análise do ensaio experimental via DIC

2.17 Comparação entre a técnica DIC e Video Traction com 7 marcas. Retirado de $[26]$

3.1 Configuração de referência $\Omega_{0}$, configuração atual $\Omega$, vetor posição inicial $\mathbf{X}$, vetor posição atual $\mathbf{x}$, vetor deslocamento $\mathbf{u}$ e função mapeamento $\mathbf{\Phi}(\mathbf{X}, t)$

3.2 Área infinitesimal $d \Gamma$ em $\Omega$, vetor unitário normal $\mathbf{n}$, força $d \mathbf{f}$

3.3 Decomposição multiplicativa do gradiente de deformações e configurações inicial, intermediária e atual, proposta por Lee em [54]

3.4 Estrutura cinemática utilizado por Boyce, Parks e Argon em [20]

3.5 Modelos com base na mecânica estatística

3.6 Modelo apresentado por Argon.

3.7 Modelo de Haward e Tackray [41]

3.8 Comparações entre resultados experimentais e predições com modelos de material para visco-elasticidade 
4.2 Geometria dos corpos de prova de tração e compressão (medidas em mm). 70

4.3 Entalhe no corpo de prova de tração.

4.4 Leiaute para usinagem dos corpos de prova a partir da placa extrudada de $400 \mathrm{~mm}$ por $600 \mathrm{~mm}$ com $10 \mathrm{~mm}$ de espessura

4.5 Esquemática de testes replicantes para obtenção dos componentes de deformação em ambas as faces

4.6 Corpo de prova fixado em máquina de tração e câmera fotográfica para captura das imagens.

4.7 Arranjo experimental utilizado no laboratório GMSIE.

4.8 Gráfico da força deslocamento dos testes em T1 capturando imagens das superfícies normais a $y$ e $z$

4.9 Evolução da deformação verdadeira no tempo, para um corpo de prova de tração de PEAD, sendo fotografada a superfície $x y$.

4.10 Evolução da deformação verdadeira no tempo, para um corpo de prova de tração de PVC, sendo fotografada a superfície $x y$.

4.11 Evolução temporal da deformação verdadeira de todas as seções transversais do teste e comparação de algumas seções com a seção central do entalhe.

4.12 Evolução da taxa de deformação verdadeira no tempo, para um corpo de prova de tração de PEAD, sendo fotografada a superfície $x y$.

4.13 Evolução da taxa de deformação verdadeira no tempo, para um corpo de prova de tração de PVC, sendo fotografada a superfície $x y$.

4.14 Evolução temporal da deformação verdadeira na seção central do entalhe e algumas outras seções e em todas as seções do teste.

4.15 Evolução temporal da deformação verdadeira na seção central do entalhe (em destaque) e algumas outras seções e em todas as seções do teste. 
4.16 Evolução temporal da tensão verdadeira em todas as seções do teste.

4.17 Curva tensão deformação em algumas seções transversais de ambos os testes replicantes com destaque para a seção transversal do entralhe e compilação para cada instante do teste dos valores de tensão, deformação de cada secção transversal.

4.18 Curvas força deslocamento dos testes replicantes com carregamento em $x$.

4.19 Evolução temporal da deformação verdadeira de todas as seções do teste.

4.20 Evolução temporal da deformação verdadeira de todas as seções do teste.

4.21 Evolução temporal da deformação verdadeira de todas as seções do teste.

4.22 Verificação da anisotropia no plano da placa em ambos os materiais.

4.23 Verificação da anisotropia nas três direções para ambos os materiais.

4.24 Verificação da sensibilidade a taxa de deformação na direção $x$ e $y$ para ambos os materiais em compressão.

4.25 Verificação da sensibilidade a taxa de deformação para ambos os materiais sob tração.

4.26 Curvas de queda de tensão no tempo.

4.27 Fase de carregamento do ensaio de relaxação para o PMMA.

4.28 Relaxação da força durante o ensaio de relaxação para o PMMA.

4.29 Análise comparativa da distribuição de deformações no corpo de prova durante o ensaio de relaxação em PMMA.

4.30 Fase de carregamento do ensaio de relaxação para o PVC.

4.31 Relaxação da força durante o ensaio de relaxação para o PVC.

4.32 Análise comparativa da distribuição de deformações no corpo de prova durante o ensaio de relaxação em PVC.

4.33 Fase de carregamento do ensaio de relaxação para o PEAD. 
4.35 Análise comparativa da distribuição de deformações no corpo de prova durante o ensaio de relaxação em PEAD.

5.1 Dispositivos de Hopkinson e Davies.

5.2 Esquemática para compreensão da Barra de Hopkinson.

5.3 Funcionamento da barra de Hopkinson.

5.4 Exemplo de ondas incidente, refletida e transmitida.

5.5 Gráficos da Velocidade de fase em função do diâmetro e comprimento de onda (a) e em função da frequência (b) para uma barra cilíndrica de aço com 24,8 mm de diâmetro.

5.6 Gráficos da velocidade de grupo em função da frequência (a) e mapa de propagação (b) para uma barra cilíndrica de aço com 24,8 mm de diâmetro.109

5.7 Correlação entre ondas de deformação em (a) e respectivas FFT em (b) e mudança do formato da onda inicial propagada em 0.5 e 1 metros.

5.8 Experimento para verificação da técnica de translação do pulso no domínio da frequência a partir de sua velocidade de fase no mapa de propagação.

5.9 Barra de Hopkinson com barras de PMMA.

5.10 Velocidade de fase e coeficiente de atenuação das barras de PMMA.

5.11 Sensoriamento para medição do coeficiente de Poisson na barra de PMMA. 116

5.12 Coeficiente de poisson complexo para o PMMA.

5.13 Módulos elásticos complexos provindos das teorias uni e tri dimensional para o PMMA.

5.14 Velocidade de fase e atenuação em função da frequência, coeficiente de poisson complexo, sensoriamento e módulos elásticos uni e tridimensional para o PVC.

5.15 Configuração experimental da nova metodologia proposta para obtenção do mapa de correções. 
5.16 Velocidade de fase e coeficiente de atenuação obtidos com os métodos antigo e novo.

5.17 Velocidade medida na extremidade livre e velocidade obtida da propagação teórica com mapa de correções antigo e novo, além da influência de cada tipo de correção, para uma barra de PMMA.

5.18 Deslocamento medido na extremidade livre e obtido da propagação teórica com mapa de correções antigo e novo, além da influência de cada tipo de correção, para uma barra de PMMA.

5.19 Ondas de deformação incidente, refletida e transmitida medidos nos extensômetros em (a) e transladados para as interfaces com o corpo de prova em (b).

5.20 Velocidades (a) e forças (b) nas interfaces com o corpo de prova.

5.21 Variação de tamanho imposta pelo equipamento ao corpo de prova em (a) e curva tensão verdadeira deformação verdadeira do corpo de prova.

6.1 Suposição feita por bergstrom

6.2 Modelos proposto Bergstrom

6.3 Após um carregamento ou descarregamento, a deformação imposta é mantida e a tensão tende a tensão de equilíbrio via processo de relaxação.

6.4 descrição esquemática do modelo proposto por Bergstrom

6.5 descrição esquemática do modelo proposto por Besrgstrom

6.6 Experimentos e simulações na parte elástica do modelo de Bergstrom e Hillbert para o PTFE

6.7 descrição esquemática do modelo proposto por Besrgstrom

6.8 Modelo proposto por Mulliken [75]

6.9 Modelos propostos. 
6.10 Comparação entre predição do modelo de material e resultados do ensaio experimental de relaxação em PMMA.

6.11 Comparação entre predição do modelo de material e resultados do ensaio experimental de propagação de ondas em barras cilíndricas de PMMA.

6.12 Comparação entre predição do modelo de material e resultados do ensaio experimental de relaxação em PVC.

6.13 Comparação entre predição do modelo de material e resultados dos ensaios experimentais quasi-estáticos de compressão e tração em PVC.

6.14 Comparação entre predição do modelo de material e resultados do ensaio experimental de propagação de ondas em barras cilíndricas de PVC.

6.15 Gráfico das tensões verdadeiras uniaxiais em função das taxas de deformação uniaxiais no início da plastificação para o PVC.

6.16 Comparação entre predição do modelo de material e resultados dos ensaios experimentais quasi-estáticos de compressão e tração em PVC.

6.17 Comparação entre predição do modelo de material e resultados do ensaio experimental de relaxação em PEAD.

6.18 Comparação entre predição do modelo de material e resultados dos ensaios experimentais quasi-estáticos de compressão e tração em PEAD.

6.19 Gráfico das tensões verdadeiras uniaxiais em função das taxas de deformação uniaxiais no início da plastificação para o PEAD.

6.20 Comparação entre predição do modelo de material e resultados dos ensaios experimentais quasi-estáticos de compressão e tração em PEAD.

7.1 Geometria da placa em (a), foto do sistema de fixação em (b) e geometria e dimensões do indentador em (c)

7.2 Dispositivo utilizado para realizar os testes de impacto em placas através de um indentador acelerado pneumaticamente. 
7.3 Dispositivo utilizado para realizar os testes carregamento quasi estático em placas com cilindro servo-hidráulico em conjunto com a luz em padrão de franjas projetada.

7.4 Imagens obtidas no carregamento central quasi-estático da placa

7.5 Imagens obtidas no carregamento central quasi-estático da placa

7.6 Imagens obtidas no carregamento central quasi-estático da placa

7.7 Detalhe do raio modelado nos anéis para a não interferência no contato com a placa.

7.8 Simulação numérica da placa, detalhes da geometria e malha.

7.9 Comparação dos resultados da simulação numérica do impacto nas placas com os resultados experimentais.

A.1 Configuração de referência $\Omega_{0}$, configuração atual $\Omega$, vetor posição inicial $\mathbf{X}$, vetor posição atual $\mathbf{x}$, vetor deslocamento $\mathbf{u}$ e função mapeamento $\mathbf{\Phi}(\mathbf{X}, t)$

A.2 Configuração de referência $\Omega_{0}$, configuração atual $\Omega$, vetor posição inicial $\mathbf{X}$, vetor posição atual $\mathbf{x}$, vetor deslocamento $\mathbf{u}$ e função mapeamento $\Phi(\mathbf{X}, t)$

A.3 Área infinitesimal $d \Gamma$ em $\Omega$, vetor unitário normal $\mathbf{n}$, força $d \mathbf{f}$, vetor tração $\mathbf{t} 229$

C.1 Padrões de correlação gerados para análise comparativa de acurácia em deslocamento.

C.2 Padrões de correlação gerados para análise comparativa de acurácia em deslocamento.

C.3 Posições em pixels da garra móvel no tempo

C.4 Padrões de correlação gerados para análise comparativa de acurácia em deslocamento. 
C.5 Superfícies de correlação

C.6 Padrão de correlação na imagem de referência, na posição determinada durante o procedimento DIC na imagem 10 e ambas superfícies de nível de cinza sobrepostas.

C.7 Áreas definidas para realização das integrais em separado

C.8 Coeficiente de correlação calculado para variações de 0.1 pixels

C.9 níveis de cinza sobrepostos e com transparência, relativos a imagem de referência e a imagem 10 na posição de coeficiente de correlação mínimo

C.10 Elemento quadrático na imagem de referência e distorcido em outra imagem com $t>t_{r e f}$

C.11 Sobreposição das figuras de referência em em t=640 s

C.12 Padrões de correlação gerados para análise comparativa de acurácia em deslocamento.

C.13 Diversas definições de deformação e coeficiente de poisson para deformação isovolumétrica, ambos em função do alongamento.

C.14 DIC aço teste x sim.

C.15 DIC aço teste $\mathrm{x}$ sim.

C.16 Comparação da distribuição da deformação verdadeira axial obtidos na simulação numérica e da análise do ensaio experimental via DIC

C.17 DIC aço teste x sim.

C.18 Comparação entre diferentes métodos de medição de deslocamentos através das curvas tensão deformação real

C.19 Comparação entre a técnica DIC e Video Traction com 7 marcas. Retirado de $[26]$

C.20 Comparação entre curva de referência para simulação numérica e resultado da simulação de ensaios de tração 
D.1 Elemento infinitesimal em equilíbrio dinâmico 280

D.2 Elemento diferencial da barra cilíndrica 294

D.3 Posição no tempo demonstrando o movimento descontínuo produzido por repetidas reflexões de um pulso de pressões longitudinais. Movimento de $(A)$ na face da frente da barra, $(B)$ no ponto médio, $(C)$ na face de trás, $(D)$ no centro de gravidade. As deformações foram exageradas no sentido $\begin{array}{ll}\text { de facilitar a compreensão do fenômeno } & 299\end{array}$

$\begin{array}{lll}\text { D.4 Velocidades de diversos tipos de onda } & 310\end{array}$ 



\section{Lista de Tabelas}

1.1 Unidades básicas de repetição de alguns dos polímeros mais utilizados na indústria.

1.2 Dados dos materiais fornecidos pelo fabricante

4.1 Denominação contendo a geometria do corpo de prova e a direção de carregamento.

4.2 Detalhamento do programa experimental para ensaios de compressão

4.3 Detalhamento do programa experimental para ensaios de tração

C.1 Desvio padrão e erro máximo, retirada de [43]

C.2 Posição de um determinado ponto nas 11 primeiras fotos, fundo de escala de um pixel

C.3 Posição de um determinado ponto nas 11 primeiras fotos, fundo de escala de um décimo de pixel

C.4 Posição de um determinado ponto nas 11 primeiras fotos, fundo de escala de um décimo de pixel

C.5 Posição de um determinado ponto nas 11 primeiras fotos, fundo de escala de um décimo de pixel

D.1 Velocidade de barra para alguns materiais 



\section{Lista de Abreviaturas e Siglas}

SHPB

HPB

$\mathrm{BH}$
Split Hopkinson Pressure Bar

Hopkinson Pressure Bar

Barra de Hopkinson 



\section{Lista de Símbolos}

\begin{tabular}{|c|c|c|}
\hline$\sigma$ & tensão mecânica & $\mathrm{Pa}$ \\
\hline$\varepsilon$ & deformação mecânica & adimensional \\
\hline $\mathrm{E}$ & módulo elástico & $\mathrm{Pa}$ \\
\hline$\Delta$ & constante do material para modelo de Johnson Cook & $\mathrm{Pa}$ \\
\hline B & constante do material para modelo de Johnson Cook & $\mathrm{Pa}$ \\
\hline & constante do material para modelo de Johnson Cook & $1 / \mathrm{s}$ \\
\hline$\sigma_{S}$ & $\begin{array}{l}\text { constante do material para modelo de Cowper Sy- } \\
\text { monds }\end{array}$ & $\mathrm{Pa}$ \\
\hline $\mathrm{D}$ & $\begin{array}{l}\text { constante do material para modelo de Cowper Sy- } \\
\text { monds }\end{array}$ & $1 / \mathrm{s}$ \\
\hline & $\begin{array}{l}\text { constante do material para modelo de Cowper Sy- } \\
\text { monds }\end{array}$ & adimensiona \\
\hline $\mathrm{F}$ & Força & $\mathrm{N}$ \\
\hline$\rho$ & densidade & $\mathrm{Kg} / \mathrm{m}^{3}$ \\
\hline & deslocamento em $x$ & $\mathrm{~m}$ \\
\hline & deslocamento em $y$ & $\mathrm{~m}$ \\
\hline & deslocamento em $z$ & $\mathrm{~m}$ \\
\hline & constante de Lamé & $\mathrm{Pa}$ \\
\hline 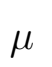 & constante de Lamé & $\mathrm{Pa}$ \\
\hline & coeficiente de Poisson & $\mathrm{Pa}$ \\
\hline & módulo volumétrico & $\mathrm{Pa}$ \\
\hline
\end{tabular}




\begin{tabular}{|c|c|c|}
\hline$\Delta$ & dilatação & adimensional \\
\hline$V_{\text {long }}$ & velocidade de onda longitudinal & $\mathrm{m} / \mathrm{s}$ \\
\hline$V_{\text {shear }}$ & velocidade de onda de cisalhamento & $\mathrm{m} / \mathrm{s}$ \\
\hline$\phi$ & função potencial & $\mathrm{m}^{2}$ \\
\hline$\varphi$ & função potencial & $\mathrm{m}^{2}$ \\
\hline $\mathrm{p}$ & velocidade angular da onda & $\mathrm{rad} / \mathrm{s}$ \\
\hline $\mathrm{c}$ & velocidade da onda & $\mathrm{m} / \mathrm{s}$ \\
\hline $\mathrm{d}$ & frequência & $\mathrm{Hz}$ \\
\hline$\Lambda$ & comprimento de onda & $\mathrm{m}$ \\
\hline f & número de onda & $\mathrm{rad} / \mathrm{m}$ \\
\hline$V_{\text {Rayleigh }}$ & velocidade de onda de Rayleigh & $\mathrm{rad} / \mathrm{s}$ \\
\hline$V_{0}$ & velocidade unidirecional de propagação de onda & $\mathrm{m} / \mathrm{s}$ \\
\hline$V_{f}$ & velocidade de fase & $\mathrm{m} / \mathrm{s}$ \\
\hline$V_{g}$ & velocidade de grupo & $\mathrm{m} / \mathrm{s}$ \\
\hline$u_{r}$ & deslocamento no eixo $r$ em coordenadas cilíndricas & $\mathrm{m}$ \\
\hline$u_{\theta}$ & deslocamento no eixo $\theta$ em coordenadas cilíndricas & $\mathrm{m}$ \\
\hline$u_{z}$ & deslocamento no eixo $z$ em coordenadas cilíndricas & $\mathrm{m}$ \\
\hline$\gamma$ & numero de onda & $\mathrm{rad} / \mathrm{m}$ \\
\hline$J$ & função de Bessel & adimensional \\
\hline$F(\omega)$ & transformada de Fourier & adimensional \\
\hline$F_{n}$ & transformada discreta de Fourier & adimensional \\
\hline$V$ & voltagem & dimensional \\
\hline$\varepsilon_{i}(t)$ & $\begin{array}{l}\text { Onda de deformação no tempo na barra de entrada } \\
\text { gerada antes do pulso atingir o corpo de prova }\end{array}$ & adimensional \\
\hline$\varepsilon_{r}(t)$ & $\begin{array}{l}\text { Onda de deformação no tempo na barra de entrada } \\
\text { gerada depois do pulso atingir o corpo de prova }\end{array}$ & adimensional \\
\hline$\varepsilon_{t}(t)$ & $\begin{array}{l}\text { Onda de deformação no tempo na barra de saída ge- } \\
\text { rada depois do pulso atingir o corpo de prova }\end{array}$ & adimensional \\
\hline
\end{tabular}




\section{Sumário}

Resumo

Abstract $\quad$ iii

$\begin{array}{ll}\text { Lista de Figuras } & \text { XV }\end{array}$

Lista de Tabelas $\quad$ xvii

Lista de Abreviaturas e Siglas $\quad$ xix

Lista de Símbolos $\quad$ xxi

1 Introdução 1

1.1 Objetivos e motivação 1

1.2 Polímeros 5

$\begin{array}{lll}\text { 1.2.1 Forma e estrutura molecular } & 7\end{array}$

1.2.2 Cristalinidade 8

1.2.3 Influência dos movimentos moleculares na resistência mecânica 9

$\begin{array}{ll}\text { 1.2.4 Polímeros escolhidos } & 10\end{array}$

$\begin{array}{lll}1.3 & \text { Simulação numérica } & 12\end{array}$

$\begin{array}{lll}\text { 1.3.1 Modelos de material } & 13\end{array}$

1.4 Estrutura da tese 16

2 Revisão de ensaios experimentais e do comportamento mecânico dos polímeros $\quad 19$

$\begin{array}{lll}2.1 \text { Introdução } & 19\end{array}$

2.2 Comportamento mecânico e ensaios experimentais 24

2.2.1 Baixas taxas de deformação: de $10^{-5} \mathrm{~s}^{-1}$ a $10^{-1} \mathrm{~s}^{-1} \quad 25$

2.2.2 Altas taxas de deformação: de $10^{2} \mathrm{~s}^{-1}$ a $10^{4} \mathrm{~s}^{-1} \quad 29$

2.2.3 Baixíssimas taxas de deformação: de $0 \mathrm{~s}^{-1}$ a $10^{-5} \mathrm{~s}^{-1} \quad 31$

2.2.4 Médias taxas de deformação: de $10^{-1} \mathrm{~s}^{-1}$ a $10^{2} \mathrm{~s}^{-1} \quad 32$

2.3 DIC 34

2.3.1 Introdução 34 
2.3.2 Comparação com outros métodos de medição por um exemplo em material metálico

3 Revisão de mecânica dos sólidos e modelos constitutivos 43

3.1 Introdução 43

3.2 Preliminares 44

3.3 Estrutura cinemática 50

3.3.1 Estrutura cinemática hipo-elastoplástica $\quad 51$

3.3.2 Estrutura cinemática hiper-elastoplástica 53

$\begin{array}{ll}3.4 & \text { Relações constitutivas }\end{array}$

3.5 Funções de escoamento plástico $\quad 61$

3.6 Funções de escoamento viscoso 64

4 Experimentos mecânicos a baixas taxas de deformação $\quad 67$

$\begin{array}{lll}4.1 & \text { Introdução } & 67\end{array}$

$\begin{array}{lll}4.1 .1 & \text { Materiais } & 68\end{array}$

$\begin{array}{lll}\text { 4.1.2 Corpos de prova } & 69\end{array}$

$\begin{array}{lll}\text { 4.1.3 Procedimento experimental } & 71\end{array}$

4.2 Análise dos resultados experimentais $\quad 75$

4.2.1 Análise de um teste de tração de PEAD e PVC 75

4.2.2 Análise de um teste de compressão de PEAD e PVC 85

$\begin{array}{lll}4.2 .3 & \text { Anisotropia } & 87\end{array}$

4.2.4 Sensibilidade à taxa de deformação $\quad 89$

$\begin{array}{lll}4.3 & \text { Ensaios experimentais de relaxação } & 91\end{array}$

$\begin{array}{lll}4.3 .1 & \text { PMMA } & 92\end{array}$

$\begin{array}{lll}\text { 4.3.2 PVC } & 95\end{array}$

$\begin{array}{lll}4.3 .3 & \text { PEAD } & 96\end{array}$

5 Experimentos mecânicos a altas taxas de deformação $\quad 99$

$\begin{array}{llr}5.1 & \text { Introdução } & 99\end{array}$

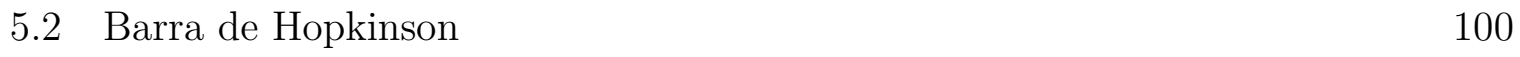

5.2.1 Histórico da Barra de Hopkinson 100

$\begin{array}{lll}5.2 .2 & \text { Modelagem matemática } & 102\end{array}$

5.3 Propagação de ondas tridimensionais elásticas 106

5.4 Influência dos componentes de alta frequência 109

5.5 Propagação de ondas unidimensionais viscoelásticas 111

5.5.1 propagação de ondas tridimensionais viscoelásticas 115

5.6 Nova calibração e influência nos resultados 119

$\begin{array}{lll}5.7 & \text { Resultados experimentais } & 123\end{array}$ 
6 Modelo constitutivo proposto

$\begin{array}{lll}6.1 \text { Introdução } & 127\end{array}$

$\begin{array}{lll}6.2 & \text { Viscoelasticidade } & 130\end{array}$

$\begin{array}{lll}\text { 6.2.1 Bergstrom-Boyce } & 130\end{array}$

$\begin{array}{lll}\text { 6.2.2 } & \text { Bergstrom-Hilbert } & 133\end{array}$

6.2.3 Termoplástico semicristalino - Bergstrom-Bischoff 136

$\begin{array}{lll}6.3 & \text { Viscoplasticidade } & 138\end{array}$

$\begin{array}{lll}\text { 6.3.1 Mulliken-Boyce } & 138\end{array}$

6.4 Modelo de material proposto e implementação numérica 142

$\begin{array}{lll}6.4 .1 & \text { programas } & 142\end{array}$

$\begin{array}{ll}\text { 6.4.2 estrutura cinemáticas } & 144\end{array}$

6.4.3 Relações hiperelásticas, leis de escoamento plástico e viscoso e as de evolução 144

6.4.4 Atualização da tensão - algoritmo de integração do modelo de material em um passo de tempo 149

$\begin{array}{ll}\text { 6.4.5 variáveis históricas } & 164\end{array}$

$\begin{array}{lll}\text { 6.4.6 Modelos finais e UMATS } & 165\end{array}$

6.5 calibração dos parâmetros 174

7 Experimentos em componentes $\quad 183$

$\begin{array}{lll}7.1 & \text { Introdução } & 183\end{array}$

$\begin{array}{lll}7.1 .1 & \text { programa e configurações experimentais } & 184\end{array}$

7.2 Medição do campo de deslocamentos verticais 186

$\begin{array}{lll}7.3 & \text { Resultados experimentais } & 188\end{array}$

$\begin{array}{lll}7.4 & \text { Simulação Numérica } & 190\end{array}$

8 Discussões e Conclusões $\quad 193$

$\begin{array}{ll}\text { Referências Bibliográficas } & 208\end{array}$

A Mecânica dos Sólidos não Linear $\quad 211$

A.1 Definições de mecânica dos sólidos não linear e movimento de corpo rígido 211

$\begin{array}{ll}\text { A.1.1 definições } & 211\end{array}$

A.1.2 Coordenadas Euleriana e Lagrangiana e cinemática 211

$\begin{array}{ll}\text { A.1.3 Deslocamento, velocidade e aceleração } & 212\end{array}$

A.1.4 Movimento de corpo rígido 213

A.2 Tensores de deformação 215

A.2.1 Gradiente de deformações 216

A.2.2 tensor de deformação direito de Cauchy-Green 217

A.2.3 tensor de deformação esquerdo de Cauchy-Green 217

A.2.4 Tensor de deformação de Green-Lagrange 218 
A.2.5 Tensor de deformação de Eulerian-Almansi 219

$\begin{array}{lll}\text { A.2.6 Decomposição polar } & 220\end{array}$

A.3 Tensores de taxa de deformação 225

A.3.1 Gradiente de velocidades 225

A.3.2 Tensor de taxa de deformação e tensor spin 225

A.3.3 Tensor de taxa de deformação de Green-Lagrange 227

$\begin{array}{ll}\text { A.3.4 Taxa de deformação infinitesimal } & 227\end{array}$

$\begin{array}{lll}\text { A.3.5 Taxa de variação de volume } & 228\end{array}$

A.4 Tensores de tensão 228

A.4.1 Tensor de tensões de Cauchy (ou verdadeiro) 229

A.4.2 Tensor de tensões nominal 230

A.4.3 Tensor de tensões de Kirchhoff 230

A.4.4 Segundo tensor de tensões de Piola-Kirchhoff 231

A.4.5 Tensor de tensões para deformações infinitesimais 231

A.4.6 Tensões principais e direções principais 231

A.4.7 Tensões hidrostática, deviatórica e equivalente de von Misses 232

A.5 Taxas de tensão objetivas 233

A.5.1 Taxa de Jaumann 234

A.5.2 Taxa de Truesdell 234

A.5.3 Taxa de Green-Naghdi 235

$\begin{array}{lll}\text { A.5.4 Taxa de convecção } & 235\end{array}$

B Equações de Conservação $\quad 236$

B.1 Introdução 236

B.2 Teorema de Gauss 236

B.3 Derivada material no tempo de um integral e teorema de transporte de $\begin{array}{ll}\text { Reynold's } & 237\end{array}$

B.4 Conservação de massa 238

B.5 Conservação de momento linear 239

B.6 Conservação de momento angular 241

B.7 Conservação de energia 242

$\begin{array}{lll}\text { C DIC - Correlação de imagens digitais } & 247\end{array}$

$\begin{array}{ll}\text { C.0.1 introdução } & 247\end{array}$

C.0.2 marcação da superfície e relação espaço físico por pixel 248

$\begin{array}{lll}\text { C.0.3 equacionamento } & 250\end{array}$

$\begin{array}{ll}\text { C.0.4 exemplo em material metálico } & 271\end{array}$

C.0.5 comparação com outros métodos de medição 273

C.0.6 Comportamento do material e influência geométrica 276 
$\begin{array}{lr}\text { D Teoria de Ondas } & 278\end{array}$

D.1 Ondas elásticas em meios infinitos 278

$\begin{array}{lll}\text { D.1.1 Tipos de ondas elásticas } & 278\end{array}$

$\begin{array}{lll}\text { D.1.2 Equações de equilíbrio } & 279\end{array}$

D.1.3 Lei de Hooke generalizada 281

D.1.4 Propagação de ondas elásticas no contínuo 283

$\begin{array}{lll}\text { D.1.5 Velocidade de ondas longitudinais } & 285\end{array}$

D.1.6 Velocidade de ondas de cisalhamento 286

D.1.7 Considerações sobre velocidades de ondas longitudinal e de cisalhamento 287

$\begin{array}{ll}\text { D.1.8 Ondas de Rayleigh } & 288\end{array}$

D.2 Ondas elásticas em meios finitos 293

D.2.1 Ondas longitudinais em barras cilíndricas finas 293

D.2.2 Características da propagação de ondas 295

$\begin{array}{lll}\text { D.3 Forma vetorial das equações de onda } & 299\end{array}$

D.4 Mudando para sistemas de coordenadas curvos 301

D.5 Equações de movimento em coordenadas cilíndricas 302

D.6 Equações de Pocchammer-Chree para barras cilíndricas 303

D.6.1 Equações de Pocchammer-Chree para ondas longitudinais em cilindros 304

D.7 Comparação entre velocidades dos tipos de onda 310

E Programas em Fortran e Matlab $\quad 311$

E.1 Programas em Fortran 311

$\begin{array}{ll}\text { E.1.1 dyn21rtm_operacoes.F } & 311\end{array}$

E.2 Programas em Matlab 313

E.2.1 operações 313

E.2.2 Relações hiperelásticas, leis de escoamento plástico e viscoso e as $\begin{array}{ll}\text { de evolução } & 316\end{array}$

$\begin{array}{lll}\text { E.2.3 Fase } \alpha & 317\end{array}$

$\begin{array}{lll}\text { E.2.4 Fase } \beta & 319\end{array}$

$\begin{array}{lll}\text { E.2.5 Fase semi-cristalina } & 320\end{array}$

E.2.6 Resistência entrópica 321

E.2.7 Atualizando taxa de temperatura e taxa de deformação termoplástico321

E.2.8 Variáveis históricas 322

E.2.9 Modelos de material $\quad 322$

$\begin{array}{ll}\text { E.2.10 UMATS } & 324\end{array}$ 



\section{Capítulo 1}

\section{Introdução}

\subsection{Objetivos e motivação}

Esta tese objetiva investigar o comportamento de polímeros sujeitos a solicitações de impacto.

Os polímeros foram primeiramente produzidos a partir de materiais orgânicos naturais, de origem vegetal ou animal. Temos como exemplo a celulose que era modificada por reações química em acetato de celulose, utilizado na produção de filmes fotográficos, embalagens e fibras têxteis. O primeiro polímero sintético foi o termoset fenolformoldeido em 1906. A primeira grande produção polimérica ocorreu em conjunto com a segunda guerra mundial, por meio da borracha. Desde então a utilização dos polímeros na indústria tem sido crescente, alcançando a produção de aproximadamente 47 milhões de toneladas de resinas poliméricas em 2010 (American Chemistry Council) e, há mais de 20 anos, tendo seu volume anual produzido superado o volume somado de todos os metais $([21])$.

A escolha do uso deste tipo de material pode ser justificada principalmente por suas características como baixo custo, facilidade de usinagem, boa razão entre resistência mecânica e peso, baixa condutividade elétrica, resistência à corrosão e a outras condições ambientais severas, variedade em propriedades óticas, indo de transparência a opacidade, além de serem recicláveis. Estas características culminaram na utilização de polímeros com as mais diversificadas funcionalidades, estando fortemente presente nas indústrias de eletrônicos, tubulações, empacotamento, automotiva, aeronáutica, entre outras. A fig. 1.1 ilustra o uso de um polímero termoplástico em próteses de quadril (figuras 1.1(a) e 1.1(b)) e de ombro (fig. 1.1(c)), devido ao baixo índice de rejeição do organismo a este 
material.

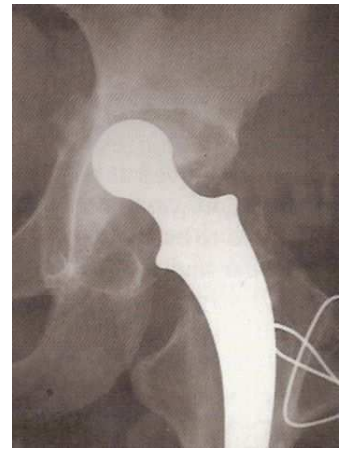

(a)

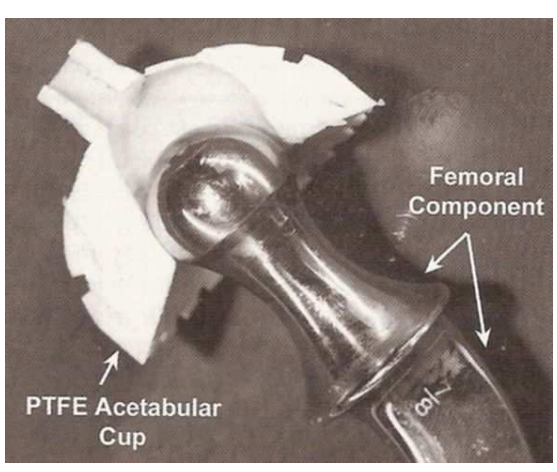

(b)

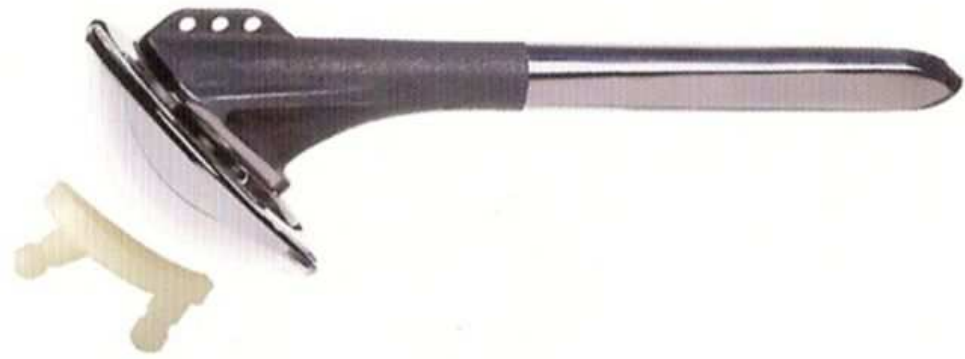

(c)

Figura 1.1: Exemplo de uso de termoplástico: (a) e (b) próteses de quadril e (c) prótese de ombro

Recentemente os polímeros tem sido utilizados para exercer uma função estrutural, ou seja, em produtos sujeitos a algum carregamento mecânico, como por exemplo em automóveis e aeronaves. O uso de polímeros com finalidades estruturais nos veículos aéreos tem ligação direta com a relação resistência mecânica peso, permitindo projetos mais leves. Essa diminuição da massa possibilita uma maior capacidade de carga transportada com a mesma quantidade de combustível. Já para a indústria automotiva, os polímeros ainda permitem um acabamento final com melhores texturas, aumentando a segurança ao cobrir arestas e cantos cortantes, isolamento acústico e maior durabilidade devido à resistência à corrosão. Um exemplo deste fato são os veículos pertencentes ao grupo BMW Series 5 [60], no qual os polímeros constituem 10\% do peso do carro, ou seja, $149 \mathrm{Kg}$, distribuídos em 13 tipos de plásticos com destaques para a poliamida (PA) com 11,9\%, polietileno (PE) com 11\%, cloreto de polivinila (PVC) com 7,7\% e o polimetilmetacrilato ou acrílico (PMMA) com 1,3\% de participação. Com relação ao lugar em que os polímeros se encontram, temos: $58 \%$ no interior, $27 \%$ no exterior, $8 \%$ no chassis 
e $7 \%$ no motor.

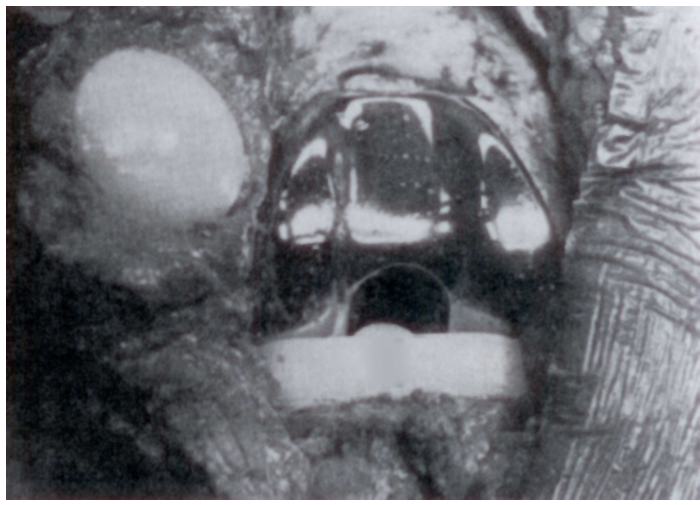

(a)

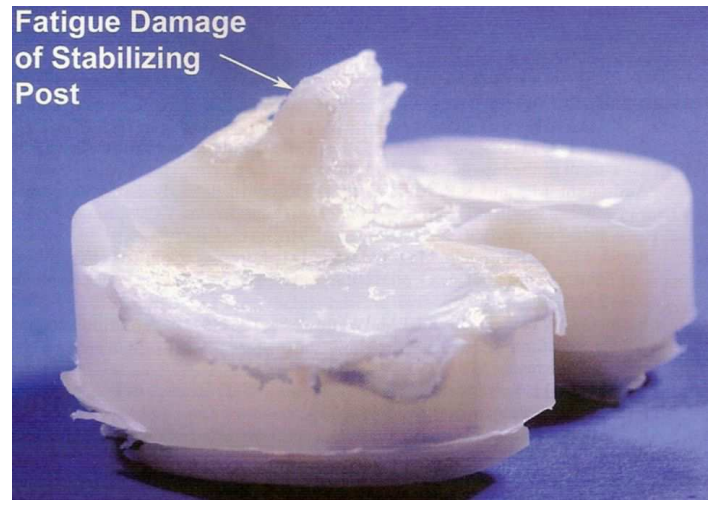

(b)

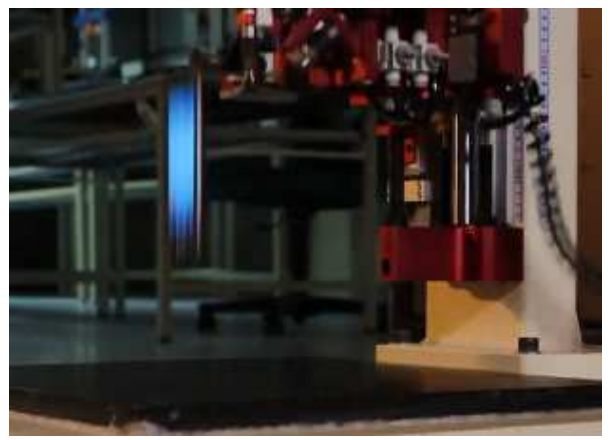

(c)

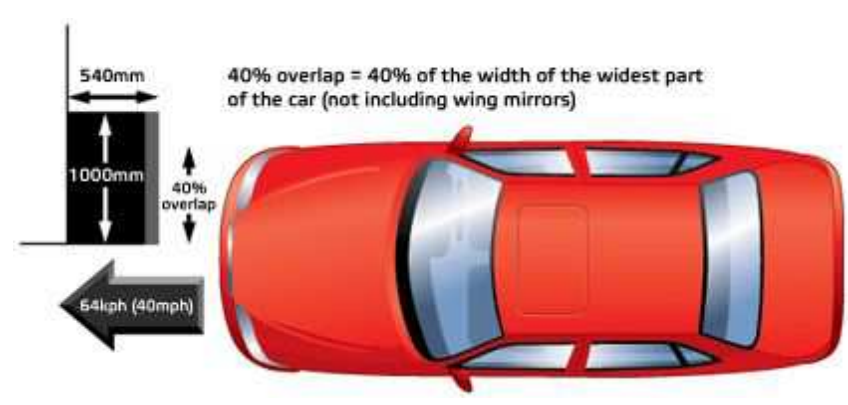

(d)

Figura 1.2: Importância do conhecimento da resposta dinâmica dos polímeros: (a) e (b) influência da fadiga em uma prótese de joelho e (c) e (d) ensaios de impacto realizados em automóveis e dispositivos eletrônicos.

Devido a esta variedade de aplicações, o estudo da resposta mecânica dinâmica do material, ou seja, o modo como este se comporta sob carregamentos que variam no tempo tornou-se importante tanto na concepção quanto no estudo de otimização de um determinado produto. Um carregamento dinâmico pode ser exemplificado por carregamento cíclico, como a força que o andar de uma pessoa exerce sobre uma prótese de joelho, levando a fadiga da mesma com o passar do tempo. A ação deste carregamento cíclico no polímero da prótese pode ser verificado ao comparar-se a fig. 1.2(a), tirada durante a cirurgia para colocação da mesma, e a fig. 1.2(b), removida após a falha. Já um carregamento efetuado em um curto intervalo é caracterizado por gerar altas taxas de deformação e denominado impacto. O crescente uso de polímeros em situações que envolvam impacto, como em caixas de polipropileno projetadas para a absorção de energia durante uma colisão de automóveis ([26]) (como no teste da fig. 1.2(d) realizado pela 
NCAP, New car assessment programme) ou mesmo ser possível dimensionar um equipamento eletrônico para ser resistente a quedas (conforme teste da fig. 1.2(c)), são exemplos do quanto é importante conhecer a resposta mecânica dinâmica destes materiais.

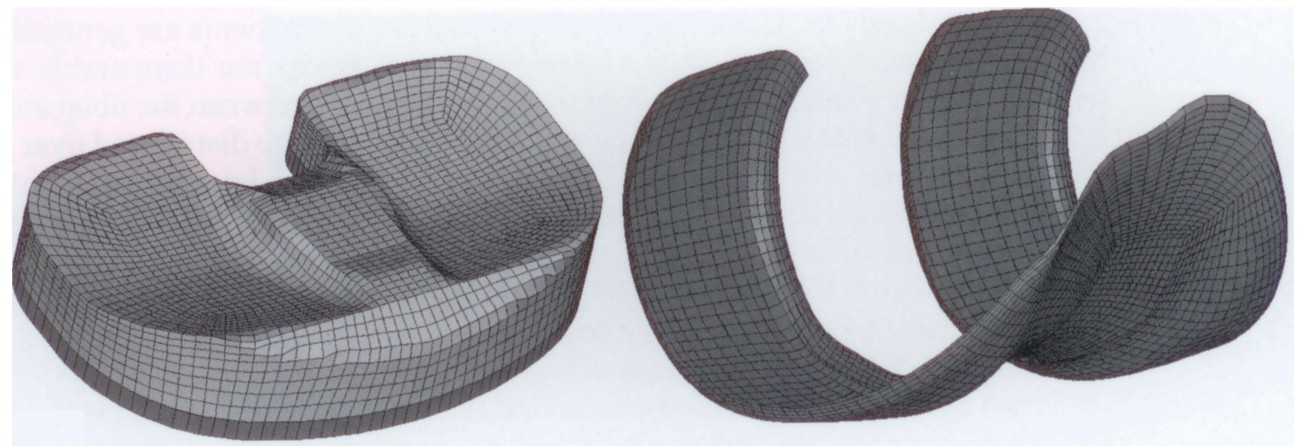

(a)

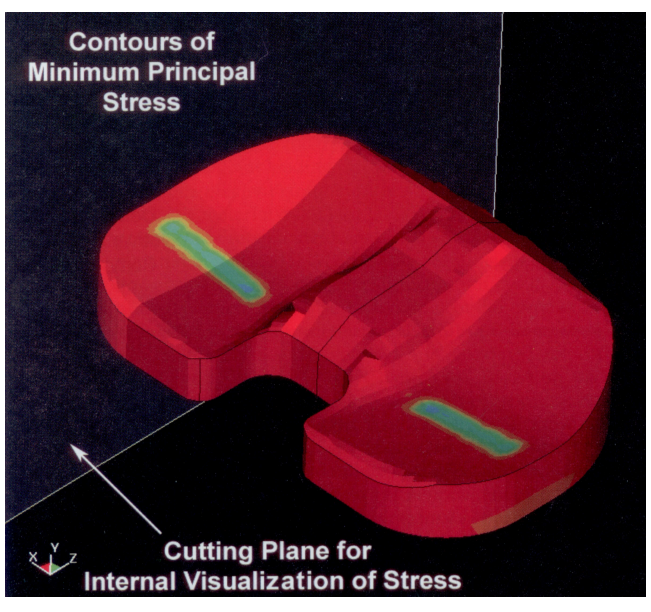

(b)

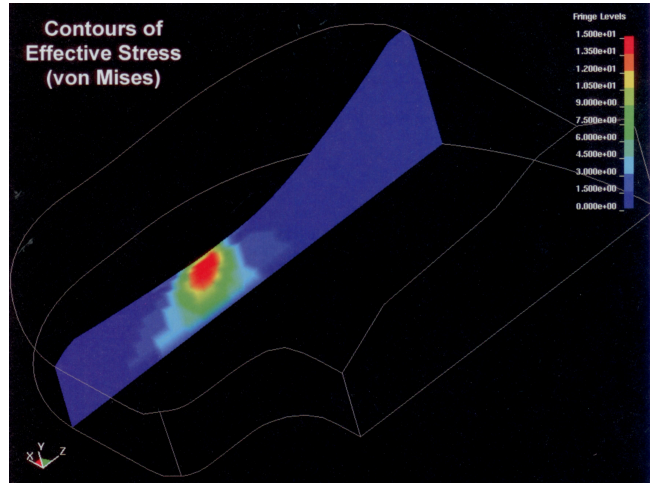

(c)

Figura 1.3: Simulação numérica em elementos finitos de uma prótese de joelho: modelagem em elementos finitos, (a), e resposta mecânica, (b) e (c). Retirados de [52].

O uso de ferramentas numéricas, como o método dos elementos finitos, na concepção e otimização de produtos é essencial para a redução do tempo gasto no desenvolvimento e melhoria na compreensão dos carregamentos e tensões envolvidas em situações nas quais o sensoriamento é complicado, como no caso de uma prótese, ou mesmo na realização de um ensaio experimental, como no caso de uma colisão de navios. Entretanto, a acurácia de uma simulação numérica depende do quão preciso é a representação matemática da resposta mecânica dinâmica do material. Nos programas comerciais de elementos finitos, a variedade dos modelos de material específicos para polímeros ainda é ínfima quando comparada à variedade disponível para as ligas metálicas, e os modelos incorporados 
às bibliotecas comerciais ainda é muito limitada ou de uso restrito a certos materiais e condições de carregamento. Este disponibilidade limitada torna importante o estudo e desenvolvimento de modelos de materiais específicos para termoplásticos. A fig. 1.3 demonstra um exemplo aplicado, disponível em [52], de como o desenvolvimento de um modelo de material para polietileno de alto peso molecular, presente em próteses de joelho, auxilia a melhor compreensão dos carregamentos, permitindo a otimização da prótese e conseguinte melhora na qualidade de vida de seus portadores.

\subsection{Polímeros}

A palavra polímero pode ser decomposta pelo prefixo poli, que quer dizer muitos, e pelo radical mero, proveniente do grego meros, que significa parte. Um polímero é uma molécula de longas cadeias formada por um processo de ligação de monômeros devido ao fornecimento de calor e/ou pressão e/ou catalisadores, chamada polimerização. Desta forma, os monômeros são a menor unidade repetitiva de um polímero. A fig. 1.4 exemplifica o processo de polimerização para o caso do monômero etileno. Nela, a ligação covalente dupla entre carbonos é quebrada em ligações covalente simples, formando o bloco básico, a ser repetido inúmeras vezes e criando uma molécula na forma de uma longa cadeia.

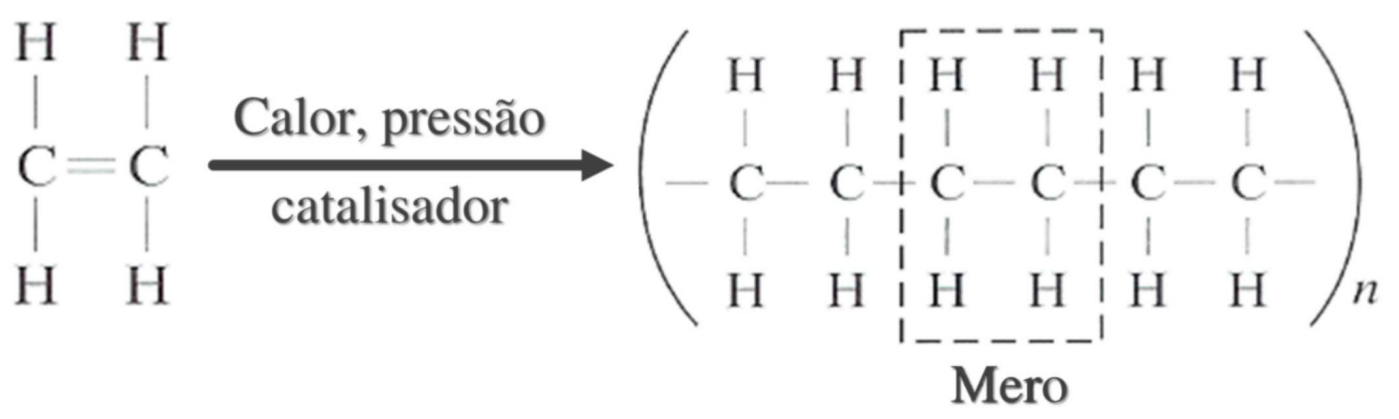

Figura 1.4: Formação do polímero polietileno a partir do monômero etileno.

De acordo com [46], a palavra polímero foi usada pela primeira vez em 1866, com os primeiros polímeros sendo compostos de material natural orgânico derivados de animais e vegetais, e o primeiro polímero orgânico sintético, o fenol-formaldeído, desenvolvido em 1906. Por sua vez, a palavra plástico foi usada pela primeira vez em 1909 e tem origem na palavra grega plastikos, que significa "capaz de ser moldado e conformado". A tabela 
1.1 exemplifica a unidade de repetição básica dos polímeros mais utilizados atualmente.

Uma propriedade importante dos polímeros é o peso molecular, que pode ser definido como a soma dos pesos dos monômeros. Quanto maior o peso molecular, maior o tamanho médio das cadeias. O MWD, mobile weight distribution é a distribuição de peso molecular e influencia algumas características, como resistência a impacto e viscosidade.

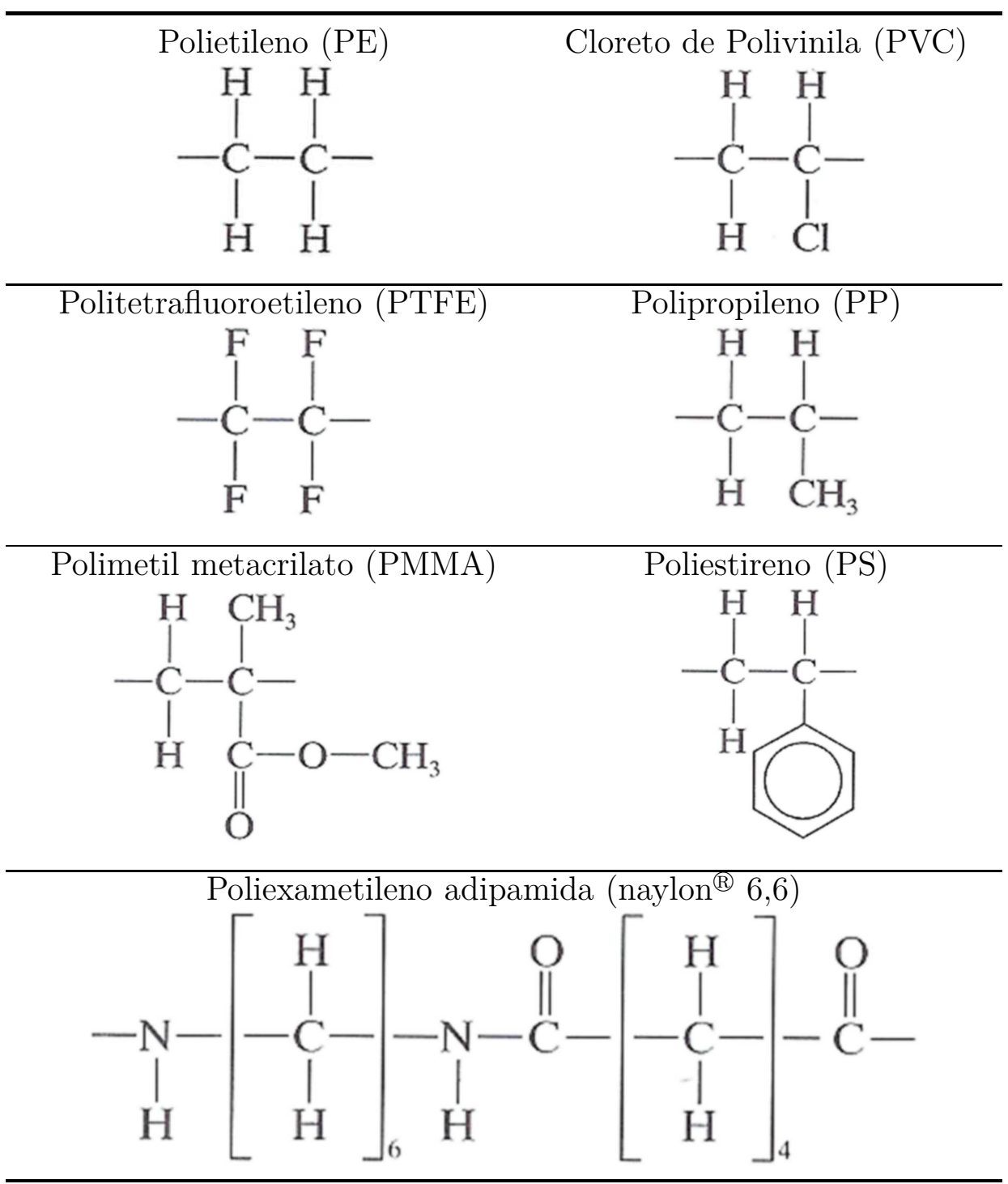

Tabela 1.1: Unidades básicas de repetição de alguns dos polímeros mais utilizados na indústria. 


\subsubsection{Forma e estrutura molecular}

Apesar da representação da fig. 1.4 apresentar um ângulo de $180^{\circ}$ entre as ligações covalentes de um mesmo átomo de carbono, esta é apenas uma representação esquemática. A estrutura real tridimensional da molécula é determinada pelo estado de menor energia, nesse caso com um ângulo de $109^{\circ}$ conforme a fig. 1.5(a), com a distância entre dois átomos de carbono de aproximadamente 0,154nm. De fato, de acordo com Callister [22], não existe qualquer razão para se supor que as moléculas das cadeias de polímeros sejam estritamente retilíneas, sendo a configuração em ziguezague da figura 1.5(b) a mais próxima de uma reta. Entretanto, quando existe uma rotação dos átomos da cadeia para outras posições, a cadeia pode ser torcida ou dobrada, como está exemplificado na figura 1.5(c). Por fim, uma molécula composta por uma única cadeia formada pelos muitos átomos pode assumir uma forma semelhante à representada na figura 1.5(d), na qual a molécula se dobra, espirala e contorce. Quanto mais diferente da forma molecular apresentada na fig. 1.5(b) e mais próxima de 1.5(d), maior é a possibilidade da molécula atingir grandes deformações sem ruptura da cadeia, uma vez que há uma maior capacidade da mesma de alinhar-se com uma força aplicada, chegando então a configuração em ziguezague.

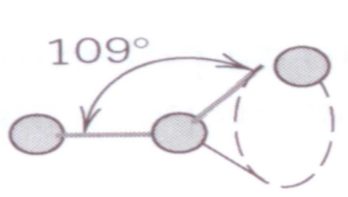

(a)

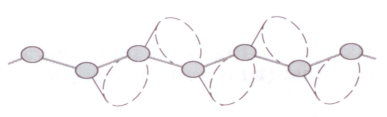

(b)

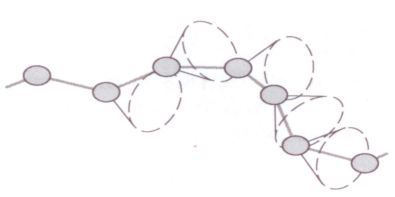

(c)

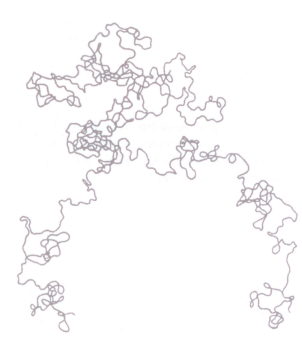

(d)

Figura 1.5: Representação esquemática tridimensional de uma molécula polimérica. Adaptado de [22]

Os polímeros são constituídos por um emaranhado de cadeias poliméricas. Assim, não somente a forma de cada cadeia influencia nas características físicas e mecânicas, mas também no tamanho da cadeia e na relação entre as mesmas. Quanto maior o peso molecular, maiores são as cadeias e mais difícil será para a mesma passar do estado emaranhado aleatório para um alinhado com as forças aplicadas. Quando consideramos a interação entre as cadeias, os polímeros são classificados conforme sua estrutura molecular em: linear, ramificada, com ligações cruzadas ou em rede, conforme a fig 1.6. 


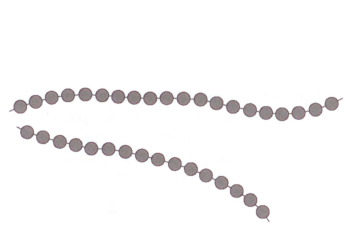

(a) linear

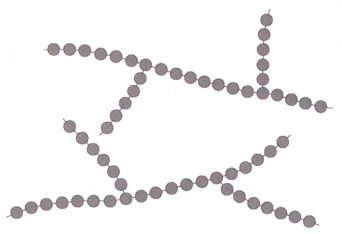

(b) ramificada

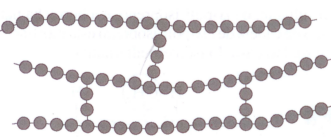

(c) ligações cruzadas

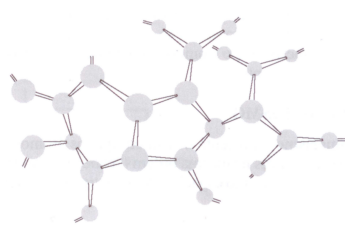

(d) em rede

Figura 1.6: Tipos de estrutura de um molécula polimérica, no qual cada círculo representa uma mero, sendo (a) linear, (b) ramificada, (c) com ligações cruzadas e (d) em rede. Adaptado de [22]

Os polímeros lineares estão representados na figura 1.6(a) e têm como característica de os meros se ligarem de ponta a ponta em cadeias únicas, flexíveis. Nos polímeros ramificados, representados na figura 1.6(b), ramificações são anexadas à cadeia principal durante a polimerização e interferem no movimento relativo entre as moléculas, resultando em aumento da resistência à deformação e à propagação de trincas, além de menores densidades na comparação com os polímeros lineares. De acordo com [21], nesses dois tipos de estruturas podem existir ligações de van der Waals e pontes de hidrogênio, conhecidas como ligações secundárias, entre as cadeias. Os polímeros com estes tipos de estruturas são conhecidos por termoplásticos e reconhecidos especialmente por sua ductibilidade e grandes deformações.

Os polímeros com ligações cruzadas, representados na figura 1.6(c), têm como característica principal as ligações covalentes entre suas cadeias. Os polímeros em rede, fig. 1.6(d), se destacam por serem constituídos de meros trifuncionais, ou seja, com três ligações covalentes ativas que formam redes tridimensionais, podendo ser classificados como pertencentes a classe dos polímeros de estrutura com ligação cruzada. Segundo [69], os polímeros com estrutura de ligação cruzada podem ser classificados como termosets, quando há aproximadamente uma ligação cruzada a cada 20 átomos de carbono, ou como elastômeros, caso exista uma ligação cruzada a cada aproximadamente 1000 átomos de carbono.

\subsubsection{Cristalinidade}

O estado cristalino nos metais é atingido pelo arranjo e alinhamento de átomos e íons. Já nos polímeros, pode-se definir um estado cristalino obtido a partir do empacotamento de cadeias moleculares, que produz uma matriz atômica ordenada, conforme a fig. 1.7(b). 
Por causa do tamanho e complexidade das moléculas, não há um polímero completamente cristalino. A presença desta cristalinidade parcial origina a classificação de semicristalino. Nos polímeros semicristalinos, as regiões cristalinas são envoltas por material amorfo (denominação para o polímero termoplástico sem organização molecular), conforme demonstrado na fig. 1.7(a). A denominação de polímero cristalino é utilizada quando há pelo menos $95 \%$ de cristalinidade.

O grau de cristalinidade depende da taxa de resfriamento do polímero durante a solidificação e da própria configuração da cadeia. No caso da taxa de resfriamento, se um polímero está se solidificando, esta passando de um estado no qual as cadeias estão entrelaças e embaraçadas, necessitando de um tempo de resfriamento grande o suficiente para que as cadeias se alinhem. No que diz respeito à complexidade das moléculas, tanto moléculas quimicamente simples quanto uma estrutura linear do polímero facilitam o alinhamento do mesmo, e consequentemente, facilitam cristalização. Um exemplo é o fato de ser difícil evitar a cristalização do polietileno devido à sua simplicidade química, mesmo em taxas de resfriamento rápidas. São exemplos de materiais amorfos o PMMA, PC, PS e PVC.

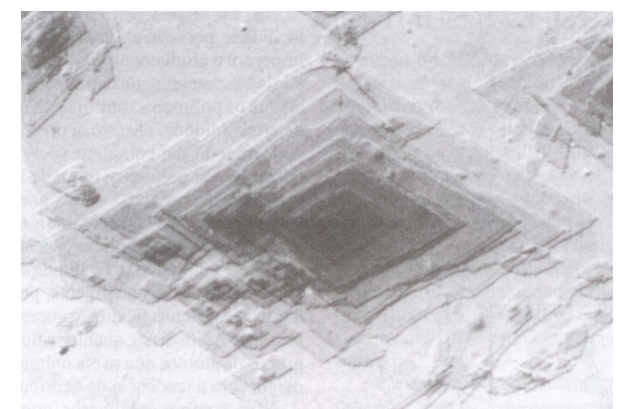

(a)

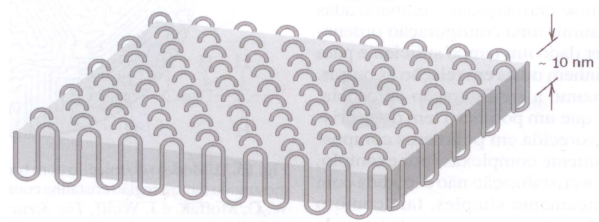

(b)

Figura 1.7: Representação da cristalização em materiais semicristalinos. Retirado de [22]

\subsubsection{Influência dos movimentos moleculares na resistência me- cânica}

Considere que uma máquina é capaz de medir o módulo elástico de um polímero termoplástico amorfo através de oscilações forçadas enquanto varia a temperatura, gerando o gráfico da fig. 1.8.

Cada patamar com respectivas quedas representam um mecanismo de deformação. 


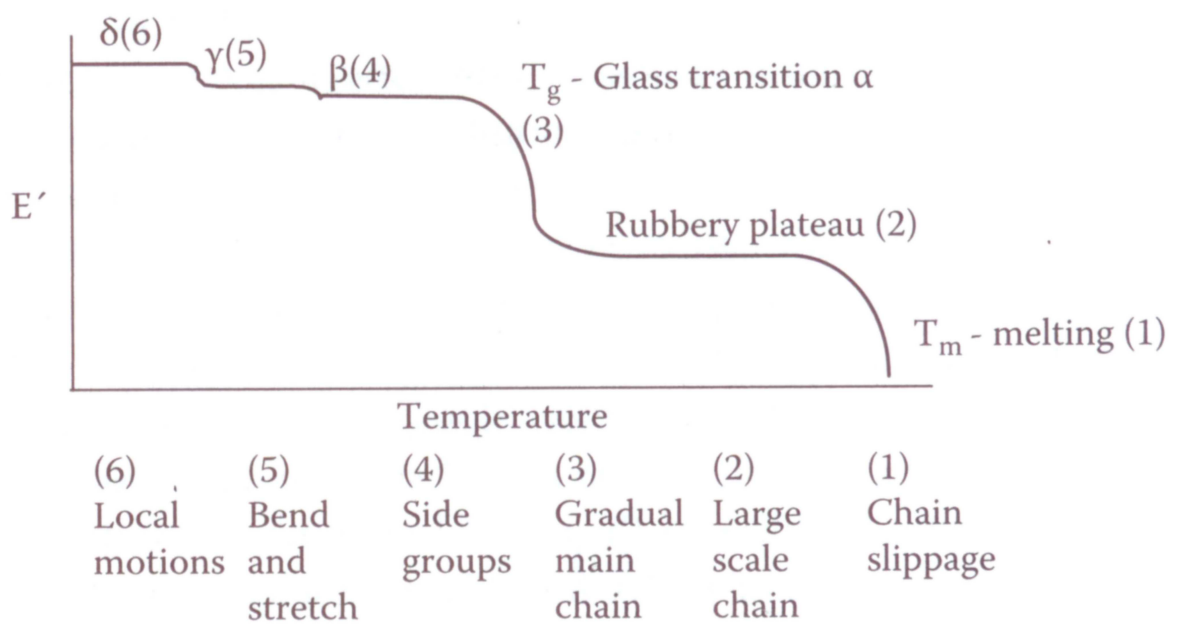

Figura 1.8: Variação do módulo elástico em função da temperatura, retirado de [61].

A temperatura na qual acontece a queda é conhecida por temperatura de transição, ou seja, em situações abaixo desta temperatura, o mecanismo necessita de uma determinada energia para acontecer e portanto implica em um resistência mecânica, sendo predominante um processo elástico de deformação característico de um sólido. Já acima desta temperatura de transição, não há restrições para o movimento, não havendo tamanha resistência mecânica, sendo predominante o escoamento característico de um fluido com alta viscosidade. Os movimentos moleculares estão ilustrados na fig. 1.9 e de acordo com [92], a transição $\alpha$ é conhecida como temperatura de transição vítrea e está associada com o grau de liberdade rotacional dos segmentos da cadeia principal entre as ligações cruzadas. É chamada de fase a resposta mecânica de cada mecanismo, estando ela ativa se o material está abaixo da temperatura de transição desta fase ou inativa se o material está acima desta temperatura.

Enquanto os polímeros amorfos possuem temperaturas de transição vítrea, os polímeros semicristalinos possuem uma temperatura equivalente à de transição vítrea denominada temperatura de fusão $T_{m}$.

\subsubsection{Polímeros escolhidos}

Nesta tese, foram escolhidos dois polímeros termoplásticos para terem sua resistência mecânica a impactos analisada: o semicristalino polietileno de alta densidade, ou PEAD, e o amorfo cloreto de polivinila, ou PVC. A razão pela escolha deles é sua grande produção, correspondendo a 12,03\% e 11,22\% do volume total de plásticos produzidos nos EUA em 


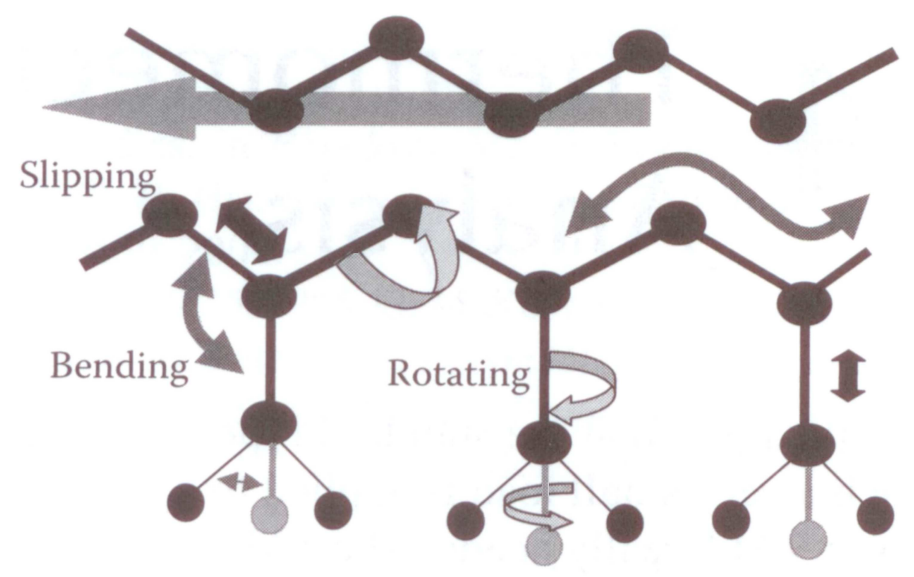

Figura 1.9: Mecanismos de movimentação possíveis em uma cadeia polimérica, retirado de $[61]$.

2001, de acordo com o American Plastics Council.

Ambos os materiais foram comprados na forma de placas extrudadas de $2 \mathrm{~m}$ por $1 \mathrm{~m}$, com direção de extrusão paralela a de maior dimensão, espessura de $5 \mathrm{~mm}$ ou $10 \mathrm{~mm}$, da fabricante alemã SIMONA ${ }^{\circledR}$, sendo o PEAD denominado PE-HWU pelo fabricante e descrito pelo mesmo como um material preto especialmente estabilizado para uso externo, com alta proteção ultravioleta, baixa absorção de água e alta resistência química e à corrosão. Já o PVC, denominado PVC-TF, é descrito pelas mesmas propriedades no que diz respeito a estabilidade, entretanto com uma maior absorção de água. Ainda segundo o fabricante, não há qualquer partícula aditiva ou fibra com intuito de aumento de resistência mecânica, mas algumas partículas são misturadas para diminuir a degradação destes materiais.

As propriedades físicas dos materiais estão identificadas na tabela 1.2, com $\rho$ sendo a densidade, $\sigma_{e}$ a tensão de escoamento, $\lambda_{e}$ e $\lambda_{q}$ os alongamentos no escoamento e na quebra, respectivamente, $E$ o módulo elástico, $\theta_{\min }$ e $\theta_{\max }$ as temperaturas de trabalho mínima e máxima, $\alpha_{\theta}$ o coeficiente de expansão térmica e $c_{p}$ o calor específico.

Mesmo com um vasto programa experimental descrito no cap. 4 utilizando técnicas sem contato de medição local de deformações, a geometria dos corpos de prova dificulta a medição e análise da propagação de ondas viscoelásticas. Entretanto, o aparato experimental descrito no cap. 5 se baseia na propagação de ondas em barras cilíndricas para a medição das propriedades viscoplásticas de um polímero. Para melhorar a acurácia 


\begin{tabular}{lccccccccc}
\hline Material & $\begin{array}{c}\rho \\
\left(\mathrm{kg} / \mathrm{m}^{3}\right)\end{array}$ & $\begin{array}{c}\sigma_{e} \\
(\mathrm{MPa})\end{array}$ & $\begin{array}{c}\lambda_{e} \\
(\%)\end{array}$ & $\begin{array}{c}\lambda_{q} \\
(\%)\end{array}$ & $\begin{array}{c}E \\
(\mathrm{MPa})\end{array}$ & $\begin{array}{c}\theta_{\min } \\
\left({ }^{o} \mathrm{C}\right)\end{array}$ & $\begin{array}{c}\theta_{\max } \\
\left({ }^{\circ} \mathrm{C}\right)\end{array}$ & $\begin{array}{c}\alpha_{\theta} \\
\left(\mathrm{K}^{-1}\right)\end{array}$ & $\begin{array}{c}c_{p} \\
\mathrm{~J} / \mathrm{kg} \mathrm{K}\end{array}$ \\
\hline PE-HWU & 950 & 22 & 9 & 300 & 800 & -50 & 70 & $1.810^{-4}$ & 2000 \\
PVC-TF & 1430 & 53 & 3 & 20 & 3000 & -10 & 60 & $0.810^{-4}$ & 1100 \\
PMMA & 1094 & 50 & - & - & 5000 & -40 & 90 & $7.410^{-5}$ & 1470 \\
\hline
\end{tabular}

Tabela 1.2: Dados dos materiais fornecidos pelo fabricante

deste equipamento, barras cilíndricas de polimetil metacrilato, ou PMMA, adquiridas da empresa nacional Acriresinas, substituíram as tradicionais de aço. Por causa dessa substituição, estudos foram feitos sobre a propagação de ondas no PMMA, levando-se em conta efeitos de dispersão e atenuação, em que a onda de deformação muda sua forma e amplitude, respectivamente. Estes estudos foram publicados em [72, 70]. Desta barra de PMMA foram usinados corpos de prova de tração para ensaios de relaxação, obtendo as características visco-elásticas do PMMA em altas e baixas taxas de deformação. Podemos portanto considerar o PMMA um terceiro polímero estudado nesta tese, o qual também possui suas principais propriedades físicas listadas na tabela 1.2.

\subsection{Simulação numérica}

O método dos elementos finitos é um método aproximado de cálculo de sistemas contínuos no qual a estrutura, componente mecânico ou corpo contínuo é dividido em um número finito de partes (os Elementos), conectados entre si por intermédio de pontos discretos, que são chamados de Nós ([33]). A montagem dos Elementos, que constitui o Modelo Matemático, tem o seu comportamento especificado por um número finito de parâmetros. Em particular, nos problemas de Análise Estrutural, os parâmetros normalmente são os Deslocamentos Nodais, que são as incógnitas do problema.

De acordo com Belytschko [10], a análise em elementos finitos não linear se tornou um componente essencial no desenvolvimento de produtos assistido por computador. Isso se deve ao fato de que cada vez mais os testes de protótipos estarem sendo substituídos por simulações numéricas, uma vez que proporcionam um modo mais rápido e econômico de avaliar conceitos e detalhes do projeto. Um exemplo é o teste de impacto de automóveis para avaliar sua segurança, no qual o custo da fabricação de carros em processos iterativos seria proibitivo. 
Para obter um resultado mais próximo da realidade, não basta apenas uma boa discretização da estrutura em elementos finitos ou ainda criar-se condições de contorno as mais próximas possíveis das reais. É necessário utilizar um modelo de material correto, que represente com exatidão a resposta mecânica tanto em baixas quando em altas taxas de deformação.

\subsubsection{Modelos de material}

Conforme explicitado anteriormente, há uma disponibilidade limitada de modelos de material para termoplásticos em bibliotecas de programas comerciais de simulação em elementos finitos. Alguns mais recentes desenvolvidos para materiais amorfos são capazes de provir respostas mecânicas excelentes, entretanto somente em baixas taxas de deformação.

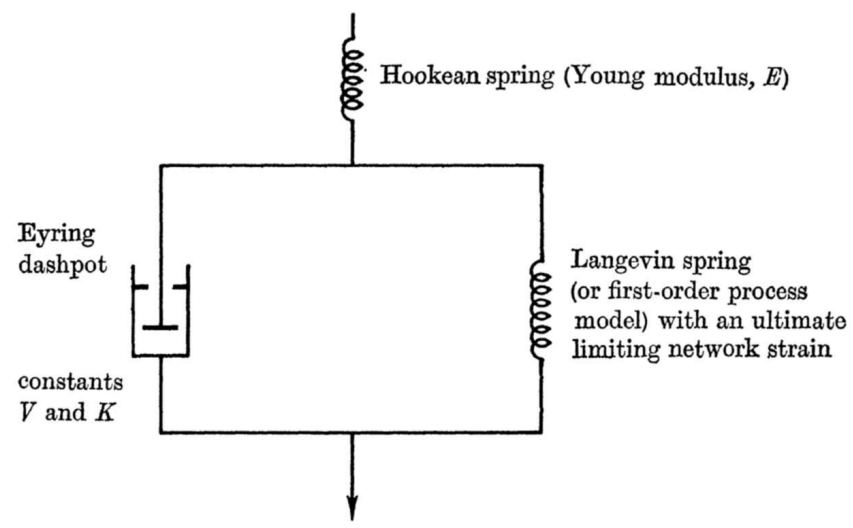

(a)

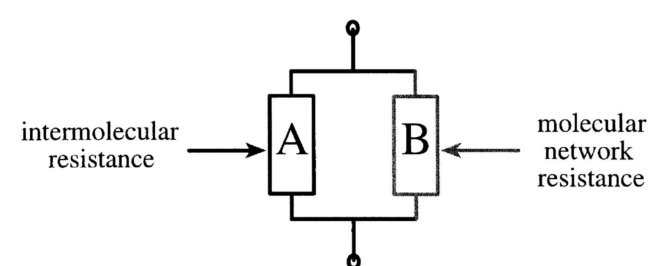

(b)

Figura 1.10: Evolução dos modelos de material para polímeros termoplásticos: (a) modelo de Haward e Tackray [41] de 1968 e (b) modelo de Boyce, Socrate e Llana [16].

Estes modelos se originaram na ideia de separar a influência de cada mecanismo de deformação polimérica, sendo inicialmente propostos por Haward e Thackray [41], conforme fig. 1.10(a), consistindo em um módulo elástico constante, uma viscosidade interna (como a de Eyring [30]) e um encruamento cinemático com equacionamento de Langevin.

Uma das evoluções do modelo de Haward e Thackray é o apresentado por Boyce, Socrate e Llana [16], fig. 1.10(b), no qual, ao invés de utilizar encruamento cinemático, são consideradas separadamente a resistência mecânica gerada pelos movimentos molecu- 
lares, ou resistência intermolecular, e a resistência devido ao alinhamento das cadeias, ou resistência das cadeias moleculares. Com essa separação e considerando uma dependência da temperatura na formulação de ambas as resistências, o modelo é capaz de prever o comportamento do material acima da temperatura de transição vítrea. O efeito desta separação na curva tensão deformação do material foi bem ilustrado por Clausen et. al. [24] e está presente na fig. 1.11.

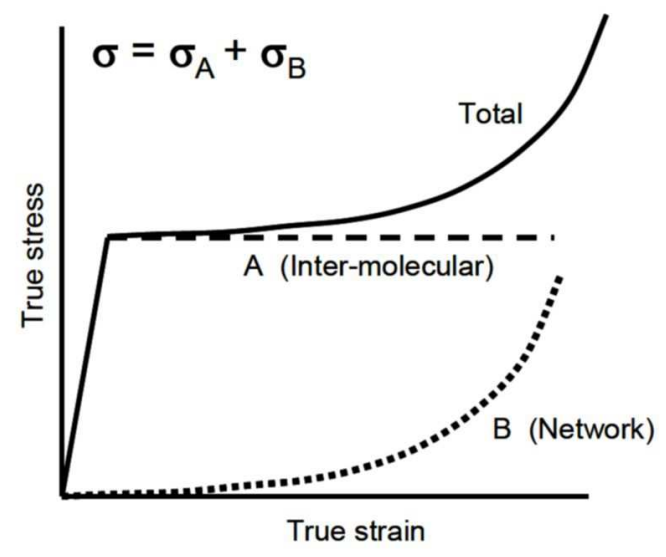

Figura 1.11: Influência de ambas as resistências na tensão verdadeira, retirado de [24].

Ayoub et al. [4] desenvolveu um modelo de material para termoplásticos semicristalinos apenas adicionando em paralelo a resistência intermolecular cristalina, conforme a fig. 1.12. Outros autores como Dusunceli e Colak [28] e Bergstrom e Bischoff [45] também obtiveram excelentes resultados utilizando-se da mesma estratégia.

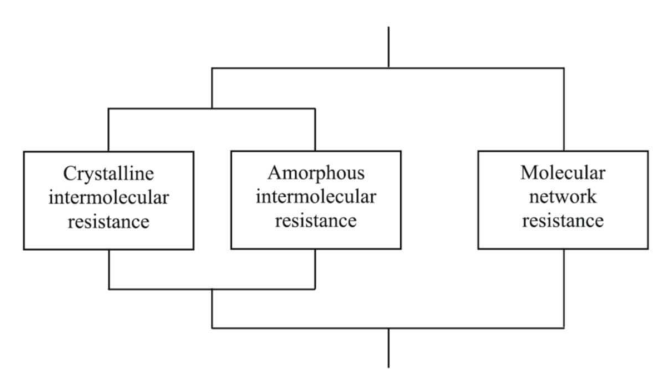

(a)

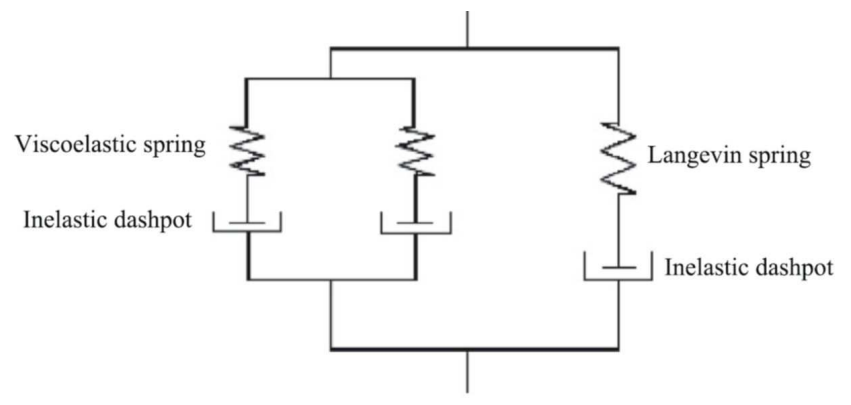

(b)

Figura 1.12: Modelo de material para polímeros termoplásticos semiceristalinos: (a) representação esquemática e (b) representação reológica. Retirados de [4]

O motivo destes modelos de material para termoplásticos amorfos não reproduzirem tão bem o comportamento mecânico dos mesmos em situações de impacto (onde 
predominam altas taxas de deformação) quanto em situação quasi-estáticas, é de que a temperatura de transição de uma fase depende da taxa de deformação. A fig. 1.13(a), retirada do manual da máquina de DTMA (dynamic thermal mechanical analysis) Thermal Analysis DMA-Q800, mostra o módulo de armazenamento (Storage modulus) e o módulo tangente, que é a relação entre o módulo de armazenamento e o módulo dissipativo ou de perda (Loss modulus). A temperatura na qual ocorre o máximo do módulo tangente indica o valor da temperatura de transição de uma fase. Considere um polímero a $107^{\circ} \mathrm{C}$ com um carregamento quasi-estático. Como a temperatura do mesmo está acima da temperatura de transição $103^{\circ} \mathrm{C}$, a fase está inativa e se comporta como um fluido viscoso escoando. Entretanto, se o carregamento for dinâmico, a temperatura do mesmo é menor que a temperatura de transição $113,25^{\circ} \mathrm{C}$, a fase está ativa e o mesmo se comporta como um sólido elástico.

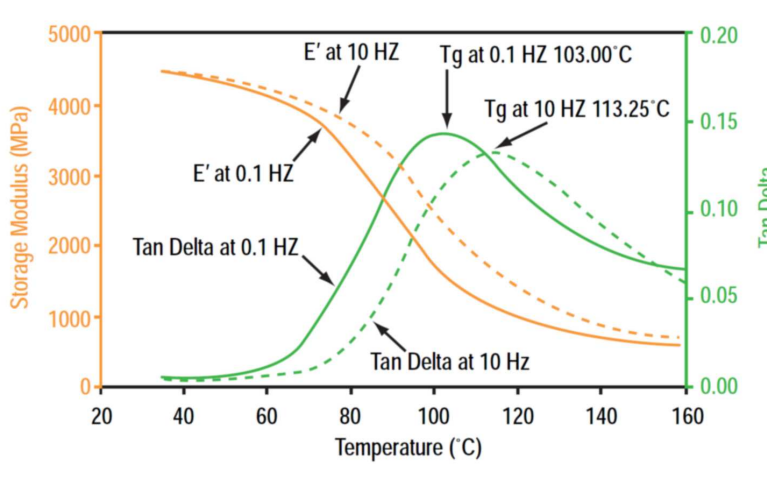

(a)

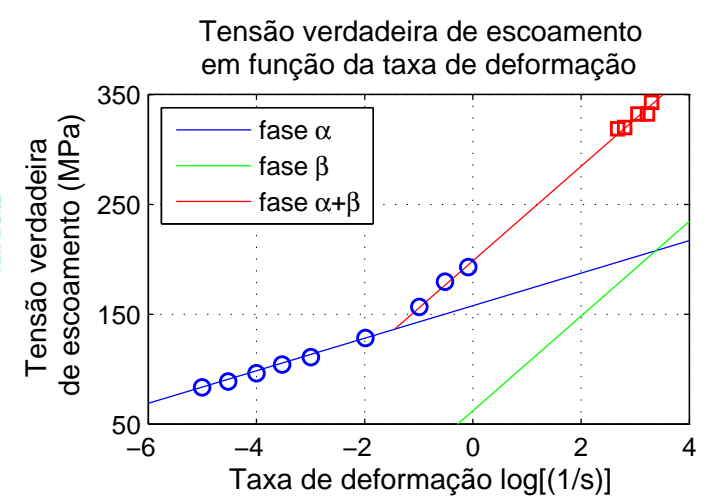

(b)

Figura 1.13: Influência da taxa de deformação na temperatura de transição das fases: (a) exemplo do manual da Thermal Analysis DMA-Q800 e (b) influência de ambas as fases na relação entre tensão e taxa de deformação para o PMMA, adaptado [75]

Mulliken [75] adicionou então mais uma fase aos modelos anteriores, sendo capaz de reproduzir o comportamento dos polímeros, especialmente sua característica viscoplástica, em baixas e altas taxas de deformação. Os resultados experimentais estáticos e dinâmicos foram reunidos e estão apresentados na fig. 1.13(b), na qual é possível compreender melhor a influência da fase $\beta$ que está ativa somente em taxas de deformação mais elevadas. 


\subsection{Estrutura da tese}

Considerando todos os aspectos apresentados a tese está organizada e dividida nos seguintes capítulos:

1. uma revisão dos ensaios experimentais adequados ao tipo de carregamento quanto à taxa de deformação do mesmo e às propriedades gerais dos termoplásticos em cada um, além da descrição da técnica DIC ("Digital Image Correlation", correlação digital de imagens em português) utilizada para medição sem contato de deslocamentos, e por consequência deformações, a partir de uma pintura da superfície do corpo de prova e de fotografias durante o ensaio;

2. uma revisão bibliográfica sobre modelagem matemática no âmbito de grandes deformações do comportamento mecânico de polímeros;

3. o estudo experimental do comportamento mecânico dos polímeros em baixas taxas de deformação, utilizando a técnica DIC em ensaios mecânicos de relaxação, tração e compressão;

4. o estudo experimental do comportamento mecânico dos polímeros em altas taxas de deformação, através da análise de propagação de onda visco-elástica em barras cilíndricas e pelo levantamento das curvas tensão-deformação no aparato experimental conhecido por SPHB ("Split Pressure Hopkinson Bar", barra de pressão dividida de Hopkinson em português);

5. implementação simples de um modelo de material viscoelastoviscoplástico a partir da inserção de um modelo de material viscoelástico capaz de reproduzir os fenômenos de fluência e propagação de ondas em um modelo de material viscoplástico de duas ou três fases, dependendo do polímero, no programa comercial de simulação numérica de elementos finitos Ls-Dyna ${ }^{\circledR}$, calibração dos parâmetros e reprodução numérica de alguns ensaios de calibração para a verificação do funcionamento do mesmo;

6. execução experimental de impactos em placas dos materiais cujo comportamento mecânico em baixas e altas taxas de deformação foram previamente obtidos, não com a intenção de descobrir o limite balístico, mas no intuito de obter informações 
do comportamento do material em altas taxas de deformação em carregamentos complexos para verificar a capacidade e acurácia do modelo de material implementado.

A estrutura da tese consiste em um capítulo de introdução, um capítulo para cada estudo itemizado acima, juntamente com um capitulo final de conclusão. 

Capítulo 2. Revisão de ensaios experimentais e do comportamento mecânico dos polímeros

\section{Capítulo 2}

\section{Revisão de ensaios experimentais e do comportamento mecânico dos polímeros}

\subsection{Introdução}

Em um primeiro instante, saber o comportamento mecânico do termoplástico é necessário para que se possa escolher o melhor modelo de material que o represente, ou mesmo propor um. Definido o modelo de material, suas constantes devem ser calibradas para reproduzir com o menor desvio possível seu comportamento mecânico.

O método mais utilizado para se analisar o comportamento mecânico é o de verificar como a variação da deformação influencia a tensão, sendo a aproximação linear desta relação conhecida por Lei de Hooke. Entretanto, há outras variáveis além da deformação que podem ter influência na resposta mecânica, sendo algumas delas:

- temperatura: não obstante as temperaturas de mudança de fase que delimitam as características físicas entre sólido, líquido e gasoso, e consequentemente o comportamento mecânico do material, a temperatura ainda influencia a resposta mesmo em um único estado. Simplificadamente, quanto maior a temperatura, mais energia as moléculas possuem, menor restrição ao movimento e consequente menor resistência mecânica. A interferência da temperatura pode ser modelada com parâmetros do material sendo funções da mesma, tanto na parte elástica, por meio do módulo elástico, quanto na parte plástica, por meio da tensão de escoamento e do módulo tangente, por exemplo; 
- taxa de deformação: em sua definição mais ampla, é a variação temporal da deformação no tempo. Mais especificamente, na mecânica do contínuo, é a parte simétrica do tensor gradiente de velocidades. Se a tensão do material é influenciada pela taxa de deformação, pode-se adjetivá-lo por sensível à taxa de deformação. O material é viscoelástico se esta sensibilidade ocorre na deformação elástica e viscoplástico se ocorrer na deformação plástica.

- variáveis internas: são variáveis de estado que podem representar diferentes fenômenos, como por exemplo a deformação plástica acumulada ou variáveis relacionadas à evolução de dano. Como estas variam conforme o fenômeno ocorre, muitas vezes possuindo leis de evolução próprias, elas de certa forma representam o resultado atual acumulado de toda a vida do material. No programa de elementos finitos Ls-Dyna ${ }^{\circledR}$, são chamadas de variáveis de história temporal.

- tipo de carregamento: existem materiais que possuem respostas mecânicas diferentes nos casos de tração e compressão. Um modo de expressar matematicamente esta dependência é utilizando-se a pressão hidrostática (definida em A.100) na formulação do modelo de material.

Um exemplo matemático da dependência da resposta mecânica em função destas variáveis é a relação de Jonhson-Cook [7] em que a taxa de deformação de cisalhamento $\dot{\gamma}$ é expressa em função da tensão de cisalhamento $\tau$, da deformação de cisalhamento $\gamma$ e da temperatura $\theta$ por

$$
\dot{\gamma}=\dot{\gamma}_{0} \exp \left\{\left[\frac{\tau}{\tau_{0}\left(A+B \gamma^{n}\right)\left(1-T^{m}\right)-1}\right] \frac{1}{C}\right\} \quad \operatorname{com} T=\left(\theta-\theta_{f}\right) /\left(\theta_{f}-\theta_{0}\right)
$$

com os parâmetros mecânicos que definem o material sendo $A, B, n, C$ e $\tau_{0}$, e os parâmetros térmicos $m, \theta_{f}$ e $\theta_{0}$ sendo os dois últimos a temperatura de fusão do material e a temperatura inicial. Esta também pode ser expressa como lei de encruamento, em seu formato mais comum [58], em que a tensão de escoamento $\sigma_{e}$ é uma função da deformação plástica acumulada $\bar{\varepsilon}^{p}$, taxa de deformação $\dot{\varepsilon}$ e da temperatura $\theta$, por

$$
\sigma_{e}=\left(A+B \bar{\varepsilon}^{p^{n}}\right)(1+C \ln \dot{\varepsilon})\left(1-T^{m}\right)
$$

Desta necessidade de compreender o comportamento mecânico dos materiais foram desenvolvidas metodologias para avaliar as propriedades mecânicas. São exemplos destas 
Capítulo 2. Revisão de ensaios experimentais e do comportamento mecânico dos polímeros

propriedades a curva tensão deformação, falha e fratura sob os mais diversos carregamentos, como compressão ou tração uniaxiais, cisalhamento, carregamentos biaxiais, entre outros. A metodologia, a partir deste momento tratada como ensaio experimental, consiste em um corpo de prova especificamente projetado para descobrir uma determinada propriedade mecânica, muitas vezes tendo sua geometria descrita em normas técnicas, e um dispositivo capaz tanto de impor o carregamento desejado quanto de medir, direta ou indiretamente, as propriedades investigadas (tensão, deformação, temperatura, taxa de deformação, entre outras).

A próxima sessão é dedicada à descrição do comportamento polimérico em diversas faixas de taxas de deformação, definidas espacialmente para que o comportamento do material se mantenha relativamente constante dentro de cada faixa, e aos ensaios experimentais mais utilizados em cada uma.

Bem estabelecidos e normalizados em sua grande maioria, devido ao desenvolvimento e testes de novos materiais, há uma demanda pela evolução de alguns aspectos nos ensaios experimentais, como por exemplo na medição das deformações. A medição da deformação é inferida indiretamente através da medição do tamanho instantâneo do corpo de prova. A partir do deslocamento $u$ e do comprimento inicial $l_{0}$, é possível calcular o comprimento atual $l=l_{0}+u$ e o alongamento $\lambda=l / l_{0}$. A deformação de engenharia ou de Cauchy, $\varepsilon^{C}$, e verdadeira ou de Hencky, $\varepsilon^{H}$, podem ser calculadas respectivamente por $\varepsilon^{C}=\lambda-1$ e $\varepsilon^{H}=\ln (\lambda)$.

Os dois modos mais utilizados para se medir o comprimento do corpo de prova a cada instante são: $i$ ) medição do deslocamento a partir do próprio sistema de controle do atuador que impõe deslocamento, seja eletromecânico ou hidráulico; ii) utilização de extensômetro de clip-on, exemplificado na fig. 2.1(a).

Apesar do ideal ser medir as deformações localmente, ou seja, em seções transversais de pequenas espessuras do corpo de prova, aproximando-se o máximo possível de uma espessura infinitesimal, as medições supracitadas incorporam medições de outros aspectos, sendo fontes de erros. No primeiro caso, é medida a variação de comprimento de todo o corpo de prova além do deslocamento gerado pela deformação da estrutura da máquina e pelas partes móveis (da ordem de décimos de milímetro a um milímetro em cargas elevadas). No segundo caso, é medida apenas variação de comprimento de uma porção menor do corpo de prova, como por exemplo 25 ou 50 milímetros, diretamente no 


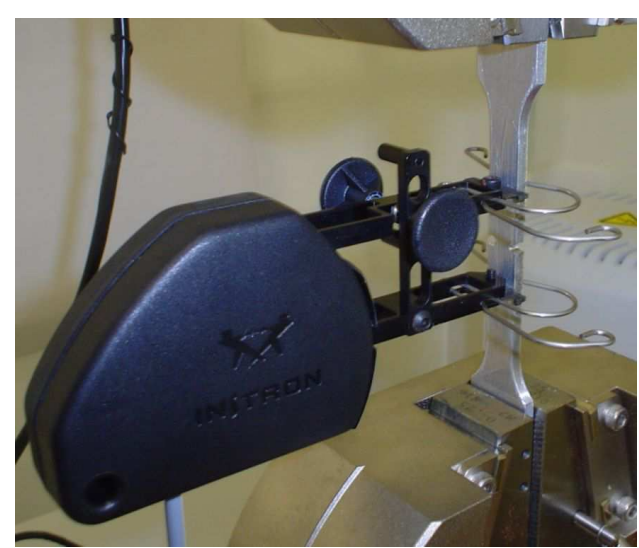

(a) Dispositivo para medição de deslocamentos denominado extensômetro estático do tipo clip-on

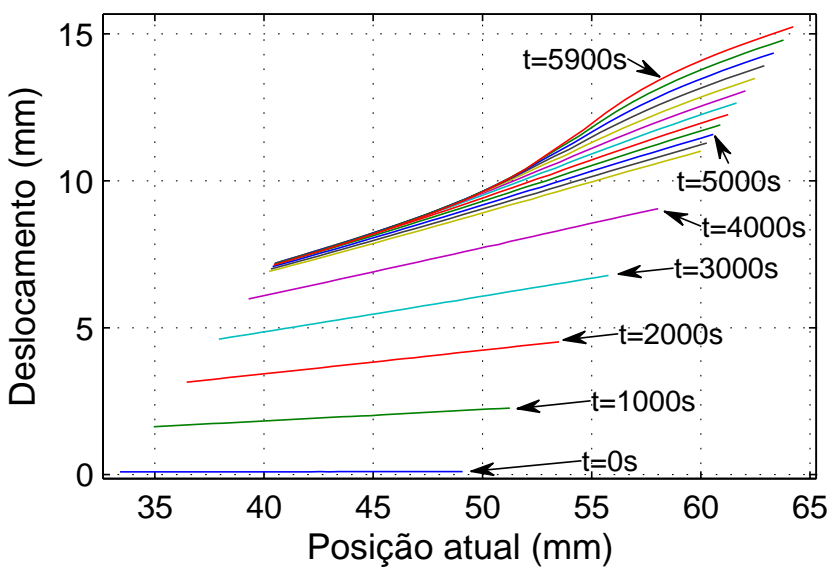

(b) Evolução do deslocamento de cada secção transversal em função da posição atual da mesma em um corpo de prova de tração de aço

Figura 2.1: Dispositivo para medição de deformação e evolução do deslocamento de cada secção transversal em função da posição atual da mesma em um corpo de prova de tração de aço. Medidas realizadas através do método de correlação de imagens digitais.

mesmo.

Mesmo com as pequenas interferências explicitadas acima, as medidas de deformação serão válidas desde que a deformação no corpo de prova seja homogênea, ou seja, a deformação pontual $\varepsilon=\partial u / \partial x$ seja constante ao longo do corpo de prova, no primeiro caso, e dentro da região delimitada pelo extensômetro estático de clip-on, no segundo.

Considerando que estes métodos de medição foram desenvolvida com o objetivo de se obter as propriedades mecânicas de metais, um ensaio uniaxial de tração foi analisado medindo-se o deslocamento $u$ de cada secção transversal ao longo do corpo de prova, resultando no gráfico da fig. 2.1(b). Neste, pode ser verificado que a deformação do corpo de prova é homogênea, ou seja, a inclinação é constante ao longo do mesmo até aproximadamente o instante 5000 s, o equivalente a $85 \%$ da duração total do teste. A partir de então se inicia uma localização mas a medição de deformação é realizada até a falha do corpo de prova no instante 5900s.

A mesma análise foi realizada para um ensaio de tração em polietilento de alta densidade, resultando no gráfico da fig. 2.2(a). Neste caso, com apenas 200s decorridos no ensaio experimental, o equivalente a apenas $11 \%$ do total do teste, já há uma localização causada pelo fenômeno de estricção. Desta forma, ambos os métodos de medição proporcionariam resultados díspares da realidade, sendo necessário medir pontualmente a 
Capítulo 2. Revisão de ensaios experimentais e do comportamento mecânico dos polímeros

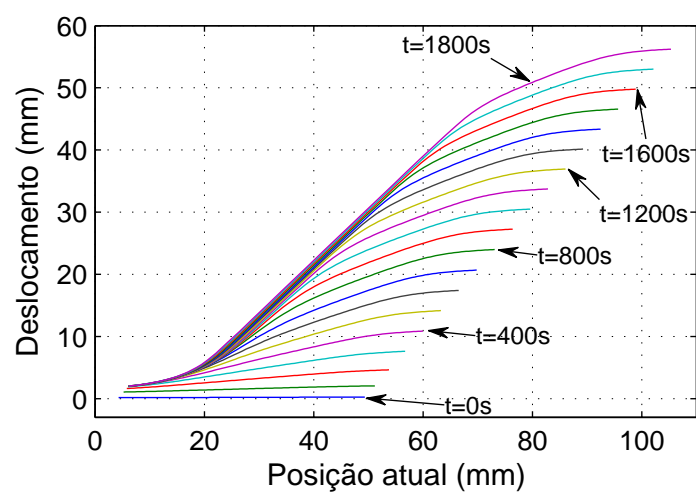

(a) Evolução do de cada secção transversal em função da posição atual da mesma em um corpo de prova de tração de PEAD

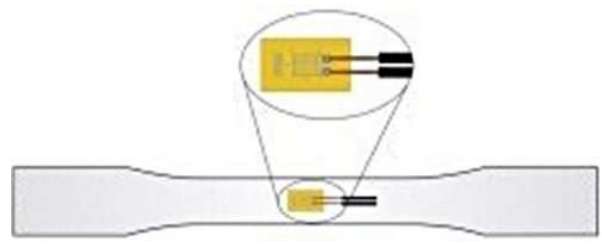

(b) Corpo de prova com extensômetro

Figura 2.2: Evolução do de cada secção transversal em função da posição atual da mesma em um corpo de prova de tração de PEAD e corpo de prova com extensômetro.

deformação.

Um método comum de se medir deformações pontuais é através da fixação de extensômetros no corpo de prova, conforme fig. 2.2(b), no qual a deformação é calculada a partir da variação da resistência elétrica ocasionada pela variação de uma de suas dimensões. Existem três problemas principais com este método: $i$ ) para a melhor acurácia possível, o uso de extensômetros menores, como o de 6 décimos de milímetros seria mais indicado do que os usuais de 4 a 6 milímetros, encarecendo o procedimento; ii) após o uso em um ensaio de tração, o extensômetro não poderá ser descolado e reutilizado novamente; iii) os termoplásticos podem se deformar muito mais do que em metais antes de falhar, atingindo a deformação máxima do extensômetro em estágios iniciais do teste, e os extensômetros podem também se descolar da superfície antes disso.

O estágio atual da velocidade dos processadores juntamente com os avanços nos sensores fotossensíveis CCD e CMOS, permitiram o desenvolvimento da técnica correlação de imagens digitais, um método de medição de deslocamentos, e consequentemente deformações, sem contato a partir de fotografias do corpo de prova devidamente demarcado por um padrão de correlação durante inúmeros instantes do ensaio experimental. Está técnica tem por principal vantagens fornecer as deformações pontuais, tanto axiais quanto transversais e cisalhantes, em todo o plano do corpo de prova fotografado. Seus principais fundamentos são explicados na secção 2.3, sendo utilizada nos ensaios experimentais quasi-estáticos descritos no cap. 4. 


\subsection{Comportamento mecânico e ensaios experimen- tais}

Embora a resposta mecânica dos polímeros dependa dos vários fatores apresentados na seção anterior, este estudo de impacto prioriza a investigação da variação do comportamento do material com a variação da taxa de deformação. Nemat-Nasser [77] constatou que há intervalos de taxas de deformação nos quais o material apresenta um comportamento mecânico semelhante, sendo estes:

- baixíssimas taxas de deformação: de $0 \mathrm{~s}^{-1}$ a $10^{-5} \mathrm{~s}^{-1}$. Nesta faixa de taxa de deformações predominam os mecanismos de rearranjo microestrutural, variando de horas e dias, nos efeitos de relaxação e fluência nos polímeros, ou de dias e meses nos efeitos de recristalização e mudança de fases do aço (austenita, bainita, martensita e perlita), conforme [22];

- baixas taxas de deformação: de $10^{-5} \mathrm{~s}^{-1}$ a $10^{-1} \mathrm{~s}^{-1}$. Nesta faixa de taxa de deformações se concentram a grande maioria dos carregamentos e é na mesma que foram obtidas e catalogadas as curvas tensão deformação para muitos materiais. Para metais, a curva tensão deformação varia pouco dentro desta faixa de taxa de deformações, ao contrario dos polímeros. O equipamento mais utilizado para se averiguar a plasticidade é a máquina de ensaios universais em testes uniaxiais de tração e compressão ou biaxiais de cisalhamento, enquanto o ensaio experimental DTMA serve para investigar a viscoelasticidade. Ambos serão abordados na próxima subseção;

- médias taxas de deformação: de $10^{-1} \mathrm{~s}^{-1}$ a $10^{2} \mathrm{~s}^{-1}$. É nesta faixa que se concentram a maioria dos impactos do cotidiano. Entretanto, as máquinas comerciais desenvolvidas para se medir a resistência mecânica nestas taxas de deformação não fornecem resultados satisfatórios, em especial por não considerarem o fenômeno de propagação de ondas. Em um ensaio a baixas taxas de deformação, o tempo total do teste é suficientemente grande para que as ondas de deformação geradas na imposição do deslocamento sejam atenuadas completamente em sucessivas reflexões, havendo um equilíbrio das forças e igualdade das mesmas no corpo de prova e na célula de carga. Já nos ensaios experimentais específicos desta faixa de taxas de de- 
Capítulo 2. Revisão de ensaios experimentais e do comportamento mecânico dos polímeros

formação, tempo total dos ensaios a médias taxas de deformação não são grandes o suficiente para desprezar-se os efeitos da propagação de ondas, acarretando em uma defasagem entre as medidas de deslocamento e força fornecidas nos equipamentos comerciais disponíveis, que não consideram este efeito.

- altas taxas de deformação: de $10^{2} \mathrm{~s}^{-1}$ a $10^{4} \mathrm{~s}^{-1}$. Taxas de deformação para impactos como colisões de veículos, na qual predomina a propagação de onda. O equipamento mais utilizado nos ensaios experimentais nestas taxas de deformação é a barra de Hopkinson, tratada em detalhes no cap. 5;

- altíssimas taxas de deformação: acima de $10^{4} \mathrm{~s}^{-1}$. Estão presentes nesta faixa de taxas de deformação fenômenos como propagações de ondas de choque de explosões e não será abordada neste estudo.

\subsubsection{Baixas taxas de deformação: de $10^{-5} \mathrm{~s}^{-1}$ a $10^{-1} \mathrm{~s}^{-1}$}

\subsubsection{Ensaios quasi-estáticos}

Essa faixa de taxas de deformação também é conhecida como quasi-estática, possui como ensaio experimental mais marcante os realizados em máquinas de ensaios universais, como a máquina Instron modelo 3369 disponível no laboratório do GMSIE e ilustrada na fig. 2.3(a). Neste tipo de máquina, geralmente há uma viga horizontal chamada crosshead na qual são fixadas células de carga. No caso de máquina eletromecânicas, o crosshead se move impondo deslocamentos ao corpo de prova do material estudado. Nas máquinas servo-hidráulicas é comum a movimentação do crosshead na parte de preparação do teste, permanecendo imóvel durante o mesmo e o deslocamento sendo imposto ao corpo de prova através de um atuador hidráulico. Em ambos os tipos de máquinas, o ensaio mais comum é o de deslocamentos monotônicos com velocidades constantes, sejam de compressão ou de tração, obtendo informações de força e deslocamento conforme a fig. 2.3(b).

A curva tensão deformação de um polímero termoplástico está descrita na fig. 2.4, sendo constituída por uma região elástica linear, uma região elástica não linear, uma região plástica com amolecimento e uma região plástica com encruamento. As teorias por trás de cada tipo de deformação e fenômeno físico dominante serão comentados durante a modelagem matemática do comportamento do material, no capítulo 3. 

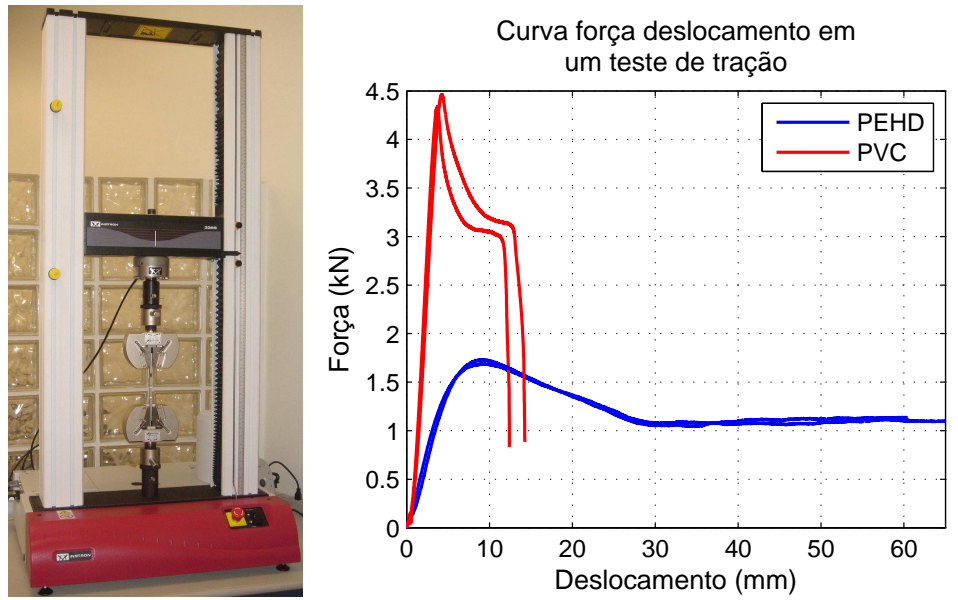

(a) máquina de en- (b) Curva força deslocamento de um ensaio saios universal experimental monotônico

Figura 2.3: Resultado de um ensaio de relaxação em PMMA.

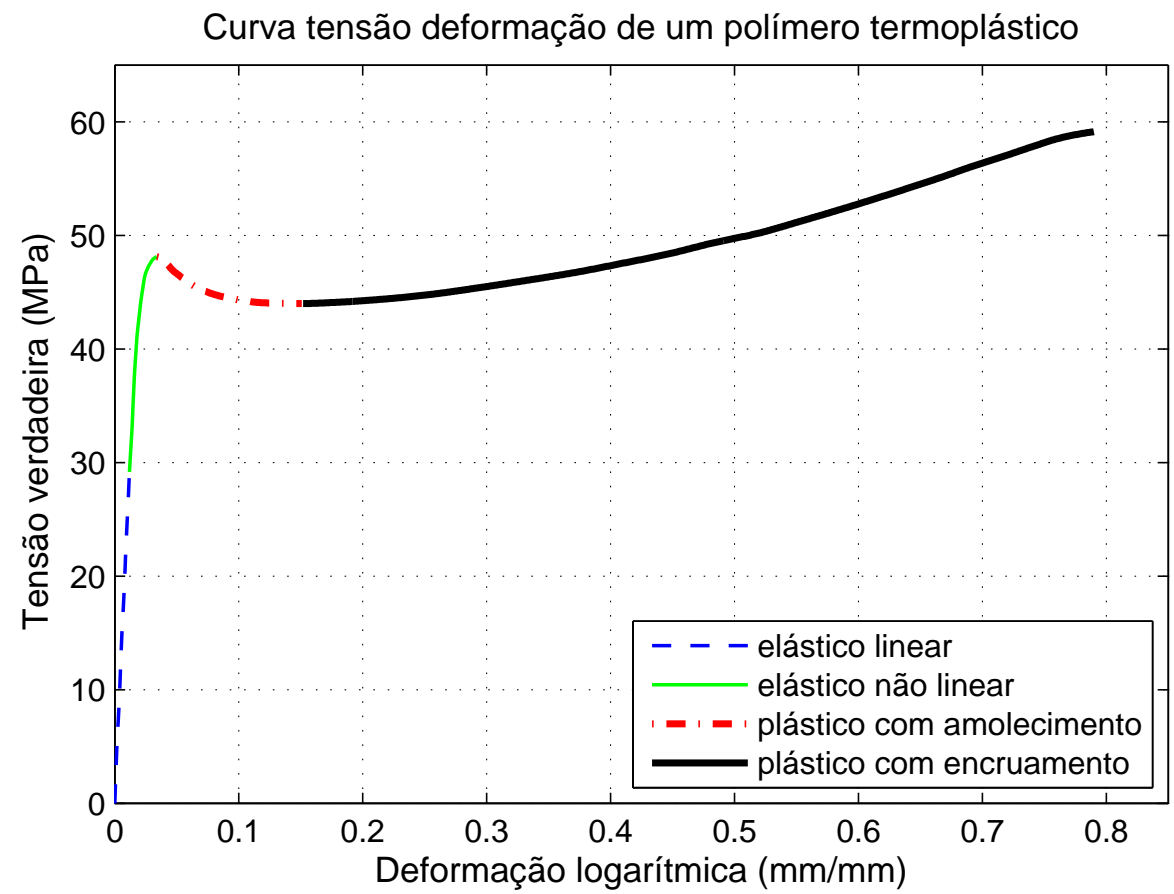

Figura 2.4: Curva tensão deformação de um polímero termoplástico.

\subsubsection{DTMA}

Os limites de operação e fundo de escala de máquinas de tração convencionais impedem seu uso para medirem as propriedades visco-elásticas do material com uma grande acurácia e precisão. Neste contexto, foi desenvolvido o ensaio conhecido como DTMA, sigla para Dynamic Thermal Mechanical Analysis (análise dinâmica termomecânica, em 
Capítulo 2. Revisão de ensaios experimentais e do comportamento mecânico dos polímeros

português) para a investigação do comportamento visco-elástico nesta faixa de taxas de deformação e em um grande espectro de temperaturas. Um exemplo é a DMA-Q800, da Thermal Analysis, ilustrada na fig. 2.5(a). Menard [61] indica que a primeira aparição de uma medição da elasticidade do material por métodos oscilatórins nonrreı em 1909.

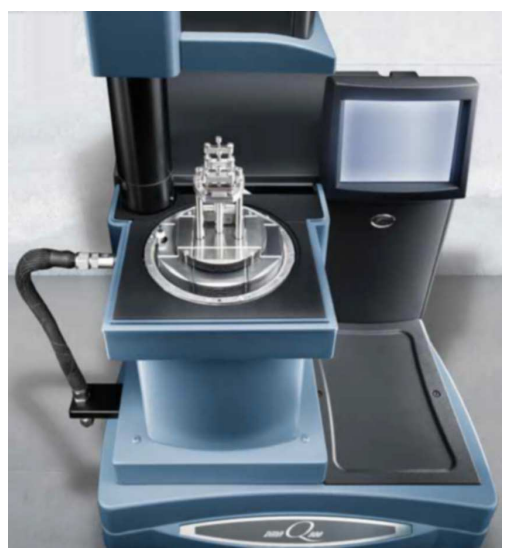

(a) Máquina para ensaios de (b) DTMA TA-Q800

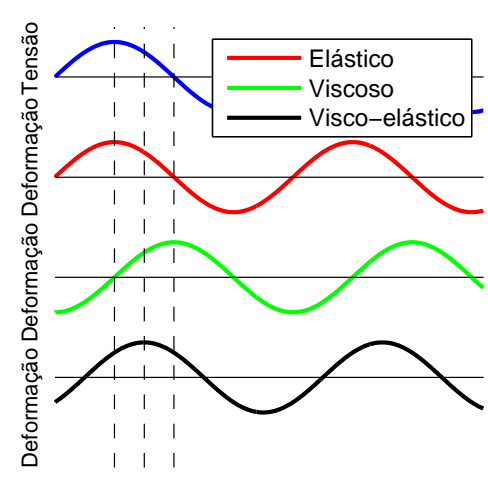

em deformação para diferentes tipos de materiais para um carregamento cíclico

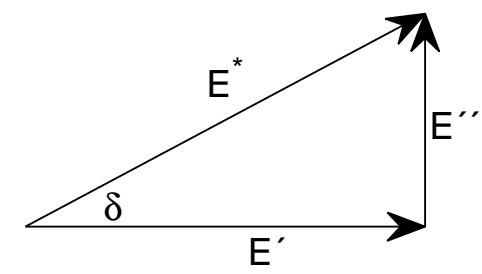

(c) Relação entre módulos Storage e Loss

Figura 2.5: Resultado de um ensaio de relaxação em PMMA.

Neste tipo de teste, cargas oscilatórias programáveis, como tração, compressão, flexão de três pontos ou cisalhamento, são impostas ao corpo de prova através de controles de deslocamento, deformação ou força, com a resposta do corpo de prova podendo estar em fase com a carga, no caso de um material elástico, ou em defasagem com o carregamento, no caso de um material visco-elástico. A fig. 2.5(b) apresenta as respostas de deformação de um material elástico, um viscoso e um visco-elástico à uma carga senoidal de tensão. Considerando uma imposição de deformação no tempo, matematicamente descrita por $\varepsilon(t)=\varepsilon_{0} \operatorname{sen}(\omega t)$, a resposta em tensão para um material visco-elástico pode ser descrita por

$$
\begin{aligned}
\sigma(t)=\sigma_{0} \operatorname{sen}(\omega t+\delta)=\sigma_{0} \cos (\delta) \operatorname{sen}(\omega t)+\sigma_{0} \operatorname{sen}(\delta) & \cos (\omega t)= \\
& =\varepsilon_{0} E^{\prime} \operatorname{sen}(\omega t)+\varepsilon_{0} E^{\prime \prime} \cos (\omega t)
\end{aligned}
$$

com $\delta$ sendo a defasagem entre os senos (conforme demonstrado na fig. 2.5(b)), $E^{\prime}$ o módulo de armazenamento, que mede a resposta em fase com a carga, ou seja, a resposta elástica e é uma medida da energia armazenada durante a deformação visco-elástica, e 
$E^{\prime \prime}$ o módulo dissipativo, que mede a resposta com defasagem de $90^{\circ}$ com a carga, ou seja, a resposta viscosa e é uma medida da energia dissipada durante a deformação viscoelástica. Se definido $E^{*}$ como a relação direta entre as amplitudes máximas de tensão e deformação, $E^{*}=\sigma_{0} / \varepsilon_{0}$, de 2.3 , pode-se concluir que a relação entre estes módulos é dada na forma da variável conhecida por módulo tangente, dada por $\operatorname{tg}(\delta)=E^{\prime} / E^{\prime \prime}$, conforme o diagrama da fig. 2.5(c).

Um gráfico que representa a resposta típica da variação do módulo de armazenamento com a temperatura está presente na fig. 2.6(a). Cada patamar com respectivas quedas à direita do mesmo representa um mecanismo de deformação presente na fig. 2.6(b). A temperatura na qual acontece a queda é conhecida por temperatura de transição, ou seja, em situações abaixo desta temperatura, o mecanismo necessita de uma determinada energia e portanto implica em um resistência mecânica, com um comportamento predominante de um processo elástico de deformação, característico de um sólido. Já acima desta temperatura de transição, não há restrições para o movimento, não havendo tamanha resistência mecânica, sendo predominante o escoamento característico de um fluido com alta viscosidade. De acordo com Ward [92], a transição $\alpha$ é conhecida como temperatura de transição vítrea e esta associada com o grau de liberdade rotacional segmentos da cadeia principal entre as ligações cruzadas.

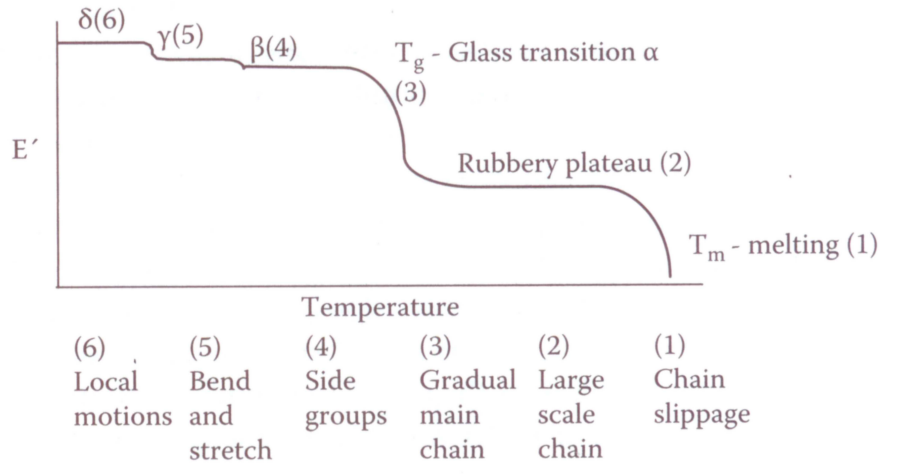

(a) Gráfico típico proveniente de uma análise de DTMA mostrando a variação do Storage modulus com a temperatura

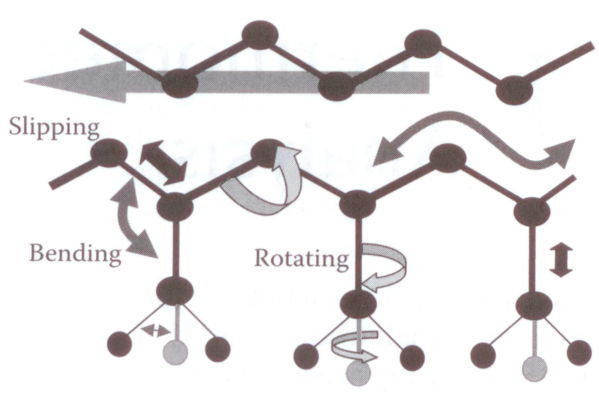

(b) Mecanismos de movimentação possíveis em uma cadeia polimérica

Figura 2.6: Ilustrações dos mecanismos de deformação nos polímeros e sua consequência no comportamento mecânico, retirados de [61].

É chamada de fase a resposta mecânica de cada mecanismo, estando ela ativa se o material está abaixo da temperatura de transição desta fase ou inativa se o material 
Capítulo 2. Revisão de ensaios experimentais e do comportamento mecânico dos polímeros

está acima desta temperatura. Apesar do escopo desta tese não envolver a modelagem numérica de polímeros levando em conta a temperatura, os dados de análises de DTMA são de importância pois determinam quantas fases estão ativas em uma determinada temperatura, já que cada fase terá seu comportamento modelado em separado por um conjunto reológico viscoelastoviscoplástico. Mais do que isso, de acordo com a dissertação de mestrado de Mulliken [74], pode-se aproximar a relação entre a taxa de deformação e a frequência angular do teste como diretamente proporcional, ou seja, quanto maior a frequência do carregamento imposto, maior a taxa de deformação característica do teste. Há um exemplo no manual da máquina da fig. 2.5(a) presente na figura 2.7, indicando que há uma variação da temperatura de transição de uma fase com a variação da taxa de deformação. Em uma temperatura de aproximadamente $105^{\circ} \mathrm{C}$, no teste a $0.1 \mathrm{~Hz}$, nenhuma fase está ativa, enquanto para o ensaio de $10 \mathrm{~Hz}$, há uma fase ativa.

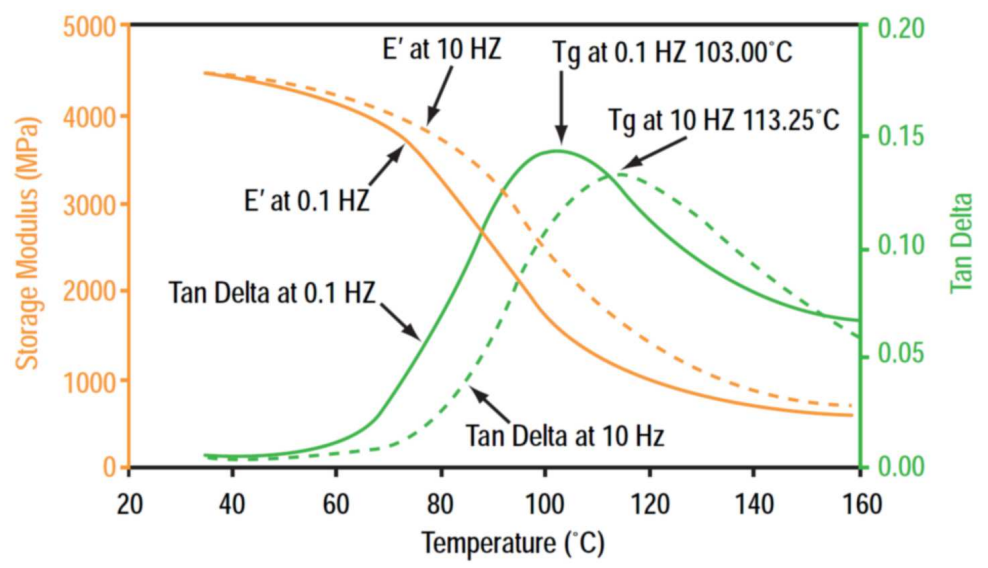

Figura 2.7: Resultados comparativos de testes DTMA para duas frequências diferentes.

Em resumo, conhecer o resultado deste teste para cada polímero estudado nesta tese é importante para estimar-se a quantidade de fases ativas em uma determinada taxa de deformações. Ou seja, determinar se na temperatura ambiente há fases ativas em altas taxas de deformação que não estão ativas nos ensaios experimentais de baixas taxas de deformação.

\subsubsection{Altas taxas de deformação: de $10^{2} \mathrm{~s}^{-1}$ a $10^{4} \mathrm{~s}^{-1}$}

Para se obter informações sobre o comportamento mecânico dos materiais nessa faixa de taxa de deformação, são utilizados os equipamentos baseados nas técnicas de Hopkinson, 
ou seja, nas técnicas de propagação de ondas mecânicas. Provavelmente o equipamento mais utilizado nesse quesito seja a SHPB, iniciais de Split Hopkinson Pressure Bar (ou barra dividida de compressão de Hopkinson, em português). Esse equipamento será detalhado no capítulo 5, mas será apresentada agora uma pequena introdução para a compreensão do seu princípio de funcionamento. A barra de Hopkinson do laboratório do GMSIE está presente na figura 2.8.

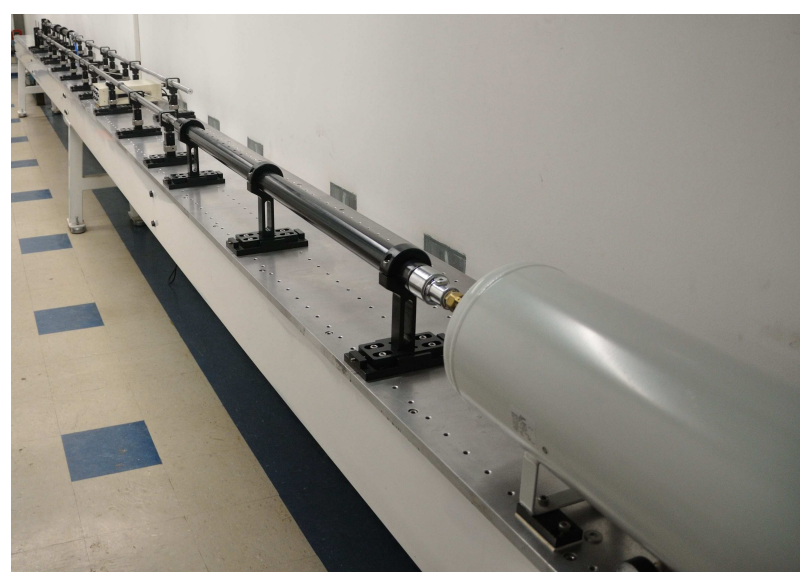

Figura 2.8: Barra de Hopkinson do laboratório do GMSIE, com configurações de compressão e de tração.

O esquema experimental deste equipamento está ilustrado na fig. 2.9, sendo composto por um pequeno cilindro, o striker, duas barras cilíndricas longas, de entrada e saída, equipadas com extensômetros próximos ao seu ponto médio, intercaladas pelo corpo de prova do material que se deseja obter o comportamento mecânico em altas taxas de deformação.

O teste na SHPB consiste em disparar o striker com uma pistola de pressão contra a barra de entrada, gerando uma onda de deformação, $\varepsilon_{i}(t)$, que a percorre. Ao atingir o corpo de prova, parte da onda é refletida, gerando uma onda de deformação $\varepsilon_{r}(t)$, e parte percorre o corpo de prova sendo transmitida para a outra barra, criando a onda de deformação $\varepsilon_{t}(t)$. De maneira semelhante ao teste experimental de compressão em baixas taxas de deformação, a barra fornece dados de deslocamentos e forças obtidos a partir dos sinais dos extensômetros. Entretanto, devido a dinâmica do ensaio, as forças em ambas as faces do corpo de prova não podem ser assumidas iguais no início do teste, com a força na interface 1 sendo maior que na interface 2.

Com esse tipo de tratamento, é obtido o comportamento visco-plástico do material. 
Capítulo 2. Revisão de ensaios experimentais e do comportamento mecânico dos polímeros

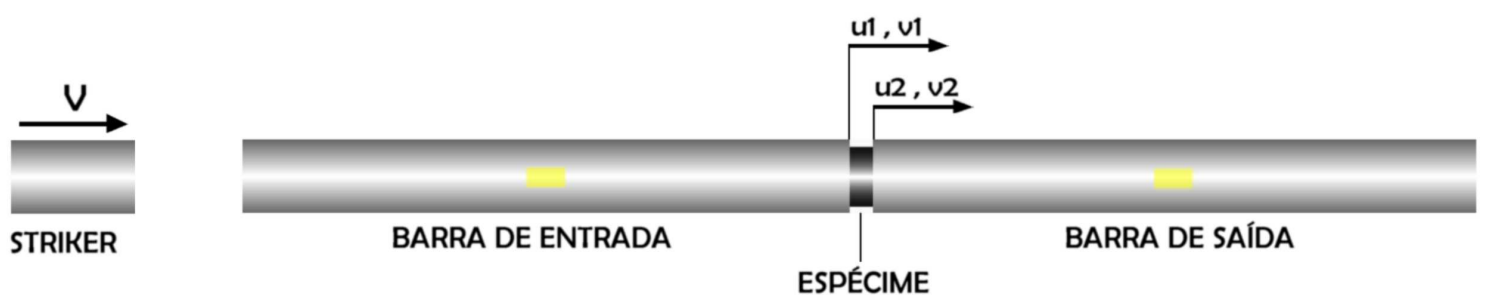

Figura 2.9: Esquemática para compreensão da Barra de Hopkinson.

Contudo, quando o corpo de prova é de polímero, a deformação transmitida é muito baixa, praticamente da mesma ordem de grandeza que o ruído eletromagnético, com ambos sendo amplificados durante o tratamento do sinal do extensômetro, tornando virtualmente impossível garantir os resultados com grande acurácia. A solução deste problema pode ser obtida pela troca de striker e barras de aço por equivalentes em polímeros. Neste ponto, torna-se imprescindível o estudo de propagação de ondas em barras cilíndricas poliméricas, ou seja, o comportamento visco-elástico do material a altas taxas de deformação, de modo a não diminuir a acurácia do ensaio experimental.

\subsubsection{Baixíssimas taxas de deformação: de $0 \mathrm{~s}^{-1}$ a $10^{-5} \mathrm{~s}^{-1}$}

Nessa faixa de taxa de deformação acontecem os fenômenos conhecidos por fluência ou relaxação. Na fluência, a carga é mantida constante e o material se deforma com o passar do tempo, medido nesse caso em horas e dias. No caso da relaxação, uma deformação é imposta ao material e o valor da tensão no mesmo também diminui com o passar do tempo, medido na mesma ordem de grandeza dos ensaios de fluência.

Devido a velocidade extremamente baixa nas partículas que compõe o material durante o ensaio experimental, os efeitos de inércia são desprezíveis. Além disso, mesmo que toda energia de deformação fosse convertida em energia térmica, o teste ainda poderia ser considerado isotérmico, já que a baixa taxa de deformação implicaria em um potência mecânica muito menor do que a potencia dissipativa térmica do material em contato com o ambiente.

É válido ressaltar que, de acordo com [92], ambas fluência e relaxação são resultantes dos mesmos mecanismos responsáveis pela visco-elasticidade polimérica. A figura 2.10 mostra o resultado da queda de tensão no tempo para um ensaio de relaxação em PMMA. 


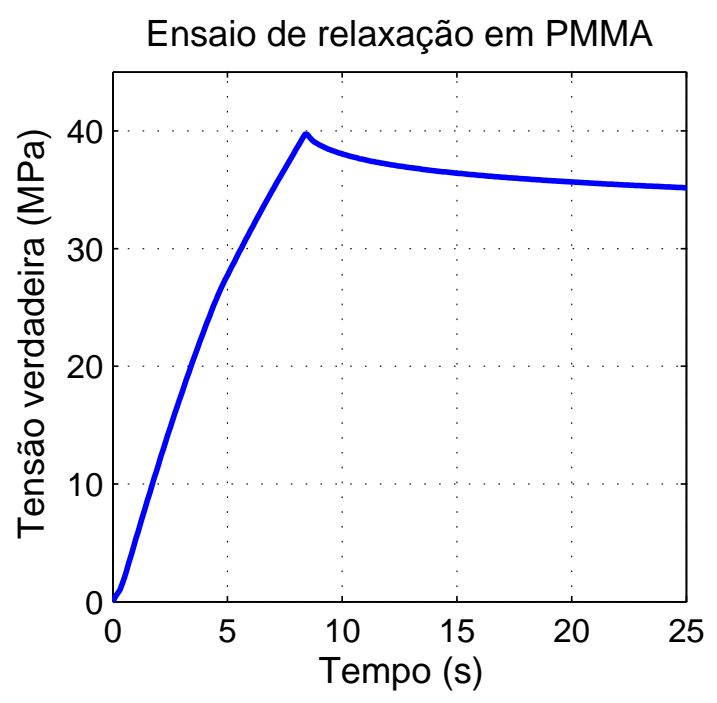

(a) início do teste com carregamento

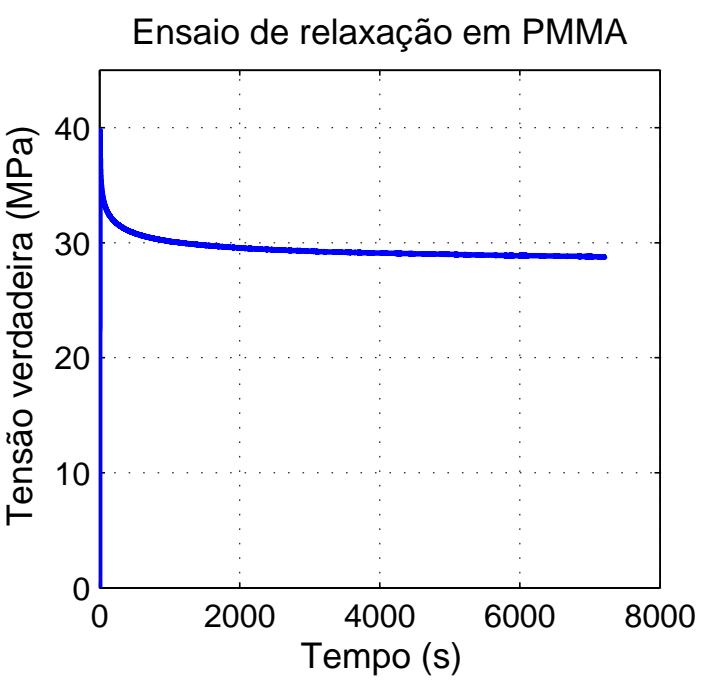

(b) teste completo

Figura 2.10: Resultado de um ensaio de relaxação em PMMA.

\subsubsection{Médias taxas de deformação: de $10^{-1} \mathrm{~s}^{-1}$ a $10^{2} \mathrm{~s}^{-1}$}

De acordo com Nemat-Nasser em 1979 [76], esta faixa de taxa de deformações é feita por máquinas servo-hidráulicas de preço elevado. O GMSIE desenvolveu um aparato experimental denominado TXM, com seu design disposto na fig 2.11(a) e a mesma com todas as peças usinadas e em posição na fig. 2.11(b).

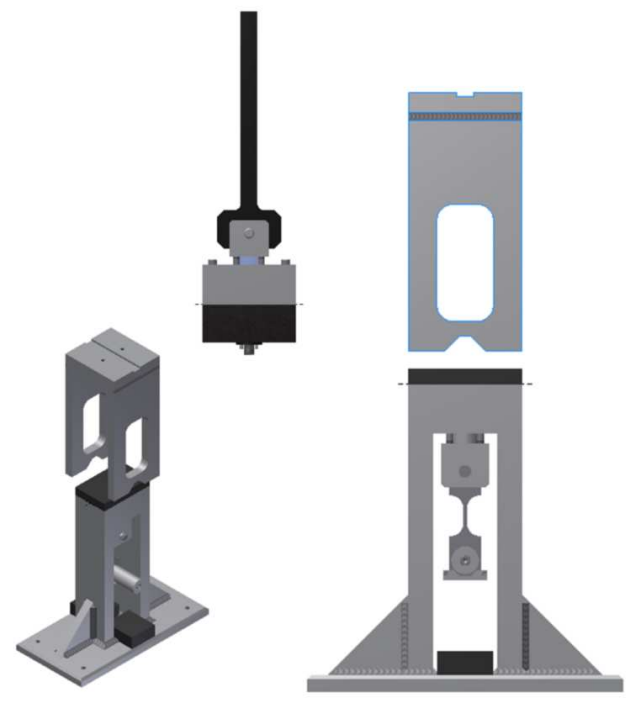

(a)

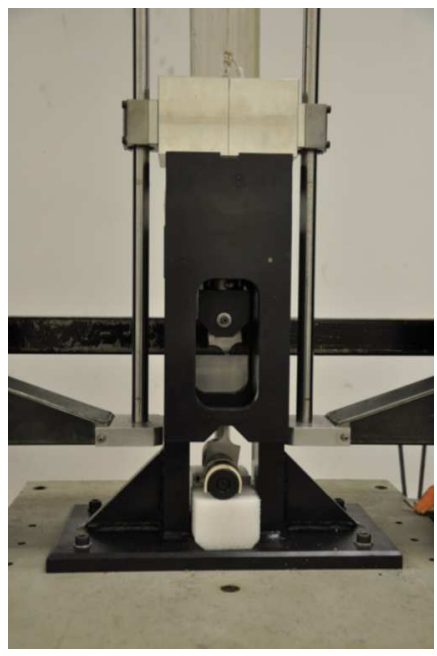

(b)

Figura 2.11: Design e conjunto montado da máquina TXM do laboratório GMSIE. 
Capítulo 2. Revisão de ensaios experimentais e do comportamento mecânico dos polímeros

O conceito por de trás do teste consistem em uma massa impactando uma haste presa na parte inferior do corpo de prova e com a massa sendo suficiente para a energia cinética ser muito maior que a energia necessária para deformar o corpo de prova. Este equipamento foi desenvolvido para ser um acessório do MIBE, ou martelo de impacto de baixas energias, desenvolvido especialmente para alguns ensaios experimentais de outra pesquisa do autor desta tese.

Atualmente, o método para medir o deslocamento imposto ao corpo de prova é o mesmo utilizado nos ensaios de impacto do equipamento, sendo que um laser passa por um orifício na bigorna medindo a velocidade do impactante. A partir de uma derivada numérica encontra-se a aceleração, que multiplicada pela massa de impacto, fornece o histórico temporal da força e a integral da medição do laser fornece a variação do deslocamento no tempo. Desta forma pode-se traçar o gráfico de força deslocamento que descreve o impacto. Durante o projeto do TXM, levou-se em conta a possibilidade de se medir somente a força pelo laser e utilizar uma câmera de alta velocidade e iluminação especial para a medição da deformação através do método ótico DIC, explicado na próxima seção. Pode-se verificar na figura 2.12(a) o espaço deixado para ser possível a filmagem do teste, assim como o resultado na forma de uma curva tensão deformação, disponível na fig. 2.12(b), obtida no ensaio de um corpo de prova de alumínio.

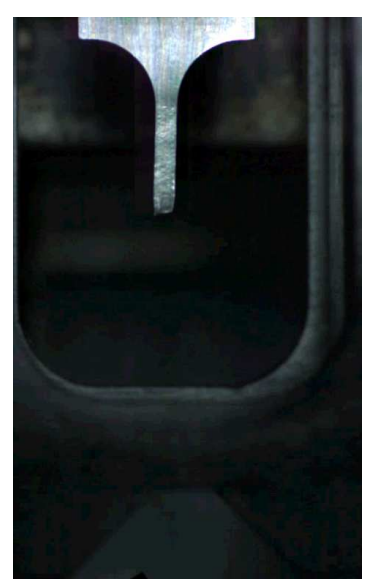

(a)

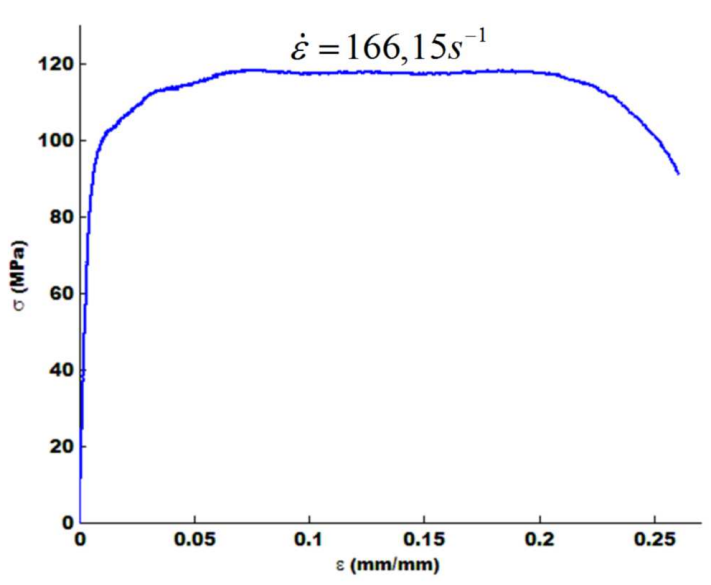

(b)

Figura 2.12: Espaço para visualização do corpo de prova e resultado do teste de um corpo de prova de alumínio. 


\section{$2.3 \quad$ DIC}

\subsubsection{Introdução}

Considere uma imagem digital (ou seja, composta de pixels) de referência, com um determinado ponto $A$. Pode-se definir o padrão de correlação como a região dos pixels no entorno de $A$. Considere também uma segunda imagem digital, diferente da imagem de referência por um deslocamento e/ou deformação.

A correlação digital de imagem ou DIC (Digital Image Correlation), em sua definição mais abrangente, consiste em localizar o ponto $A$ na segunda imagem através de comparação de padrões de correlação. Em outras palavras, DIC é uma técnica utilizada para se medir campos de deslocamento em uma superfície ao correlacionar a imagens da mesma em diferentes estados, em RoI (region of interest, região de interesse em português) delimitada pelo usuário.

Além da imagem digital, também são elementos que caracterizam a técnica DIC:

- marcação por meio de depósitos de materiais que não alterem as propriedades mecânicas do material analisado, de modo a ser possível calcular o deslocamento de um determinado ponto. Em análises macromecânicas, como ensaios de tração, é comum a utilização de uma pintura da superfície do corpo de prova com tinta nas cores branca e preta;

- função para cálculo do coeficiente de correlação entre as funções de nível de cinza na figura de referência, $f(x, y)$, e na figura atual, $f^{*}\left(x^{*}, y^{*}\right)$;

- função de interpolação para calcular a distribuição de nível de cinza entre pixels, permitindo melhorar a acurácia para um nível de subpixel;

- funções representativas do campo de deslocamento $u(x, y)$ e $v(x, y)$, sendo utilizadas tanto para a melhora da acurácia em um processo iterativo de mudança de forma e tamanho do padrão de correlação quanto no cálculo do gradiente de deformações, possibilitando a obtenção de diversos tipos de tensores de deformação.

Um dos motivos da popularização deste método é o seu baixo custo, já que na grande maioria dos casos o padrão é randomicamente aplicado através de tintas pulverizadas sobre a superfície, sendo aplicada primeiro uma camada branca, seguida de uma aplicação 
Capítulo 2. Revisão de ensaios experimentais e do comportamento mecânico dos polímeros

com uma distância necessária para se obter apenas pontos esparsos de tinta preta. É de supra importância a realização do teste prontamente após a pintura para que a tinta se deforme com a superfície, uma vez que se esta secar, irá craquelar durante a deformação da mesma. Não existe uma regra para a pintura da superfície, entretanto [90] criou duas leis empíricas, sendo elas: i) o tamanho médio de um ponto deve ser menor que 20 pixels; ii) os níveis de cinza podem variar entre 0 e 255, mas devem variar entre dois pixels consecutivos. Deve sempre haver um compromisso entre a dimensão física do padrão, da resolução, zoom (ótico) da foto e da acurácia pretendida. Por exemplo, dada a pintura de uma superfícies com tintas spray, não há sentido em utilizar-se de técnicas óticas para aumentar a relação pixels por metros e obter mais de 50 pixels em um ponto preto no padrão randômico. Neste caso, para se obter uma maior acurácia nos resultados, seriam necessários outros métodos de aplicação do padrão em conjunto com as técnicas óticas, sendo um exemplo utilizar-se de um pó fino preto (comum em tonners de impressoras a laser) aplicado sobre a pintura branca. Apesar de haverem outras marcações possíveis, como utilizar-se uma grade regular de círculos, discos ou cruzes, Doumalin e Bornert [43] comprovaram que a acurácia é melhor no padrão randômico.

O procedimento matemático desta técnica consiste em calcular o coeficiente de correlação de uma determinada área, denominada padrão de correlação, ao redor do ponto que se deseja descobrir a posição na segunda imagem, por meio das funções de nível de cinza $f(x, y)$ na imagem de referência e $f^{*}\left(x^{*}, y^{*}\right)$ na segunda imagem, repetindo-se este procedimento entre a imagem de referência e a terceira, entre a imagem de referência e a quarta e assim por diante.

Para melhorar a acurácia no cálculo, é utilizada uma função de interpolação a cada 4 pixels adjacentes, com um sistema de coordenadas naturais locais variando entre 0 e 1. Esta pode ser bilinear ou bicúbica. Neste trabalho foi escolhido este segundo tipo por facilitar a localização do mínimo global na superfície de correlação ao deixá-la sem ruídos, apesar de possuir maior custo computacional.

Uma particularidade do software 7D utilizado é sua capacidade iterativa. Em uma análise, a região de interesse é dividida em elementos quadrados, de tamanho determinado pelo usuário, com uma região quadrada no entorno de cada vértice, que será o padrão de correlação daquele ponto, também com tamanho definido pelo usuário. É importante ressaltar que cada elemento quadrilátero da região de interesse possui quatro pontos inde- 
pendentes dos vértices de outros quadriláteros. O processo iterativo, realizado para cada elemento, consiste em: $i$ ) localizar a posição de cada vértice do elemento na segunda imagem, com um padrão de correlação igual ao definido pelo usuário para a imagem de referência; ii) Com as novas posições dos quatro vértices, calcular o campo de deslocamentos interior ao elemento; iii) recalcular a posição de cada um dos quatro vértices de um elemento, aplicando-se o campo de deslocamentos no padrão de correlação de cada vértice, ou seja, deformando-o da mesma maneira que o elemento inicial quadrado foi deslocado. Os passos ii e iii se repetem até que o deslocamento em cada ponto para cada iteração seja menor que um delta definido pelo usuário ou até um número limite de iterações também definido pelo usuário. Este tipo de iteração é importante ao se trabalhar com materiais que sofrem grandes deformações. Um exemplo está ilustrado na fig. 2.13, que mostra o padrão de correlação na imagem de referência e em outra 640 segundos depois. Uma análise visual através de todas as imagens possibilitou a determinação do padrão de correlação na imagem de referência e no instante 640 segundos, com a medida horizontal aumentando e a vertical diminuindo. Para facilitar a comparação com a imagem de referência, a proporção entre os eixos vertical e horizontal foi modificado e exibido na fig. 2.13(b) com o intuito de deixá-la aproximadamente com as mesmas medidas da imagem de referência.

\subsubsection{Cálculo de deformações e tensões}

O software comercial de DIC 7D foi utilizado para o tratamento das imagens, fornecendo arquivos .mat como saída. Estes contém a deformação de Green em $x$, em $y$ e $x y$. As análises destes arquivos .mat foram realizados no software comercial Matlab ${ }^{\circledR}$, primeiro gerando as imagens das fotografias sobrepostas das malhas com representação com níveis de cores em escala representando deformações axiais ou deformações transversais ou taxa de deformação axial (após o cálculo levando em conta o intervalo entre uma fotografia e a seguinte). A partir de então, é feita uma média destes valores para cada secção transversal analisada no 7D. Com estes valores médio, calcula-se a tensão verdadeira, a partir dos dados de força coletados pela célula de carga, deformação logarítmica e taxa de deformação logarítmica em cada seção transversal.

Considere agora um corpo de prova de tração, de comprimento inicial $l=l_{0}$, largura inicial $w=w_{0}$ e espessura inicial $t h=t h_{0}$, e que durante o ensaio experimental, o 
Capítulo 2. Revisão de ensaios experimentais e do comportamento mecânico dos polímeros

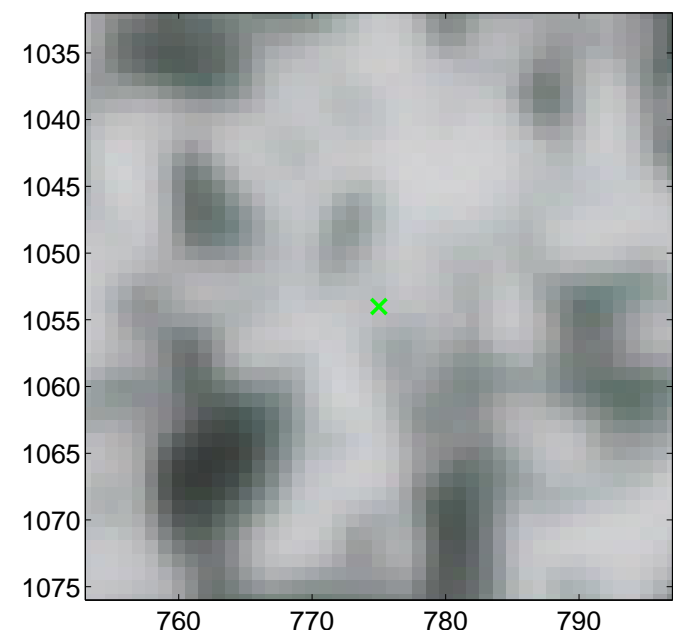

(a) figura de referência obtida antes do teste

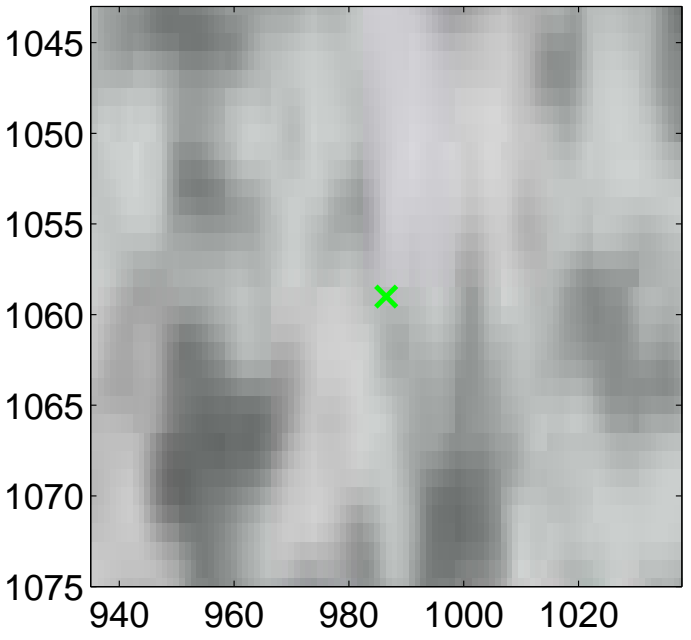

(b) Sexagésima quarta figura obtida no decorrer do teste, no instante $\mathrm{t}=640 \mathrm{~s}$, com proporção entre eixos x e y diferente de 1

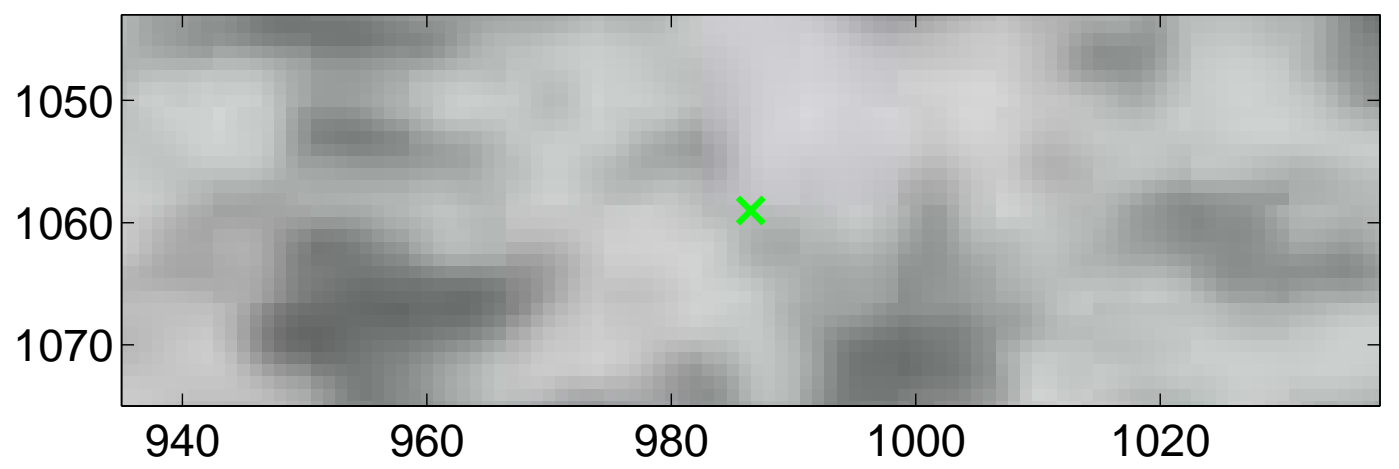

(c) Sexagésima quarta figura obtida no decorrer do teste, no instante $t=640 \mathrm{~s}$, com proporção entre eixos $\mathrm{x}$ e $\mathrm{y}$ de 1

Figura 2.13: Padrões de correlação gerados para análise comparativa de acurácia em deslocamento.

comprimento $l$ aumenta e tanto a largura $w$ quanto a espessura th diminuem (para a maioria dos materiais, nos quais o coeficiente de poisson $\nu>0$ ). A medida mais simples de deformação axial é conhecida por alongamento (stretch), $\lambda_{1}$, e definida pelo coeficiente do comprimento atual pelo inicial, $\lambda_{1}=\frac{l}{l_{0}}$, com o subscrito ${ }_{1}$ indicando a direção principal que coincide com a direção no qual é realizado o ensaio de tração neste tipo de experimento. As outras medidas de deformação podem ser definidas a partir dos comprimento inicial e atual ou da relação entre eles, o alongamento, sendo estas com suas respectivas datas de origem e formulações:

- Deformação de Cauchy (1827) $\varepsilon^{C}=\frac{l-l_{0}}{l_{0}}=\lambda-1$; 
- Deformação de Green (1839) $\varepsilon^{G}=\frac{l^{2}-l_{0}^{2}}{2 l_{0}^{2}}=\frac{1}{2}\left(\lambda^{2}-1\right)$;

- Deformação de Almansi (1911) $\varepsilon^{A}=\frac{l^{2}-l_{0}^{2}}{2 l^{2}}=\frac{1}{2}\left(1-\lambda^{-2}\right)$;

- Deformação de Swainger (1947) $\varepsilon^{S}=\frac{l-l_{0}}{l}=1-\lambda^{-1}$;

- Deformação de Hencky (1839) $\varepsilon^{H}=\int_{l_{0}}^{l} \frac{d l}{l}=\ln \left(\frac{l}{l_{0}}\right)=\ln (\lambda)$;

De acordo com [87], uma dada formulação não possui grandes vantagens sobre as outras se o problema no qual forem empregadas for resolvido de maneira consistente. A escolha de uma ou outra formulação, na maioria dos casos, depende da relação desta com a tensão ou com a função de energia.

A transformação da deformação de Green em deformação de Hencky ou logarítmica pode ser dada por

$$
\left.\begin{array}{l}
\varepsilon^{G}=\frac{1}{2}\left(\lambda^{2}-1\right) \rightarrow \lambda=\sqrt{2 \varepsilon^{G}+1} \\
\varepsilon^{H}=\ln (\lambda)
\end{array}\right\} \rightarrow \varepsilon^{H}=\ln \left(\sqrt{2 \varepsilon^{G}+1}\right)
$$

No que diz respeito a tensão, assumindo um estado uniaxial de tensões enquanto a deformação axial é homogênea por todo o corpo de prova, e que a aproximação por um estado uniaxial de tensões durante a localização na estricção não acarretará em grandes erros, a tensão de engenharia é calculada por $\sigma_{e n g}=F / A_{0}$ e real ou verdadeira por $\sigma=F / A \operatorname{com} F$ a força axial medida na célula de carga, $A_{0}$ a área inicial e $A$ a área atual. Como o programa utilizado fornece as deformações de Green, é válido escrever a área em função da deformação transversal de Green, $\varepsilon_{\text {trans }}^{G}$, e da área inicial, $A_{0}=w_{0} t h_{0}$, por

$$
\begin{aligned}
A & =w t h \\
& =w_{0} \sqrt{2 \varepsilon_{\text {trans }}^{G}+1} t h_{0} \sqrt{2 \varepsilon_{\text {trans }}^{G}+1} \\
& =w_{0} t h_{0}\left(2 \varepsilon_{\text {trans }}^{G}+1\right) \\
& =A_{0}\left(2 \varepsilon_{\text {trans }}^{G}+1\right)
\end{aligned}
$$

uma vez assumida a hipótese de que a deformação na largura é a mesma deformação na espessura. 
Capítulo 2. Revisão de ensaios experimentais e do comportamento mecânico dos polímeros

\subsubsection{Comparação com outros métodos de medição por um exem- plo em material metálico}

Um corpo de prova de tração de aço foi usinado a partir de uma chapa de $3 \mathrm{~mm}$ de espessura com largura de $12,5 \mathrm{~mm}$ e comprimento de $82,5 \mathrm{~mm}$. A velocidade imposta pela máquina de ensaios universais Instron 3369 foi de $0.004125 \mathrm{~mm} / \mathrm{s}$, resultando em um taxa de deformação nominal de $510^{-5} \mathrm{~s}^{-1}$. As fotos foram obtidas em intervalos de 10 segundos. Duas análises foram feitas com a técnica DIC, sendo uma utilizando todas as fotos somente na região elástica e outra utilizando uma a cada cinco fotos mas cobrindo todo o ensaio experimental. A figura 2.14 avalia a distribuição da componente de deformação verdadeira no eixo do corpo de prova.

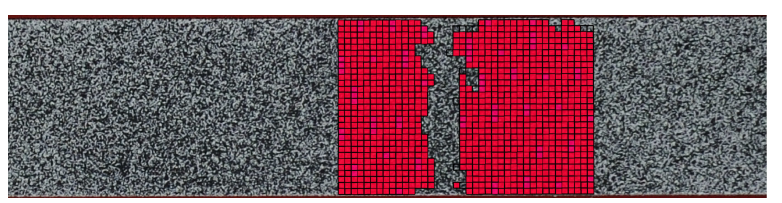

(a) $\mathrm{t}=0 \mathrm{~s}$

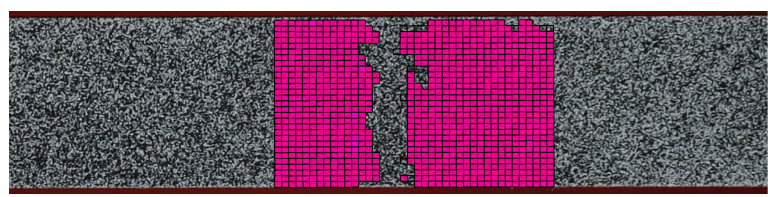

(c) $\mathrm{t}=2050 \mathrm{~s}$

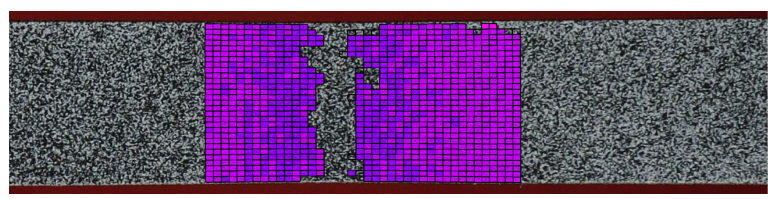

(e) $\mathrm{t}=4050 \mathrm{~s}$

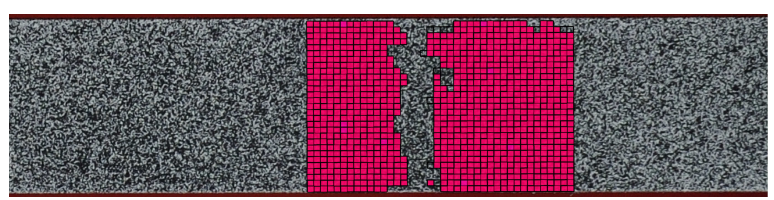

(b) $\mathrm{t}=1050 \mathrm{~s}$

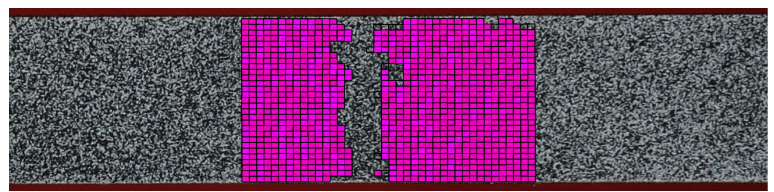

(d) $\mathrm{t}=3050 \mathrm{~s}$

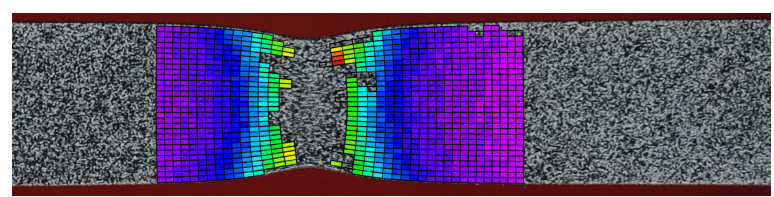

(f) $\mathrm{t}=5050 \mathrm{~s}$

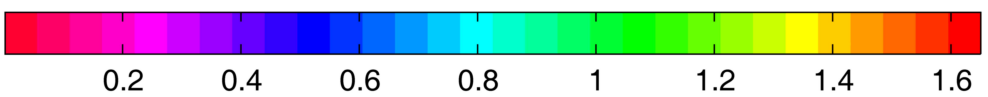

Figura 2.14: DIC aço teste $\mathrm{x}$ sim.

Até o instante $\mathrm{t}=3050$, o campo de deformações é homogêneo, sendo o inicio da localização em aproximadamente $\mathrm{t}=4050 \mathrm{~s}$. A partir de então, a distribuição de deslocamentos deixa de ser linear, com a região próxima da secção de menor área da estricção concentrando grande parte de cada acréscimo de deslocamento imposto pela máquina, mantendo assim constante ou mesmo reduzindo a deformação do restante do corpo de prova. Outro corpo de prova idêntico de aço foi ensaiado na mesma máquina, sob os mesmos parâmetros, embora desta vez utilizou-se de 2 clip-gages, de $25 \mathrm{~mm}$ e $50 \mathrm{~mm}$ de 
comprimento, para a medição da deformação. A fig 2.15 contém a curva tensão deformação calculada a partir de cada método de medição, com o ponto em destaque sendo o valor máximo de força, ou seja, o momento em que se inicia a estricção.

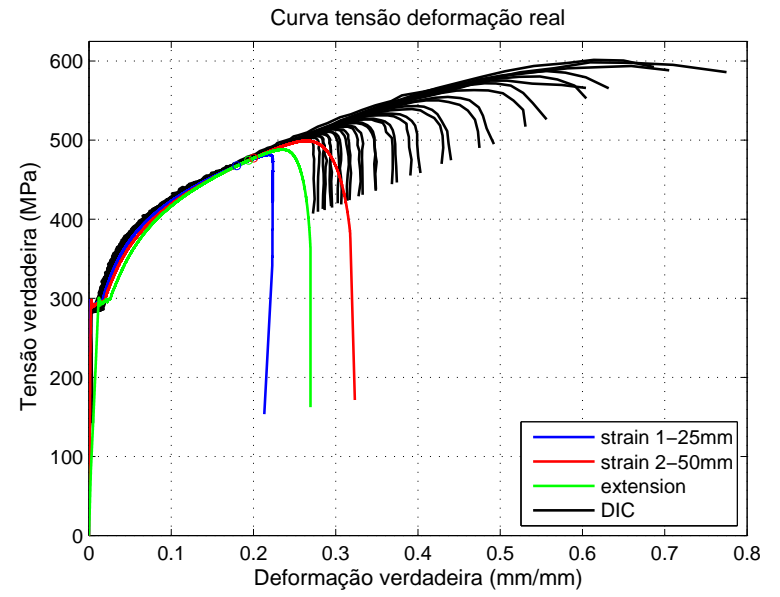

(a) simulação
Comparação entre simulação numérica e resultados provindos do DIC

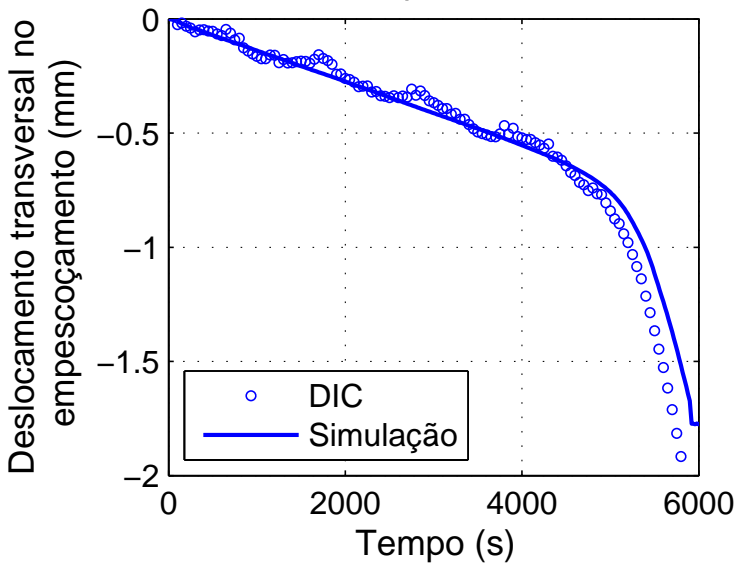

(b) comparação dos resultados

Figura 2.15: DIC aço teste $\mathrm{x}$ sim.

Apesar dos valores aceitavelmente próximos obtidos pelos três métodos e de um mesmo comportamento durante a maior parte do teste, há uma diferença no início que apesar de pequena, influenciará no cálculo futuro do módulo elástico. Esta diferença pode ser explicada pelo seguinte raciocínio: apesar de manualmente forçar uma cunha contra a outra de modo a fixar o corpo de prova, durante a imposição de deslocamentos pelo crosshead, o efeito de cunha irá forçar ainda mais uma cunha contra a outra, havendo um movimento relativo entre as mesmas e cross-head, ou seja, parte do deslocamento imposto é absorvido por uma movimentação vertical da cunha e a outra parte será aplicada ao corpo de prova. Como os clip-gages estão afixados diretamente no corpo de prova, os valores medidos são idênticos ao da técnica DIC no início do teste. A partir deste momento de força máxima, começa o processo de localização que invalida os resultados obtidos pelos clip-gages, já que estes medem o deslocamento total e é assumida homogeneidade durante o cálculo da deformação real (além de isovolumetria). Enquanto a localização é pequena, os resultados estão próximos, mas conforme a localização aumenta, os resultados obtidos pelos clip-gages se distanciam dos obtidos pela técnica DIC. Vale ressaltar que, enquanto os métodos comuns foram capazes de medir com precisão até deformações 
Capítulo 2. Revisão de ensaios experimentais e do comportamento mecânico dos polímeros

de aproximadamente 0.25 , o método óptico conseguiu medir as deformações até o valor de 0.7 , quase o triplo.

Com o objetivo de testar os resultados obtidos, a curva tensão-deformação referente a secção transversal central da estricção foi modelada em segmentos de reta, servindo de dados de entrada para o modelo de material de plasticidade linear por partes (MAT_024 ou MAT_PIECEWISE_LINEAR_PLASTICITY) do programa comercial de elementos finitos Ls-Dyna. Como elemento de avaliação, foi escolhido o deslocamento transversal no tempo do elemento nó superior da secção transversal central da estricção, com os resultados explicitados na fig. 2.15(b).

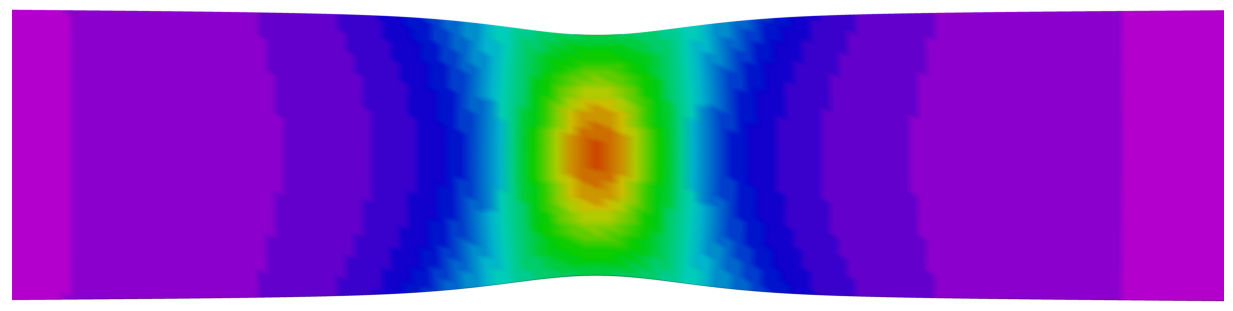

(a) simulação numérica em elementos finitos
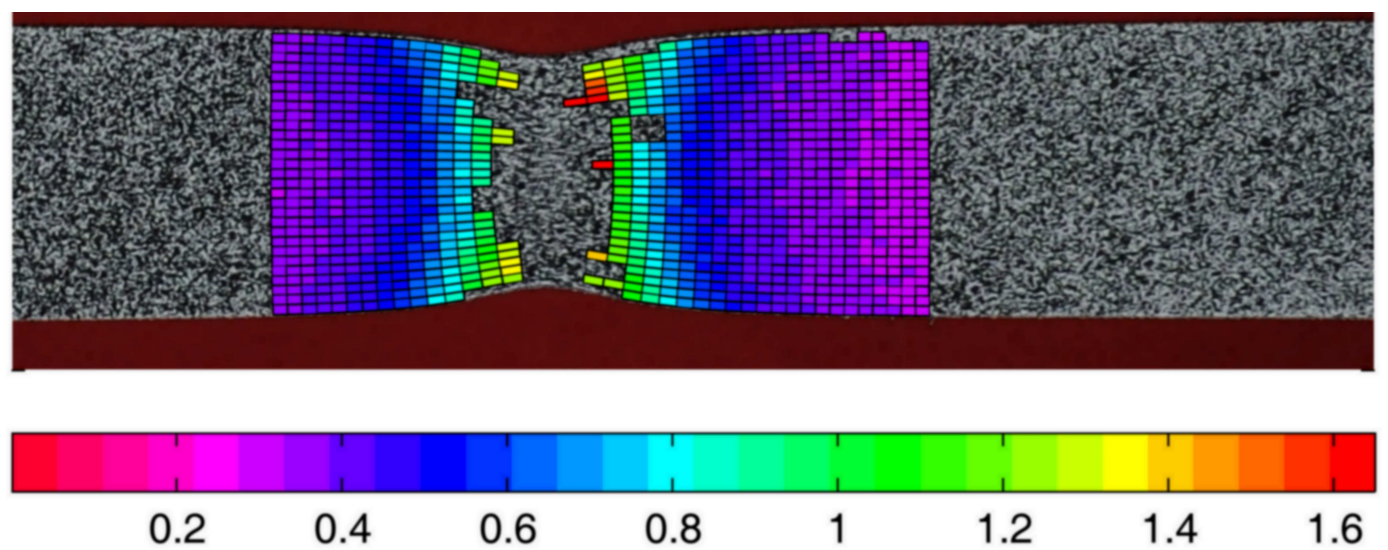

(b) resultado DIC

Figura 2.16: Comparação da distribuição da deformação verdadeira axial obtidos na simulação numérica e da análise do ensaio experimental via DIC

Não somente a geometria da estricção foi obtida na simulação numérica, como visto pela excelente grau de coincidência entre o deslocamento transversal obtidos na simulação numérica, sem o uso de nenhum tipo de modelo de dano, e experimental, pode-se notar na fig. 2.16 que até mesmo as distribuições das deformações axiais são coincidentes. Estes resultados não somente validam a técnica de análise de deformações DIC, como também mostram todo o potencial da mesma. 
Ainda sob uma perspectiva de comparação com outras técnicas de medição de deslocamentos e deformações, é válido citar o trabalho de Delhaye [26] que comparou a técnica DIC com outra técnica óptica de video traction com 7 marcas em um polímero com matriz de prolipropileno e partículas de borracha etileno-propileno. Nesta outra técnica óptica, são marcados 7 pontos na região do entalhe, conforme a fig. 2.17(a). A deformação axial real no meio do elemento de volume representativo é calculada pela interpolação das quatro deformações parciais $\varepsilon_{A B}^{H}, \varepsilon_{B C}^{H}, \varepsilon_{C D}^{H}, \varepsilon_{D E}^{H}$ enquanto a transversal é calculada pela interpolação de $\varepsilon_{F C}^{H}$ e $\varepsilon_{C G}^{H}$. Os resultados finais comparativos na forma de curvas tensão deformação real encontram-se na fig. 2.17(b). Os resultados estão próximos o suficiente para serem considerados iguais, entretanto enquanto a técnica DIC fornece a distribuição de deformações ao longo de grande parte do corpo de prova, a técnica de video traction fornece apenas no elemento de volume representativo.

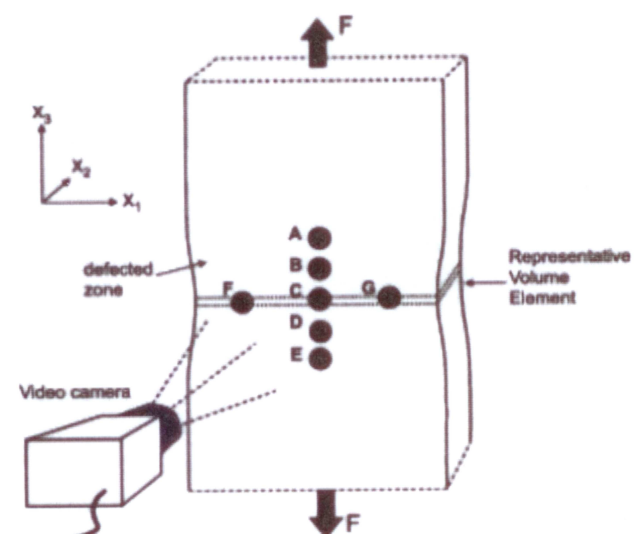

(a) esquemática da técnica de Video Traction com 7 marcas

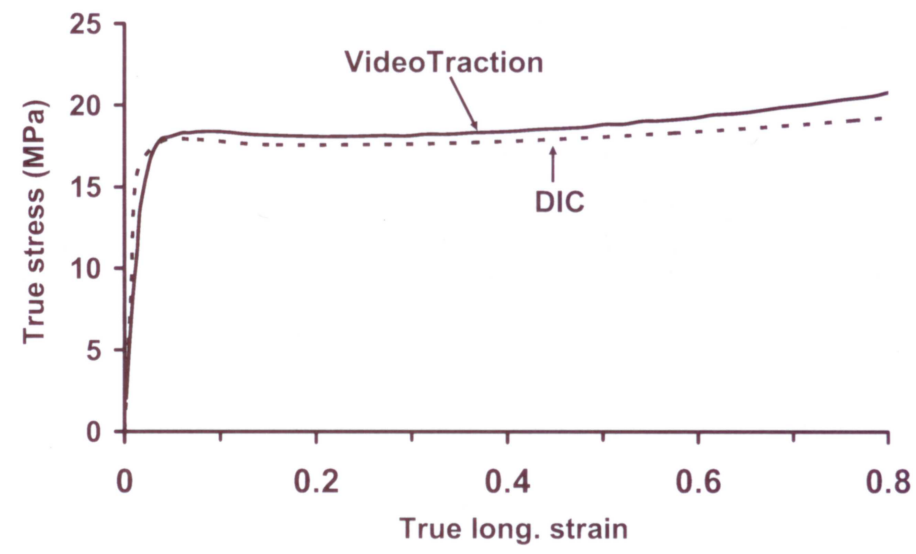

(b) comparação com resultado obtido por DIC

Figura 2.17: Comparação entre a técnica DIC e Video Traction com 7 marcas. Retirado de $[26]$ 


\section{Capítulo 3}

\section{Revisão de mecânica dos sólidos e modelos constitutivos}

\subsection{Introdução}

Esse capítulo tem por objetivo principal revisar as principais ferramentas matemáticas tensoriais, as leis da mecânica dos sólidos e alguns modelos constitutivos para polímeros através de leis hiperelásticas, leis de escoamento plástico e leis de escoamento viscoso. Esses conhecimentos são essenciais para a proposição de um modelo de material para polímeros capaz de representar seu comportamento mecânico a altas taxas de deformação, tanto em regime elástico quanto plástico. Este novo modelo é a combinação do modelo de material visco-plástico proposto por Mulliken [75] com a estrutura cinemática visco-elástica proposta por Bergstrom [13], com seu equacionamento e implementação em Matlab ${ }^{\circledR}$ e Fortran detalhados no cap.6 .

Serão apresentadas as ferramentas matemáticas necessárias para a compreensão da álgebra tensorial e a definição sucinta dos tensores de deformação e tensão e suas taxas temporais. Estas definições e operações tensoriais formam a base para a compreensão dos modelos de material descritos no âmbito de mecânica dos sólidos não linear para grandes deformações.

Este embasamento é seguido por uma descrição do framework cinemático baseado na divisão multiplicativa do gradiente de deformações, o qual de acordo com Belytschko et al. [10] surgiu quando do desenvolvimento de modelos hiper-elastoplásticos como uma alternativa ao modelo hipo-elastoplástico.

A seguir, são descritas as relações constitutivas elásticas mais utilizadas para políme- 
ros, assim como as funções mais comuns de escoamento tanto plástico quanto viscoso. Estas relações constitutivas e funções de escoamento, juntamente com uma estrutura cinemática, constituem o conjunto de equações que representam o comportamento mecânico de um material. Por fim, apresenta-se um resumo de alguns modelos de material desenvolvidos nas últimas décadas.

\subsection{Preliminares}

Nesta seção, serão apresentadas de maneira sucinta algumas definições dos tensores de mecânica do contínuo não linear, priorizando a descrição da estrutura cinemática baseado na divisão multiplicativa do gradiente de deformações, de relações constitutivas, de funções de escoamento plástico e de funções de escoamento viscoso. O apêndice A apresenta detalhes da mecânica do contínuo linear e o apêndice B apresenta propriedades dos tensores e as equações de conservação de massa, momento linear, momento angular e energia.

Vetores podem ser definidos como a representação matemática de quantidades físicas que possuem módulo, direção e sentido. Versor é um vetor de módulo unitário. Um vetor pode ser representado como uma combinação linear de três versores, cada um sobre um eixo cartesiano, através da notação de Einstein ou por uma matriz coluna, ou seja,

$$
\mathbf{v}=\sum_{i=1}^{3} v_{i} \mathbf{e}_{i}=v_{i} \mathbf{e}_{i}=\left[\begin{array}{c}
v_{1} \\
v_{2} \\
v_{3}
\end{array}\right]
$$

Um tensor $\mathbf{S}$ de segunda ordem é um mapeamento linear entre dois vetores. Neste caso, as notações são matematicamente representadas por [15]

$$
\begin{aligned}
& \mathbf{v}=\mathbf{S u} \Leftrightarrow \sum_{i=1}^{3} v_{i} \mathbf{e}_{i}=\sum_{i=1}^{3}\left(\sum_{j=1}^{3} S_{i j} v_{j}\right) \mathbf{e}_{i} \Leftrightarrow v_{i}=S_{i j} v_{j} \Leftrightarrow \\
& \Leftrightarrow\left[\begin{array}{l}
v_{1} \\
v_{2} \\
v_{3}
\end{array}\right]=\left[\begin{array}{lll}
S_{11} & S_{12} & S_{13} \\
S_{21} & S_{22} & S_{23} \\
S_{31} & S_{32} & S_{33}
\end{array}\right]\left[\begin{array}{l}
u_{1} \\
u_{2} \\
u_{3}
\end{array}\right]
\end{aligned}
$$

com os tensores de terceira e quarta ordem podendo ser representados matricialmente apenas pela notação de Voigt (verificar [10] para mais detalhes.)

Uma síntese das operações tensoriais mais utilizadas na mecânica dos sólidos pode ser dada por: 
- · é o produto escalar entre vetores, $\mathbf{a} \cdot \mathbf{b}=a_{i} b_{i}=[\mathbf{b}]^{T}[\mathbf{a}]$, ou a contração para operação entre um vetor e um tensor, $\mathbf{A} \cdot \mathbf{a}=A_{i j} a_{j}$ e entre tensores $\mathbf{A} \cdot \mathbf{B}=A_{i j} B_{j k}$;

- : é a contração entre tensores dada por $\mathbf{A}: \mathbf{B}=A_{i j} B_{i j}=\operatorname{tr}\left(\mathbf{A}^{T} \mathbf{B}\right)$ ou $\mathbf{C}: \mathbf{D}=$ $C_{i j k l} D_{k l}$. O traço de um tensor, tr, pode ser definido como a contração com o tensor identidade, $\operatorname{tr}(\mathbf{A})=\mathbf{I}: \mathbf{A}$;

- $\times$ é o produto cruzado, definido por $\mathbf{a} \times \mathbf{b}=e_{i j k} a_{j} b_{k}$;

- $\otimes$ é o produto vetorial ou produto diádico, definido por $\mathbf{a} \otimes \mathbf{b}=a_{i} b_{j}=[\mathbf{a}]^{T}[\mathbf{b}]$, com uma relação interessante sendo $\operatorname{tr}(\mathbf{a} \otimes \mathbf{b})=\mathbf{a} \cdot \mathbf{b}$;

- ||$_{F}$ é o módulo de Frobenius, definido por $|\mathbf{A}|_{F}=\sqrt{\mathbf{A}: \mathbf{A}}=\sqrt{\operatorname{tr}\left(\mathbf{A}^{T} \mathbf{A}\right)}$. Para um vetor, o módulo pode ser calculado por $|\mathbf{u}|=\sqrt{\mathbf{u} \cdot \mathbf{u}}$;

Uma propriedade importante de tensores utilizada na mecânica do contínuo é a possibilidade de decompô-los em uma parte simétrica e uma anti-simétrica. Um tensor A é simétrico quando $\mathbf{A}=\mathbf{A}^{T}$ e anti-simétrico quando $\mathbf{A}=-\mathbf{A}^{T}$. Essa decomposição pode ser deduzida por

$$
\mathbf{A}=\frac{1}{2}\left(\mathbf{A}+\mathbf{A}+\mathbf{A}^{T}-\mathbf{A}^{T}\right)=\frac{1}{2}\left(\mathbf{A}+\mathbf{A}^{T}\right)+\frac{1}{2}\left(\mathbf{A}-\mathbf{A}^{T}\right)=\mathbf{A}^{s i m}+\mathbf{A}^{a n t}
$$

Os três invariantes importantes de um tensor A são definidos por

$$
I_{1}=\mathbf{I}: \mathbf{A} \quad I_{2}=\mathbf{A}: \mathbf{A} \quad I_{3}=\operatorname{det}(\mathbf{A})
$$

Considere agora um corpo em seu estado inicial, denotado por $\Omega_{0}$, no instante $t=0$, fig. 3.1, o qual será a configuração de referencia adotada aqui. Já o domínio do corpo na configuração atual é denotado $\Omega$, também chamada de configuração deformada.

O vetor posição de um ponto do material na configuração inicial é dado por $\mathbf{X}$ e chamado de coordenada material ou de Lagrange e não varia com o tempo. Já o vetor posição, $\mathbf{x}$, de uma partícula referenciada pelo vetor na sua configuração inicial $\mathbf{X}$ determinado ponto material $\mathbf{X}$ pode ser escrito por $\mathbf{x}=\mathbf{\Phi}(\mathbf{X}, t)$ com $\mathbf{\Phi}$ uma função de mapeamento.

Para correlacionar um segmento infinitesimal na configuração de referência, $d \mathbf{X}$, com o segmento infinitesimal correspondente na configuração atual, $d \mathbf{x}$, utiliza-se o gradiente 


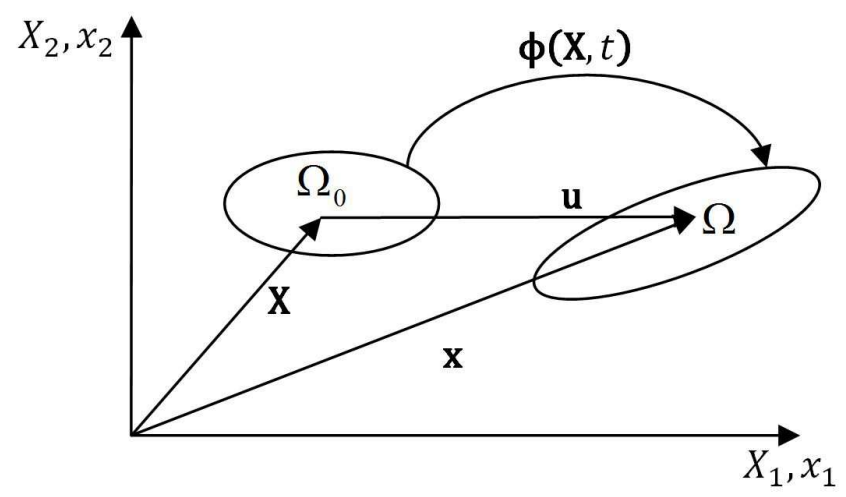

Figura 3.1: Configuração de referência $\Omega_{0}$, configuração atual $\Omega$, vetor posição inicial $\mathbf{X}$, vetor posição atual $\mathbf{x}$, vetor deslocamento $\mathbf{u}$ e função mapeamento $\mathbf{\Phi}(\mathbf{X}, t)$

de deformações, $\mathbf{F}$, por meio de $d \mathbf{x}=\mathbf{F} \cdot d \mathbf{X}$, ou seja,

$$
\mathbf{F}=\frac{\partial \mathbf{x}}{\partial \mathbf{X}} \equiv \frac{\partial \Phi}{\partial \mathbf{X}} \equiv\left(\nabla_{0} \boldsymbol{\Phi}\right)^{T} \text { ou } F_{i j}=\frac{\partial x_{i}}{\partial X_{j}} \equiv \frac{\partial \Phi_{i}}{\partial X_{j}}
$$

sendo $\nabla_{0}$ o gradiente em relação às coordenadas materiais. O tensor gradiente de deformações pode ser classificado como um tensor de dois pontos, ou seja, um tensor de segunda ordem definido pela contração de um vetor lagrangeano e um vetor euleriano. Como neste caso o vetor euleriano está na esquerda e o lagrangeano na direita, o gradiente de deformações $\mathbf{F}$ é um tensor euleriano-lagrangeanos.

O determinante do gradiente de deformações é conhecido por Jacobiano, $J=\operatorname{det}(\mathbf{F}) \mathrm{e}$ relaciona os volumes inicial e atual por meio de $d v=J d V$. Como a massa de um elemento infinitesimal pode ser relacionada com o volume deste através de $d m=\rho_{0} d V=\rho d v$, a conservação de massa pode ser expressa por $\rho_{0}=J \rho$.

É interessante observar que o gradiente de deformações pode ser decomposto, através do teorema da decomposição polar, no produto de uma matriz ortogonal $\mathbf{R}$ e um tensor simétrico $\mathbf{U}$, conhecido como tensor direito de alongamento, ou seja,

$$
\mathbf{F}=\mathbf{R} \cdot \mathbf{U} \text { ou } F_{i j}=\frac{\partial x_{i}}{\partial X_{j}}=R_{i k} U_{k j} \operatorname{com} \mathbf{R}^{T}=\mathbf{R}^{-1} \text { e } \mathbf{U}=\mathbf{U}^{T}
$$

Um elemento de linha $d \mathbf{X}$ é um elemento de linha lagrangeano, pois está representado na configuração de referência. A partir dele, do elemento de linha na configuração deformada, $d \mathbf{x}$, e do gradiente de deformações, F, pode-se definir várias medidas de deformação, com duas lagrangeanas comuns sendo: 
- Tensor de deformações direito de Cauchy-Green, C: pode ser definido a partir de produtos escalares baseados na fig. 3.1 por $\mathrm{d} \mathbf{x}_{1} \cdot \mathbf{I} \cdot \mathrm{d} \mathbf{x}_{2}=\mathrm{d} \mathbf{X}_{1} \cdot \mathbf{C} \cdot \mathrm{d} \mathbf{X}_{2}$. A partir desta definição, $\mathbf{C}$ pode ser expresso em função do gradiente de deformações por $\mathbf{C}=\mathbf{F}^{T} \cdot \mathbf{F}$.

- Tensor de deformações de Green-Lagrange, E: considerando $\mathrm{d} S^{2}=\mathrm{d} \mathbf{X}_{1} \cdot \mathrm{d} \mathbf{X}_{2}$ e $\mathrm{d} s^{2}=\mathrm{d} \mathbf{x}_{1} \cdot \mathrm{d} \mathbf{x}_{2}$, pode-se definir o tensor de deformações de Green-Lagrange por $\mathrm{d} s^{2}-\mathrm{d} S^{2}=2 \mathrm{~d} \mathbf{X} \cdot \mathbf{E} \cdot \mathrm{d} \mathbf{X}$. O mesmo pode então ser definido em função do tensor de deformações direito de Cauchy-Green e do gradiente de deformações por $\mathbf{E}=\frac{1}{2}\left(\mathbf{F}^{T} \cdot \mathbf{F}-\mathbf{I}\right)=\frac{1}{2}(\mathbf{C}-\mathbf{I})$, i.e. $E_{i j}=\frac{1}{2}\left(F_{k i} F_{k j}-\delta_{i j}\right)$. É comum também encontrar na literatura o tensor de deformações de Green-Lagrange definido em função do deslocamento $u_{i}=x_{i}-X_{i}$ por

$$
E_{i j}=\frac{1}{2}\left(\frac{\partial u_{i}}{\partial X_{j}}+\frac{\partial u_{j}}{\partial X_{i}}+\frac{\partial u_{k}}{\partial X_{i}} \frac{\partial u_{k}}{\partial X_{j}}\right) \text { ou } \mathbf{E}=\frac{1}{2}\left(\left(\nabla_{0} \mathbf{u}\right)^{T}+\nabla_{0} \mathbf{u}+\nabla_{0} \mathbf{u} \cdot\left(\nabla_{0} \mathbf{u}\right)^{T}\right)
$$

De uma forma análoga à definição de um tensor lagrangeano, pode-se definir um tensor euleriano, representado na configuração atual. Seja o elemento de linha $d \mathbf{x}$ definido na configuração atual um elemento de linha euleriano, ou vetor euleriano, assim como sua derivada material no tempo $d \mathbf{v}$. Tensores de segunda ordem definidos por contrações com vetores eulerianos são tensores de segunda ordem eulerianos. Os dois tensores de deformação eulerianos mais conhecidos são:

- Tensor de deformações esquerdo de Cauchy-Green, b: pode ser definido a partir de produtos escalares baseados na fig. 3.1 por $\mathrm{d} \mathbf{X}_{1} \cdot \mathbf{I} \cdot \mathrm{d} \mathbf{X}_{2}=\mathrm{d} \mathbf{x}_{1} \cdot \mathbf{b}^{-1} \cdot \mathrm{d} \mathbf{x}_{2}$. A partir desta definição, o mesmo pode ser expresso em função do gradiente de deformações por $\mathbf{b}=\mathbf{F} \cdot \mathbf{F}^{T}$.

- Tensor de deformações de Euler-Almansi, e: considerando novamente $\mathrm{d} S^{2}=\mathrm{d} \mathbf{X}_{1}$. $\mathrm{d} \mathbf{X}_{2}$ e $\mathrm{d} s^{2}=\mathrm{d}_{1} \cdot \mathrm{d} \mathbf{x}_{2}$, pode-se definir o tensor de deformações de Euler-Almansi por $\mathrm{d} s^{2}-\mathrm{d} S^{2}=2 \mathrm{~d} \mathbf{x} \cdot \mathbf{e} \cdot \mathrm{d} \mathbf{x}$. O mesmo pode então ser definido em função do tensor de deformações esquerdo de Cauchy-Green e do gradiente de deformações por $\mathbf{e}=\frac{1}{2}\left(\mathbf{I}-\left(\mathbf{F} \cdot \mathbf{F}^{T}\right)^{-1}\right)=\frac{1}{2}\left(\mathbf{I}-\mathbf{B}^{-1}\right)$, ou $e_{i j}=\frac{1}{2}\left(\delta_{i j}-F_{k i}^{-1} F_{k j}^{-1}\right)$. É comum também encontrar na literatura o tensor de deformações de Green-Lagrange definido em 
função do deslocamento $u_{i}=x_{i}-X_{i}$ por

$$
e_{i j}=\frac{1}{2}\left(\frac{\partial u_{i}}{\partial x_{j}}+\frac{\partial u_{j}}{\partial x_{i}}-\frac{\partial u_{k}}{\partial x_{i}} \frac{\partial u_{k}}{\partial x_{j}}\right) \text { ou } \mathbf{e}=\frac{1}{2}\left((\nabla \mathbf{u})^{T}+\nabla \mathbf{u}-\nabla \mathbf{u} \cdot(\nabla \mathbf{u})^{T}\right)
$$

O gradiente de velocidades, L, é um tensor euleriano definido pela variação do vetor velocidade ao longo de uma linha infinitesimal na configuração atual. Ou seja

$$
d \mathbf{v}=\frac{\partial \mathbf{v}}{\partial \mathbf{x}} d \mathbf{x}=\mathbf{L} d \mathbf{x} \Rightarrow \mathbf{L}=\frac{\partial \mathbf{v}}{\partial \mathbf{x}}=(\nabla \mathbf{v})^{T} \text { ou } L_{i j}=\frac{\partial v_{i}}{\partial x_{j}}
$$

L pode ser definido também a partir do gradiente de deformações,

$$
\mathbf{L}=\frac{\partial \mathbf{v}}{\partial \mathbf{x}}=\frac{\partial \mathbf{v}}{\partial \mathbf{X}} \frac{\partial \mathbf{X}}{\partial \mathbf{x}}=\frac{\partial \mathbf{x}}{\partial t \partial \mathbf{X}} \frac{\partial \mathbf{X}}{\partial \mathbf{x}}=\frac{\partial}{\partial t}\left(\frac{\partial \mathbf{x}}{\partial \mathbf{X}}\right)\left(\frac{\partial \mathbf{X}}{\partial \mathbf{x}}\right)=\dot{\mathbf{F}} \mathbf{F}^{-1} \text { ou } L_{i j}=\dot{F}_{i k} F_{k j}^{-1}
$$

Da decomposição do gradiente de velocidades em suas partes simétrica e anti-simétrica, surgem os tensores taxa de deformação (ou deformação da velocidade), $\mathbf{D}=\frac{1}{2}\left(\mathbf{L}+\mathbf{L}^{T}\right.$ ), e o tensor spin, $\mathbf{W}=\frac{1}{2}\left(\mathbf{L}-\mathbf{L}^{T}\right)$, respectivamente. Pode-se relacionar o tensor taxa de deformação com a taxa de deformação de Green-Lagrange, $\dot{\mathbf{E}}$, e com o tensor taxa de deformação direito de Cauchy-Green, $\dot{\mathbf{C}}$, por

$$
\mathbf{F}^{T} \mathbf{D F}=\frac{1}{2}\left(\dot{\mathbf{F}}^{T} \mathbf{F}+\mathbf{F}^{T} \dot{\mathbf{F}}\right)=\dot{\mathbf{E}}=\frac{1}{2}(\dot{\mathbf{C}})
$$

Com relação aos tensores de tensão, considere o elemento de área infinitesimal em $\Omega, \mathrm{d} \Gamma$, cujo vetor unitário normal é dado por $\mathbf{n}$, a força $\mathrm{d} \mathbf{f}$ atuando em $\mathrm{d} \Gamma$, todos representados na figura 3.2. Podemos definir os vetores de tração $\mathbf{t}$ e $\mathbf{t}_{0}$ como força sobre unidade de área atual, $\mathrm{d} \Gamma$, e inicial, $\mathrm{d} \Gamma_{0}$, respectivamente, por $\mathrm{d} \mathbf{f}=\mathbf{t} \mathrm{d} \Gamma=\mathbf{t}_{0} \mathrm{~d} \Gamma_{0}$.

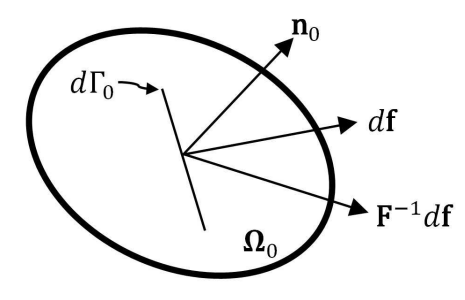

(a) Configuração inicial

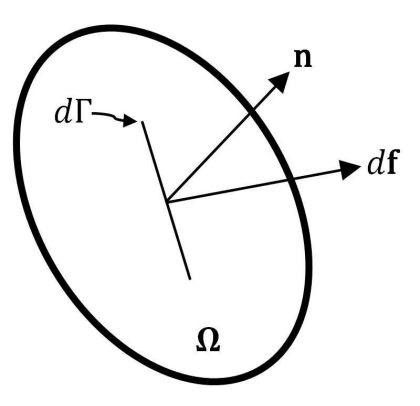

(b) Configuração atual

Figura 3.2: Área infinitesimal $d \Gamma$ em $\Omega$, vetor unitário normal $\mathbf{n}$, força $d \mathbf{f}$

O tensor de tensão de Cauchy ou tensor de tensão verdadeira, $\boldsymbol{\sigma}$, é um tensor euleriano, ou seja, formulado na configuração atual, e definido por $\mathbf{n} \cdot \boldsymbol{\sigma} \mathrm{d} \Gamma=\mathrm{d} \mathbf{f}=\mathbf{t} \mathrm{d} \Gamma$. Uma 
propriedade importante do tensor de tensão de Cauchy é que o mesmo é simétrico, ou seja, $\boldsymbol{\sigma}=\boldsymbol{\sigma}^{T}$.

O tensor de tensões nominal, $\mathbf{P}$, é um tensor lagrangeano, ou seja, formulado na configuração inicial, e definido por $\mathbf{n}_{0} \cdot \mathbf{P} \mathrm{d} \Gamma_{0}=\mathrm{d} \mathbf{f}=\mathbf{t}_{0} \mathrm{~d} \Gamma_{0}$. A relação de Nanson diz que $\mathbf{n} \mathrm{d} \Gamma=J \mathbf{n}_{0} \cdot \mathbf{F}^{-1} \mathrm{~d} \Gamma_{0}$, possibilitando relacionar o tensor de tensão nominal e o tensor de tensão de Cauchy por $\mathbf{P}=J \mathbf{F}^{-1} \cdot \boldsymbol{\sigma}$.

O segundo tensor de tensão de Piola-Kirchhoff, S, é um tensor lagrangeano definido por $\mathbf{n}_{0} \cdot \mathbf{S} \mathrm{d} \Gamma_{0}=\mathbf{F}^{-1} \cdot \mathrm{d} \mathbf{f}=\mathbf{F}^{-1} \cdot \mathbf{t}_{0} \mathrm{~d} \Gamma_{0}$. Este se relaciona com o tensor de tensão nominal por $\mathbf{P}=\mathbf{S} \cdot \mathbf{F}^{T}$ e com o tensor de tensão de Cauchy por $\boldsymbol{\sigma}=J^{-1} \mathbf{F} \cdot \mathbf{S} \cdot \mathbf{F}^{T}$.

O tensor de tensão de Kirchhoff, $\boldsymbol{\tau}$, é quase idêntico ao tensor de tensões de Cauchy, mas escalonado pelo Jacobiano, sendo portanto também conhecido como tensor ponderado de tensões de Cauchy, ou seja $\boldsymbol{\tau}=J \boldsymbol{\sigma}$.

O principal diferencial entre a mecânica do contínuo não linear para grandes deformações e pequenas deformações é a diferenciação entre os domínios inicial e o atual. Sob a hipótese de pequenas deformações, a diferença entre estes domínios é pequena o suficiente para ser desprezada sem implicar em erros, não fazendo mais sentido dizer se a deformação ou a tensão está formulada na configuração de origem ou na atual, o que implica na não distinção das deformações definidas na subseção 3.2. Já na hipótese de grandes deformações, há operações que relacionam tensores eulerianos e lagrangeanos, indicando as contrapartes de tensores de deformação e tensores de tensão em ambos os domínios, sempre considerando a conservação da energia mecânica.

A operação de avançar (tradução adotada pelo autor para push-forward) é definida por $\phi_{*}(\bullet)=\mathbf{F}^{-T} \cdot(\bullet) \cdot \mathbf{F}^{-1}$, para tensores de deformação e respectivas taxas temporais, e por $\phi_{*}(\bullet)=\mathbf{F} \cdot(\bullet) \cdot \mathbf{F}^{T}$, para os tensores de tensão. Já a operação de retroceder (tradução adotada pelo autor para pull-back) é definida por $\phi^{*}(\bullet)=\mathbf{F}^{T} \cdot(\bullet) \cdot \mathbf{F}$, para tensores de deformação e respectivas taxas temporais, e por $\phi^{*}(\bullet)=\mathbf{F}^{-1} \cdot(\bullet) \cdot \mathbf{F}^{-T}$, para os tensores de tensão.

O melhor exemplo para a compreensão das operações de avançar e retroceder são os tensores de deformação de Green-Lagrange e Eulerian-Almansi, já que ambos representam a mesma quantidade, em domínios diferentes, ou seja, $\frac{1}{2}\left(\mathrm{~d} s^{2}-\mathrm{d} S^{2}\right)=\mathrm{d} \mathbf{X} \cdot \mathbf{E} \cdot \mathrm{d} \mathbf{X}=$ $\mathrm{d} \mathbf{x} \cdot \mathbf{e} \cdot \mathrm{d} \mathbf{x}, \operatorname{com} \phi_{*}(\mathbf{E})=\mathbf{e}$ e $\phi^{*}(\mathbf{e})=\mathbf{E}$. No que diz respeito a deformações, pode-se também exemplificar o conceito por $\phi_{*}(\mathbf{I})=\mathbf{b}^{-1}, \phi^{*}\left(\mathbf{b}^{-1}\right)=\mathbf{I}$ e $\phi_{*}(\mathbf{C})=\mathbf{I}$ e $\phi^{*}(\mathbf{I})=\mathbf{C}$. 
No caso de tensores de tensão, o exemplo mais importante relaciona o segundo tensor de tensão de Piola-Kirchhoff e o tensor de tensão de Kirchhoff por $\phi_{*}(\mathbf{S})=\boldsymbol{\tau}$ e $\phi^{*}(\boldsymbol{\tau})=\mathbf{S}$

Este tipo de operação é utilizado com frequência em estruturas cinemáticas baseadas na decomposição multiplicativa do gradiente de deformações para descobrir os equivalentes de tensores de deformação ou tensão em diferentes configurações, uma vez que possuem uma ou mais configurações intermediárias da inicial e da atual. Esse conceito se torna importante para alguns modelos de material poliméricos que utilizam encruamento cinemático com back-stress. O tensor de tensões responsável pela deformação plástica deve ser calculado nas seguintes etapas: $i$ ) passar subtensão (tradução adotada pelo autor para back-stress) para a configuração atual por uma operação de push-forward com $\left.\mathbf{F}^{e} ; i i\right)$ subtrair seu equivalente da tensão elástica; $\left.i i i\right)$ e passar o resultado da subtração para a configuração intermediária por uma operação de pull-back com $\mathbf{F}^{e} ; i v$ ) calcular o multiplicador plástico (módulo do tensor taxa de velocidade plástico) a partir da norma de Frobenius do mesmo.

\subsection{Estrutura cinemática}

O objetivo desta seção é apresentar a divisão multiplicativa elastoplástica do gradiente de deformações, ou seja, $\mathbf{F}=\mathbf{F}^{e} \mathbf{F}^{p}$ e suas extensões para outros tipos de modelos de material.

Um material elástico é caracterizado por sua deformação reversível, ou seja, após a indução de deformação via carregamento e posterior descarregamento, o formato original é completamente recuperado. A relação constitutiva hipo-elástica relaciona tensão e deformação por meio de suas derivadas temporais, ou na nomenclatura mais utilizada, por suas respectivas taxas, ou seja,

$$
\boldsymbol{\sigma}^{\nabla}=\mathbf{f}(\boldsymbol{\sigma}, \mathbf{D})
$$

sendo $\boldsymbol{\sigma}^{\nabla}$ uma taxa objetiva de tensão. As taxas objetivas de tensão foram criadas para que as rotações induzam erros desprezíveis nas relações hipo-elásticas e têm por exemplos mais comuns a taxa de Jaumann $\boldsymbol{\sigma}^{\nabla J}=\frac{\mathrm{D}}{\mathrm{D} t} \boldsymbol{\sigma}-\mathbf{W} \cdot \boldsymbol{\sigma}-\boldsymbol{\sigma} \cdot \mathbf{W}^{T}$, taxa de Truesdell $\boldsymbol{\sigma}^{\nabla \mathcal{T}}=\frac{\mathrm{D}}{\mathrm{D} t} \boldsymbol{\sigma}+\operatorname{div}(\mathbf{v}) \boldsymbol{\sigma}-\mathbf{L} \cdot \boldsymbol{\sigma}-\boldsymbol{\sigma} \cdot \mathbf{L}^{T}$ e a taxa de Green-Naghdi (ou taxa de Dienes ou taxa corrotacional) $\boldsymbol{\sigma}^{\nabla \mathcal{G}}=\frac{\mathrm{D}}{\mathrm{D} t} \boldsymbol{\sigma}-\boldsymbol{\Omega} \cdot \boldsymbol{\sigma}-\boldsymbol{\sigma} \cdot \boldsymbol{\Omega}^{T}$. Esse tipo de relação em pequenas de- 
formações elásticas resulta em pequenos incrementos de tensão e deformação linearmente relacionados e reversíveis com descarregamento. Entretanto, para grandes deformações, a relação é classificada como dependente do caminho de carga (tradução adotada pelo autor para path-dependent), ou seja, a energia não é necessariamente conservada implicando no trabalho em um ciclo fechado não sendo necessariamente nulo. Desta forma, leis hipo-elásticas são normalmente utilizadas para modelar a resposta de leis elastoplásticas na qual as deformações elásticas são pequenas.

Já a relação constitutiva hiper-elástica é independente do caminho de carga (tradução adotada pelo autor para path-independent), ou seja, não dissipativa por ter trabalho nulo em um ciclo fechado. Por não haver dissipação, a energia mecânica é armazenada na forma de energia potencial e pode ser representada por funções densidade de energia por unidade de volume, como por exemplo $w(\mathbf{E})=\psi(2 \mathbf{E}+\mathbf{I})$, que podem ser usadas para se obter relações constitutivas do tipo (lembrando que o tensor de deformação e o tensor de tensão devem sempre ser um par conjugado energeticamente, conforme deduzido em B.7)

$$
\mathbf{S}=2 \frac{\partial \psi(\mathbf{C})}{\partial \mathbf{C}}=\frac{\partial w(\mathbf{E})}{\partial \mathbf{E}}
$$

Um modelo de material elastoplástico é path-dependent e dissipativo, com grande parte do trabalho executado durante a deformação plástica do material sendo convertido em outras formas de energia, especialmente calor. A tensão depende do histórico da deformação e não pode ser determinada apenas como uma função da deformação, ou seja, cada incremento de deformação pode ser divido em uma parte elástica e uma parte plástica, com a parte elástica determinando a tensão no material através de uma relação constitutiva hipo ou hiper-elástica e a deformação plástica como uma variável interna histórica, atualizada por uma lei de escoamento que determinará a direção e o módulo do fluxo plástico.

\subsubsection{Estrutura cinemática hipo-elastoplástica}

Conforme demonstrado por Lee[54], definir os incrementos de deformações elástica e plástica, em um corpo sujeito a tensão $\sigma$, pela adição e remoção de um incremento infinitesimal de tensão, $\Delta \sigma$, e posteriormente observando a deformação reversível (elástica) e residual (plástica), utilizando-se da teoria de pequenas deformações, induz a resultados errôneos, uma vez que parte da nova configuração $\Omega$ provêm de rotação do corpo rígido. 
Na formulação hipo-elastoplástica de grandes deslocamentos, há divisão do tensor taxa de deformação em partes elástica e plástica por $\mathbf{D}=\mathbf{D}^{e}+\mathbf{D}^{p}$, com a parte elástica do tensor taxa de deformação usada para calcular a taxa de tensão de Jaumann, ou seja, $\boldsymbol{\sigma}^{\nabla J}=\mathbf{C}_{\mathrm{el}}^{\sigma J}: \mathbf{D}^{e}=\mathbf{C}_{\mathrm{el}}^{\sigma J}:\left(\mathbf{D}-\mathbf{D}^{p}\right)$.

A parte plástica do tensor taxa de deformação pode ser decomposto em um módulo e uma direção, $\mathbf{D}^{p}=\dot{\lambda} \mathbf{r}(\boldsymbol{\sigma}, \mathbf{q})$, com o módulo $\dot{\lambda}$ chamado multiplicador plástico ou taxa de escoamento plástico e a direção $\mathbf{r}$ sendo uma função do tensor de tensão $\boldsymbol{\sigma}$ e de um vetor de variáveis internas q, como deformação plástica acumulada, fração volumétrica de vazios, back-stress, entre outros. Esta direção do escoamento plástico geralmente é especificada como uma derivada de um potencial plástico $\Psi$ por $\mathbf{r}=\frac{\partial \Psi}{\partial \boldsymbol{\sigma}}$. A condição para que haja plastificação é que a função de escoamento seja igual a zero, ou seja, $f(\boldsymbol{\sigma}, \mathbf{q})=0$. Já a evolução das variáveis internas é modelada a partir da taxa de escoamento plástico por $\dot{\mathbf{q}}=\dot{\lambda} \mathbf{h}(\boldsymbol{\sigma}, \mathbf{q})$, com $\mathbf{h}$ sendo um vetor que contém as equações de evolução de cada variável interna. Desta forma, as dimensões dos tensores $\mathbf{q}, \dot{\mathbf{q}}$ e $\mathbf{h}$ dependem do número de variáveis internas.

Para materiais sensíveis à taxa de deformação, o multiplicador plástico é prescrito constitutivamente. Caso contrário, o multiplicador plástico é definido a partir da condição de consistência. Durante o escoamento, o estado de tensão permanece sobre a superfície de escoamento, o que pode ser traduzido matematicamente por $\dot{f}(\boldsymbol{\sigma}, \mathbf{q})=0$, equação conhecida por condição de consistência. Esta pode ser definida pela regra da cadeia por $\dot{f}=f_{\boldsymbol{\sigma}}: \dot{\boldsymbol{\sigma}}+f_{\mathbf{q}} \cdot \dot{\mathbf{q}}, \operatorname{com} f_{\boldsymbol{\sigma}}=\frac{\partial f}{\partial \boldsymbol{\sigma}}$ e $f_{\mathbf{q}}=\frac{\partial f}{\partial \mathbf{q}}$.

De acordo com Prager [81], se há propriedade comutativa $f_{\boldsymbol{\sigma}} \cdot \boldsymbol{\sigma}=\boldsymbol{\sigma} \cdot f_{\boldsymbol{\sigma}}$, temos que $f_{\sigma}: \dot{\boldsymbol{\sigma}}=f_{\sigma}: \boldsymbol{\sigma}^{\nabla J}$ e então

$$
\begin{aligned}
\dot{f}= & f_{\sigma}: \boldsymbol{\sigma}^{\nabla J}+f_{\mathbf{q}} \cdot \dot{\mathbf{q}}=0 \\
& f_{\sigma}: \mathbf{C}_{\mathrm{el}}^{\sigma J}:\left(\mathbf{D}-\mathbf{D}^{p}\right)+f_{\mathbf{q}} \cdot \dot{\lambda} \mathbf{h}=0 \\
& f_{\boldsymbol{\sigma}}: \mathbf{C}_{\mathrm{el}}^{\sigma J}:(\mathbf{D}-\dot{\lambda} \mathbf{r})+f_{\mathbf{q}} \cdot \dot{\lambda} \mathbf{h}=0 \\
\text { e } & \therefore \quad \dot{\lambda}=\frac{f_{\sigma}: \mathbf{C}_{\mathrm{el}}^{\sigma J}: \mathbf{D}}{-f_{\mathbf{q}} \cdot \mathbf{h}+f_{\boldsymbol{\sigma}}: \mathbf{C}_{\mathrm{el}}^{\sigma J}: \mathbf{r}}
\end{aligned}
$$

Também é possível modelar o encruamento cinemático através do uso do tensor de tensões de sobretensão (tradução adotada pelo autor para over-stress), $\boldsymbol{\Sigma}=\boldsymbol{\tau}-\boldsymbol{\alpha}$, no qual $\boldsymbol{\tau}$ o tensor de tensões de Kirchhoff e $\boldsymbol{\alpha}$ é o tensor de tensões conhecido como tensor de subtensões (tradução adotada pelo autor para backstress) e tem como significado físico o centro da superfície de escoamento. A evolução do tensor de subtensão é dada pela 
taxa de tensão de Jaumann, $\boldsymbol{\alpha}^{\nabla J}=\kappa \mathbf{D}^{p}=\kappa \dot{\lambda} \mathbf{r}$, sendo $\kappa$ o módulo de encruamento cinemático. O multiplicador plástico é encontrado de maneira similar a partir da função de escoamento $\dot{f}(\boldsymbol{\Sigma}, \mathbf{q})$ e a condição de consistência se torna

$$
\dot{\lambda}=\frac{f_{\boldsymbol{\Sigma}}: \mathbf{C}_{\mathrm{el}}^{\tau J}: \mathbf{D}}{-f_{\mathbf{q}} \cdot \mathbf{h}+f_{\boldsymbol{\Sigma}}: \kappa \mathbf{r}+f_{\boldsymbol{\Sigma}}: \mathbf{C}_{\mathrm{el}}^{\tau J}: \mathbf{r}}
$$

\subsubsection{Estrutura cinemática hiper-elastoplástica}

Em vez de se usar a decomposição aditiva do tensor taxa de deformação, $\mathbf{D}=\mathbf{D}^{e}+\mathbf{D}^{p}$, pode-se usar a decomposição multiplicativa do gradiente de deformações em suas partes elástica e plástica, $\mathbf{F}=\mathbf{F}^{e} \mathbf{F}^{p}$, originando assim os modelos hiper-elastoplásticos.

O conceito da decomposição multiplicativa do gradiente de deformações foi proposta por Lee [55], ao introduzir uma configuração intermediária $p$ entre as configurações de referência e atual, fig. 3.3.2. A definição do gradiente de deformações permite escrever $\mathbf{F}=\frac{\partial \mathbf{x}}{\partial \mathbf{X}}=\frac{\partial \mathbf{x}}{\partial \mathbf{p}} \frac{\partial \mathbf{p}}{\partial \mathbf{X}}$, com a configuração intermediária sendo um estado livre de tensões.

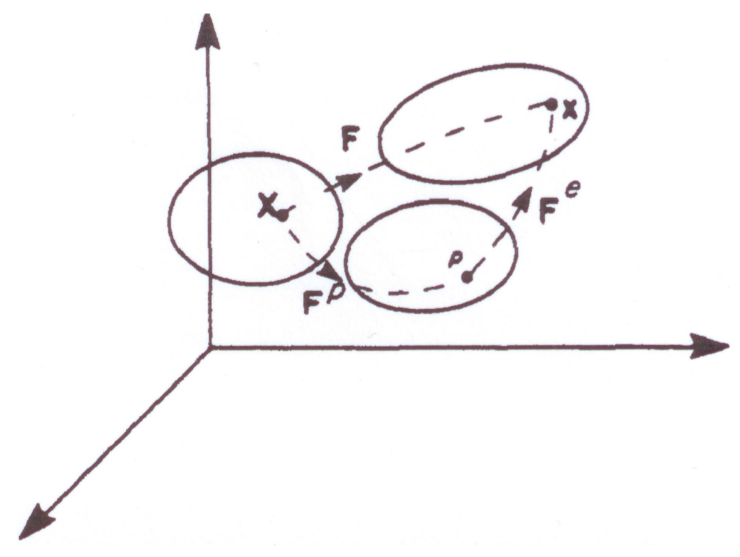

Figura 3.3: Decomposição multiplicativa do gradiente de deformações e configurações inicial, intermediária e atual, proposta por Lee em [54]

A formulação hiper-elastoplástica não foi aceita no início, devido a uma não unicidade na definição dos gradientes de deformação elástico e plástico, conforme descrito por Nemat-Nasser em 1979 [76], ao decompor os gradientes de deformações em rotações de corpo rígido e tensores de deformações conhecidos por stretch por

$$
\mathbf{F}^{e}=\mathbf{V}^{e} \mathbf{R}^{e}, \quad \mathbf{F}^{p}=\mathbf{R}^{p} \mathbf{U}^{p}, \quad \mathbf{F}=\mathbf{V}^{e} \mathbf{R}^{e} \mathbf{R}^{p} \mathbf{U}^{p}=\mathbf{F}=\mathbf{V}^{e} \mathbf{R} \mathbf{U}^{p} \quad \operatorname{com} \mathbf{R}=\mathbf{R}^{e} \mathbf{R}^{p}
$$


chegando a conclusão de que é necessária alguma hipótese sobre a componente de rotação de corpo rígido ou do gradiente de deformações elástico $\mathbf{R}_{e}$ ou do gradiente de deformações plástico $\mathbf{R}_{p}$, ou mesmo sobre o tensor velocidade de rotação (tradução adotada pelo autor para spin) plástico $\mathbf{W}_{p}$.

Simo [86] desenvolveu seu framework baseado na decomposição multiplicativa sendo que a lei de escoamento é associativa (a direção do tensor resultante entre a derivada do potencial plástico com relação ao tensor de tensões é a mesma direção do tensor resultante da derivada da função de escoamento em função do tensor de tensões) e unicamente definida como a condição ótima de Kuhn-Tucker originada no princípio da máxima dissipação plástica, adotando $\mathbf{R}_{e}=\mathbf{I}$ para sua decomposição polar esquerda $\mathbf{F}^{e}=\mathbf{V}^{e} \mathbf{R}^{e}$, obtendo por consequência $\mathbf{V}^{e}=\mathbf{F}^{e}=\mathbf{F}^{e^{T}}$.

Boyce, Parks e Argon [20] propuseram um modelo de material hiper-elastoplástico com encruamento cinemático para a modelagem de polímeros termo-plásticos abaixo da transição vítrea. Diferentemente das razões técnicas adotadas por Simo para a adoção de $\mathbf{R}=\mathbf{R}^{p}$ e consequentemente $\mathbf{R}^{e}=\mathbf{I}$, Boyce, Parks e Argon [20] justificam a escolha puramente para simplificar o procedimento computacional. Essa simplificação pode ser explicada pelo uso do tensor de subtensão em seu modelo, além do conceito de que podese realizar adições e subtrações de tensores de tensão apenas quando estão no mesmo domínio. Desta forma, a adoção de $\mathbf{R}=\mathbf{R}^{p}$ implica no tensor de subtensões do encruamento cinemático já estará em uma configuração rotacionada, não havendo necessidade de executar operações de retroceder e avançar para a subtração dos tensores de tensão. Entretanto, os autores ainda mostraram como ficariam os tensores caso fosse escolhida a hipótese $\mathbf{R}^{p}=\mathbf{I}$.

Moran, Ortiz e Shih [67] propuseram a terceira forma de ter-se a unicidade na decomposição multiplicativa do gradiente de deformações, sendo que nesta não há restrição da rotação estar totalmente inclusa na parte elástica ou plástica do gradiente de deformações, ao prescreverem constitutivamente o tensor spin na configuração intermediária, $\overline{\mathbf{W}}^{p}=0$ na nomenclatura dos autores.

Em 1989, Boyce, Weber e Parks [17] provaram que qualquer uma das hipóteses acima adotada leva ao mesmo resultado, ao simularem o comportamento do termo-plástico PMMA em cisalhamento utilizando primeiro a hipótese de $\mathbf{R}_{e}=\mathbf{I}$ e consequente $\mathbf{R}_{p}=$ $\mathbf{R}$ e depois o tensor velocidade de rotação prescrito na configuração intermediária por 
$\overline{\mathbf{W}}^{p}=0$, obtendo resultados idênticos em todos os casos.

Na estrutura cinemática apresentada por Moran, Ortiz e Shih [67] são utilizadas letras minúsculas para a configuração de referência, maiúsculas para a configuração inicial e maiúsculas com barra sobre as mesmas para as da configuração intermediária. O gradiente de velocidades na configuração atual foi determinado como

$$
\mathbf{l}=\dot{\mathbf{F}} \mathbf{F}^{-1}=\dot{\mathbf{F}}^{e} \mathbf{F}^{e-1}+\mathbf{F}^{e} \dot{\mathbf{F}}^{p} \mathbf{F}^{p-1} \mathbf{F}^{e-1}=\mathbf{l}^{e}+\mathbf{l}^{p}
$$

com partes simétricas $\mathbf{d}^{e}$ e $\mathbf{d}^{p}$ e anti-simétricas $\mathbf{w}^{e}$ e $\mathbf{w}^{p}$. A partir do mapeamento dos gradientes de velocidade $\mathbf{l}^{e}$ e $\mathbf{l}^{p}$ para a configuração intermediária por operações de pullback pelo tensor gradiente de deformações elástico, obtém-se

$$
\overline{\mathbf{L}}^{e}=\mathbf{F}^{e-1} \dot{\mathbf{F}}^{e}, \quad \text { e } \overline{\mathbf{L}}^{p}=\dot{\mathbf{F}}^{p} \mathbf{F}^{p-1}
$$

com partes simétricas e anti-simétricas dadas por $\overline{\mathbf{D}}^{e}, \overline{\mathbf{W}}^{e}, \overline{\mathbf{D}}^{p}$ e $\overline{\mathbf{W}}^{p}$.

A resposta elástica é normalmente descrita como uma função hiper-elástica do tensor direito de deformações de Cauchy-Green na configuração intermediária, $\overline{\mathbf{C}}$, [67] e pode depender da deformação plástica, da temperatura e do dano. O segundo tensor de tensões de Piola-Kirshhoff na configuração intermediária é definido por uma relação hiper-elástica, ou seja $\overline{\mathbf{S}}=2 \partial \bar{W} / \partial \overline{\mathbf{C}}$, através de uma operação de avançar, tornando-se o tensor de tensão de Kirchhoff na configuração atual, $\boldsymbol{\tau}=\mathbf{F}^{e} \overline{\mathbf{S}} \mathbf{F}^{e T}$.

Já a lei de escoamento é descrita na configuração intermediária por $\overline{\mathbf{L}}^{p}=\dot{\mathbf{F}}^{p} \mathbf{F}^{p-1}=$ $\dot{\lambda} \overline{\mathbf{r}}(\overline{\mathbf{S}}, \overline{\mathbf{q}})$, no qual $\dot{\lambda}$ é o multiplicador plástico, muitas vezes igual à deformação plástica acumulada $\dot{\bar{\varepsilon}}, \overline{\mathbf{r}}$ é a direção do escoamento plástico e $\overline{\mathbf{q}}$ um conjunto de variáveis internas definidas na configuração intermediária. A evolução deste conjunto pode ser matematicamente definida pela lei de encruamento na forma $\dot{\mathbf{q}}=\dot{\lambda} \overline{\mathbf{H}}(\overline{\mathbf{S}}, \overline{\mathbf{q}})=\dot{\bar{\varepsilon}} \overline{\mathbf{H}}(\overline{\mathbf{S}}, \overline{\mathbf{q}})$, na qual $\overline{\mathbf{H}}$ é o módulo de encruamento ou módulo plástico.

No caso do material ser hiper-elastoviscoplástico, o multiplicado plástico é definido por uma lei de escoamento. Caso o material seja insensível à taxa de deformação, o mesmo pode ser calculado a partir da função de escoamento $\bar{f}(\overline{\mathbf{S}}, \overline{\mathbf{q}})$ e da condição de consistência a partir dela obtida, em procedimento igual ao da estrutura cinemática hipoelastoplástica, i.e. [10]

$$
\dot{\lambda}=\frac{\bar{f}_{\overline{\mathbf{S}}}: \mathbf{C}_{\mathrm{el}} \overline{\mathbf{S}}: \overline{\mathbf{D}}}{-\bar{f}_{\overline{\mathbf{q}}} \cdot \overline{\mathbf{h}}+\bar{f}_{\overline{\mathbf{s}}}: \mathbf{C}_{\mathrm{el}}^{\overline{\mathbf{S}}: \operatorname{sim} \overline{\mathbf{r}}}}
$$


Um modelo de material para polímeros e estrutura cinemática viscoplástica com encruamento cinemático foi proposta por Boyce, Parks e Argon [20]. Em seu trabalho, foi focada a modelagem de polímeros termo-plásticos abaixo da transição vítrea, fig. 3.4. Foi utilizada a hipótese de que a rotação de corpo rígido está na parte plástica do gradiente de deformações, ou seja, $\mathbf{R}^{e}=\mathbf{I}$.

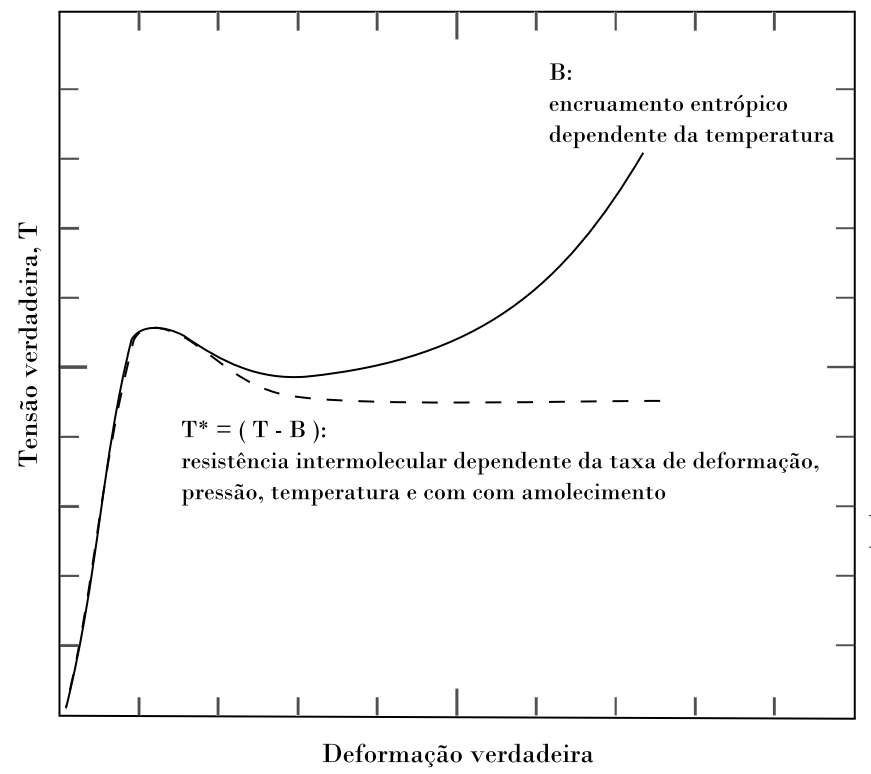

(a) Componentes da curva tensão deformação

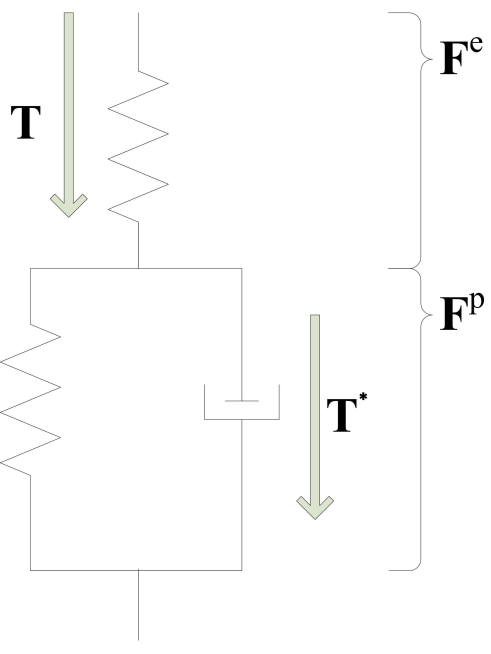

(b) Representação reológica

Figura 3.4: Estrutura cinemática utilizado por Boyce, Parks e Argon em [20]

Os tensores de tensão de Cauchy da parte de subtensão, B, e da parte elástica, T, são calculados por relações hiper-elásticas, neste caso a Neohookeana para a parte elástica e a chamada oito cadeias (tradução adotada pelo autor para eight-chain) (normalmente utilizada para elastômeros) para o tensor de subtensões do encruamento cinemático.

O fluxo plástico é determinado pelo tensor taxa de deformação plástico, $\widehat{\mathbf{D}}^{p}=\dot{\gamma}^{p} \mathbf{N}$. Boyce e co-autores comentam que definir o fluxo plástico na configuração intermediária, ou seja, $\widehat{\mathbf{D}}^{p}=\overline{\mathbf{D}}$, ou na configuração atual, $\widehat{\mathbf{D}}^{p}=\mathbf{D}$, neste caso não fará uma diferença significativa, uma vez que como toda rotação está na parte plástica do gradiente de deformações, o gradiente de deformações elástico é composto apenas pelo tensor alongamento, muito pequeno neste caso por conter apenas as deformações elásticas, se aproximando do tensor identidade, ou seja, $\mathbf{F}^{e} \cong \mathbf{I}$.

A taxa de deformação cisalhante plástica, $\dot{\gamma}^{p}$, é determinada constitutivamente. Já a direção $\mathbf{N}$ é calculada a partir da parte deviatórica do tensor de tensão de Cauchy 
denominado driving stress state, $\mathbf{T}^{*}$, que por sua vez é calculado a partir da subtração do tensor de subtensão, B, do tensor de tensão T. Entretanto, os tensores $\mathbf{T}^{*}$ e $\mathbf{B}$ encontramse na configuração intermediária e o tensor de tensões $\mathbf{T}$ encontra-se na configuração atual. O procedimento para poder efetuar a subtração seria fazer o avanço de $\mathbf{B}$ e encontrar o equivalente de $\mathbf{T}^{*}$ na configuração atual, $\mathbf{t}^{*}$, por

$$
\mathbf{t}^{*}=\mathbf{T}-\mathbf{F}^{e} \mathbf{B} \mathbf{F}^{e T}=\mathbf{T}-\mathbf{F}^{e} \mathbf{B} \mathbf{F}^{e}
$$

e então realizar o procedimento de retroceder $\mathbf{t}^{*}$ para a configuração intermediária e dividir cada elemento pelo módulo do tensor, descobrindo assim um tensor representativo de sua direção com módulo unitário, ou seja, o tensor N. Porém, como toda a rotação foi transferida para a parte plástica do gradiente de deformação, $\mathbf{R}=\mathbf{R}^{p}$ e $\mathbf{R}^{e}=\mathbf{I}, \mathbf{t}^{*}$ e $\mathbf{T}^{*}$ possuem módulos diferentes, correlacionados por operações de avançar e retroceder que envolvem tensores de alongamento mas não tensores de rotação, possuindo portanto a mesma direção.

A estrutura cinemática hiper-elastoplástica baseado na divisão multiplicativa do gradiente de deformações foi o bloco básico para o desenvolvimento de muitas outras estruturas cinemáticas, como por exemplo a termo-elastoplástica, na qual a expansão térmica é considerada, descrita por $\mathbf{F}=\mathbf{F}^{e} \mathbf{F}^{t h} \mathbf{F}^{p}$ em [93], ou o modelo viscoelástico de Bergstrom para elastômeros, no qual uma parte da estrutura cinemática é obtida pelo gradiente de deformações viscoelástico $\mathbf{F}^{v e}=\mathbf{F}^{e} \mathbf{F}^{v}[13]$. Em especial, as estruturas cinemáticas termo-viscoplástica e viscoelástica serão detalhadas com profundidade no capítulo em que é proposto e implementado um modelo de material termo-viscoelastoviscoplástico, tanto para polímeros amorfos quanto para polímeros semicristalinos.

É valido dizer que, respeitando o equacionamento desta estrutura cinemática e ponderando o número de parâmetros de material a serem calibrados, há uma enorme possibilidade de novos modelos de material baseados na decomposição multiplicativa do gradiente de deformações.

\subsection{Relações constitutivas}

A estrutura cinemática da mecânica dos sólidos não linear apenas proporciona relações entre tensores que dizem respeito a geometria, ou seja, deformação e taxas de deformação. 
Para representar o comportamento mecânico de material, é necessário definir uma relação hiper-elástica entre o tensor de tensões e o tensor de deformações (calculado com base na parte elástica do gradiente de deformações), ou seja, $(\sigma)=f\left((F)^{e}\right)$. No caso de viscoplasticidade, o gradiente de velocidades (calculado com base na parte plástica do gradiente de deformações) também deve ser definido constitucionalmente, ou seja, $(D)^{p}=$ $f\left((F)^{p}\right)=g((\sigma))$.

Como explicitado anteriormente, um material hiper-elástico se caracteriza por uma função densidade de energia elástica armazenada da qual o tensor de tensões pode ser obtido por $\overline{\mathbf{S}}=2 \partial \bar{W} / \partial \overline{\mathbf{C}}=\overline{\mathbf{S}}(\overline{\mathbf{C}})$. Como a densidade de energia pode ser escrita a partir dos invariantes do tensor direito de deformações de Cauchy-Green, C, o segundo tensor de tensões de Piola-Kirchhoff, S, fica

$$
\mathbf{S}=2 \frac{\partial \psi(\mathbf{C})}{\partial \mathbf{C}}=2\left(\frac{\partial \psi}{\partial I_{1}} \frac{\partial I_{1}}{\partial \mathbf{C}}+\frac{\partial \psi}{\partial I_{2}} \frac{\partial I_{2}}{\partial \mathbf{C}}+\frac{\partial \psi}{\partial I_{3}} \frac{\partial I_{3}}{\partial \mathbf{C}}\right)
$$

Conforme deduzido no apêndice $\mathrm{A}$, as derivadas dos invariantes de um tensor de segunda ordem A com respeito ao próprio tensor A são calculadas por

$$
\frac{\partial I_{1}}{\partial \mathbf{A}}=\mathbf{I} \quad \frac{\partial I_{2}}{\partial \mathbf{A}}=I_{1} \mathbf{I}-\mathbf{A}^{T} \quad \frac{\partial I_{3}}{\partial \mathbf{A}}=I_{3} \mathbf{A}^{-T}
$$

e sabendo que $\mathbf{C}$ é simétrico, 3.21, pode ser reescrita por

$$
\begin{gathered}
\mathbf{S}=2 \frac{\partial \psi(\mathbf{C})}{\partial \mathbf{C}}=2\left(\frac{\partial \psi}{\partial I_{1}} \frac{\partial I_{1}}{\partial \mathbf{C}}+\frac{\partial \psi}{\partial I_{2}} \frac{\partial I_{2}}{\partial \mathbf{C}}+\frac{\partial \psi}{\partial I_{3}} \frac{\partial I_{3}}{\partial \mathbf{C}}\right)= \\
=2\left(\frac{\partial \psi}{\partial I_{1}} \mathbf{I}+\frac{\partial \psi}{\partial I_{2}}\left(I_{1} \mathbf{I}-\mathbf{C}^{T}\right)+\frac{\partial \psi}{\partial I_{3}} I_{3} \mathbf{C}^{-T}\right)= \\
=2\left(\frac{\partial \psi}{\partial I_{1}}+I_{1} \frac{\partial \psi}{\partial I_{2}}\right) \mathbf{I}-2 \frac{\partial \psi}{\partial I_{2}} \mathbf{C}+2 I_{3} \frac{\partial \psi}{\partial I_{3}} \mathbf{C}^{-1}
\end{gathered}
$$

Disso resulta o tensor de tensões de Kirchhoff

$$
\boldsymbol{\tau}=\mathbf{F} \cdot \mathbf{S} \cdot \mathbf{F}^{T}=2\left(\frac{\partial \psi}{\partial I_{1}}+I_{1} \frac{\partial \psi}{\partial I_{2}}\right) \mathbf{B}-2 \frac{\partial \psi}{\partial I_{2}} \mathbf{B}^{2}+2 I_{3} \frac{\partial \psi}{\partial I_{3}} \mathbf{I}
$$

Rivlin [84], em 1948, propos a seguinte forma geral de função densidade de energia

$$
\psi=\psi\left(I_{1}, I_{2}\right)=\sum_{i=0}^{\infty} \sum_{j=0}^{\infty} \bar{c}_{i j}\left(I_{1}-3\right)^{i}\left(I_{2}-3\right)^{j} \quad \operatorname{com} c_{00}=0
$$

Já a função densidade de energia elástica

$$
\psi(\mathbf{C})=\frac{1}{2} \lambda_{0}(\ln J)^{2}-\mu_{0} \ln J+\frac{1}{2} \mu_{0}\left(I_{1}-3\right)
$$


leva a relação constitutiva Neohookeana

$$
\mathbf{S}=\lambda_{0} \ln J \mathbf{C}^{-1}+\mu_{0}\left(\mathbf{I}-\mathbf{C}^{-1}\right)
$$

com $\lambda_{0}$ e $\mu_{0}$ sendo as constantes de Lamé. Na sua versão incompressível, ou seja, com $J=1 \rightarrow \psi(\mathbf{C})=\frac{1}{2} \mu_{0}(\operatorname{tr}[\mathbf{C})-3]$ a relação constitutiva Neohookeana se torna um caso específico da regra geral proposta por Rivlin.

Mooney, em 1940 [66], extendeu o modelo Neohookeano incompressível para incorporar o termo com o segundo invariante, obtendo uma função densidade de energia conhecida por Mooney-Rivlin, na qual

$$
\psi(\mathbf{C})=c_{10}\left(I_{1}-3\right)+c_{01}\left(I_{2}-3\right)
$$

De acordo com Arruda e Boyce [19], este modelo foi extensivamente utilizado para o estudo de elastômeros, pois foi capaz de captar a diferença entre o comportamento em tração/compressão e o comportamento em cisalhamento, algo não diferenciado no modelo Neohookeano.

Yeoh [94] ressaltou experimentalmente que a dependência do segundo invariante é muito menor do que a dependência do primeiro invariante. Além disso, utilizou termos com funções de $I_{1}$ de ordem mais alta para capturar o comportamento dos elastômeros em alongamentos maiores. Yeoh então propôs, em 1993, sua função de energia [94]

$$
\psi(\mathbf{C})=c_{10}\left(I_{1}-3\right)+c_{20}\left(I_{1}-3\right)^{2}+c_{30}\left(I_{1}-3\right)^{3}
$$

Já em 1996, Gent [35] propos uma função densidade de energia alternativa, não baseada em Rivlin, de alta ordem de $I_{1}$ com

$$
\psi(\mathbf{C})=-\frac{E}{6} \ln \left[1-\frac{\left(I_{1}-3\right)}{J_{M}}\right]
$$

com $E$ e $J_{M}$ sendo parâmetros do material.

Bergstrom calibrou os parâmetros destas relações constitutivas com relação aos resultados experimentais uniaxiais, biaxiais e em cisalhamento puro, de Treloar [89], e constatou via análise estatística a capacidade destes modelos de reproduzirem o comportamento real dos materiais. O modelo Neohookeano obteve $R^{2}=0.775, R^{2}=0.843$ para o de Money-Rivlin, $R^{2}=0.981$ para o de Yeoh e $R^{2}=0.922$ para o de Gent. Apesar da 
qualidade com que o modelo de Yeoh representa o material, Arruda e Boyce [19] enfatizaram que modelos baseados em funções de alta ordem de $I_{1}$ possuem restrições nos valores de seus parâmetros para obedecerem ao critério de estabilidade de Drucker, devendo ser utilizado com parcimônia.

Arruda e Boyce [19] descreveram outro tipo de material hiper-elástico no qual a tensão é calculada derivando-se a função densidade de energia com relação aos alongamentos nas direções principais de um tensor, ou seja, em relação aos seus autovalores. Matematicamente, temos as tensões principais do tensor de tensões de Cauchy calculadas por

$$
\sigma_{i}=\frac{\lambda_{i}}{J}\left[\frac{\partial W}{\partial I_{1}} \frac{\partial I_{1}}{\partial \lambda_{i}}+\frac{\partial W}{\partial I_{2}} \frac{\partial I_{2}}{\partial \lambda_{i}}+\frac{\partial W}{\partial I_{3}} \frac{\partial I_{3}}{\partial \lambda_{i}}\right], \quad i=1,2,3
$$

com as funções energia $W$ deste tipo de material deduzida por tratamentos mecânicos estatísticos. Em um primeiro momento, a mecânica estatística assume uma estrutura de longas moléculas orientada aleatoriamente, como por exemplo na distribuição gaussiana de cadeias com diferentes comprimentos de ponta a ponta, $r$, dada por

$$
P(r)=4 \pi\left(\frac{3}{2 \pi n l^{2}}\right)^{\frac{3}{2}} r^{2} \exp \left(-\frac{3 r^{2}}{2 \pi l^{2}}\right)
$$

com $n$ sendo o número de ligações e $l$ o comprimento de cada ligação, possibilitando descobrir o comprimento inicial médio de cada cadeia, $L_{0}$, pelo valor quadrático médio de $r$, ou seja, $L_{0}=\sqrt{r^{2}}=\sqrt{n l^{2}}=\sqrt{n} l$. Quando uma deformação é aplicada, os alongamentos da estrutura de cadeias e sua entropia na configuração diminuem. Para uma deformação na qual $r \ll n l$ (ou seja, as cadeias não atingem seu tamanho máximo), em um grupo de $N$ cadeias e alongamentos principais $\left(\lambda_{1}, \lambda_{2}, \lambda_{3}\right)$, temos uma função densidade de energia

$$
W_{G}=\frac{1}{2} N K \theta\left(\lambda_{1}^{2}+\lambda_{2}^{2}+\lambda_{3}^{2}-3\right)
$$

com $k$ sendo a constante de Boltzmann e $\theta$ a temperatura absoluta. Esta função densidade de energia proporciona exatamente a mesma relação constitutiva que a Neohookeana incompressível, com $N K \theta=2 C_{10}$.

Há quatro modelos com base na mecânica estatística de distribuição não gaussiana que se destacam, conforme a fig. 3.5. Destes, o que apresenta maior coeficiente de determinação é a rede de 8 cadeias, com $R=0.973$, estável para qualquer escolha de parâmetros e com função densidade de energia dada por

$$
W_{8 c h}=N k \theta \sqrt{n}\left[\beta_{\text {chain }} \lambda_{\text {chain }}+\sqrt{n} \ln \left(\frac{\beta_{\text {chain }}}{\operatorname{senh} \beta_{\text {chain }}}\right)\right]
$$


com $\lambda_{\text {chain }}=\sqrt{(1 / 3)\left(\lambda_{1}^{2}+\lambda_{2}^{2}+\lambda_{3}^{2}\right)}, \quad \beta_{\text {chain }}=\mathcal{L}^{-1}\left(\lambda_{\text {chain }} / \sqrt{n}\right), \mathcal{L}(a)=\operatorname{coth}(a)-1 / a$ sendo a função de Langevin e $\mathcal{L}^{-1}$ a função inversa de langevin, $N$ e $\sqrt{n}$ os parâmetros do material.

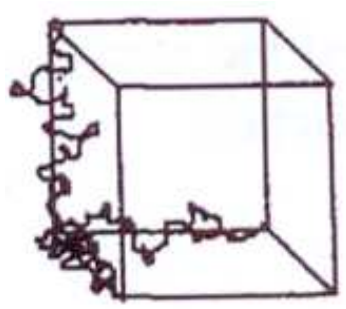

(a) rede de 3 cadeias

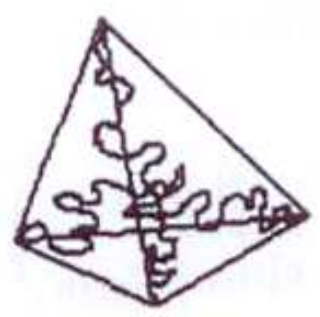

(b) rede de 4 cadeias

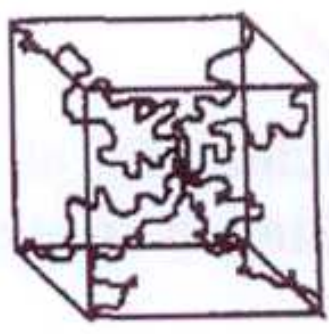

(c) rede de 8 cadeias

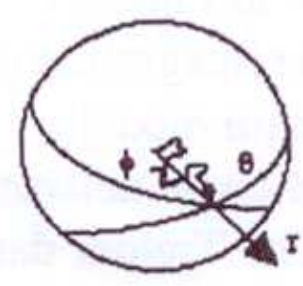

(d) rede completa

Figura 3.5: Modelos com base na mecânica estatística

\subsection{Funções de escoamento plástico}

Eyring, em 1936 [30], desenvolveu uma teoria de escoamento para estudo de viscosidade em gases e líquidos, na qual uma molécula muda de um estado para outro apenas quando supera um determinado valor energético, ou seja, um processo de taxa ativado energeticamente. Utilizada para o escoamento plástico em polímeros amorfos, esta teoria apresenta a seguinte relação entre a taxa de deformação cisalhante $\dot{\gamma}$, a tensão cisalhante $\tau$ e a temperatura absoluta $\theta$

$$
\dot{\gamma}=\dot{\gamma}_{0} \exp \left(-\frac{\Delta H}{R \theta}\right) \sinh \left(\frac{\Omega \tau}{R \theta}\right)
$$

no qual $\dot{\gamma}_{0}$ é um parâmetro do material, $\Delta H$ é a energia de ativação, $\Omega$ é o volume de ativação e $R$ é a constante universal dos gases. Da definição do seno hiperbólico, pode-se desenvolver

$$
\dot{\gamma}=\frac{\dot{\gamma}_{0}}{2} \exp \left(\frac{-\Delta H+\Omega \tau}{R \theta}\right)-\frac{\dot{\gamma}_{0}}{2} \exp \left(\frac{-\Delta H-\Omega \tau}{R \theta}\right)
$$

De acordo com Mulliken em sua dissertação de mestrado [74], o primeiro termo pode ser considerado como o progresso do escoamento, já que a tensão atua contra a energia de ativação, por terem sinais opostos. O segundo termo captura o regresso do escoamento, não desprezível em casos de descarregamento ou baixas tensões. Simplificando e rearranjando a eq. 3.35 após este raciocínio, a relação se torna

$$
\frac{\tau}{\theta}=A\left[\ln \left(2 C \dot{\gamma}+\frac{\Delta H}{R \theta}\right)\right]
$$


$\operatorname{com} A=\frac{R}{\Omega}$ e $C=\frac{1}{\dot{\gamma}}$.

Bauwens et al. [8] em 1969, testaram experimentalmente PC e PVC com o objetivo de encontrar a tensão de escoamento para taxas de deformação entre $10^{-5} \mathrm{~s}^{-1}$ e $10^{0} \mathrm{~s}^{-1}$, variando a temperatura entre $20^{\circ} \mathrm{C}$ e $140^{\circ} \mathrm{C}$, e reescreveram a eq. (3.35) em função da tensão de escoamento uniaxial $\sigma_{y}$ e da taxa de deformação uniaxial, $\dot{\varepsilon}$

$$
\frac{\sigma}{\theta}=\bar{A}\left[\ln \left(2 \bar{C} \dot{\varepsilon}+\frac{Q}{R \theta}\right)\right]
$$

com $Q$ sendo a energia de ativação.

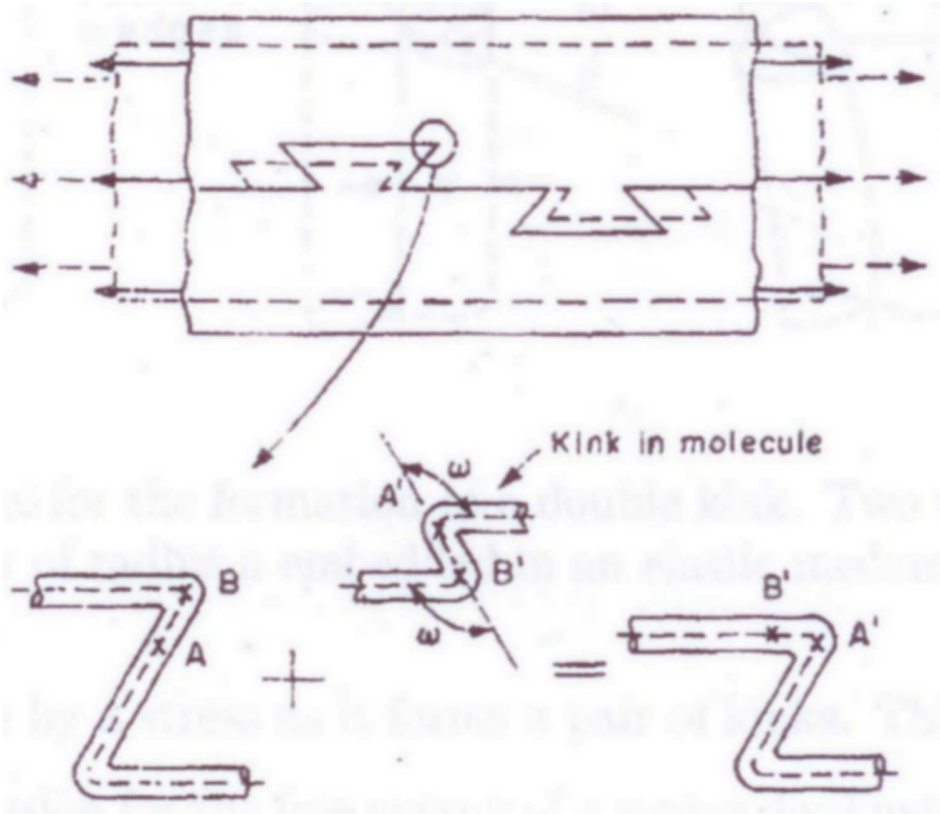

Figura 3.6: Modelo apresentado por Argon.

Já em 1968, Argon [2] propos uma lei de escoamento para polímeros amorfos na qual forças intermoleculares governavam o movimento plástico. Aproximando uma molécula por um cilindro elástico, calculou a energia livre associando-a com um movimento denominado dobras (tradução adotada pelo autor para kink), ilustrado na fig. 3.6. Argon considerou não somente a barreira energética, mas também a estabilidade na nova configuração, obtendo

$$
\dot{\gamma}=\gamma_{0} \nu_{a} N_{a} \exp \left[-\frac{\Delta G}{2 k \theta}\right]
$$

com $\gamma_{0}$ sendo a unidade de incremento de deformação de cisalhamento resultante do produto do par de dobras, $\nu_{a}$ a frequência que captura a taxa com que as dobras ocorrem, $N_{a}$ a densidade de estados ativados e $\Delta G$ a energia livre de ativação determinada em 
função da tensão de cisalhamento $\tau$, do módulo cisalhante $\mu$ e da pressão hidrostática $p$ por

$$
\Delta G=\frac{3 \pi \mu \omega^{2} a^{3}}{16(1-\nu)}\left[1-8.5(1-\nu)^{\frac{5}{6}}\left(\frac{\tau}{\mu}\right)^{\frac{5}{6}}\right]+0.15 \nu a^{3}\left(\omega-\omega_{c}\right)^{2}\left(\frac{p}{\mu}\right)
$$

com $\nu$ sendo o coeficiente de Poisson e $\omega$ e a parâmetros geométricos do cilindro elástico.

Ree e Eyring criaram um modelo em 1955 [83] que permite, de maneira simples, a atuação conjunta de diversos processos, ao invés de apenas um como no modelo de Eyring. O modelo consiste na seguinte relação constitutiva

$$
\frac{\sigma_{y}}{\theta}=\sum_{i} \frac{1}{A_{i}} \operatorname{senh}^{-1}\left[\frac{C_{i} \dot{\varepsilon}}{\theta} \exp \left(\frac{\Delta H_{i}}{R \theta}\right)\right]
$$

Esses modelos conseguiram predizer com sucesso o início do escoamento, dependente de temperatura e de pressão, mas infelizmente não possuem artifícios para considerar escoamento após seu início. Não há uma variável histórica de modo a possibilitar formulação de encruamento cinemático ou mesmo um amolecimento. Entretanto, em 1968, Haward e Thackray [41] propuseram um framework cinemático (o qual serviu de base para o trabalho de Boyce, Parks e Argon [20] ), representado na fig. 3.7, simplificando o escoamento de Eyring [30] por $\dot{\varepsilon}=K \sinh (V \tau / 2 k \theta)$, com $k$ sendo a constante de Boltzman e $K$ e $V$ as constantes do material.

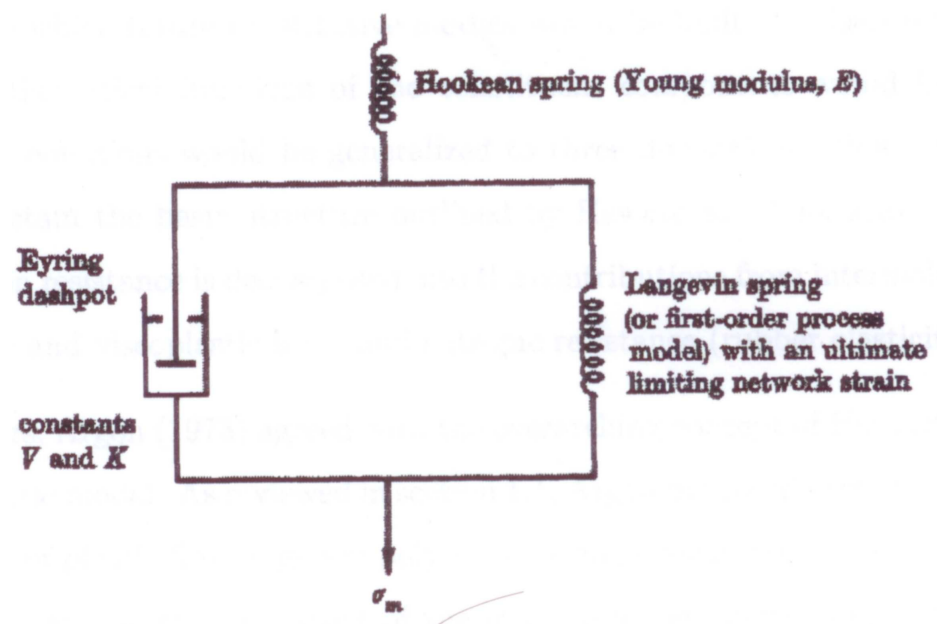

Figura 3.7: Modelo de Haward e Tackray [41]

Com base nesse modelo, Argon propos em 1973 [1] uma reformulação de seu trabalho 
anterior, simplificando e reescrevendo suas equações como

$$
\begin{gathered}
\dot{\gamma}=\gamma_{0} \exp \left[-\frac{\Delta G}{2 k \theta}\right] \\
\Delta G=\frac{3 \pi \mu \omega^{2} a^{2}}{16(1-\nu)}\left[1-\left(\frac{\tau}{\frac{0.077 \mu}{1-\nu}}\right)^{\frac{5}{6}}\right]
\end{gathered}
$$

Em 1988, Boyce, Parks e Argon [20] publicaram o trabalho cuja estrutura cinemática foi explicada previamente neste mesmo capítulo, com função de escoamento

$$
\dot{\gamma}=\dot{\gamma}_{0} \exp \left[-\frac{A \bar{s}}{\theta}\left(-1\left(\frac{\tau}{\bar{s}}\right)^{\frac{5}{6}}\right)\right]
$$

com $A$ e $\bar{s}$ sendo os parâmetros do material. Entretanto, $\bar{s}$ se tornou uma variável histórica $s$ que evolui com a taxa de deformação cisalhante plástica e valor inicial $s_{0}$

$$
\dot{s}=h\left(1-\frac{s}{s_{s s}}\right) \dot{\gamma} \quad \text { e } \quad s_{0}=\frac{0.077 \mu}{1-\nu}
$$

com $s_{s s}$ representando um regime estacionácio (tradução adotada pelo autor para steady state) e $h$ sendo o módulo de amolecimento. Em uma última evolução, $\bar{s}$ se tornou $\tilde{s}=s+\alpha p$, com $s$ mantendo seu valor inicial e equação de progressão, mas com um parâmetro $\alpha$, que multiplicado pela valor da pressão hidrostática, $p$, consegue definir comportamentos diferentes para um mesmo material em estados de tração ou compressão.

Por fim, Mulliken propôs em sua dissertação de mestrado [74], em 2004, uma função de escoamento na forma de

$$
\dot{\gamma}=2 \dot{\gamma}_{0} \exp \left(-\frac{\Delta G}{k \theta}\right) \sinh \left[\frac{\tau\left(\frac{\Delta G}{s+\alpha p}\right)}{k \theta}\right]
$$

\subsection{Funções de escoamento viscoso}

A formulação viscoelástica mais simples é a linear, no qual a taxa de deformação $\dot{\gamma}^{v}$ e tensão $\tau$ cisalhantes se relacionam por

$$
\dot{\gamma}^{v}=\dot{\gamma}_{0}\left[\frac{\tau}{\tau_{0}}\right]
$$

no qual $\dot{\gamma}_{0}=1 / s$ serve para correção dimensional apenas e $\tau_{0}$ é a única constante do material. Esta lei de escoamento é largamente utilizada na teoria de relaxação e fluência nos elementos de Maxwell, reologicamente descrito por uma mola (relação constitutiva 
entre tensão e deformação) em série com um amortecedor (lei de escoamento entre taxa de deformação e tensão), e nos elementos de Kelvin, com descrição reológica de uma mola e um amortecedor em paralelo.

Apesar da limitação da relação linear, a combinação em paralelo de diversos elementos de Maxwell, conforme demonstrado por Klompen [49], calibrados com aproximadamente um elemento de Maxwell por década de taxa de deformação, é capaz de reproduzir tanto a parte não linear do carregamento elástico de termoplásticos, conforme apresentado na fig. 3.8(a), quanto a relaxação do mesmo, fig. 3.8(b), nos quais os símbolos são dados experimentais e as linhas sólidas são as predições do modelo.

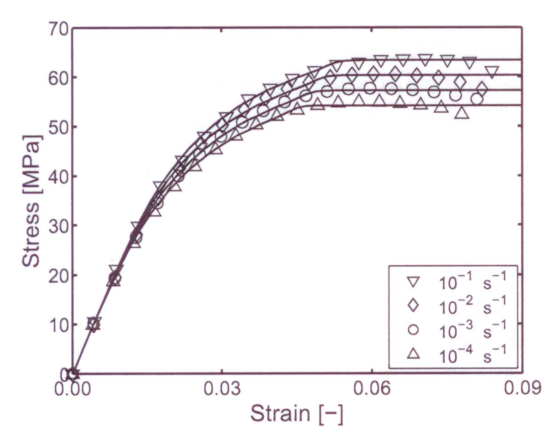

(a) Curvas tensão deformação em $\mathrm{PC}[49]$

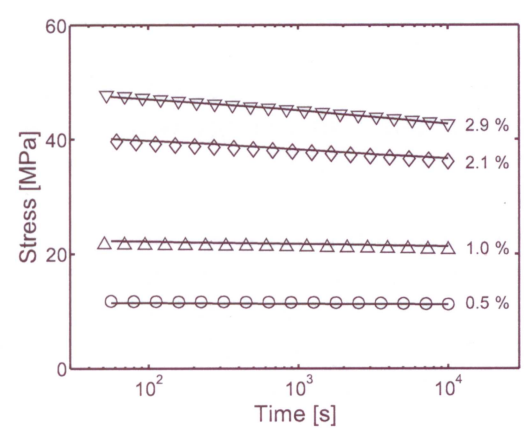

(b) Curvas de relaxação em PC [49]

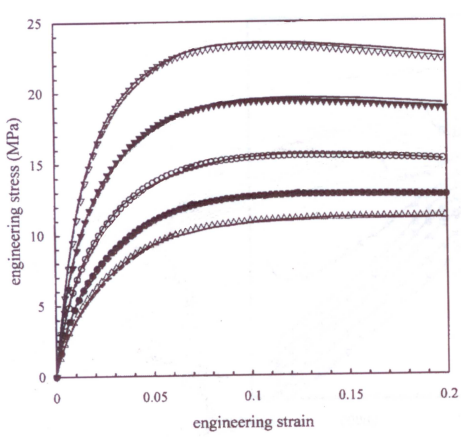

(c) rede de 8 cadeias

Figura 3.8: Comparações entre resultados experimentais e predições com modelos de material para visco-elasticidade

Bergstrom [12] descreve outra lei de escoamento visco-elástica denominada modelo de escoamento potencial, matematicamente descrito por

$$
\dot{\gamma}^{v}=\dot{\gamma}_{0}\left[\frac{\tau}{\tau_{0}}\right]^{m}
$$

com o parâmetro $m>1$, sendo um caso específico do modelo Bergstrom-Boyce, implementado pelo nome ${ }^{*}$ hysteresis no software comercial de elementos finitos Abaqus. A lei de escoamento da mesma é dada por

$$
\dot{\gamma}=C_{1}\left[\overline{\lambda_{B}^{v}}-1\right]^{c_{2}}\left[\frac{\tau}{\tau_{0}}\right]^{m}
$$

no qual o termo $C_{1}\left[\overline{\lambda_{B}^{v}}-1\right]^{c_{2}}$ o diferencia da lei de escoamento potencial. Sob um ponto de vista de controle, pode-se interpretar a equação acima como um controle de malha fechada, na qual a resposta taxa de deformação cisalhante depende do valor de $\overline{\lambda_{B}^{v}}=\sqrt{\operatorname{tr} \mathbf{B}}$, ou seja, do quanto já existe de desvio do valor de equilíbrio. 
Por fim, Beijer e Spoormaker [9] utilizaram dois conjuntos reológicos paralelos de mola em série amortecedor não linear com a relação de Eyring de lei escoamento viscoso, e obtiveram resultados excelentes ao reproduzirem com este modelo o início visco-elástico de curvas tensão deformação em taxas de deformação de $10^{-6}$ a $10^{-2}$ em polietileno de alta densidade, conforme mostra a fig. 3.8(c), com os símbolos representando os dados experimentais e as curvas sólidas representando as predições do modelo. 


\section{Capítulo 4}

\section{Experimentos mecânicos a baixas taxas de deformação}

\subsection{Introdução}

O objetivo deste capítulo é investigar o comportamento mecânico de um polímero amorfo, o PVC, e de um polímero semicristalino, o PEAD, através de ensaios experimentais de tração, em diferentes baixas taxas de deformação e em relaxação, e de compressão somente em baixas taxas de deformação. Para os ensaios de relaxação, também analisou-se o PMMA para a obtenção do seu comportamento visco-elástico em baixíssimas taxas de deformação possibilitando o contraste com seu comportamento na propagação de ondas (altíssimas taxas de deformação). Apesar destes materiais estarem bem caracterizados na literatura, a utilização de uma técnica ótica conhecida por DIC (Digital Image Correlation, ou correlação digital de imagem em português) para a medição individual de deformações longitudinais e transversais para diversas seções transversais do corpo de prova motivou a execução dos mesmos.

Além de servirem para a compreensão do comportamento mecânico dos polímeros, fornecendo por exemplo o grau de anisotropia e a sensibilidade a taxa de deformação, os testes devem fornecer dados suficiente para calibrar alguns parâmetros dos modelos de material vistos no capítulo 3, tanto na parte visco-elástica dada pela relação da tensão em função da deformação e taxa de deformação, no regime de pequenas deformações, quanto na parte de visco-plasticidade em que o escoamento é determinado pela taxa de deformação, calculada em função da tensão deviatórica e da tensão hidrostática.

Este capítulo pode ser dividido nas seguintes seções: 
- detalhamento de algumas propriedades físicas dos materiais estudados, tipos e geometrias dos corpos de prova usinados, procedimento e configuração experimentais além de uma breve explicação da técnica de correlação digital de imagens;

- uma seção para análise dos resultados experimentais, dissertando primeiro sobre o comportamento de apenas um ensaio com respeito a evolução das deformações, localização, distribuição de deformações, taxas de deformação e tensões ao longo de um mesmo corpo de prova e finalizando com as curvas tensão deformação representativas de cada ensaio experimental;

- uma seção sobre os ensaios de relaxação, com a metodologia, os resultados da redução da tensão ao se manter aplicada a mesma deformação global no corpo de prova e a variação local da deformação;

Por fim, vale ressaltar que grande parte dos resultados apresentados neste capítulo já foram publicados no congresso Impact Loading of Lightweight Structures [68], realizado na Noruega em 2008 e posteriormente no International Journal of Impact Engineering [69], em 2010.

\subsubsection{Materiais}

Ambos os materiais foram comprados na forma de placas extrudadas, sendo o polietileno de alta densidade, ou PEAD, um termoplástico semicristalino denominado PE-HWU pelo fabricante e descrito pelo mesmo como um material preto especialmente estabilizado para uso externo, com alta proteção ultravileta, baixa absorção de água e alta resistência química e à corrosão. Já o PVC, denominado PVC-TF, é descrito pelas mesmas propriedades no que diz respeito a estabilidade, entretanto com uma maior absorção de água. Ainda segundo o fabricante, não há qualquer partícula aditiva ou fibra com intuito de aumento de resistência mecânica, mas algumas partículas misturadas para diminuir a degradação destes materiais. Algumas das propriedades mecânicas e térmicas destes materiais foram apresentadas no cap. 1.

Os polímeros foram adquiridos sob o formato de placas extrudadas de $2 \mathrm{~m}$ por $1 \mathrm{~m}$, com a direção de extrusão de paralela a direção de maior dimensão, e em espessuras de $5 \mathrm{~mm}$ e $10 \mathrm{~mm}$. A figura 4.1 é uma representação esquemática da usinagem das placas em 
quadriláteros de $600 \mathrm{~mm}$ por $600 \mathrm{~mm}$ ou $600 \mathrm{~mm}$ por $400 \mathrm{~mm}$, com o subproduto de maior área sendo utilizado em ensaios experimentais de impacto em placas, não com a intenção de encontrar o limite balístico das mesmas, mas para realizar ensaios que possibilitem carregamentos complexos cobrindo uma ampla faixa de taxas de deformação, pressão, regime elástico ou plástico. Os resultados desses ensaios serão utilizados para validação de modelos de material utilizados no ensaio numérico semelhante. Será adotado o termo ensaio de componente para este tipo de ensaio experimental.

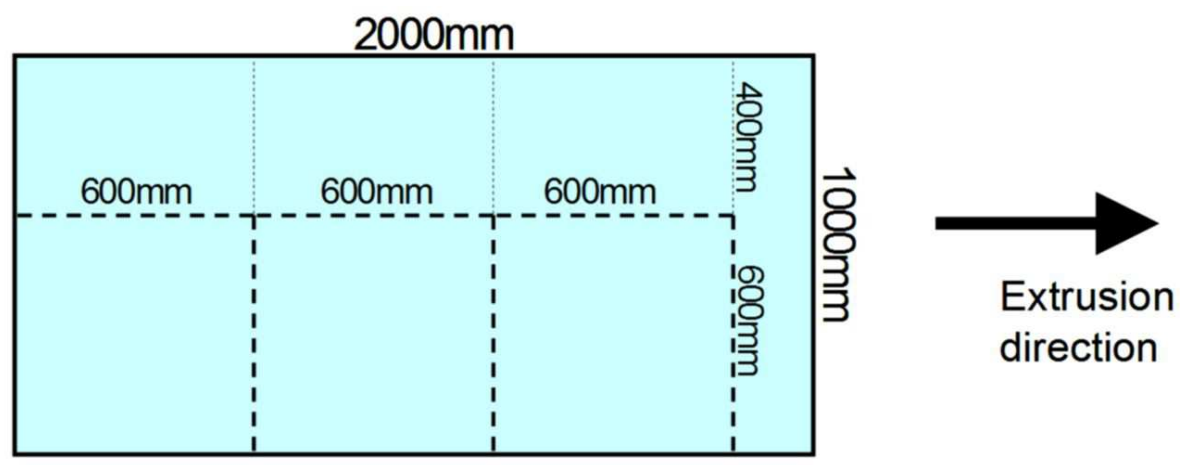

Figura 4.1: Esquema de corte das placas poliméricas

\subsubsection{Corpos de prova}

Da placa retangular de $600 \mathrm{~mm}$ x $400 \mathrm{~mm}$ e $10 \mathrm{~mm}$ de espessura foram usinados corpos de prova para ensaios de tração e compressão. Os corpos de prova de tração foram denominados $\mathrm{T} 1$, com espessura de $8 \mathrm{~mm}$, ou T2, com espessura de $4 \mathrm{~mm}$, conforme fig. 4.2(b) e 4.2(d). Os corpos de prova de compressão foram denominados C1, um cubo de $10 \mathrm{~mm}$ de aresta, ou C2, no qual uma das dimensões de C1 é alterada para 15mm, conforme figuras $4.2(\mathrm{a})$ e $4.2(\mathrm{c})$.

Para determinar previamente a posição do início da estricção e também evitar o fenômeno de estriç̧ão dupla, uma técnica similar à publicada por Fang et al. [32] foi aplicada usinando-se uma imperfeição geométrica na forma de um entalhe com 100mm de raio e somente $0,1 \mathrm{~mm}$ de profundidade nos corpos de prova de tração, fig. 4.3. Este é pequeno o suficiente para não ser considerado um concentrador de tensões, entretanto eficiente na função de inicializar a estricção. 


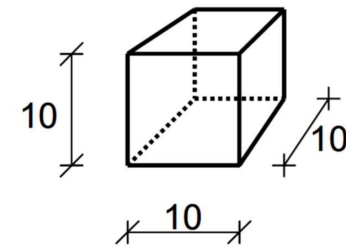

(a) $\mathrm{C} 1$

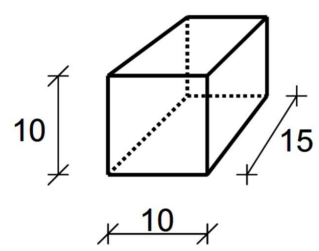

(c) $\mathrm{C} 2$

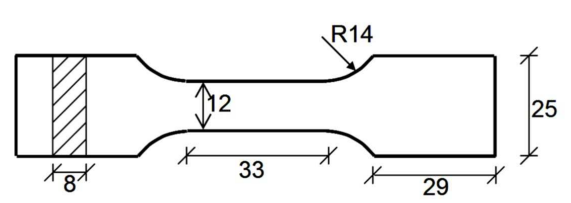

$115 x$

(b) $\mathrm{T} 1$

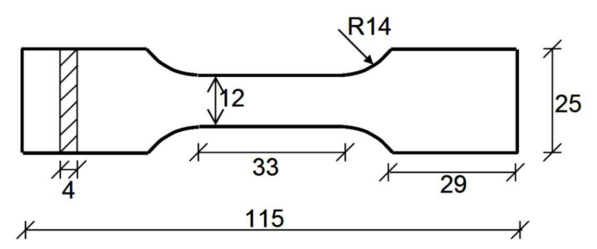

(d) $\mathrm{T} 2$

Figura 4.2: Geometria dos corpos de prova de tração e compressão (medidas em mm).

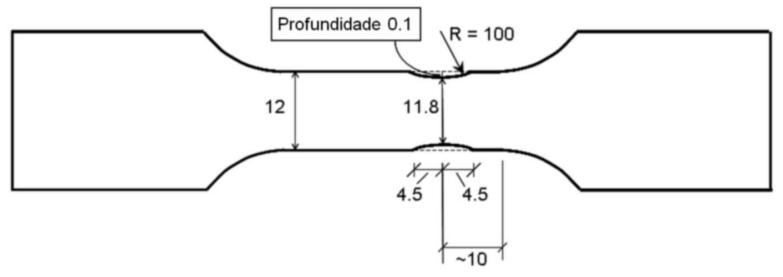

Figura 4.3: Entalhe no corpo de prova de tração.

Um sistema cartesiano foi indexado com a direção $x$ sendo a de extrusão e a direção $z$ normal à placa, na finalidade de comparar as relações entre a deformação na direção de extrusão e as deformações em $y$ ou $z$. No caso de serem suficientemente próximas, a diferença é desprezada por hipótese e é possível estimar a área de uma seção transversal apenas medindo-se as deformações axial e transversal em uma face do corpo de prova.
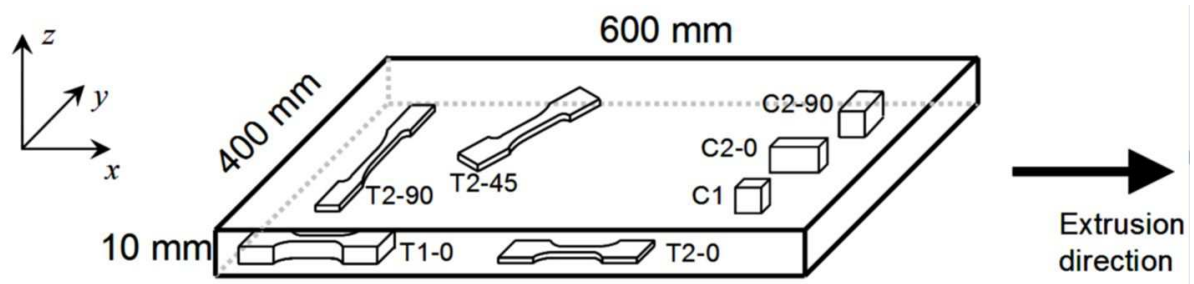

Figura 4.4: Leiaute para usinagem dos corpos de prova a partir da placa extrudada de $400 \mathrm{~mm}$ por $600 \mathrm{~mm}$ com $10 \mathrm{~mm}$ de espessura

A figura 4.4 indica a denominação de cada corpo de prova relativa à posição no qual foi usinado da placa, para os corpos de prova T1, T2 e C2, além da direção de carregamento para os corpos de prova $\mathrm{C} 1$, constando na tabela 4.1. 
Capítulo 4. Experimentos mecânicos a baixas taxas de deformação

\begin{tabular}{|c|c|c|}
\hline Denominação & $\begin{array}{l}\text { geometria do } \\
\text { corpo de prova }\end{array}$ & direção do carregamento \\
\hline $\mathrm{T} 1-0$ & $\mathrm{~T} 1$ & $x$ - direção de extrusão \\
\hline $\mathrm{T} 2-0$ & $\mathrm{~T} 2$ & $x$ - direção de extrusão \\
\hline $\mathrm{T} 2-45$ & $\mathrm{~T} 2$ & $\begin{array}{c}\text { no plano da placa, } x y \text {, formando um } \\
\text { ângulo de } 45^{\circ} \text { com a direção de extrusão } x\end{array}$ \\
\hline $\mathrm{T} 2-90$ & $\mathrm{~T} 2$ & $\begin{array}{l}y \text {-no plano da placa, } x y \text {, formando um } \\
\text { ângulo de } 90^{\circ} \text { com a direção de extrusão } x\end{array}$ \\
\hline $\mathrm{C} 1-\mathrm{x}$ & C1 & $x$ - direção de extrusão \\
\hline $\mathrm{C} 1-\mathrm{y}$ & C1 & $\begin{array}{l}y \text { - no plano da placa, } x y \text {, formando um } \\
\text { ângulo de } 90^{\circ} \text { com a direção de extrusão } x\end{array}$ \\
\hline $\mathrm{C} 1-\mathrm{Z}$ & C1 & $z$ - perpendicular ao plano da placa, $x y$ \\
\hline $\mathrm{C} 2-0$ & $\mathrm{C} 2$ & $x$ - direção de extrusão \\
\hline $\mathrm{C} 2-90$ & $\mathrm{C} 2$ & $\begin{array}{l}y \text { - no plano da placa, } x y, \text { formando um } \\
\text { ângulo de } 90^{\circ} \text { com a direção de extrusão } x\end{array}$ \\
\hline
\end{tabular}

Tabela 4.1: Denominação contendo a geometria do corpo de prova e a direção de carregamento.

\subsubsection{Procedimento experimental}

É sabido que os termoplásticos variam seu volume de maneira significativa durante a deformação plástica $[29,32,47,65,79]$, invalidando o uso da fórmula que relaciona as tensões verdadeira e de engenharia, $\sigma=\sigma_{e n g}\left(1+\varepsilon^{C}\right)$, comumente utilizada ao se estudar metais sob hipótese de um estado de carregamento unidimensional e isovolumétrico. Ainda, a estriç̧ão ocorre em estágios anteriores aos dos ensaios em metais, resultando em uma concentração das deformações axiais, ou seja, em um campo de deformações não homogêneo. Desta forma, o uso da técnica de correlação de imagens digitais foi fundamental para a obtenção de resultados acurados, permitindo a medição sem contato das deformações axial e transversal em um plano.

O cálculo da tensão verdadeira envolve a área atual, que não pode ser obtida de maneira precisa durante um teste utilizando apenas uma câmera e sem o uso de espelhos.Por este motivo foram realizados testes replicantes. Representados na fig. 4.5, os testes replicantes fornecem informações sobre todas as três componentes perpendiculares de deformação. Com ambos os cubos carregados na direção $z$, a câmera é posicionada em maneiras diferentes, sendo que captura a face $x z$ no teste (1), fornecendo os dados para calcular $\varepsilon_{z}, \varepsilon_{x}$ e $\gamma_{x z}$. De maneira análoga, as componentes $\varepsilon_{z}$, $\varepsilon_{y}$ e $\gamma_{y z}$ são obtidas 
do teste (2), tornando possível a comparação da evolução de $\varepsilon_{x}$ e $\varepsilon_{y}$ em função de uma referência em comum $\varepsilon_{z}$. Para a relação entre a deformação axial e ambas as deformações transversais, testes replicantes foram feitos em C1 variando-se a direção de carregamento (C1-x, C1-y e C1-z) no caso de compressão e em T1-0 no caso de tração.

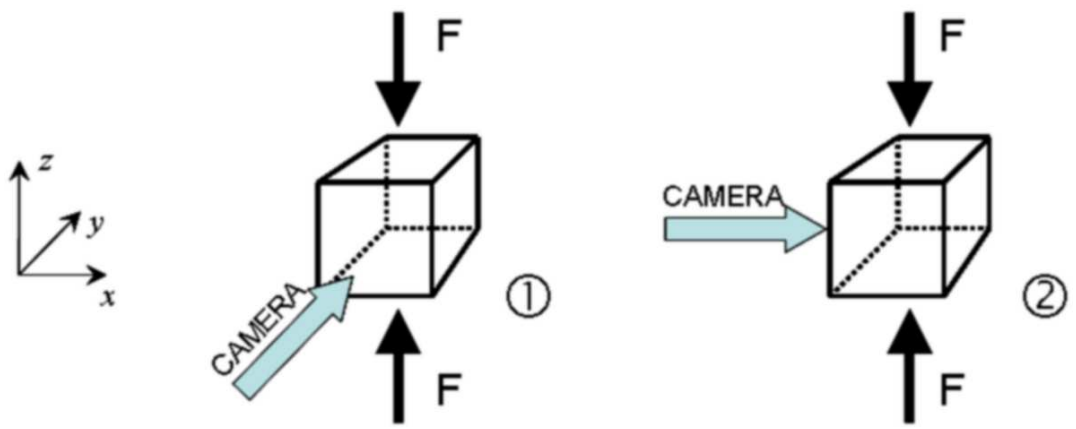

Figura 4.5: Esquemática de testes replicantes para obtenção dos componentes de deformação em ambas as faces

No caso de compressão, os testes C1-x, C1-y e C1-z também servem ao propósito de verificar a anisotropia do material, e os testes C2-0 e C2-90 foram executados com diferentes velocidades com o objetivo de avaliar a sensibilidade à taxa de deformação. Já no caso de tração, os testes T2-0, T2-45 e T2-90 forneceram dados para estudar a anisotropia enquanto a sensibilidade à taxa de deformação foi avaliada variando-se a velocidade dos testes T2-0. As informações sobre os testes com sua denominação, direção de carregamento, número de testes replicantes e intenção estão listadas nas tabelas 4.2 e 4.3 .

\begin{tabular}{ccccl}
\hline $\begin{array}{c}\text { Corpo } \\
\text { de prova }\end{array}$ & $\begin{array}{c}\text { direção de } \\
\text { carregamento }\end{array}$ & $\begin{array}{c}\text { taxa de deformação } \\
\text { nominal }\left(\mathrm{s}^{-1}\right)\end{array}$ & $\begin{array}{c}\text { testes } \\
\text { replicantes }\end{array}$ & Objetivo \\
\hline C1-x & $x$ & 0,001 & 2 & comparar a relação \\
C1-y & $y$ & 0,001 & 2 & entre a deformação \\
C1-z & $z$ & 0,001 & 2 & axial e cada transversal \\
\hline C2-0 & $x$ & 0,0002 & 1 & estimar a sensibilidade \\
C1-0 & $x$ & 0,001 & 1 & à taxa de deformação \\
C1-0 & $x$ & 0,005 & 1 & na direção $x$ \\
\hline C2-90 & $y$ & 0,0002 & 1 & estimar a sensibilidade \\
C2-90 & $y$ & 0,001 & 1 & à taxa de deformação \\
C2-09 & $y$ & 0,005 & 1 & na direção $y$ \\
\hline
\end{tabular}

Tabela 4.2: Detalhamento do programa experimental para ensaios de compressão 
Capítulo 4. Experimentos mecânicos a baixas taxas de deformação

\begin{tabular}{ccccl}
\hline $\begin{array}{c}\text { Corpo } \\
\text { de prova }\end{array}$ & $\begin{array}{c}\text { direção de } \\
\text { carregamento }\end{array}$ & $\begin{array}{c}\text { taxa de deformação } \\
\text { nominal }\left(\mathrm{s}^{-1}\right)\end{array}$ & $\begin{array}{c}\text { testes } \\
\text { replicantes }\end{array}$ & Objetivo \\
\hline T1-0 & $x$ & 0,001 & 2 & $\begin{array}{l}\text { comparar a relação } \\
\text { entre a deformação } \\
\text { axial e cada transversal }\end{array}$ \\
\hline $\mathrm{T} 2-0$ & $x$ & 0,001 & 1 & estimar a anisotropia \\
$\mathrm{T} 2-45$ & $45^{\circ}$ & 0,001 & 1 & no plano da placa \\
$\mathrm{T} 2-90$ & $y$ & 0,001 & 1 & $x y$ \\
\hline $\mathrm{T} 2-0$ & $x$ & 0,001 & 1 & estimar a sensibilidade \\
$\mathrm{T} 2-0$ & $x$ & 0,01 & 1 & $\begin{array}{l}\text { à taxa de deformação } \\
\text { na direção } x\end{array}$ \\
\hline
\end{tabular}

Tabela 4.3: Detalhamento do programa experimental para ensaios de tração

Os ensaios foram realizados em uma máquina servo-hidráulica Dartec com sistema de controle Instron, célula de carga de $20 \mathrm{kN}$ e deslocamento máximo do atuador hidráulico de $100 \mathrm{~mm}$. As fotos para posterior análise de DIC foram obtidas por uma Canon EOS-1D Mark II com resolução de 8.2MPixels na proporção de 3504 pixels por 2336 pixels, com 24 bits de profundidade de cor e tempo de exposição de 1/200 segundos. Esta configuração experimental está ilustrado na fig. 4.6.
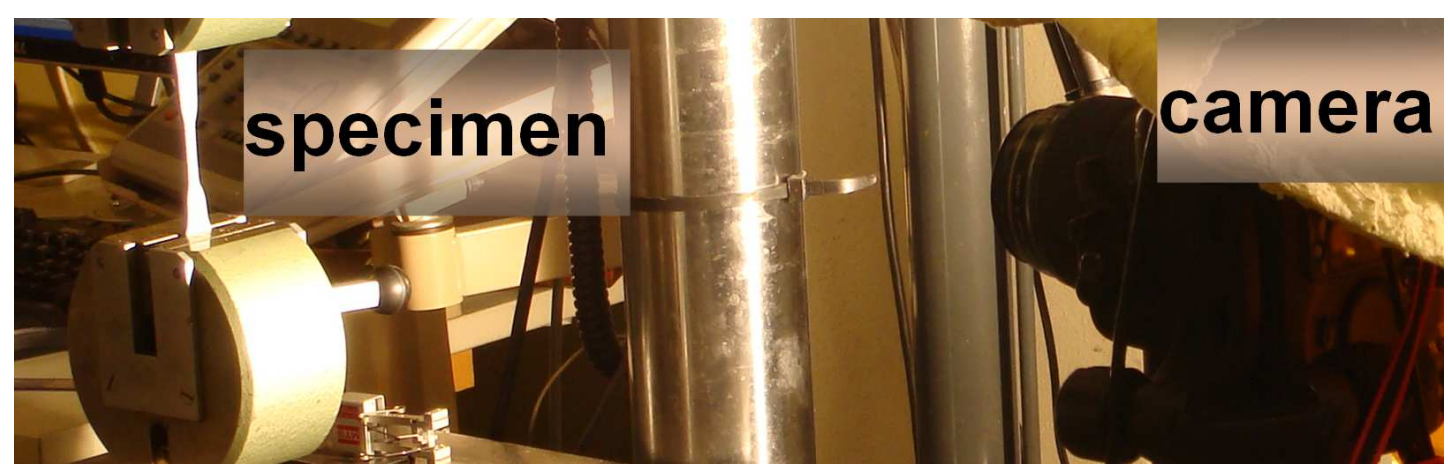

Figura 4.6: Corpo de prova fixado em máquina de tração e câmera fotográfica para captura das imagens.

O programa experimental descrito até aqui foi realizado no Structural Impact Laboratory (SIMLab) da Universidade Técnica Norueguesa, em Trondheim. Também foram realizados testes de relaxação nas dependências do Grupo de Mecânica dos Sólidos e Impacto em Estruturas (GMSIE), USP, com duas finalidades: 
- obter o comportamento mecânico dos polímeros PVC, PEAD e PMMA a baixíssimas taxas de deformação, por volta de $10^{-7} \mathrm{~S}^{-1}$ a $10^{-8} \mathrm{~S}^{-1}$, em regime elástico, para posterior contraste com os testes de propagação de ondas elásticas que ocorrem a altas taxas de deformação;

- observar o comportamento local das deformações durante um ensaio de relaxação com a técnica DIC.

Estes ensaios foram realizados em uma máquina de ensaios universais Instron, modelo 3369, célula de carga de $50 \mathrm{kN}$ e as imagens obtidas por uma câmera NIKON D90, resolução de 12.2MPixels na proporção de 4288 pixels por 2848 pixels, com 24 bits de profundidade de cor e tempo de exposição de 1/640 segundos, a partir do programa Camera Control Pro 2.7.1W no modo de time lapse shooting. O menor tempo de exposição implica no sensor captar a imagem em um menor intervalo de tempo, possibilitando imagens com mais precisas. Para tanto, foi utilizado um sistema especial de iluminação LED, da Visual Instrumentation Corporation com aproximadamente 12500 lúmens, conforme o arranjo na fig. 4.7.

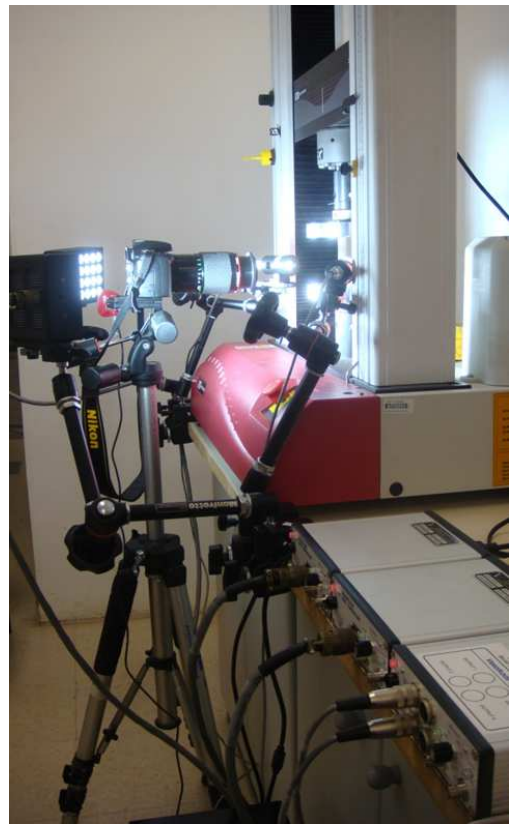

(a)

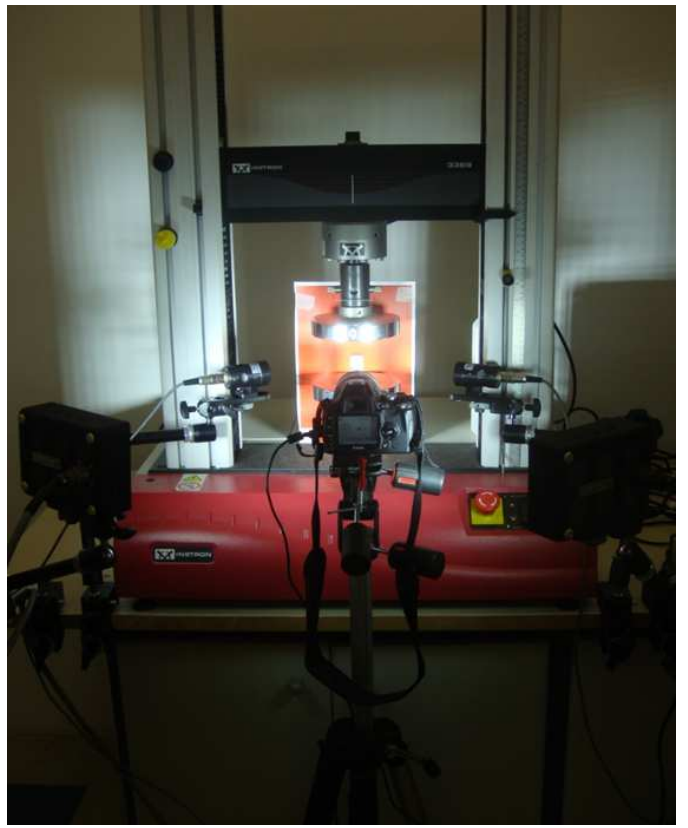

(b)

Figura 4.7: Arranjo experimental utilizado no laboratório GMSIE. 


\subsection{Análise dos resultados experimentais}

Primeiro serão analisados os experimentos de tração, com a análise minuciosa e entendimento do comportamento de todo o corpo de prova nos ensaios experimentais que envolvem o corpo de prova T1, com carregamento na direção de extrusão usinados das placas de PEAD, e câmera registrando inicialmente as superfícies de normais $z$ e $y$ em seguida. Então os resultados serão comparados com os outros ensaios, permeando o grau de anisotropia e sensibilidade à taxa de deformação. O mesmo procedimento é adotado no caso de compressão.

\subsubsection{Análise de um teste de tração de PEAD e PVC}

Ambos os testes com o corpo de prova T1-0 com fotografias nas faces de normais $z$ e $y$ serão analisados em paralelo, uma vez que o objetivo é obter testes replicantes, ou seja, de mesma resposta global. O gráfico força deslocamento destes testes estão presentes na fig. 4.8(a) para o PEAD e na fig. 4.8(b) para o PVC. Visualmente pode-se avaliar que os testes replicantes possuem mesmo comportamento global para ambos os materiais.

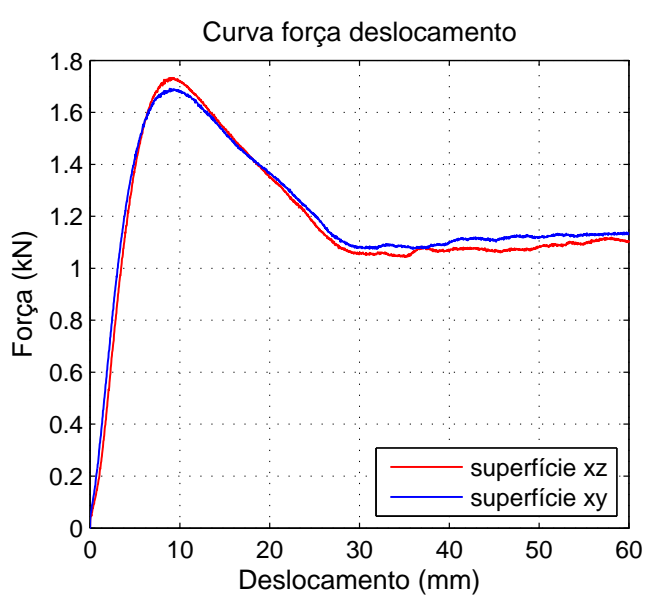

(a) PEAD

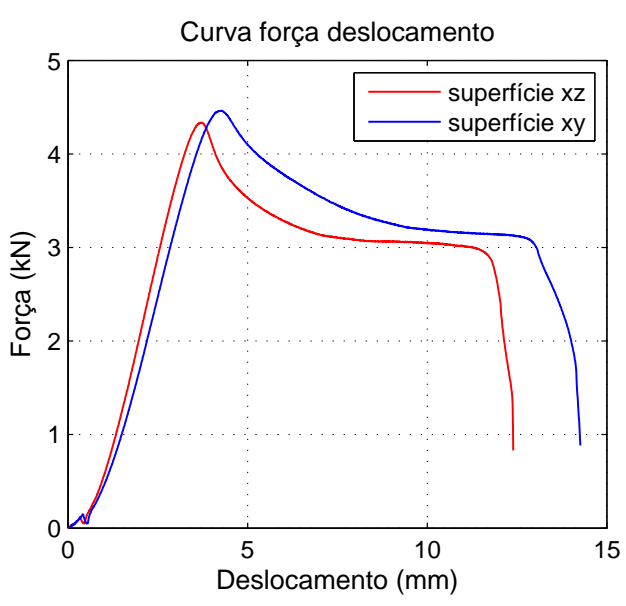

(b) PVC

Figura 4.8: Gráfico da força deslocamento dos testes em T1 capturando imagens das superfícies normais a $y$ e $z$

Após o tratamento dos dados e análise DIC das imagens durante a progressão de ambos testes, foi medida a distribuição de deformação verdadeira axial nos planos $x y$ para PEAD e PVC, conforme figuras 4.9 e 4.10, respectivamente. 


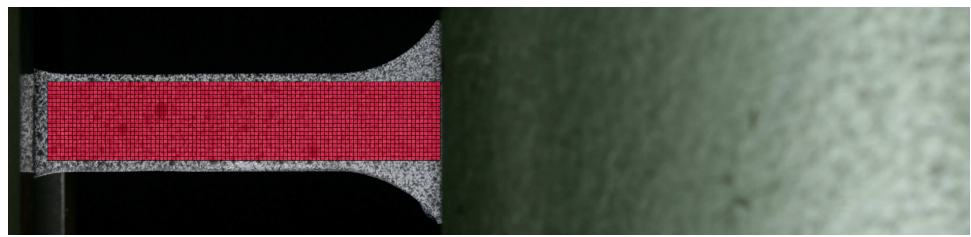

(a) $\mathrm{t}=0 \mathrm{~s}$

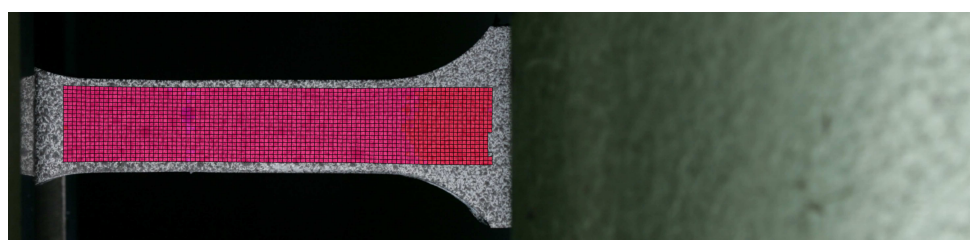

(b) $\mathrm{t}=250 \mathrm{~s}$

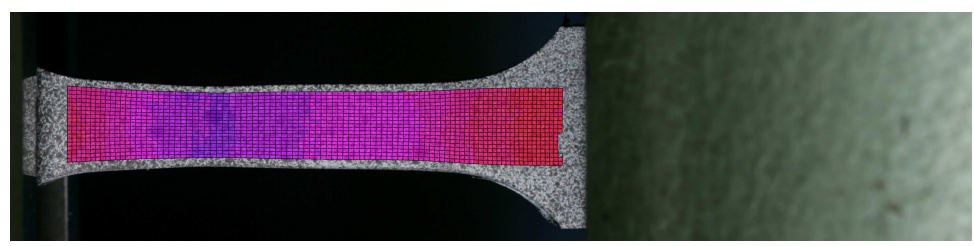

(c) $\mathrm{t}=500 \mathrm{~s}$

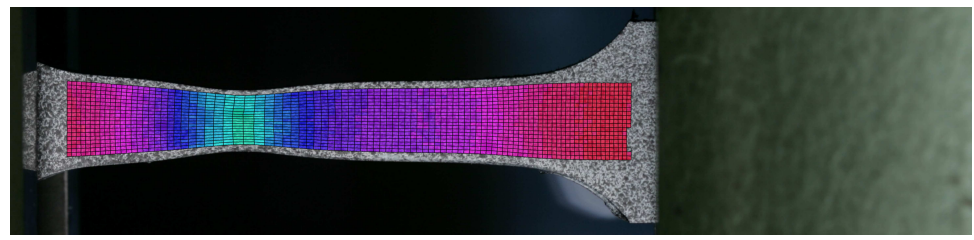

(d) $\mathrm{t}=750 \mathrm{~s}$

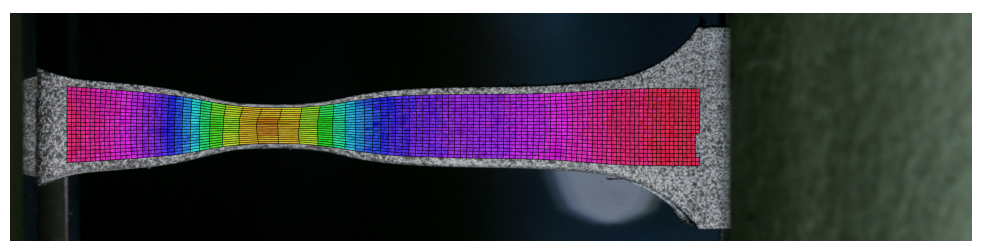

(e) $\mathrm{t}=1000 \mathrm{~s}$

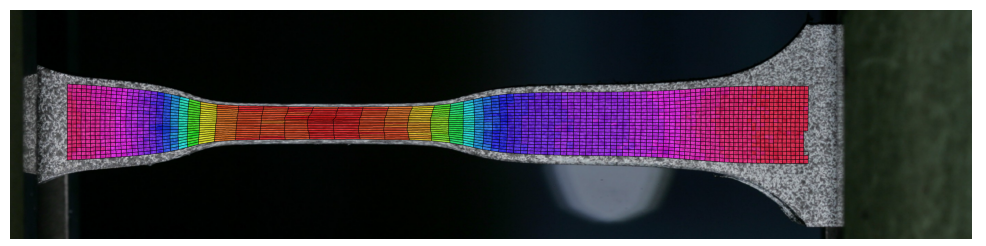

(f) $\mathrm{t}=1400 \mathrm{~s}$

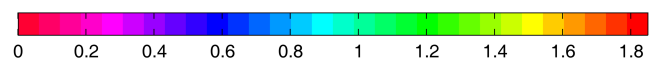

Figura 4.9: Evolução da deformação verdadeira no tempo, para um corpo de prova de tração de PEAD, sendo fotografada a superfície $x y$. 


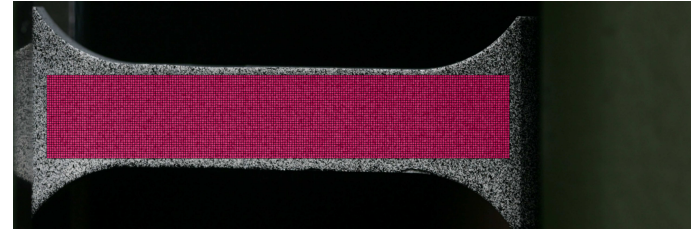

(a) $\mathrm{t}=0 \mathrm{~s}$

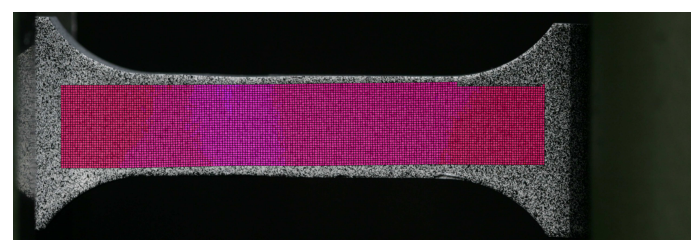

(c) $\mathrm{t}=160 \mathrm{~s}$

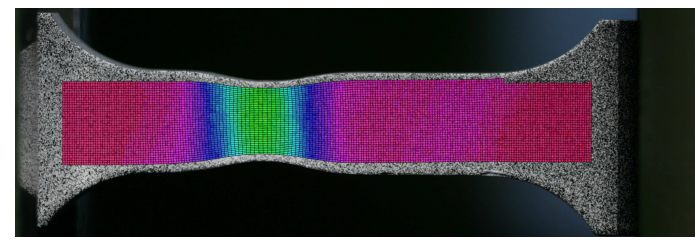

(e) $\mathrm{t}=320 \mathrm{~s}$

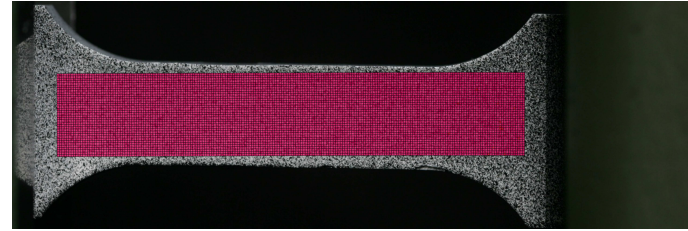

(b) $\mathrm{t}=80 \mathrm{~s}$

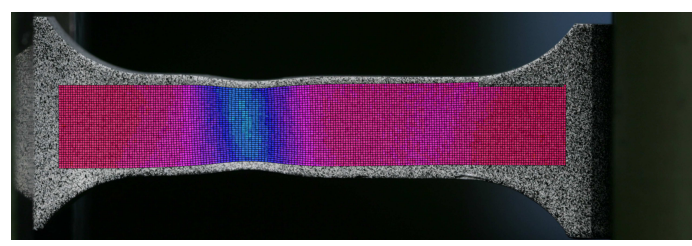

(d) $\mathrm{t}=240 \mathrm{~s}$

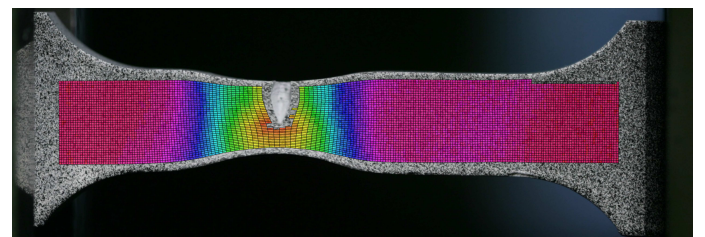

(f) $\mathrm{t}=420 \mathrm{~s}$

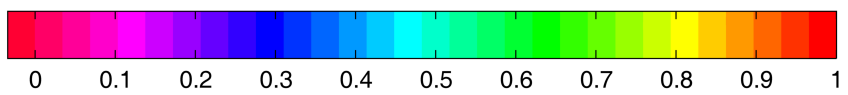

Figura 4.10: Evolução da deformação verdadeira no tempo, para um corpo de prova de tração de PVC, sendo fotografada a superfície $x y$.

Nos testes em PEAD, o atuador hidráulico atinge seu curso máximo, enquanto no ensaios experimentais em PVC, ocorre falha do material. Pode-se observar nas fig. 4.9 e 4.10 que a deformação é constante o suficiente ao longo de cada seção transversal para podermos usar a média das deformações dos elementos em cálculos futuros sem perda de informações. A partir desta média dos elementos de uma mesma secção, da posição horizontal na foto de cada seção do corpo de prova e da evolução temporal destas duas variáveis, foi possível obter a figura 4.11, com a seção transversal que contem o entalhe inicialmente na posição 456 pixels para o PEAD e na posição 718 pixels no teste com PVC.

No teste de PEAD, há um comportamento homogêneo nos primeiros 300 segundos, cessando em uma deformação logarítmica axial de aproximadamente $0,2 \mathrm{~mm} / \mathrm{mm}$. Há então uma localização, ou seja, cada seção transversal segue uma evolução temporal diferente, com a deformação logarítmica da seção transversal do entalhe crescendo com uma taxa superior as outras seções transversais no intervalo de deformações logarítmicas de $0,2 \mathrm{~mm} / \mathrm{mm}$ a $1,6 \mathrm{~mm} / \mathrm{mm}$, entre os instantes $300 \mathrm{~s}$ e $1000 \mathrm{~s}$. A partir de então, a 


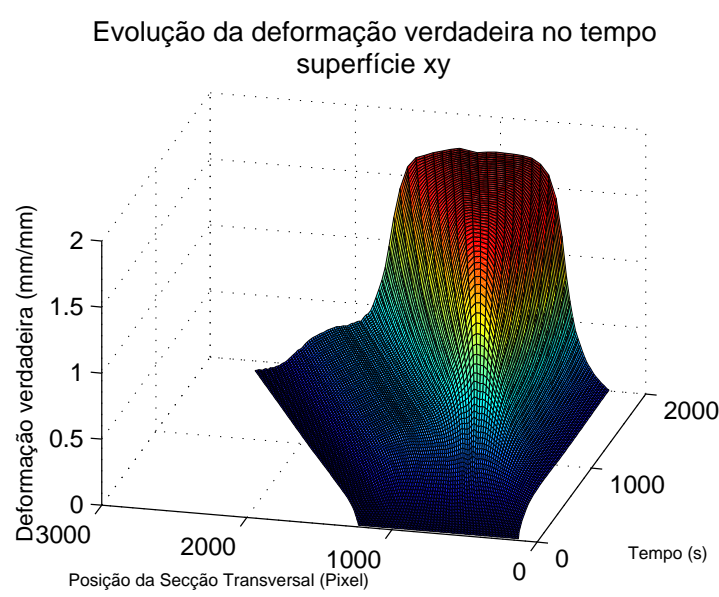

(a) PEAD

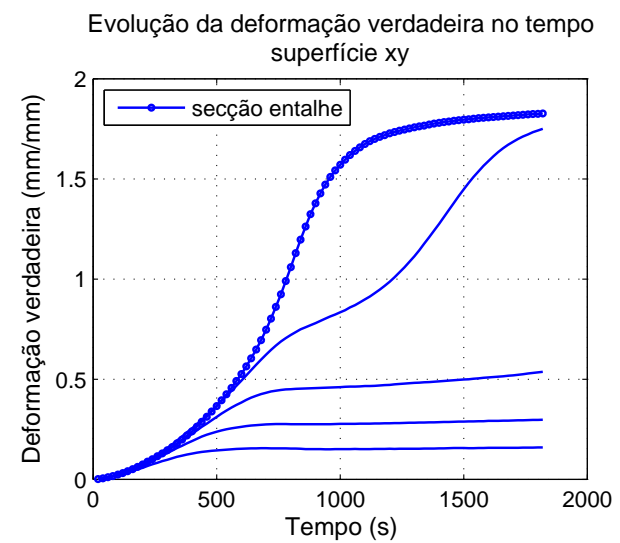

(c) PEAD

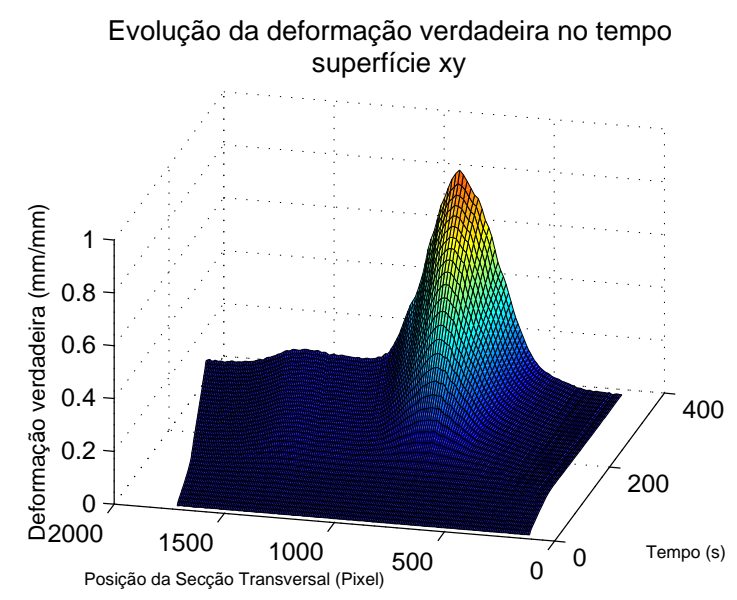

(b) PVC

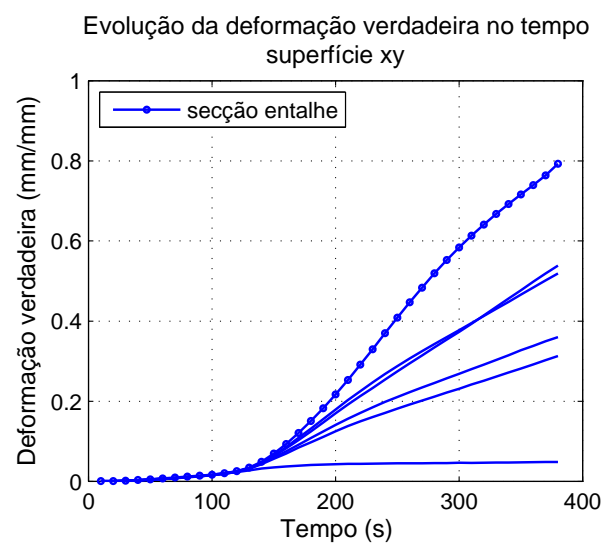

(d) PVC

Figura 4.11: Evolução temporal da deformação verdadeira de todas as seções transversais do teste e comparação de algumas seções com a seção central do entalhe.

deformação logarítmica aumenta em taxas decrescentes, porém positivas, até atingir um valor próximo de $1,8 \mathrm{~mm} / \mathrm{mm}$, com este fazendo o papel de um assíntota. As outras seções transversais possuem um comportamento semelhante, porém após a deformação homogênea, passam por uma fase em que a deformação logarítmica cresce pouco, até que as taxas de deformação aumentam e o comportamento se assemelha ao na região do entalhe, com uma maior taxa de deformação até deformações de 1,6 mm/mm, seguido por taxas de deformação decrescentes porém positivas em direção a assíntota de 1,8 mm/mm.

No PVC, o comportamento é semelhante, havendo um período homogêneo até aproximadamente 110 segundos e deformação logarítmica de $0,02 \mathrm{~mm} / \mathrm{mm}$, uma localização caracterizada pela seção transversal ter uma taxa de deformação superior as outras seções, porém há falha do material em aproximadamente $0.8 \mathrm{~mm} / \mathrm{mm}$, antes de a deformação lon- 
gitudinal encontrar sua assíntota. Este raciocínio pode ser melhor compreendido com a análise da distribuição da taxa de deformação durante a evolução dos testes experimentais. Estas podem ser analisadas a partir das fig. 4.12 e 4.13.

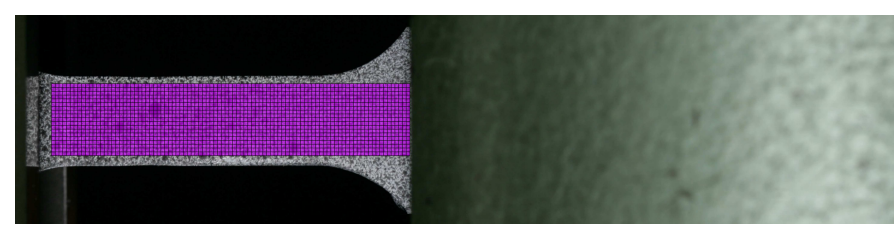

(a) $\mathrm{t}=0 \mathrm{~s}$

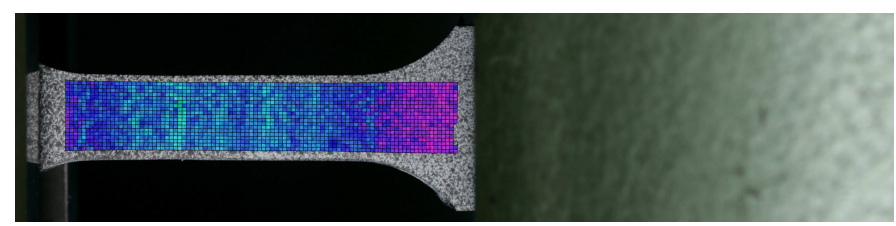

(b) $\mathrm{t}=250 \mathrm{~s}$

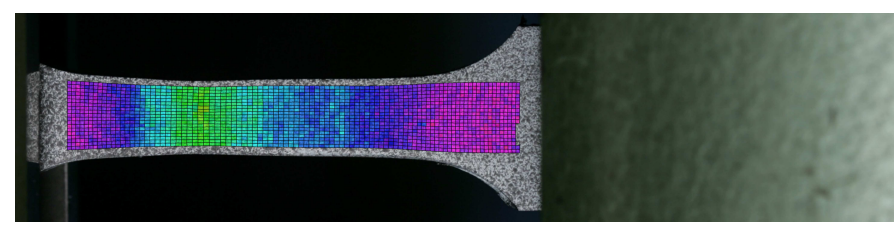

(c) $\mathrm{t}=500 \mathrm{~s}$

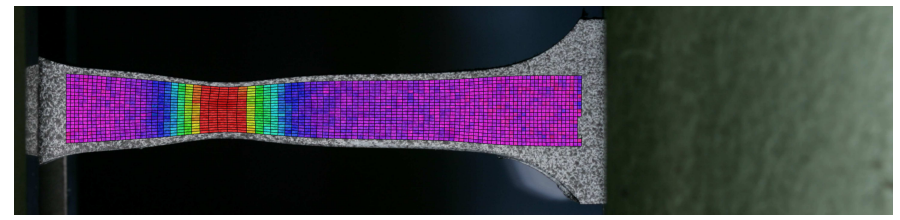

(d) $\mathrm{t}=750 \mathrm{~s}$

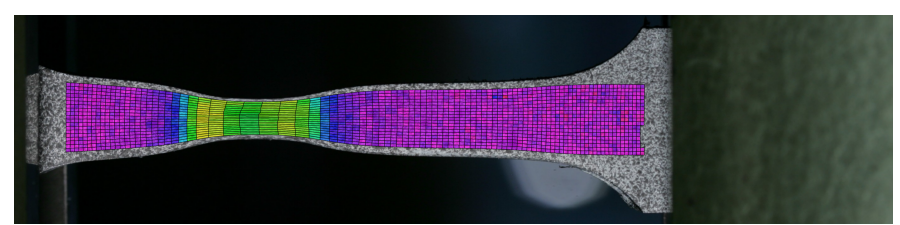

(e) $\mathrm{t}=1000 \mathrm{~s}$

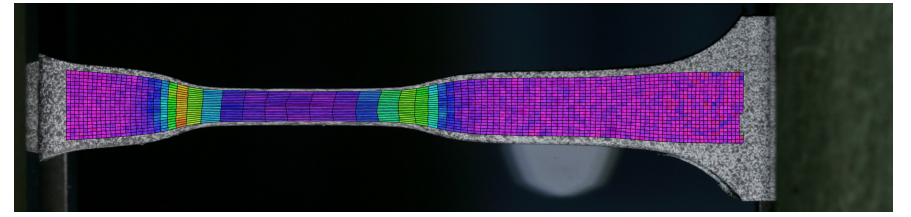

(f) $\mathrm{t}=1400 \mathrm{~s}$

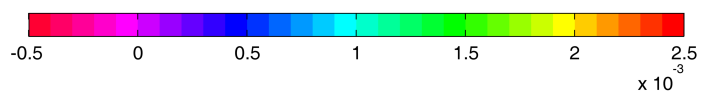

Figura 4.12: Evolução da taxa de deformação verdadeira no tempo, para um corpo de prova de tração de PEAD, sendo fotografada a superfície $x y$. 


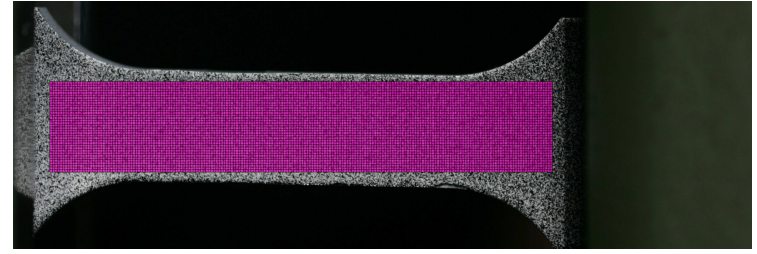

(a) $\mathrm{t}=0 \mathrm{~s}$

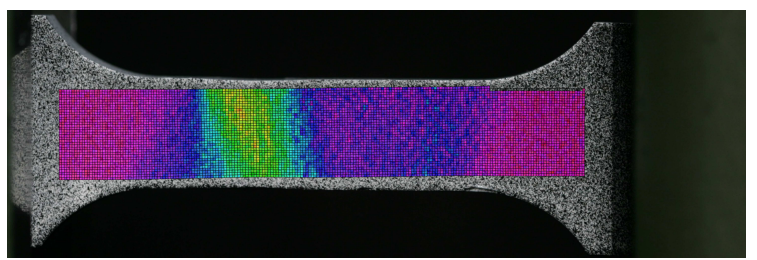

(c) $\mathrm{t}=160 \mathrm{~s}$

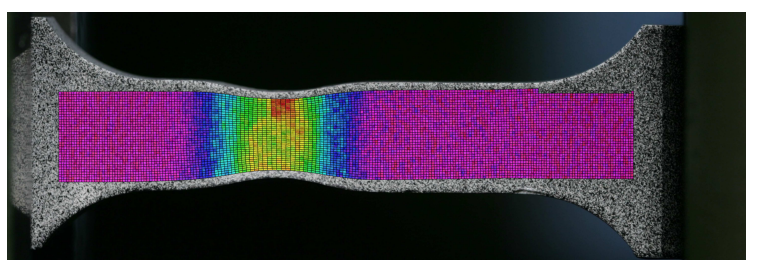

(e) $\mathrm{t}=320 \mathrm{~s}$

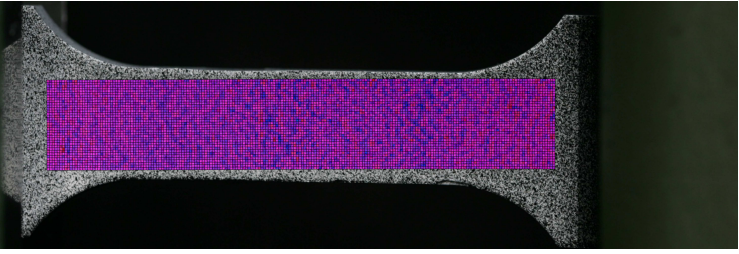

(b) $\mathrm{t}=80 \mathrm{~s}$

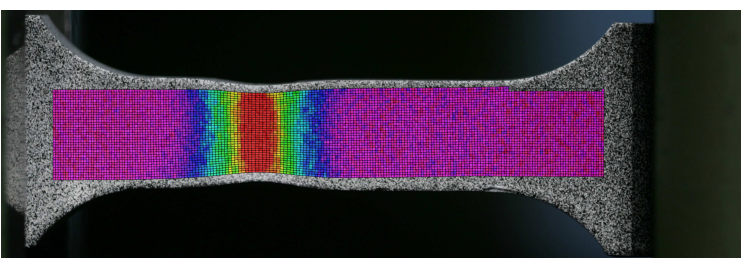

(d) $\mathrm{t}=240 \mathrm{~s}$

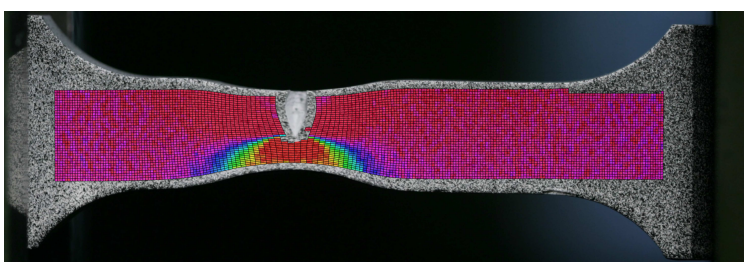

(f) $\mathrm{t}=420 \mathrm{~s}$

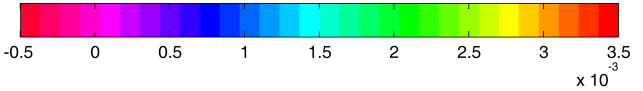

Figura 4.13: Evolução da taxa de deformação verdadeira no tempo, para um corpo de prova de tração de PVC, sendo fotografada a superfície $x y$.

As três fases citadas na análise da deformação logarítmica nas seções transversais do corpo de prova também pode ser explicada do ponto de vista da taxa de deformação. Considerando o teste de PEAD, no início do teste temos uma taxa de deformação logarítmica de aproximadamente $0.510^{-3} \mathrm{~S}^{-1}$ até o instante 300 segundos. Neste momento, há início da localização, ou estricção, com a taxa de deformação no entalhe em $3.510^{-3} \mathrm{~s}^{-1}$, muito superior ao restante do corpo do prova em torno de $510^{-5} \mathrm{~S}^{-1}$. Criam-se três regiões: a estricção, com baixa taxa de deformação e deformações almejando a assíntota de $1.8 \mathrm{~mm} / \mathrm{mm}$, a região fora da estricção, também com baixas taxas de deformação e deformações entre $0.4 \mathrm{~mm} / \mathrm{mm}$ e $0.55 \mathrm{~mm} / \mathrm{mm}$, e a região de transição ou propagação da estriç̧ão, com uma taxa de deformação mais alta do que nas outras duas regiões e inferior ao pico durante o início do empescoçamento. A evolução temporal destas regiões ao longo do corpo de prova pode ser demonstrada na fig. 4.14, com destaque para o pico de taxa de deformação no entalhe no início da estricção e a movimentação da região de transição, aumentando a região da estricção e reduzindo a restante. Já no PVC, o material 
falha pouco antes do início da propagação da estricção, apresentando um comportamento semelhante ao PEAD até então.

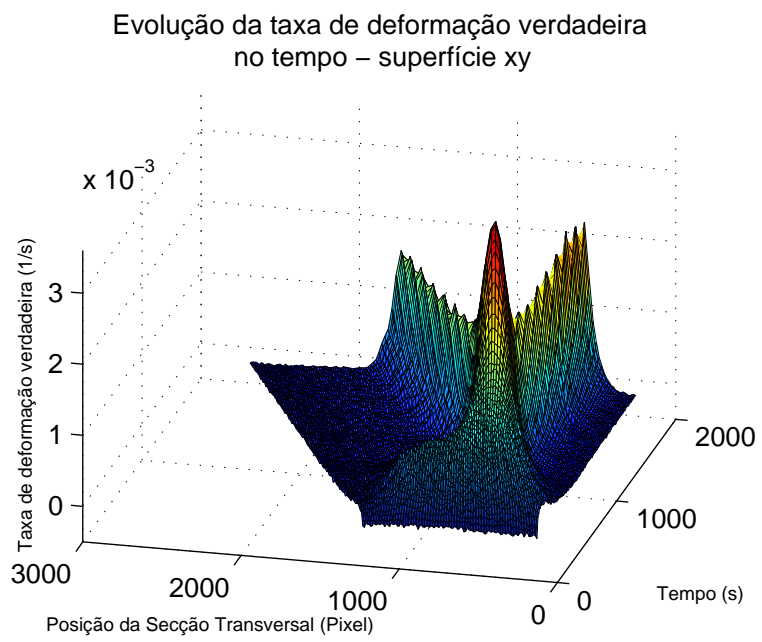

(a) PEAD

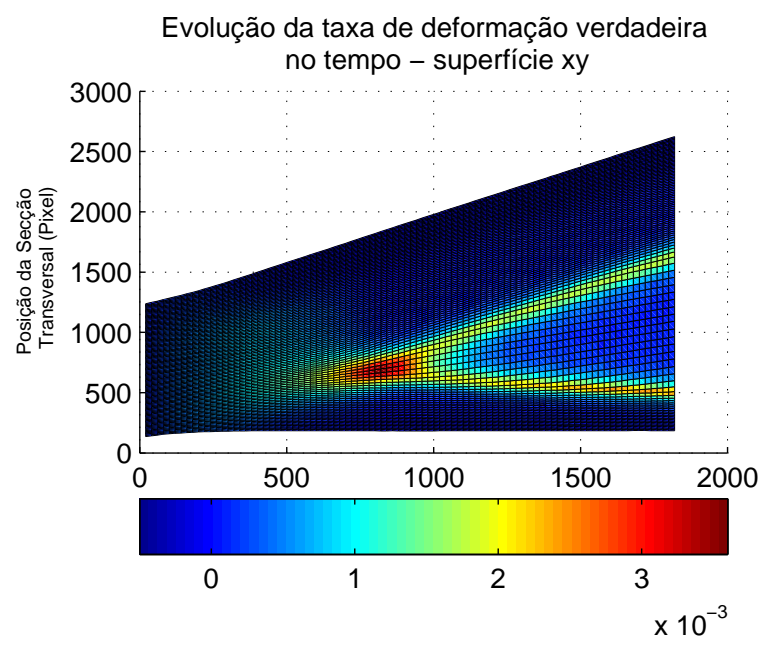

(c) PEAD

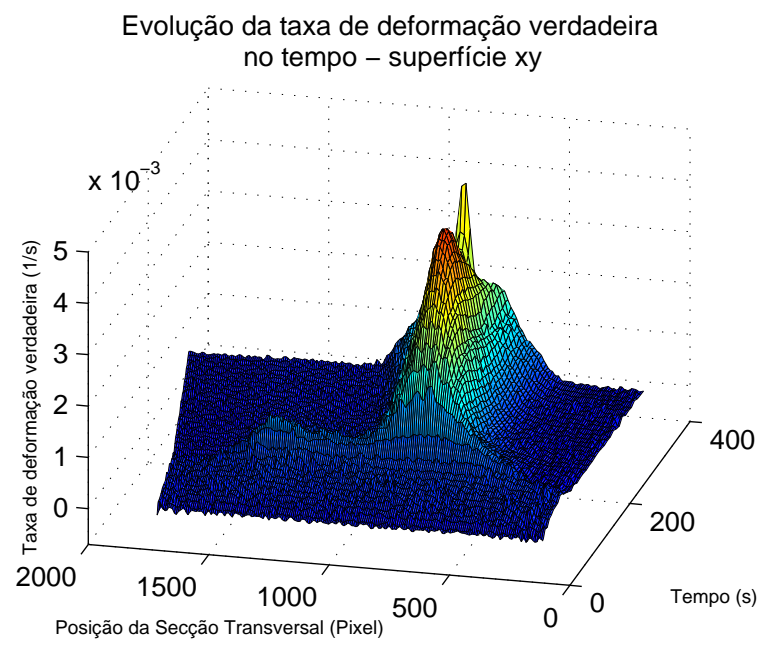

(b) PVC

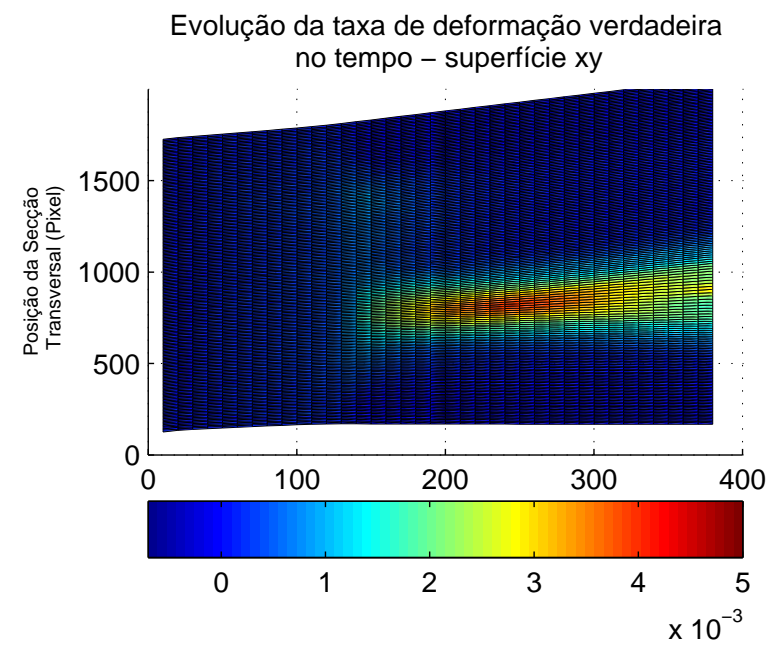

(d) PVC

Figura 4.14: Evolução temporal da deformação verdadeira na seção central do entalhe e algumas outras seções e em todas as seções do teste.

Além de permitir esse estudo detalhado da evolução temporal das deformação locais e taxas de deformação locais no corpo de prova, a técnica DIC permite também a análise da deformação transversal. Conforme explicado na seção anterior, foram feitos testes replicados, fotografando a superfície $x y$ em um e a $x z$ em outro, na intenção de comparar ambas as deformações transversais utilizando a deformação longitudinal como elemento comum. Os resultados da deformação transversal e da comparação das deformações 
transversais em função da deformação longitudinal estão dispostos na fig. 4.15.

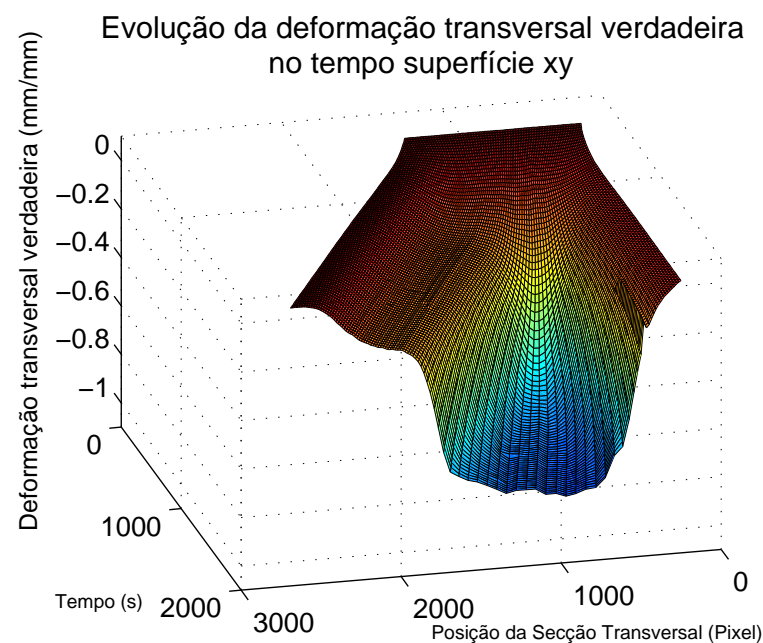

(a) PEAD

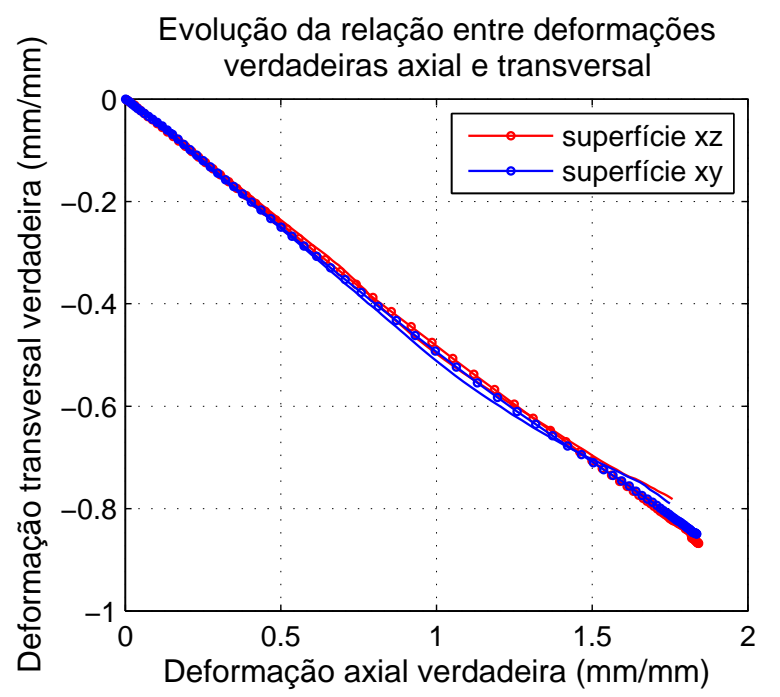

(c) PEAD

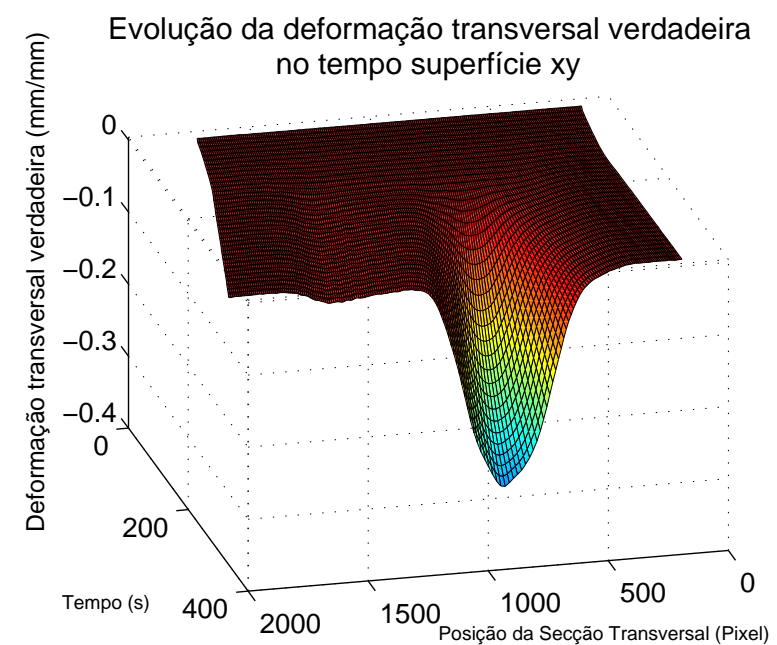

(b) PVC

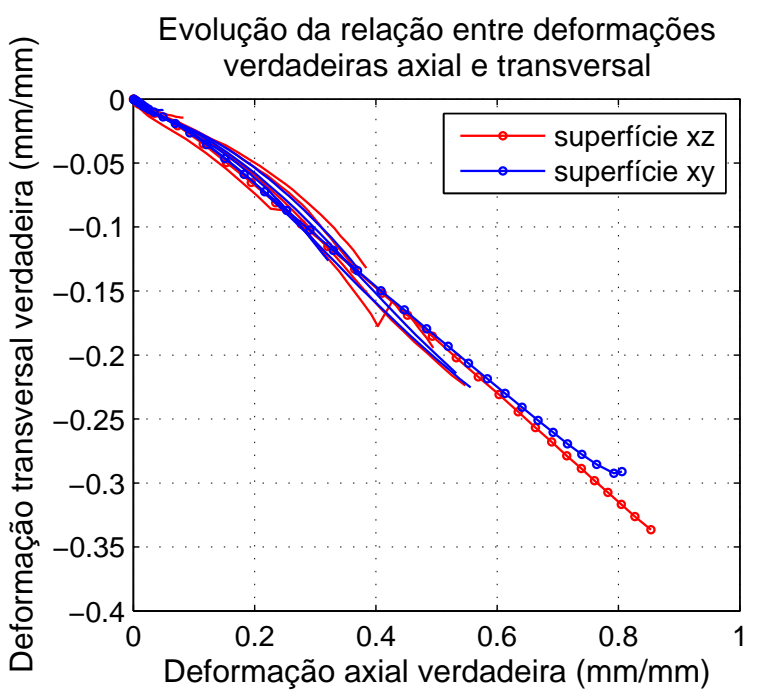

(d) PVC

Figura 4.15: Evolução temporal da deformação verdadeira na seção central do entalhe (em destaque) e algumas outras seções e em todas as seções do teste.

A partir dos gráficos 4.15(c) e 4.15(d), pode-se assumir tranquilamente que as deformações transversais na largura e na profundidade do corpo de prova são iguais, possibilitando o cálculo da área atual de acordo com a eq. 2.5, tornando possível o cálculo da tensão verdadeira em cada seção transversal do corpo de prova, conforme mostra a fig. 4.16 .

No período em que a deformação é homogênea, as deformações transversais e consequentemente a área também serão homogêneas ao longo do corpo de prova. Pode-se 


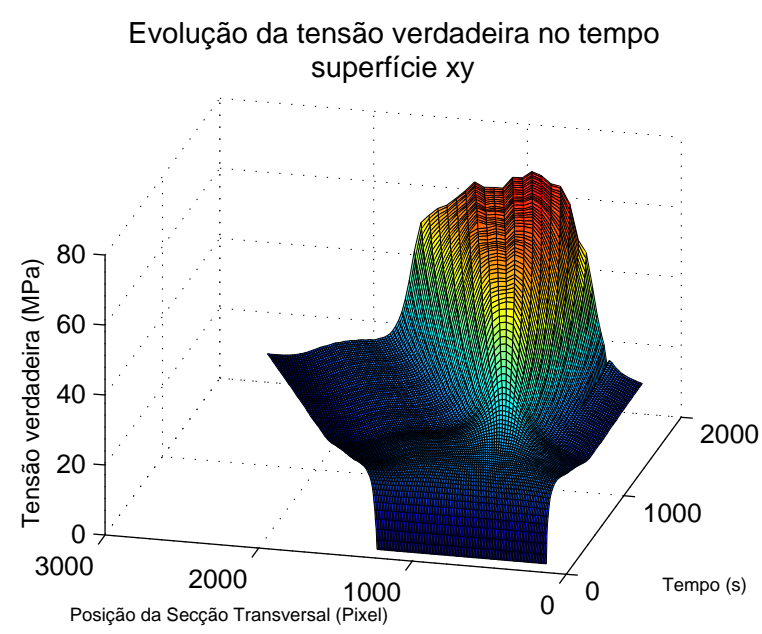

(a) PEAD
Evolução da tensão verdadeira no tempo
superfície xy

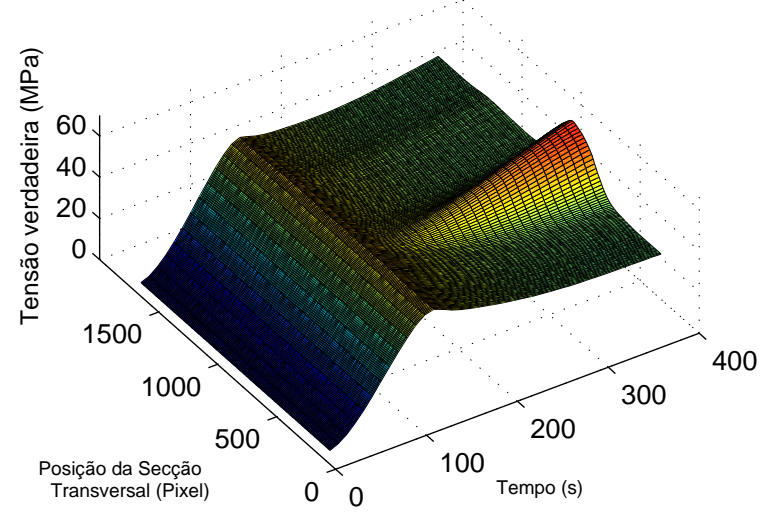

(b) PVC

Figura 4.16: Evolução temporal da tensão verdadeira em todas as seções do teste.

verificar essa homogeneidade da tensão verdadeira nas seções transversais no início do ensaio experimental, tanto para o PEAD quanto para o PVC. Considerando-se apenas o teste em PEAD, no início da estricção, a seção transversal do entalhe conta com um aumento significativo de tensão até atingir uma assíntota, mantendo-se constante ou até diminuindo. Como a deformação interna à estricção tem seu valor mantido praticamente constante, aquela região está susceptível aos movimentos moleculares típicos de relaxação buscando um menor nível energético, reduzindo a força necessária para manter aquela configuração estrutural e reduzindo a tensão. Já a diminuição da tensão na região fora da estricção pode ser explicada no seguinte raciocínio: a estricção reduz a área da seção transversal, sendo necessário então um valor de força menor para manter a tensão constante e como a área não variou na região fora da estricção, a redução de força implica em uma redução da tensão.

As curvas de tensão deformação podem ser obtidas a partir dos dados da tensão no tempo e deformação no tempo em cada seção. Os gráficos tensão deformação de diversas seções transversais dos testes replicantes de cada material estão presentas na fig 4.17, com destaque para a seção transversal do entalhe.

As figuras 4.17(c) e 4.17(d) foram traçadas a partir da evolução temporal da tensão e deformação em cada seção transversal. Eles mostram claramente que a partir do momento em que o ensaio não é mais homogêneo, para cada instante de tempo, há uma distribuição contínua de deformações no corpo de prova, sendo impossível sua medição acurada 


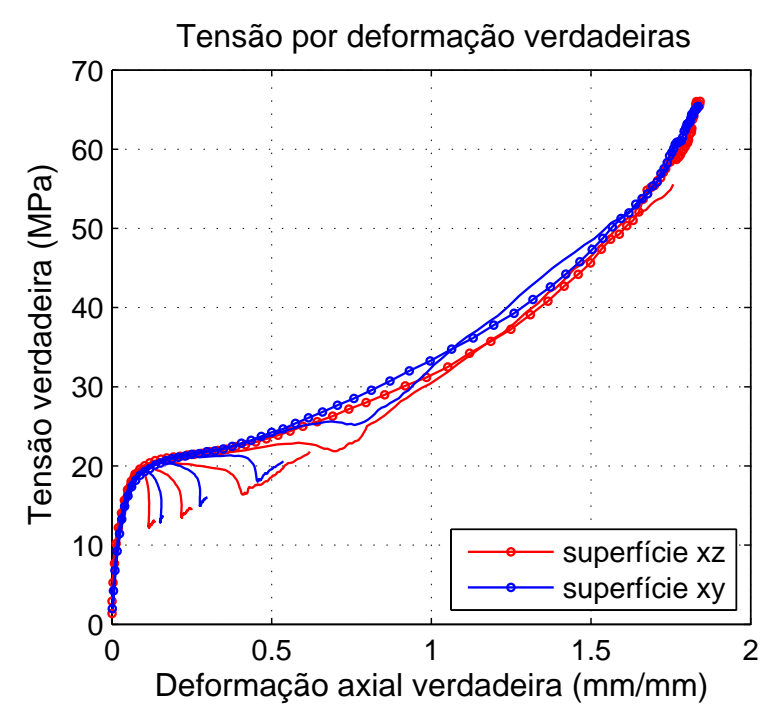

(a) PEAD

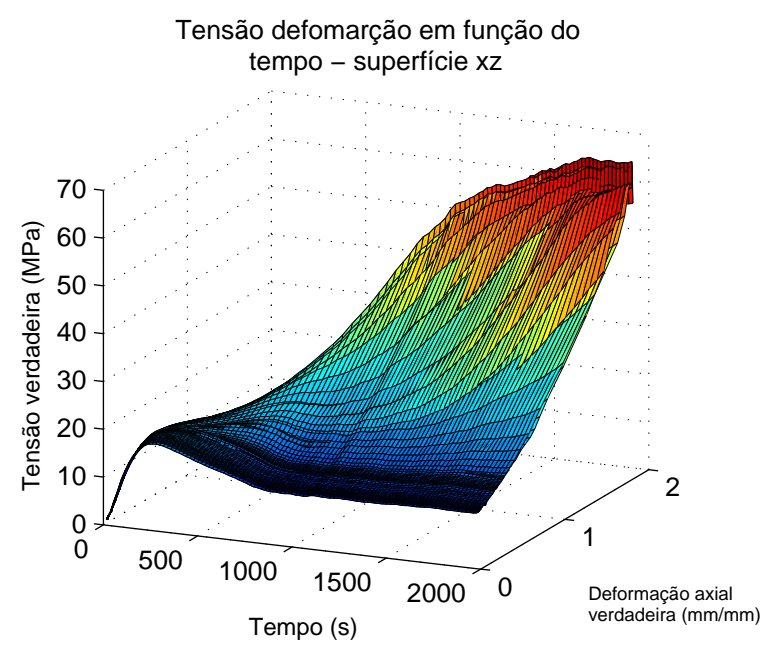

(c) PEAD

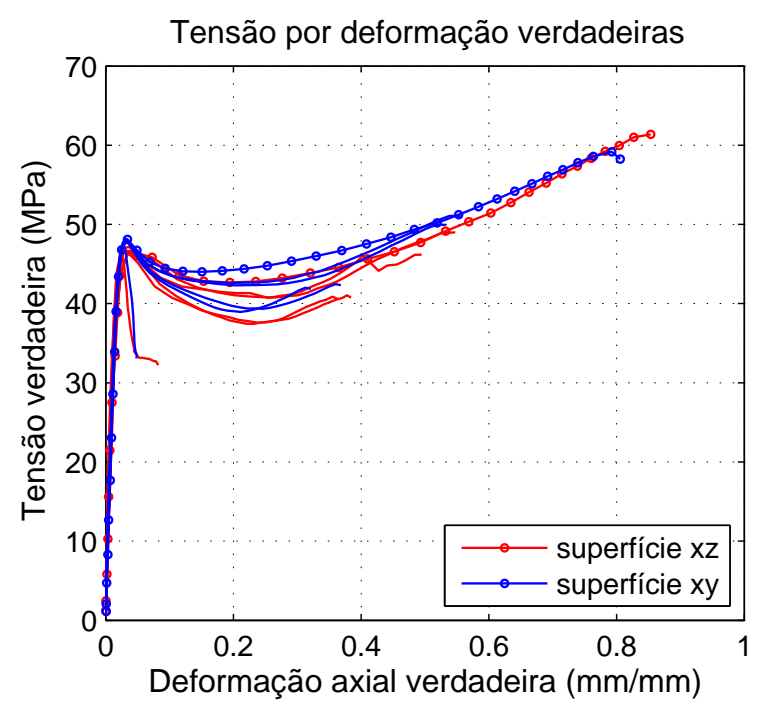

(b) PVC

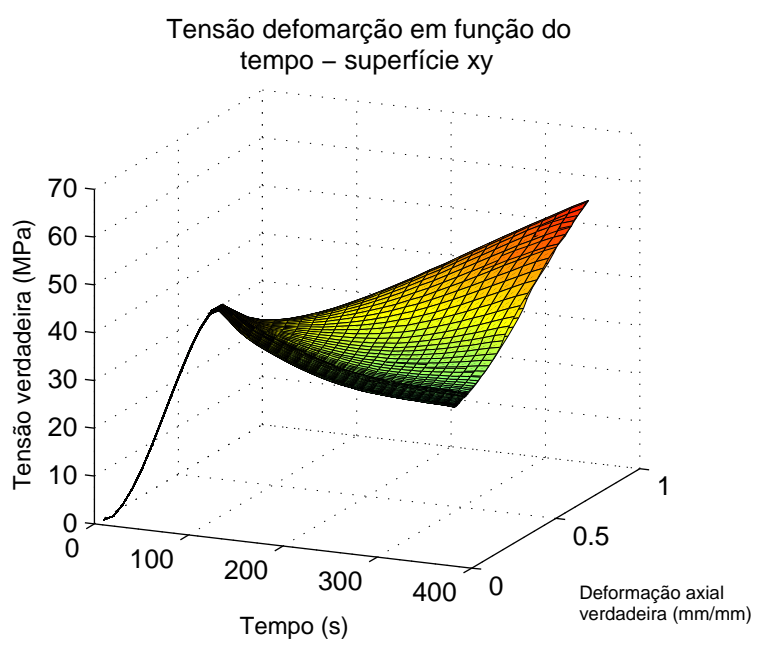

(d) PEAD

Figura 4.17: Curva tensão deformação em algumas seções transversais de ambos os testes replicantes com destaque para a seção transversal do entralhe e compilação para cada instante do teste dos valores de tensão, deformação de cada secção transversal.

com as técnicas convencionais de clip-gauge. Para a medição acurada, torna-se necessário uma técnica ótica de medição de deformações, implicando em novos parâmetros a serem minunciosamente calibrados, como a iluminação, foco, resolução das imagens, perpendicularidade entre superfície do corpo de prova e a câmera, espaço de memória para o armazenamento das imagens, sincronização das imagens com as medidas da célula de carga, entre outros, além do fato de ser extremamente mais trabalhosa a obtenção dos resultados finais em curvas tensão deformação. Entretanto, uma vantagem significativa 
é que, enquanto métodos tradicionais fornecem apenas uma curva tensão deformação por corpo de prova ensaiado, o método DIC fornece uma curva tensão deformação para cada seção transversal do mesmo, sendo possível o uso de todas elas na calibração de parâmetros de modelos de material para simulação numérica em elementos finitos. Ou seja, com um único ensaio experimental, uma quantidade maior de dados experimentais significativos é obtida, algo almejado pela indústria atualmente.

\subsubsection{Análise de um teste de compressão de PEAD e PVC}

Os corpos de prova de geometria $\mathrm{C} 1$ foram utilizados para verificar se ha diferenças significativas entre as deformações transversais na largura e na profundidade, sendo divididos em três pares de testes replicantes, com cada par sujeito a diferentes direções de carregamentos: $x, y$ e $z$. Nestes seis testes, foi imposto um deslocamento de compressão com velocidade de $0,01 \mathrm{~mm} / \mathrm{s}$ para obter uma taxa de deformação de aproximadamente $10^{-3} s^{-1}$.

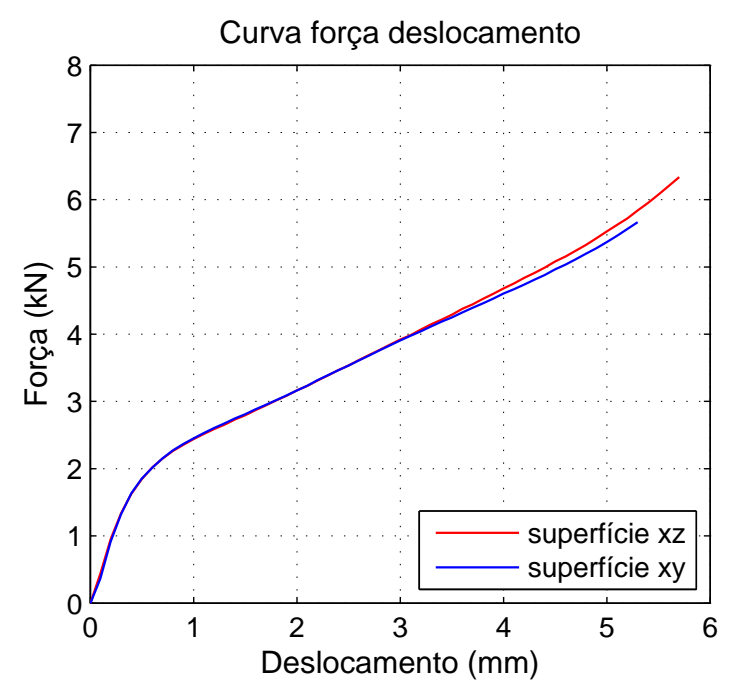

(a) PEAD

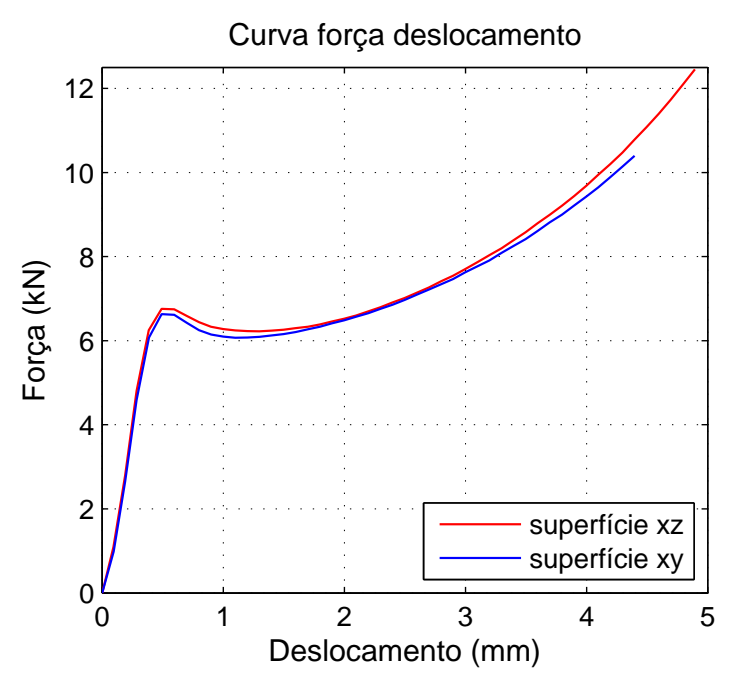

(b) PVC

Figura 4.18: Curvas força deslocamento dos testes replicantes com carregamento em $x$.

Os gráficos com as curvas força deslocamento dos testes replicantes na direção $x$ de ambos os materiais estão ilustrados na fig. 4.18. As evoluções tanto da deformação logarítmica quanto da taxa de deformação logarítmica em função do tempo, para todas as seções transversais do corpo de prova, estão representas na fig. 4.19. Diferentemente dos resultados de tração no qual foram utilizadas posições atuais das seções transversais, neste 
gráfico usa-se a posição inicial, para melhor visualização, já que as seções transversais se aproximariam com o tempo.

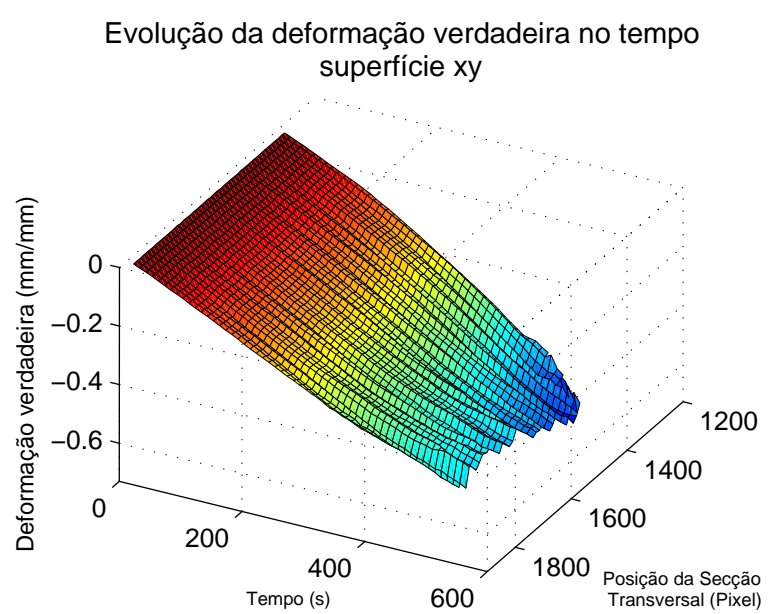

(a) PEAD

Evolução da taxa de deformação verdadeira no tempo - superfície $x y$

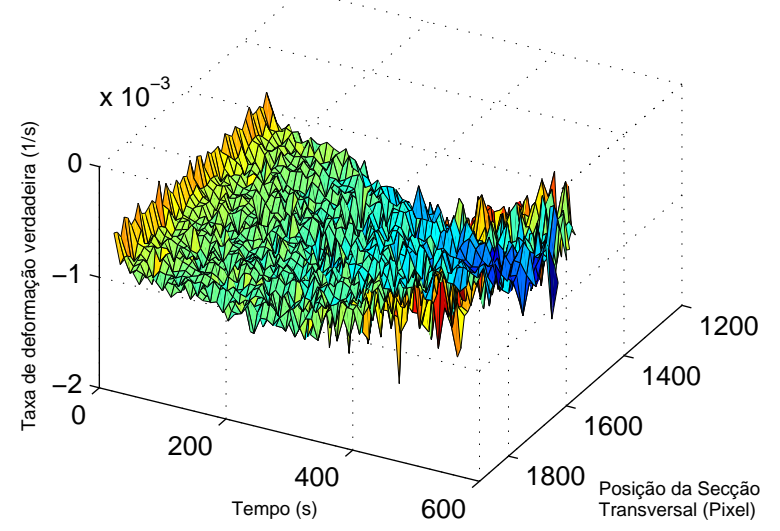

(c) PEAD

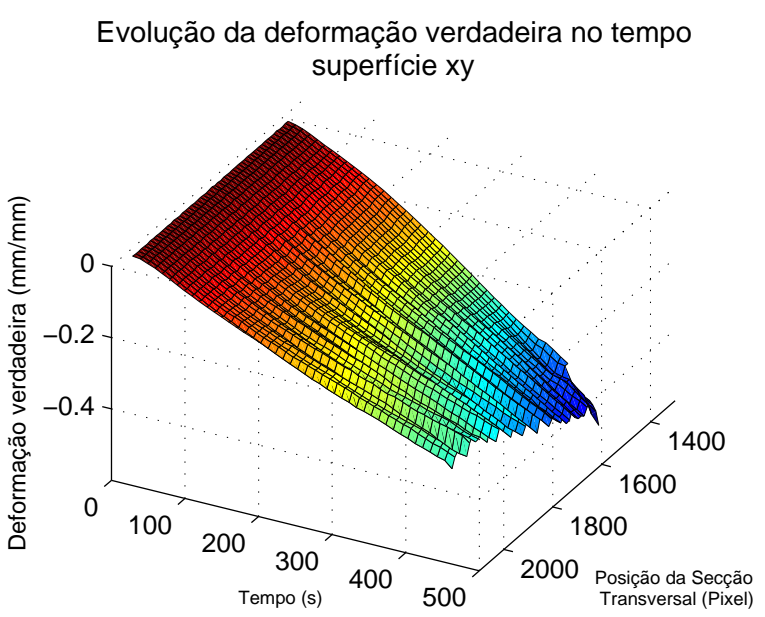

(b) PVC

Evolução da taxa de deformação verdadeira no tempo - superfície xy

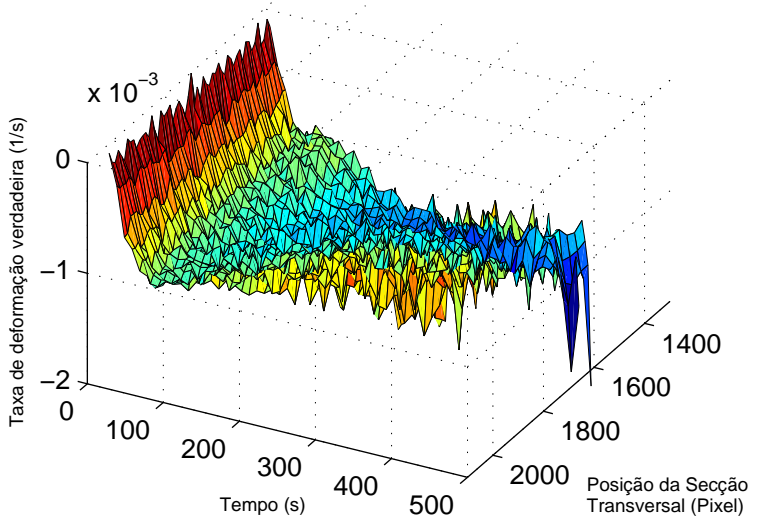

(d) PVC

Figura 4.19: Evolução temporal da deformação verdadeira de todas as seções do teste.

Dos 10mm disponíveis para a fotografia no instante inicial, os gráficos de 4.19 se referem apenas aos $8 \mathrm{~mm}$ internos, uma vez que a graxa lubrificante, necessária para reduzir o atrito entre o corpo de prova e os suportes, com a pressão dos mesmos, era expulsa e encobria a pintura DIC na foto. Entretanto, apesar da quantidade considerável de lubrificantes especial para altas pressões, pode-se notar que ainda houve atrito, uma vez que o corpo de prova sofreu o fenômeno conhecido por abaulamento. Este abaulamento introduziu certa dispersão nos resultados. Desta forma, com base em uma investigação visual no corpo de prova e nas imagens obtidas durante o teste, foi escolhida uma se- 
ção representativa, na qual foram calculados as curvas tensão deformação do teste. O gráfico da figura 4.20 compara a relação entre a deformação transversal na largura e a deformação longitudinal com a relação entre a deformação transversal na profundidade e a deformação longitudinal nesta seção representativa, nas três direções de carregamento.

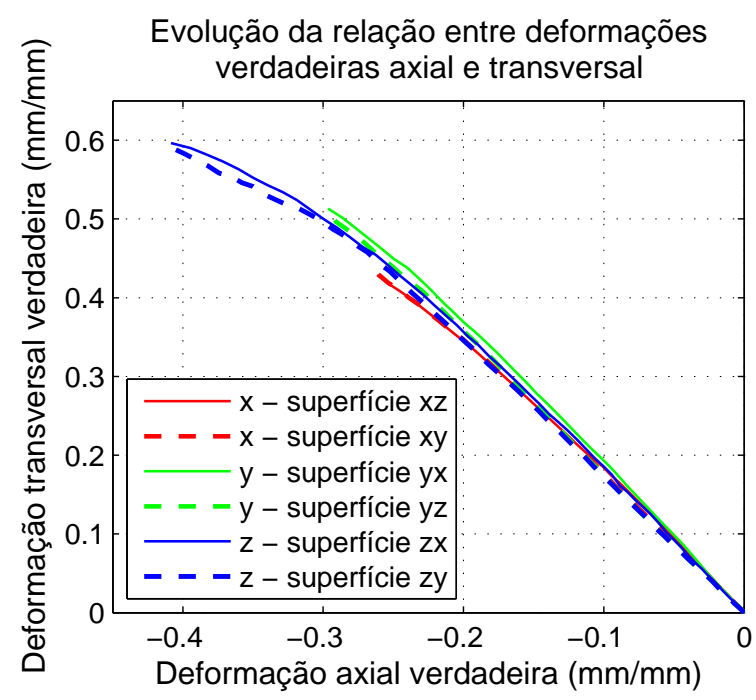

(a) PEAD

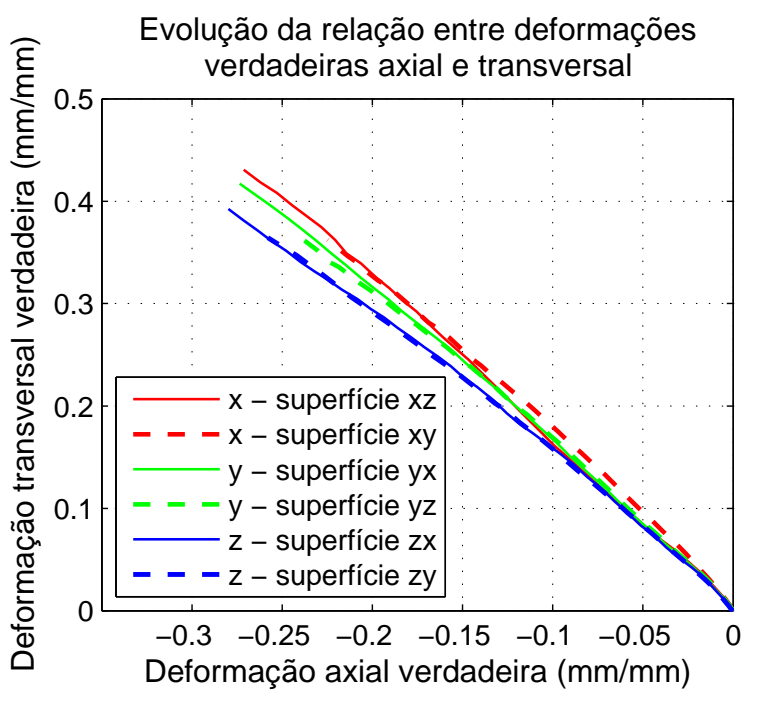

(b) PVC

Figura 4.20: Evolução temporal da deformação verdadeira de todas as seções do teste.

Podendo-se desprezar a diferença da relação entre a deformação transversal na largura e a deformação longitudinal e da relação entre a deformação transversal na profundidade e a deformação longitudinal, novamente calculou-se a área através da eq. ?? e consequentemente a tensão verdadeira. Assim como esperado, como não há localização, o valor da tensão verdadeira é homogênea ao longo do corpo de prova para cada instante. Vale ressaltar que a tensão cresce monotonicamente para o PEAD, enquanto o fenômeno de softening está presente no PVC, mesmo quando este sofre uma pressão negativa. Os gráficos contendo as curvas tensão verdadeira deformação logarítmica na seção representativa (em destaque) e em outras seções pode então ser traçado e encontra-se na fig. 4.21

\subsubsection{Anisotropia}

Para os ensaios de tração, a anisotropia é dada variando-se a direção de carregamento no plano em 3 direções: na direção $x$, a $45^{\circ}$ da direção $x$ no sentido da direção $y$, utilizando-se 
Evolução da tensão verdadeira no tempo superfície xy

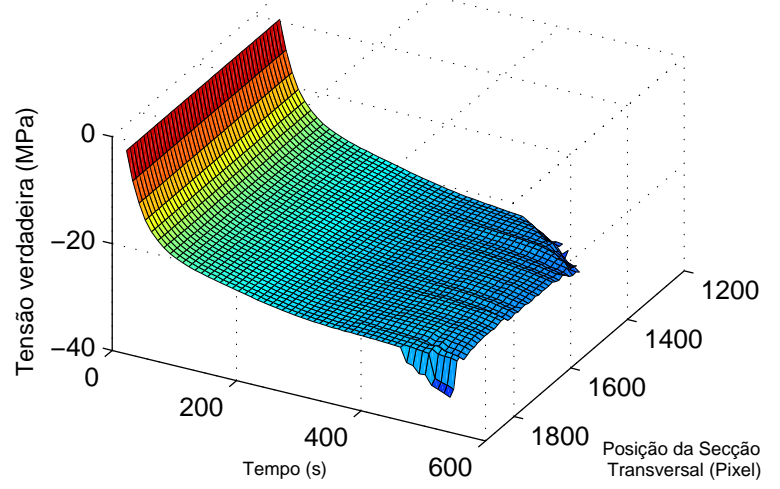

(a) PEAD

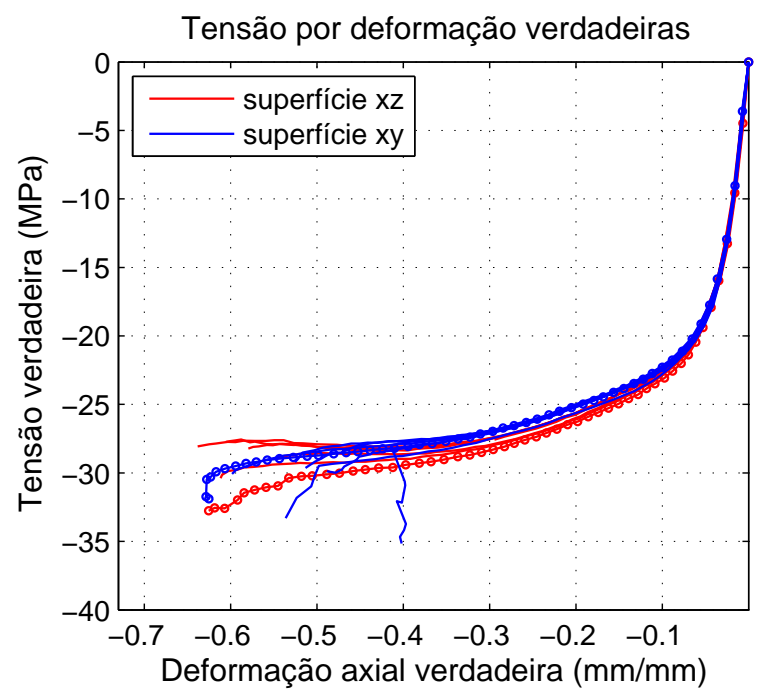

(c) PEAD
Evolução da tensão verdadeira no tempo superfície $x y$

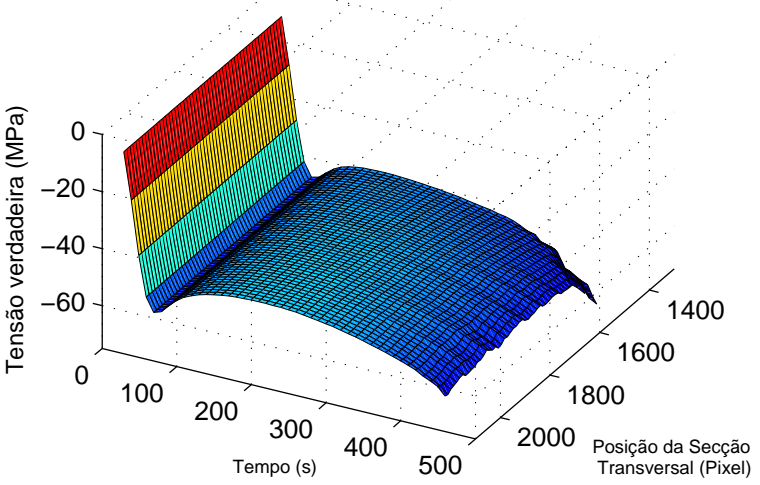

(b) PVC

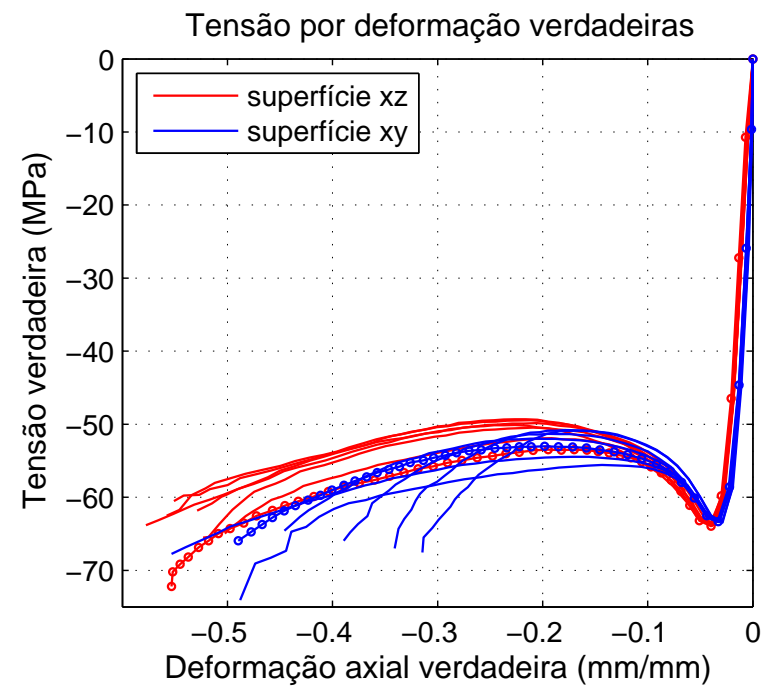

(d) PVC

Figura 4.21: Evolução temporal da deformação verdadeira de todas as seções do teste.

sempre o espécime com a geometria T2. Para efeito de comparação do comportamento do material, foi traçada apenas a curva tensão verdadeira deformação logarítmica da seção transversal do entalhe. Os resultados estão presentes na fig. 4.22.

Já no caso de compressão, conforme mencionado anteriormente, foram realizados ensaios experimentais no corpo de prova de geometria $\mathrm{C} 1$ com carregamento na três direções: $x, y$ e $z$, sendo que a comparação também é feita através da curva tensão verdadeira deformação logarítmica nas seções representativas de cada corpo de prova. Os resultados estão exibidos na fig. 4.23 . 


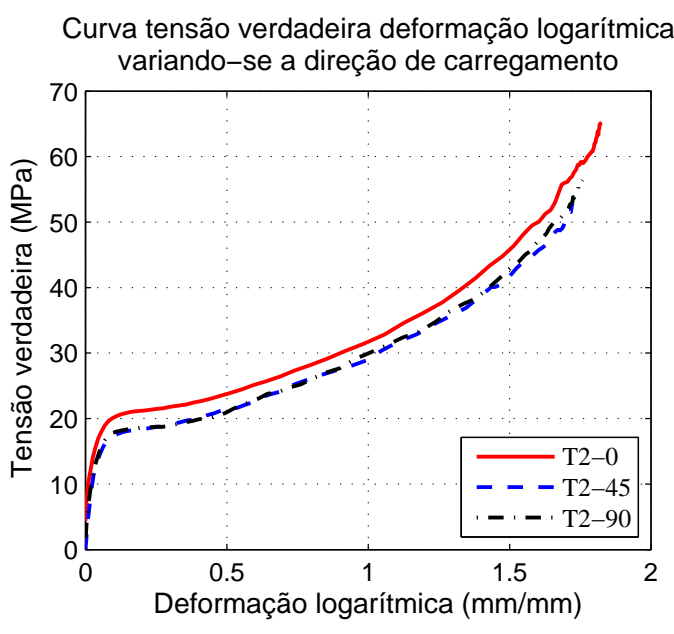

(a) PEAD

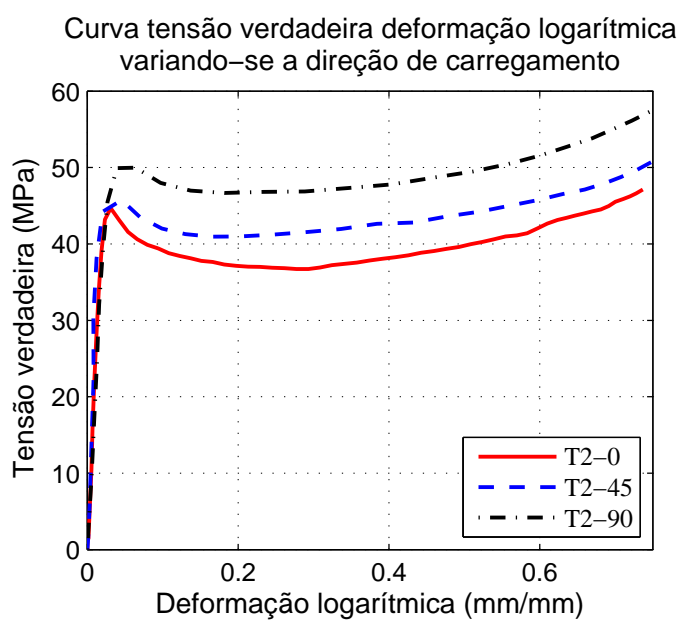

(b) PVC

Figura 4.22: Verificação da anisotropia no plano da placa em ambos os materiais.

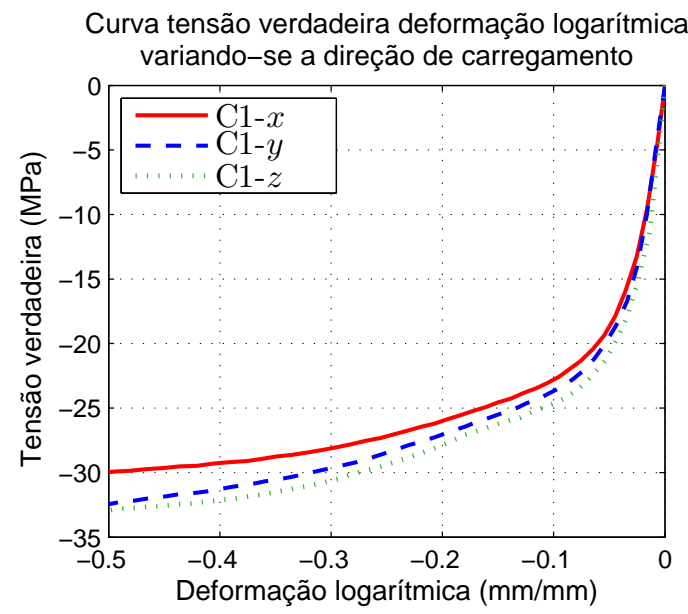

(a) PEAD

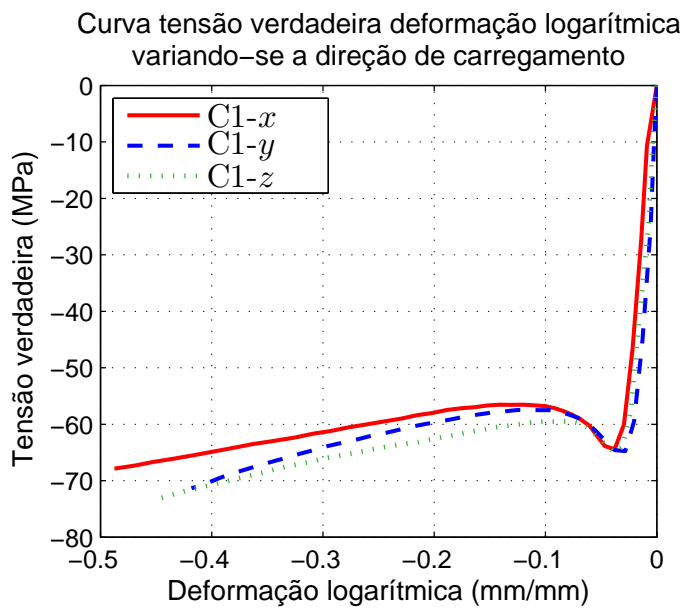

(b) PVC

Figura 4.23: Verificação da anisotropia nas três direções para ambos os materiais.

\subsubsection{Sensibilidade à taxa de deformação}

Para os testes de compressão, a sensibilidade à taxa de deformação foi examinada testando corpos de prova de geometria $\mathrm{C} 2$ nas direções $x$ e $y$ em três diferentes velocidades, com a comparação feita através da curva tensão verdadeira deformação logarítmica nas seções representativas. Os resultados estão dispostos nos gráficos da fig. 4.24.

Na análise do efeito da taxa de deformação nos ensaios de tração, devido à localização e à grande variação da taxa de deformação ao longo do corpo de prova, não faz sentido traçar uma curva tensão verdadeira deformação logarítmica e dizer que a mesma é repre- 
Curva tensão verdadeira deformação logarítmica

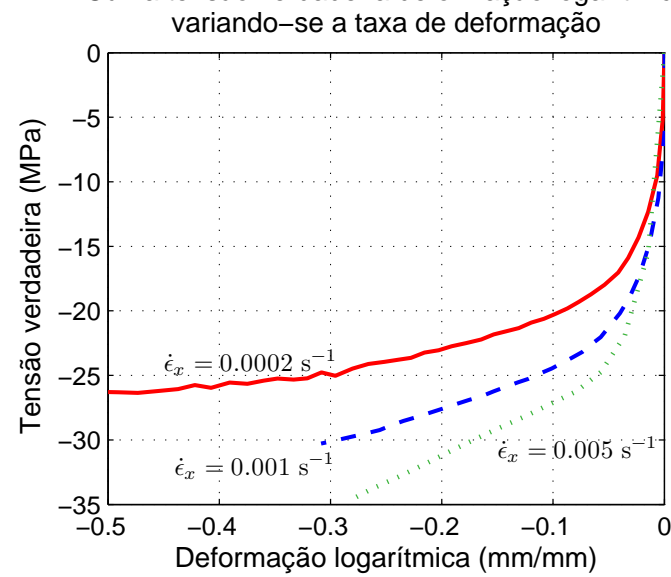

(a) PEAD, direção $x$

Curva tensão verdadeira deformação logarítmica

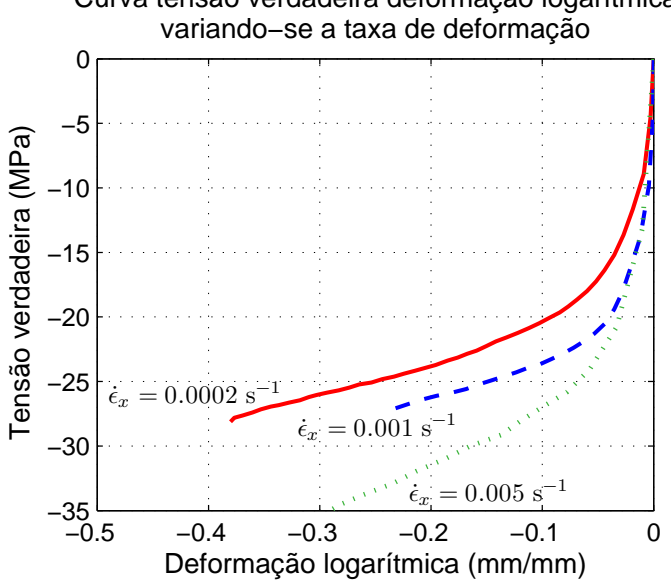

(c) PEAD, direção $y$

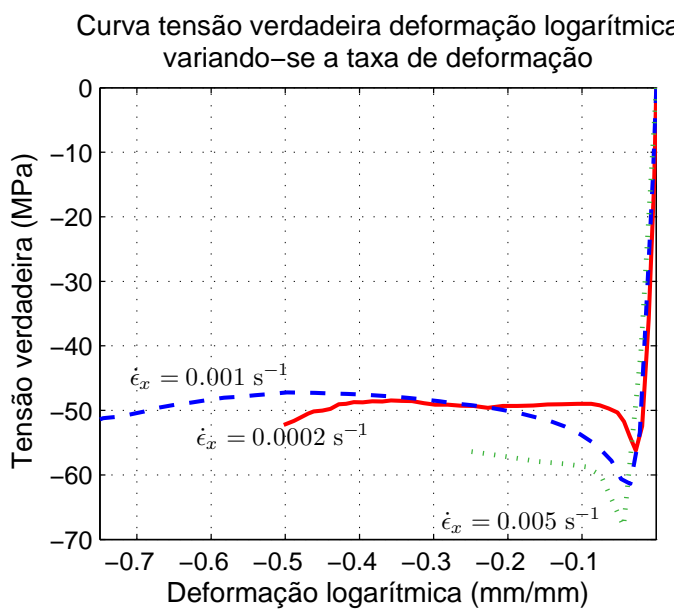

(b) PVC, direção $x$

Curva tensão verdadeira deformação logarítmica variando-se a taxa de deformação

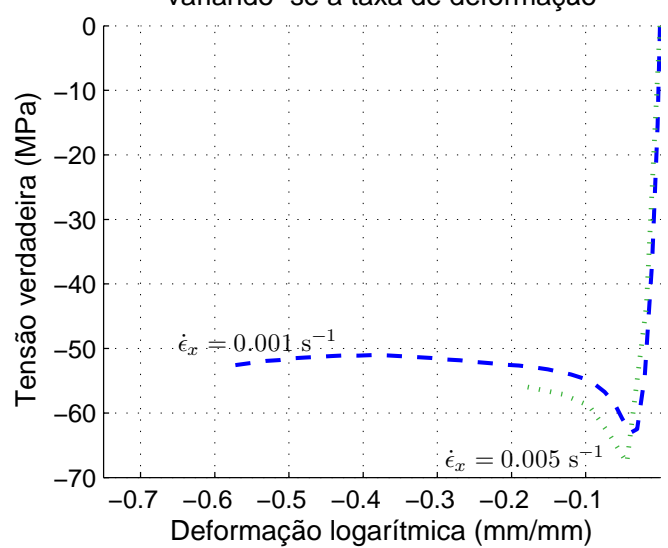

(d) PVC, direção $y$

Figura 4.24: Verificação da sensibilidade a taxa de deformação na direção $x$ e $y$ para ambos os materiais em compressão.

sentativa de uma determinada taxa de deformação. O gráfico que melhor representaria a sensibilidade a taxa de deformação seria tridimensional com o eixo vertical sendo a tensão verdadeira e os outros a deformação logarítmica e a taxa de deformação logarítmica. 


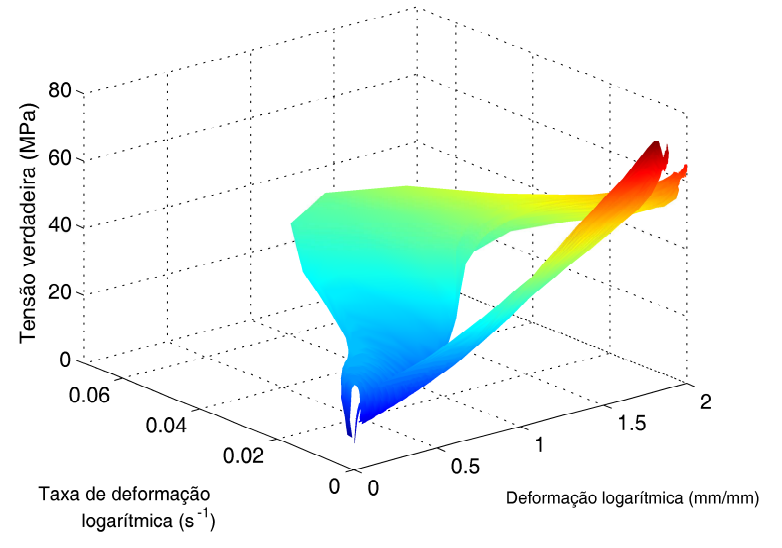

(a) PEAD

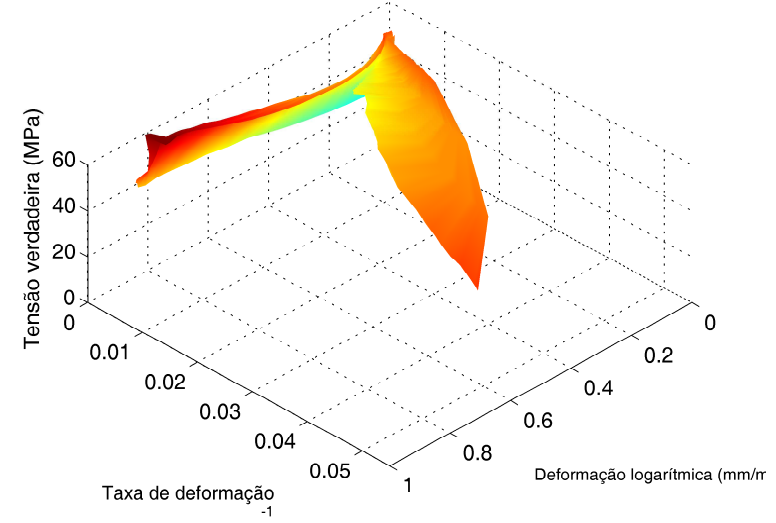

(b) PVC

Figura 4.25: Verificação da sensibilidade a taxa de deformação para ambos os materiais sob tração.

\subsection{Ensaios experimentais de relaxação}

Esta seção tem por finalidade analisar os ensaios experimentais de relaxação em PMMA, PVC e PEAD. O carregamento se deve em um curto espaço de tempo, mantendo as tensões baixas o suficiente para não entrar em regime plástico, conforme pode ser notado nas figuras 4.26(a) 4.26(b) e 4.26(c). Nos três testes, mantendo-se o deslocamento inicialmente imposto constante, em duas horas a tensão caiu em pelo menos um terço do valor máximo atingido no fim do carregamento, conforme explicitado nas figuras 4.26(d) 4.26(e) e 4.26(f). Estes dados serão utilizados para a calibração das constantes viscoelásticas do material, juntamente com os dados de propagação de ondas obtidos no próximo capítulo.

Além da medição da força pela célula de carga, utilizou-se o método DIC para obter a distribuição de deformações ao longo do corpo de prova, tanto na fase de carregamento quanto na fase de relaxação. Os resultados estão dispostos nas próximas subseções. 


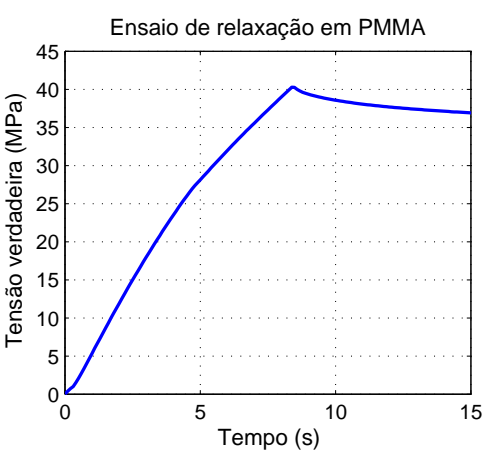

(a) PMMA

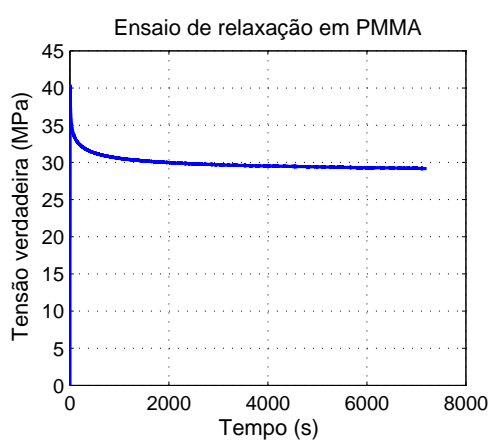

(d) PMMA

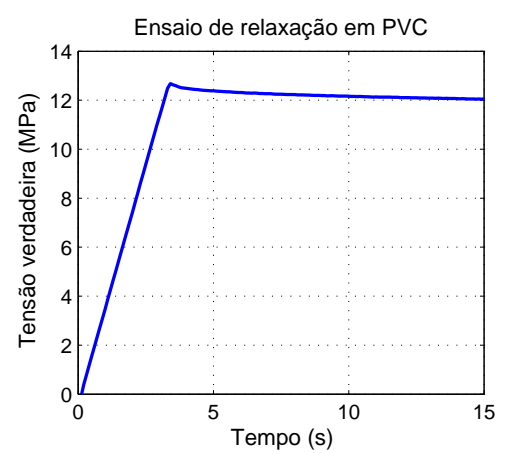

(b) PVC

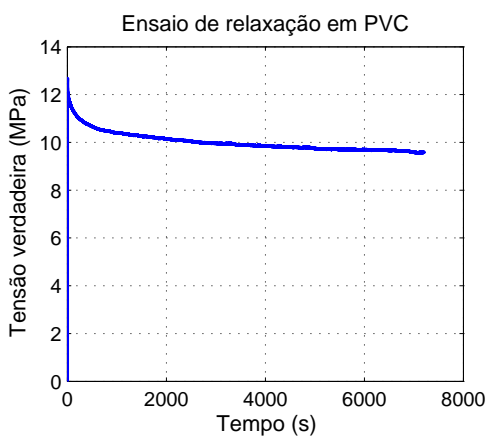

(e) PVC

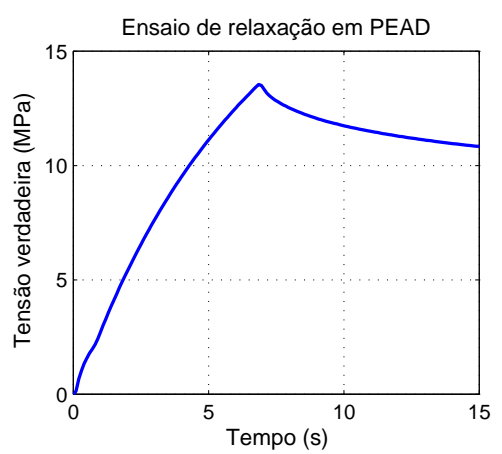

(c) PEAD

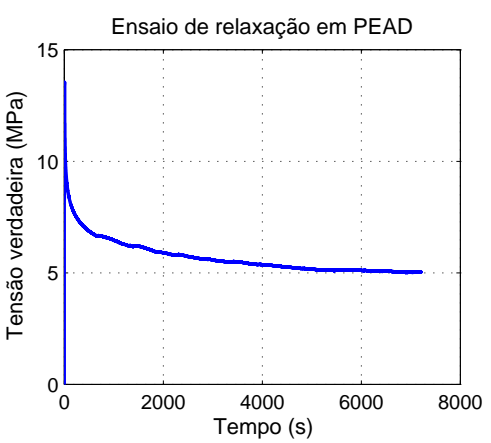

(f) PEAD

Figura 4.26: Curvas de queda de tensão no tempo.

\subsubsection{PMMA}

No caso do ensaio em PMMA, foi ativado o modo disparo contínuo (tradução adotada pelo autor para a palavra burst), capaz de obter 3 fotos por segundo, e num total de 12 fotos. Deste momento em diante o intervalo passou a ser de 120 segundos até o fim do teste, fixado em duas horas. Após o tratamento das imagens no software 7D, utilizouse o programa MATLABß para converter as deformações de Green em deformações logarítmicas. A figura 4.27 detalha a fase de carregamento.

Apesar da distribuição quase homogênea das deformações durante o carregamento, pode-se notar nas imagens da fig. 4.28 que durante o descarregamento formam-se localizações em ângulo, comprovando que a modelagem da relaxação pode ser feita baseando-se em energia de distorção, como acontece na plasticidade, o que foi dito por Mulliken no apêndice de sua tese de doutorado [75].

A figura 4.29 foi desenvolvida com a intenção de melhor compreender a evolução destas localizações, ao se colocar todas as imagens tratadas, uma ao lado da outra, com relativa transparência. 


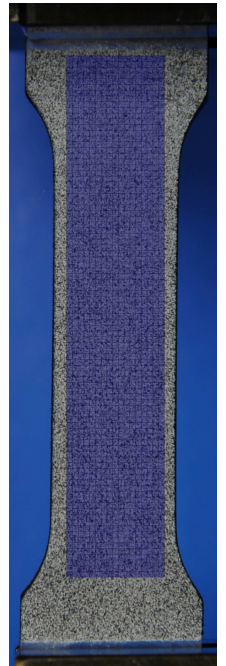

(a) $\mathrm{t}=0 \mathrm{~s}$

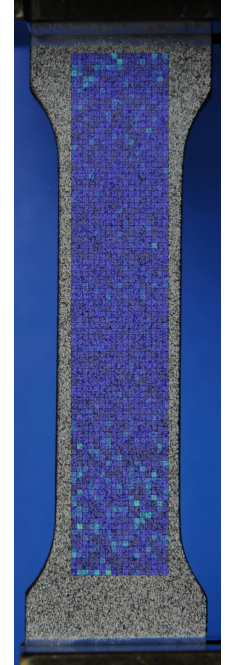

(b) $\mathrm{t}=0,66 \mathrm{~s}$

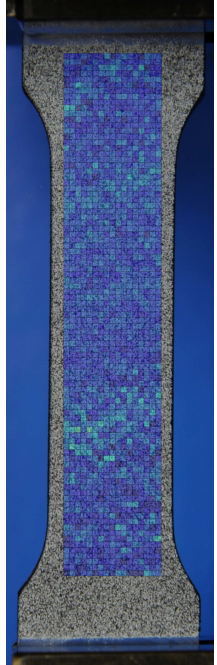

(c) $\mathrm{t}=1,33 \mathrm{~s}$

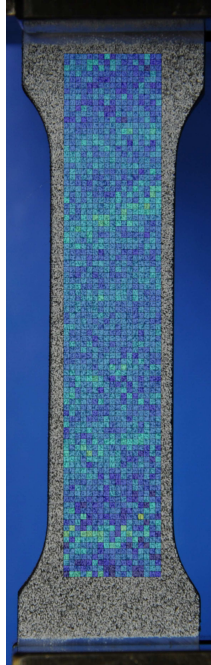

(d) $\mathrm{t}=2,0 \mathrm{~s}$

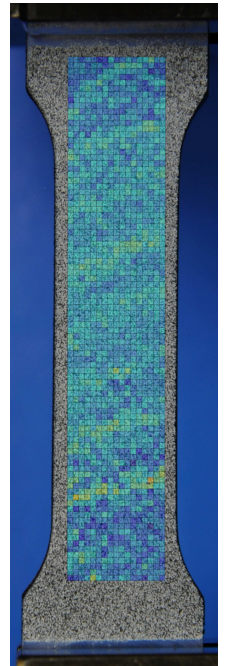

(e) $\mathrm{t}=2,66 \mathrm{~s}$

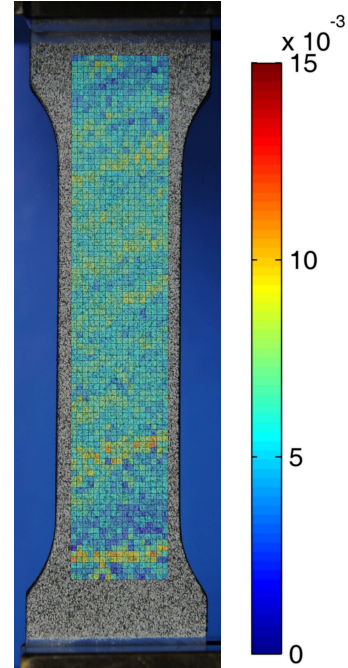

(f) $\mathrm{t}=3,33 \mathrm{~s}$

Figura 4.27: Fase de carregamento do ensaio de relaxação para o PMMA.

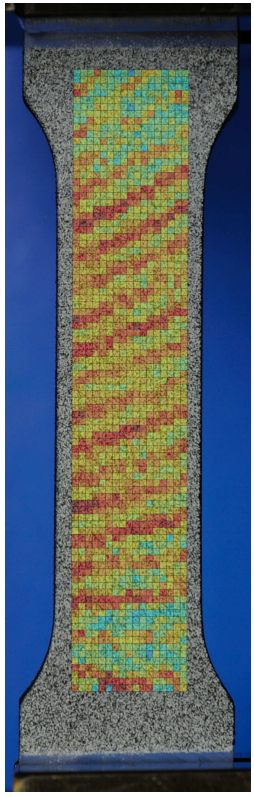

(a) $t=225 \mathrm{~s}$

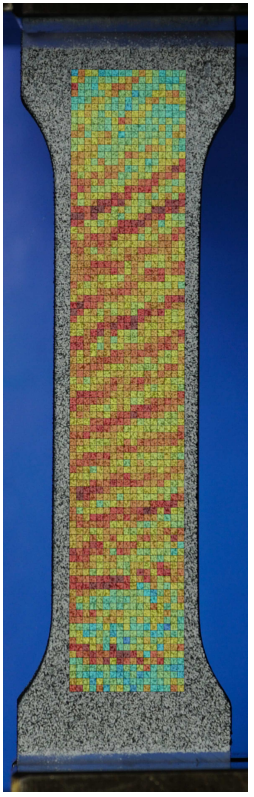

(b) $\mathrm{t}=2475 \mathrm{~s}$

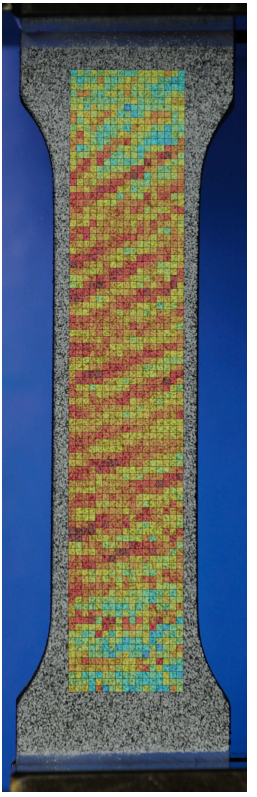

(c) $\mathrm{t}=4725 \mathrm{~s}$
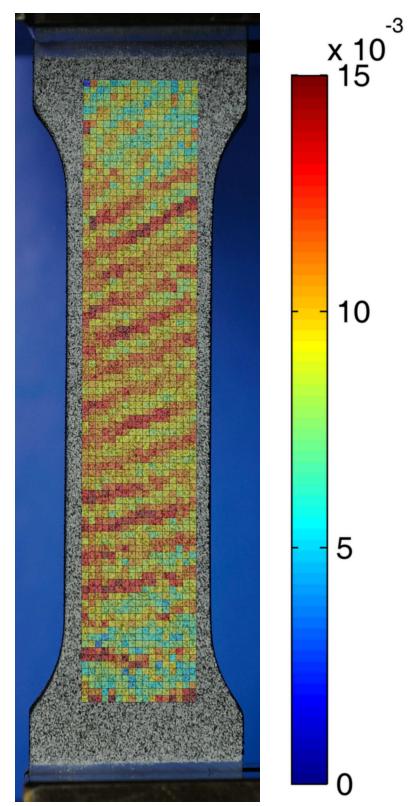

(d) $\mathrm{t}=6975 \mathrm{~s}$

Figura 4.28: Relaxação da força durante o ensaio de relaxação para o PMMA. 


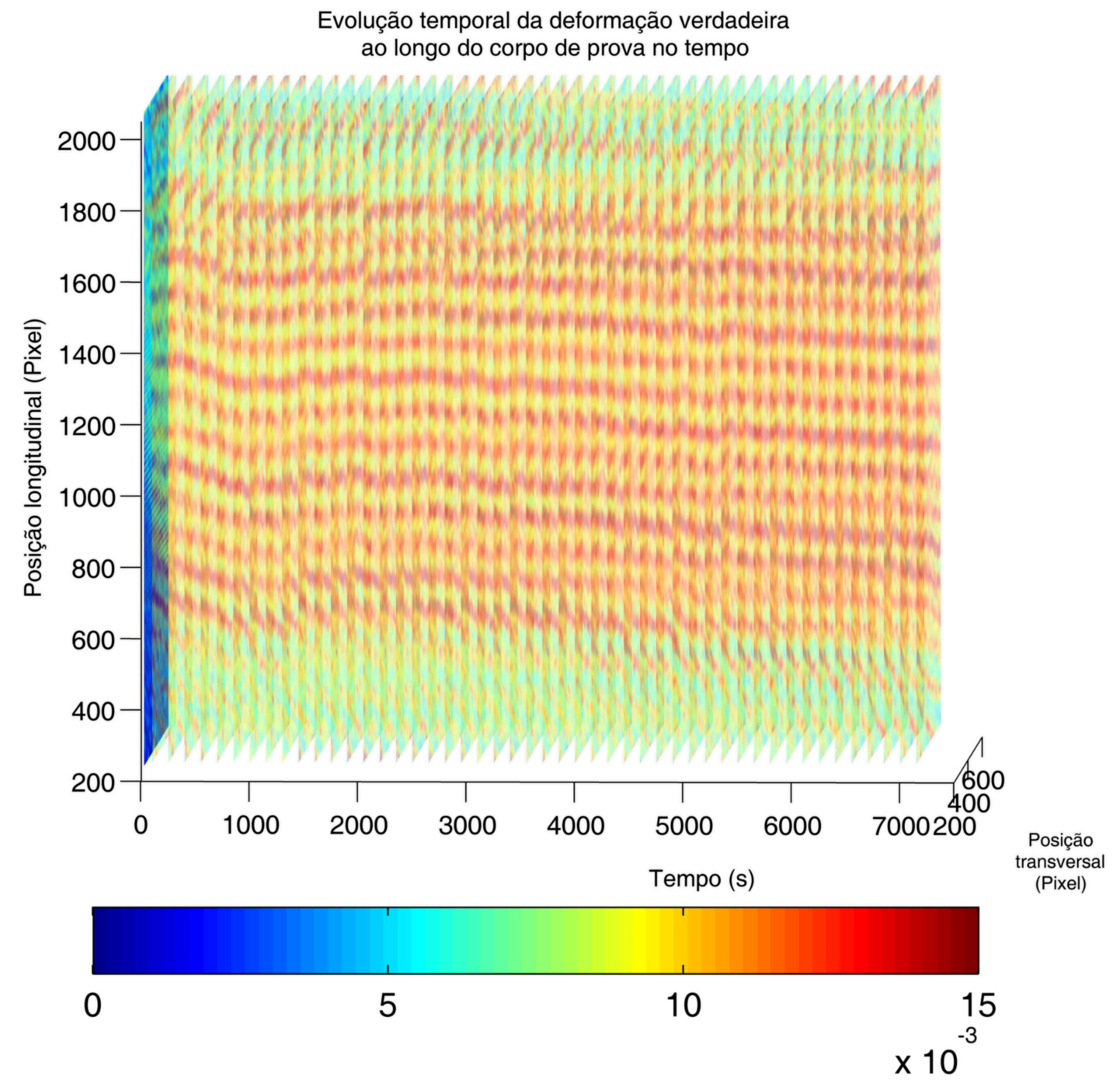

Figura 4.29: Análise comparativa da distribuição de deformações no corpo de prova durante o ensaio de relaxação em PMMA. 


\subsubsection{PVC}

No PVC, assim como no PMMA, é observado um carregamento quase homogêneo, conforme pode ser visto na figura 4.30, com o intervalo entre fotos igual ao ensaio com PMMA.

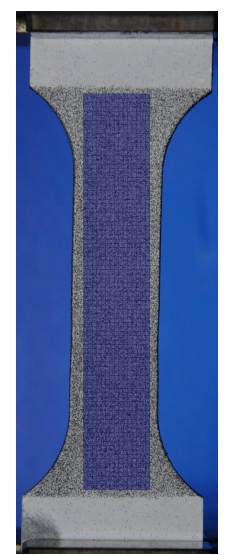

(a) $\mathrm{t}=0 \mathrm{~s}$

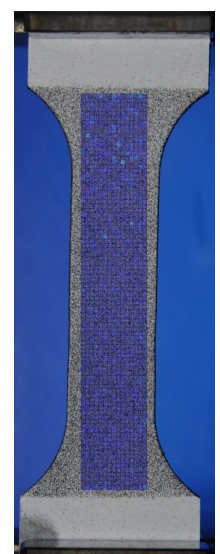

(b) $\mathrm{t}=0,66 \mathrm{~s}$

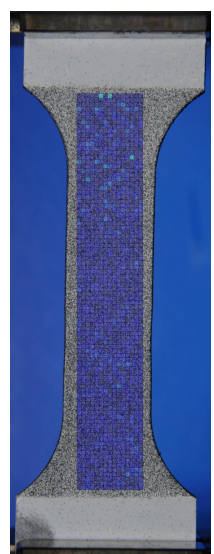

(c) $\mathrm{t}=1,33 \mathrm{~s}$

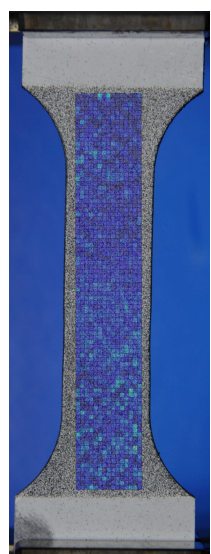

(d) $\mathrm{t}=2,0 \mathrm{~s}$

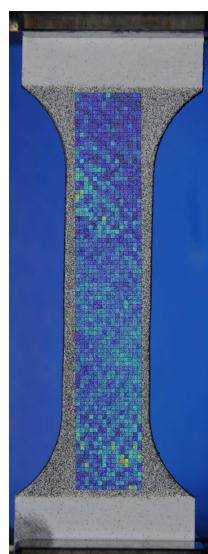

(e) $\mathrm{t}=2,66 \mathrm{~s}$

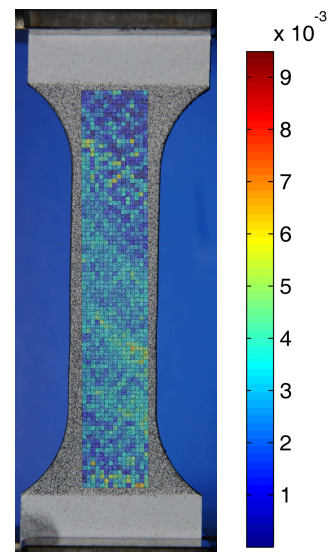

(f) $\mathrm{t}=3,33 \mathrm{~s}$

(g)

Figura 4.30: Fase de carregamento do ensaio de relaxação para o PVC.

Já durante a relaxação, o intervalo entre imagens foi de 300 segundos, com o tempo total de teste também de duas horas. Pode-se notar na figura 4.31 as localizações, com a figura 4.32 mostrando a evolução das mesmas.

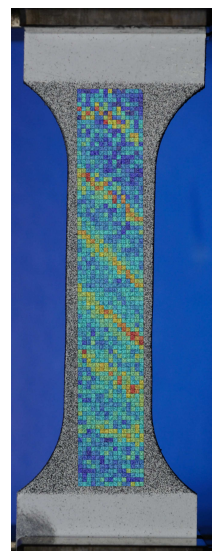

(a) $\mathrm{t}=300 \mathrm{~s}$

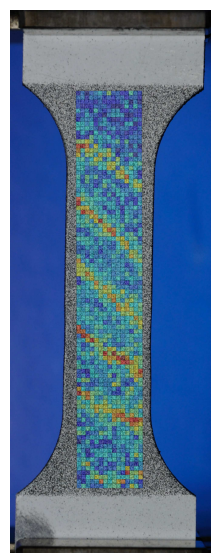

(b) $\mathrm{t}=2400 \mathrm{~s}$

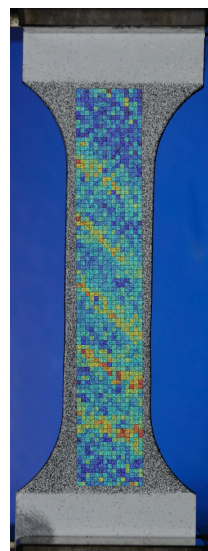

(c) $\mathrm{t}=4500 \mathrm{~s}$

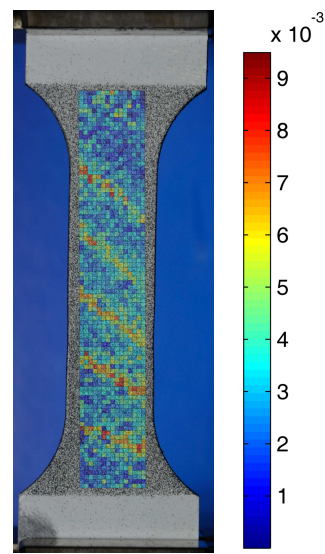

(d) $\mathrm{t}=6600 \mathrm{~s}$ (e)

Figura 4.31: Relaxação da força durante o ensaio de relaxação para o PVC. 


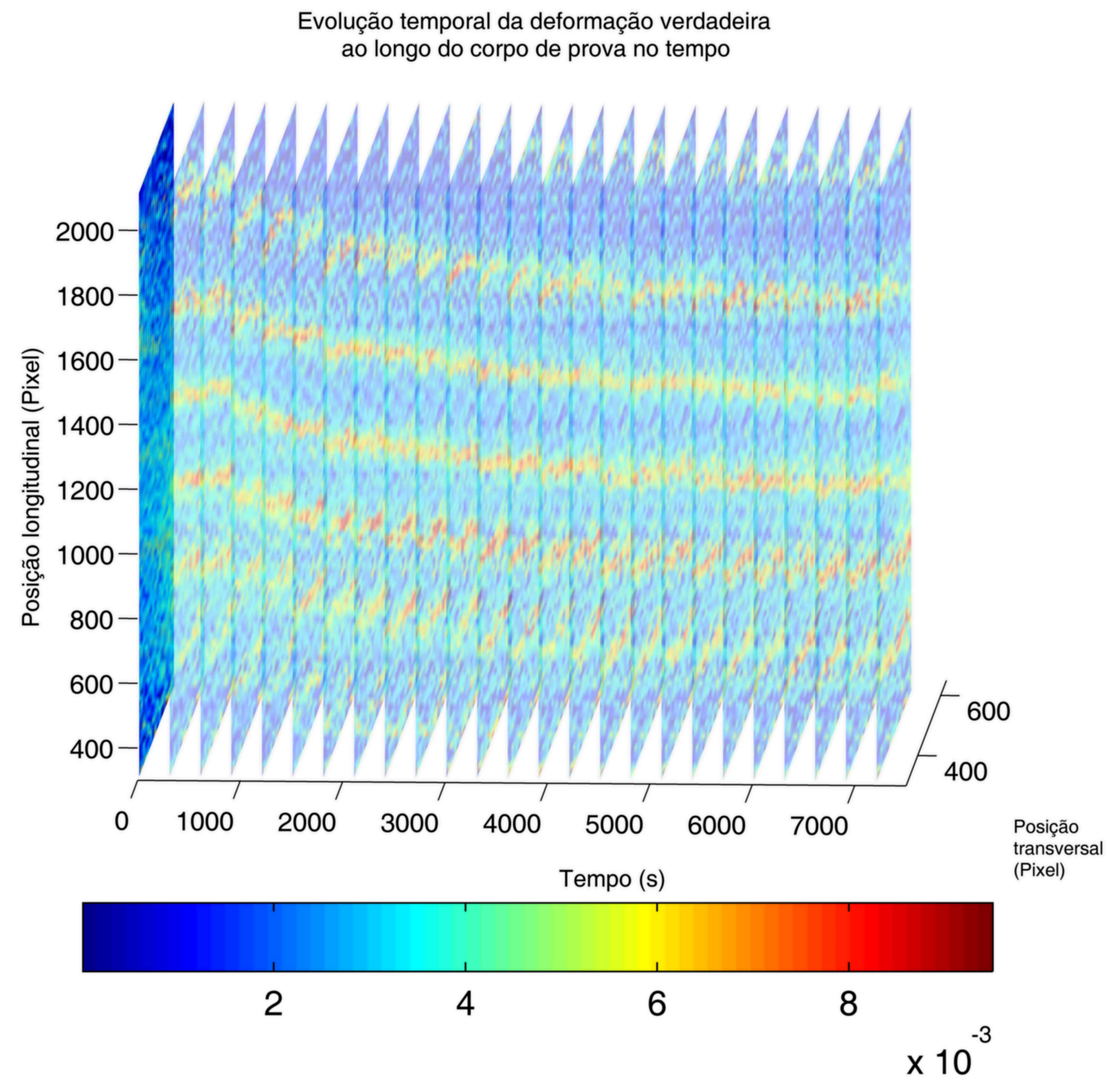

Figura 4.32: Análise comparativa da distribuição de deformações no corpo de prova durante o ensaio de relaxação em PVC.

\subsubsection{PEAD}

No ensaio de relaxação do PEAD, as fotos foram tiradas a cada terço de segundo durante o carregamento e a cada 120 segundos durante a relaxação. Conforme pode ser ver nas figuras 4.334 .34 e 4.35, há uma tendência local do efeito visto nos ensaios de relaxação de PMMA e PVC. Uma possível explicação pode ser encontrada se considerarmos que em um material amorfo há possibilidade de movimentação das moléculas, buscando uma configuração de menor energia, e que o PEAD é um material semicristalino, ou seja, cristais cercados por regiões amorfas, cada região amorfa irá tender a sofrer uma localização independente das outras. 


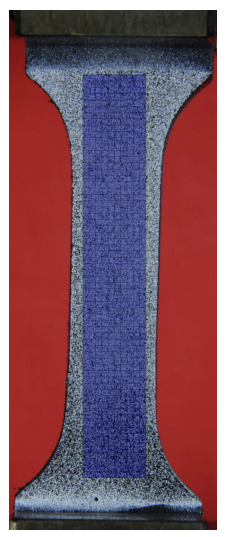

(a) $\mathrm{t}=0 \mathrm{~s}$

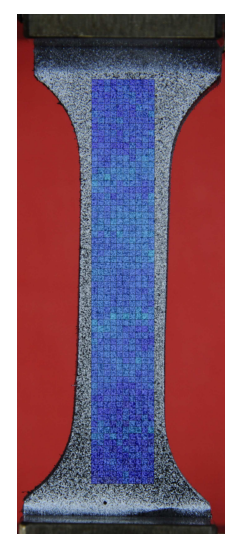

(b) $\mathrm{t}=0,66 \mathrm{~s}$

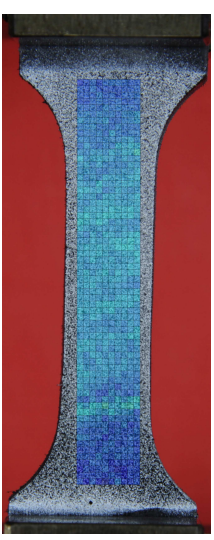

(c) $\mathrm{t}=1,33 \mathrm{~s}$

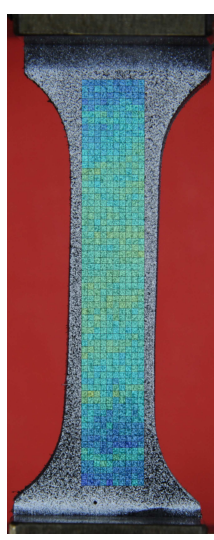

(d) $\mathrm{t}=2,0 \mathrm{~s}$

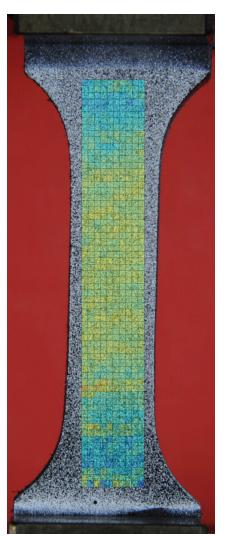

(e) $\mathrm{t}=2,66 \mathrm{~s}$

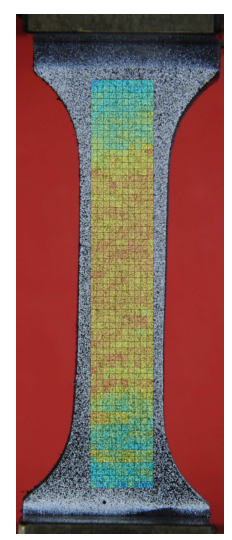

(f) $\mathrm{t}=3,33 \mathrm{~s}$

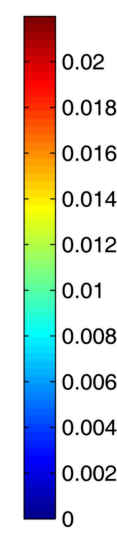

(g)

Figura 4.33: Fase de carregamento do ensaio de relaxação para o PEAD.

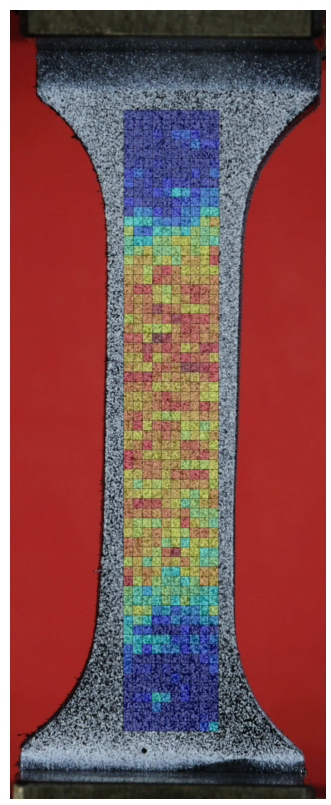

(a) $\mathrm{t}=120 \mathrm{~s}$

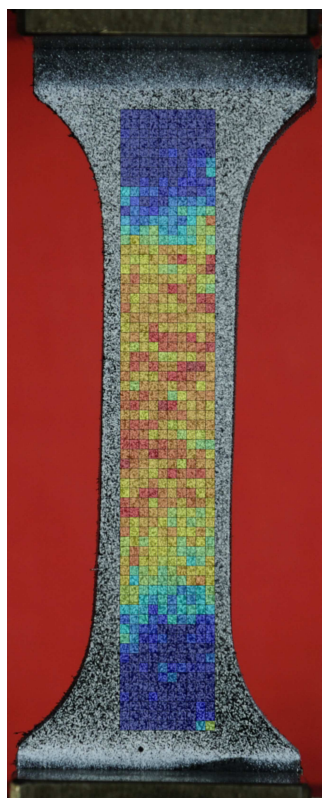

(b) $\mathrm{t}=1920 \mathrm{~s}$

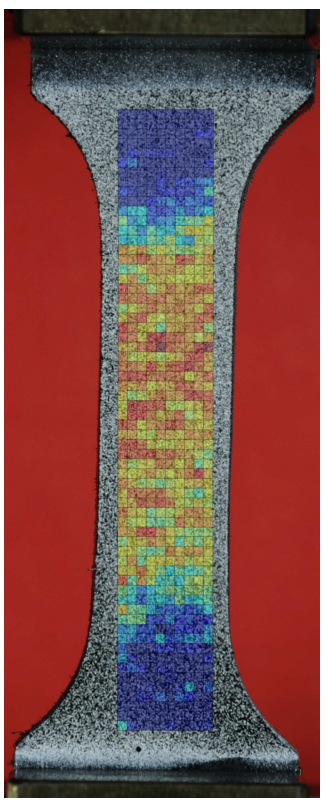

(c) $\mathrm{t}=3720 \mathrm{~s}$

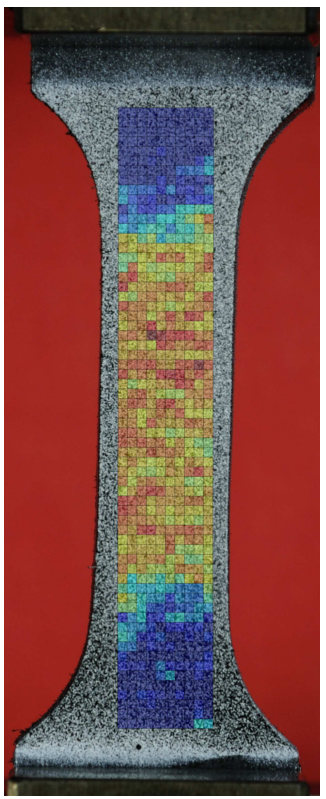

(d) $\mathrm{t}=5520 \mathrm{~s}$

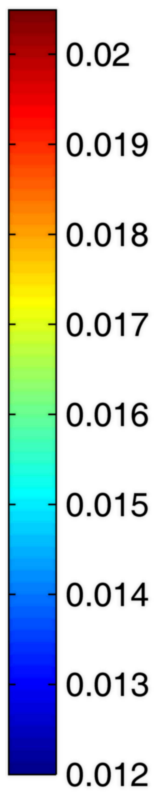

(e)

Figura 4.34: Relaxação da força durante o ensaio de relaxação para o PEAD. 


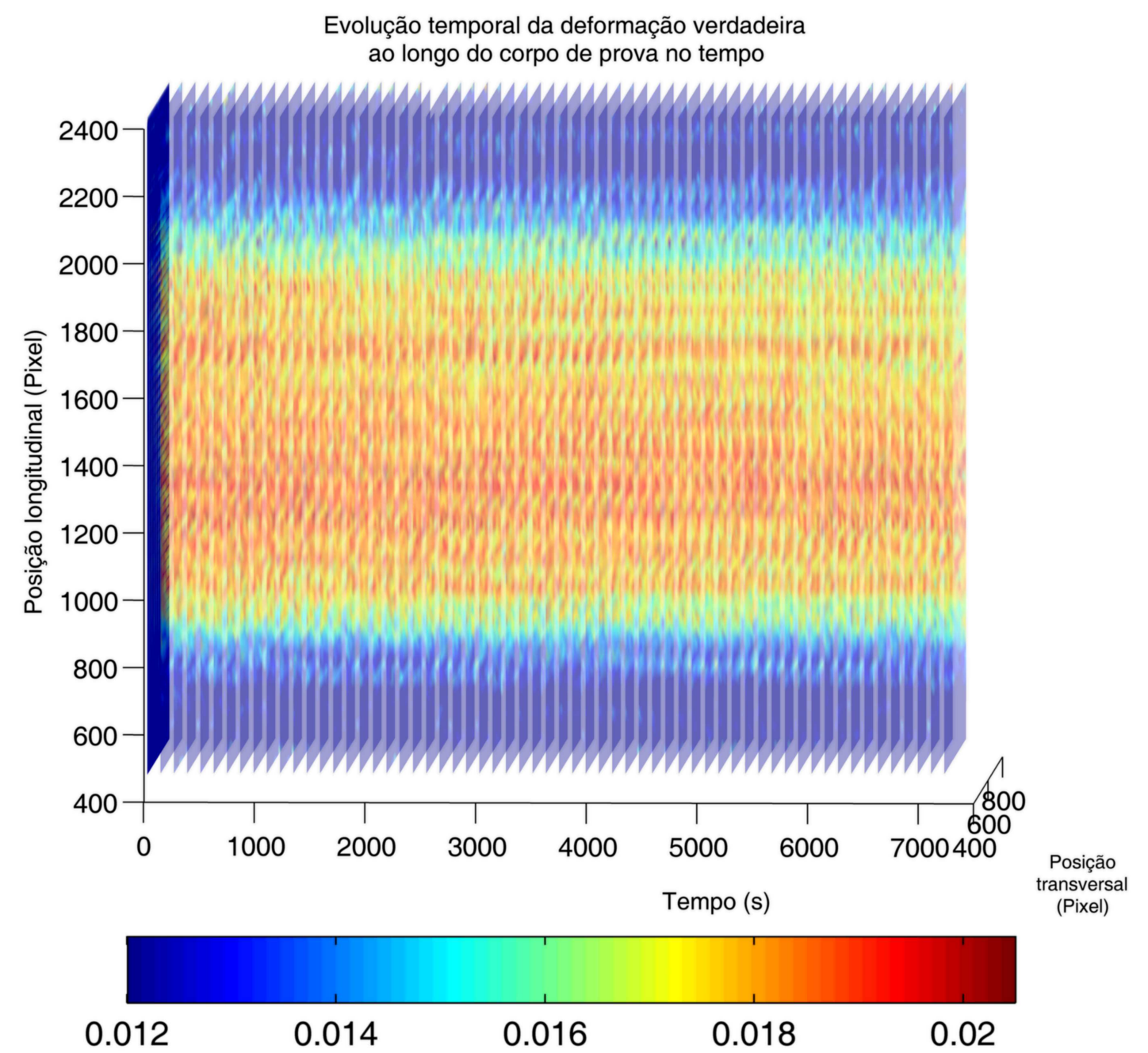

Figura 4.35: Análise comparativa da distribuição de deformações no corpo de prova durante o ensaio de relaxação em PEAD. 


\section{Capítulo 5}

\section{Experimentos mecânicos a altas taxas de deformação}

\subsection{Introdução}

O Capítulo 2 ressaltou dois motivos para o estudo do comportamento mecânico dos materiais sob carregamentos de altas taxas de deformação:

- motivos econômicos: há uma série de produtos nos quais se deseja uma maior resistência mecânica ao impacto de modo a se destacarem no mercado, tanto de alto valor agregado como no caso de celulares e tablets, quanto de baixo custo, como suplas, copos, entre outros;

- motivos de segurança: a maior compreensão do comportamento do material quando submetido a situações de impacto permite um projeto mais adequado a este tipo de solicitação. Um bom exemplo são os estudos de colisão veicular, através de simulações e experimentos, em prol da verificação das condições de desaceleração durante um teste.

O aparato experimental mais utilizado para medir as propriedades mecânicas do material a altas taxas de deformação é conhecido por Barra de Hopkinson. Este dispositivo se baseia na propagação de ondas em duas barras longas, entre as quais o material a ser testado é colocado.

Uma caracterização dinâmica adequada de materiais poliméricos requer o uso de barras com impedância mecânica similar, como o PMMA. O uso desse material como barra introduz uma atenuação nos pulsos, mudando sua amplitude. Como o módulo elástico 
deste material é viscoso, ou seja, depende da taxa de deformação, ao decompormos o pulso no domínio da frequência percebe-se que cada componente possui uma velocidade de propagação diferente, ou em outras palavras, há uma dispersão denominada dispersão material. Adotando o ambiente de propagação de onda unidimensional viscoelástica, foi possível modelar a atenuação e dispersão material e ampliar a acurácia do resultado final do teste.

Assim, a força passou a ser calculada, no domínio da frequência, a partir da multiplicação da deformação pelo modo elástico, com este último sendo capaz de reproduzir os efeitos de dispersão material e atenuação. Como a calibração deste módulo elástico foi realizada experimentalmente em barras cilíndricas, o mesmo acaba contendo implicitamente a dispersão geométrica. Com o estudo da propagação de ondas tridimensionais viscoelásticas, foi possível retirar a influência da dispersão geométrica do módulo elástico no domínio da frequência e melhorar a acurácia na medida de tensão da barra e consequentemente da força aplicada no corpo de prova. Este procedimento de separação fez parte de um estudo sobre impacto axial de tubos cilíndricos de nano-naylon66 [71].

A propagação de onda viscoelástica tridimensional fornece o comportamento viscoelástico do polímero a altas taxas de deformação. Este será utilizado, em conjunto com os resultados dos ensaios experimentais de relaxação, a baixíssimas taxas de deformação, e os de tração e compressão, a baixas taxas de deformação, para propor um modelo viscoelastoviscoplástico de material.

\subsection{Barra de Hopkinson}

\subsubsection{Histórico da Barra de Hopkinson}

A HPB (Hopkinson pressure bar, ou barra de Hopkinson de pressão em português) foi introduzida por Hopkinson [42] como um método de medição do pico de pressão durante o carregamento devido a uma detonação explosiva ou o impacto de balas. O dispositivo desenvolvido por Hopkinson está ilustrado na fig. 5.1(a)

Já Davies [25] instrumentou a HPB com sensores capacitivos, permitindo a medida da história da pressão no tempo. Kolsky [50,51] adaptou-a para testar materiais a altas taxas de deformação, obtendo a configuração final como na fig. (2.9), com o dispositivo passando a ser chamado "Kolsky Bar"ou "Split Hopkinson Pressure Bar"desde então. 


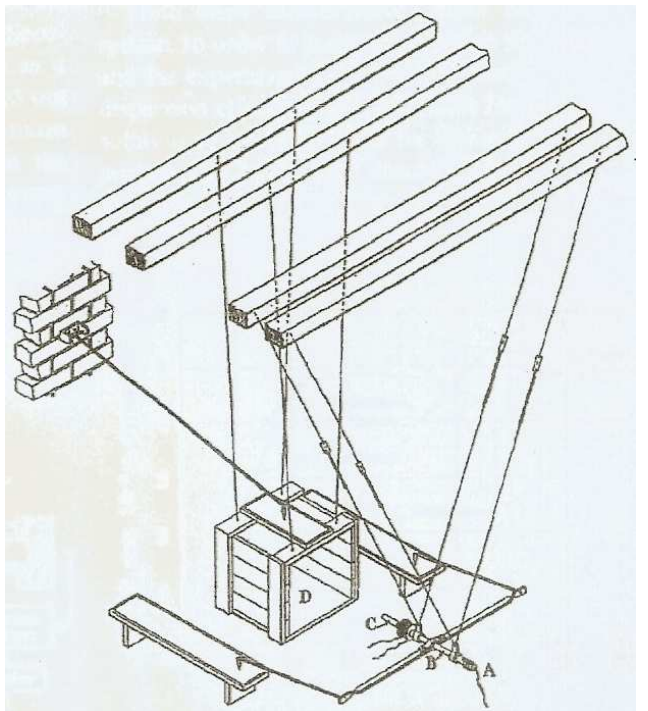

(a)

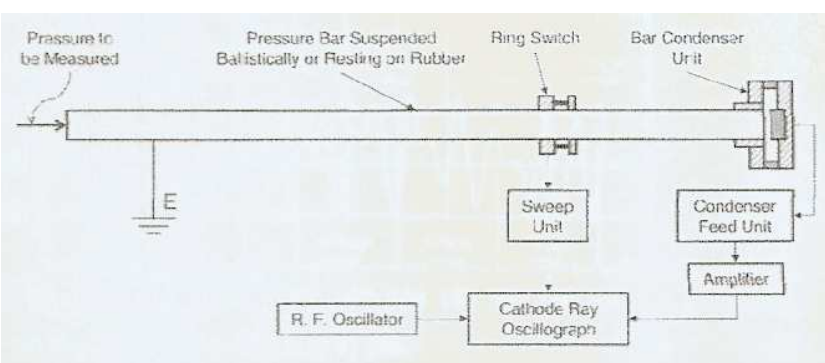

(b)

Figura 5.1: Dispositivos de Hopkinson e Davies.

Segundo Zhao [95], a SHPB passou por diversas mudanças, como ser adaptada para testes de tração [57], torção [27], compressão combinada a torção [56], fratura dinâmica [48], entre outras variações. Harding [40] também apresenta diversas destas variações a que a SHPB foi submetida ao longo do tempo. Em particular, Nemat-Nasser et al. [78] desenvolveram novas técnicas para a $\mathrm{BH}$, as quais permitem realizar testes de compressão seguido de tração, possibilitando a análise do efeito de Bauschinger sob elevadas taxas de deformação. As técnicas apresentadas nesse artigo [78] também possibilitam a realização de experimentos de recuperação dinâmica, nos quais o corpo de prova é submetido a um pulso de tensão pré-definido e então é recuperado sem carregamento adicional para a análise pós teste da microestrutura. Testes com a Barra de Hopkinson em condições de elevada temperatura também foram estudados por Muller et al. [73].

Meng e Li [62] utilizaram uma técnica de separação de ondas para reduzir a distância entre a interface barra-corpo de prova e o extensômetro, minimizando desta forma a dispersão e atenuação de onda durante o teste. Esta técnica de separação consiste em um método de medição de deformação em dois pontos distintos, sendo capaz de separar as ondas incidentes e refletida. 


\subsubsection{Modelagem matemática}

A Barra de Hopkinson utilizada neste trabalho consiste em um reservatório de ar comprimido (em vermelho na figura) ligado a um tubo de lançamento por uma válvula de dois estágios, 3 barras cilíndricas e suportes para alinhamento do sistema, conforme fig. 5.3(a). A menor das três barras é denominada striker e posicionada dentro do tubo de lançamento o mais próximo possível do reservatório de ar comprimido, conforme fig. 5.3(c), é acelerado pneumaticamente após a válvula passar do estágio fechado para aberto. O striker impacta um conjunto de três elementos formados pela barra de entrada, corpo de prova do material a ser testado e barra de saída, conforme a fig. 5.2, sendo denominada $\mathbf{1}$ a interface entre barra de entrada e corpo de prova e $\mathbf{2}$ a interface entre o corpo de prova e barra de saída.

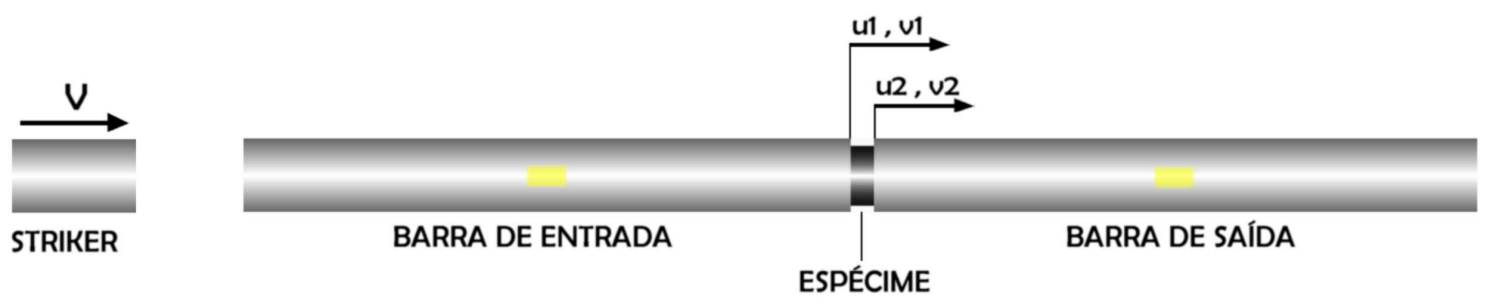

Figura 5.2: Esquemática para compreensão da Barra de Hopkinson.

O impacto do striker neste conjunto de três elementos, gera uma onda de compressão na barra de entrada $\varepsilon_{I}$, conforme fig. 5.3(e). Esta onda percorre a barra de entrada, que possui um par de extensômetros diametralmente opostos fixados próximos à sua metade, até encontrar o corpo de prova, conforme fig. $5.3(\mathrm{~g})$, sendo a onda dividida em uma onda refletida, $\varepsilon_{R}$, de tração na barra de entrada e uma onda transmitida, $\varepsilon_{T}$, de compressão na barra saída, que também é medida por um par de extensômetros diametralmente opostos fixados próximos à metade da barra de saída.

Pode-se definir a deformação logarítmica axial do corpo de prova como

$$
\varepsilon_{c p}=\ln \left(\frac{L_{c p}}{L_{0 c p}}\right)=\ln \left(\frac{L_{0 c p}+u_{2}-u_{1}}{L_{0 c p}}\right)
$$

com $u_{1}$ e $u_{2}$ sendo os deslocamentos das interfaces $\mathbf{1}$ e $\mathbf{2}, L_{0 c p}$ e $L_{c p}$ sendo respectivamente os comprimentos inicial e atual do corpo de prova. Considerando que há diferenças entre as forças nas interfaces $\mathbf{1}$ e $\mathbf{2}$ devido a propagação de ondas dentro do corpo de prova, 
pode-se calcular a tensão verdadeira do mesmo por

$$
\sigma_{c p}=\left(\frac{F_{1}+F_{2}}{2}\right) \frac{1}{A_{c p}}=\left(\frac{F_{1}+F_{2}}{2}\right) \frac{L_{c p}}{A_{0 c p} L_{0 c p}}=\left(\frac{F_{1}+F_{2}}{2}\right) \frac{L_{0 c p}+u_{2}-u_{1}}{A_{0 c p} L_{0 c p}}
$$

com $F_{1}$ e $F_{2}$ sendo as forças das interfaces $\mathbf{1}$ e $\mathbf{2}, A_{0 c p}$ e $A_{c p}$ sendo respectivamente as áreas inicial e atual do corpo de prova e assumindo-se isovolumetria do ensaio, ou seja, $A_{0 c p} L_{0 c p}=A_{c p} L_{c p}$.
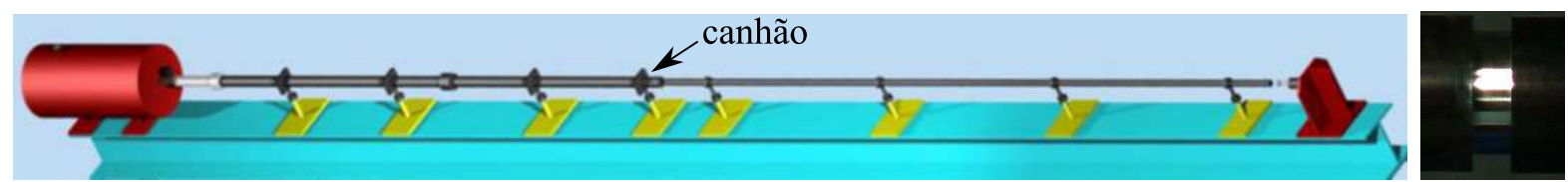

(a)
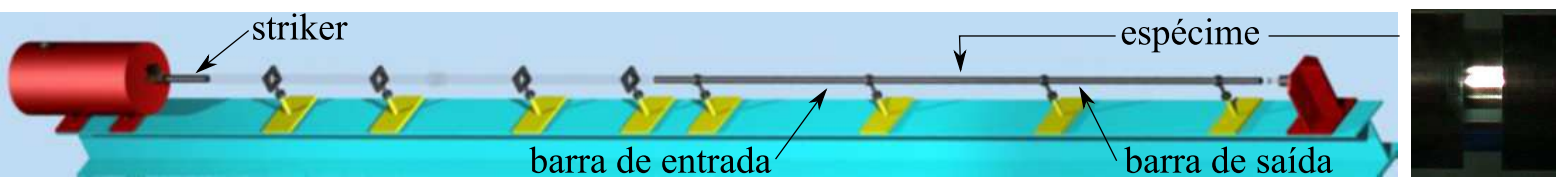

(c)
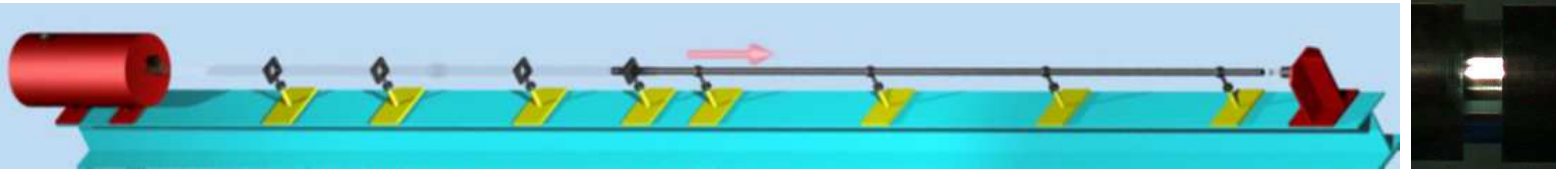

(e)
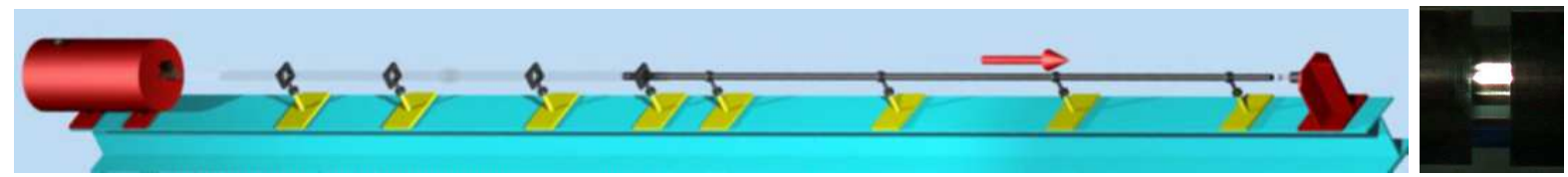

(g)
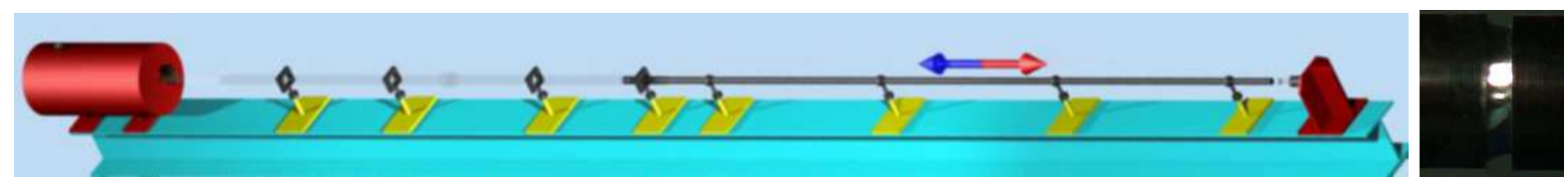

(i)
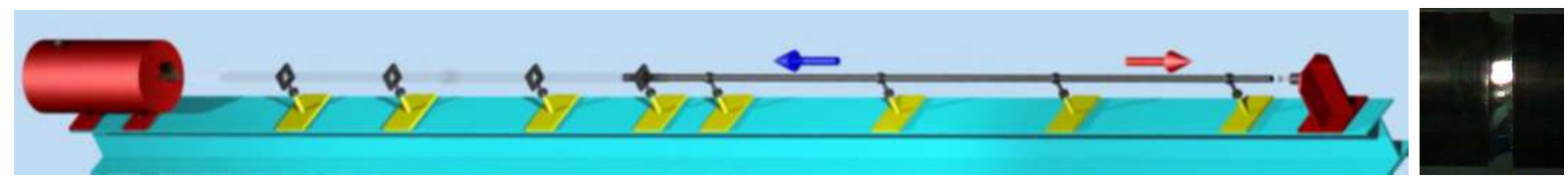

(k)

Figura 5.3: Funcionamento da barra de Hopkinson.

De acordo com as equações que regem a propagação de ondas unidimensionais elásticas, as ondas elásticas não sofrem modificações em sua forma ou amplitude durante a propagação, sendo iguais na medição pelo extensômetro no meio da barra de entrada e 
na interface da mesma com o corpo de prova, ocorrendo o mesmo para a barra de saída, ou seja, as ondas de deformação $\varepsilon_{I}, \varepsilon_{R}$ medidas na estação de medição são as mesmas na interface $\mathbf{1}$, ocorrendo o mesmo entre $\varepsilon_{T}$ medida nos extensômetros da barra de saída e na interface 2. A velocidade das partículas de uma dada secção transversal da barra, pela qual passa uma onda de deformação, pode ser calculada por [51]

$$
v=-c \varepsilon
$$

sendo $c$ a velocidade de propagação de onda unidimensional, significando que uma onda de compressão, de sinal negativo por convenção, propagando-se horizontalmente para a direita, por exemplo, passando por uma determinada seção transversal, movimentará as partículas também para a direita, ou seja, culminando em uma velocidade positiva ao ter-se adotado o eixo positivo para a direita. Para o cálculo da velocidade na interface 1, a onda incidente propaga-se no sentido adotado como positivo e a onda refletida no sentido contrário. Analogamente, a onda transmitida se propaga no sentido positivo, possibilitando escrever

$$
v_{1}=v_{I}-v_{R}=-c \varepsilon_{I}-\left(-c \varepsilon_{R}\right)=c\left(\varepsilon_{R}-\varepsilon_{I}\right) \quad \text { e } \quad v_{2}=v_{T}=-c \varepsilon_{T}
$$

com os deslocamentos $u_{1}$ e $u_{2}$ calculados pela integral no tempo

$$
u_{1}=\int v_{1} \mathrm{~d} t=\int c\left(\varepsilon_{R}-\varepsilon_{I}\right) \mathrm{d} t \quad \text { e } \quad u_{2}=\int v_{2} \mathrm{~d} t=\int-c \varepsilon_{T} \mathrm{~d} t
$$

No cálculo das forças, estas são obtidas a partir das tensões nas interfaces $\mathbf{1}$ e $\mathbf{2}$, respectivamente $\sigma_{1}$ e $\sigma_{2}$, e das áreas das barras de entrada e saída, $A_{\text {Bentrada }}$ e $A_{B \text { saida }}$, por $F_{1}=\sigma_{1} A_{\text {Bentrada }}$ e $F_{2}=\sigma_{2} A_{B \text { saida }}$. Como as tensões tem sentido mas não direção, as forças podem ser dadas por

$$
F_{1}=F_{I}-F_{R}=\left(\sigma_{I}+\sigma_{R}\right) A_{B e n t r a d a} \quad \text { e } \quad F_{2}=F_{T}=\sigma_{T} A_{B s a i d a}
$$

e como é uma teoria elástica, o módulo elástico $E$ não depende da taxa de deformação e podemos concluir que

$$
F_{1}=\left(\varepsilon_{I}+\varepsilon_{R}\right) \text { E } A_{\text {Bentrada }} \quad \text { e } \quad F_{2}=\varepsilon_{T} E A_{B \text { saida }}
$$

Desta forma, pode-se calcular a tensão verdadeira e a deformação logarítmica do corpo de prova a partir dos pulsos incidente, $\varepsilon_{I}$, refletido, $\varepsilon_{R}$, e transmitido, $\varepsilon_{T}$. A figura 5.4 
mostra um exemplo destas ondas em um ensaio experimental em aço, lembrando que ambas as ondas incidente e refletida são medidas no mesmo par de extensômetros da barra de entrada.

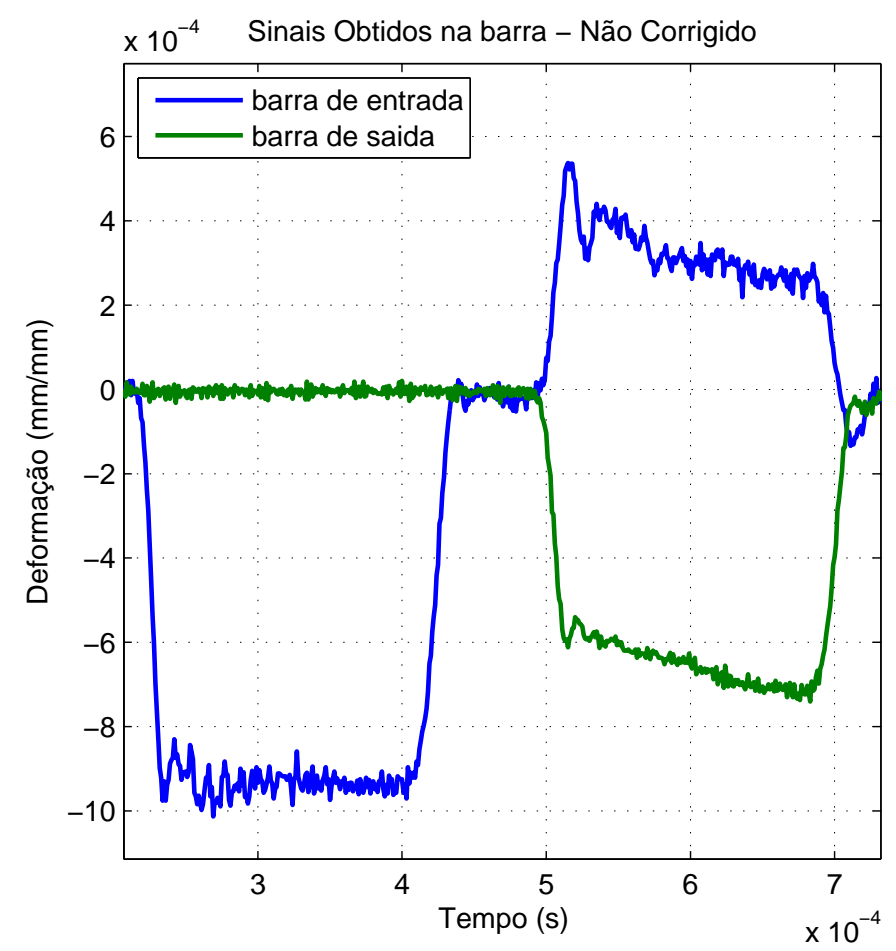

Figura 5.4: Exemplo de ondas incidente, refletida e transmitida.

As ondas de deformação incidente e refletidas devem então ser transladadas para a interface 1 e a onda transmitida para a interface 2. Para tanto, é utilizada a Transformada de Fourier. Esta diz que qualquer pulso não periódico no tempo, $f(t)$, pode ser transformado em componentes no domínio da frequência, $F(\omega)$, através de:

$$
F(\omega)=\int_{-\infty}^{\infty} f(t) e^{-i \omega t} \mathrm{~d} t \Leftrightarrow f(t)=\frac{1}{2 \pi} \int_{-\infty}^{\infty} F(\omega) e^{i \omega} \mathrm{d} \omega
$$

sendo de interesse neste trabalho esta propriedade da Transformada de Fourier

$$
f(t+\tau) \Leftrightarrow F(\omega) e^{-i \omega \tau}
$$

na qual para descobrir o valor de $f$ no instante $t+\tau, f(t+\tau)$, basta realizar a transformada inversa de Fourier de $F(\omega) e^{-i \omega \tau}$. Como a velocidade de propagação de onda $c$ é constante para qualquer componente de frequência, adotando a distância entre os extensômetros e a interface por $z$, temos que $\tau=z / c$. A Transformada de Fourier para sinais discretos 
é denominada DFT, sigla para Discrete Fourier Transform (ou transformada discreta de Fourier, em português) e teve a eficiência computacional de seu algoritmo melhorada originando a FFT, (Fast Fourier Transform, ou transformada rápida de Fourier, em português). Pode-se então determinar a onda de deformação transladada, $\varepsilon_{\text {trans }}$, por

$$
\varepsilon_{\text {trans }}(t)=\operatorname{FFT}^{-1}\left(\operatorname{FFT}(\varepsilon(t)) e^{\frac{-i \omega z}{c}}\right)
$$

e que será usado mais à frente, quando do processamento dos sinais medidos.

\subsection{Propagação de ondas tridimensionais elásticas}

Os efeitos de inércia lateral nas barras durante a propagação das ondas de deformação elástica causa o efeito chamado dispersão, que muda o formato do pulso durante sua propagação. A acurácia do teste pode ser melhorada, então, ao se descrever matematicamente a propagação de ondas tridimensionais elásticas em um cilindro, possibilitando calcular o modo como a onda tem seu formato alterado ao se propagar. Para tanto, a teoria de propagação de ondas foi estudada por muitos, com Pochammer [80] e Chree [23] chegando, de maneira independente, à mesma solução da equação diferencial de propagação de ondas em barras cilíndricas, a qual diz que a velocidade de propagação da onda é uma função do comprimento de onda e apresentava de maneira implícita o fenômeno da distorção.

Outra tentativa de introduzir os efeitos de inércia lateral na vibração longitudinal foi apresentada por Rayleigh [82]. Love [59] apresentou a equação governante, fundamentado em considerações energéticas. Bancroft [6] e Davies [25] descreveram métodos numéricos para a solução das equações de dispersão de Pochammer-Chree. Nesta mesma direção de corrigir a dispersão, Ghorham [36] e Follansbee e Frantz [34] levaram o pulso do domínio do tempo para o domínio da frequência, aplicando então a correção e voltando o sinal para o domínio do tempo através da transformada inversa de Fourier, conforme explicado no fim da seção anterior.

Faz-se então necessário um estudo sobre a propagação de ondas tridimensionais de maneira obter a equação de Pochammer-Chree e compreender como aplicar sua solução na propagação de uma onda utilizando como ferramenta a FFT. O apêndice D contém detalhadamente cada evolução do raciocínio matemático que convergirá para a equação de 
Pochammer-Chree. Entretanto, faz-se necessário um pequeno resumo do mesmo, sendo o primeiro passo converter as equações de movimento para coordenadas polares $(r, \theta, z)$, obtendo segundo Kolsky [51]

$$
\begin{gathered}
\rho \frac{\partial^{2} u_{r}}{\partial t^{2}}=(\lambda+2 \mu) \frac{\partial \Delta}{\partial r}-\frac{2 \mu}{r} \frac{\partial w_{z}}{\partial \theta}+2 \mu \frac{\partial w_{\theta}}{\partial z} \\
\rho \frac{\partial^{2} u_{\theta}}{\partial t^{2}}=(\lambda+2 \mu) \frac{1}{r} \frac{\partial \Delta}{\partial \theta}-2 \mu \frac{\partial w_{r}}{\partial z}+2 \mu \frac{\partial w_{z}}{\partial r} \\
\rho \frac{\partial^{2} u_{z}}{\partial t^{2}}=(\lambda+2 \mu) \frac{\partial \Delta}{\partial z}-\frac{2 \mu}{r} \frac{\partial}{\partial r}\left(r w_{\theta}\right)+\frac{2 \mu}{r} \frac{\partial w_{r}}{\partial \theta}
\end{gathered}
$$

no qual $\Delta$ é a dilatação em coordenadas polares, dada por

$$
\Delta=\frac{1}{r} \frac{\partial\left(r u_{r}\right)}{\partial r}+\frac{1}{r} \frac{\partial u_{\theta}}{\partial \theta}+\frac{\partial u_{z}}{\partial z}
$$

com $\lambda$ e $\mu$ sendo as constantes de Lamé, $w_{r}, w_{\theta}$ e $w_{z}$ as componentes de rotação em torno dos eixos e $u_{r}, u_{\theta}$ e $u_{z}$ os deslocamentos. Como a propagação é axi-simétrica, $u_{r}$ é nulo assim como os outros dois componentes de tensão na superfície da barra, $\sigma_{r r}$ e $\sigma_{r z}$.

A relação entre essas componentes de tensão e as deformações é matematicamente descrita por

$$
\left\{\begin{array}{l}
\sigma_{r r}=\lambda \Delta+2 \mu \frac{\partial u_{r}}{\partial r} \\
\sigma_{r z}=\mu\left[\frac{\partial u_{r}}{\partial z}+r \frac{\partial u_{z}}{\partial r}\right]
\end{array}\right.
$$

levando a relação entre as propriedades do material, a velocidade de fase $V_{f}$ e o raio do cilindro $a$ descrita por

$$
\frac{\left[2 \mu \frac{\partial^{2}}{\partial a^{2}} J_{0}\left(h^{\prime} a\right)-\frac{\lambda}{\lambda+2 \mu} \omega^{2} \rho J_{0}\left(h^{\prime} a\right)\right]}{2 \mu \gamma \frac{\partial}{\partial a} J_{1}\left(k^{\prime} a\right)}=\frac{2 \gamma \frac{\partial}{\partial a} J_{0}\left(h^{\prime} a\right)}{\left(2 \gamma^{2}-\frac{\omega^{2} \rho}{\mu}\right) J_{1}\left(k^{\prime} a\right)}
$$

$\left.\operatorname{com} \frac{\partial}{\partial r}\right|_{r=a}=\frac{\partial}{\partial a}, J_{0}$ e $J_{1}$ as funções de Bessel de ordem 0 e 1 respectivamente, $\omega$ a frequência angular e $\Lambda=2 \pi / \gamma$ o comprimento de onda, com $\gamma$ sendo o número de onda e $h^{\prime}$ e $k^{\prime}$ são dados por

$$
\begin{gathered}
{h^{\prime 2}}^{2}=\frac{\rho \omega^{2}}{\lambda+2 \mu}-\gamma^{2} \\
k^{\prime 2}=\frac{\rho \omega^{2}}{\mu}-\gamma^{2}
\end{gathered}
$$


Para cada frequência angular $\omega$, vários $\gamma$ satisfazem a equação de frequências de Pochhammer-Crhee, sendo que cada $\gamma$ representa um modo de vibrar da barra. A velocidade de fase é calculada por $V_{f}=\omega / \gamma$.

Os gráficos da fig. 5.5 ilustram a velocidade de fase em função do comprimento de onda adimensionalizado, ou seja, a razão entre o comprimento de onda e o diâmetro, para uma barra cilíndrica de aço com 25,4 mm de diâmetro. A fig. 5.5 também indica a velocidade de onda uniaxial, $\sqrt{E / \rho}$, e a velocidade de onda de dilatação, que é a velocidade de uma onda longitudinal em um meio infinito (também conhecida por "bulk sound speed") e dada por

$$
V_{\text {long }}=\left(\frac{\lambda+2 \mu}{\rho}\right)^{\frac{1}{2}}
$$

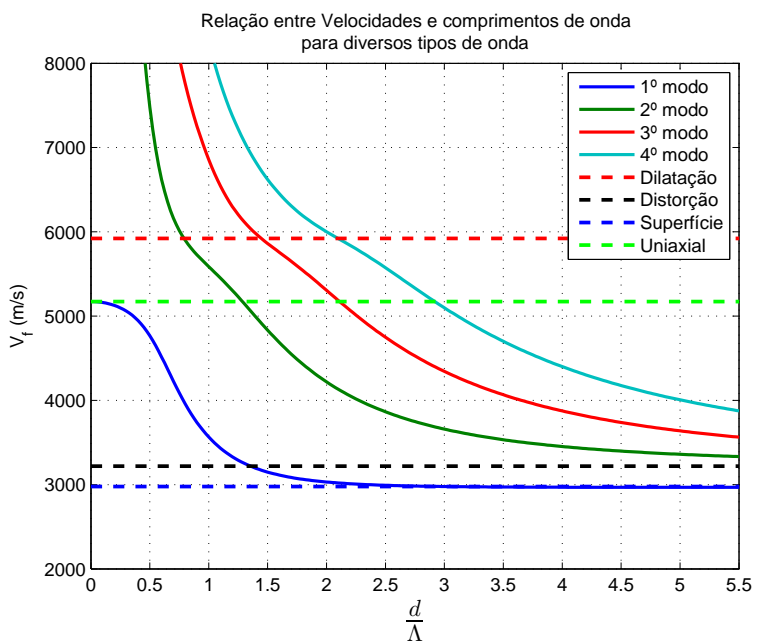

(a)

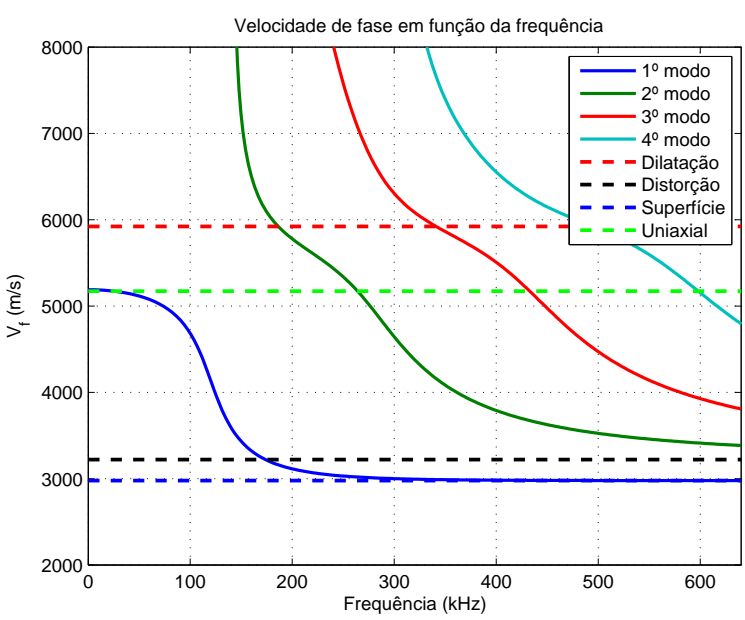

(b)

Figura 5.5: Gráficos da Velocidade de fase em função do diâmetro e comprimento de onda (a) e em função da frequência (b) para uma barra cilíndrica de aço com 24,8 mm de diâmetro.

Como indicado na fig. 5.5, a uma dada frequência existem várias modos de vibração, cada um com sua respectiva velocidade de fase. Ocorre que o método de propagação de ondas por FFT consegue lidar apenas com uma velocidade de fase por frequência. Para determinar qual velocidade de fase utilizar, calcula-se a velocidade de grupo, a qual é definida como a velocidade de propagação de um conjunto de ondas com o comprimento próximos de $\Lambda$. Em outras palavras, o modo de vibrar com maior velocidade de grupo em uma determinada frequência será predominante e escolhido para compilarmos o mapa 
de propagação. A velocidade de grupo, $V_{g}$, pode ser calculada em função da densidade $\rho$ e das constantes de Lamé $\lambda$ e $\mu$, por [25]

$$
V_{g}=V_{f}-\Lambda \frac{\partial V_{f}}{\partial \Lambda}
$$

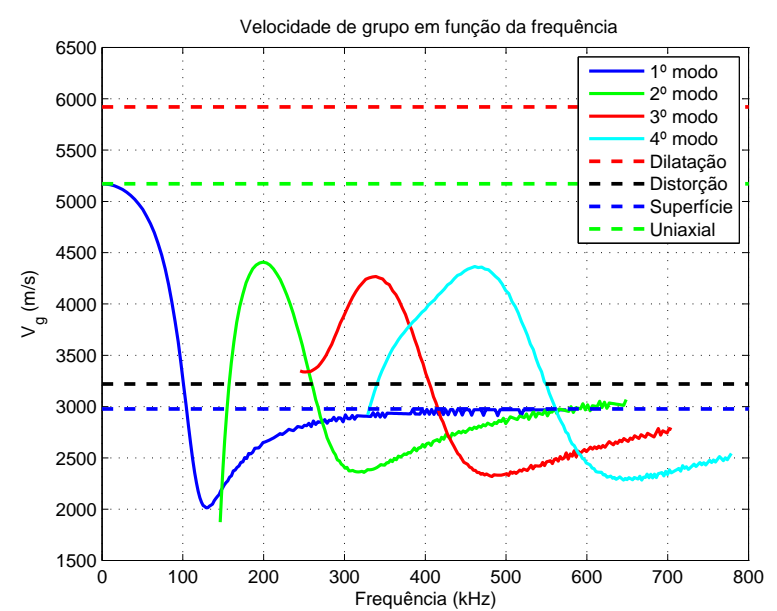

(a)

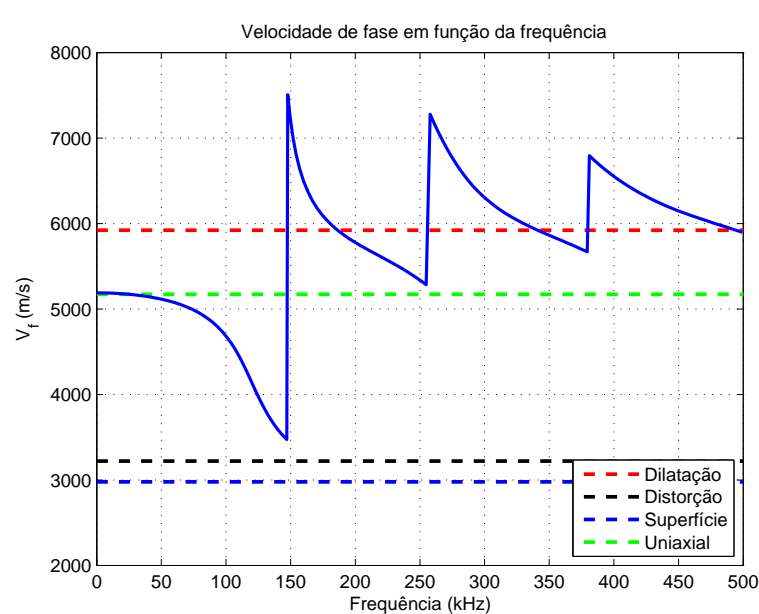

(b)

Figura 5.6: Gráficos da velocidade de grupo em função da frequência (a) e mapa de propagação (b) para uma barra cilíndrica de aço com 24,8 mm de diâmetro.

O gráfico final do mapa de propagação de ondas, fig. 5.6(b), contém a velocidade de fase específica de cada frequência, permitindo o cálculo da propagação de onda no domínio da frequência. Para comprimentos de onda muito maiores que o diâmetro, as frequências são baixas e a velocidade de onda se aproxima da velocidade de onda uniaxial. Já para comprimentos de onda muito menores que o diâmetro, a propagação se dá como em um meio infinito e a velocidade de propagação se aproxima da velocidade de onda longitudinal de dilatação, em uma tendência percebida na fig. 5.6(b).

\subsection{Influência dos componentes de alta frequência}

A partir da solução da equação de Pochammer-Chree, pode-se encontrar várias velocidades de fase para uma mesma frequência e, via velocidade de grupo, determinar as velocidades de fase que representam o modo de vibrar dominante (de maior energia) em uma determinada frequência. Para tanto serão analisados os componentes de alta frequência, localizando-os em uma onda incidente ideal. 


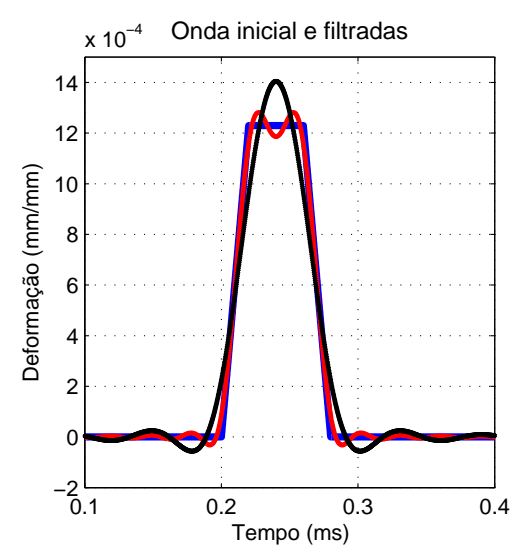

(a)

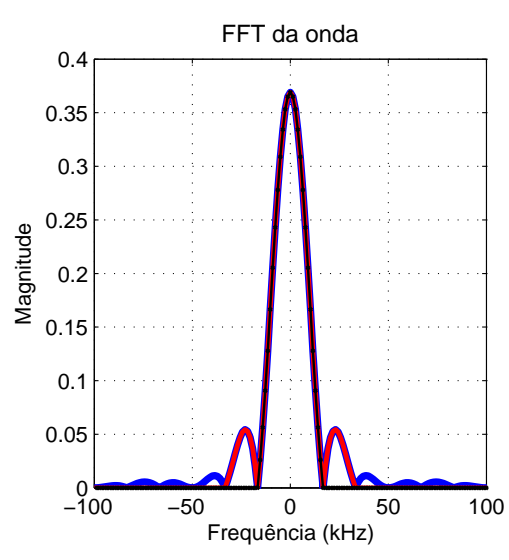

(b)

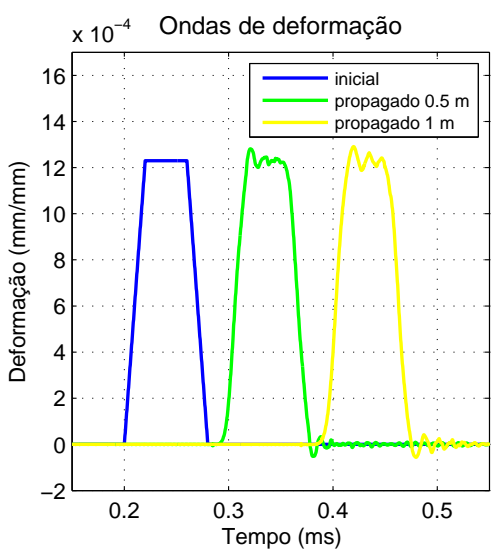

(c)

Figura 5.7: Correlação entre ondas de deformação em (a) e respectivas FFT em (b) e mudança do formato da onda inicial propagada em 0.5 e 1 metros.

Para se entender como a onda mudará seu formato devido a velocidades de fase maiores em mais altas frequências, considere uma onda inicial idealizada como na fig. 5.7(a), em azul e com cantos vivos. A FFT desta onda está representada na fig. 5.7(b), também em azul. Para verificar a influência dos altos componentes de frequência na onda inicial, todas as componentes de frequência, exceto pelos três montes centrais, tiveram seus valores de magnitude e fase igualados a zero, criando a curva FFT vermelha da fig. 5.7(b). Através da operação de FFT inversa, obteve-se a onda vermelha da fig. 5.7(a). O mesmo processo foi realizado para a curva preta, mas desta vez foram zerados os valores de magnitude e fase de todos os componentes de frequência que não fizessem parte do monte central. Da análise da figura 5.7(a), pode-se concluir que os altos componentes de frequência são os responsáveis pelos cantos vivos e pela alta inclinação na subida e descida do sinal.

O pulso ideal descrito na fig. 5.7(a) foi propagado em 0.5 e 1 metros a partir do mapa de propagações da fig.5.6(b). Uma análise visual indicando que os componentes de mais alta frequência em velocidades maiores são responsáveis por maiores tempos de subida e descida do pulso, além de criar ondulações na parte superior do pulso e à direita do mesmo.

Com a intenção de validar o mapa de correções e a técnica de transladar o pulso para qualquer posição da barra a partir da leitura nos extensômetros, foi idealizado e executado um experimento no qual a barra de saída é retirada e em seu lugar é colocado 
um vibrômetro a laser, capaz de medir a velocidade da extremidade da barra, conforme fig. 5.8(a). Uma onda de deformação medida nos extensômetros foi transformada para o domínio da frequência, transladada e multiplicada pelo negativo de sua velocidade de fase, obtendo-se a velocidade da partícula, antes de ser transformada novamente para o domínio do tempo. As velocidades medida e calculada estão na fig. 5.8(b).

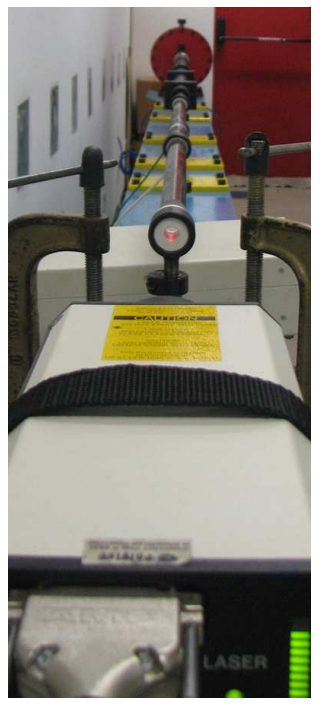

(a)

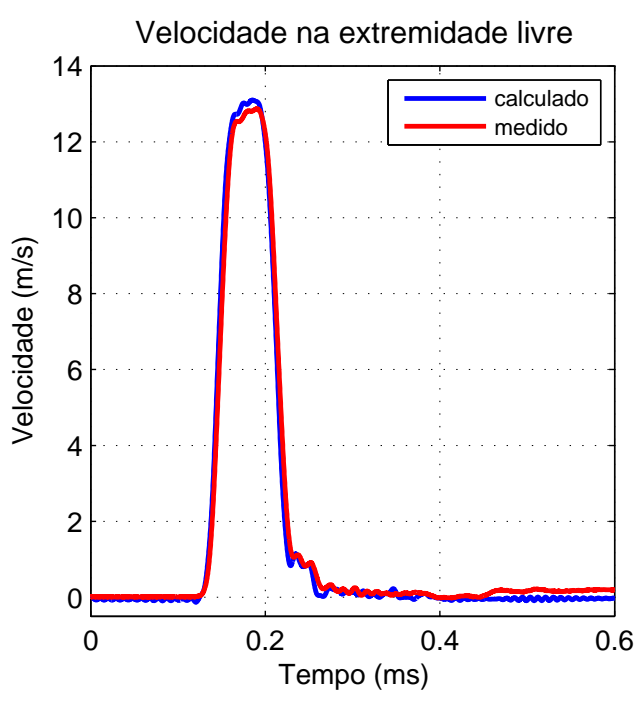

(b)

Figura 5.8: Experimento para verificação da técnica de translação do pulso no domínio da frequência a partir de sua velocidade de fase no mapa de propagação.

\subsection{Propagação de ondas unidimensionais viscoelás- ticas}

Devido à grande diferença de impedância mecânica entre os materiais é desaconselhável utilizar barras de aço quando se quer avaliar as curvas tensão-deformação dinâmicas de materiais macios como elastômeros e termo-plásticos [96]. A impedância mecânica representa a resistência imposta pelo material à propagação de ondas no meio. É a diferença de impedâncias mecânica que determina o quanto de uma onda mecânica incidente, em uma interface entre materiais distintos, é refletida e o quanto é transmitida. Pode ser calculada matematicamente multiplicando-se a densidade pela velocidade de onda longitudinal, sendo aproximadamente $3,8.10^{7} \mathrm{~kg} / \mathrm{m}^{2} \mathrm{~s}$ para o aço, $1,4.10^{7} \mathrm{~kg} / \mathrm{m}^{2} \mathrm{~s}$ para o alumínio e $0,27.10^{7} \mathrm{~kg} / \mathrm{m}^{2} \mathrm{~s}$ para o PMMA. 
Se a impedância do material das barras de entrada e saída é muito maior que a do material testado, temos muita reflexão e pouca transmissão. A acurácia do resultado é em muito diminuída nesta situação, pois o sinal elétrico originado pela onda transmitida nos extensômetros será da mesma ordem de grandeza do ruído causado por sinais eletromagnéticos. Ao amplificar o sinal do extensômetro, será também amplificado o ruído eletromagnético, tornando o dado muito difícil de ser tratado.

Por este motivo, ao se testar polímeros com a Barra de Hopkinson, são utilizadas barras de alumínio ou PMMA. Neste trabalho foi escolhida a barra de PMMA em razão de sua menor impedância mecânica. Desta forma, as impedâncias mecânicas das barras e corpo de prova são compatíveis, ocasionando em amplitudes das ondas incidente e transmitida na mesma ordem de grandeza, muito acima do nível de sinal do ruído eletromagnético.

É sabido que a velocidade de onda em um material depende do módulo elástico do mesmo. Como o PMMA é um material viscoelástico, seu módulo elástico depende da taxa de deformação e consequentemente a velocidade de onda também dependerá da taxa de deformação. Esse tipo de dependência da velocidade de onda é denominada dispersão material.

Entretanto, além de introduzir a dispersão material, a viscoelasticidade do PMMA é responsável pela atenuação da onda, ou seja, pela diminuição da amplitude de cada componente de frequência da onda ao se propagar.

Ademais da dispersão material e atenuação causadas pela viscoelasticidade, ainda há a dispersão geométrica, uma vez que a barra não possui coeficiente de Poisson nulo ou um diâmetro extremamente pequeno.

Como o fenômeno de propagação de ondas em barras de materiais poliméricos é um fenômenos complexo com diversas variáveis interferindo na amplitude e forma do pulso de deformação, foram desenvolvidos novos suportes no intuito de minimizar a influência de fatores externos, como desalinhamento do eixo da mesma ou interferência na expansão radial. A configuração final da Barra de Hopkinson do laboratório do GMSIE com barras de PMMA está ilustrada na fig. 5.9(a). Os novos suportes, fig. 5.9(b), permitem a expansão radial e um melhor alinhamento horizontal, além de estarem presentes em maior número do que na configuração com barras de aço com o objetivo de melhorar o alinhamento vertical, já que a deflexão por peso próprio é maior em barras de PMMA do 
que de aço.

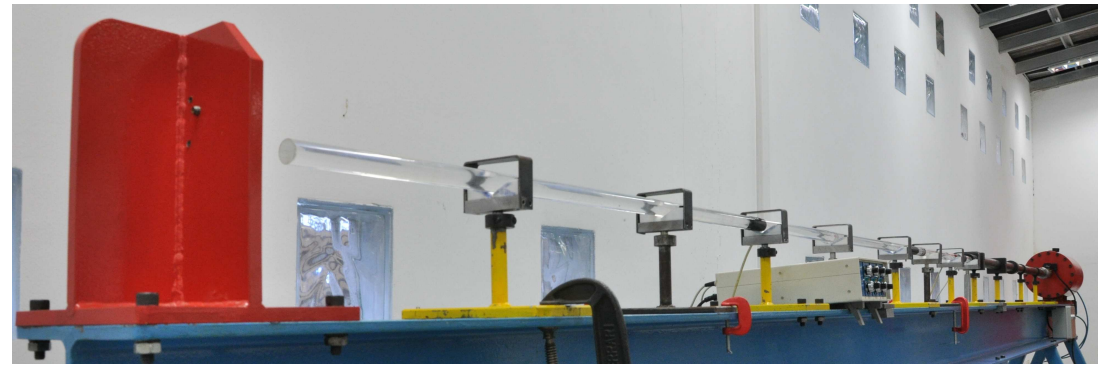

(a)

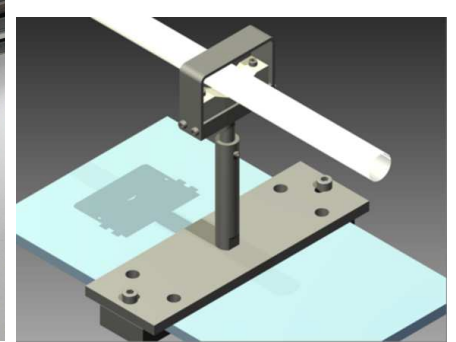

(b)

Figura 5.9: Barra de Hopkinson com barras de PMMA.

De acordo com Bacon [5], utilizar a teoria de propagação de ondas unidimensionais visco-elásticas com uma calibração experimental já é suficiente para se obter a onda de deformação em qualquer posição da barra a partir da onda de deformação medida nos extensômetros. O impacto do striker, também de PMMA, irá gerar uma tensão axial $\sigma(x, t)$ e uma deformação axial $\varepsilon(x, t)$ com o deslocamento $u(x, t)$ relacionados por

$$
\frac{\partial \sigma(x, t)}{\partial x}=\rho \frac{\partial^{2} u(x, t)}{\partial t^{2}} \quad \operatorname{com} \quad \varepsilon(x, t)=\frac{\partial u(x, t)}{\partial x}
$$

e aplicando a transformada de Fourier na equação de movimento unidimensional descrita acima, obtém-se

$$
\frac{\partial^{2} \tilde{\sigma}(x, \omega)}{\partial x^{2}}=-\rho \omega^{2} \tilde{\varepsilon}(x, \omega)
$$

no qual $\tilde{\sigma}(x, \omega)$ e $\tilde{\varepsilon}(x, \omega)$ são as transformadas de Fourier da tensão e deformação, respectivamente, com $\omega$ sendo a frequência angular em radianos por segundo. A lei de Hooke tem sua contraparte no domínio da frequência descrita por

$$
\tilde{\sigma}(x, \omega)=E^{*}(\omega) \tilde{\varepsilon}(x, \omega)
$$

no qual $E^{*}(\omega)$ é conhecido por módulo de Young complexo.

O coeficiente de propagação, é definido por

$$
(\gamma(\omega))^{2}=-\frac{\rho \omega^{2}}{E^{*}}
$$

e da combinação destas três equações, a equação de movimento se torna

$$
\left(\frac{\partial^{2}}{\partial x^{2}}-\gamma^{2}\right) \tilde{\varepsilon}(x, \omega)=0
$$


com solução

$$
\tilde{\varepsilon}(x, \omega)=\tilde{P}(\omega) e^{-\gamma x}+\tilde{N}(\omega) e^{\gamma x}
$$

sendo $\tilde{P}(\omega)$ e $\tilde{N}(\omega)$ as transformadas de Fourier das deformações em $x=0$ devida a propagação de duas ondas, uma no sentido positivo de $x$ e outra no sentido negativo de $x$. A velocidade $\tilde{v}(x, \omega)$ e a força $\tilde{F}(x, \omega)$ em uma determinada seção transversal $x$ podem ser obtidas por

$$
\begin{gathered}
\tilde{v}(x, \omega)=-\frac{i \omega}{\gamma}\left[\tilde{P}(\omega) e^{-\gamma x}-\tilde{N}(\omega) e^{\gamma x}\right] \\
\tilde{F}(x, \omega)=-\frac{\rho A \omega^{2}}{\gamma^{2}}\left[\tilde{P}(\omega) e^{-\gamma x}-\tilde{N}(\omega) e^{\gamma x}\right]
\end{gathered}
$$

com $A$ sendo a área da seção transversal da barra.

O coeficiente de propagação é um numero complexo, com sua parte real sendo o coeficiente de atenuação, $\alpha(\omega)$, e sua parte imaginária sendo chamada de número de onda, $k(\omega)$, fornecendo dados relacionados à dispersão. O coeficiente de propagação é matematicamente definido por

$$
\gamma(\omega)=\alpha(\omega)+i k(\omega)=\alpha(\omega)+i \frac{\omega}{V_{f}(\omega)}
$$

Bacon [5] propôs calibrar os parâmetros $\alpha(\omega)$ e $V_{f}(\omega)$, através do impacto de uma esfera em uma barra de polímero com ambas as extremidades livres. O impacto da esfera irá gerar uma onda de deformação que percorrerá a barra, será refletida na extremidade livre e voltará para a extremidade no qual houve o impacto, sendo refletida. Este ciclo se repetirá inúmeras vezes, sempre com a amplitude diminuindo devido a atenuação. Considerando apenas o primeiro ciclo, $x_{0}$ a distância dos extensômetros a extremidade livre, $\varepsilon_{i}$ a onda de deformação incidente, $\varepsilon_{r}$ a onda de deformação refletida nos valores de $P$ e $N$ respectivamente, como a força é nula na extremidade livre, tem-se

$$
\begin{aligned}
\tilde{F}(x, \omega)=-\frac{\rho A \omega^{2}}{\gamma^{2}}\left[\tilde{P}(\omega) e^{-\gamma x}-\tilde{N}(\omega) e^{\gamma x}\right] & \\
& =-\frac{\rho A \omega^{2}}{\gamma^{2}}\left[\tilde{\varepsilon}_{i}(\omega) e^{-\gamma x_{0}}-\tilde{\varepsilon}_{r}(\omega) e^{-\gamma\left(-x_{0}\right)}\right]=0
\end{aligned}
$$

ou seja,

$$
\tilde{\varepsilon}_{i} e^{-\gamma x_{0}}-\tilde{\varepsilon}_{r} e^{\gamma x_{0}}=0
$$

com $x_{0}$ sendo a distância do extensômetro à extremidade livre e $\tilde{\varepsilon}_{i}$ e $\tilde{\varepsilon}_{r}$ sendo as transformadas de Fourier da onda de deformação incidente e refletida respectivamente. 
O testes foram realizados com uma pequenas esfera de aço de $25.4 \mathrm{~mm}$ de diâmetros em barras de PMMA de mesmo diâmetro. Um total de 20 testes divididos em 5 testes para cada uma das 4 diferentes velocidades de impacto foram realizados. O resultado da velocidade de fase e coeficiente de atenuação em função da frequência estão ilustrados na fig. 5.10, com o desvio padrão representado pela área verde claro.

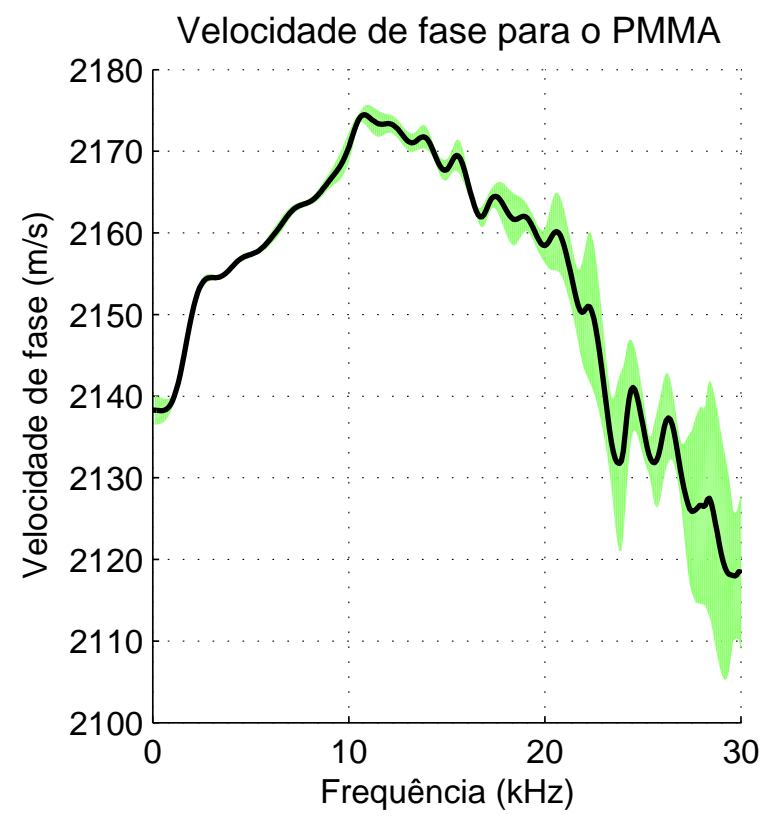

(a)

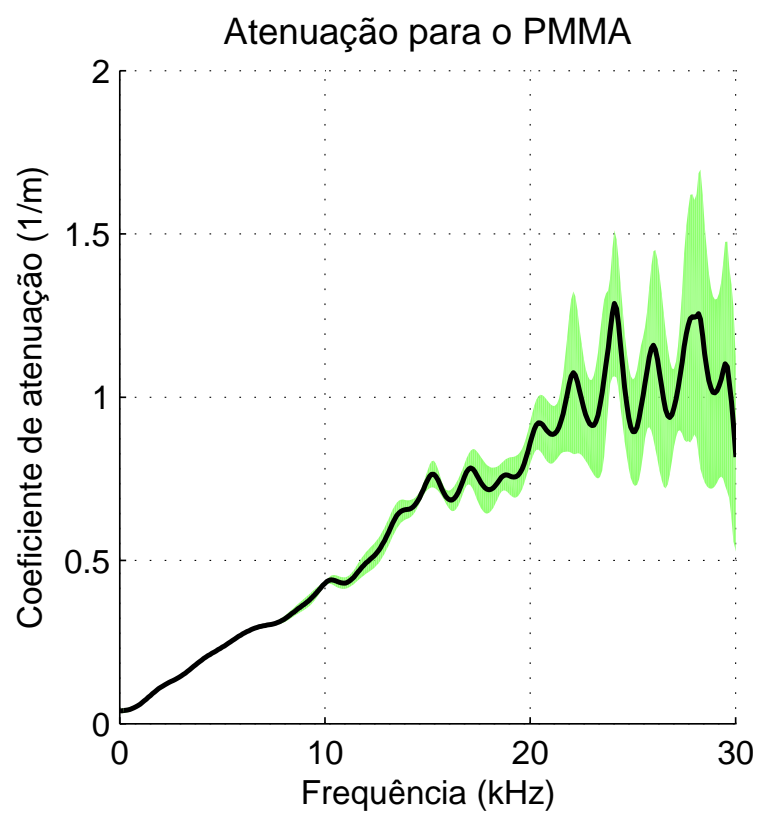

(b)

Figura 5.10: Velocidade de fase e coeficiente de atenuação das barras de PMMA.

\subsection{1 propagação de ondas tridimensionais viscoelásticas}

Os efeitos da dispersão geométrica não podem ser desprezados em barras visco-elásticas. Entretanto, para considerar dispersão geométrica, do material e atenuação, seria necessário resolver a equação de Pochammer-Chree no domínio da frequência, através de um processo de otimização para determinar ao mesmo tempo o valor do módulo de Young complexo e do número de onda [96].

Porém, Zhao [96] afirma que, mesmo sendo utilizada uma formulação visco-elástica unidimensional para a obtenção experimental do número de onda, conforme explicado anteriormente, como a medição é experimental, os efeitos geométricos estão inclusos no coeficiente de propagação. Portanto, o coeficiente de propagação medido é uma excelente aproximação do resultado que seria obtido na solução da equação de Pochammer-Chree 
no domínio da frequência por meio de processos de otimização.

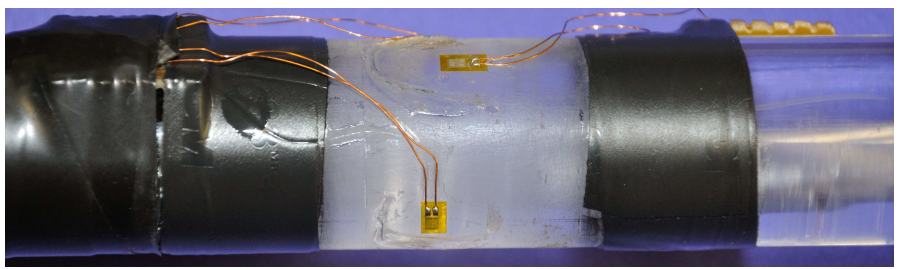

Figura 5.11: Sensoriamento para medição do coeficiente de Poisson na barra de PMMA.

Nesse caso, após a medição experimental do coeficiente de Poisson complexo e do coeficiente de propagação, a única variável da equação de Pochammer-Chree no domínio da frequência seria o módulo elástico complexo. Normalmente o coeficiente de Poisson é assumido constante na frequência, mas o mesmo foi medido experimentalmente, a partir de extensômetros foram colados em uma mesma secção transversal da barra, fig 5.11, tanto longitudinalmente como circunferencialmente, sabendo-se que a simples divisão de ambos resultara no coeficiente de Poisson. A figura 5.12 mostra a variação do coeficiente de Poisson no domínio da frequência para uma barra de PMMA.

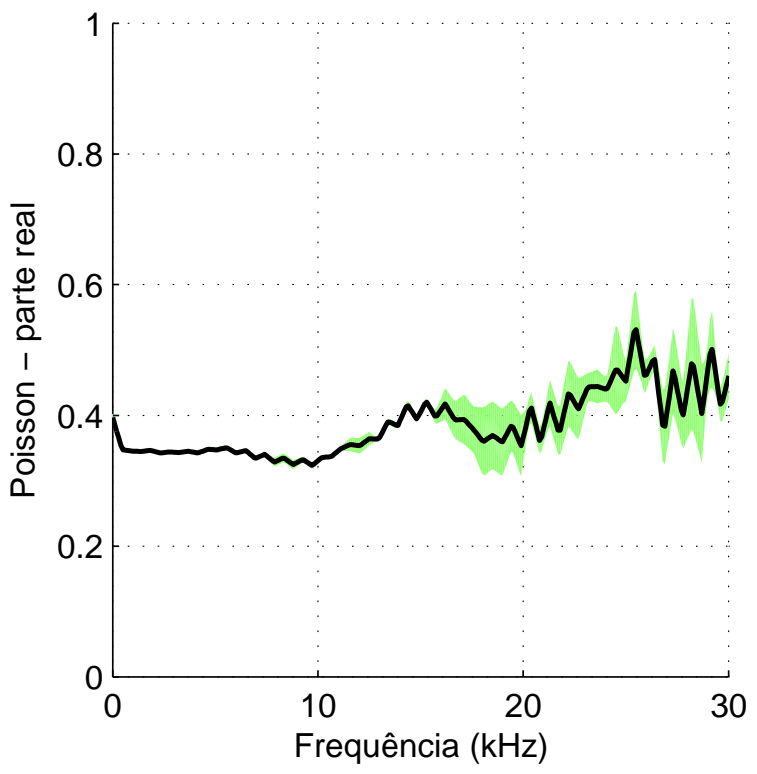

(a)

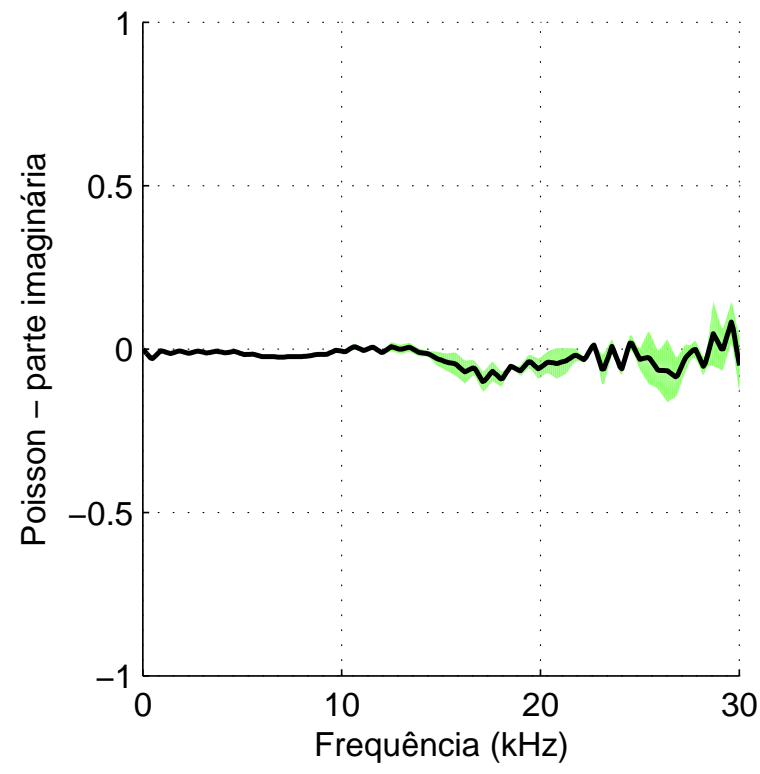

(b)

Figura 5.12: Coeficiente de poisson complexo para o PMMA. 
Então resolvendo a equação de Pochammer-Chree

$$
\frac{2 h^{\prime}}{a}\left(k^{\prime 2}-\gamma^{2}\right) J_{1}\left(h^{\prime} a\right) J_{1}\left(k^{\prime} a\right)-\left(k^{\prime 2}-\gamma^{2}\right)^{2} J_{0}\left(h^{\prime} a\right) J_{1}\left(k^{\prime} a\right)+a \gamma^{2} h^{\prime} k^{\prime} J_{1}\left(h^{\prime} a\right) J_{0}\left(k^{\prime} a\right)=0
$$

com as variáveis definidas anteriormente, pode-se comparar o módulo elástico complexo obtido da formulação de propagação de ondas unidimensionais visco-elástica com a propagação de ondas tridimensionais viscoelástica, na fig. 5.13. Com o módulo elástico tridimensional, em conjunto com os ensaios experimentais de relaxação, é possível calibrar a parte viscoelástica do modelo de material proposto, tanto em baixas quanto em altas taxas de deformação.

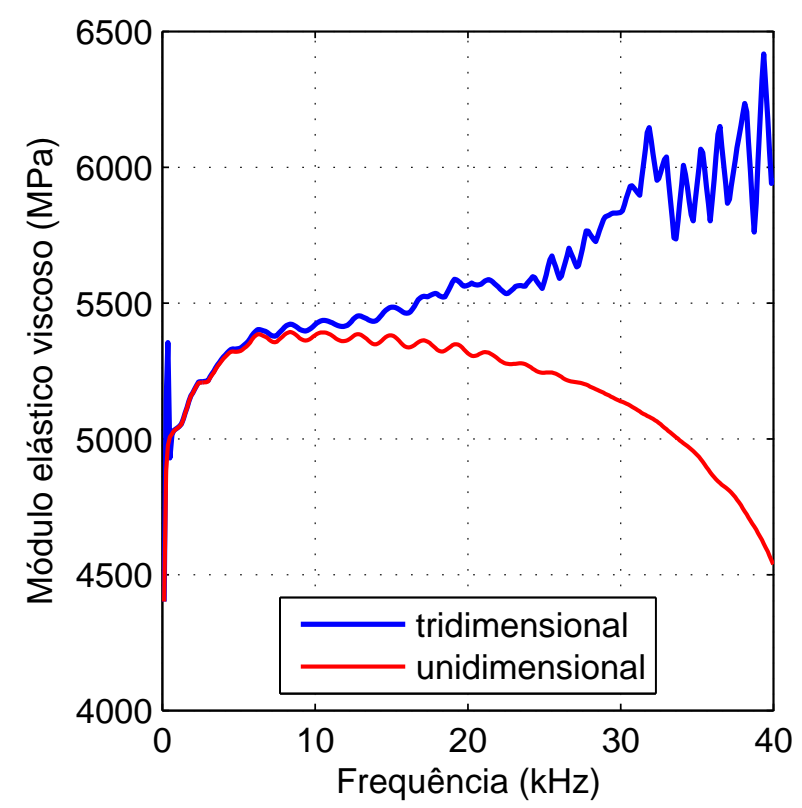

Figura 5.13: Módulos elásticos complexos provindos das teorias uni e tri dimensional para o PMMA.

Este procedimento de obtenção do módulo elástico complexo variando na frequência é importante para se analisar a viscoelasticidade ou mesmo calibrar parâmetros de modelos de material ou mesmo testa-los quanto a acurácia na simulação de uma onda se propagando em um material viscoelástico, especialmente no caso de termoplásticos amorfos, que possuem uma fase inativa a baixas taxas de deformação e ativa em altas taxas de deformação (a temperatura ambiente).

A pequena espessura das chapas de PVC inviabilizou a usinagem de barras para o estudo da propagação de ondas e obtenção do módulo elástico complexo. Desta maneira, 
para se obter uma noção do comportamento mecânico elástico a altas taxas de deformação, foi adquirida uma barra de PVC, de uma empresa nacional, com $2 \mathrm{~m}$ de comprimento e $25 \mathrm{~mm}$ de diâmetro. Apesar de não possuir as mesmas propriedades mecânicas que o PVC analisado em baixas taxas de deformação, o comportamento será pelo menos semelhante o suficiente para se obter uma estimativa e auxiliar na calibração do modelo de material proposto.

Desta forma, as fig. 5.14(a) e 5.14(b) ilustram as velocidades de fase e coeficiente de atenuação medidos. Já a fig. 5.14(c) apresenta o sensoriamento com 4 extensômetros em um diâmetro para medição do coeficiente de Poisson, cujas partes real e imaginária encontram-se nas fig. 5.14(d) e 5.14(e). Os módulos elásticos complexos uni e tridimensionais encontram-se na fig. 5.14(f) .

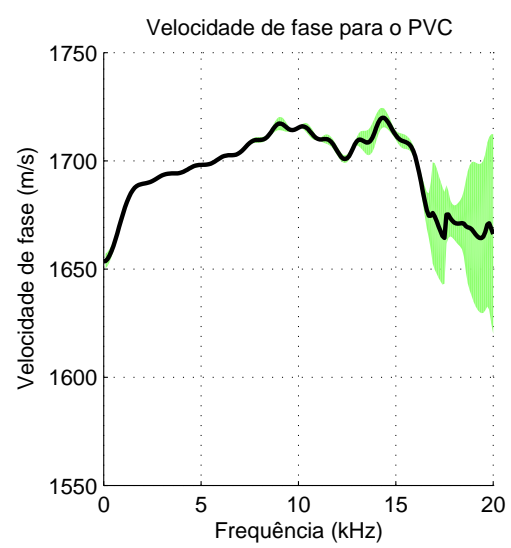

(a)

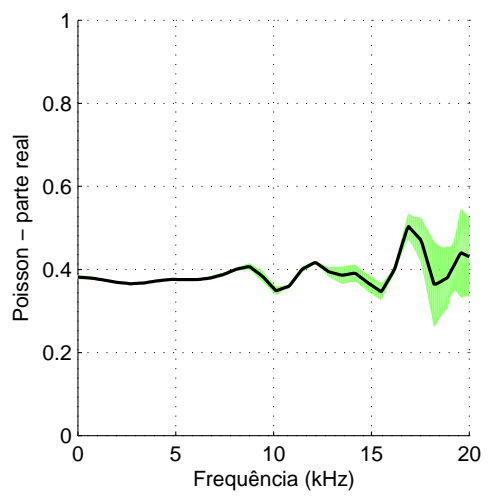

(d)

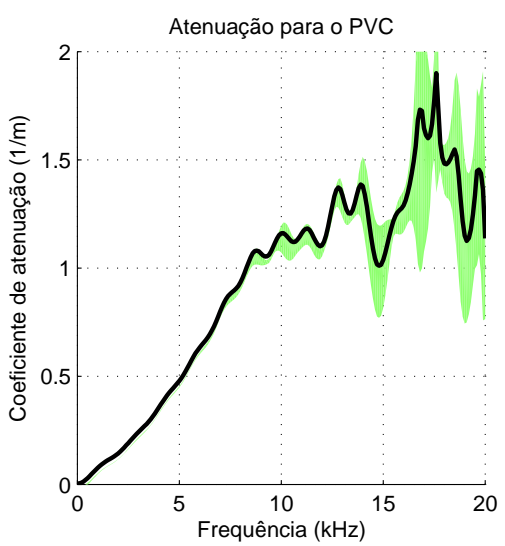

(b)

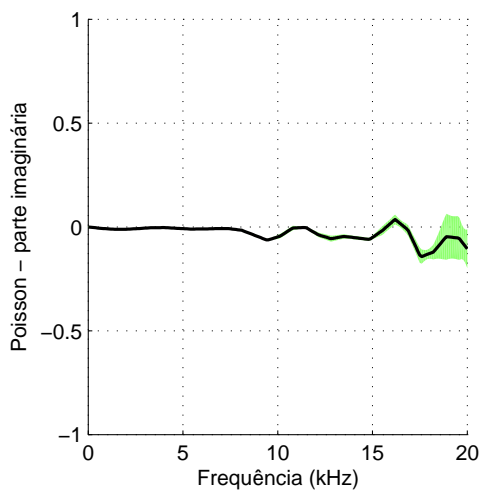

(e)

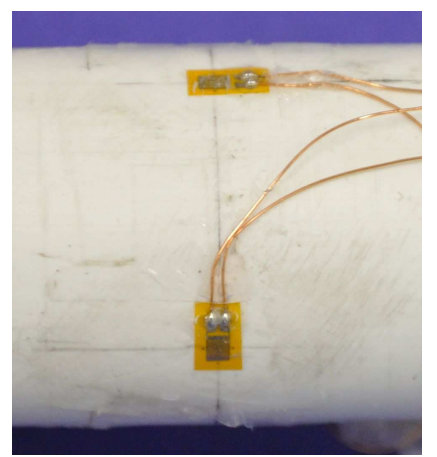

(c)

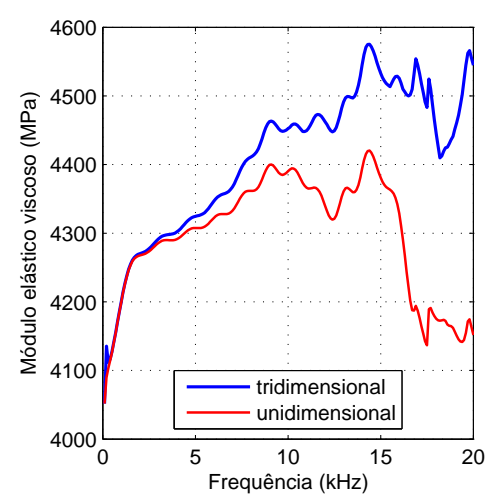

(f)

Figura 5.14: Velocidade de fase e atenuação em função da frequência, coeficiente de poisson complexo, sensoriamento e módulos elásticos uni e tridimensional para o PVC. 


\subsection{Nova calibração e influência nos resultados}

Apesar do método proposto por Bacon [5] proporcionar um mapa de correções que permite predizer a forma e amplitude de um pulso de deformação durante sua propagação, o mesmo possui ao menos duas desvantagens:

- conforme os altos componentes de frequência são atenuados, a onda de deformação se modifica do formato trapezoidal inicial para a forma de um seno. Neste processo, a base do seno é mais larga que a do trapézio, chegando a haver sobreposição das ondas incidente e refletida, reduzindo a acurácia do mapa de correções obtido;

- Conforme visto nas fig. 5.10(a) e 5.14(b), o coeficiente de atenuação é crescente com a frequência, ou seja, quanto maior a frequência do componente, mais rápido este será atenuado. Desta forma, as amplitudes dos componentes de frequência mais altos gerados no impacto da esfera foram atenuados consideravelmente entre o impacto e a estação de medição próxima do meio da barra polimérica. Esse efeito pode ser notado pelo aumento do desvio (em verde) nas figuras citadas com o aumento da frequência.

Foi proposto então um novo método para a obtenção do mapa de correções, ilustrado na fig. 5.15. A $50 \mathrm{~mm}$ da extremidade no qual é impactada a esfera, são fixados dois pares de extensômetros na mesma circunferência, medindo a deformação axial e circunferencial, conforme figs. 5.11 e 5.14(c). Outro para de extensômetros é fixado próximo ao meio da barra. Um dispositivo para a parada da barra separa a extremidade livre de um vibrômetro a laser, capaz de medir a velocidade desta extremidade. Os sinais dos três pares de extensômetros e do laser são por um amplificador dinâmico com boa largura de banda $(1 \mathrm{MHz})$, sendo a frequência de corte do laser configurada para $100 \mathrm{kHz}$ e os extensômetros com $3 \mathrm{~mm}$ de comprimento possuindo frequência de corte acima de 100 $\mathrm{kHz}$. 


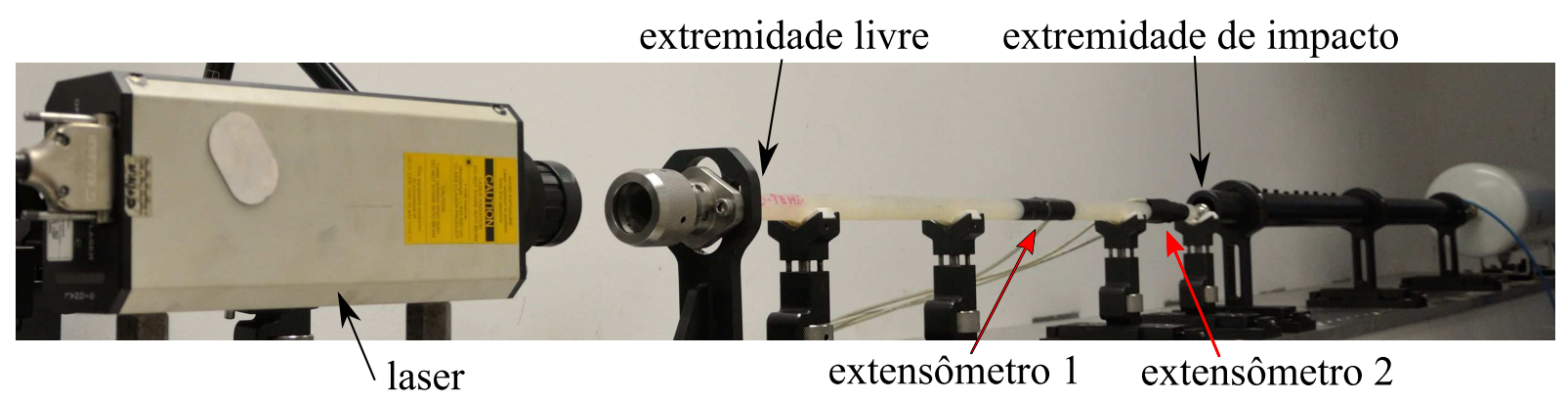

Figura 5.15: Configuração experimental da nova metodologia proposta para obtenção do mapa de correções.

Foram realizados testes impactando-se a esfera, um striker de $105 \mathrm{~mm}$ e outro com $300 \mathrm{~mm}$ de comprimento, variando-se 5 vezes a velocidade, com 3 testes por velocidade. Destes, foram obtidos dois mapas de correção: $i$ ) um considerando-se apenas as medições de deformação nos pares de extensômetros fixados no início e meio da barra e ii) um considerando-se apenas a medida de deformação no par de extensômetros fixado próximo à extremidade impactada e a medição de velocidade na extremidade livre.

O primeiro mapa de correções permite analisar a atenuação dos altos componentes de frequência, pois a medição é feita próxima o suficiente da extremidade impactada para que se atenuem pouco, além de que a comparação com o pulso antes da reflexão impede o problema de sobreposição do sinal incidente com o refletido. Porem, o segundo mapa de correções proporciona um mapa de correções mais acurado, já que além de envolver uma maior distância de propagação, a velocidade é calculada no domínio da frequência por $\tilde{v}(\omega)=-c(\omega) \tilde{\varepsilon}(\omega)$, com $\tilde{\varepsilon}(\omega)$ já propagado para a extremidade livre, envolvendo duas vezes a velocidade de fase, uma na propagação e outra na multiplicação. Os resultados obtidos por ambos os métodos, o mapa de correções final obtido estatisticamente a partir dos dois e o mapa de correções obtido com o método de Bacon [5] encontram-se na fig. 5.16 . 


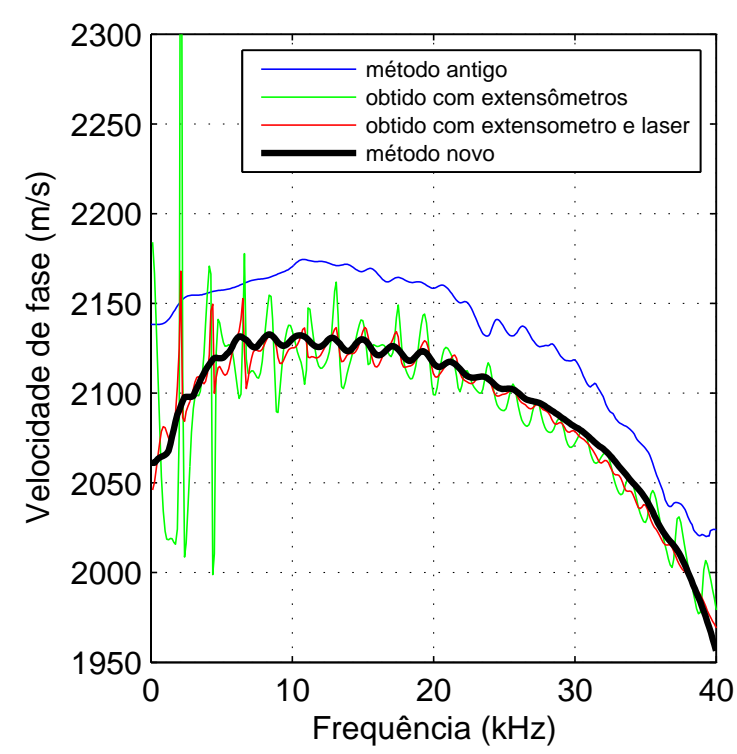

(a)

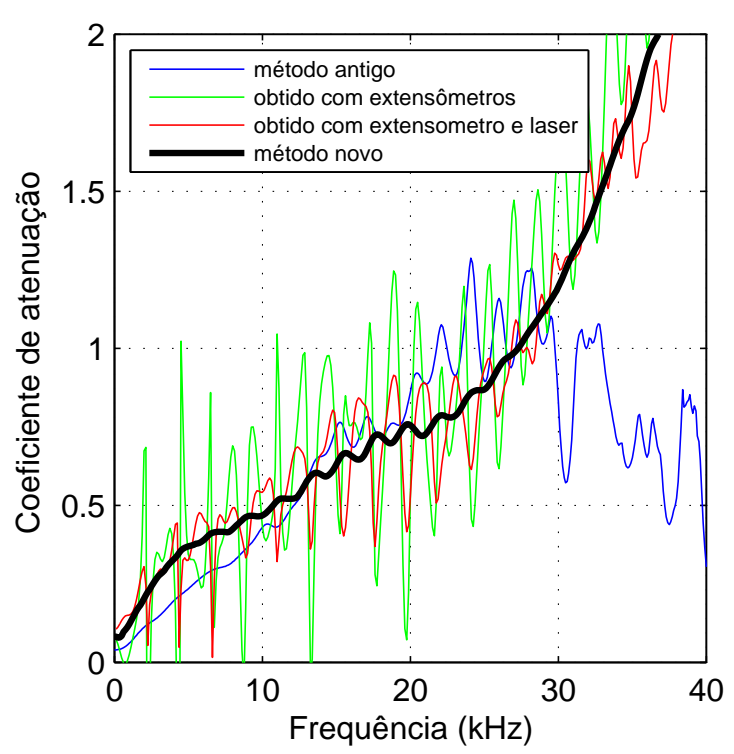

(b)

Figura 5.16: Velocidade de fase e coeficiente de atenuação obtidos com os métodos antigo e novo.

O gráfico da fig. 5.17 permite uma análise da influência da correção da dispersão e da atenuação durante a propagação de uma onda de deformação em uma barra cilíndrica de material visco-elástico. A mesma foi feita a partir de um dos testes de calibração utilizando o maior striker. A curva preta corresponde ao pulso de deformação transladado para a extremidade de impacto utilizando o novo mapa de correções e multiplicado pelo velocidade de fase. A curva vermelha representa a medição da velocidade na extremidade livre realizada com o laser, sendo a referência. As fig. 5.17(a) e 5.17(b) mostram o quão mais preciso é o mapa de correções obtido com esta nova metodologia. Já as fig. 5.17(c) e 5.17(d) permitem averiguar a influência que a correção da dispersão e da atenuação tem sobre a velocidade da extremidade livre. A curva azul escuro foi obtida sem nenhuma correção e corresponde ao dobro da velocidade da extremidade impactada. A curva azul claro foi obtida corrigindo-se a dispersão apenas. Pode-se observar a as diferentes velocidades entre os componentes de alta e baixa frequência tem por consequência a introdução de oscilações de período aproximadamente 15 vezes menor que o do pulso de deformações. Ao se considerar apenas a atenuação do pulso de deformações durante sua propagação, foi obtida a curva verde. Os cantos vivos, originados de altos componentes de frequência, possuem um coeficiente de atenuação maior e o pulso se aproxima do formato 
senoidal.

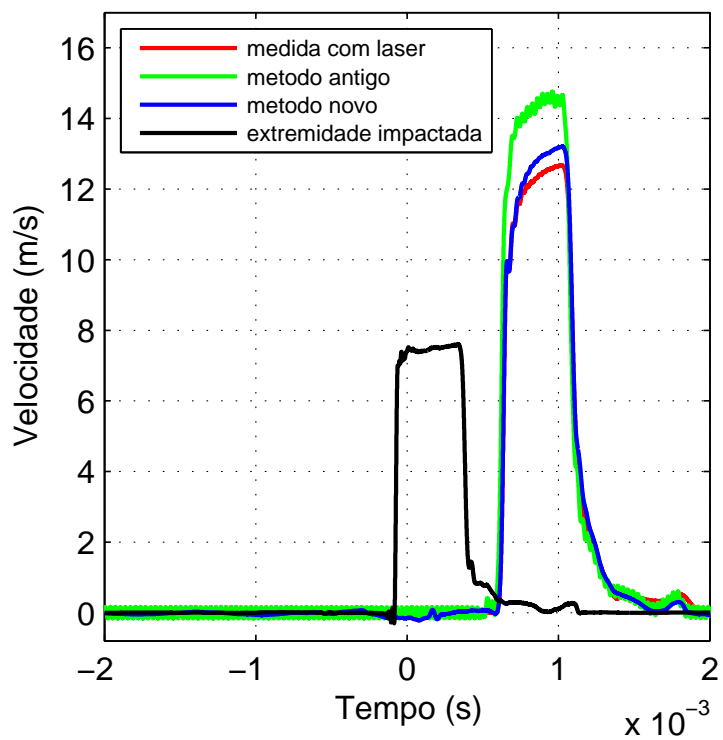

(a)

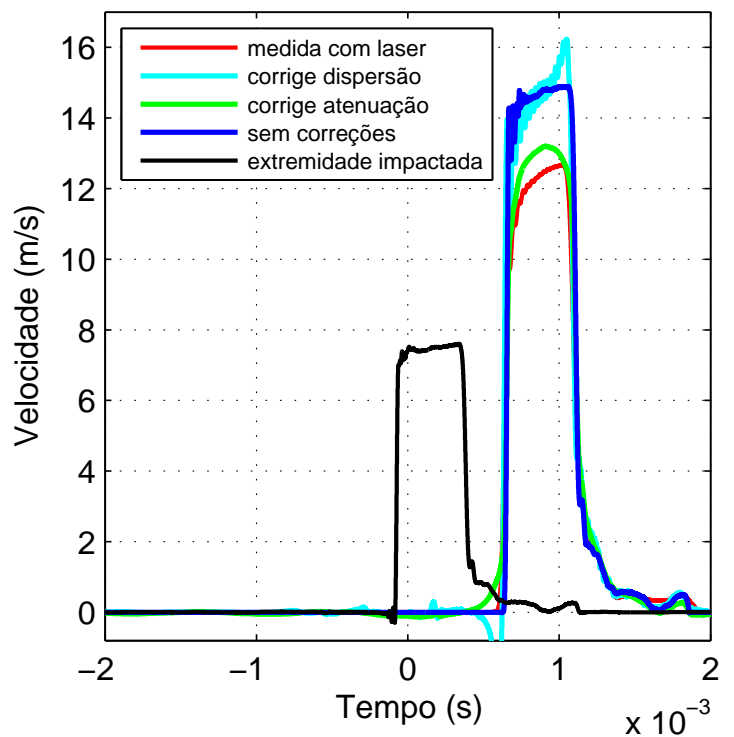

(c)

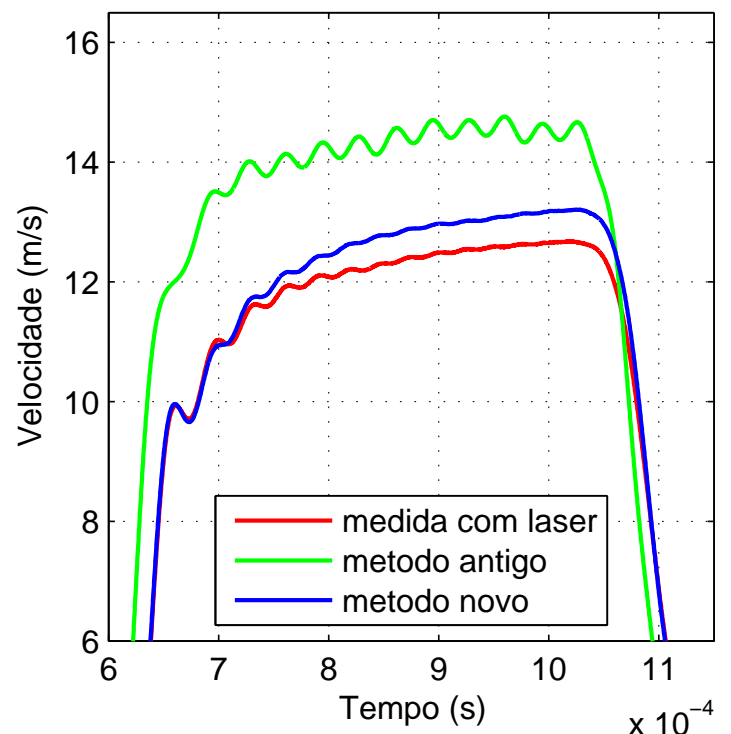

(b)

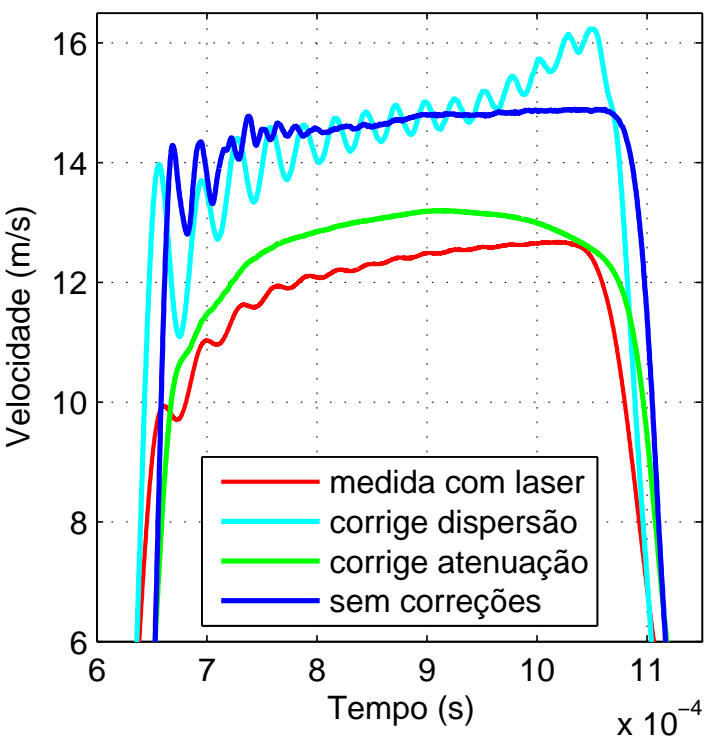

(d)

Figura 5.17: Velocidade medida na extremidade livre e velocidade obtida da propagação teórica com mapa de correções antigo e novo, além da influência de cada tipo de correção, para uma barra de PMMA.

Pode-se observar que apesar de haverem dois tipos de dispersão envolvidas (geométrica e material), considerar os efeitos de atenuação durante a propagação aproxima mais o pulso transladado do medido do que apenas considerar os efeitos de dispersão. Essa 
maior aproximação do pulso real obtida com a consideração da atenuação se torna ainda mais evidente ao se analisar a fig. 5.18, obtida da integral numérica das velocidades utilizando-se o método de Simpson.

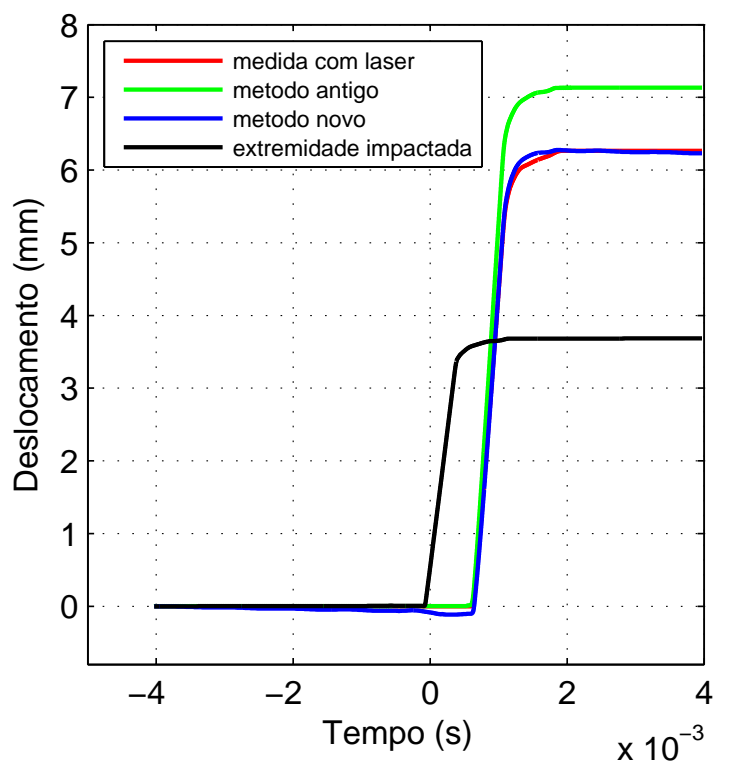

(a)

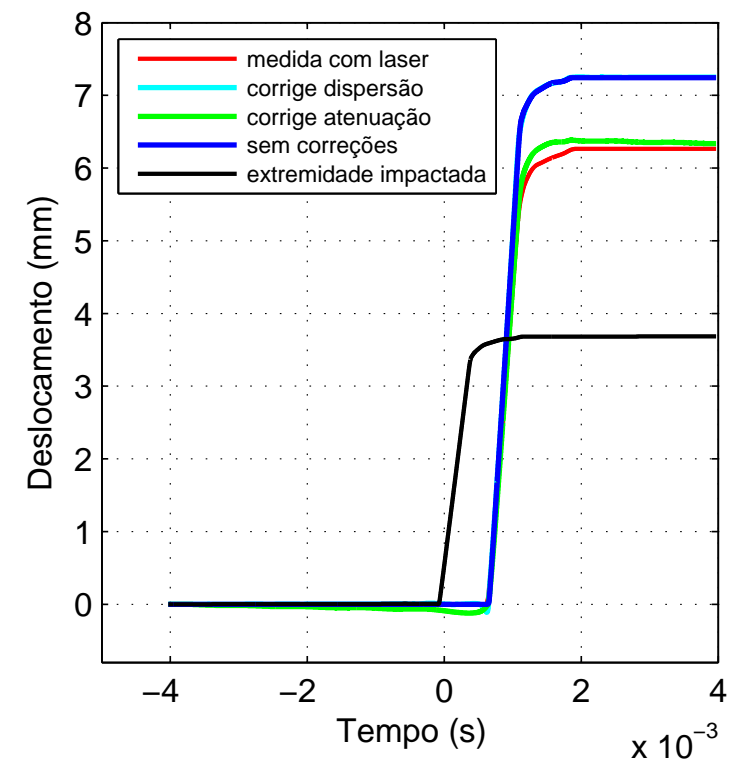

(b)

Figura 5.18: Deslocamento medido na extremidade livre e obtido da propagação teórica com mapa de correções antigo e novo, além da influência de cada tipo de correção, para uma barra de PMMA.

Dado que qualquer medida de deformação é essencialmente obtida a partir do comprimento inicial e da variação do mesmo, fica claro a necessidade da correção utilizando-se o novo mapa de correções, especialmente ao se atentar que o corpo de prova normalmente utilizado na SHPB tem espessura de poucos milímetros.

\subsection{Resultados experimentais}

As ondas de deformação incidente, refletida e transmitida estão representados na fig. 5.19(a), com os dois primeiro medidos pelos extensômetros posicionados próximos ao meio da barra de entrada e a transmitida medida na barra de saída. Como o tamanho de ambas as barras de entrada e saída é aproximadamente o mesmo, assim como a distância entre os extensômetros e o corpo de prova, as ondas refletida e transmitida são obtidas aproximadamente no mesmo intervalo de tempo. As ondas de deformação são então propagadas para o corpo de prova, com a distância positiva no caso da onda incidente 
e negativa no caso das ondas refletida e transmitida, considerando-se tanto a dispersão quanto a atenuação, conforme explicado na seção anterior.

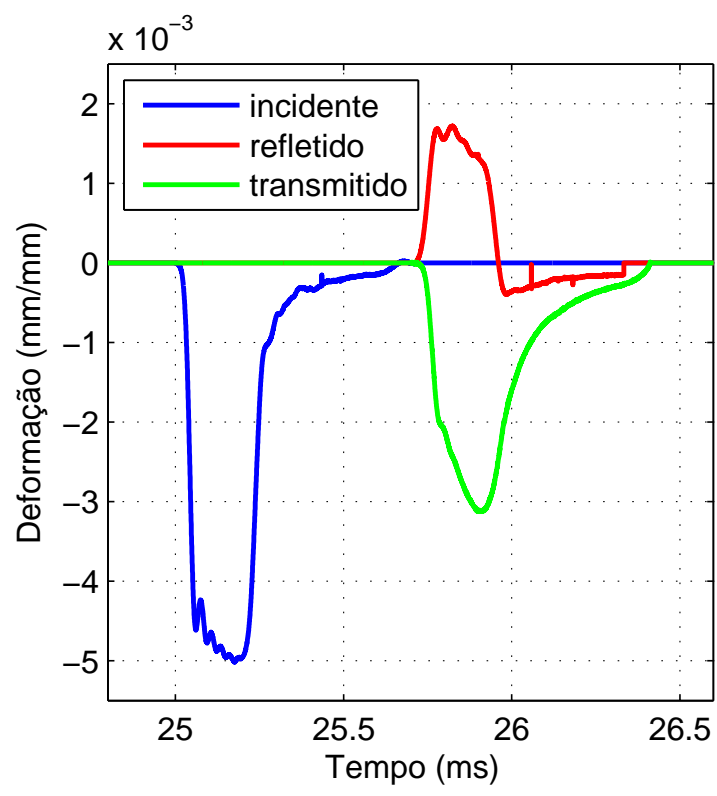

(a)

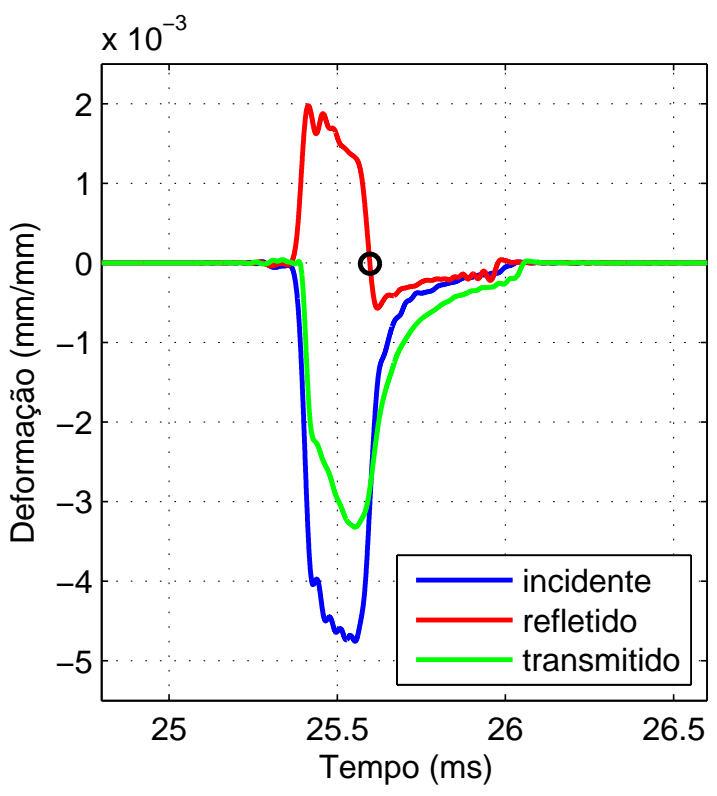

(b)

Figura 5.19: Ondas de deformação incidente, refletida e transmitida medidos nos extensômetros em (a) e transladados para as interfaces com o corpo de prova em (b).

O círculo preto indica o instante que limita a parte válida da curva tensão deformação obtida no teste e é o momento em que a onda de deformação refletida se torna de compressão. Neste instante, a energia da onda não é suficiente para aumentar ou manter a deformação no corpo de prova, que começa a se descarregar, exercendo uma força na barra e fazendo com que a onda refletida passe de tração para compressão. Essa hipótese pode ser corroborada analisando-se o gráfico das velocidades das interfaces 1 e 2 na fig. 5.20(a), no qual nesse instante a velocidade da interface 2 se torna maior que a da interface 1, ou seja, o corpo de prova atingiu seu comprimento mínimo e expandindo. Além disso, é possível encontrar a tensão na barra utilizando as ondas de deformação nas interfaces e o módulo elástico tridimensional. Com estas tensões e as áreas da barra, calcula-se a força em ambas as interfaces 1 e 2, conforme fig. 5.20(b).

Da integral numérica das velocidades no tempo, pode-se encontrar a variação de tamanho do corpo de prova, conforme fig. 5.21(a). Com este dados e utilizando a conservação de volume, $V=A L=A_{0} L_{0}=V_{0}$, pode-se calcular a área atual $A$ do corpo de prova e traçar a curva tensão verdadeira pela deformação verdadeira, conforme 


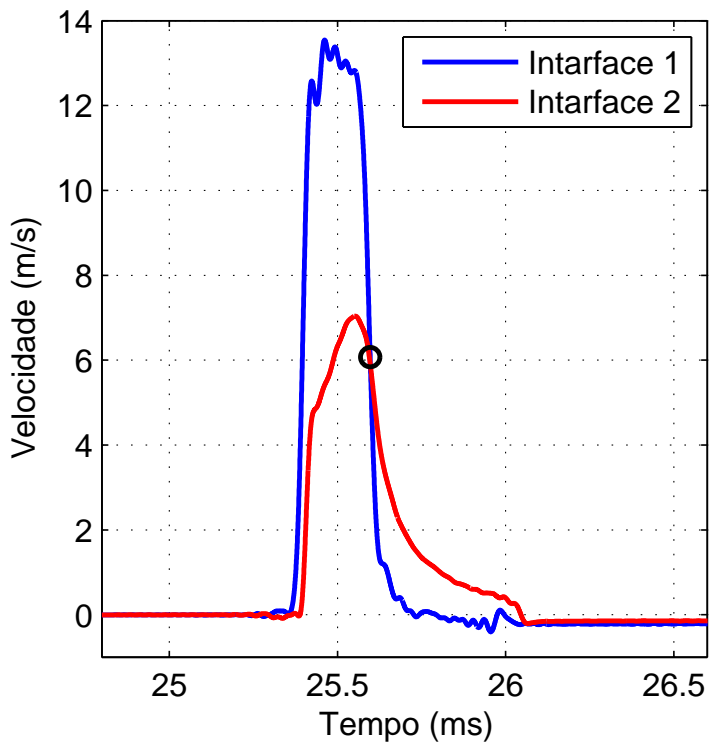

(a)

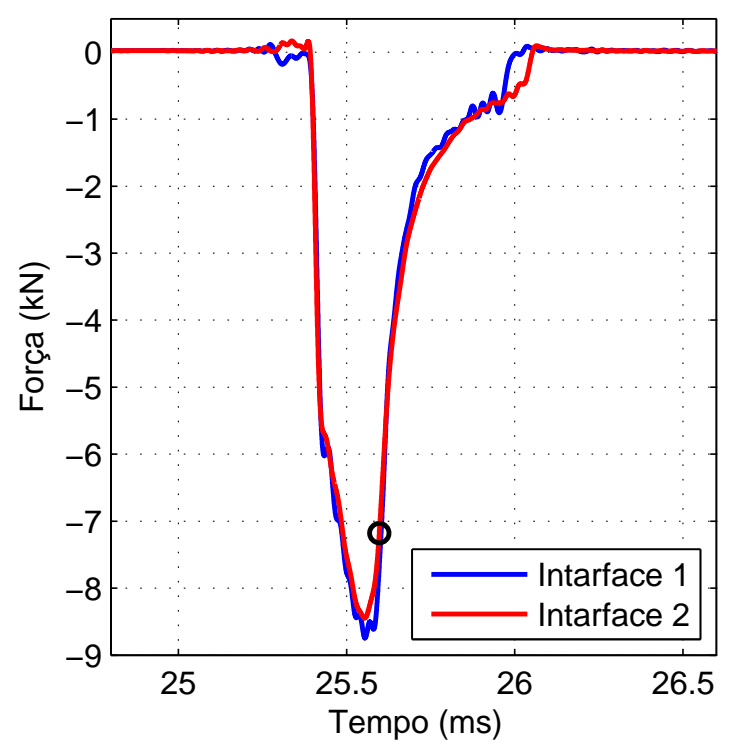

(b)

Figura 5.20: Velocidades (a) e forças (b) nas interfaces com o corpo de prova.

o gráfico da fig. 5.21(b).

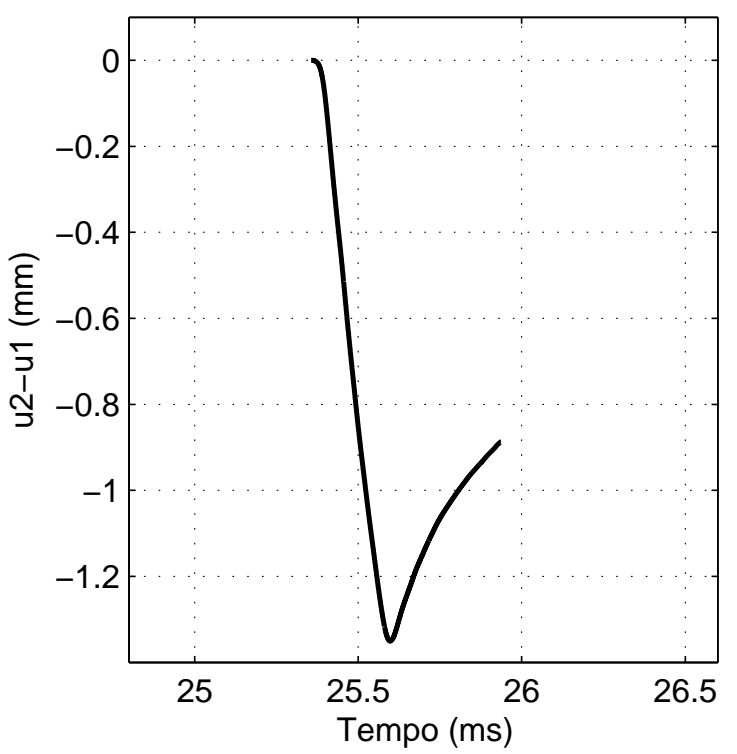

(a)

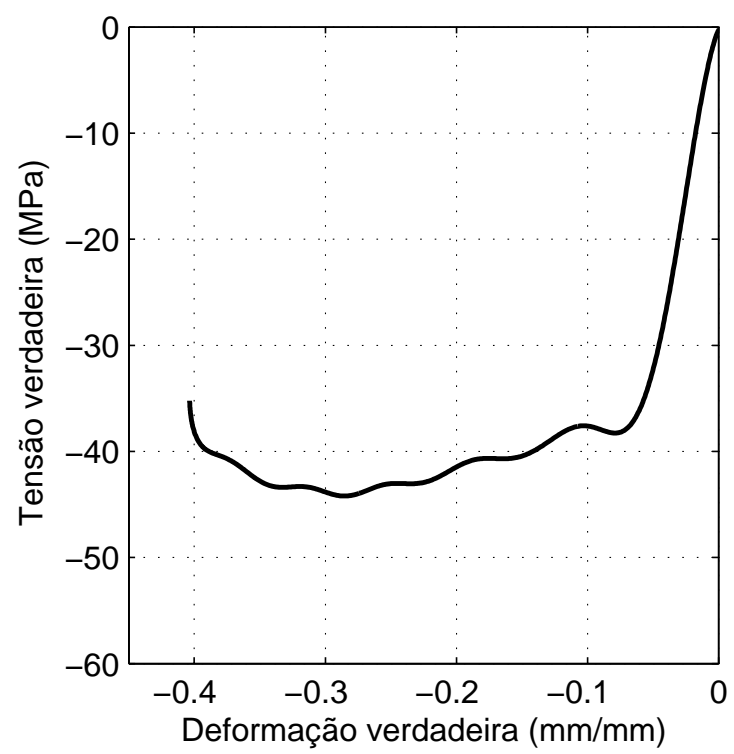

(b)

Figura 5.21: Variação de tamanho imposta pelo equipamento ao corpo de prova em (a) e curva tensão verdadeira deformação verdadeira do corpo de prova.

A figura 5.22 expõe o resultado médio dos testes dinâmicos de compressão utilizando a SHPB e barras de entrada e saída de PMMA. A área sombreada representa o desvio pa- 
drão. Para melhor compreensão, o gráfico apresenta os resultados no primeiro quadrante.

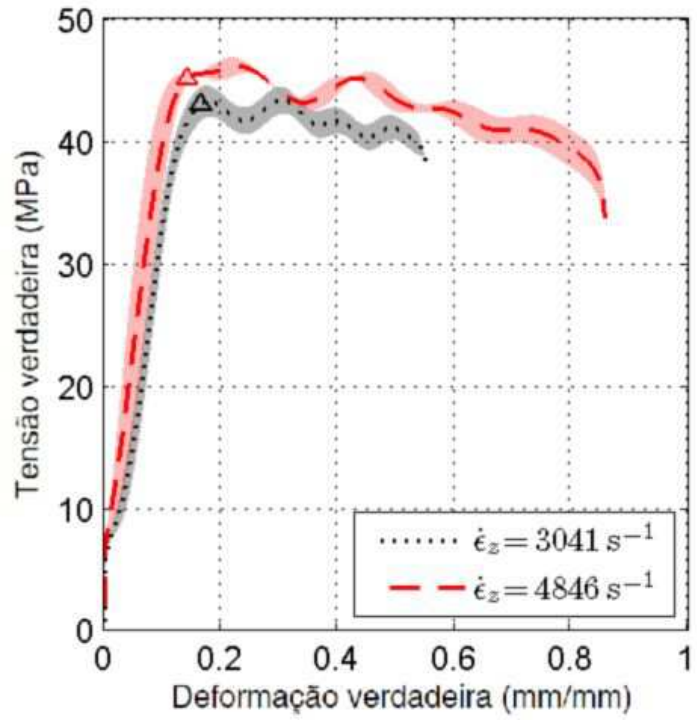

(a) PEAD

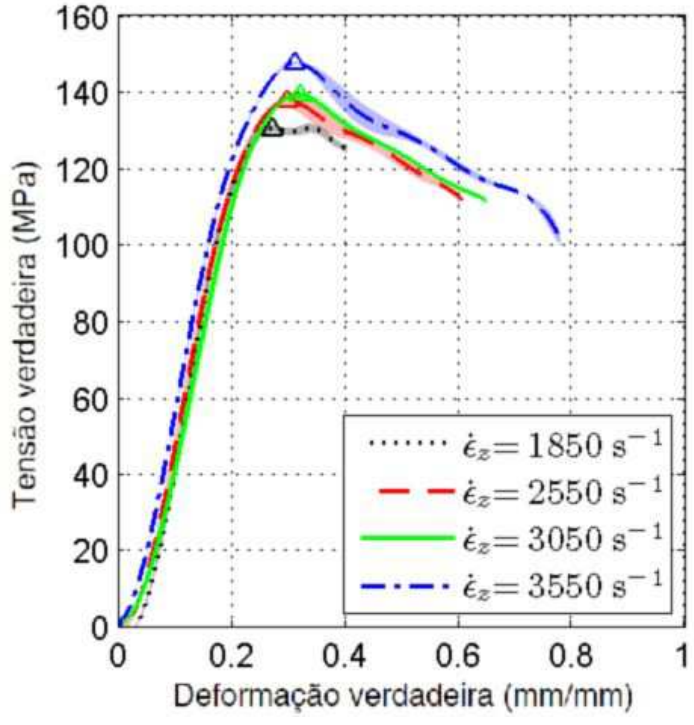

(b) PVC

Figura 5.22: Resultados para os testes dinâmicos de PEAD e PVC. 


\section{Capítulo 6}

\section{Modelo constitutivo proposto}

\subsection{Introdução}

Em seu trabalho, Du Bois [14] afirmou que não há um modelo de material polimérico capaz de reproduzir as características mecânicas de um termoplástico, especialmente sob carregamentos em altas taxas de deformação, implementado nos softwares comerciais atuais de elementos finitos. Entretanto, a pesquisa sobre este tipo de material tem crescido nas ultimas 3 décadas, fato comprovado pela existência de grupos de pesquisa focados na modelagem numérica desse tipo de material, como o grupo de MIT, iniciado por Argon [2, 1], seguido por Parks [17], Boyce [18, 20], Arruda [3], Mulliken [75], assim como o grupo holandês na Universidade de Eindhoven com Tervoort [88], Govaert e Meijer [91] e Klompen [49] e mais recentemente na Universidade de Trondheim, Noruega, com Hopperstad, Langseth e Clausen [69].

Apesar desta vasta disposição de estudos sobre o comportamento mecânico dos termoplásticos, esta tese terá como base o trabalho de Mulliken, [74, 75], na qual foi proposto e avaliado um modelo de material para polímeros termoplásticos amorfos capaz de reproduzir o comportamento do material em ensaios quasi-estáticos e dinâmicos. Mulliken verificou as propriedades mecânicas à altas taxas de deformação utilizando uma SHPB com barras de entrada e saída de alumínio.

Apesar dos excelentes resultados, em especial devido a parte termo-viscoplástica de seu modelo, Mulliken implementou, como parte visco-elástica, uma relação constitutiva Neohookeana cujos parâmetros do material dependem da temperatura, taxa de deformação e pressão hidrostática. Esta é capaz de prever com certa acurácia o comportamento visco-elástico de um material, apesar de não ser capaz de captar efeitos em baixíssimas 
taxas de deformação uma vez não há variáveis históricas para dizer o estado atual do material.

No modelo implementado por Mulliken e reproduzido em partes neste trabalho, não há superfície de escoamento, ou seja, sempre que o material sofrer uma deformação, parte dela será elástica e parte será plástica. Desta forma, é imprescindível maximizar a capacidade de reproduzir com exatidão a parte visco-elástica. Além disso, conforme observado anteriormente, para que um modelo seja capaz de reproduzir o fenômeno de propagação de ondas em materiais visco-elásticos, o mesmo estar apto a reproduzir implicitamente a atenuação e dispersão material. A mesma fase responsável pelos fenômenos de relaxação e fluência, a fase $\alpha$, terá grande influência na propagação de ondas, somada a outra fase ativa somente em altas taxas de deformação, a fase $\beta$.

Neste contexto, o modelo proposto tem por base o modelo de Mulliken, substituindo-se os elementos de mola com parâmetros dependentes da taxa de deformação pela estrutura cinemática visco-elástica de Bergstrom [13]. Esta consiste de uma parte de equilíbrio, insensível à taxa de deformação, em paralelo com outra responsável pelo desvio do equilíbrio, sensível à taxa de deformação. Mesmo esta estrutura cinemática sendo inicialmente proposta e validada para elastômeros, Bergstrom e Hilbert [11] propuseram uma mudança na formulação da lei de escoamento viscoso, validando este modelo ao reproduzir ensaios de relaxação, carregamento e descarregamento elástico e curvas tensão deformação a diferentes baixas taxas de deformação para o termoplástico PTFE.

De acordo com Jordan et. al. [44], o semicristalino PEAD apresenta uma relação linear entre a tensão e a taxa de deformação. Uma possível explicação para esse fenômeno é a restrição dos movimentos moleculares ligados a fase $\beta$ imposta pelas regiões cristalinas dispersas na fase $\alpha$. Durante ensaios de DTMA em PVC com e sem aditivos, Mulliken [75] observou uma redução da contribuição mecânica da fase $\beta$ no material com aditivos, o suficiente para poder ser desprezada. Desta forma, será proposto um modelo específico para o semicristalino PEAD no qual não há fase $\beta$, mas sim uma contribuição viscoelástica da região semicristalina. Para tal, será utilizada a formulação apresentada por Bergstrom e Birschhoff, [45], no qual o módulo de cisalhamento é uma variável interna que evolui com taxa proporcional à variação temporal da deformação plástica da fase $\alpha$. Isso porque os domínios cristalinos se subdividem com a deformação plástica do material, diminuindo sua influência na resistência mecânica do material conforme este se plastifica. 
Em suma, serão propostos dois modelos, cada um contendo 3 partes em paralelo. O modelo de material para termoplástico amorfo consiste em:

- uma parte com a estrutura cinemática termo-viscoelastoviscoplástica proposta por Mulliken [75], com sua relação hiperelástica substituída pela estrutura cinemática proposta por Bergstrom [13] e a formulação de escoamento viscoso de Bergstrom e Birschhoff [45]. Esta parte representará a fase $\alpha$ e terá seus parâmetros calibrados a partir dos ensaios de relaxação e tensão deformação, tanto em tração quanto em compressão;

- uma parte com a estrutura cinemática termo-viscoelastoviscoplástica proposta por Mulliken [75], com sua relação hiperelástica substituída pela estrutura cinemática proposta por Bergstrom [13] e a formulação de escoamento viscoso de Bergstrom e Birschhoff [45]. Esta parte representará a fase $\beta$, ativa somente em altas taxas de deformação, e terá seus parâmetros calibrados a partir dos ensaios de propagação de ondas elásticas;

- uma parte representando a elasticidade das cadeias, na forma da relação hiperelástica de oito cadeias com dependência de primeira ordem de $I_{2}$, proposto em [45]. Esta parte terá seus parâmetros calibrados a partir das curvas tensão deformação na região de altas deformações, no qual esta parte é predominante e responsável por grande parte da resistência mecânica do material.

Enquanto o modelo de material para termoplástico semicristalino consiste em:

- uma parte com a estrutura cinemática termo-viscoelastoviscoplástica proposta por Mulliken [75], com sua relação hiperelástica substituída pela estrutura cinemática proposta por Bergstrom [13] e a formulação de escoamento viscoso de Bergstrom e Birschhoff [45]. Esta parte representará a fase $\alpha$;

- uma parte com a estrutura cinemática viscoelástica proposta Bergstrom e Birschhoff, [45], na qual o módulo de cisalhamento é uma variável interna e evolui concomitantemente com a deformação plástica da fase $\alpha$. As partes termoviscoelastoviscoplástica e esta terão os parâmetros da parte visco-elástica calibrados em conjunto, partindo do valor inicial proposto por Bergstrom e Birschhoff para o polietileno de alto peso molecular; 
- uma parte representando a elasticidade das cadeias, na forma da relação hiperelástica de oito cadeias com dependência de primeira ordem de $I_{2}$, proposto em [45]. Esta parte terá seus parâmetros calibrados a partir das curvas tensão deformação na região de altas deformações, no qual esta parte é predominante e responsável por grande parte da resistência mecânica do material.

Por esta razão, a seguir serão descritos a origem, hipóteses, estrutura cinemática, relações hiperelásticas, leis de escoamento plástico, viscoso e de evolução dos quatro modelos de material utilizados como base.

\subsection{Viscoelasticidade}

\subsubsection{Bergstrom-Boyce}

O modelo de Bergstrom-Boyce foi proposto inicialmente para modelar o comportamento mecânico de elastômeros e sua dependência da taxa de deformação. O mecanismo proposto por Bergstrom [13] pode ser explicado, de maneira simplificada, considerando-se um elastômero com poucas ligações cruzadas e longas cadeias entre as mesmas, conforme a fig. 6.1(a). Nesta, está ilustrada a seção transversal de uma cadeia e os pontos são intersecções com outras cadeias. Ainda segundo a fig. 6.1(a) pode-se notar que devido a interações com as outras cadeias, cada uma se encontra confinada dentro de uma região tubular.

Ao se aplicar um carregamento a altas taxas de deformação, esta cadeia se deforma de maneira semelhante ao material de seu entorno, com a entropia da mesma caindo e, consequentemente, adicionando resistência mecânica ao material. O resultado deste carregamento está ilustrado na fig. 6.1(b).

Se a deformação no material é mantida constante, a cadeia irá retornar vagarosamente para um estado relaxado, conforme a fig. 6.1(c), aumentando seu entropia num movimento favoravelmente energético, reduzindo a resistência mecânica.

A verificação desta teoria foi feita através de ensaios experimentais em borrachas naturais, com e sem aditivos, de compressão uniaxial, compressão biaxial e cisalhamento. Todos os ensaios foram cíclicos, variando-se a deformação máxima, fig. 6.2(a), e/ou a taxa de deformação, fig. 6.2(b). Nos testes para averiguação da sensibilidade à taxa de deformação, o deslocamento foi imposto ao corpo de prova em intervalos intercala- 


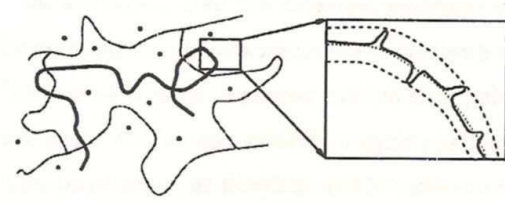

(a) Material não deformado

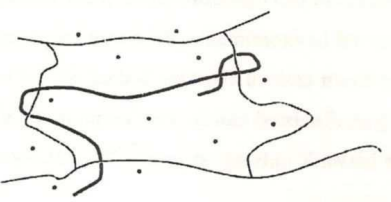

(b) Material deformado

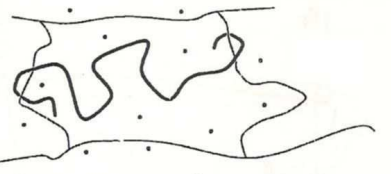

(c) Material deformado e relaxado

Figura 6.1: Suposição feita por bergstrom

dos, de mesmo período de tempo, de velocidades constantes não nula e velocidade nula, combinando ensaios de compressão com ensaios de relaxação.

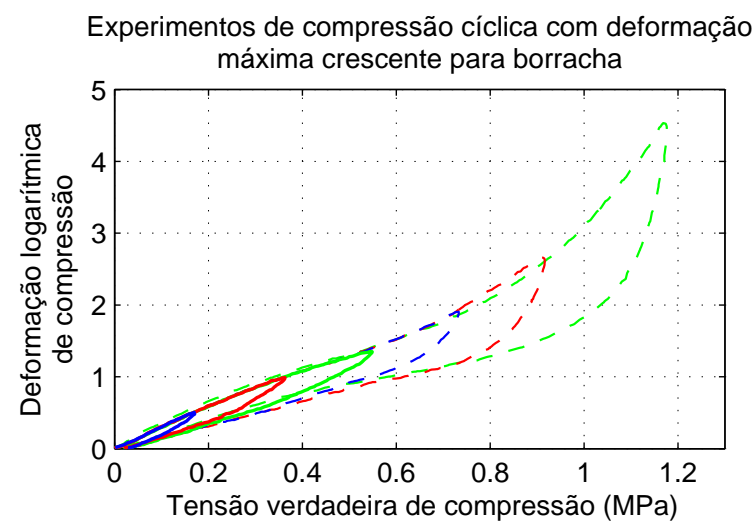

(a) Ensaios cíclicos variando deformação máxima

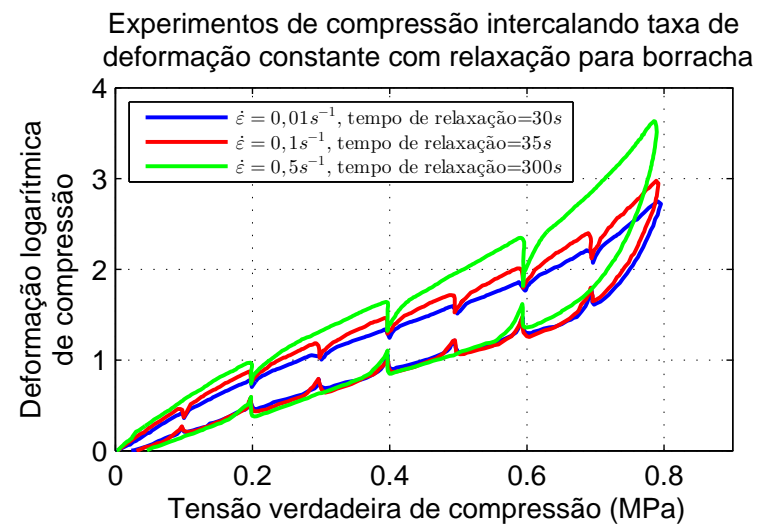

(b) Ensaios cíclicos variando deformação máxima

Figura 6.2: Modelos proposto Bergstrom

Desta forma, o autor concluiu que para representar-se o comportamento mecânico de um elastômero e sua dependência da taxa de deformação, deve-se modelar uma parte de equilíbrio, independente do tempo ou taxa de deformação, denominada $A$ e representada pela curva azul do gráfico da fig. do modelo da fig. 6.3. A parte viscosa deve estar modelada em paralelo, representando o desvio do equilíbrio. Esta última é denominada $B$ seu efeito afasta a curva da tensão de equilíbrio conforme a curva vermelha do gráfico.

Esta parte $B$ é modelada como $\mathbf{F}_{B}=\mathbf{F}^{e} \mathbf{F}^{v}$, com base na estrutura cinemática hiperelastoplástica. Nesse tipo de combinação, pode-se afirmar que $\mathbf{F}=\mathbf{F}_{A}=\mathbf{F}_{B}$ e que o tensor de tensão de Cauchy é calculado por $\boldsymbol{\sigma}=\boldsymbol{\sigma}_{A}+\boldsymbol{\sigma}_{B}$. A representação reológica deste modelo encontra-se na fig. 6.4(a), assim como as configurações de referência, atual e relaxada, com os respectivos gradientes de deformação, estão ilustrados na fig. 6.4(b). 


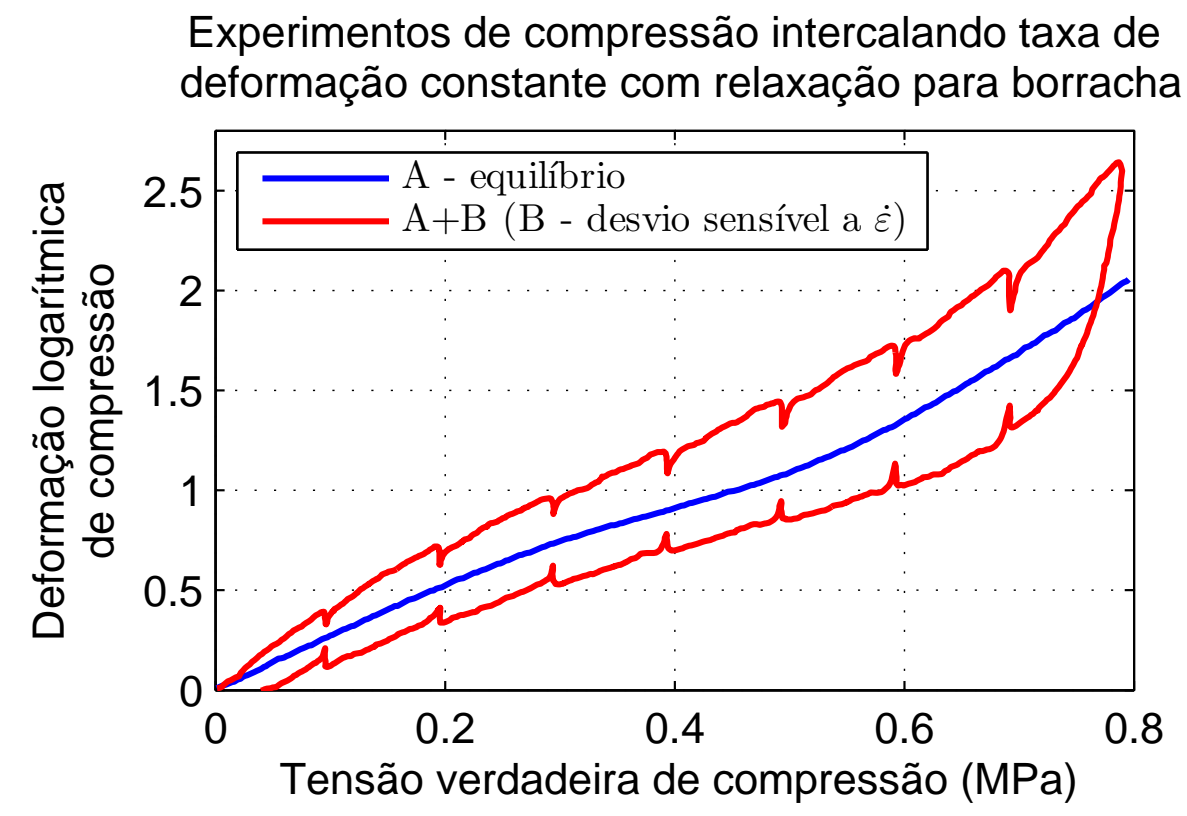

Figura 6.3: Após um carregamento ou descarregamento, a deformação imposta é mantida e a tensão tende a tensão de equilíbrio via processo de relaxação.

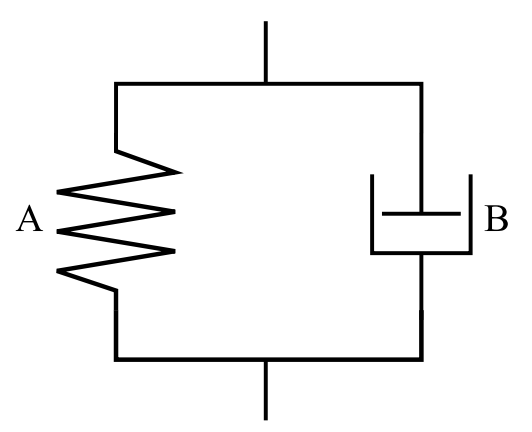

(a) Representação reológica do modelo proposto por Bergstrom

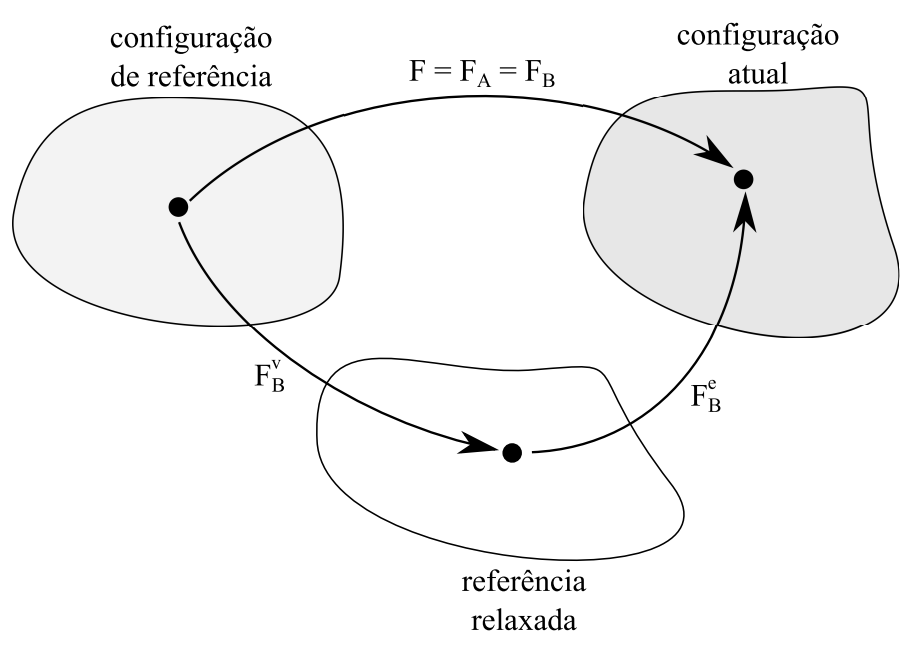

(b) Configurações do modelo proposto por Bergstrom

Figura 6.4: descrição esquemática do modelo proposto por Bergstrom 


\subsubsection{Escolhas para leis hiperelásticas e de escoamento viscoso}

A tensão de Cauchy da parte $A$ pode ser calculada por

$$
\boldsymbol{\sigma}_{A}=\frac{\mu}{J \bar{\lambda}^{*}} \frac{\mathcal{L}^{-1}\left(\bar{\lambda}^{*} / \lambda^{\text {lock }}\right)}{\mathcal{L}^{-1}\left(1 / \lambda^{\text {lock }}\right)} \operatorname{dev}\left(\mathbf{B}^{*}\right)+\kappa(J-1) \mathbf{I}
$$

$\operatorname{com} \mathbf{F}=J^{\frac{1}{3}} \mathbf{F}^{*}, J=\operatorname{det}(\mathbf{F}), \mathbf{B}^{*}=\mathbf{F}^{*} \mathbf{F}^{* T}, \lambda^{*}=\sqrt{\operatorname{tr}\left(\mathbf{B}^{*}\right) / 3}$ e os parâmetros do modelo sendo $\mu, \lambda^{\text {lock }} \mathrm{e} \kappa$.

Decompondo o gradiente de deformações da parte $\mathrm{B}$ em componentes elástico e vis$\operatorname{coso}, \mathbf{F}_{B}=\mathbf{F}_{B}^{e} \mathbf{F}_{B}^{v}$, pode-se calcular a tensão de cauchy da parte $B$ por

$$
\boldsymbol{\sigma}_{B}=\frac{\mu_{B}}{J_{B}^{e} \bar{\lambda}_{B}^{e}} \frac{\mathcal{L}^{-1}\left({\overline{\lambda_{B}^{e}}}^{*} / \lambda_{B}^{\text {lock }}\right)}{\mathcal{L}^{-1}\left(1 / \lambda_{B}^{\text {lock }}\right)} \operatorname{dev}\left(\mathbf{B}_{B}^{e *}\right)+\kappa\left(J_{B}^{e}-1\right) \mathbf{I}
$$

$\operatorname{com} \mathbf{F}_{B}^{e}=J_{B}^{e \frac{1}{3}} \mathbf{F}_{B}^{e *}, J_{B}^{e}=\operatorname{det}\left(\mathbf{F}_{B}^{e}\right), \mathbf{B}_{B}^{e *}=\mathbf{F}_{B}^{e *} \mathbf{F}_{B}^{e * T}, \overline{\lambda_{B}^{e *}}=\sqrt{\operatorname{tr}\left(\mathbf{B}_{B}^{e *}\right) / 3}$ e os parâmetros do modelo sendo $\mu_{B}, \lambda_{B}^{\text {lock }}$, mas com $\kappa$ sendo o mesmo da parte $A$.

Sob a hipótese que o tensor spin na configuração relaxada é nulo, $\overline{\mathbf{W}}_{B}=0$ e que somente a parte deviatórica da tensão em $B$ implica em escoamento viscoso, a taxa de deformação da parte $B$ na configuração relaxada é dada por $\overline{\mathbf{D}}_{B}^{v}=\dot{\gamma}_{B} \mathbf{N}_{B}$, com $\dot{\gamma}_{B}$ sendo a taxa de deformação efetiva e $\mathbf{N}_{B}$ sendo a direção do escoamento viscoso dada por $\mathbf{N}_{B}=\boldsymbol{\sigma}_{B}^{\prime} / \tau_{B}$, uma vez que $\boldsymbol{\sigma}_{B}^{\prime}$ é a parte deviatórica do tensor de tensão de Cauchy da parte B e o módulo de Frobenius da mesma, $\tau_{B}=\left|\boldsymbol{\sigma}_{B}^{\prime}\right|_{F}$, é a tensão efetiva.

A taxa de deformação efetiva é prescrita constitucionalmente por

$$
\dot{\gamma}_{B}=C_{1}\left[\lambda_{B}^{v}-1\right]_{2}^{C}\left(\tau_{B}\right)^{m}
$$

com $C_{1}$ e $m$ sendo positivos e $C_{2}$ é próximo de -1 .

\subsubsection{Bergstrom-Hilbert}

Este modelo de material foi proposto por Bergstrom e Hilbert com o intuito de predizer o comportamento mecânico dependente tanto do tempo quanto da temperatura para polímeros com flúor, como o PTFE (usado pelos autores para ensaios experimentais de validação do modelo), PFA ou FEP.

Este se baseia na viscoelasticidade proposta por Bergstrom descrita na subseção anterior, mas incorporando uma sensibilidade quanto ao tipo de carregamento. Para tanto, 
a taxa de deformação efetiva da parte viscosa $\dot{\gamma}^{v}$ se torna uma função da pressão hidrostática, positiva para compressão e negativa para tração. Outra modificação foi a adição da modelagem de deformação viscoplástica sensível a taxa de deformação mas não a temperatura.

O modelo reológico utilizado por Bergstrom e Hilbert encontra-se na fig. 6.5(a), com a configuração dos domínios na fig. 6.5(b).

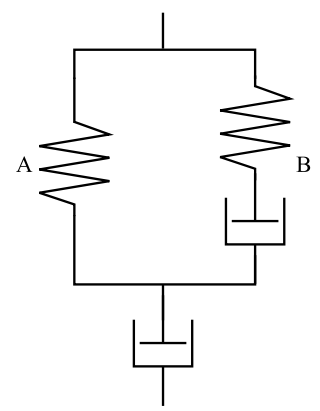

(a) Representação reológica

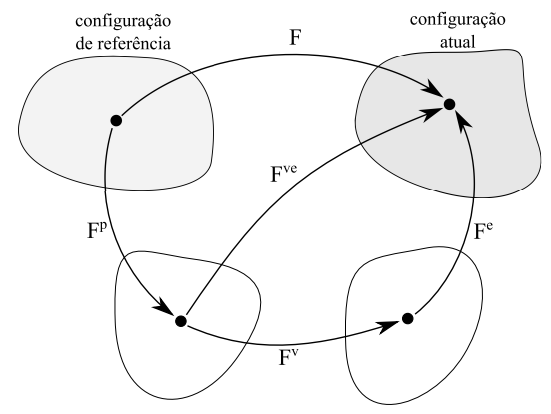

(b) Configurações do modelo proposto por Bergstrom

Figura 6.5: descrição esquemática do modelo proposto por Besrgstrom

Neste modelo pode-se decompor o gradiente de deformações e parte viscoelástica e viscoplástica por $\mathbf{F}=\mathbf{F}^{v e} \mathbf{F}^{p}$, com $\mathbf{F}^{p}$ representando a deformação plástica e $\mathbf{F}^{v e}$ a parte de equilíbrio da deformação elástica. Esta ultima está em paralelo com o desvio do equilíbrio, sensível a taxa de deformação, sendo $\mathbf{F}^{v e}=\mathbf{F}^{e} \mathbf{F}^{v}$.

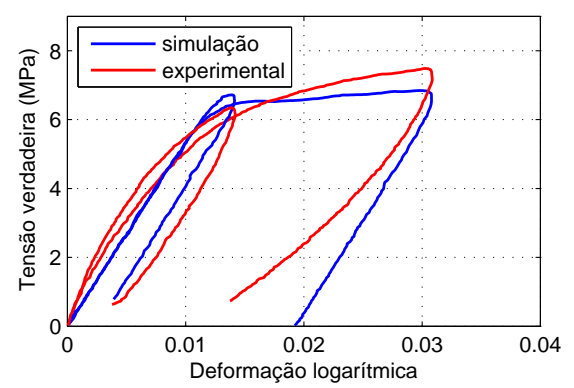

(a) Carregamento e descarregamento

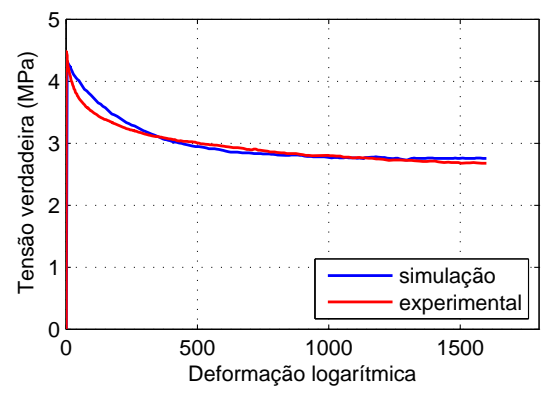

(b) Relaxação

Figura 6.6: Experimentos e simulações na parte elástica do modelo de Bergstrom e Hillbert para o PTFE

Conforme pode ser notado na fig. 6.6, o modelo é capaz de representar bem o comportamento viscoelástico tanto em condições de carregamento e descarregamento quanto em 
baixíssimas taxas de deformação no qual ocorrem os fenômenos de fluência e relaxação.

\subsubsection{Escolhas para leis hiperelásticas e de escoamento viscoso}

A tensão de Cauchy da parte $A$ é calculada também pelo modelo de oito cadeias, levemente modificado na dependência de $\kappa$, por

$$
\boldsymbol{\sigma}^{v e}=\frac{\mu_{A}(\theta)}{J^{v e} \bar{\lambda}^{*}} \frac{\mathcal{L}^{-1}\left(\overline{\lambda^{v e^{*}}} / \lambda^{l o c k}\right)}{\mathcal{L}^{-1}\left(1 / \lambda^{l o c k}\right)} \operatorname{dev}\left(\mathbf{B}^{v e *}\right)+\frac{\kappa \ln \left[J^{v e}\right]}{J^{v e}} \mathbf{I}
$$

com $J^{v e}=\operatorname{det}\left(\mathbf{F}^{v e}\right), \mathbf{B}^{v e *}=J^{v e-\frac{2}{3}} \mathbf{F}^{v e *} \mathbf{F}^{v e * T}, \overline{\lambda^{v e^{*}}}=\sqrt{\operatorname{tr}\left(\mathbf{B}^{v e^{*}}\right) / 3}$ e os parâmetros do modelo sendo $\mu_{A}(\theta)$ o módulo de cisalhamento com dependência da temperatura, $\lambda^{\text {lock }}$ sendo o alongamento limite e $\kappa$ o módulo de bulk.

Já a tensão na parte $B$ é calculada por

$$
\boldsymbol{\sigma}^{e}=s_{B} \frac{\mu_{A}(\theta)}{J^{e} \bar{\lambda}^{*}} \frac{\mathcal{L}^{-1}\left(\overline{\lambda^{e^{*}}} / \lambda^{\text {lock }}\right)}{\mathcal{L}^{-1}\left(1 / \lambda^{\text {lock }}\right)} \operatorname{dev}\left(\mathbf{B}^{e *}\right)+\frac{\kappa \ln \left[J^{e}\right]}{J^{e}} \mathbf{I}
$$

com os parâmetros do material idênticos aos utilizados na parte $A$ e o parâmetro $s_{B}$ sendo um fator escalar multiplicativo.

Novamente assumindo $\overline{\mathbf{W}}^{v}=0$, tempos que $\overline{\mathbf{L}}^{v}=\overline{\mathbf{D}}^{v}=\dot{\gamma}_{\mathrm{dev}}^{v} \mathbf{N}_{\mathrm{dev}}^{v}+\dot{\gamma}_{\mathrm{vol}}^{v} \mathbf{N}_{\mathrm{vol}}^{v}$, com $\mathbf{N}_{\operatorname{dev}}^{v}=\boldsymbol{\sigma}^{e^{\prime}} / \tau^{e}$, uma vez que $\boldsymbol{\sigma}^{e^{\prime}}$ é a parte deviatórica do tensor de tensão de Cauchy da parte B e o módulo de Frobenius da mesma é dado por $\tau^{e}=\left|\boldsymbol{\sigma}^{e^{\prime}}\right|_{F}$. A taxa de deformação efetiva deviatórica pode ser calculada por

$$
\dot{\gamma}_{\mathrm{dev}}^{v}=\dot{\gamma}_{0}\left[\lambda^{v}-1\right]^{C}\left(\frac{\tau^{e}}{\tau^{\text {base }}+\beta p^{e}}\right)^{m}\left(\frac{\theta}{\theta_{\text {base }}}\right)^{n}
$$

$\operatorname{com} \lambda^{v}=\sqrt{\operatorname{tr}\left(\mathbf{B}^{v *}\right) / 3}$ e $\mathbf{B}^{v *}=\left(J^{v}\right)^{-\frac{2}{3}} \mathbf{F}^{v}\left(\mathbf{F}^{v}\right)^{T}$ e $p^{e}=-\left(\boldsymbol{\sigma}_{11}^{e}+\boldsymbol{\sigma}_{22}^{e}+\boldsymbol{\sigma}_{33}^{e}\right) / 3$. A gradiente de velocidades viscoso pode ser então calculado por

$$
\mathbf{L}^{v}=\mathbf{F}^{e-1}\left(\dot{\gamma}_{\mathrm{dev}}^{v} \frac{\operatorname{dev}\left(\boldsymbol{\sigma}^{e}\right)}{\tau^{e}}+\dot{\gamma}_{\mathrm{vol}}^{v} \mathbf{I}\right) \mathbf{F}^{e}
$$

A parte plástica é calculada por um representação fenomenológica

$$
\dot{\gamma}^{p}= \begin{cases}a b\left(\varepsilon-\varepsilon_{0}\right)^{b-1} \dot{\varepsilon}, & \text { se } \tau>\sigma_{0} \\ 0, & \text { qualquer outra forma. }\end{cases}
$$

$\operatorname{com} a, b, \sigma_{0}$ parâmetros do material positivos, $\varepsilon=\left|\mathbf{E}_{\mathbf{l n}}\right|_{F}$ e $E_{l n}=\ln (\mathbf{V})$.

O gradiente de velocidades plástico pode ser calculado por (assumindo-se $\mathbf{W}^{p}=0$ por hipótese)

$$
\mathbf{L}^{p}=\dot{\gamma}^{p} \mathbf{F}^{v e-1} \frac{\operatorname{dev}(\boldsymbol{\sigma})}{\tau} \mathbf{F}^{e}
$$

$\operatorname{com} \boldsymbol{\sigma}=\boldsymbol{\sigma}^{v e}+\boldsymbol{\sigma}^{e}$. 


\subsubsection{Termoplástico semicristalino - Bergstrom-Bischoff}

Foi desenvolvido por Bergstrom e Bischoff em 2010 para representar o comportamento mecânico do polietileno de alto peso molecular, utilizado na indústria biomédica, em próteses, pela não rejeição do organismo além da resistência ao impacto e a fadiga. A reologia deste modelo de material está representada na fig. 6.7, com uma parte viscoplástica representando o material amorfo, a esquerda, denominada $A$, uma parte central viscoelástica representando a fase semicristalina e a resistência entrópica que controla a resposta mecânica para grandes valores de deformação.

O polímero utilizado nos ensaios foram usinados e depois tratados com calor a $11^{\circ} \mathrm{C}$ por 2 horas, atingindo um grau de cristalinidade de 61

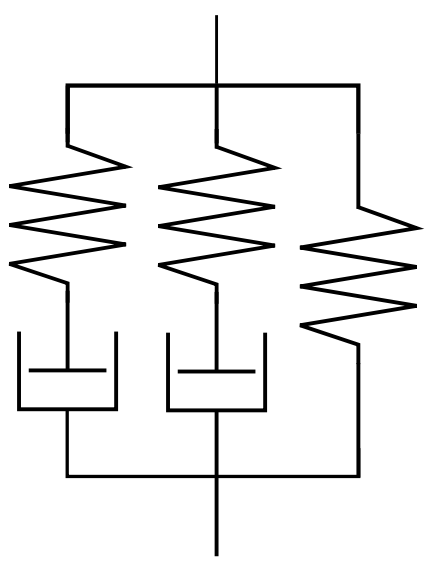

(a) Representação reológica

Figura 6.7: descrição esquemática do modelo proposto por Besrgstrom

\subsubsection{Escolhas para leis hiperelásticas e de escoamento plástico}

A tensão da parte $A$ é dada por

$$
\boldsymbol{\sigma}_{A}=\frac{\mu_{A}}{J_{A}^{e} \bar{\lambda}_{A}^{e *}}\left[1+\frac{\theta-\theta_{0}}{\hat{\theta}}\right] \frac{\mathcal{L}^{-1}\left(\overline{\lambda_{A}^{e *}} / \lambda^{l o c k}\right)}{\mathcal{L}^{-1}\left(1 / \lambda^{l o c k}\right)} \operatorname{dev}\left(\mathbf{B}_{A}^{e *}\right)+\kappa\left[J_{A}^{e}-1\right] \mathbf{I}
$$

com $\mathbf{F}=\mathbf{F}_{A}^{e} \mathbf{F}_{A}^{p}$, sendo assumido $\overline{\mathbf{W}}_{A}^{p}=0$, temos que $\overline{\mathbf{D}}_{A}^{p}=\dot{\gamma}_{A} \mathbf{N}_{A}$, com $\dot{\gamma}_{A}$ sendo a taxa de deformação efetiva e $\mathbf{N}_{A}$ sendo a direção do escoamento plástico dada por $\mathbf{N}_{A}=\boldsymbol{\sigma}_{A}^{\prime} / \tau_{A}$, uma vez que $\boldsymbol{\sigma}_{A}^{\prime}$ é a parte deviatórica do tensor de tensão de Cauchy da parte $A$ e o módulo de Frobenius da mesma, $\tau_{A}=\left|\boldsymbol{\sigma}_{S}^{\prime}\right|_{F}$, é a tensão efetiva. 
A taxa de deformação efetiva $\dot{\gamma}_{A}$ é prescrita constitucionalmente por

$$
\dot{\gamma}_{A}=\dot{\gamma}_{0}\left(\frac{\tau_{A}}{\hat{\tau}_{A}+a R\left(p_{A}\right)}\right)^{m}\left(\frac{\theta}{\theta_{0}}\right)^{n}
$$

$\operatorname{com} p_{A}=-\left(\boldsymbol{\sigma}_{A 11}+\boldsymbol{\sigma}_{A 22}+\boldsymbol{\sigma}_{A 33}\right) / 3$ e $R(x)=(x+|x|) / 2$.

O gradiente de velocidades de $A$ é dado por

$$
\mathbf{L}_{A}^{p}=\dot{\gamma}_{A} \mathbf{F}_{A}^{e-1}\left(\frac{\operatorname{dev}\left(\boldsymbol{\sigma}_{A}\right)}{\tau_{A}}\right) \mathbf{F}_{A}^{e}
$$

A tensão da parte $B$ é dada por

$$
\boldsymbol{\sigma}_{B}=\frac{\mu_{B}}{J_{B}^{e} \bar{\lambda}_{B}^{e *}}\left[1+\frac{\theta-\theta_{0}}{\hat{\theta}}\right] \frac{\mathcal{L}^{-1}\left(\overline{\lambda_{B}^{e *}} / \lambda^{l o c k}\right)}{\mathcal{L}^{-1}\left(1 / \lambda^{l o c k}\right)} \operatorname{dev}\left(\mathbf{B}_{B}^{e *}\right)+\kappa\left[J_{B}^{e}-1\right] \mathbf{I}
$$

com $\mathbf{F}=\mathbf{F}_{B}^{e} \mathbf{F}_{B}^{V}$, sendo assumido $\overline{\mathbf{W}}_{B}^{V}=0$, temos que $\overline{\mathbf{D}}_{B}^{V}=\dot{\gamma}_{B} \mathbf{N}_{B}$, com $\dot{\gamma}_{B}$ sendo a taxa de deformação efetiva e $\mathbf{N}_{B}$ sendo a direção do escoamento plástico dada por $\mathbf{N}_{B}=\boldsymbol{\sigma}_{B}^{\prime} / \tau_{B}$, uma vez que $\boldsymbol{\sigma}_{B}^{\prime}$ é a parte deviatórica do tensor de tensão de Cauchy da parte $B$ e o módulo de Frobenius da mesma, $\tau_{B}=\left|\boldsymbol{\sigma}_{S}^{\prime}\right|_{F}$, é a tensão efetiva.

A taxa de deformação efetiva $\dot{\gamma}_{B}$ é prescrita constitucionalmente por

$$
\dot{\gamma}_{B}=\dot{\gamma}_{0}\left(\frac{\tau_{B}}{\hat{\tau}_{B}+a R\left(p_{B}\right)}\right)^{m}\left(\frac{\theta}{\theta_{0}}\right)^{n}
$$

$\operatorname{com} p_{B}=-\left(\boldsymbol{\sigma}_{B 11}+\boldsymbol{\sigma}_{B 22}+\boldsymbol{\sigma}_{B 33}\right) / 3$ e $R(x)=(x+|x|) / 2$.

O gradiente de velocidades de $B$ é dado por

$$
\mathbf{L}_{B}^{v}=\dot{\gamma}_{B} \mathbf{F}_{B}^{e-1}\left(\frac{\operatorname{dev}\left(\boldsymbol{\sigma}_{B}\right)}{\tau_{B}}\right) \mathbf{F}_{B}^{e}
$$

com a única diferença sendo a evolução do módulo de cisalhamento $\mu_{B}$ com a taxa de deformação plástica cisalhante $\dot{\gamma}_{A}$ por

$$
\dot{\mu}_{B}=-\beta\left[\mu_{B}-\mu_{B f}\right] \dot{\gamma}_{A}
$$

A tensão na resistência entrópica pode ser dada por

$$
\begin{array}{r}
(\sigma)_{C}=f_{8_{\text {cadeias }}+I_{2}}(\mathbf{F})=\frac{1}{1+q}\left[\frac{\mu_{C}}{J \lambda_{\text {chain }}}\left[1+\frac{\theta-\theta_{0}}{\hat{\theta}}\right] \frac{\mathcal{L}^{-1}\left(\lambda_{\text {chain }} / \lambda^{\text {lock }}\right)}{\mathcal{L}^{-1}\left(1 / \lambda^{\text {lock }}\right)} \operatorname{dev}\left(\mathbf{B}^{*}\right)\right. \\
\left.+\kappa(J-1) \mathbf{I}++q \frac{\mu}{J}\left(I_{1}^{*} \mathbf{B}^{*}-\frac{2 I_{2}^{*}}{3} \mathbf{I}-\left(\mathbf{B}^{*}\right)^{2}\right)\right]
\end{array}
$$




\subsection{Viscoplasticidade}

\subsubsection{Mulliken-Boyce}

A fig. mostra a reologia do modelo de Mulliken, similar ao modelo desenvolvido por Boyce, Parks e Argon, mas com o encruamento cinemático deslocado para uma fase em um ramo separado $B$, com o ramo $A$ sendo divididos em duas fases, conforme explicado no gráfico da fig. 6.8(b).

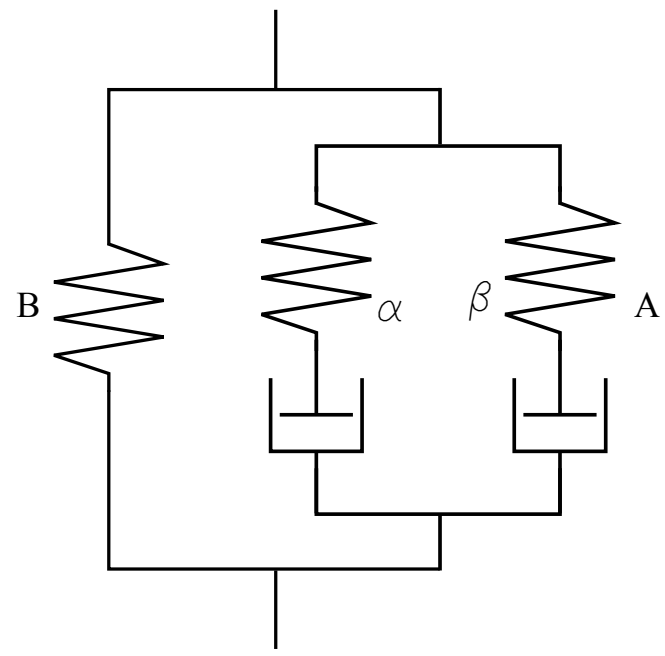

(a) Modelo reológico do modelo proposto (b) Diagrama dos estados do modelo proposto por Mulpor Mulliken [75]

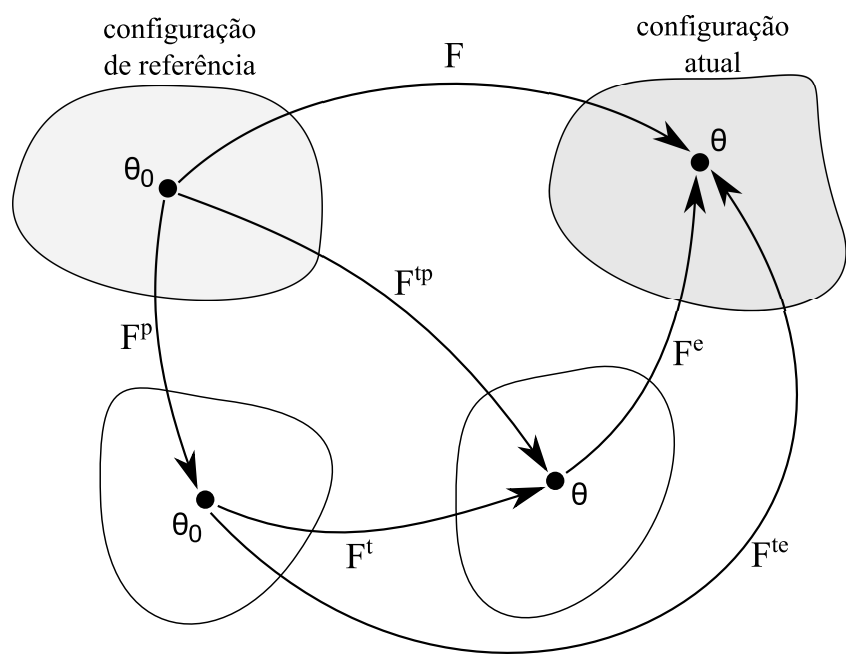

liken $[75]$

Figura 6.8: Modelo proposto por Mulliken [75]

O gráfico da fig. 6.3.1 demonstra a divisão do comportamento mecânico dos polímeros termoplásticos amorfos, com uma fase $\alpha$, responsável pelos fenômenos de relaxação e fluência em baixíssimas taxas de deformação, além da transição vítrea, mas que também ativamente contribui para o comportamento viscoelástico em altas taxas de deformação. Entretanto, conforme explicado na Capítulo 2, há uma fase $\beta$, inativa na contribuição de resistência mecânica a baixas taxas de deformação, mas ativa em altas.

A estrutura cinemática utilizada termo-viscoelastocistoplástica utilizada por Mulliken será a base do modelo proposto para um termoplástico amorfo, sendo substituída a relação hiper-elástica com parâmetros dependentes da taxa de deformação pela estrutura cinemática proposta por Bergstrom e formulação de escoamento viscoso proposto por Bergstrom e Hilbert. 


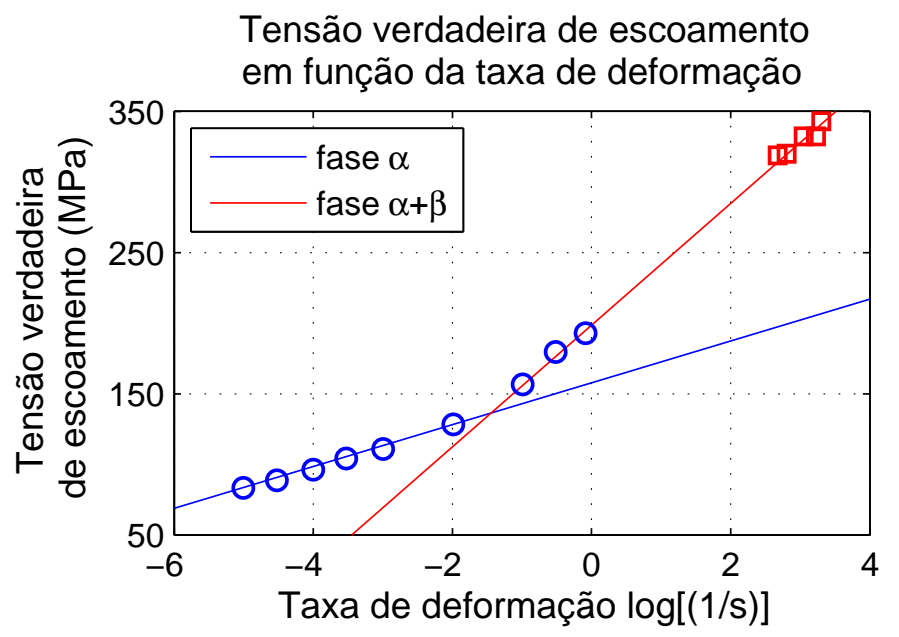

\subsubsection{Estrutura Cinemática termo-elastoviscoplástica}

Esta estrutura cinemática permite uma análise termo-mecânica acoplada, ou seja, ao mesmo tempo que a energia mecânica durante a deformação plástica é convertida em energia térmica, considera-se também, além da deformação elástica e plástica, uma deformação causada pela expansão térmica, descontada da deformação total durante o cálculo das tensões pelo modelo de material. Apesar de não ser o foco desta tese, esta estrutura cinemática permite modelar o comportamento mecânico com sensibilidade a temperatura, ou seja, uma influência da temperatura em relações hiper-elástica e funções de escoamento plástico ou viscoso pode ser modelada em futuras pesquisas do laboratório.

A estrutura cinemática escolhida [75], consiste na decomposição multiplicativa do gradiente de deformações em três partes: uma elástica $\mathbf{F}^{e}$, uma devido a expansão térmica $\mathbf{F}^{t}$ e uma plástica $\mathbf{F}^{p}$, conforme

$$
\mathbf{F}=\mathbf{F}^{e} \mathbf{F}^{t} \mathbf{F}^{p}
$$

com o gradiente de velocidades $\mathbf{L}=\dot{\mathbf{F}} \mathbf{F}^{-1}$ sendo decomposto em

$$
\mathbf{L}=\mathbf{L}^{e}+\mathbf{F}^{e}\left[\mathbf{L}^{t}+\mathbf{F}^{t} \mathbf{L}^{p}\left(\mathbf{F}^{t}\right)^{-1}\right]\left(\mathbf{F}^{e}\right)^{-1}
$$

na qual $\mathbf{L}^{e}=\dot{\mathbf{F}}^{e}\left(\mathbf{F}^{e}\right)^{-1}, \mathbf{L}^{t}=\dot{\mathbf{t}}^{e}\left(\mathbf{F}^{t}\right)^{-1}$ e $\mathbf{L}^{p}=\dot{\mathbf{F}}^{p}\left(\mathbf{F}^{p}\right)^{-1}$. Entretanto, a parte térmica e plástica serão agrupadas em um único gradiente de deformações termo-plástico $\mathbf{F}^{t p}=$ $\mathbf{F}^{t} \mathbf{F}^{p}$, originando o gradiente de velocidades $\mathbf{F}^{t p}$, dado por

$$
\mathbf{L}^{t p}=\dot{\mathbf{F}^{t p}}\left(\mathbf{F}^{t p}\right)^{-1}=\mathbf{L}^{t}+\mathbf{F}^{t} \mathbf{L}^{p}\left(\mathbf{F}^{t}\right)^{-1}=\mathbf{D}^{t p}+\mathbf{W}^{t p}
$$


com $\mathbf{D}^{t p}$ sendo simétrico e denominado tensor taxa de deformação termo-plástica e $\mathbf{W}^{t p}$ sendo anti-simétrico e denominado tensor spin termo-plástica. Assumindo o fluxo termoplástico como irrotacional, $\mathbf{W}^{t p}=0$, temos

$$
\dot{\mathbf{F}}^{t p}=\mathbf{D}^{t p} \mathbf{F}^{t p}
$$

Através da integração da taxa temporal do gradiente de deformações termo-plástico, eq. 6.21, e como o tensor $\mathbf{F}^{t}$ deve ser prescrito constitucionalmente, $\mathbf{F}^{e}$ e $\mathbf{F}^{p}$ podem ser calculados por

$$
\begin{aligned}
\mathbf{F}^{e} & =\mathbf{F}\left(\mathbf{F}^{t p}\right)^{-1} \\
\mathbf{F}^{p} & =\left(\mathbf{F}^{t}\right)^{-1} \mathbf{F}^{t p}
\end{aligned}
$$

\subsubsection{Gradiente de velocidades termo-viscoplástico}

O gradiente de velocidades termo-viscoplástico, $\mathbf{L}^{t p}$, deve ser desenvolvido corretamente para que um escoamento plástico sensível a temperatura possa ser utilizado. Assumindo o fluxo termo-plástico como irrotacional e considerando o mesmo como a soma de duas contribuições, pode-se definí-lo por

$$
\mathbf{L}^{t p}=\mathbf{D}^{t p}=\overline{\mathbf{D}}^{p}(\mathbf{T}, \theta, \mathbf{A})+\overline{\mathbf{M}}(\theta, \mathbf{A}) \dot{\theta}
$$

com $\overline{\mathbf{D}}^{p}$ sendo a taxa de deformação plástica na configuração descarregada, $\overline{\mathbf{M}}$ sendo a taxa de expansão térmica na configuração descarregada, $\theta$ a temperatura atual, A um conjunto de variáveis internas e $\mathbf{T}$ a tensão de Cauchy.

Por sua vez, a taxa de deformação plástica nesta estrutura cinemática termo-elastoplástica também pode ser considerada a soma de duas componentes: a parte simétrica do gradiente de velocidades termo-plástico definida na configuração descarregada e a evolução do gradiente de velocidades térmico com respeito a variação das variáveis internas (como por exemplo uma anisotropia ocasionada pelo alinhamento das moléculas), também descrito na configuração descarregada, ou seja,

$$
\overline{\mathbf{D}}^{p}=\operatorname{sim}\left(\mathbf{F}^{t} \mathbf{L}^{p}\left(\mathbf{F}^{t}\right)^{-1}\right)+\operatorname{sim}\left(\frac{\partial \mathbf{F}^{t}(\mathbf{T}, \theta, \mathbf{A})}{\partial \mathbf{A}} \mathbf{F}^{t}\right)
$$

A taxa de expansão térmica pode ser definida como a porção do gradiente de velocidades térmico que evolui com a variação da temperatura, ou seja,

$$
\overline{\mathbf{M}} \dot{\theta}=\operatorname{sim}\left(\frac{\partial \mathbf{F}^{t}(\mathbf{T}, \theta, \mathbf{A})}{\partial \theta}\left(\mathbf{F}^{t}\right)^{-1}\right) \dot{\theta}
$$


O gradiente de velocidades pode ser então definido por

$$
\mathbf{L}^{t p}=\mathbf{D}^{t p}=\operatorname{sim}\left(\mathbf{F}^{t} \mathbf{L}^{p}\left(\mathbf{F}^{t}\right)^{-1}+\frac{\partial \mathbf{F}^{t}}{\partial \mathbf{A}} \mathbf{F}^{t}+\frac{\partial \mathbf{F}^{t}}{\partial \theta}\left(\mathbf{F}^{t}\right)^{-1} \dot{\theta}\right)
$$

sendo $\mathbf{L}^{p}$ e $\mathbf{F}^{t}$ descritos constitucionalmente.

\subsubsection{3 definições constitutivas desta estrutura cinemática}

Na parte termo-viscoplástica, serão utilizadas as mesmas leis constitutivas definidas em [75] para o gradiente de deformações da expansão térmica $\mathbf{F}^{t}$ e para o gradiente de velocidades plástico $\mathbf{L}^{p}$. O primeiro, assumindo um comportamento térmico isotrópico, pode ser expressado em função do coeficiente de expansão térmica $\alpha$ por

$$
\mathbf{F}^{t}=\exp \left[\alpha\left(\theta-\theta_{0}\right)\right] \mathbf{I}
$$

A partir de então, temos que

$$
\begin{gathered}
\operatorname{sim}\left(\frac{\partial \mathbf{F}^{t}(\mathbf{T}, \theta, \mathbf{A})}{\partial \mathbf{A}} \mathbf{F}^{t}\right)=0 \quad \mathrm{e} \\
\overline{\mathbf{M}} \dot{\theta}=\operatorname{sim}\left(\frac{\partial \mathbf{F}^{t}(\mathbf{T}, \theta, \mathbf{A})}{\partial \theta}\left(\mathbf{F}^{t}\right)^{-1}\right) \dot{\theta}=\alpha \dot{\theta} \mathbf{I}
\end{gathered}
$$

O gradiente de velocidades plástico, assumindo escoamento irrotacional, pode ser decomposto em um módulo, $\dot{\gamma}^{p}$, e uma direção $\mathbf{N}^{t p}$, sendo

$$
\overline{\mathbf{D}}^{p}=\operatorname{sim}\left(\mathbf{F}^{t} \mathbf{L}^{p}\left(\mathbf{F}^{t}\right)^{-1}\right)=\dot{\gamma}^{p} \mathbf{N}^{t p}
$$

com $\mathbf{N}^{t p}$ sendo coaxial com a parte deviatórica do tensor de tensões de Cauchy definida na configuração descarregada, $\mathbf{T}^{\prime}$, ou seja,

$$
\mathbf{N}^{t p}=\frac{\left(\mathbf{F}^{e}\right)^{-1} \mathbf{T}^{\prime} \mathbf{F}^{e}}{\left|\mathbf{T}^{\prime}\right|_{F}}
$$

Então, inserindo 6.30, 6.28 e 6.29 em 6.26, o gradiente de velocidades termo-plástico é definido por

$$
\mathbf{L}^{t p}=\mathbf{D}^{t p}=\dot{\gamma}^{p} \mathbf{N}^{t p}+\alpha \dot{\theta} \mathbf{I}=\dot{\gamma}^{p} \frac{\left(\mathbf{F}^{e}\right)^{-1} \mathbf{T}^{\prime} \mathbf{F}^{e}}{\left|\mathbf{T}^{\prime}\right|_{F}}+\alpha \dot{\theta} \mathbf{I}
$$




\subsubsection{Escolhas para leis hiperelásticas e de escoamento plástico}

O escoamento viscoplástico da fase $\alpha$ é dado por:

$$
{ }^{\alpha} \dot{\gamma}^{p}=f_{\alpha \dot{\gamma}^{p}}\left(\tau, p, s^{p}\right)={ }^{\alpha} \dot{\gamma}_{0} \exp \left(\frac{\tau}{s^{p}+{ }^{\alpha} n_{p} p}+{ }^{\alpha} b\right)
$$

com $s^{p}$ evoluindo de acordo com

$$
{ }^{\alpha} \dot{s}^{p}=f_{\alpha \dot{s}^{p}}\left({ }^{\alpha} s^{p},{ }^{\alpha} \dot{\gamma}^{p}\right)={ }^{\alpha} h\left(1-\frac{{ }^{\alpha} s^{p}}{{ }^{\alpha} s_{f}^{p}}\right){ }^{\alpha} \dot{\gamma}^{p}
$$

Já a fase $\beta$ possui escoamento viscoplástico determinado por

$$
{ }^{\beta} \dot{\gamma}^{p}=f_{\beta \dot{\gamma}^{p}}(\tau)={ }^{\beta} \dot{\gamma}_{0} \sinh \left(\frac{\tau}{\beta_{S^{p}}}\right)
$$

sendo valido salientar que Mulliken adotou $\tau$ como sendo a tensão de cisalhamento, dada por

$$
\tau=\sqrt{\frac{1}{2} \boldsymbol{\sigma}^{\prime}: \boldsymbol{\sigma}^{\prime}}
$$

Por fim, além da resistência entrópica modelada pela lei hiperelástica de 8 cadeias, o fenômeno é modelado como adiabático, ou seja

$$
\dot{\theta}=\frac{\operatorname{tr}\left({ }^{\alpha} \boldsymbol{\sigma}^{\prime} \alpha \mathbf{D}^{p}\right)}{\rho c_{p}}+\frac{\operatorname{tr}\left({ }^{\beta} \boldsymbol{\sigma}^{\prime \beta} \mathbf{D}^{p}\right)}{\rho c_{p}}
$$

\subsection{Modelo de material proposto e implementação numérica}

\subsection{1 programas}

O software comercial Ls-Dyna ${ }^{\circledR}$ permite a implementação de um modelo de material do usuário através de uma função computacional. Neste, as variáveis de entrada podem ser as deformações ou gradiente de deformações no começo e no fim do passo de tempo, o instante atual, o passo de tempo, um vetor computacional contendo os parâmetros do material, além de poder receber outras variáveis, como temperatura. A variável de saída deve ser as 6 tensões independentes do tensor de tensões de Cauchy (uma vez que o mesmo é simétrico).

Para tal, a empresa Livermore fornece dois arquivos .f em conjunto com bibliotecas .dll para compilação do programa. O usuário deve implementar sua função computacional 
dentro destes arquivos .f, programados em Fortran V77. Uma função computacional em Fortran é declarada como subrotina e passa as variáveis de entrada e de saída como parâmetros de entrada, sendo do tipo void, ou seja, sem retorno.

Para cada versão do Ls-Dyna em que se deseja implementar um modelo de material, há uma versão específica do compilador Intel Fortran e o Microsoft Visual Studio (de modo a instalar a ferramentas de compilação cruzada para arquiteturas x64). Neste caso, será utilizada a versão 10.1.032 do compilador e a versão 2008.

De maneira a facilitar a compreensão do código e otimização do mesmo via processo de refatoração, ao contrario do usual procedimento de implementação procedural, foram utilizadas inúmeras subrotinas. A implementação vetorizada e o avanço computacional permitem esse tipo de implementação sem reduzir a performance do programa, alguns novos compiladores até mesmo tornariam o código igual a uma implementação procedural durante a etapa de compilação.

Desta forma, as subrotinas consideradas como operações básicas, como operações entre matrizes ou alocação de matrizes em vetores, estão disponíveis em seu código fonte no Apêndice E.

Devido a grande quantidade de parâmetros, cada função implementada em fortran teve sua equivalente implementada em Matlab, de modo a permitir a utilização da biblioteca de otimização. A partir de um conjunto de parâmetros que permita ao modelo de material ter um comportamento mecânico semelhante ao real, são usados algoritmos tipo mead simplex para diminuir o erro entre as curvas numéricas e experimentais.

Este algoritmo de otimização terá como entrada os parâmetros e irá realizar o mesmo procedimento que o programa de elementos finitos em questão: fornece o gradiente de deformações e as variáveis históricas solicitadas, atualiza as mesmas e retorna os valores de tensão. A utilização da técnica DIC possibilitou medir-se as deformações longitudinais e transversais em cada secção transversal do corpo de prova, sendo possível o cálculo então do gradiente de deformações. A função a ser minimizada foi programada a partir da soma dos desvios de tensão em pontos considerados chaves para assegurar que o comportamento mecânico do modelo seja semelhante ao material real, sendo o erro calculado em um determinado ponto como o absoluto da diferença entre a tensão simulada e a medida experimentalmente, se esta diferençar for menor que $1 \%$ ou de 20 a 40 vezes esse valor se for maior que $1 \%$. 


\subsection{2 estrutura cinemáticas}

As estruturas cinemáticas do material proposto para o polímero termoplástico amorfo encontra-se na fig. 6.9(a) e a para polímeros termoplásticos semi-cristalinos encontra-se na fig. 6.9(b).

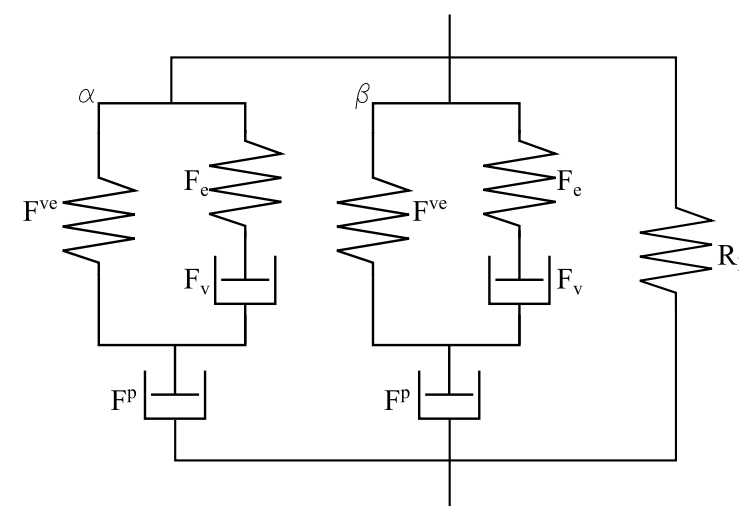

(a) Modelo reológico do modelo de material proposto para polímeros termoplásticos amorfos

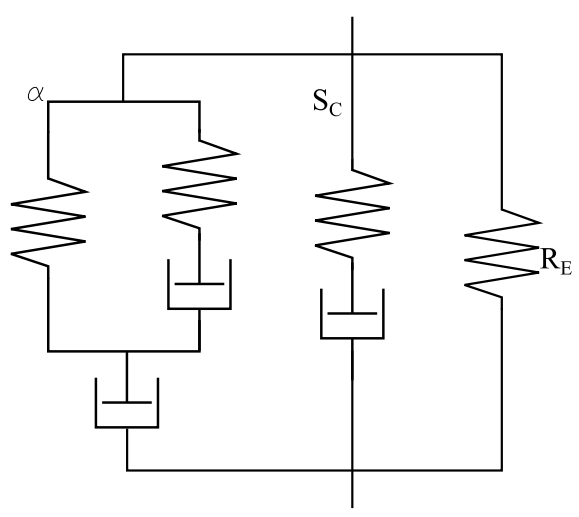

(b) Modelo reológico do modelo de material proposto para polímeros termoplásticos semicristalinos

Figura 6.9: Modelos propostos.

A seguir serão apresentadas as relações hiper-elásticas, leis de escoamento plástico e viscoso e as de evolução a implementação em Fortran. A implementação em Matlab encontra-se no Apêndice E.

\subsubsection{Relações hiperelásticas, leis de escoamento plástico e vis- coso e as de evolução}

\subsubsection{1 hiper-elasticidade das fases $\alpha, \beta$ e semicristalina}

A lei hiper-elástica das fases $\alpha, \beta$ e semicristalina será a neohookeana, dada em Belytschko [10] por

$$
\boldsymbol{\sigma}=\frac{\mu}{J} \mathbf{B}+\frac{\lambda \ln (J)-\mu}{J} \mathbf{I}
$$

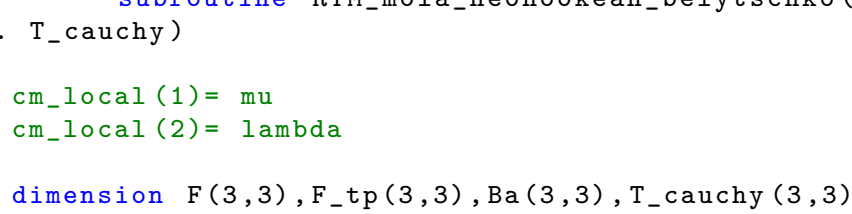




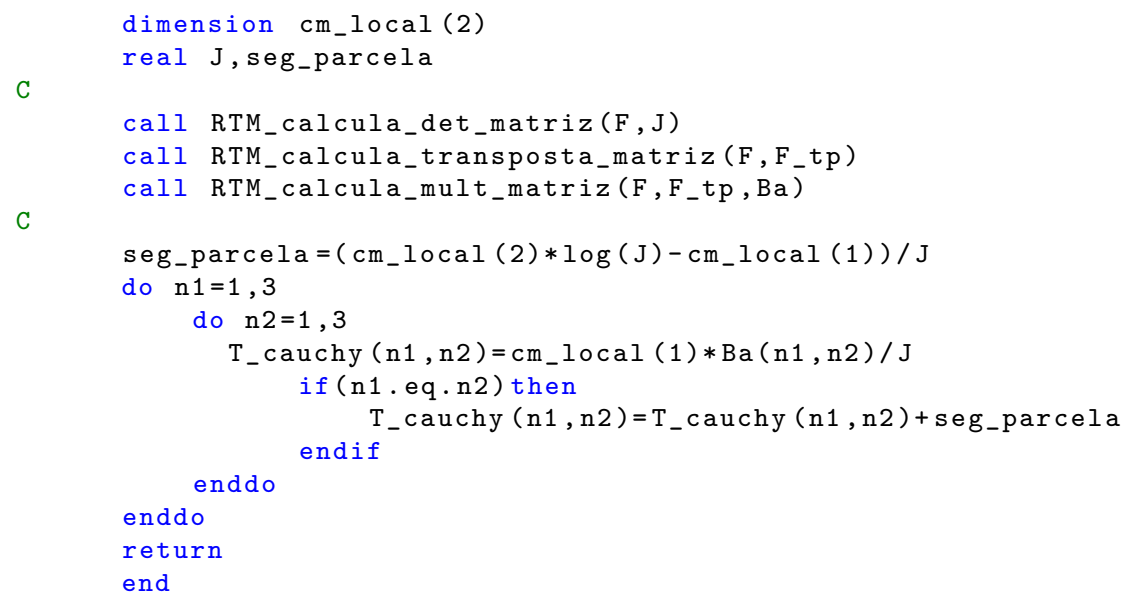

\subsubsection{2 hiper-elasticidade da resistência entrópica}

A lei hiper-elástica das resistência entrópica é modelada usando-se a mesma lei hiperelásticas das outras fases, mas com um dependência de primeira ordem do segundo invariante $I_{2}$, ou seja, uma representação próxima de um modelo de Mooney-Rivlin com estatística não gaussiana na distribuição das cadeias. Seu representação matemática é dada por

$$
\begin{aligned}
\boldsymbol{\sigma}=f_{8_{\text {cadeias }}+I_{2}}(\mathbf{F})=\frac{1}{1+q}\left[\frac{\mu}{J \bar{\lambda}^{*}} \frac{\mathcal{L}^{-1}\left(\bar{\lambda}^{*} / \lambda^{l o c k}\right)}{\mathcal{L}^{-1}\left(1 / \lambda^{l o c k}\right)}\right. & \operatorname{dev}\left(\mathbf{B}^{*}\right)+\kappa(J-1) \mathbf{I}+ \\
& \left.+q \frac{\mu}{J}\left(I_{1}^{*} \mathbf{B}^{*}-\frac{2 I_{2}^{*}}{3} \mathbf{I}-\left(\mathbf{B}^{*}\right)^{2}\right)\right]
\end{aligned}
$$

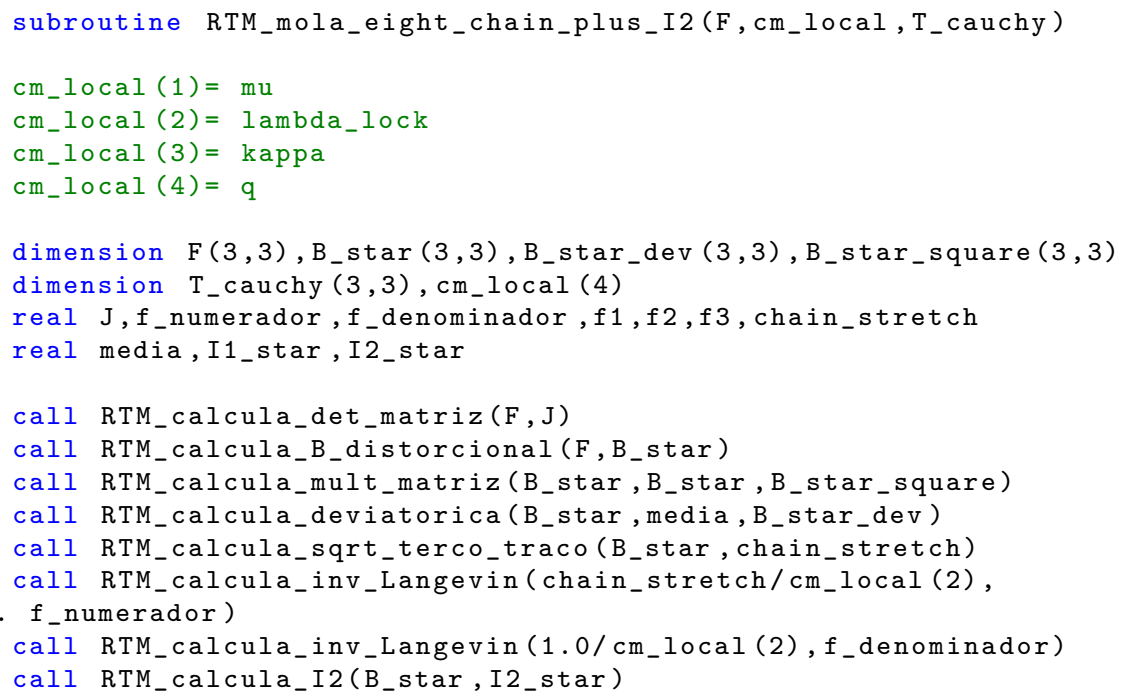


C

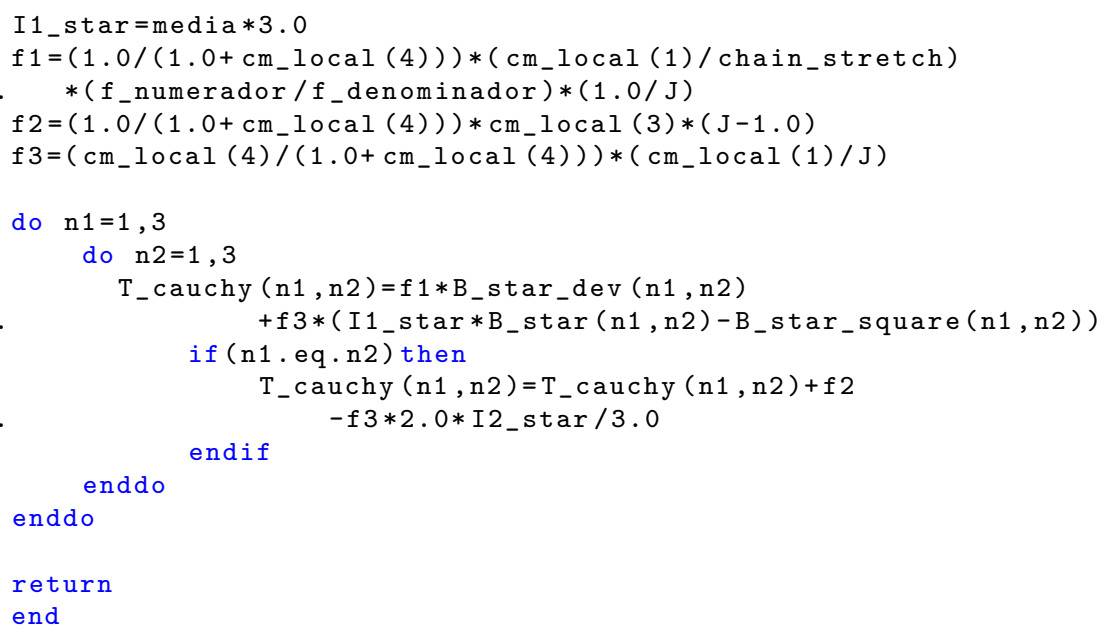

\subsubsection{3 escoamento plástico da fase $\alpha$}

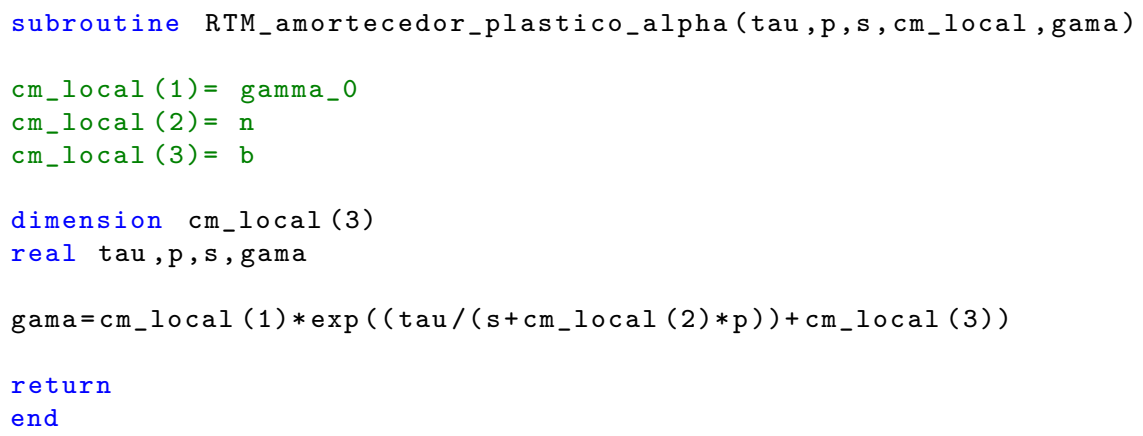

\subsubsection{4 escoamento plástico da fase $\beta$}

$$
\beta \dot{\gamma}^{p}=f_{\beta} \dot{\gamma}^{p}(\tau)={ }^{\beta} \dot{\gamma}_{0} \sinh \left(\frac{\tau}{{ }^{\beta} s^{p}}\right)
$$

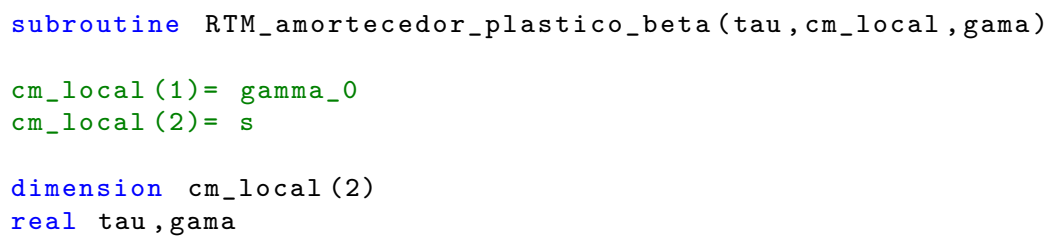


gama $=\mathrm{cm}_{-} l o c a l(1) * \sinh \left(\mathrm{tau} / \mathrm{cm}_{-} l o c a l(2)\right)$

$\mathrm{C}$

return

end

\subsubsection{5 escoamento viscoso amorfo e semicristalino}

$$
\dot{\gamma}_{d e v}^{v}=f_{\dot{\gamma}_{\text {dev }}^{v}}\left(\tau, p, \overline{\lambda^{v}}\right)=\dot{\gamma}_{0}\left[\overline{\lambda^{v}}-1\right]^{C}\left(\frac{\tau}{s^{v}+n_{v} p}\right)^{m}
$$

subroutine RTM_amortecedor_viscoso_dev(tau,p, chain_stretch,

- cm_local, gama_v_dev)

$\mathrm{cm}_{-}$local $(1)=$ gamma_0

$\mathrm{cm}_{-}$local $(2)=\mathrm{C}$

$\mathrm{cm}_{-}$local $(3)=\mathrm{s}_{-} \mathrm{v}$

$\mathrm{cm}$ local $(4)=\mathrm{n}$ v

$\mathrm{cm}_{-}$local $(5)=\mathrm{m}$

dimension $\mathrm{cm}_{-}$local (5)

real tau, chain_stretch, gama_v_dev, eps

eps $=0.001$

C

gama_v_dev $=\mathrm{cm}_{-}$local $(1) *\left((\right.$ chain_stretch $-1.0+$ eps $\left.) * * \mathrm{~cm}_{-} 10 \mathrm{cal}(2)\right)$

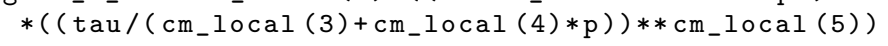

return

end

$$
\dot{\gamma}_{v o l}^{v}=f_{\dot{\gamma}_{v o l}^{v}}(p)=\frac{p}{\eta_{v o l}}
$$

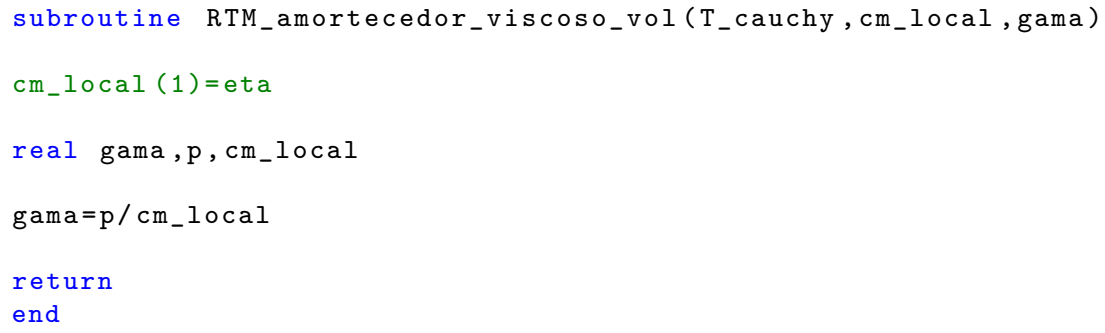

6.4.3.6 evolução de ${ }^{\alpha} s^{p}$

$$
{ }^{\alpha} \dot{s}^{p}=f_{\alpha_{\dot{s}}^{p}}\left({ }^{\alpha} s^{p},{ }^{\alpha} \dot{\gamma}^{p}\right)={ }^{\alpha} h\left(1-\frac{{ }^{\alpha} s^{p}}{{ }^{\alpha} s_{f}^{p}}\right){ }^{\alpha} \dot{\gamma}^{p}
$$




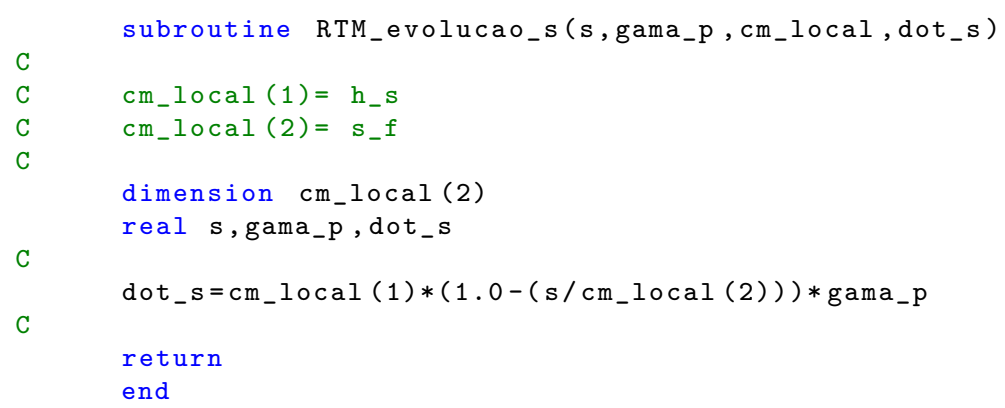

\subsubsection{7 evolução de ${ }^{S C} \mu$}

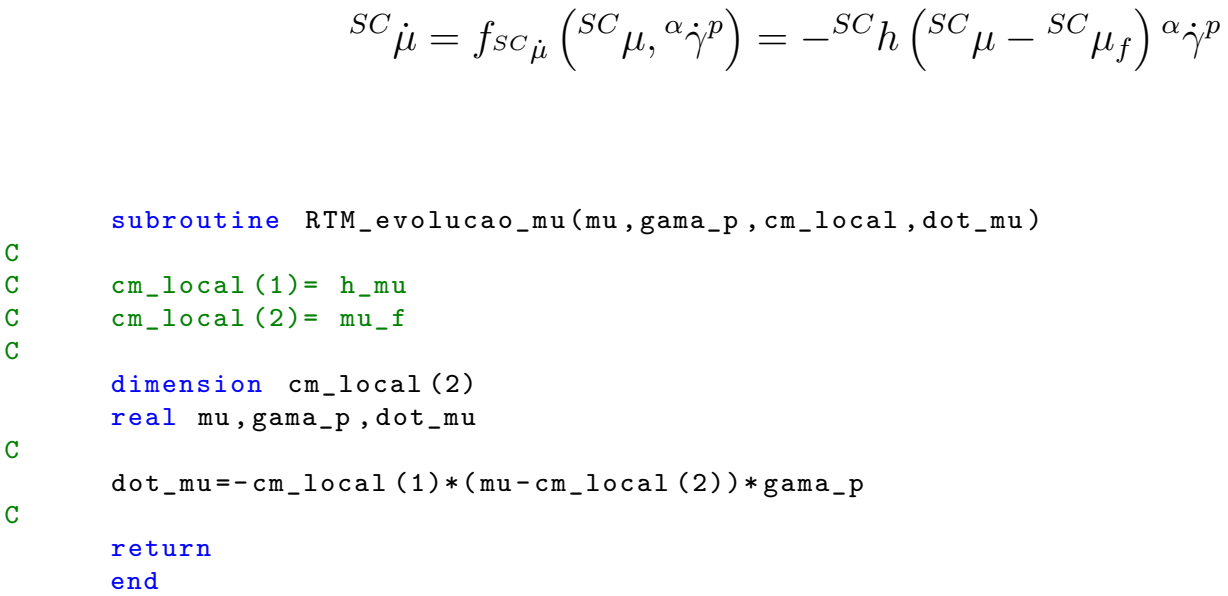

\subsubsection{8 gradiente de expansão térmica $\mathbf{F}^{t}$}

O gradiente de expansão térmica é calculado por

$$
\mathbf{F}^{t}=\exp \left[\alpha\left(\theta-\theta_{0}\right)\right] \mathbf{I}
$$$$
\text { C }
$$

subroutine RTM_calcula_Ft(cm_local, temper, Ft)

dimension Ft $(3,3), \mathrm{cm}_{-}$local (2)

real temper

CET $=\mathrm{cm}_{-}$local (1)

temper_- $0=\mathrm{cm}_{-}$local (2)

Ft $(1,1)=\exp \left(\mathrm{cm}_{-} 10 \mathrm{cal}(1) *\left(\right.\right.$ temper $-\mathrm{cm}_{-}$local $\left.\left.(2)\right)\right)$

Ft $(1,2)=0$

Ft $(1,3)=0$

Ft $(2,1)=0$

Ft $(2,2)=\exp \left(\mathrm{cm}_{-}\right.$local $(1) *\left(\right.$ temper $-\mathrm{cm}_{-}$local $\left.\left.(2)\right)\right)$

Ft $(2,3)=0$

Ft $(3,1)=0$ 


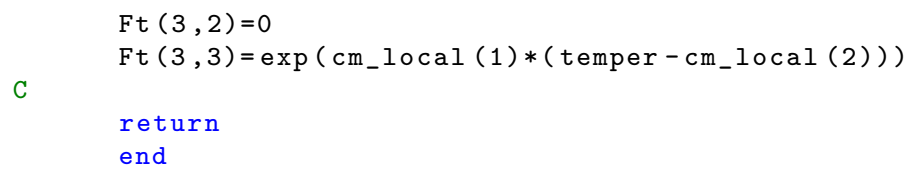

\subsubsection{Atualização da tensão - algoritmo de integração do mo- delo de material em um passo de tempo}

Como o modelo de material será implementado objetivando simulações numérica de fenômenos explícitos, pode-se considerar que os passos de tempo serão pequenos o suficiente para tornar desprezível o erro da aproximação

$$
\dot{\mathbf{F}}_{t}=\frac{\mathbf{F}_{t+\Delta t}-\mathbf{F}_{t}}{\Delta t} \Rightarrow \mathbf{F}_{t+\Delta t}=\dot{\mathbf{F}} \Delta t+\mathbf{F}_{t}
$$

Entretanto, da definição do tensor taxa de deformação, temos

$$
\mathbf{D}_{t}=\dot{\mathbf{F}}_{t} \mathbf{F}_{t}^{-1} \Rightarrow \dot{\mathbf{F}}_{t}=\mathbf{D}_{t} \mathbf{F}_{t}
$$

e dessa maneira podemos calcular o gradiente de deformações no instante $t+\Delta t$ a partir do tensor taxa de deformação no instante $t$ e do gradiente de deformações também no instante $t$ por

$$
\left.\begin{array}{c}
\mathbf{F}_{t+\Delta t}=\dot{\mathbf{F}} \Delta t+\mathbf{F}_{t} \\
\dot{\mathbf{F}}_{t}=\mathbf{D}_{t} \mathbf{F}_{t}
\end{array}\right\} \Rightarrow \mathbf{F}_{t+\Delta t}=\left(\mathbf{D}_{t} \mathbf{F}_{t}\right) \Delta t+\mathbf{F}_{t}=\left(\mathbf{D}_{t} \Delta t+\mathbf{I}\right) \mathbf{F}_{t}
$$

subroutine RTM_calcula_F_-TmaisDT_com_F - $_{-} \mathrm{T}_{-} \mathrm{e}_{-} \mathrm{D}_{-} \mathrm{T}_{-}$(F, D, dt, Ftmdt)

dimension $F(3,3), D(3,3), F t m d t(3,3)$, Parcela $(3,3)$

real dt

C

Parcela $(1,1)=D(1,1) * d t+1.0$

Parcela $(2,1)=D(2,1) * d t$

Parcela $(3,1)=\mathrm{D}(3,1) * d t$

Parcela $(1,2)=\mathrm{D}(1,2) * d t$

Parcela $(2,2)=D(2,2) * d t+1.0$

Parcela $(3,2)=\mathrm{D}(3,2) * d t$

Parcela $(1,3)=D(1,3) * d t$

Parcela $(2,3)=\mathrm{D}(2,3) * d t$

Parcela $(3,3)=D(3,3) * d t+1.0$

call RTM_calcula_mult_matriz (Parcela,F, Ftmdt)

C

return

end 


\subsubsection{1 temperatura}

- Cálculo temperatura

1. $\theta_{t+\Delta t}=\dot{\theta}_{t} \Delta t+\theta_{t}$

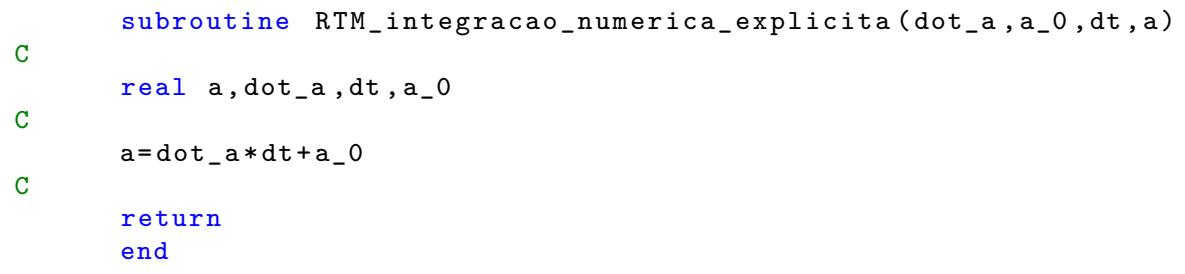

\subsubsection{2 fase $\alpha$}

Sejam conhecidos no instante $t$ :

- ${ }^{\alpha} \mathbf{F}_{t}^{t p},{ }^{\alpha} \mathbf{F}_{t}^{v}$

- ${ }^{\alpha} \mathbf{D}_{t}^{t p},{ }^{\alpha} \mathbf{D}_{t}^{v}$

- ${ }^{\alpha} \dot{s}_{t}^{p},{ }^{\alpha} s_{t}^{p}$,

além do gradiente de deformações e da temperatura no instante $t+\Delta t, \mathbf{F}_{t+\Delta t}$ e $\theta_{t+\Delta t}$ respectivamente, do passo de tempo $\Delta t$ e do coeficiente de expansão linear térmica $\alpha_{\text {termico }}$. Todos podem ser calculados no instante $t+\Delta t$ a partir das seguintes etapas:

- Cálculo dos gradientes de deformação térmico, termo-plásticos, plástico, viscoelástico, viscoso e elástico

1. ${ }^{\alpha} \mathbf{F}_{t+\Delta t}^{t}=\exp \left[\alpha_{\text {termico }}\left(\theta_{t+\Delta t}-\theta_{0}\right)\right] \mathbf{I}$

2. ${ }^{\alpha} \mathbf{F}_{t+\Delta t}^{t p}=\left({ }^{\alpha} \mathbf{D}_{t}^{t p} \Delta t+\mathbf{I}\right){ }^{\alpha} \mathbf{F}_{t}^{t p}$

3. ${ }^{\alpha} \mathbf{F}_{t+\Delta t}^{p}=\left({ }^{\alpha} \mathbf{F}_{t+\Delta t}^{t}\right)^{-1}{ }^{\alpha} \mathbf{F}_{t+\Delta t}^{t p}$;

4. ${ }^{\alpha} \mathbf{F}_{t+\Delta t}^{v e}=\mathbf{F}_{t+\Delta t}\left({ }^{\alpha} \mathbf{F}_{t+\Delta t}^{t p}\right)^{-1}$;

5. ${ }^{\alpha} \mathbf{F}_{t+\Delta t}^{v}=\left({ }^{\alpha} \mathbf{D}_{t}^{v} \Delta t+\mathbf{I}\right){ }^{\alpha} \mathbf{F}_{t}^{v}$;

6. ${ }^{\alpha} \mathbf{F}_{t+\Delta t}^{e}={ }^{\alpha} \mathbf{F}_{t+\Delta t}^{v e}\left({ }^{\alpha} \mathbf{F}_{t+\Delta t}^{v}\right)^{-1}$; 


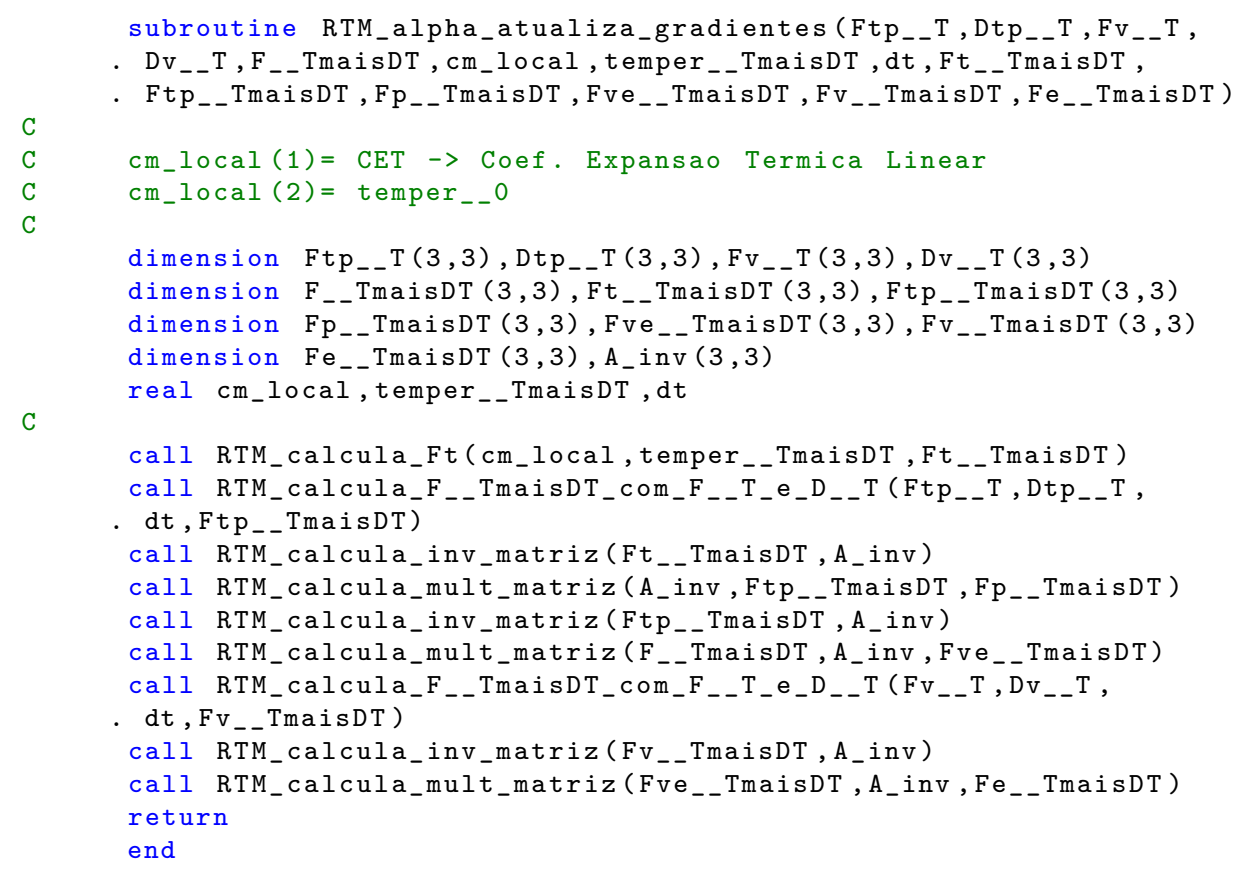

- Cálculo dos tensores de tensão de Cauchy viscoelástico e elástico através de relações constitutivas hiper-elásticas

7. ${ }^{\alpha} \mathbf{T}_{t+\Delta t}^{v e}=f_{8_{\text {cadeias }}}\left({ }^{\alpha} \mathbf{F}_{t+\Delta t}^{v e}\right)$;

8. ${ }^{\alpha} \mathbf{T}_{t+\Delta t}^{e}={ }^{\alpha} s^{v} f_{8_{\text {cadeias }}}\left({ }^{\alpha} \mathbf{F}_{t+\Delta t}^{e}\right)$;

9. ${ }^{\alpha} \mathbf{T}_{t+\Delta t}={ }^{\alpha} \mathbf{T}_{t+\Delta t}^{v e}+{ }^{\alpha} \mathbf{T}_{t+\Delta t}^{e} ;$

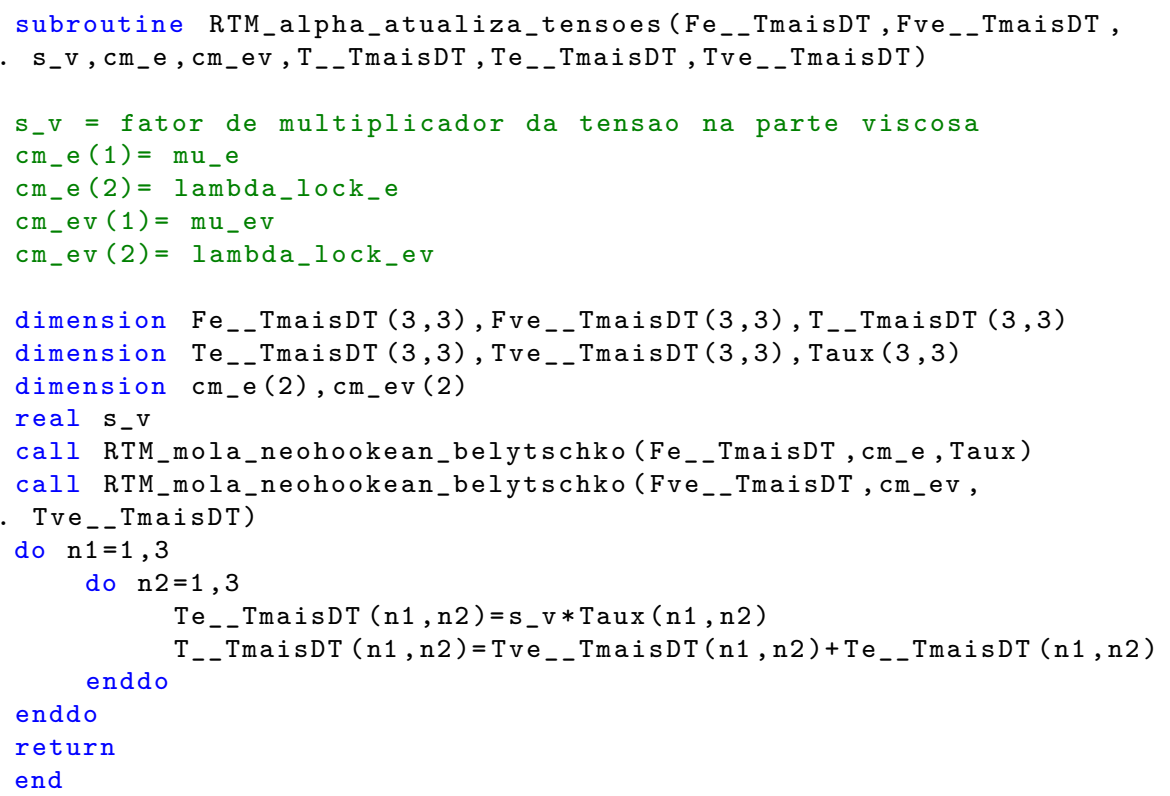


- Cálculo do tensor taxa de deformação plástico através da lei de escoamento e da evolução da variável interna

$$
\begin{aligned}
& \text { 10. }{ }^{\alpha} s_{t+\Delta t}^{p}={ }^{\alpha} \dot{s}_{t}^{p} \Delta t+{ }^{\alpha} s_{t}^{p} ; \\
& \text { 11. }{ }^{\alpha} p_{t+\Delta t}=-\frac{1}{3} \operatorname{tr}\left({ }^{\alpha} \mathbf{T}_{t+\Delta t}\right) ; \\
& \text { 12. }{ }^{\alpha} \mathbf{T}_{t+\Delta t}^{\prime}={ }^{\alpha} \mathbf{T}_{t+\Delta t}+{ }^{\alpha} p_{t+\Delta t} \mathbf{I} ; \\
& \text { 13. }{ }^{\alpha} \tau_{t+\Delta t}=\sqrt{\alpha \mathbf{T}_{t+\Delta t}^{\prime}:{ }^{\alpha} \mathbf{T}_{t+\Delta t}^{\prime}} ; \\
& \text { 14. }{ }^{\alpha} \dot{\gamma}_{t+\Delta t}^{p}=f \dot{\gamma}^{p}\left({ }^{\alpha} \tau_{t+\Delta t},{ }^{\alpha} p_{t+\Delta t},{ }^{\alpha} s_{t+\Delta t}^{p}\right) ; \\
& \text { 15. }{ }^{\alpha} \tilde{\mathbf{T}}_{t+\Delta t}^{\prime}=\left({ }^{\alpha} \mathbf{F}_{t+\Delta t}^{v e}\right){ }^{-1}{ }^{\alpha} \mathbf{T}_{t+\Delta t}^{\prime} \mathbf{F}_{t+\Delta t}^{v e} ; \\
& \text { 16. }{ }^{\alpha} \mathbf{D}_{t+\Delta t}^{p}={ }^{\alpha} \dot{\gamma}_{t+\Delta t}^{p} \frac{{ }^{\alpha} \tilde{\mathbf{T}}_{t+\Delta t}^{\prime}}{{ }^{\alpha} \tau_{t+\Delta t}} ; \\
& \text { 17. }{ }^{\alpha} \dot{s}_{t+\Delta t}^{p}=f_{\alpha \dot{s}^{p}}\left({ }^{\alpha} s_{t+\Delta t}^{p},{ }^{\alpha} \dot{\gamma}_{t+\Delta t}^{p}\right) ;
\end{aligned}
$$

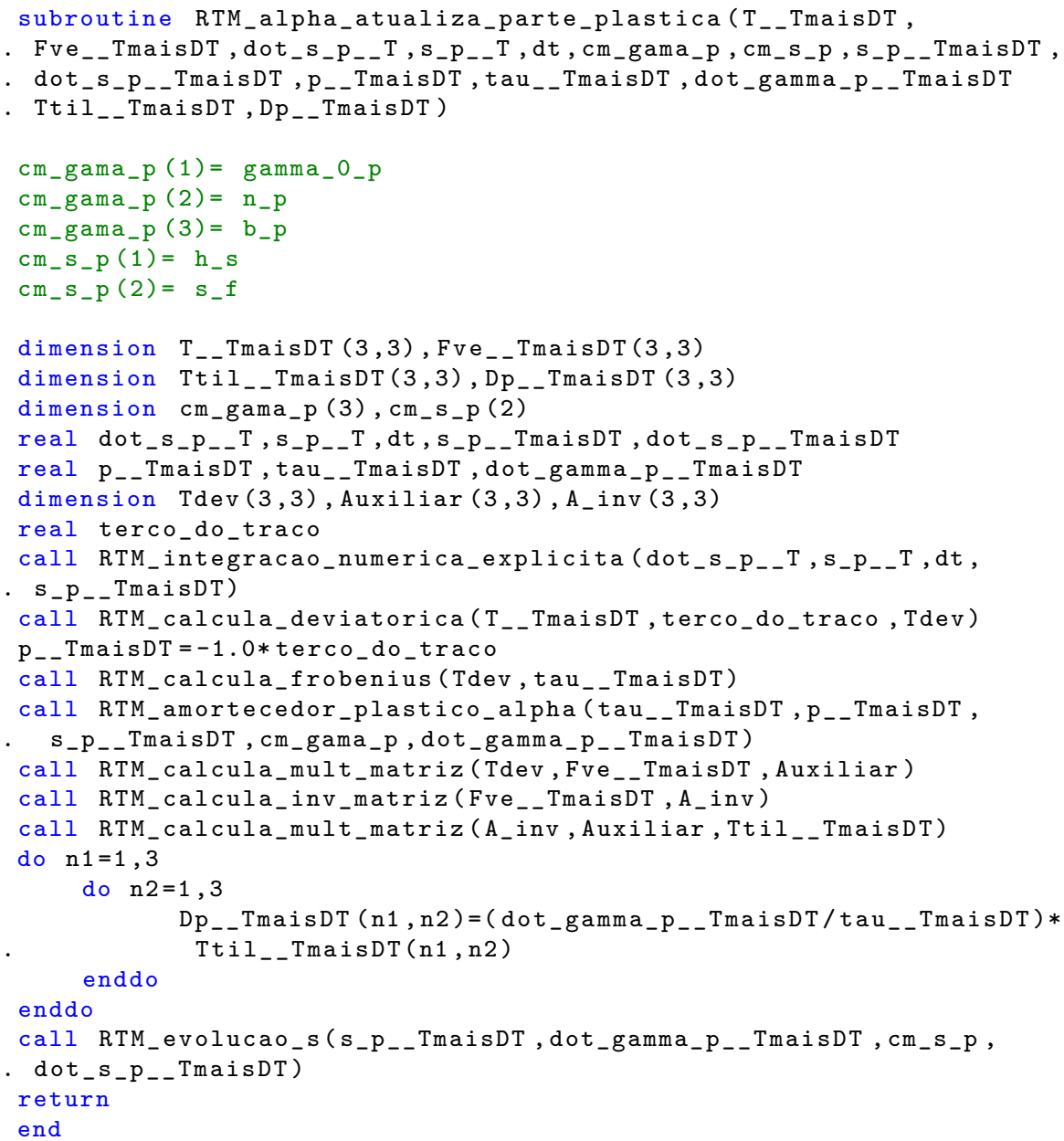


- Cálculo do tensor taxa de deformação viscoso através da lei de escoamento

18. ${ }^{\alpha} p_{t+\Delta t}^{e}=-\frac{1}{3} \operatorname{tr}\left({ }^{\alpha} \mathbf{T}_{t+\Delta t}^{e}\right)$;

19. ${ }^{\alpha} \mathbf{T}_{t+\Delta t}^{e^{\prime}}={ }^{\alpha} \mathbf{T}_{t+\Delta t}^{e}+{ }^{\alpha} p_{t+\Delta t}^{e} \mathbf{I}$;

20. ${ }^{\alpha} \tau_{t+\Delta t}^{e}=\sqrt{{ }^{\alpha} \mathbf{T}_{t+\Delta t}^{e^{\prime}}:{ }^{\alpha} \mathbf{T}_{t+\Delta t}^{e^{\prime}}} ;$

21. ${ }^{\alpha} \mathbf{B}_{t+\Delta t}^{v *}=\left({ }^{\alpha} J_{t+\Delta t}^{v}\right)^{-2 / 3}{ }^{\alpha} \mathbf{F}_{t+\Delta t}^{v}\left({ }^{\alpha} \mathbf{F}_{t+\Delta t}^{v}\right)^{T}$

22. ${ }^{\alpha} \bar{\lambda}_{t+\Delta t}=\sqrt{\frac{\operatorname{tr}\left({ }^{\alpha} \mathbf{B}_{t+\Delta t}^{v *}\right)}{3}}$

23. ${ }^{\alpha} \dot{\gamma}_{d e v_{t+\Delta t}}^{v}=f_{\dot{\gamma}_{\text {dev }}^{v}}\left({ }^{\alpha} \tau_{t+\Delta t}^{e},{ }^{\alpha} p_{t+\Delta t}^{e},{ }^{\alpha} \bar{\lambda}_{t+\Delta t}\right)$;

24. ${ }^{\alpha} \dot{\gamma}_{v o l_{t+\Delta t}}^{v}=f_{\dot{\gamma}_{\text {vol }}^{v}}\left({ }^{\alpha} p_{t+\Delta t}^{e}\right)$

25. ${ }^{\alpha} \mathbf{D}_{t+\Delta t}^{v}=\left({ }^{\alpha} \mathbf{F}_{t+\Delta t}^{e}\right)^{-1}\left({ }^{\alpha} \dot{\gamma}_{d e v_{t+\Delta t}}^{v} \frac{{ }^{\alpha} \mathbf{T}_{t+\Delta t}^{e^{\prime}}}{{ }^{\alpha} \tau_{t+\Delta t}^{e}}+{ }^{\alpha} \dot{\gamma}_{v o l_{t+\Delta t}}^{v} \mathbf{I}\right){ }^{\alpha} \mathbf{F}_{t+\Delta t}^{e}$

Conforme verificado nos ensaios experimentais de relaxação com DIC, há um comportamento predominante de cisalhamento na parte visco-elástica, com a implementação desconsiderando ${ }^{\alpha} \dot{\gamma}_{v_{o l} l_{t+\Delta}}$.

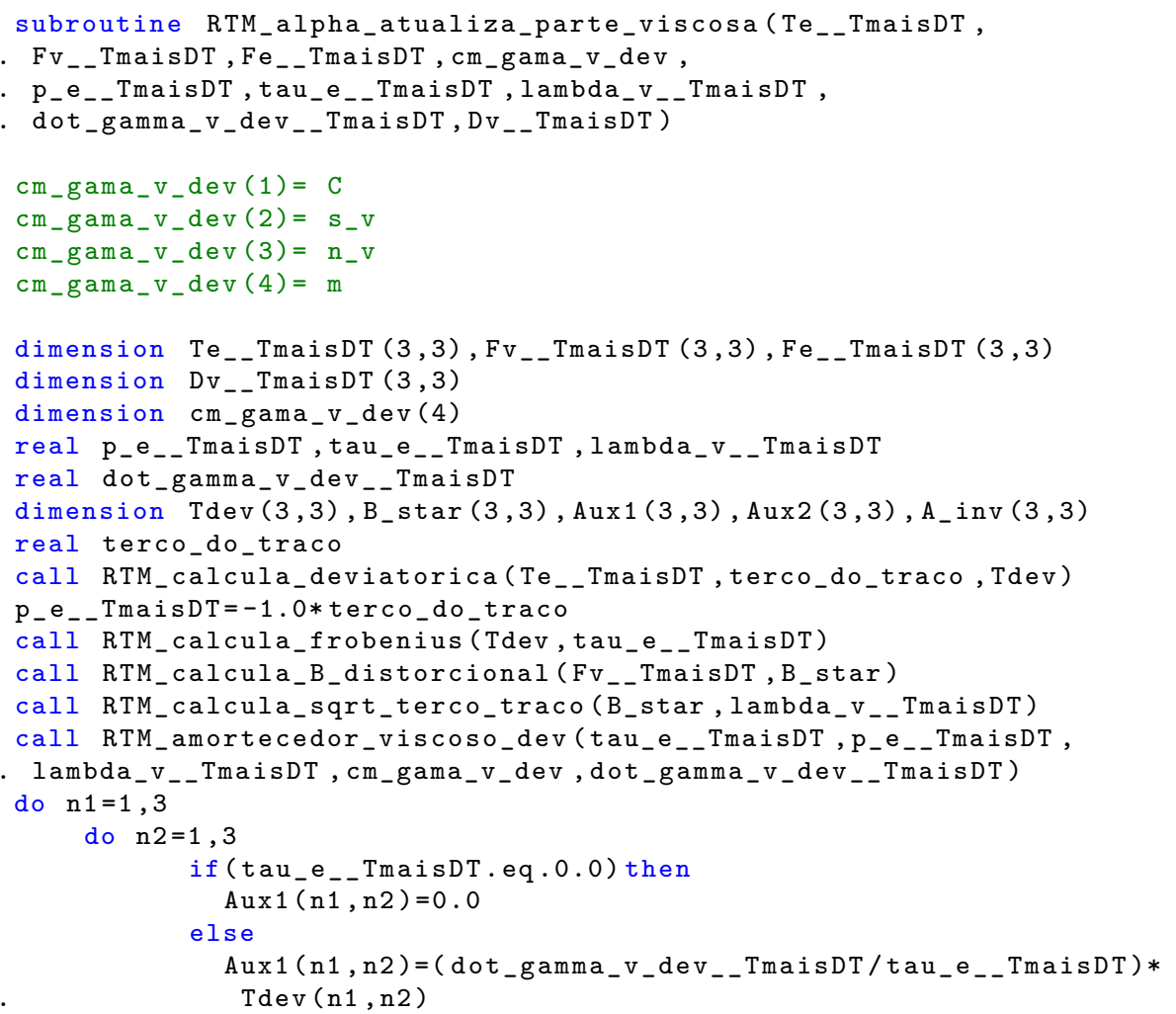




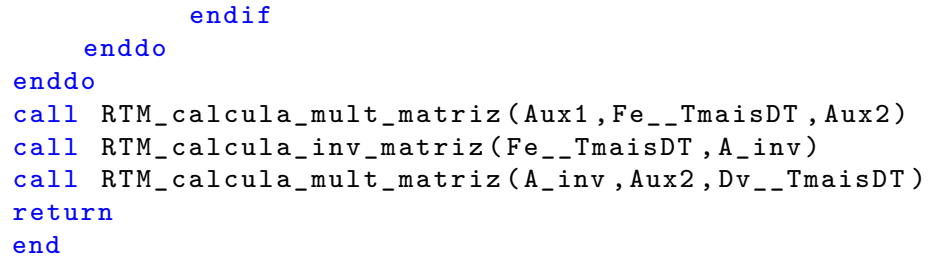

\subsubsection{3 fase $\beta$ (apenas para o modelo de material para termo-plásticos amor- fos)}

Sejam conhecidos no instante $t$ :

- ${ }^{\beta} \mathbf{F}_{t}^{t p},{ }^{\beta} \mathbf{F}_{t}^{v}$

- ${ }^{\beta} \mathbf{D}_{t}^{t p},{ }^{\beta} \mathbf{D}_{t}^{v}$

além do gradiente de deformações e da temperatura no instante $t+\Delta t, \mathbf{F}_{t+\Delta t}$ e $\theta_{t+\Delta t}$ respectivamente, do passo de tempo $\Delta t$ e do coeficiente de expansão linear térmica $\alpha_{\text {termico }}$. Todos podem ser calculados no instante $t+\Delta t$ a partir das seguintes etapas:

- Cálculo dos gradientes de deformação térmico, termo-plásticos, plástico, viscoelástico, viscoso e elástico

1. ${ }^{\beta} \mathbf{F}_{t+\Delta t}^{t}=\exp \left[\alpha_{\text {termico }}\left(\theta_{t+\Delta t}-\theta_{0}\right)\right] \mathbf{I}$;

2. ${ }^{\beta} \mathbf{F}_{t+\Delta t}^{t p}=\left({ }^{\beta} \mathbf{D}_{t}^{t p} \Delta t+\mathbf{I}\right){ }^{\beta} \mathbf{F}_{t}^{t p}$;

3. ${ }^{\beta} \mathbf{F}_{t+\Delta t}^{p}=\left({ }^{\beta} \mathbf{F}_{t+\Delta t}^{t}\right)^{-1}{ }^{\beta} \mathbf{F}_{t+\Delta t}^{t p}$;

4. ${ }^{\beta} \mathbf{F}_{t+\Delta t}^{v e}=\mathbf{F}_{t+\Delta t}\left({ }^{\beta} \mathbf{F}_{t+\Delta t}^{t p}\right)^{-1}$;

5. ${ }^{\beta} \mathbf{F}_{t+\Delta t}^{v}=\left({ }^{\beta} \mathbf{D}_{t}^{v} \Delta t+\mathbf{I}\right){ }^{\beta} \mathbf{F}_{t}^{v}$;

6. ${ }^{\beta} \mathbf{F}_{t+\Delta t}^{e}={ }^{\beta} \mathbf{F}_{t+\Delta t}^{v e}\left({ }^{\beta} \mathbf{F}_{t+\Delta t}^{v}\right)^{-1}$;

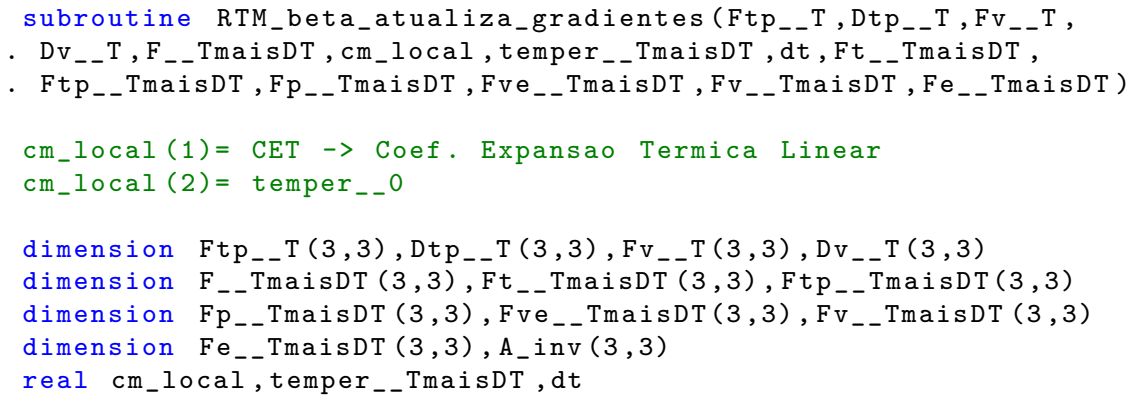




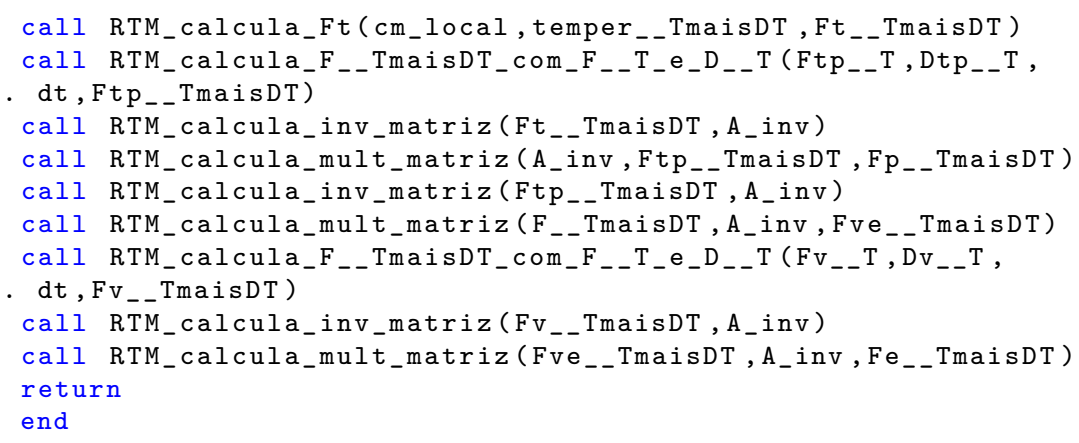

- Cálculo dos tensores de tensão de Cauchy viscoelástico e elástico através de relações constitutivas hiper-elásticas

7. ${ }^{\beta} \mathbf{T}_{t+\Delta t}^{v e}=f_{8_{\text {cadeias }}}\left({ }^{\beta} \mathbf{F}_{t+\Delta t}^{v e}\right) ;$

8. ${ }^{\beta} \mathbf{T}_{t+\Delta t}^{e}={ }^{\beta} s^{v} f_{8_{\text {cadeias }}}\left({ }^{\beta} \mathbf{F}_{t+\Delta t}^{e}\right)$;

9. ${ }^{\beta} \mathbf{T}_{t+\Delta t}={ }^{\beta} \mathbf{T}_{t+\Delta t}^{v e}+{ }^{\beta} \mathbf{T}_{t+\Delta t}^{e} ;$

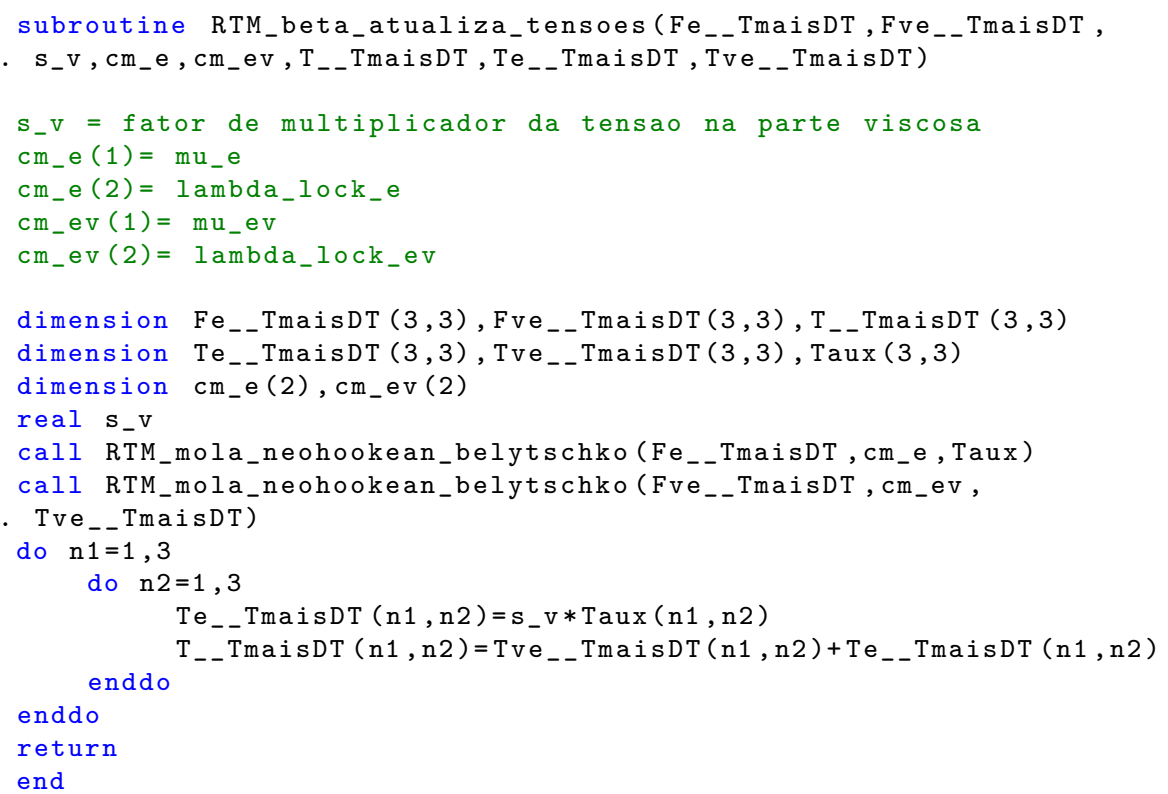

- Cálculo do tensor taxa de deformação plástico através da lei de escoamento e da evolução da variável interna
10. ${ }^{\beta} p_{t+\Delta t}=-\frac{1}{3} \operatorname{tr}\left({ }^{\beta} \mathbf{T}_{t+\Delta t}\right) ;$
11. ${ }^{\beta} \mathbf{T}_{t+\Delta t}^{\prime}={ }^{\beta} \mathbf{T}_{t+\Delta t}+{ }^{\beta} p_{t+\Delta t} \mathbf{I} ;$ 
12. ${ }^{\beta} \tau_{t+\Delta t}=\sqrt{{ }^{\beta} \mathbf{T}_{t+\Delta t}^{\prime}:{ }^{\beta} \mathbf{T}_{t+\Delta t}^{\prime}} ;$

13. ${ }^{\beta} \dot{\gamma}_{t+\Delta t}^{p}=f_{\beta \dot{\gamma}^{p}}\left({ }^{\beta} \tau_{t+\Delta t}\right)$;

14. ${ }^{\beta} \tilde{\mathbf{T}}_{t+\Delta t}^{\prime}=\left({ }^{\beta} \mathbf{F}_{t+\Delta t}^{v e}\right)^{-1}{ }^{\beta} \mathbf{T}_{t+\Delta t}^{\prime}{ }^{\beta} \mathbf{F}_{t+\Delta t}^{v e} ;$

15. ${ }^{\beta} \mathbf{D}_{t+\Delta t}^{p}={ }^{\beta} \dot{\gamma}_{t+\Delta t}^{p} \frac{\beta}{\beta} \tilde{\mathbf{T}}_{t+\Delta t}^{\prime} \tau_{t+\Delta t}$

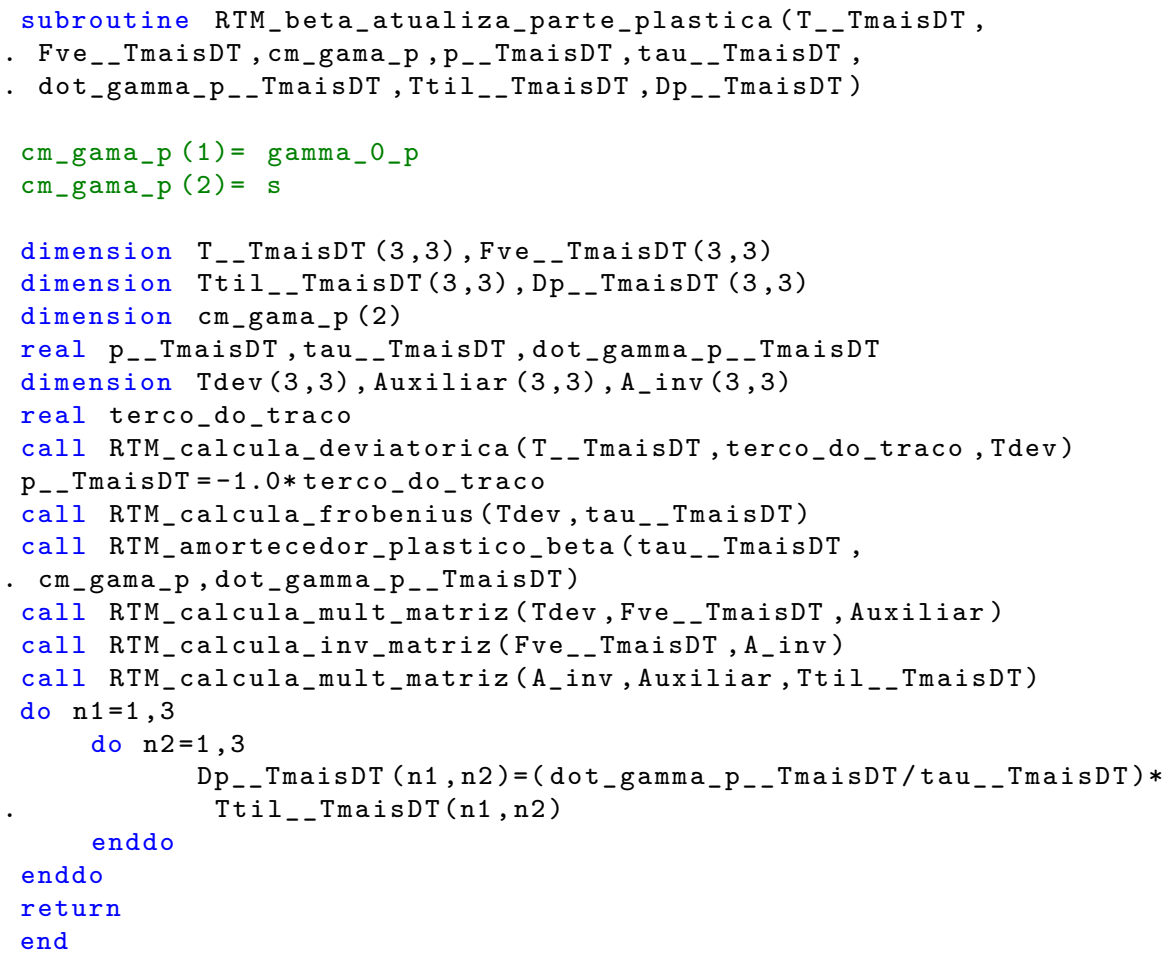

- Cálculo do tensor taxa de deformação viscoso através da lei de escoamento
16. ${ }^{\beta} p_{t+\Delta t}^{e}=-\frac{1}{3} \operatorname{tr}\left({ }^{\beta} \mathbf{T}_{t+\Delta t}^{e}\right)$;
17. ${ }^{\beta} \mathbf{T}_{t+\Delta t}^{e^{\prime}}={ }^{\beta} \mathbf{T}_{t+\Delta t}^{e}+{ }^{\beta} p_{t+\Delta t}^{e} \mathbf{I}$
18. ${ }^{\beta} \tau_{t+\Delta t}^{e}=\sqrt{{ }^{\beta} \mathbf{T}_{t+\Delta t}^{e^{\prime}}:{ }^{\beta} \mathbf{T}_{t+\Delta t}^{e^{\prime}}} ;$
19. ${ }^{\beta} \mathbf{B}_{t+\Delta t}^{v *}=\left({ }^{\beta} J_{t+\Delta t}^{v}\right)^{-2 / 3}{ }^{\beta} \mathbf{F}_{t+\Delta t}^{v}\left({ }^{\beta} \mathbf{F}_{t+\Delta t}^{v}\right)^{T}$
20. ${ }^{\beta} \bar{\lambda}_{t+\Delta t}=\sqrt{\frac{\operatorname{tr}\left({ }^{\beta} \mathbf{B}_{t+\Delta t}^{v *}\right)}{3}}$
21. ${ }^{\beta} \dot{\gamma}_{d e v_{t+\Delta t}}^{v}=f_{\dot{\gamma}_{d e v}^{v}}\left({ }^{\beta} \tau_{t+\Delta t}^{e},{ }^{\beta} p_{t+\Delta t}^{e},{ }^{\beta} \bar{\lambda}_{t+\Delta t}\right)$;
22. ${ }^{\beta} \dot{\gamma}_{v_{\text {ol }}}^{v+\Delta t}=f_{\dot{\gamma}_{\text {vol }}^{v}}\left({ }^{\beta} p_{t+\Delta t}^{e}\right)$ 
23. ${ }^{\beta} \mathbf{D}_{t+\Delta t}^{v}=\left({ }^{\beta} \mathbf{F}_{t+\Delta t}^{e}\right)^{-1}\left({ }^{\beta} \dot{\gamma}_{d e v_{t+\Delta t}}^{v} \frac{{ }^{\beta} \mathbf{T}_{t+\Delta t}^{e^{\prime}}}{\beta} \tau_{t+\Delta t}^{e}+{ }^{\beta} \dot{\gamma}_{v o l_{t+\Delta t}}^{v} \mathbf{I}\right){ }^{\beta} \mathbf{F}_{t+\Delta t}^{e}$

Conforme verificado nos ensaios experimentais de relaxação com DIC, há um comportamento predominante de cisalhamento na parte visco-elástica, com a implementação desconsiderando ${ }^{\beta} \dot{\gamma}_{v o l_{t+\Delta t}}^{v}$

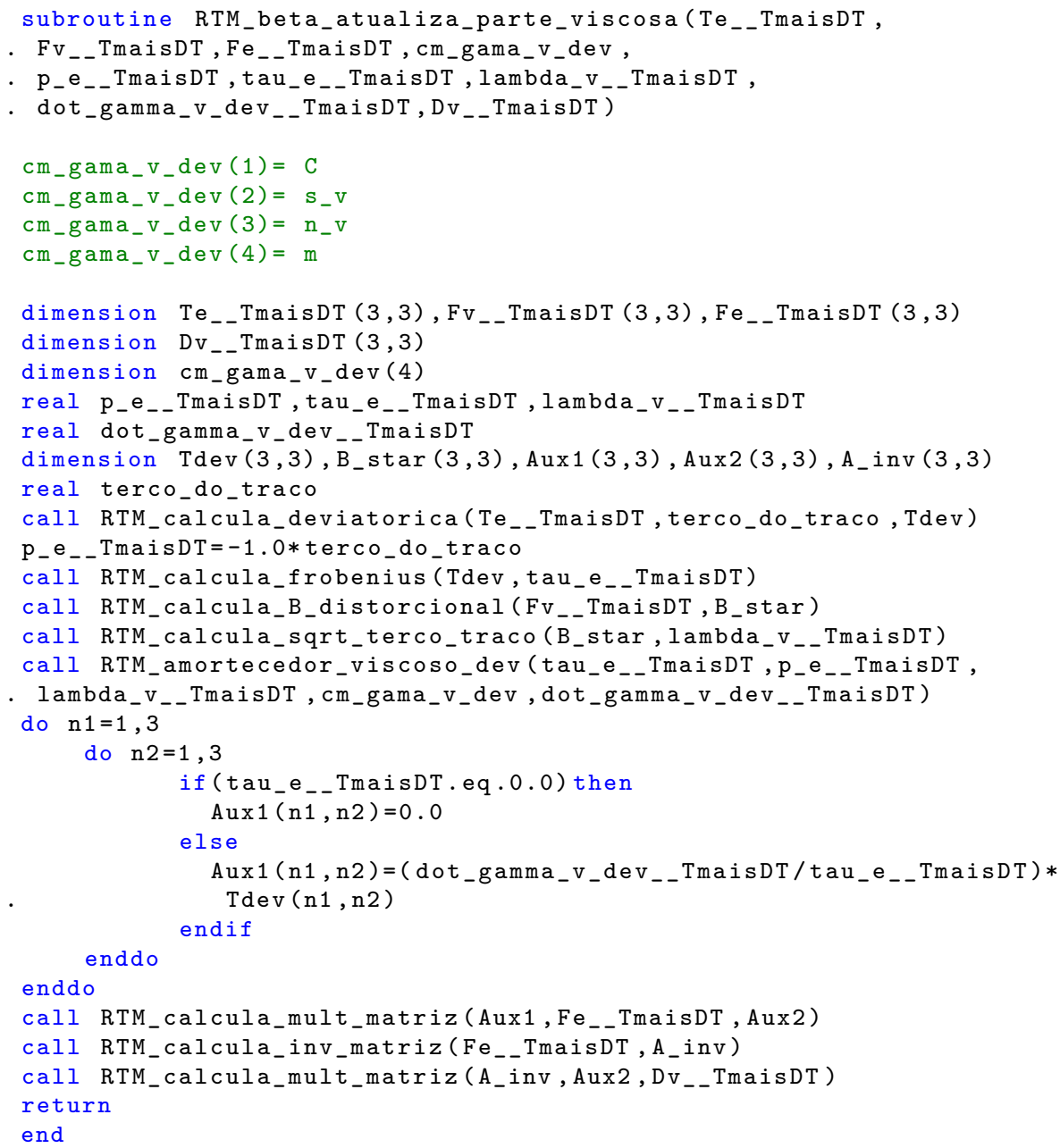

\subsubsection{4 fase semicristalina (apenas para o modelo de material para termo- plásticos semiclistalinos)}

Sejam conhecidos no instante $t$ :

- ${ }^{S C} \mathbf{F}_{t}^{v}$

- ${ }^{S C} \mathbf{D}_{t}^{v}$ 
- ${ }^{S C} \dot{\mu}_{t},{ }^{S C} \mu_{t}$

além do gradiente de deformações e do módulo do tensor taxa de deformação plástica da fase $\alpha$ no instante $t+\Delta t, \mathbf{F}_{t+\Delta t} \mathrm{e}^{\alpha} \dot{\gamma}_{t+\Delta t}^{p}$ respectivamente, e do passo de tempo $\Delta t$. Todos podem ser calculados no instante $t+\Delta t$ a partir das seguintes etapas:

- Cálculo dos gradientes de deformação viscoso e elástico

$$
\begin{aligned}
& \text { 1. }{ }^{S C} \mathbf{F}_{t+\Delta t}^{v}=\left({ }^{S C} \mathbf{D}_{t}^{v} \Delta t+\mathbf{I}\right){ }^{S C} \mathbf{F}_{t}^{v} \\
& \text { 2. }{ }^{S C} \mathbf{F}_{t+\Delta t}^{e}={ }^{S C} \mathbf{F}_{t+\Delta t}\left({ }^{S C} \mathbf{F}_{t+\Delta t}^{v}\right)^{-1} ;
\end{aligned}
$$

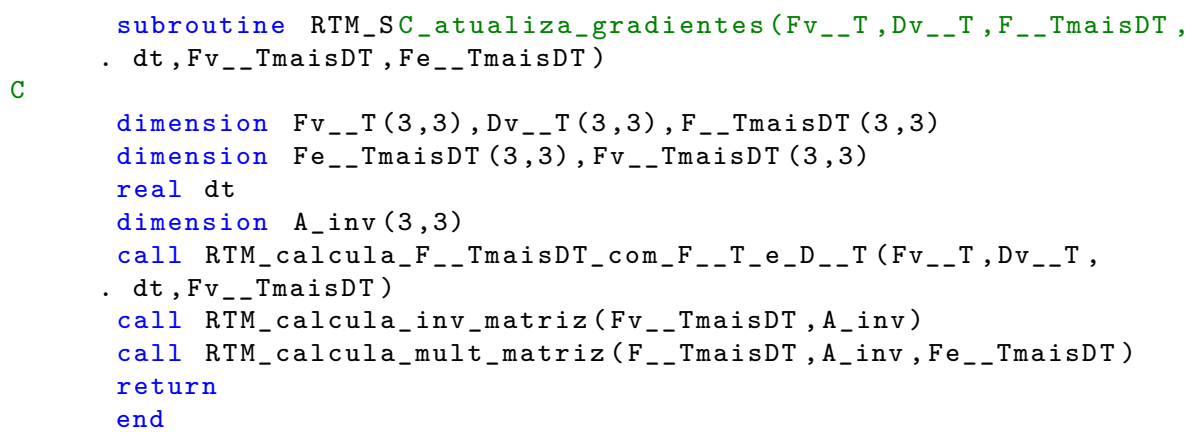

- Cálculo da evolução da variável interna, neste caso o módulo cisalhante,

$$
\begin{aligned}
& \text { 3. }{ }^{S C} \mu_{t+\Delta t}={ }^{S C} \dot{\mu}_{t} \Delta t+{ }^{S C} \mu_{t} ; \\
& \text { 4. }{ }^{S C} \dot{\mu}_{t+\Delta t}=f_{S C \dot{\mu}}\left({ }^{S C} \mu_{t+\Delta t},{ }^{\alpha} \dot{\gamma}_{t+\Delta t}^{p}\right) \text {; }
\end{aligned}
$$

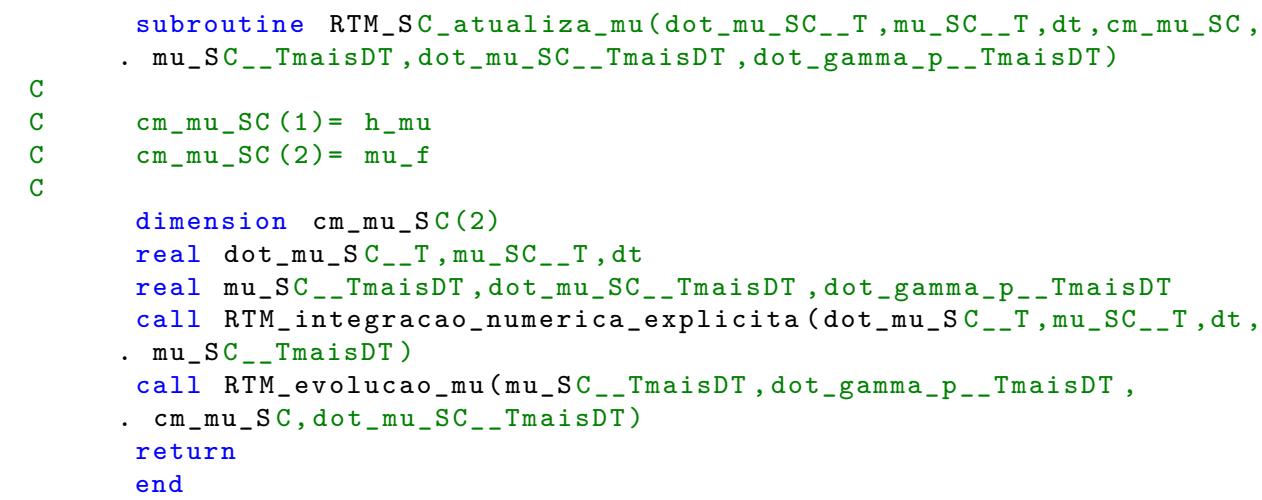

- Cálculo do tensor de tensão de Cauchy elástico através de uma relação constitutiva hiper-elástica 
5. ${ }^{S C} \mathbf{T}_{t+\Delta t}=f_{8_{\text {cadeias }}}\left({ }^{S C} \mathbf{F}_{t+\Delta t}^{e},{ }^{S C} \mu_{t+\Delta t}\right) ;$

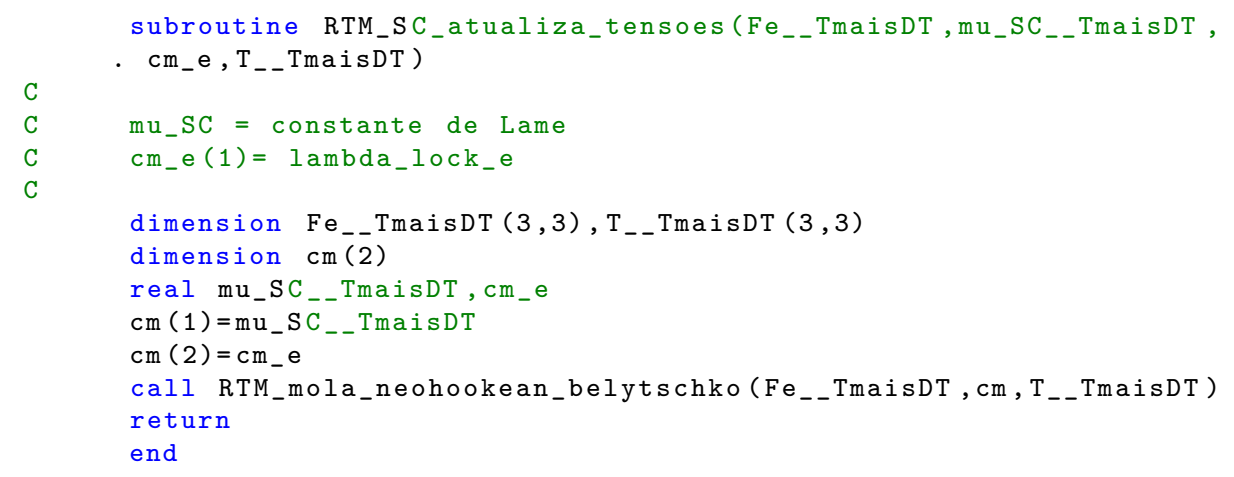

- Cálculo do tensor taxa de deformação viscoso através da lei de escoamento

$$
\begin{aligned}
& \text { 6. }{ }^{S C} p_{t+\Delta t}=-\frac{1}{3} \operatorname{tr}\left({ }^{S C} \mathbf{T}_{t+\Delta t}\right) ; \\
& \text { 7. }{ }^{S C} \mathbf{T}_{t+\Delta t}^{\prime}={ }^{S C} \mathbf{T}_{t+\Delta t}+{ }^{S C} p_{t+\Delta t} \mathbf{I} \text {; } \\
& \text { 8. }{ }^{S C} \tau_{t+\Delta t}=\sqrt{{ }^{S C} \mathbf{T}_{t+\Delta t}^{\prime}:{ }^{S C} \mathbf{T}_{t+\Delta t}^{\prime}} ; \\
& \text { 9. }{ }^{S C} \mathbf{B}_{t+\Delta t}^{v *}=\left({ }^{S C} J_{t+\Delta t}^{v}\right)^{-2 / 3}{ }^{S C} \mathbf{F}_{t+\Delta t}^{v}\left({ }^{S C} \mathbf{F}_{t+\Delta t}^{v}\right)^{T} \\
& \text { 10. }{ }^{S C} \overline{\lambda v}_{t+\Delta t}=\sqrt{\frac{\operatorname{tr}\left({ }^{S C} \mathbf{B}_{t+\Delta t}^{v *}\right)}{3}} \\
& \text { 11. }{ }^{S C} \dot{\gamma}_{d e v_{t+\Delta t}}^{v}=f_{\dot{\gamma}_{\text {dev }}^{v}}\left({ }^{S C} \tau_{t+\Delta t}^{e},{ }^{S C} p_{t+\Delta t}^{e},{ }^{S C} \bar{\lambda}_{t+\Delta t}\right) \text {; } \\
& \text { 12. }{ }^{S C} \dot{\gamma}_{v_{o l} l_{t+\Delta t}}^{v}=f_{\dot{\gamma}_{\text {dev }}^{v}}\left({ }^{S C} p_{t+\Delta t}\right) \\
& \text { 13. }{ }^{S C} \mathbf{D}_{t+\Delta t}^{v}=\left({ }^{S C} \mathbf{F}_{t+\Delta t}^{e}\right)^{-1}\left({ }^{S C} \dot{\gamma}_{d e v_{t+\Delta t}} \frac{{ }^{S C} \mathbf{T}_{t+\Delta t}^{\prime}}{S C} \tau_{t+\Delta t}{ }^{S C} \dot{\gamma}_{v o l+\Delta t}^{v} \mathbf{I}\right){ }^{S C} \mathbf{F}_{t+\Delta t}^{e}
\end{aligned}
$$

Conforme verificado nos ensaios experimentais de relaxação com DIC, há um comportamento predominante de cisalhamento na parte visco-elástica, com a imple-

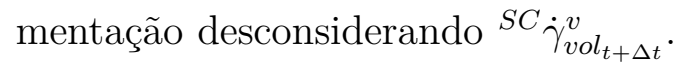

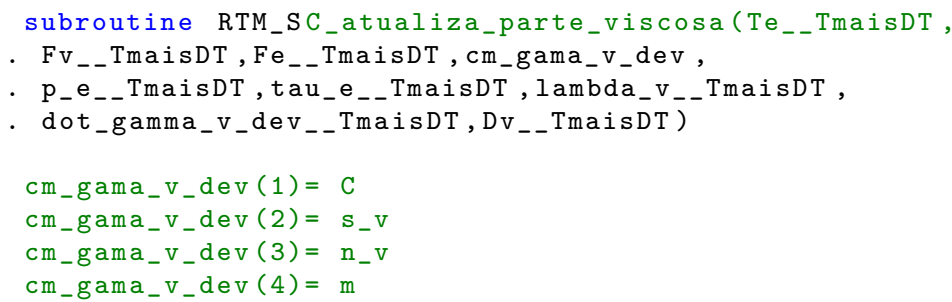


C

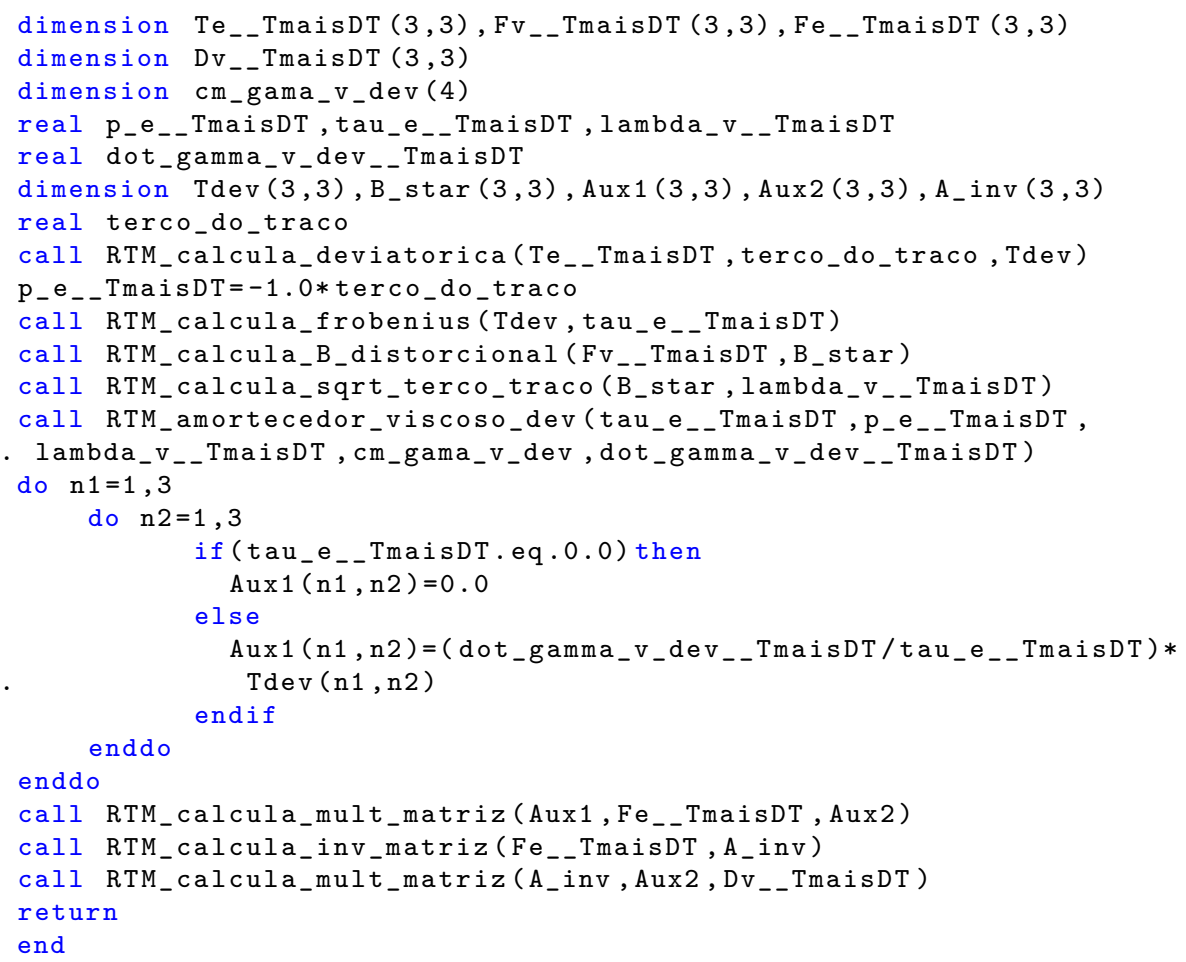

\subsubsection{5 resistência entrópica}

Seja conhecido o gradiente de deformações no instante $t+\Delta t, \mathbf{F}_{t+\Delta t}$, pode-se obter o tensor de tensões de Cauchy do mesmo no instante $t+\Delta t$ através de

1. ${ }^{R E} \mathbf{T}_{t+\Delta t}=f_{8_{\text {cadeias }}+I_{2}}\left({ }^{R E} \mathbf{F}_{t+\Delta t}\right)$;

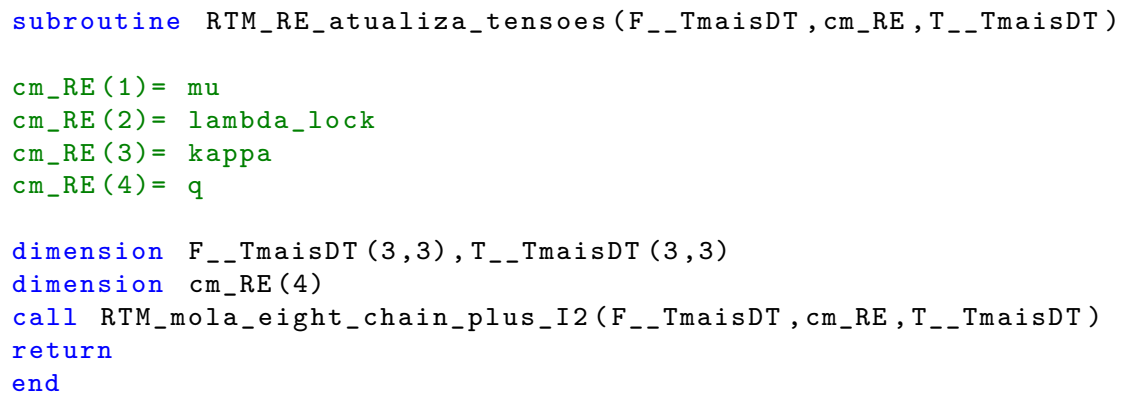

\subsubsection{6 taxa de temperatura}

No modelo para termoplásticos amorfos, a fase $\beta$ sempre irá contribuir para o aumento da temperatura do material na conversão de energia mecânica oriunda da deformação 
plástica em energia térmica uma vez que está ativa somente em altas taxas de deformação, ou seja, não há tempo suficiente para que haja transferência de calor, configurando-se um sistema adiabático. Entretanto, a colaboração da fase $\alpha$ poderá ser tratada como um sistema adiabático, isotérmico ou uma interpolação dos dois através do módulo de Frobenius do tensor taxa de deformação plástica.

Desta forma, podemos ter:

- fase $\alpha$ adiabática

$$
\text { 1. } \dot{\theta}_{t+\Delta t}=\frac{\operatorname{tr}\left(\alpha \tilde{\mathbf{T}}_{t+\Delta t}^{\prime}{ }^{\alpha} \mathbf{D}_{t+\Delta t}^{p}\right)}{\rho c_{p}}+\frac{\operatorname{tr}\left({ }^{\beta} \tilde{\mathbf{T}}_{t+\Delta t}^{\prime}{ }^{\beta} \mathbf{D}_{t+\Delta t}^{p}\right)}{\rho c_{p}}
$$

- fase $\alpha$ isotérmica

$$
\text { 1. } \dot{\theta}_{t+\Delta t}=\frac{\operatorname{tr}\left({ }^{\beta} \tilde{\mathbf{T}}_{t+\Delta t}^{\prime}{ }^{\beta} \mathbf{D}_{t+\Delta t}^{p}\right)}{\rho c_{p}}
$$

- fase $\alpha$ com comportamento intermediário entre adiabático e isotérmico através de uma interpolação com um fator $f_{\text {termico }}$, calculado em função do módulo de Frobenius do tensor taxa de deformação plástica, regulando a porcentagem de energia convertida mecânica plástica convertida em calor

$$
\text { 1. } \dot{\theta}_{t+\Delta t}=f_{\text {termico }} \frac{\operatorname{tr}\left({ }^{\alpha} \tilde{\mathbf{T}}_{t+\Delta t}^{\prime}{ }^{\alpha} \mathbf{D}_{t+\Delta t}^{p}\right)}{\rho c_{p}}+\frac{\operatorname{tr}\left({ }^{\beta} \tilde{\mathbf{T}}_{t+\Delta t}^{\prime}{ }^{\beta} \mathbf{D}_{t+\Delta t}^{p}\right)}{\rho c_{p}}
$$

no qual

$$
\text { 2. } f_{\text {termico }}= \begin{cases}0, & \text { se } \log _{10}\left({ }^{\alpha} \dot{\gamma}_{t+\Delta t}^{p}\right)<-3 \\ \frac{\log _{10}\left({ }^{\alpha} \dot{\gamma}_{t+\Delta t}^{p}\right)+3}{5}, & \text { se }-3<\log _{10}\left({ }^{\alpha} \dot{\gamma}_{t+\Delta t}^{p}\right)<2 \\ 1, & \text { se } \log _{10}\left({ }^{\alpha} \dot{\gamma}_{t+\Delta t}^{p}\right)>2\end{cases}
$$

No modelo de material para termo-plásticos semicristalinos, não há fase $\beta$ e a taxa temporal da temperatura depende apenas da deformação plástica da fase $\alpha$, sendo

- fase $\alpha$ adiabática

$$
\text { 1. } \dot{\theta}_{t+\Delta t}=\frac{\operatorname{tr}\left({ }^{\alpha} \tilde{\mathbf{T}}_{t+\Delta t}^{\prime}{ }^{\alpha} \mathbf{D}_{t+\Delta t}^{p}\right)}{\rho c_{p}}
$$

- fase $\alpha$ isotérmica

1. $\dot{\theta}_{t+\Delta t}=0$ 
- fase $\alpha$ com comportamento intermediário entre adiabático e isotérmico através de uma interpolação com um fator $f_{\text {termico }}$, calculado em função do módulo de Frobenius do tensor taxa de deformação plástica, regulando a porcentagem de energia convertida mecânica plástica convertida em calor

1. $\dot{\theta}_{t+\Delta t}=f_{\text {termico }} \frac{\operatorname{tr}\left({ }^{\alpha} \tilde{\mathbf{T}}_{t+\Delta t}^{\prime}{ }^{\alpha} \mathbf{D}_{t+\Delta t}^{p}\right)}{\rho c_{p}}$

no qual, novamente,

2. $f_{\text {termico }}= \begin{cases}0, & \text { se } \log _{10}\left({ }^{\alpha} \dot{\gamma}_{t+\Delta t}^{p}\right)<-3 \\ \frac{\log _{10}\left({ }^{\alpha} \dot{\gamma}_{t+\Delta t}^{p}\right)+3}{5}, & \text { se }-3<\log _{10}\left({ }^{\alpha} \dot{\gamma}_{t+\Delta t}^{p}\right)<2 \\ 1, & \text { se } \log _{10}\left({ }^{\alpha} \dot{\gamma}_{t+\Delta t}^{p}\right)>2\end{cases}$

\subsubsection{7 tensor taxa de deformação termoplástico}

No modelo para termoplásticos amorfos, após o cálculo da taxa de temperatura, é possível calcular os tensores taxa de deformação termoplástico de ambas as fases $\alpha$ e $\beta$ no instante $t+\Delta t$ através de

- fase $\alpha$

1. ${ }^{\alpha} \mathbf{D}_{t+\Delta t}^{t p}={ }^{\alpha} \mathbf{D}_{t+\Delta t}^{p}+\alpha_{\text {termico }} \dot{\theta}_{t+\Delta t} \mathbf{I}$

- fase $\beta$

2. ${ }^{\beta} \mathbf{D}_{t+\Delta t}^{t p}={ }^{\beta} \mathbf{D}_{t+\Delta t}^{p}+\alpha_{\text {termico }} \dot{\theta}_{t+\Delta t} \mathbf{I}$

subroutine RTM_amorfo_atualiza_dot_temper_e_Dtp(alpha_Dp_-TmaisDT ,

- beta_Dp_-TmaisDT, alpha_Ttil__TmaisDT, beta_Ttil__TmaisDT,

- alpha_dot_gamma_p__TmaisDT, cm_local, alpha_Dtp_-TmaisDT,

- beta_Dtp_-TmaisDT, f_termico, dot_temper__TmaisDT)

cm_local $(1)=$ CET $\rightarrow$ Coef. Expansao Termica Linear

$\mathrm{cm}$-local $(2)=$ densidade

$\mathrm{cm}_{-}$local $(3)=\mathrm{Cp} \rightarrow$ calor espec;fico

dimension alpha_Ttil__TmaisDT $(3,3)$, beta_Ttil__TmaisDT $(3,3)$

dimension alpha Dp TmaisDT $(3,3)$, beta Dp TmaisDT $(3,3)$

dimension alpha_Dtp_-TmaisDT $(3,3)$, beta_Dtp_-TmaisDT $(3,3)$

dimension cm_local (3)

real alpha_dot_gamma_p__TmaisDT, dot_temper__TmaisDT,f_termico

dimension Parcela1 $(3,3)$, Parcela2 $(3,3)$

call RTM_calcula_fator_termico(alpha_dot_gamma_p_-TmaisDT,

f_termico)

call RTM_calcula_mult_matriz(alpha_Ttil__TmaisDT, 


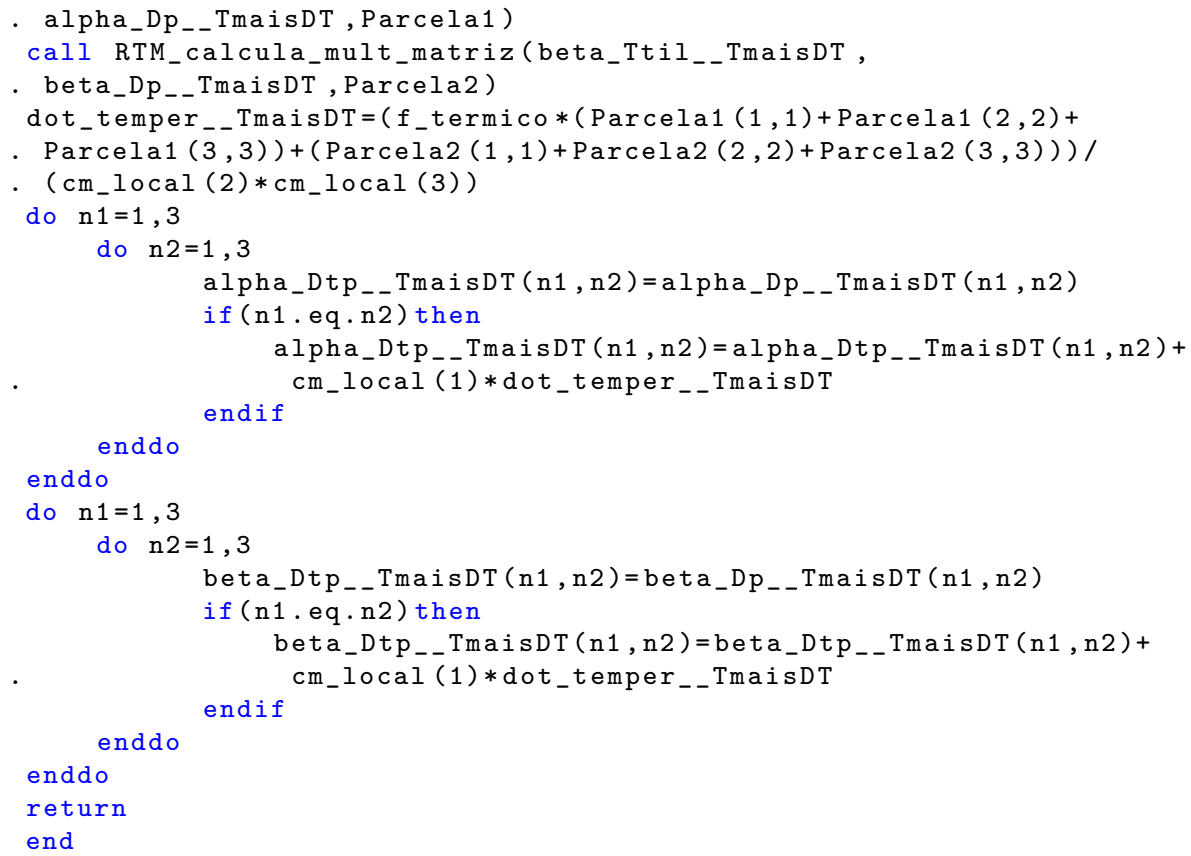

No modelo para termo-plásticos semicristalinos, após o cálculo da taxa de temperatura, é possível calcular o tensor taxa de deformação termoplástico da fase $\alpha$ no instante $t+\Delta t$ através de

- $\quad$ 1. ${ }^{\alpha} \mathbf{D}_{t+\Delta t}^{t p}={ }^{\alpha} \mathbf{D}_{t+\Delta t}^{p}+\alpha_{\text {termico }} \dot{\theta}_{t+\Delta t} \mathbf{I}$

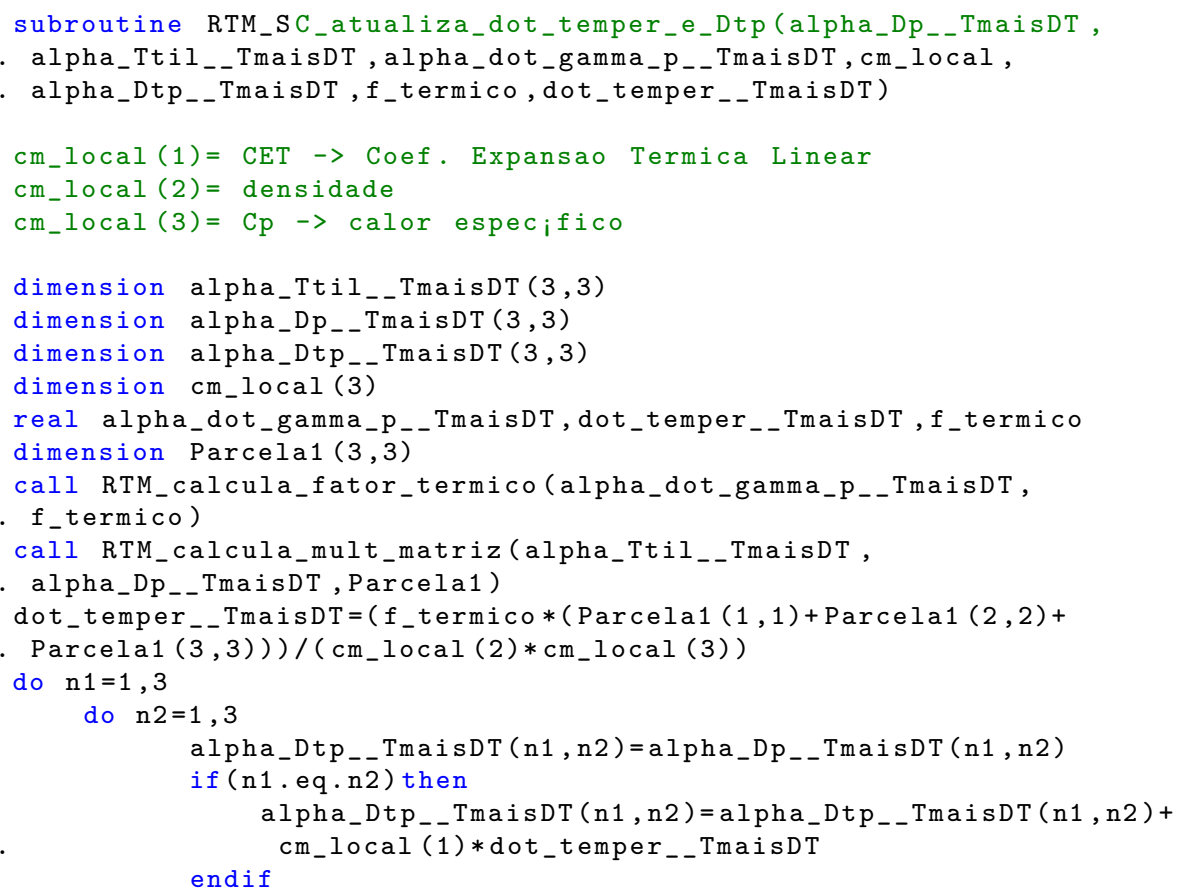




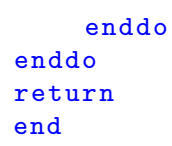

\subsubsection{8 tensor de tensões de Cauchy total}

No modelo para termo-plásticos amorfos, em que estão presentes em paralelo as fases $\alpha$, $\beta$ e a resistência entrópica, o tensor de tensões de Cauchy no instante $t+\Delta t$ pode ser calculado por

- $\quad$ 1. $\mathbf{T}_{t+\Delta t}={ }^{\alpha} \mathbf{T}_{t+\Delta t}+{ }^{\beta} \mathbf{T}_{t+\Delta t}+{ }^{R E} \mathbf{T}_{t+\Delta t}$

No modelo para termo-plásticos semicristalinos, em que estão presentes em paralelo as fases $\alpha$, semicristalina e a resistência entrópica, o tensor de tensões de Cauchy no instante $t+\Delta t$ pode ser calculado por

- $\quad$ 1. $\mathbf{T}_{t+\Delta t}={ }^{\alpha} \mathbf{T}_{t+\Delta t}+{ }^{S C} \mathbf{T}_{t+\Delta t}+{ }^{R E} \mathbf{T}_{t+\Delta t}$

\subsection{5 variáveis históricas}

Durante a implementação de um modelo de material personalizado no Ls-Dyna ${ }^{\circledR}$, o usuário tem a opção de armazenar variáveis internas do material para evoluí-las com a deformação do mesmo, ou mesmo alguma variável para estudo, como a triaxialidade. Neste caso, para que possa ser utilizado o modelo de material com estrutura cinemática termoviscoelastoviscoplástica, as opções ITHERMAL e IIHYER deve receber o valor 1 na chamada do modelo de material durante a elaboração do arquivo de entrada com extensão .k.

Quando o valor atribuído a ITHERMAL no cartão de entrada do material, a temperatura estará disponível para a subrotina do usuário de duas formas possíveis: i) através da variável temper para o caso de uma implementação escalar da subrotina (IVECT =0 no cartão de entrada do material) ou ii) através do arranjo temps, sendo um bloco de vetores computacionais de comprimento $n l q$, com índices variando de lft a $l l t$.

Como o modelo de material implementado se baseia na mecânica dos sólidos não linear, é necessário utilizar-se o gradiente de deformação. Para que este esteja disponível para a rotina do usuário, o valor IHYPER deve ter o valor 1 atribuído no cartão de entrada da simulação numérica. Os valor do gradiente de deformações $F_{11}, F_{21}, F_{31}, F_{12}, F_{22}, F_{32}$, $F_{13}, F_{23}, F_{33}$ estão disponíveis no arranjo de variáveis históricas, nos índices de $N H V+1$ a 
$N H V+9$, sendo $N H V$ o valor de variáveis históricas a ser utilizado pelo software definido no cartão de entrada da simulação (utilizado para alocação dinâmica de memória durante a execução do programa). Assim como a temperatura, o gradiente de deformação pode estar disponível: $i$ ) no arranjo $h s v(n)$, com $n$ variando de 1 a $(N H V+9)$ para uma implementação escalar ou ii) no arranjo hsvs(nlq, n).

Há ainda a necessidade de se alterar o valor da variável NHISVAR dentro do arquivo nhisparm.inc, necessário para a compilação do arquivo executável do solver com o modelo de material implementado pelo usuário, caso o número de variáveis históricas utilizadas pelo model seja superior a 142.

A seguinte subrotina foi escrita de forma a armazenar uma matriz no vetor de variáveis históricas ou passar os valores do vetor para a matriz.

C

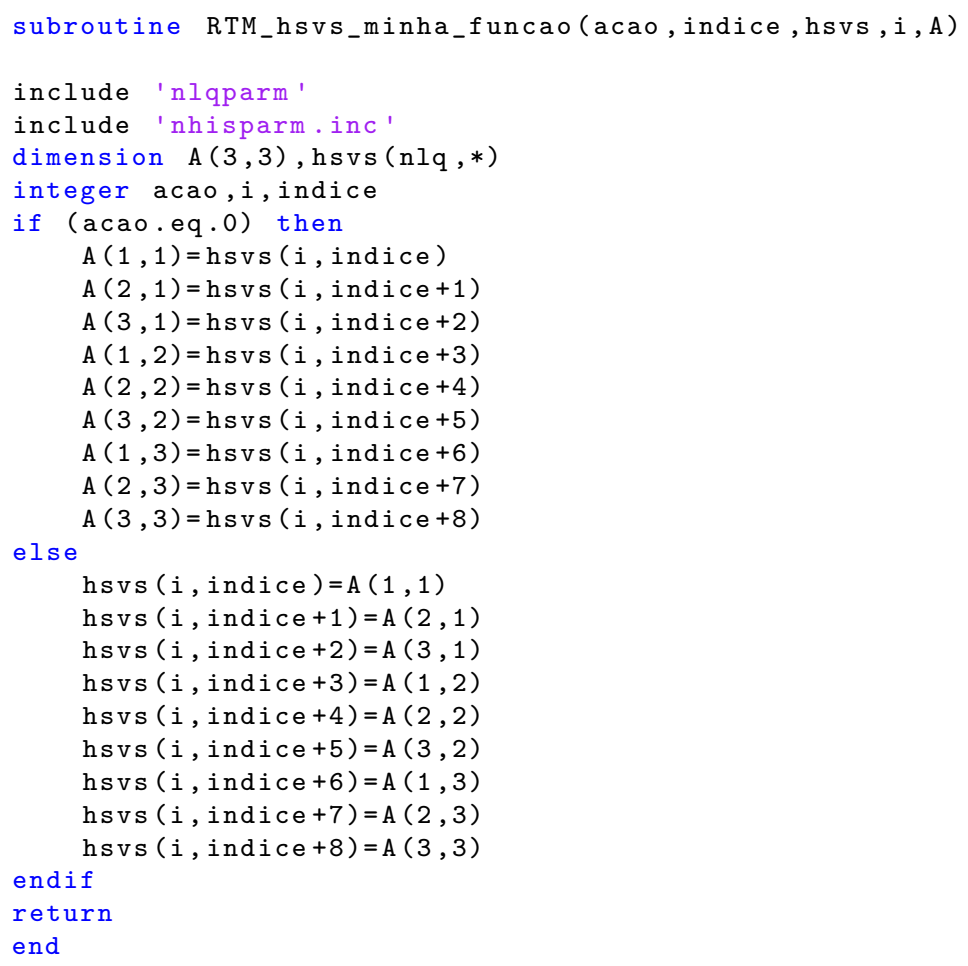

\subsubsection{Modelos finais e UMATS}

Abaixo se encontram o código do modelo de material para termoplásticos amorfos e a UMAT que o chama durante a execução do programa 
subroutine RTM_AMORFO (cm_termico, A_s_v, A_cm_e, A_cm_ve, A_cm_gama_p ,

- $A_{-} c m_{-} s_{-} p, A_{-} c m_{-} g a m a_{-} v_{-} d e v, B_{-} s_{-} v_{,} B_{-} c m_{-} e, B_{-} c m_{-} v e$,

- $B_{-} c m_{-} g a m a_{-} p, B_{-} c m_{-} g a m a_{-} v_{-} d e v, c m_{-} R E$,

cm_dot_temper, dt, temper_-T, dot_temper_-T, F_-TmaisDT

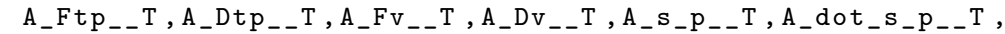

- B_Ftp_- T, B_Dtp_- T, B_Fv B $_{--} T, B_{-}$Dv $_{--} T, T_{--}$TmaisDT, temper__TmaisDT,

- dot_temper_-TmaisDT, A_Ftp_-TmaisDT, A_Dtp_-TmaisDT, A_Fv__TmaisDT,

- A_Dv__TmaisDT, A_s_p_-TmaisDT, A_dot_s_p_-TmaisDT, B_Ftp_-TmaisDT,

- B_Dtp__TmaisDT, B_Fv_-TmaisDT, B_Dv_-TmaisDT)

$\mathrm{cm}(3)=\mathrm{A}_{-} \mathrm{s}_{-} \mathrm{P}_{--} \mathrm{O}$

$\mathrm{cm}(4)=\mathrm{cm}_{\text {_termico }}(1)=\mathrm{CET}$

$\mathrm{cm}(5)=\mathrm{cm}_{-}$termico $(2)=$ temperatura_inicial

$\mathrm{cm}(6)=\mathrm{A}_{-} \mathrm{S}_{-} \mathrm{V}=$ fator de multiplicador da tensao na parte viscosa

$\mathrm{cm}(7) \quad=A_{-} \mathrm{cm} \mathrm{m}_{-} \mathrm{e}(1)=\mathrm{mu} \mathrm{u}_{-} \mathrm{e}$

$\mathrm{cm}(8)=\mathrm{A}_{-} \mathrm{cm} \mathrm{m}_{-} \mathrm{e}(2)=\mathrm{lambda} \mathrm{a}_{-} \mathrm{e}$

$\mathrm{cm}(9)=A_{-} \mathrm{cm} \mathrm{m}_{-} \mathrm{ve}(1)=\mathrm{mu} u_{-} \mathrm{ev}$

$\mathrm{cm}(10)=\bar{A}_{-} \mathrm{cm} \mathrm{m}_{-} \mathrm{ve}(2)=\mathrm{lambda} \mathrm{a}_{-} \mathrm{ev}$

$\mathrm{cm}(11)=\mathrm{A}_{-} \mathrm{cm} \mathrm{m}_{-}$gama_p $(1)=$ gamma $0_{-} \mathrm{p}$

$\mathrm{cm}(12)=A_{-} c m_{-} g a m a_{-} p(2)=n_{-} p$

$\mathrm{cm}(13)=A_{-} \mathrm{cm}_{-}$gama $\mathrm{p}(3)=\mathrm{b}_{-} \mathrm{p}$

$\mathrm{cm}(14)=\mathrm{A}_{-} \mathrm{cm}_{-} \mathrm{s}_{-} \mathrm{p}(1)=\mathrm{h}_{-} \mathrm{s}$

$\mathrm{cm}(15)=\mathrm{A}_{-} \mathrm{cm} \mathrm{s}_{-} \mathrm{p}(2)=\mathrm{s}_{-} \mathrm{f}$

$\mathrm{cm}(16)=\mathrm{A}_{-} \mathrm{cm}-\mathrm{gama} \mathrm{v}_{-} \mathrm{dev}(1)=\mathrm{C}$

$\mathrm{cm}(17)=\mathrm{A}_{-} \mathrm{cm}-\mathrm{gama} \mathrm{v}_{-} \mathrm{dev}(2)=\mathrm{s}_{-} \mathrm{v}$

$\mathrm{cm}(18)=\mathrm{A}_{-} \mathrm{cm}-\mathrm{gama} \mathrm{v}_{-} \mathrm{dev}(3)=\mathrm{n}_{-} \mathrm{v}$

$\mathrm{cm}(19)=A_{-} \mathrm{cm}-g a m a_{-} v_{-} \operatorname{dev}(4)=\mathrm{m}$

$\mathrm{cm}(20)=B_{-} s_{-} \mathrm{v}=$ fator de multiplicador da tensao na parte viscosa

$\mathrm{cm}(21)=B_{-} \mathrm{cm}_{-} \mathrm{e}(1)=\mathrm{mu} u_{-} \mathrm{e}$

$\mathrm{cm}(22)=B_{-} \mathrm{cm} m_{-} \mathrm{e}(2)=1 \mathrm{ambda} \mathrm{a}_{-} \mathrm{e}$

$\mathrm{cm}(23)=\mathrm{B}_{-} \mathrm{cm} \mathrm{m}_{-} \mathrm{ve}(1)=\mathrm{mu} \mathrm{u}_{-} \mathrm{ev}$

$\mathrm{cm}(24)=B_{-} \mathrm{cm}_{-} \mathrm{ve}(2)=\mathrm{lambda} \mathrm{a}_{-} \mathrm{v}$

$\mathrm{cm}(25)=\mathrm{B}_{-} \mathrm{cm}_{-}$gama $\mathrm{p}(1)=$ gamma $0_{-} \mathrm{p}$

$\mathrm{cm}(26)=B_{-} \mathrm{cm}_{-} g a m a_{-} \mathrm{p}(2)=\mathrm{s}$

$\mathrm{cm}(27)=\mathrm{B}_{-} \mathrm{cm}$-gama_v_dev $(1)=\mathrm{C}$

$\mathrm{cm}(28)=\mathrm{B}_{-} \mathrm{cm} \mathrm{m}_{-} \mathrm{gama} \mathrm{v}_{-} \mathrm{dev}(2)=\mathrm{s}_{-} \mathrm{v}$

$\mathrm{cm}(29)=B_{-} c m_{-} g a m a_{-} v_{-} \operatorname{dev}(3)=n_{-} v$

$\mathrm{cm}(30)=B_{-} \mathrm{cm}_{-} \mathrm{gama} \mathrm{v}_{-} \mathrm{dev}(4)=\mathrm{m}$

$\mathrm{cm}(31)=\mathrm{cm}_{-} \mathrm{RE}(1)=\mathrm{mu}^{-}$

$\mathrm{cm}(32)=\mathrm{cm}_{-} \mathrm{RE}(2)=1 \mathrm{ambda} \mathrm{a}_{-} 10 \mathrm{ck}$

$\mathrm{cm}(33)=\mathrm{cm}_{-} \mathrm{RE}(3)=\mathrm{kappa}$

$\mathrm{cm}(34)=\mathrm{cm} R E(4)=\mathrm{q}$

$\mathrm{cm}(4)=\mathrm{cm}_{-}$dot_temper $(1)=\mathrm{CET}$

$\mathrm{cm}(35)=\mathrm{cm}_{-}$dot_temper $(2)=$ densidade

$\mathrm{cm}(36)=\mathrm{cm}_{-}$dot_temper $(3)=\mathrm{Cp} \rightarrow$ calor especifico

C Declarando as constantes de material

dimension cm_termico (2), A_cm_e (2), A_cm_ve (2), A_cm_gama_p (3)

dimension $A_{-} c_{-} s_{-} p(2), A_{-} c_{-}$gama v $_{-}$dev (4)

dimension $B_{-} c m_{-} e(2), B_{-} c m_{-} v e(2), B_{-} c_{-} m_{-} g a m a \_p(2), B_{-} c m_{-} g a m a-v_{-} d e v(4)$

dimension $\mathrm{cm}_{-} \mathrm{RE}(4)$

dimension $\mathrm{cm}_{-} \mathrm{dot}_{-}$temper(3)

real A_s_v, B_s_v

C Vari veis reais gerais

real dt, dot_temper_- T, temper_- T, dot_temper__TmaisDT

real temper_-TmaisDT

C Tensores gradiente de deformałko total em TmaisDT

dimension F_-TmaisDT $(3,3)$

C Tensores de Tensto de Cauchy

dimension T_- TmaisDT $(3,3)$

C--------- Necessario em $\mathrm{T}$ para calculo

C Tensores da fase ALPHA em $T$

dimension A_Ftp_- T $(3,3), A_{-} D t p_{--} T(3,3), A_{-} F v_{--} T(3,3), A_{-} D_{--} T(3,3)$

C Vari veis reais da fase ALPHA em $T$

real A_s_p_- T, A_dot_s_p_- T

C Tensores da fase BETA em T

dimension B_Ftp_- T $(3,3), B_{-} D_{t}$ _ $_{-} \mathrm{T}(3,3), \mathrm{B}_{-} \mathrm{Fv}_{--} \mathrm{T}(3,3), \mathrm{B}_{-} \mathrm{DV}_{--} \mathrm{T}(3,3)$ 


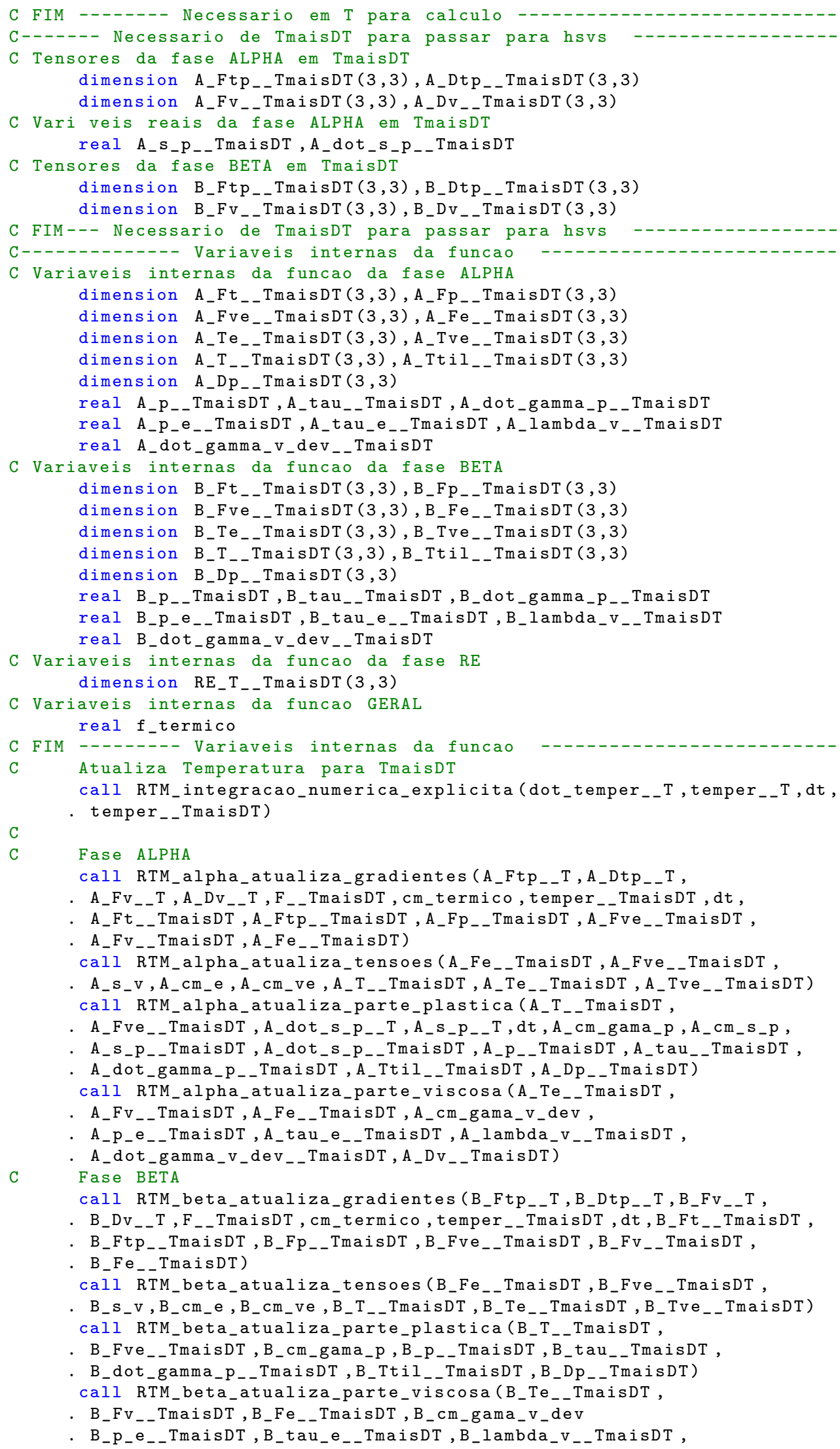




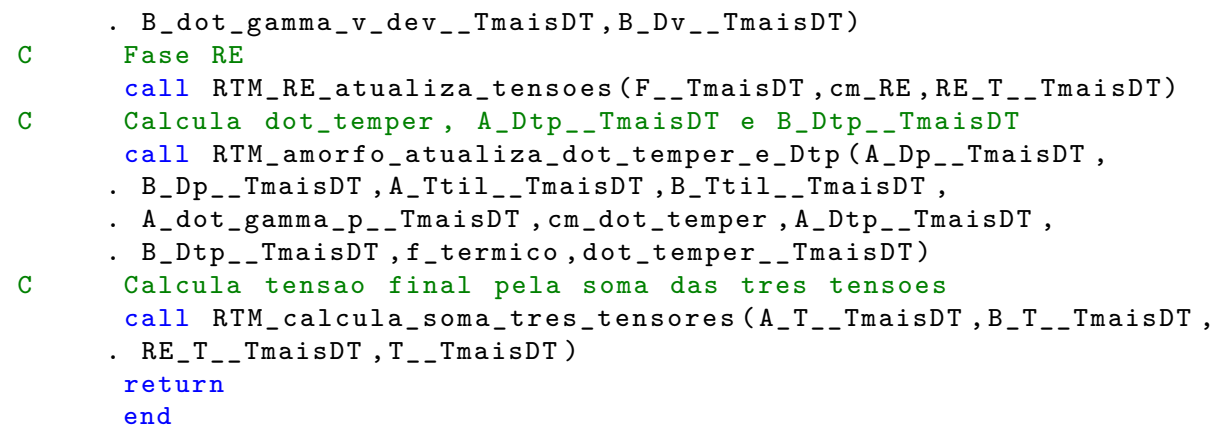

subroutine umat42v(cm, d1, d2, d3, d4, d5, d6, sig1, sig2,

- sig3, sig4, sig5, sig6, epsps, hsvs, lft, llt, dt1siz, capa,

- etype,tt, temps,failels, nlqa, crv, cma)

C

include 'nlqparm '

include 'nhisparm. inc'

include 'iounits.inc'

dimension $\mathrm{d} 1(*), \mathrm{d} 2(*), \mathrm{d} 3(*), \mathrm{d} 4(*), \mathrm{d} 5(*), \mathrm{d} 6(*)$

dimension $\operatorname{sig} 1(*), \operatorname{sig} 2(*), \operatorname{sig} 3(*), \operatorname{sig} 4(*), \operatorname{sig} 5(*), \operatorname{sig} 6(*)$

dimension $\mathrm{cm}(*)$, epsps $(*)$, hsvs $(\mathrm{nlq}, *)$, dt1siz $(*)$

dimension temps $(*), \operatorname{crv}(1 \mathrm{q} 1,2, *), \operatorname{cma}(*)$

logical failels $(*)$

character $* 5$ etype

C Declarando as constantes de material

dimension cm_termico (2), $A_{-} \mathrm{cm}_{-}$e (2), $\mathrm{A}_{-} \mathrm{cm} \mathrm{m}_{-} \mathrm{ve}(2), \mathrm{A}_{-} \mathrm{cm}$-gama_p (3)

dimension $A_{-} c_{-} m_{-}$p (2), $A_{-} c m_{-} g a m a_{-} v_{-} d e v(4)$

dimension $B_{-} c m_{-} e(2), B_{-} c m_{-} v e(2), B_{-} c m_{-} g a m a-p(2), B_{-} c m_{-} g a m a v_{-} d_{e v}(4)$

dimension $\overline{c m}_{-} \mathrm{RE}(4)$

dimension cm_dot_temper(3)

real A_s_v, B_s_v

real A_s_p_- 0 , temper te $_{-} 0$

C Vari veis reais gerais

real dt, dot_temper_- T, temper_- T, dot_temper__TmaisDT

real temper_- TmaisDT

C Tensores gradiente de deformałte total em TmaisDT dimension F_- TmaisDT $(3,3)$

C Tensores de Tensto de Cauchy dimension T_- TmaisDT $(3,3)$

C-.--.-.-- Necessario em T para calculo

C Tensores da fase ALPHA em $T$

dimension A_Ftp_-T $(3,3)$, A_Dtp_- $_{-}(3,3)$, A_F $_{-}$T $(3,3)$, A_Dv $_{--} T(3,3)$

C Vari veis reais da fase ALPHA em $T$

real A_s P_- $_{-}$T, A_dot_s A $_{-} \mathrm{P}_{--} \mathrm{T}$

$C$ Tensores da fase BETA em $T$

dimension B_Ftp_- T $(3,3)$, B_Dtp_-T $(3,3), B_{-} F_{-} v_{-} T(3,3), B_{-} D_{--} T(3,3)$

C FIM ---.-- Necessario em $T$ para calculo

C------ Necessario de TmaisDT para passar para hsvs -.-.-.-.-...-..-

C Tensores da fase ALPHA em TmaisDT

dimension A_Ftp_- TmaisDT $(3,3)$, A_Dtp__TmaisDT $(3,3)$

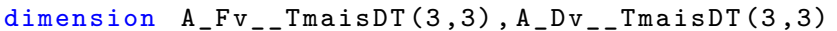

C Vari veis reais da fase ALPHA em TmaisDT

real A_s_p_-TmaisDT, A_dot_s_p_-TmaisDT

C Tensores da fase BETA em TmaisDT

dimension B_Ftp__TmaisDT $(3,3)$, B_Dtp_-_TmaisDT $(3,3)$

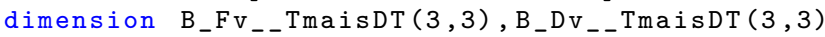

C FIM--- Necessario de TmaisDT para passar para hsvs

$\mathrm{C} * * * * * * * * * * * * * * * * * * * * * * * *$ A

$\mathrm{A}_{-} \mathrm{s}_{-} \mathrm{P}_{-} \mathrm{O}=\mathrm{cm}(3)$

$\mathrm{cm}$-termico $(1)=\mathrm{cm}(4)$

$\mathrm{cm}_{-}$termico $(2)=\mathrm{cm}(5)$

$A_{-} S_{-} \mathrm{V}=\mathrm{cm}(6)$ 


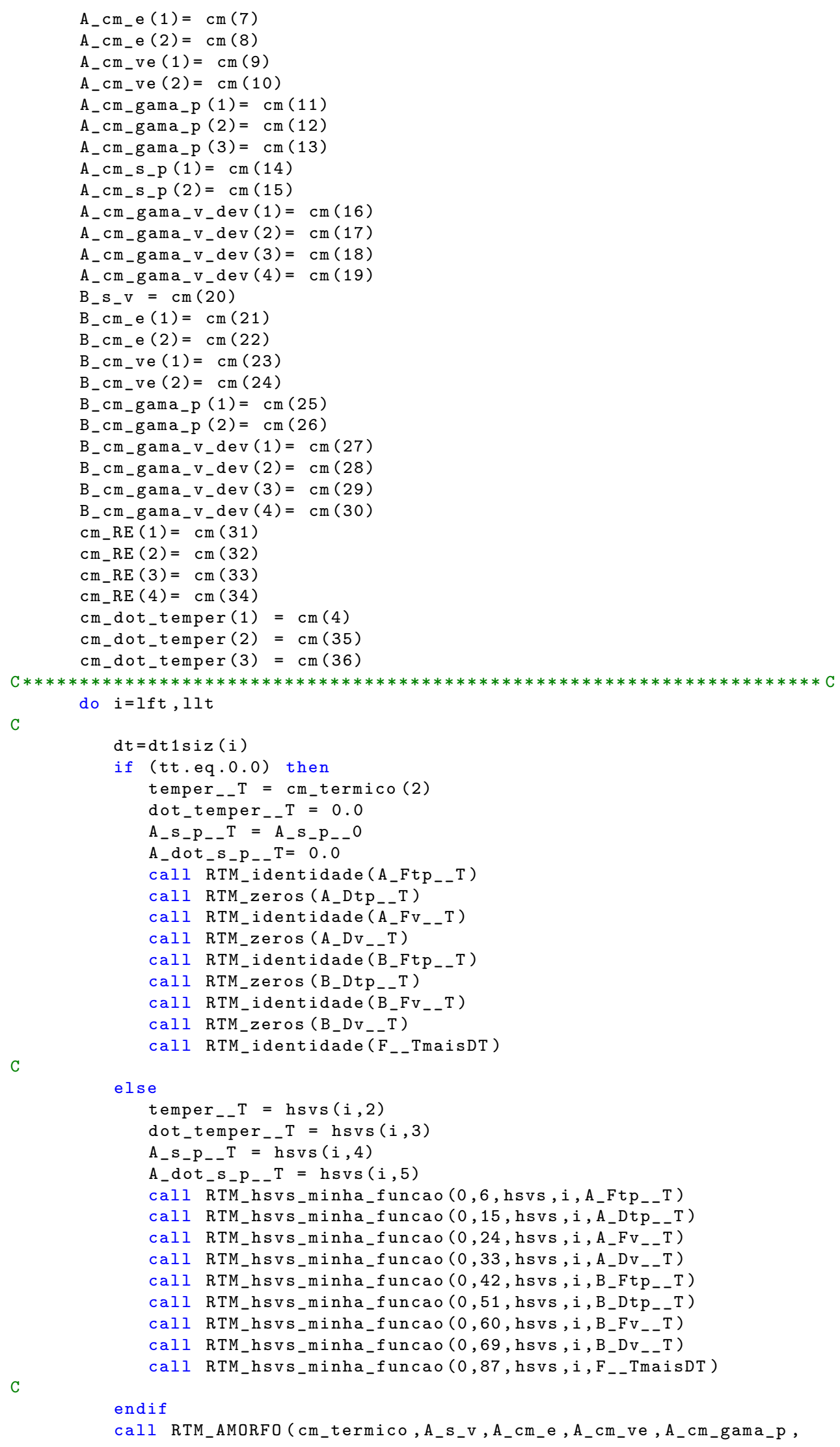




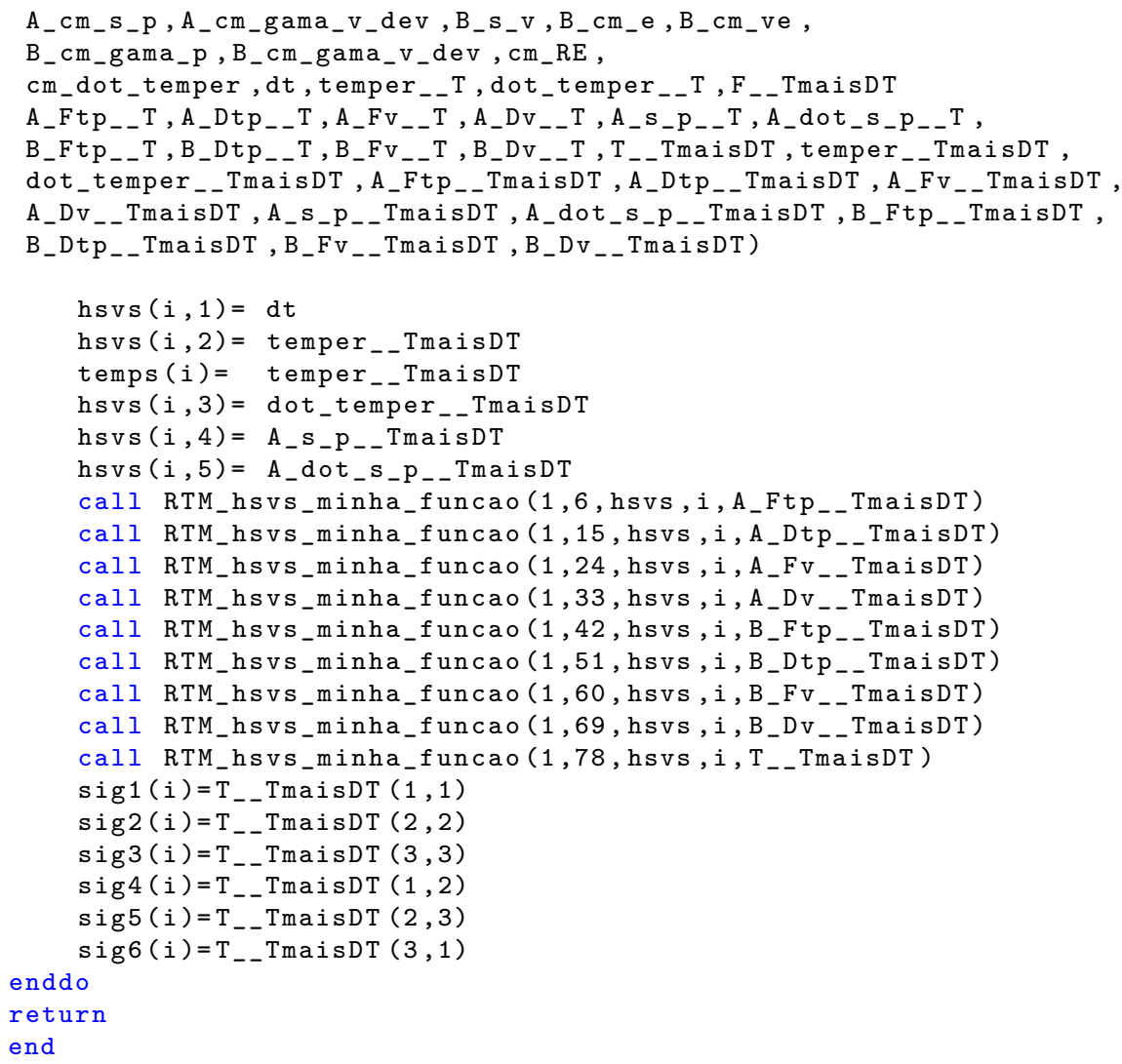

Abaixo se encontram o código do modelo de material para termoplásticos semicristalinos e a UMAT que o chama durante a execução do programa

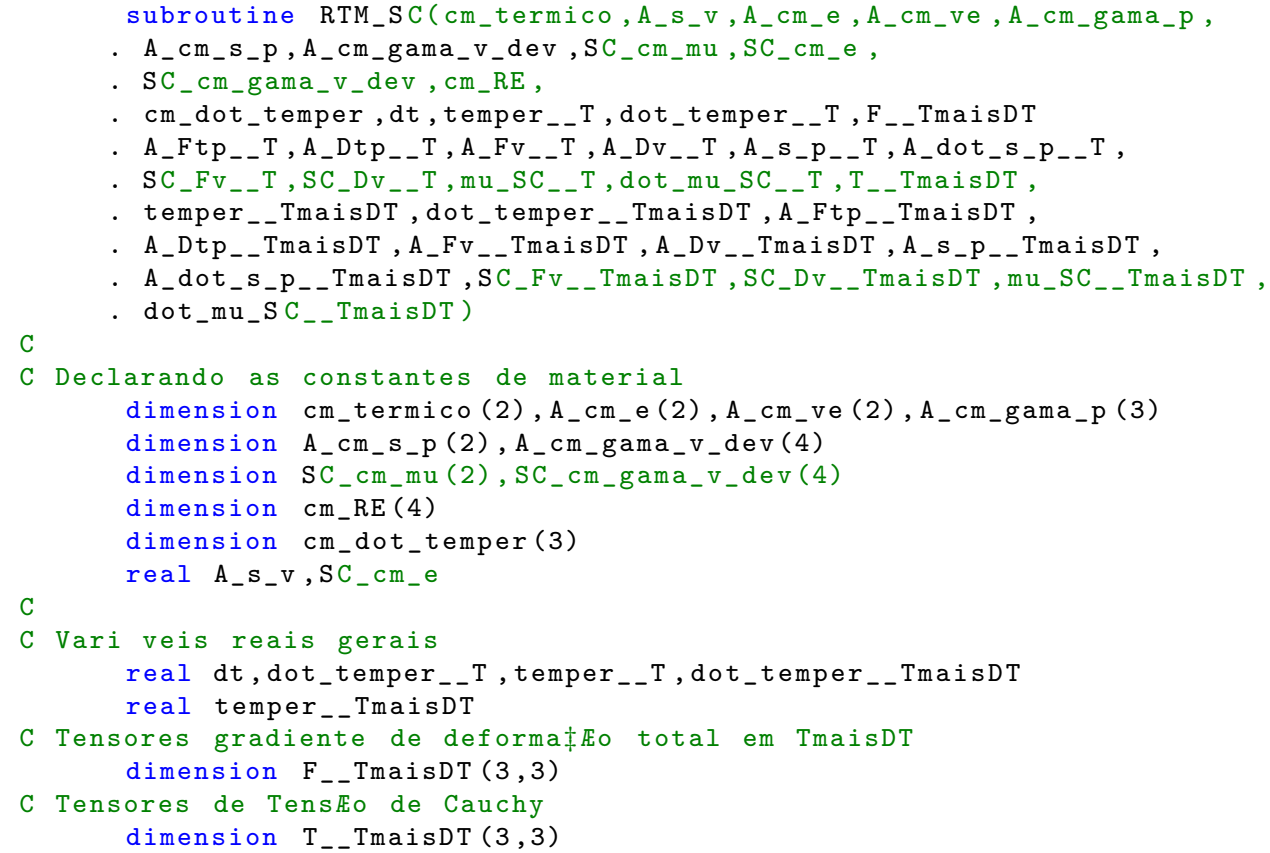




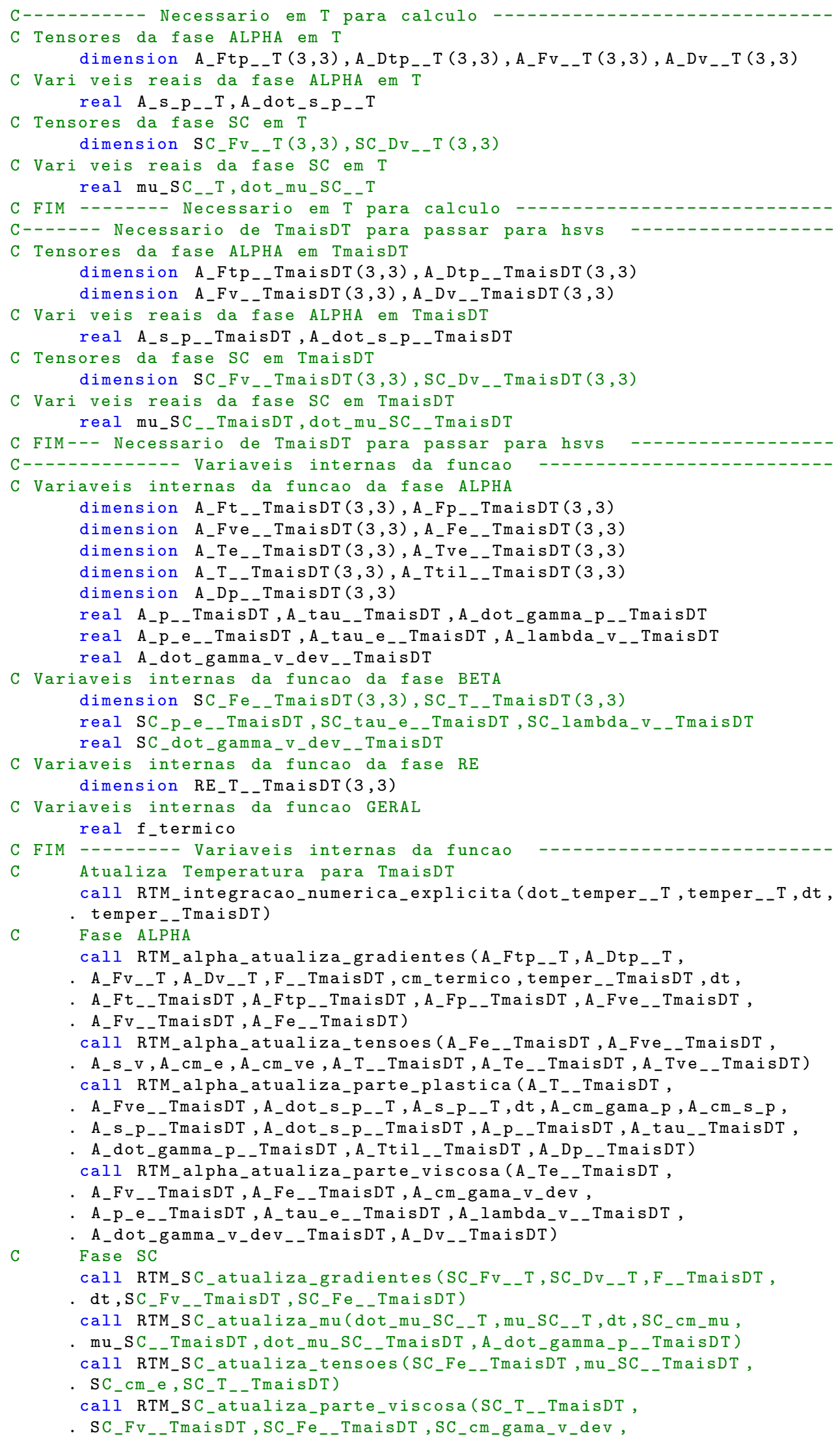




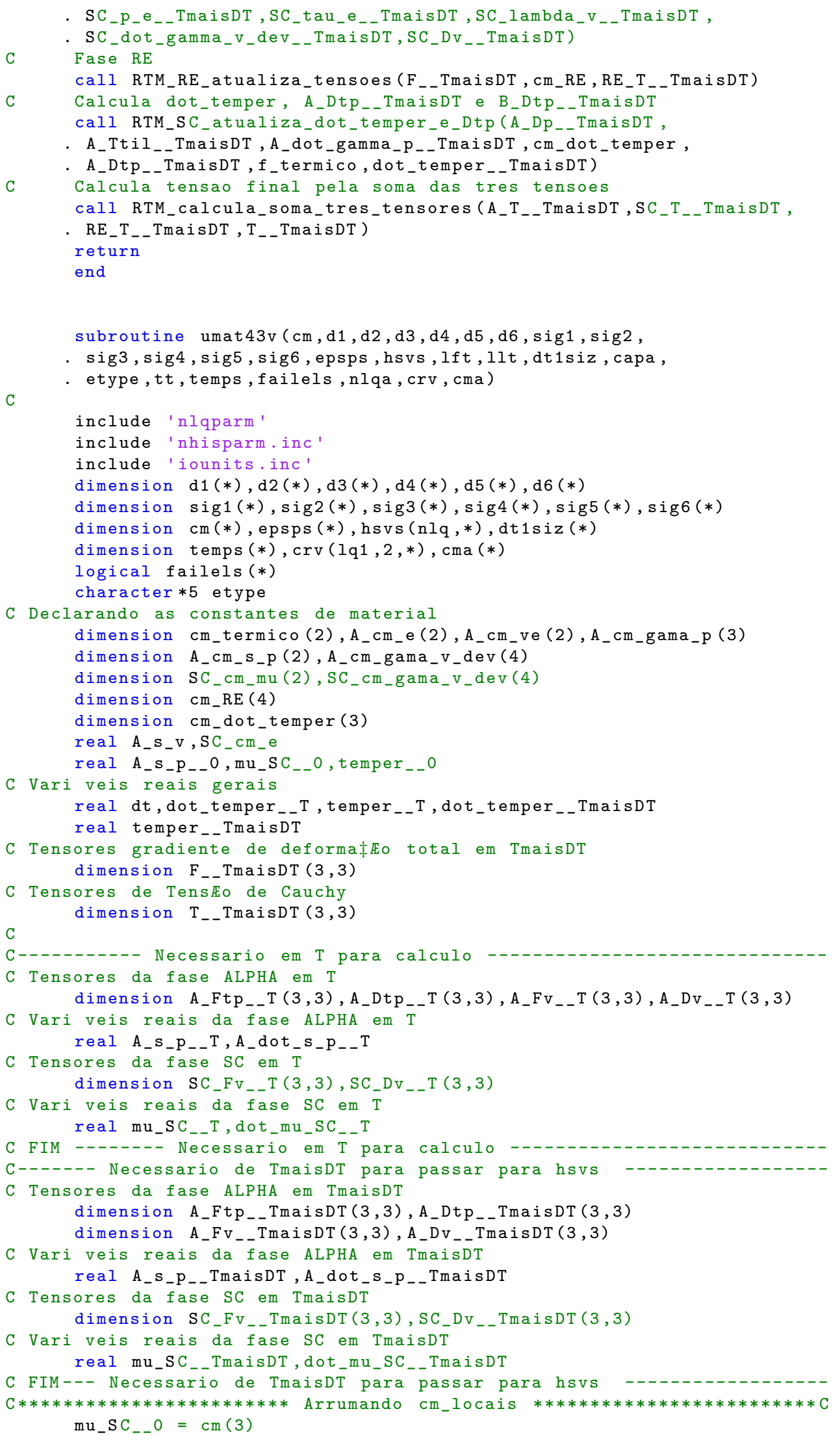




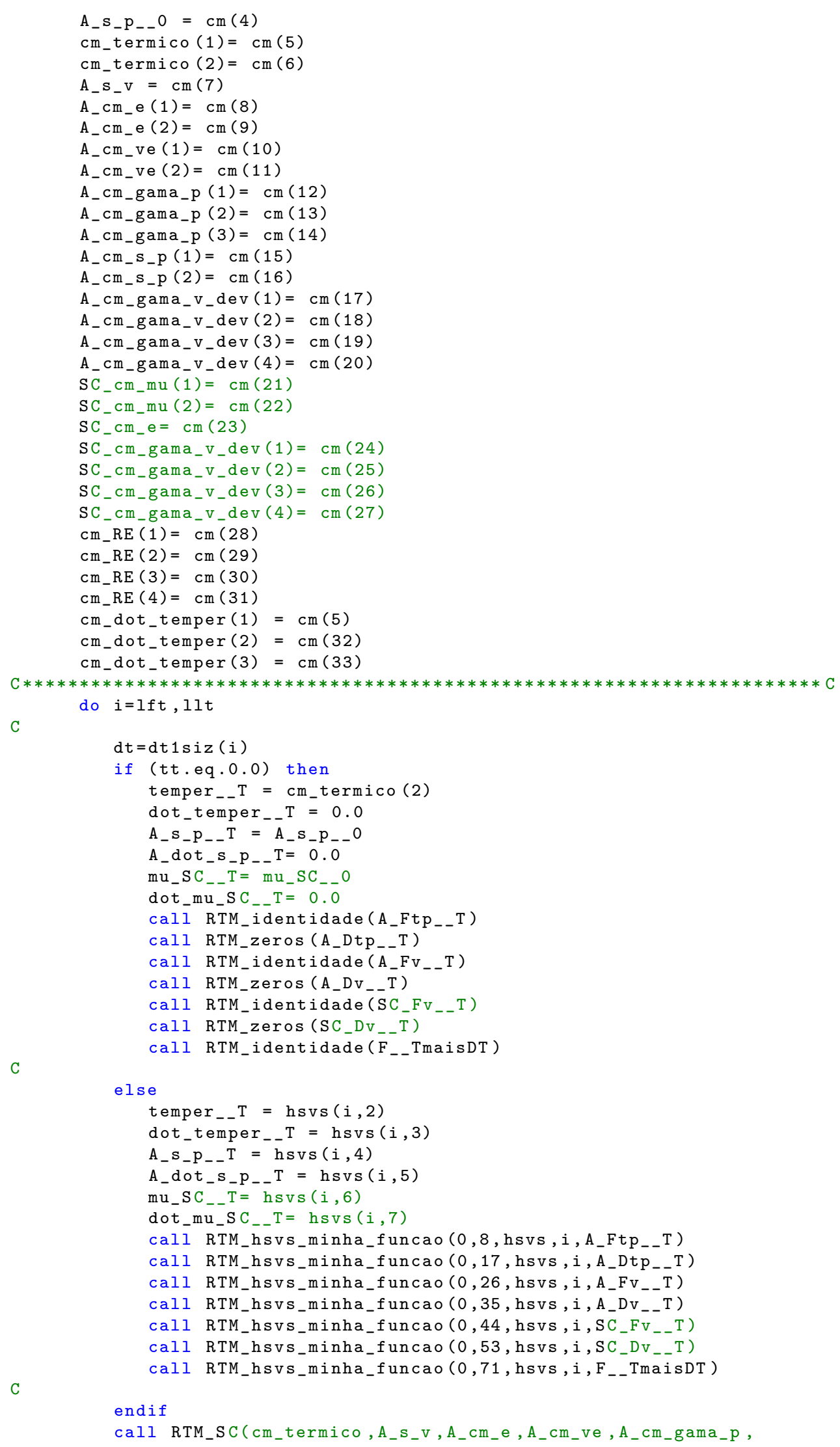




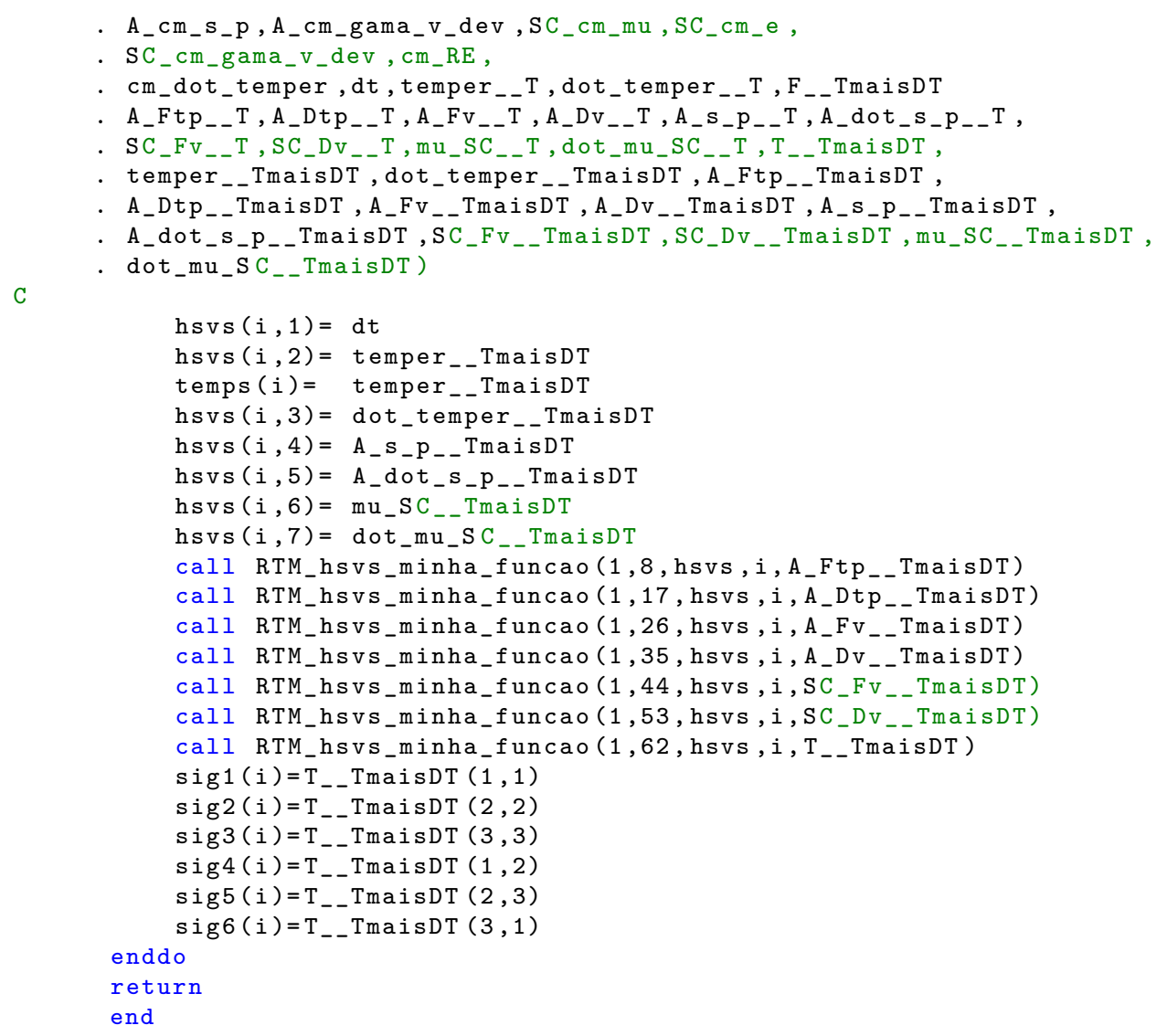

\section{5 calibração dos parâmetros}

Conforme explicado anteriormente, os parâmetros foram obtidos utilizando-se as funções de otimização disponíveis no matlab. Para o PMMA os ensaios de propagação de ondas e de relaxação foram realizados a partir do mesmo material. Os gráficos da fig. 6.10 demonstram o resultado na predição dos efeitos de relaxação.

Pode-se observar uma boa correlação entre a predição do modelo e o resultado experimental. Apesar de ter sido utilizado uma lei hiper-elástica linear, pode-se observar que o viscoelasticidade é capaz de reproduzir a não linearidade no início do teste. Seria interessante avaliar esta boa correlação com outros ensaios de relaxação, no qual o tempo total do ensaio e a deformação máxima sejam mantidos, variando-se o tempo necessário para atingir esta deformação, verificando a influência da taxa de deformação durante a fase de carregamento de um ensaio de relaxação e a capacidade do modelo de material proposto de reproduzí-la. 

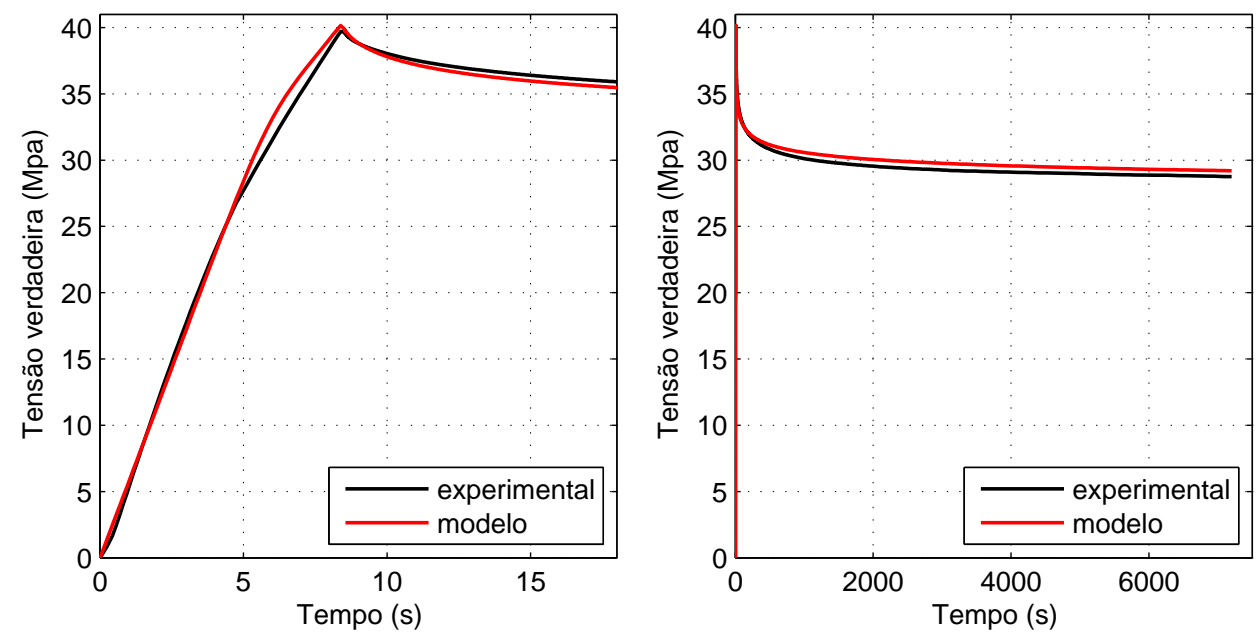

(a) Início do ensaio de relaxação em (b) Ensaio completo de relaxação em PMMA.

PMMA.

Figura 6.10: Comparação entre predição do modelo de material e resultados do ensaio experimental de relaxação em PMMA.

A fig. 6.11 Mostra primeiro a reprodução do ensaio de propagação de ondas em barras cilíndricas de PMMA utilizando-se somente a fase $\alpha$.

A diferença entre o resultado experimental e o previsto pelo modelo é utilizado como objetivo na calibração da fase $\beta$. Novamente foram obtidas boas correlações entre os procedimentos numérico e experimental.

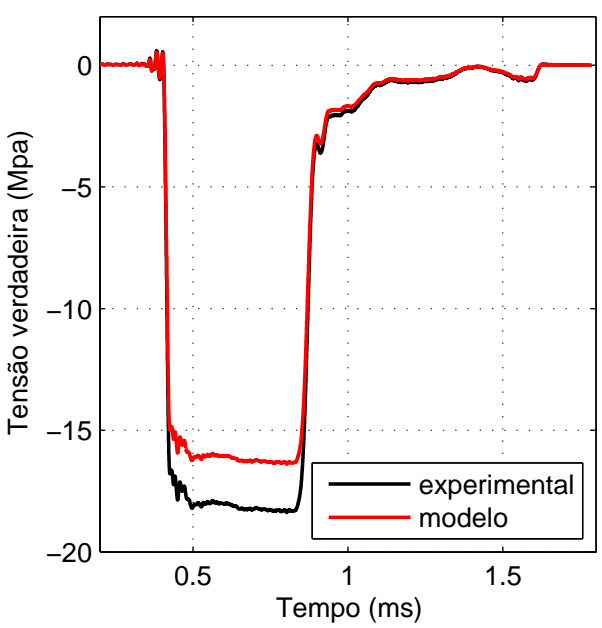

(a) Tensão durante a propagação de uma onda de deformação utilizando apenas a fase $\alpha$ em PMMA.

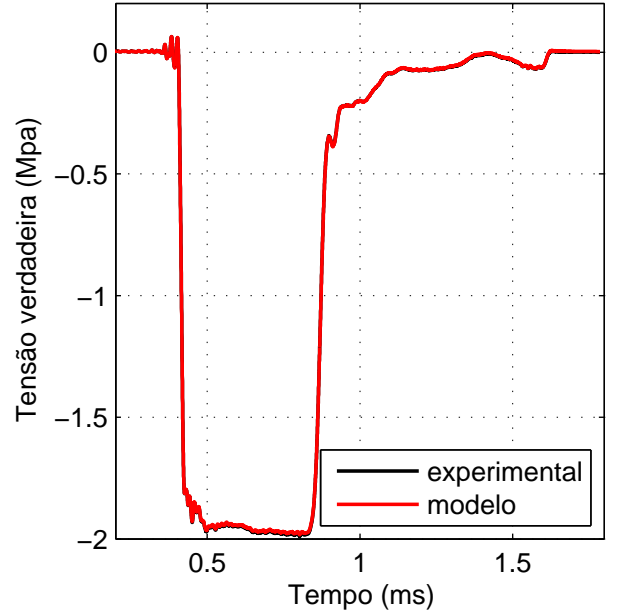

(b) Tensão durante a propagação de uma onda de deformação utilizando apenas a fase $\beta$ em PMMA.

Figura 6.11: Comparação entre predição do modelo de material e resultados do ensaio experimental de propagação de ondas em barras cilíndricas de PMMA. 
Considerando-se o PVC, foram utilizados os dados do ensaio de relaxação e dos ensaios quasi-estáticos de tração e compressão. Os melhores resultados obtidos na calibração encontram-se demonstrados nas fig. 6.12 e 6.13 , sendo utilizados os mesmos parâmetros de entrada.

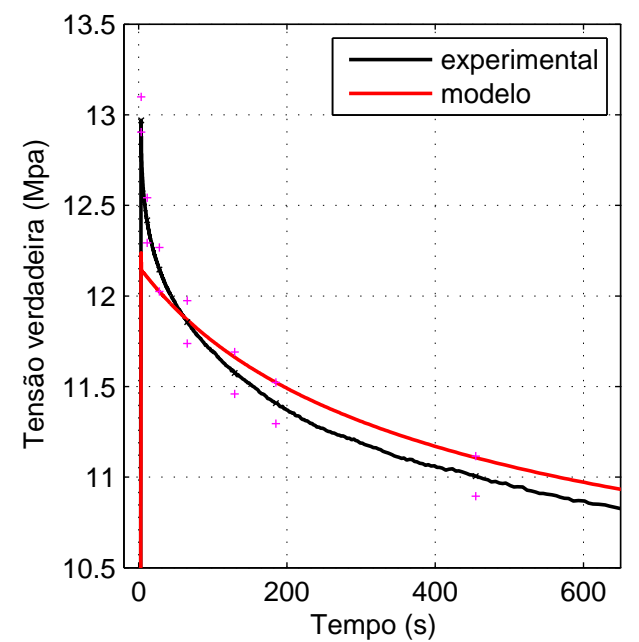

(a) Início do ensaio de relaxação em PVC.

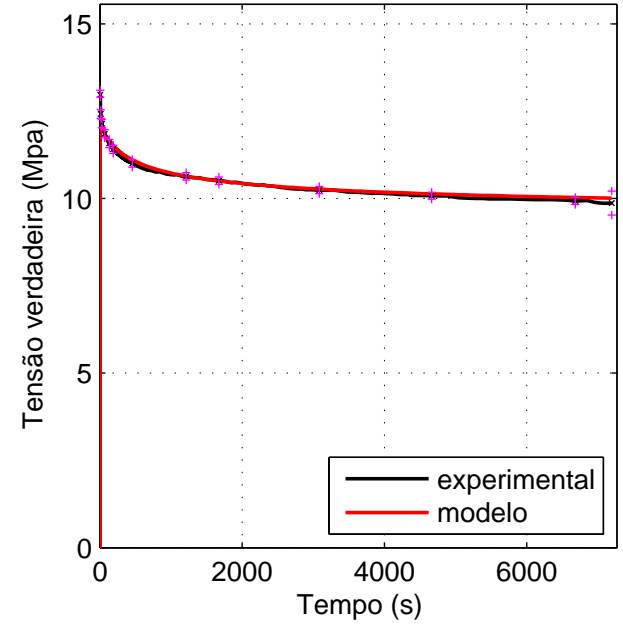

(b) Ensaio completo de relaxação em PVC.

Figura 6.12: Comparação entre predição do modelo de material e resultados do ensaio experimental de relaxação em PVC.

Entretanto, esse resultado foi possível somente com a mudança da formulação viscosa em relação ao utilizado no PMMA, sendo adotada $R(p)(R(x)=(x+|x|) / 2)$ ao invés da pressão hidrostática $p$, pois como as tensões são muito menores do que no caso do PMMA, o aumento da tensão e consequente aumento da pressão hidrostática tornava o denominador negativo. Este resultava numa taxa de deformação plástica cisalhante negativa, induzindo um aumento na tensão. Esse ciclo gerava instabilidades e dificultava ou mesmo impossibilitava a convergência da otimização.

Para a função erro a ser minimizada durante a otimização, foram escolhidos somente alguns pontos considerados necessários da curva de relaxação. Caso a diferença entre a tensão obtida no modelo e a medida no ensaio passasse de 10\%, esta era multiplicada por fatores variando entre 20 e 50 e somada ao erro acumulado. Caso fosse menor, a própria diferença era somada ao erro acumulado. Estes pontos e os limites de $10 \%$ de erro podem ser vistos na fig. 6.12 .

Para o caso do ensaio quase-estático de tração, foram escolhidos 4 pontos do ensaio de 
compressão, igualmente espaçados entre nenhuma deformação e o máximo de deformação. Para os ensaios quasi-estáticos de compressão, foram escolhidos apenas 2 pontos. A não utilização de todos os ensaios experimentais se motivo certa na incoerência dos resultados de alguns ensaios, quando os realizados em maiores taxas de deformação possuiam tensões menores do que os em menores taxas de deformação. De todos, foram escolhidos estes três como representativos do comportamento mecânico do material.

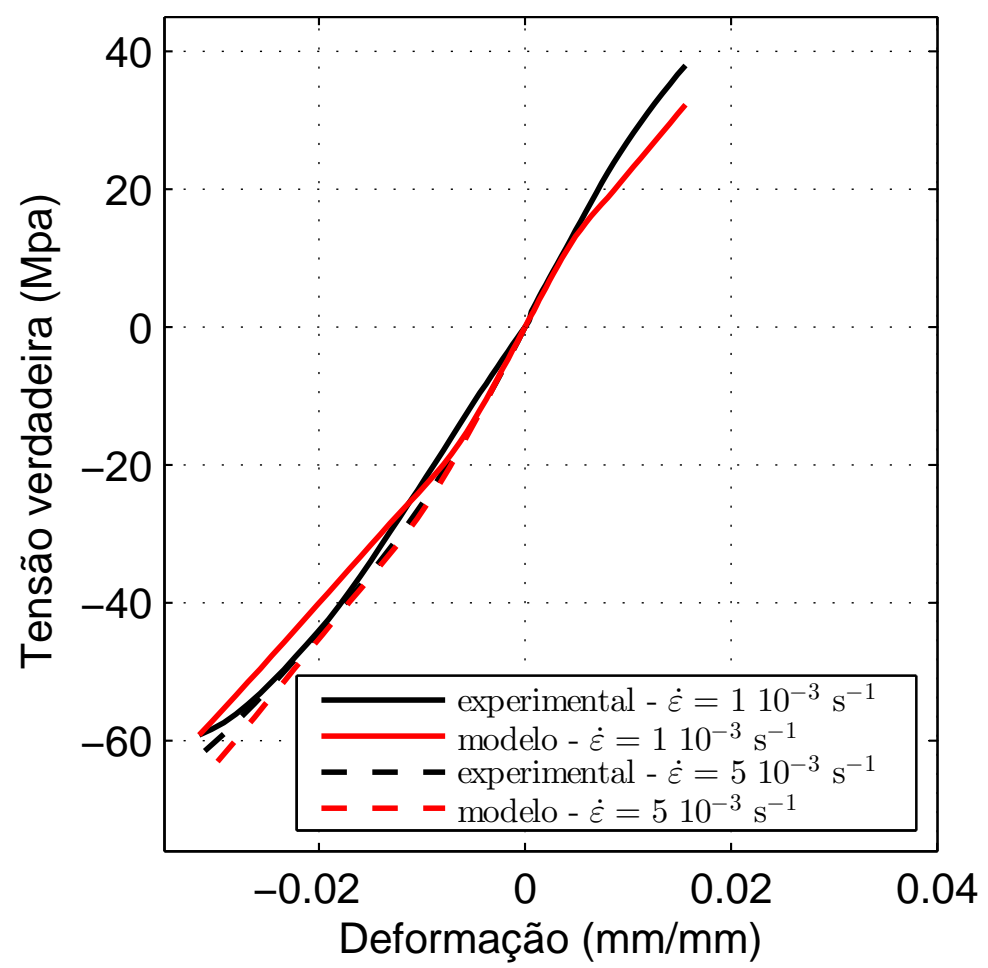

Figura 6.13: Comparação entre predição do modelo de material e resultados dos ensaios experimentais quasi-estáticos de compressão e tração em PVC.

De maneira análoga ao procedimento realizado na calibração dos parâmetros no caso do PMMA, a fase $\beta$ foi calibrada utilizando-se o ensaio de propagação de ondas. Entretanto, a dificuldade de se usinar barras cilíndricas a partir das placas fez com que fosse comprado uma barra cilíndrica de PVC de outro fornecedor. Desta forma, o resultado da calibração deve ser utilizado com parcimônia, pois apesar de serem do mesmo polímero, estes podem ter comportamentos mecânicos diferentes. Os resultados estão dispostos na fig. 6.11. 

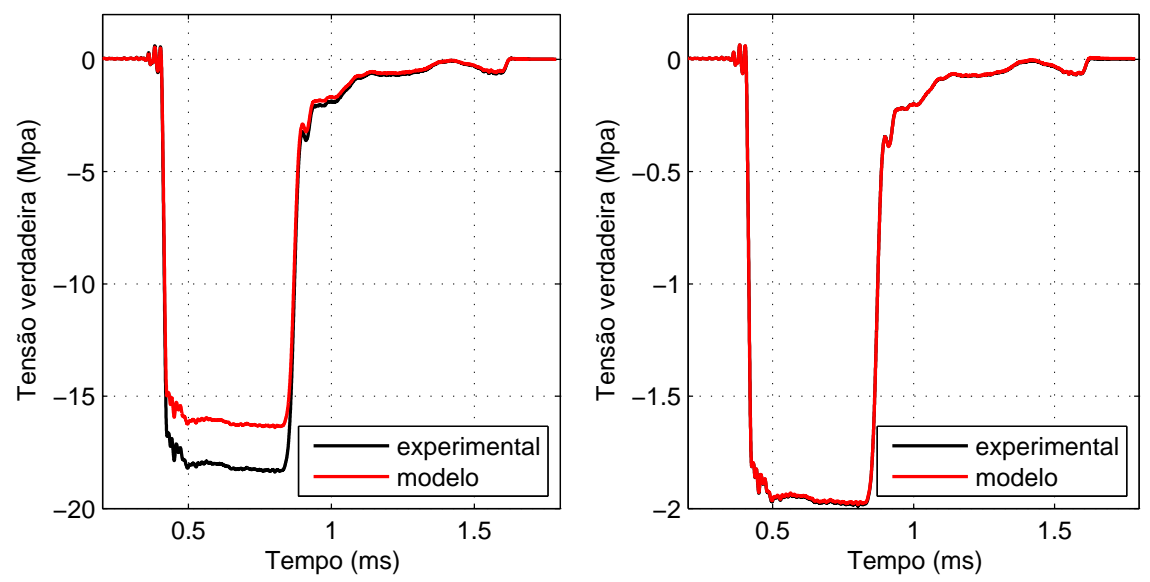

(a) Tensão durante a propagação de (b) Tensão durante a propagação de uma onda de deformação utilizando apenas a fase $\alpha$ em PVC. uma onda de deformação utilizando apenas a fase $\beta$ em PVC.

Figura 6.14: Comparação entre predição do modelo de material e resultados do ensaio experimental de propagação de ondas em barras cilíndricas de PVC.

Os valores iniciais para a otimização dos parâmetros da viscoplasticidade podem ser obtidos analisando-se o gráfico da fig. 6.15. O outro gráfico desta figura mostra a adaptação dos valores de tensão para o utilizado no modelo de material (obtido pela norma de frobenius) em função da taxa de deformação cisalhante (obtida multiplicando a taxa de deformação uniaxial por $\sqrt{3}$ ).
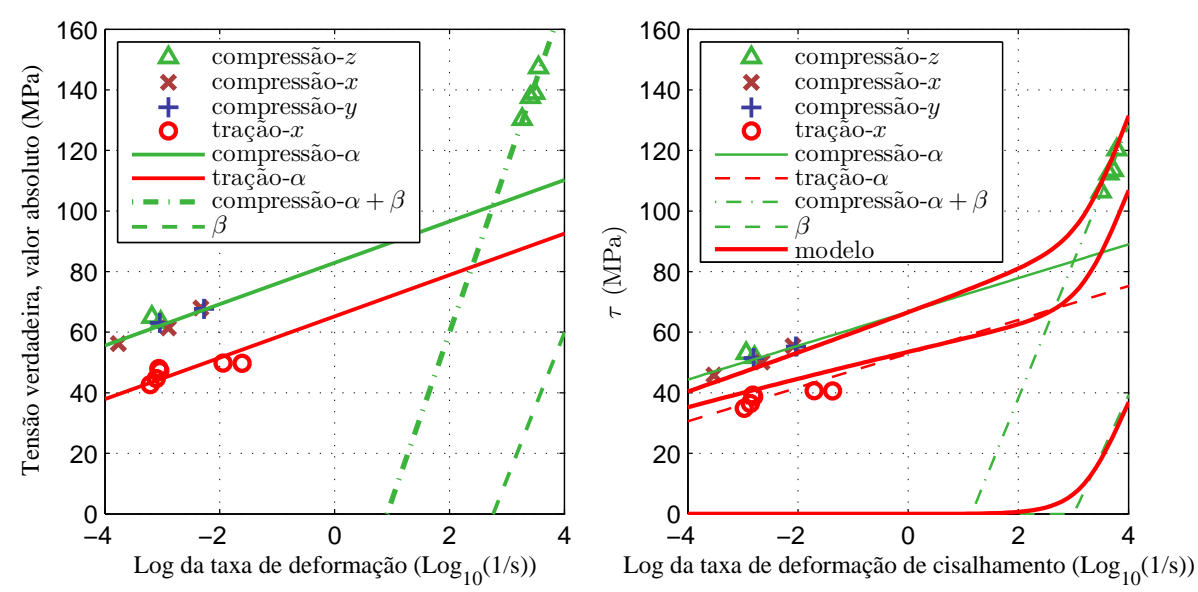

(a) Tensão de escoamento para diver- (b) Tensão de escoamento para diversas sas taxas de deformação em PVC. taxas de deformação em PVC.

Figura 6.15: Gráfico das tensões verdadeiras uniaxiais em função das taxas de deformação uniaxiais no início da plastificação para o PVC. 
Estes foram inseridos numa função de otimização juntamente com os parâmetros para a evolução de ${ }^{\alpha} s^{p}$ e os da resistência entrópica, obtendo os resultados encontrados na fig. 6.20 .

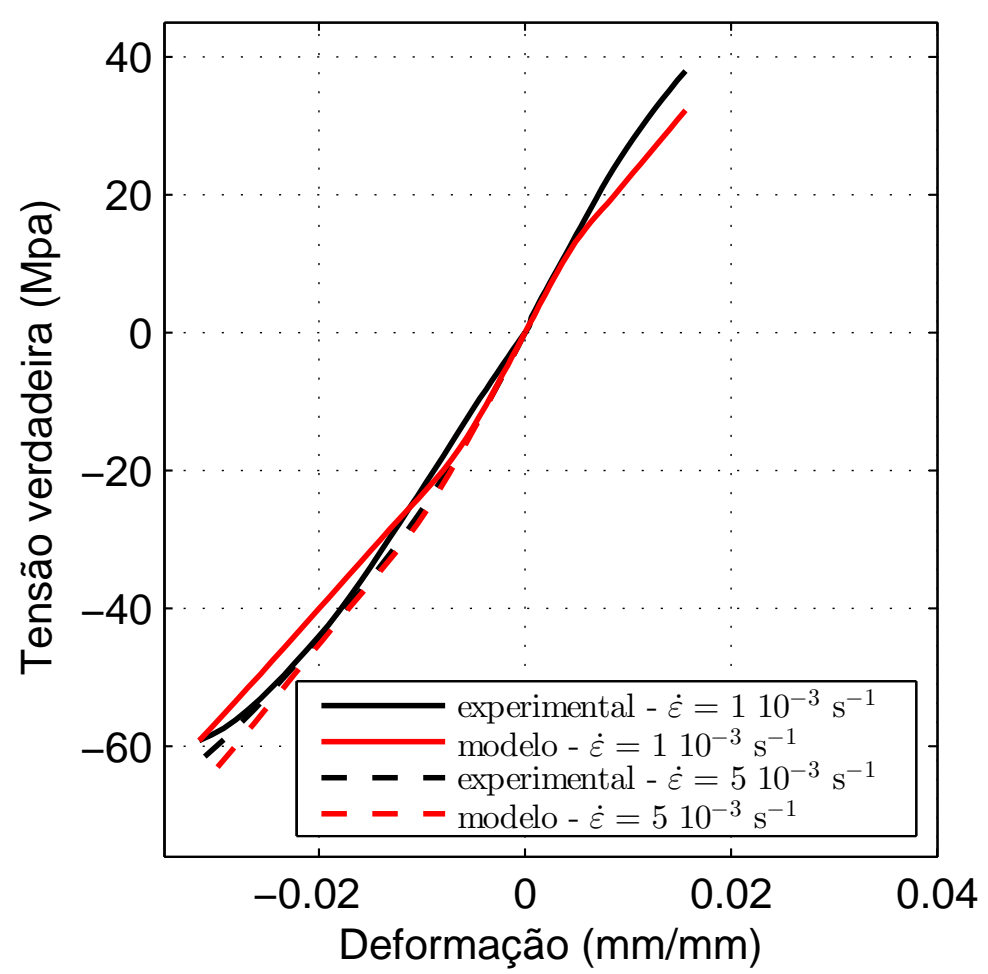

Figura 6.16: Comparação entre predição do modelo de material e resultados dos ensaios experimentais quasi-estáticos de compressão e tração em PVC.

No caso do PEAD, não há fase $\beta$, mas sim uma fase semicristalina presente tanto em baixas quanto em altas taxas de deformação. Devido a semelhança entre o comportamento do material estudado com o polietileno de alto peso molecular, foram adotados na fase semicristalina os mesmo valores encontrados por Bergstrom e Bischoff.

A calibração da parte visco-elástica resultou então nos gráficos das fig. 6.17 e 6.18. 

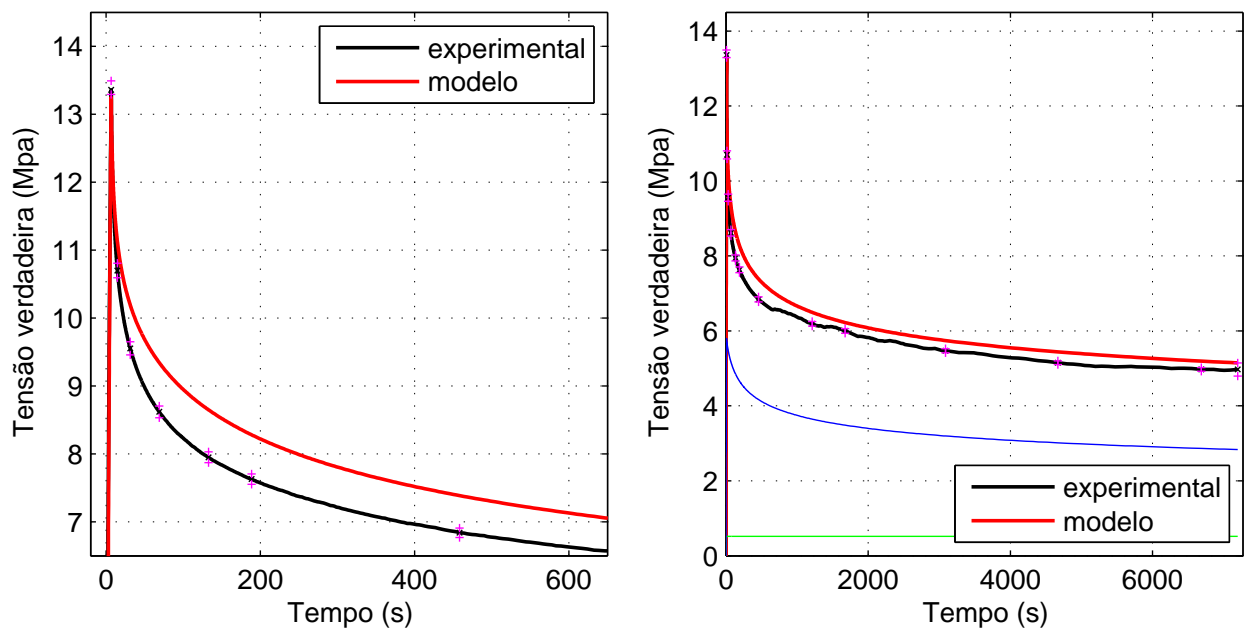

(a) Início do ensaio de relaxação em (b) Ensaio completo de relaxação em PEAD.

PEAD.

Figura 6.17: Comparação entre predição do modelo de material e resultados do ensaio experimental de relaxação em PEAD.

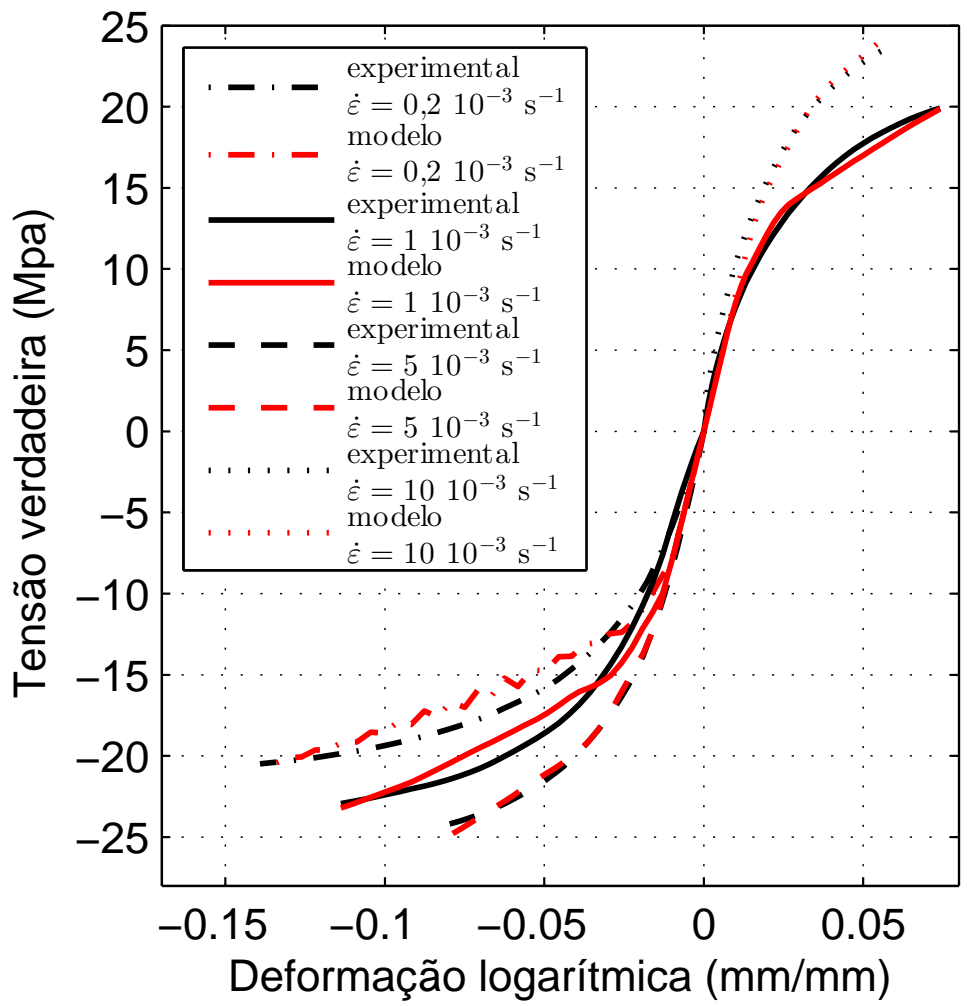

Figura 6.18: Comparação entre predição do modelo de material e resultados dos ensaios experimentais quasi-estáticos de compressão e tração em PEAD. 
Já os valores iniciais para a otimização dos parâmetros da viscoplasticidade podem ser obtidos analisando-se o gráfico da fig. 6.15. O outro gráfico desta figura mostra a adaptação dos valores de tensão para o utilizado no modelo de material (obtido pela norma de frobenius), após ser descontada tensão proporcionada pela fase semicristalina, em função da taxa de deformação cisalhante (obtida multiplicando a taxa de deformação uniaxial por $\sqrt{3})$.

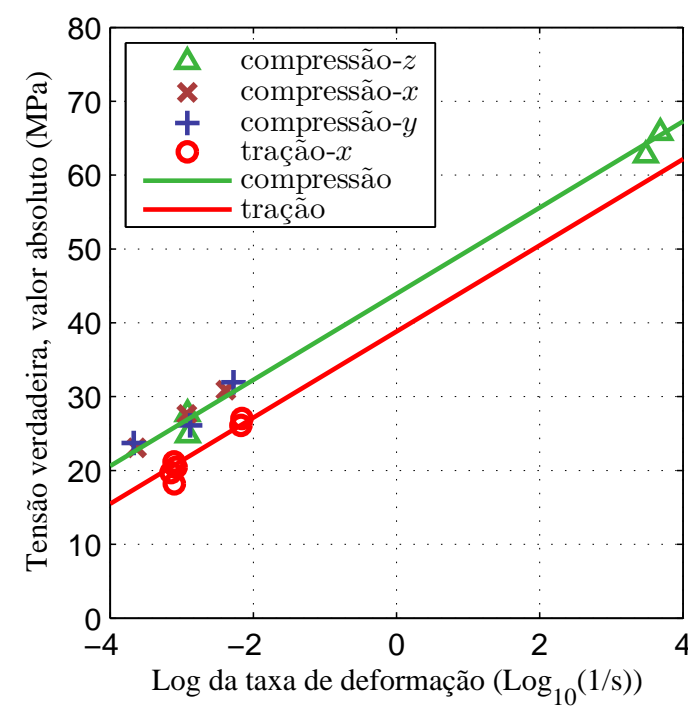

(a) Tensão de escoamento para diversas taxas de deformação em PEAD.

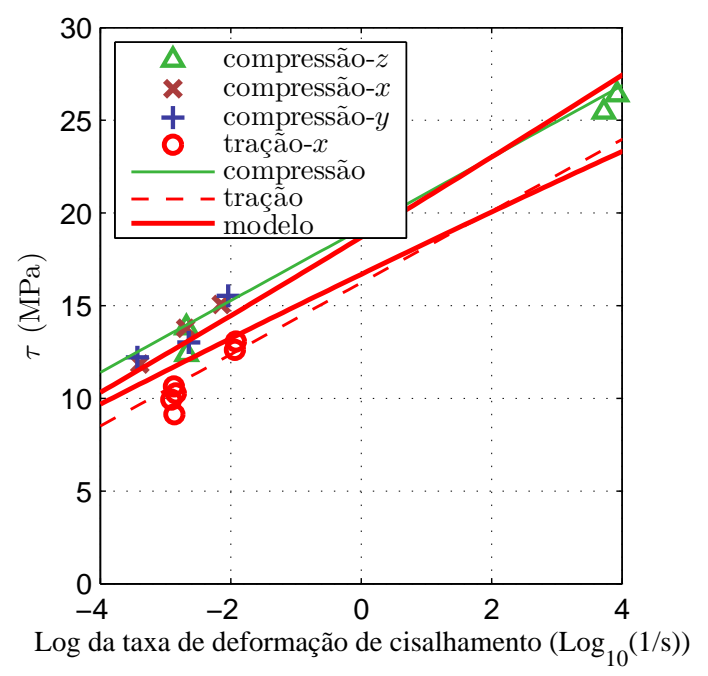

(b) Tensão de escoamento para diversas taxas de deformação em PEAD.

Figura 6.19: Gráfico das tensões verdadeiras uniaxiais em função das taxas de deformação uniaxiais no início da plastificação para o PEAD.

Estes foram inseridos numa função de otimização juntamente com os parâmetros para a evolução de ${ }^{S C} \dot{\mu}$ e os da resistência entrópica, sendo considerado que ${ }^{\alpha} s^{p}$ não irá evoluir, obtendo os resultados encontrados na fig. 6.20.

Neste caso não é considerada a utilização de ensaios de propagação de ondas na calibração dos parâmetros do modelo por causa da dificuldade da usinagem de barras cilíndricas das placas e do fato de não haverem fases presentes apenas em altas taxas de deformação. 


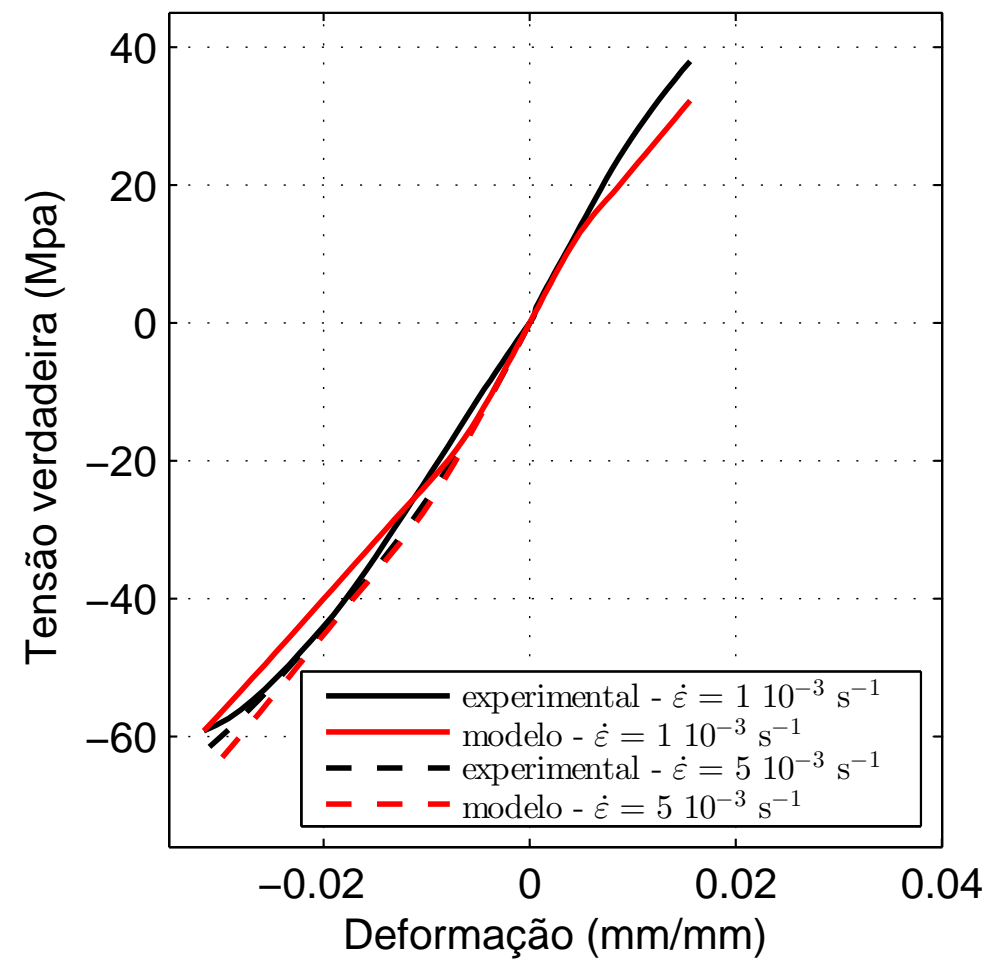

Figura 6.20: Comparação entre predição do modelo de material e resultados dos ensaios experimentais quasi-estáticos de compressão e tração em PEAD. 


\section{Capítulo 7}

\section{Experimentos em componentes}

\subsection{Introdução}

Conforme foi esclarecido nos capítulos anteriores, os testes de impacto em placas não tem por objetivo determinar o limite balístico do material fornecido pela empresa alemã SIMONA ${ }^{\circledR}$, mas sim de serem ensaios experimentais de benchmark de um modelo de material e conseguinte calibração dos parâmetros do mesmo.

Ensaios de benchmark tem por definição a fornecer dados quantitativos da qualidade de um determinado sistema. Neste caso, queremos validar o modelo de material proposto no cap. 3. A calibração dos parâmetros visco-elástica é feita através dos dados dos ensaios de relaxação e da parte elástica das curvas tensão deformação do cap. 4 e dos ensaios de propagação de ondas do cap. 5. Os parâmetros visco-plásticos serão calibrados através da tensão de escoamento dos ensaios quasi-estáticos do cap. 4 e dos resultados da Barra de Hopkinson do cap. 5.Por fim, os parâmetros de encruamento são modelados a partir das curvas tensão deformação do cap. 4. O mínimo que o modelo de material deve fazer após essa calibração é reproduzir, através de simulações com o método dos elementos finitos, os ensaios de relaxação, compressão, tração e propagação de ondas.

Entretanto estes ensaios foram desenvolvidos com o intuito de calibrar parâmetros de modelos de material, com carregamentos uniaxiais, simples, constantes e controlados, geometrias simples. Um ensaio de benchmark tem por objetivo fornecer dados de um ensaio experimental com carregamentos tri-axiais complexos e variados. Quanto mais próximo o resultado numérico provindo da simulação do ensaio experimental de benchmark dos dados obtidos no experimento, melhor o modelo de material.

Como estamos estudando impactos em polímeros termoplásticos, um excelente en- 
saio experimental de benchmark é o impacto em placas. Para base de comparação e avaliação dos efeitos dinâmicos, também foram realizados experimentos de carregamento quasi-estático nas mesmas. No decorrer deste capítulo, serão descritos o programa experimental, os equipamentos e configurações utilizadas, uma breve descrição sobre uma técnica ótica capaz de medir a distribuição de deslocamentos verticais inferiores da placa e por fim os resultados experimentais na forma de curvas força deslocamento.

\subsection{1 programa e configurações experimentais}

As placas quadradas da fig. 3.1, de PEAD e PVC, com lateral de 600mm e espessuras de $5 \mathrm{~mm}$ ou $10 \mathrm{~mm}$ foram utilizadas como corpo de prova nestes testes, após usinagem de furos passantes para fixação no suporte, conforme fig. 7.1(a). O aparato de fixação consiste em dois anéis circulares de aço com diâmetro interno de $500 \mathrm{~mm}$ e unidos, com a placa entre ambos, por 24 parafusos M16 instalados com uma parafusadeira de impacto pneumática. O aparato de fixação está ilustrado na fig. 7.1(b). Como indentador, utilizou-se um cilindro de $60 \mathrm{~mm}$ de diâmetro com arrestas arredondadas em um raio de $5 \mathrm{~mm}$, conforme fig. 7.1(c), tanto para os carregamentos quasi-estáticos quanto para os dinâmicos.

No que diz respeito aos testes quasi-estáticos, para cada combinação de material (PEAD ou PVC) e espessura ( $5 \mathrm{~mm}$ ou $10 \mathrm{~mm})$, foram realizados dois testes em um equipamento com pistão servo-hidráulico, nas velocidades de $1 \mathrm{~mm} / \mathrm{s}$ e $0.1 \mathrm{~mm} / \mathrm{s}$. Um projetor e uma câmera gravando em 4 quadros por segundo foram utilizados para medir o campo de deslocamentos perpendiculares ao plano inicial da placa, conforme será explicado na seção 7.2 .

Já para os testes dinâmicos, foi utilizado um acelerador pneumático [53, 38], que consiste em um reservatório de ar comprimido conectado a um tubo vertical, conforme fig. 7.2. Este acelerava um indentador, que consistia em um cilindro central, com o nariz da fig. 7.1(c) na extremidade em que há o impacto e um dispositivo para fixação de massas, podendo-se determinar com precisão a massa de impacto, em $18.4 \mathrm{~kg}$.

Os dados experimentais são obtidos por dois extensômetros fixados na parte cilíndrica do indentador, de maneira diametralmente oposta e em uma posição próxima do nariz. Considerando o material elástico e não visco-elástico, da deformação fornecida pela extensômetro é encontrada a tensão e a partir desta é calculada a força, uma vez que a 


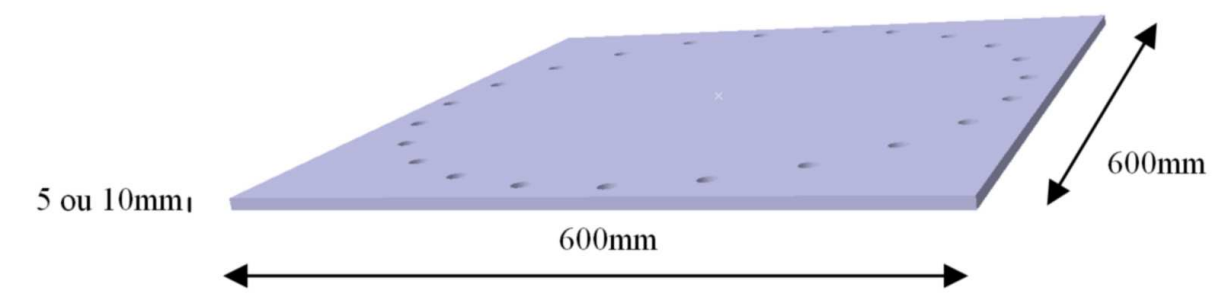

(a)

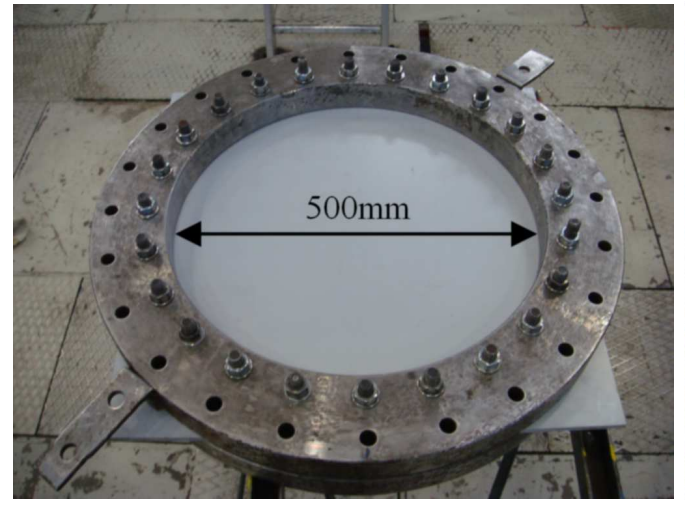

(b)

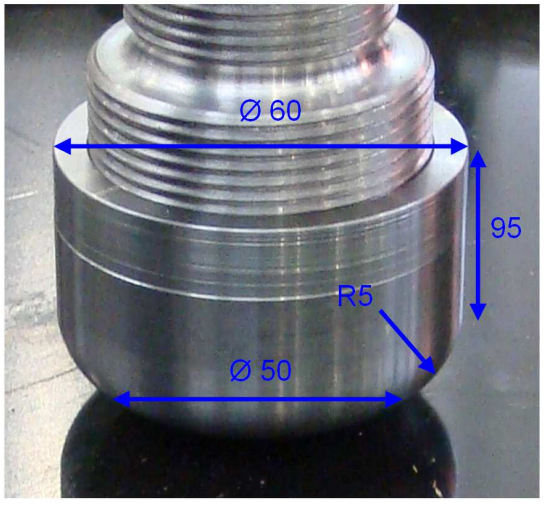

(c)

Figura 7.1: Geometria da placa em (a), foto do sistema de fixação em (b) e geometria e dimensões do indentador em (c)

área é conhecida. Este equipamento é calibrado em uma máquina de ensaios de compressão com um célula de carga de alta resolução. Como a força e a massa do indentador são conhecidas, a aceleração é calculada a partir da segunda lei de Newton e, integrada numericamente duas vezes, fornece os valores da velocidade e deslocamento em função do tempo [53]. É válido ressaltar que há um tratamento da força por filtro passa baixa entre o valor fornecido pelo equipamento e a utilizado nos resultados, com o objetivo de minimizar as oscilações provenientes da propagação de ondas internamente no indentador. As velocidades de impacto são medidas imediatamente antes do contato indentador placa por células foto-voltaicas [38]. As velocidades de impacto variaram de acordo com material, estando entre $4 \mathrm{~m} / \mathrm{s}$ e $16 \mathrm{~m} / \mathrm{s}$. Neste caso, em especial para a proteção do equipamento, foi utilizado um espelho para poder afastar a câmera de alta velocidade da área de impacto com esta última operando em uma frequência de $10 \mathrm{KHz}$. 


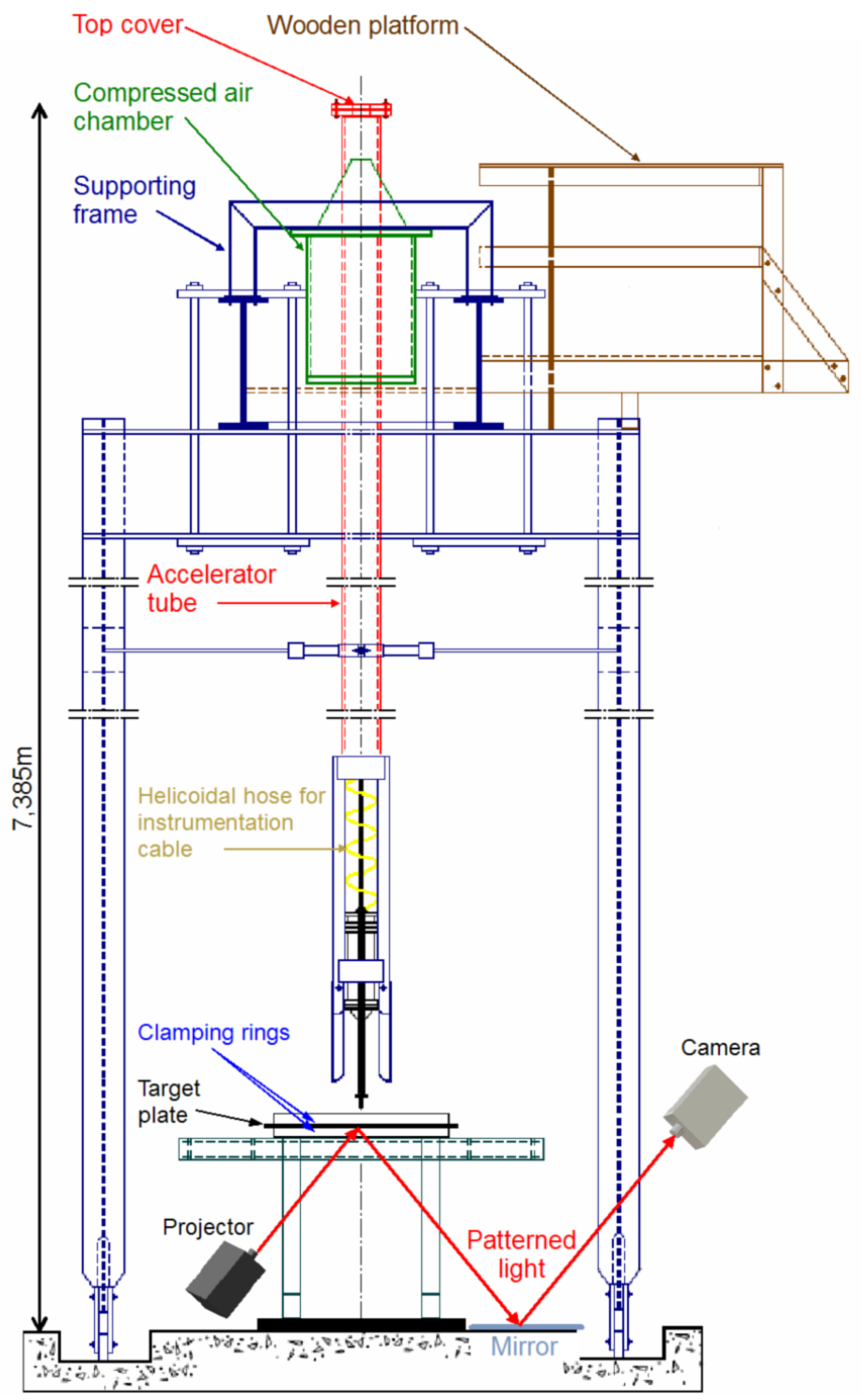

Figura 7.2: Dispositivo utilizado para realizar os testes de impacto em placas através de um indentador acelerado pneumaticamente.

\subsection{Medição do campo de deslocamentos verticais}

Em alguns testes foi utilizada uma técnica óptica para medir o campo de deslocamentos perpendiculares ao plano inicial da placa. Está técnica foi desenvolvida por Fagerholt em sua tese de mestrado e utilizada anteriormente em ensaios quasi-estáticos e dinâmicos em placas de alumínio [39, 31].

A técnica consiste em projetar uma luz com padrão de franjas, ou seja, faixas horizontais de luz intercaladas por faixas de sombra, na parte inferior da placa e uma câmera 


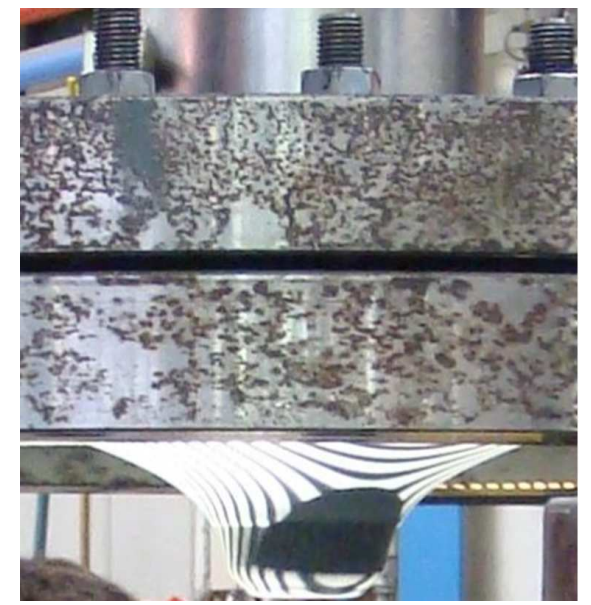

Figura 7.3: Dispositivo utilizado para realizar os testes carregamento quasi estático em placas com cilindro servo-hidráulico em conjunto com a luz em padrão de franjas projetada.

registra imagens do teste, conforme ilustrado na fig. 7.3. Para uma explicação mais detalhada da calibração ou dos algoritmos utilizados, verificar o trabalho de Grytten [39] e Fagerholt [31].

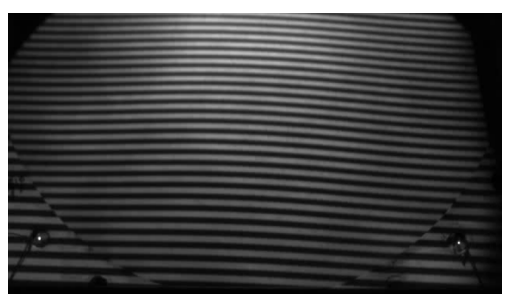

(a)

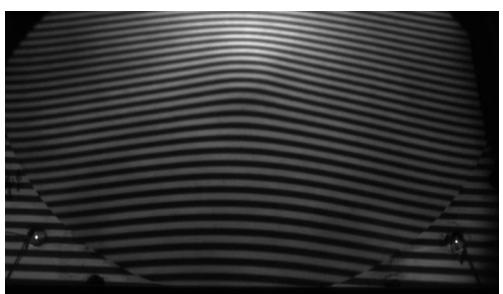

(b)

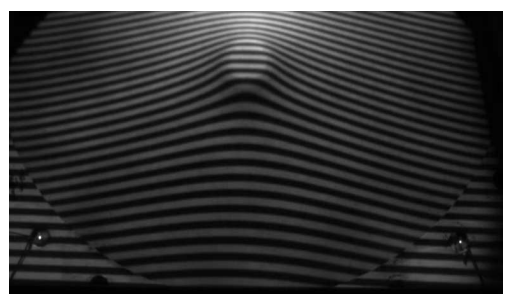

(c)

Figura 7.4: Imagens obtidas no carregamento central quasi-estático da placa

Durante o ensaio experimental de impacto central na placa de PEAD de $5 \mathrm{~mm}$ de espessura foram obtidas as seguintes imagens da fig. 7.4. Através da técnica ótica, são calculados os deslocamentos verticais em uma região da placa correspondentes ao instante registrado na fig. 7.4(c). Como é possível obter os valores de deslocamento vertical apenas na região iluminada pelo padrão de franjas, $\mathrm{O}$ motivo da técnica registrar apenas uma região da superfície deformada se deve ao fato de a própria deformação da placa induzir sombras e regiões pouco iluminadas. A evolução do peril de deformação da placa está ilustrada na fig. 7.5(b). Ainda nesta figura, os deslocamentos verticais no centro da placa são comparados com os dados de deslocamento obtidos pelo tratamento do sinal de força do indentador, demarcados com símbolos $\mathbf{x}$. A correlação entre ambos sistemas em geral 
é boa, exceto pelo desvio mais acentuado na deformação máxima.

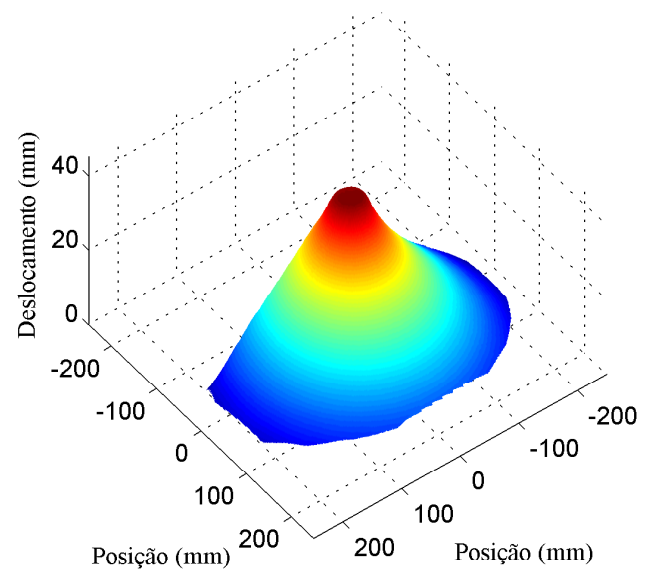

(a)

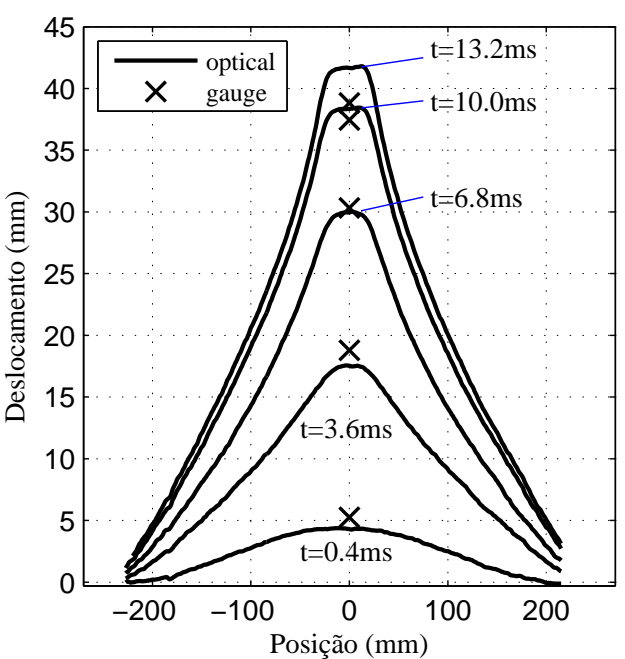

(b)

Figura 7.5: Imagens obtidas no carregamento central quasi-estático da placa

\subsection{Resultados experimentais}

A figura 7.6, mostra a curva força deslocamento das quatro combinações possíveis de material e espessura de chapa. As placas que sofreram falha no impacto estão demarcadas com um x no fim da curva força deslocamento. Também para facilitar o entendimento, as curvas oriundas dos ensaios quasi-estáticos mais fina. Ainda sobre estes ensaios de baixa velocidade, todos os testes em PVC resultaram em falha, enquanto apenas um teste em PEAD teve o mesmo comportamento, sendo a justificativa a limitação $100 \mathrm{~mm}$ de deslocamento do atuador hidráulico.

Conforme intuído, a curva força deslocamento apresenta um valor para os ensaios em placas de espessura de $10 \mathrm{~mm}$ de aproximadamente o dobro da de $5 \mathrm{~mm}$. Além disso, a força máxima qua quase o dobro nos ensaios de PVC quando comparado com os testes em PEAD, fato também esperado devido a diferença nas curvas tensão deformação dos materiais, conforme visto no cap. 4 .

Nos ensaios dinâmicos, pode-se notar que a propagação de ondas na placa entre as bordas e o indentador induz um fenômeno de vibração, que pode ser verificado nas curvas força deslocamento. Quanto a comparação ensaios quasi-estáticos e dinâmicos, a resposta 


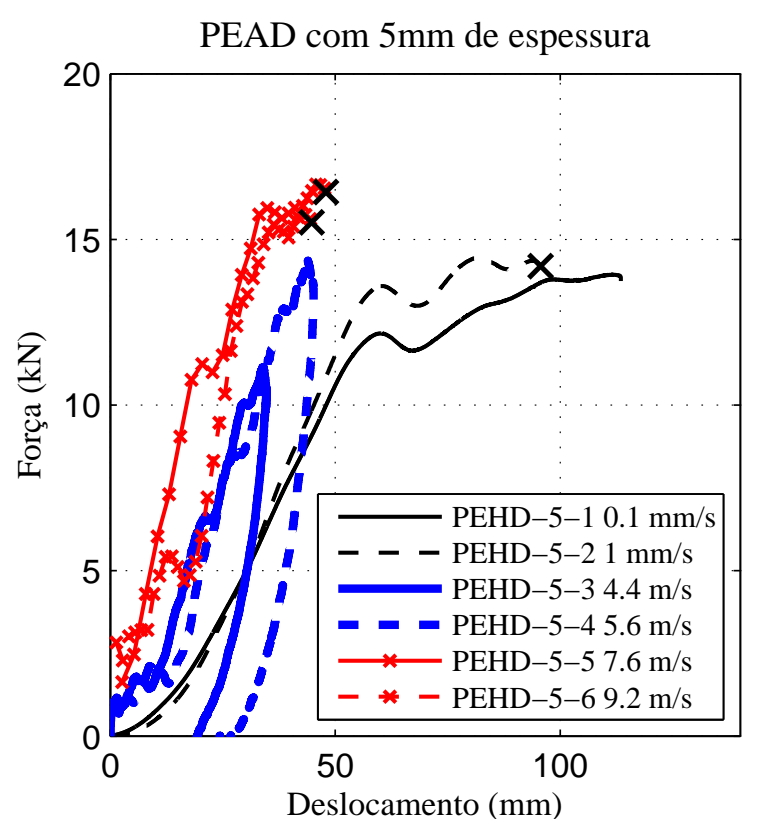

(a)

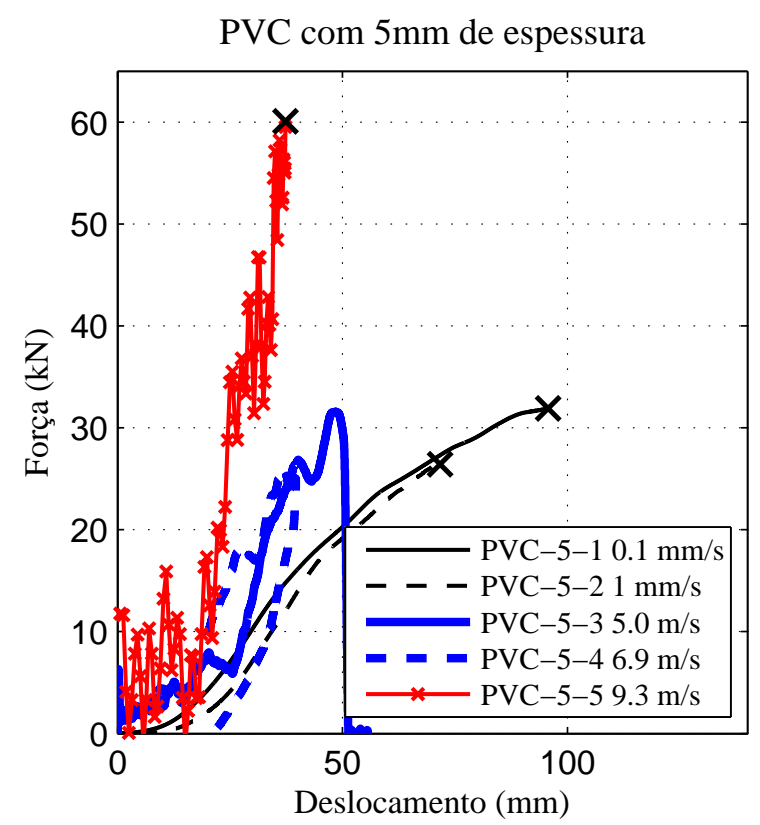

(c)

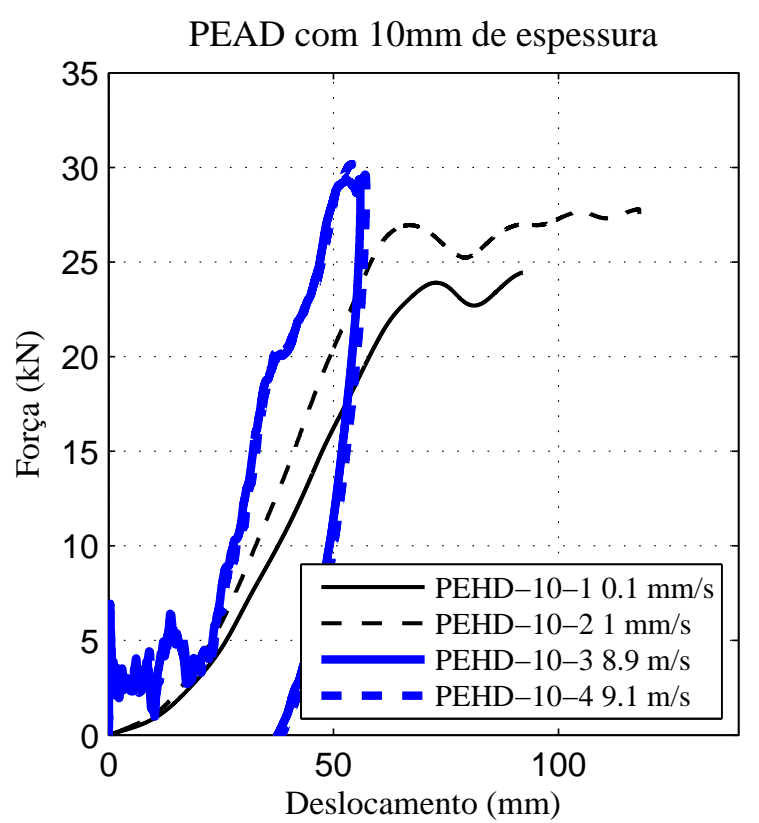

(b)

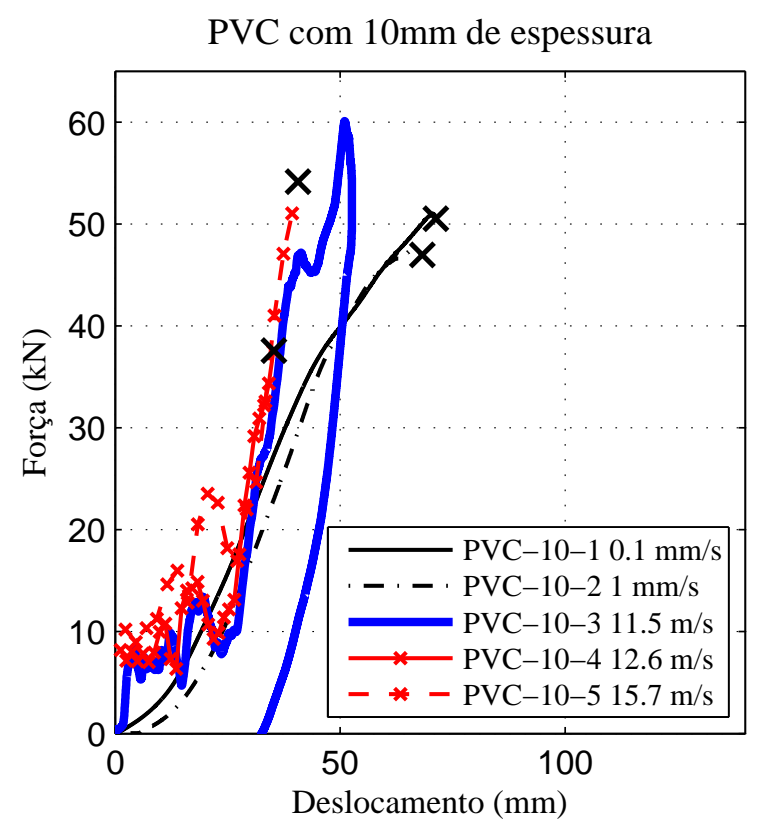

(d)

Figura 7.6: Imagens obtidas no carregamento central quasi-estático da placa

dinâmica dos materiais é mais rígida, possibilitando uma maior força máxima, mas por outro lado, os deslocamentos máximos na fratura são maiores nos casos quasi-estáticos, podendo-se concluir o aumento do comportamento frágil em resposta a maiores taxas de deformação. 


\subsection{Simulação Numérica}

Para a representação do impacto de um indentador contra a placa de PEAD e PVC foram modelados em elementos finitos: a placa, os suportes como rígidos e os parafusos como elásticos. Em todos os componentes foram utilizados elementos sólidos tal que representasse de forma mais acurada a interação entre essas geometrias. Um exemplo disso é a interação entre a placa e a borda dos suportes de fixação, sendo considerados os raios destas no modelo numérico, fig. 7.7.

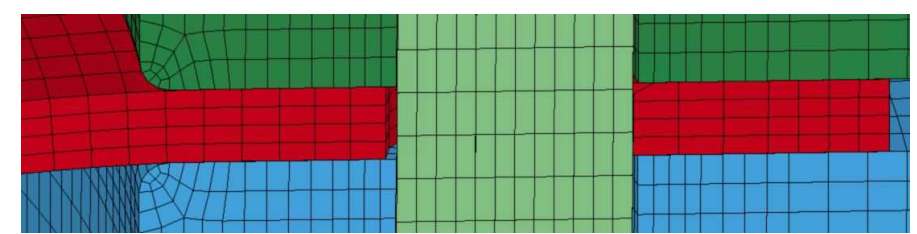

Figura 7.7: Detalhe do raio modelado nos anéis para a não interferência no contato com a placa.

A placa foi modelada com 4 elementos ao longo da espessura e com refino central, de modo a manter uma razão de aspecto favorável à deformação no sentido radial. Foram utilizados elementos sólidos, com 8 nós e integração reduzida (1 ponto), conforme 7.8.

O efeito do torque aplicado, bem como da geometria dos parafusos, foi considerado relevante para representar o evento. Tal abordagem exigiu que a simulação fosse dividida em duas partes: fase inicial de estabilização das tensões devido ao torque dos parafusos e o evento de impacto. Após estabilizado o carregamento de $72 \mathrm{kN}$ (calculado a partir das propriedades da parafusadeira pneumática, tipo, diâmetro e número de parafusos) aplicado ao suporte superior, na fase de relaxação dinâmica da simulação, a posição do anel superior foi mantida e teve início o evento de impacto propriamente dito. De forma a simplificar os contatos entre as partes, os parafusos foram modelados como se agissem somente como pinos, não tensionados no sentido axial, somente resistindo à movimentação da placa no sentido horizontal.

Os resutados encontram-se na fig. 7.9. 


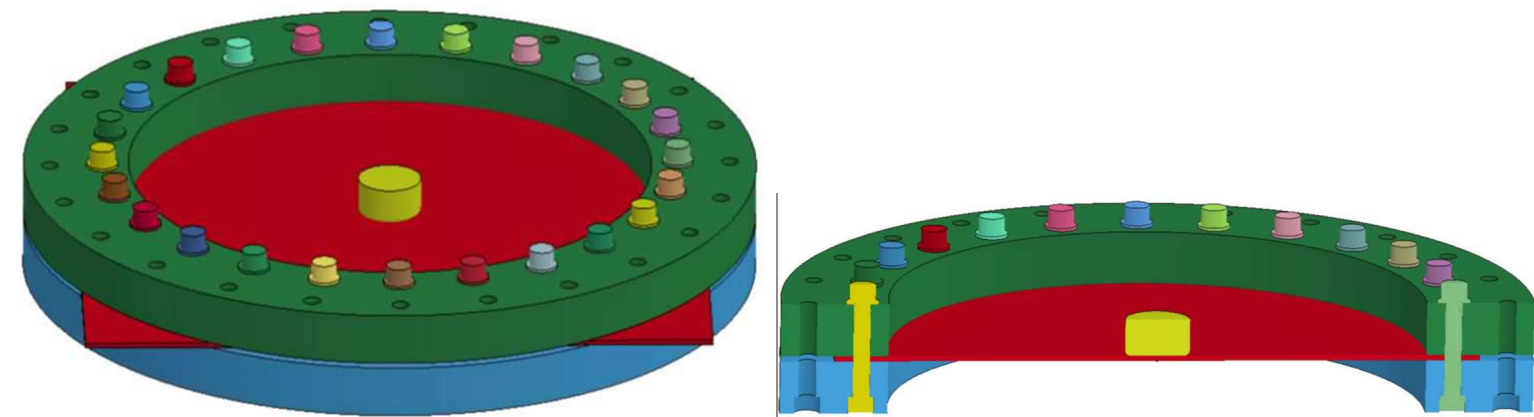

(a)

(b)

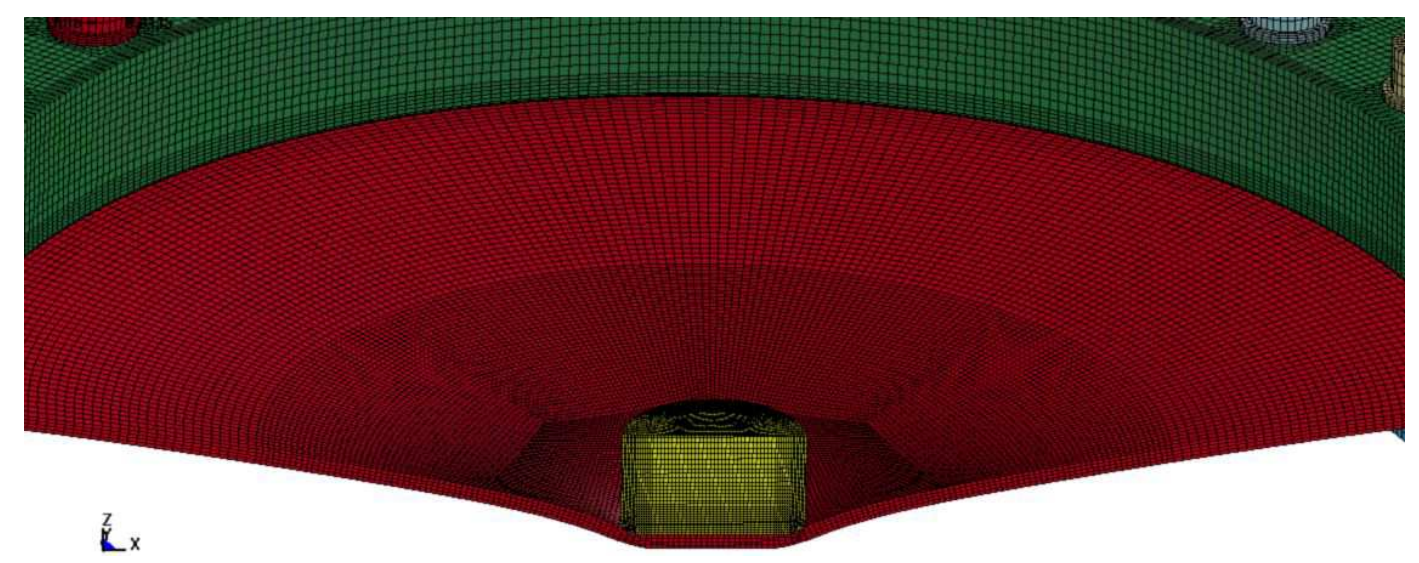

(c)

Figura 7.8: Simulação numérica da placa, detalhes da geometria e malha. 


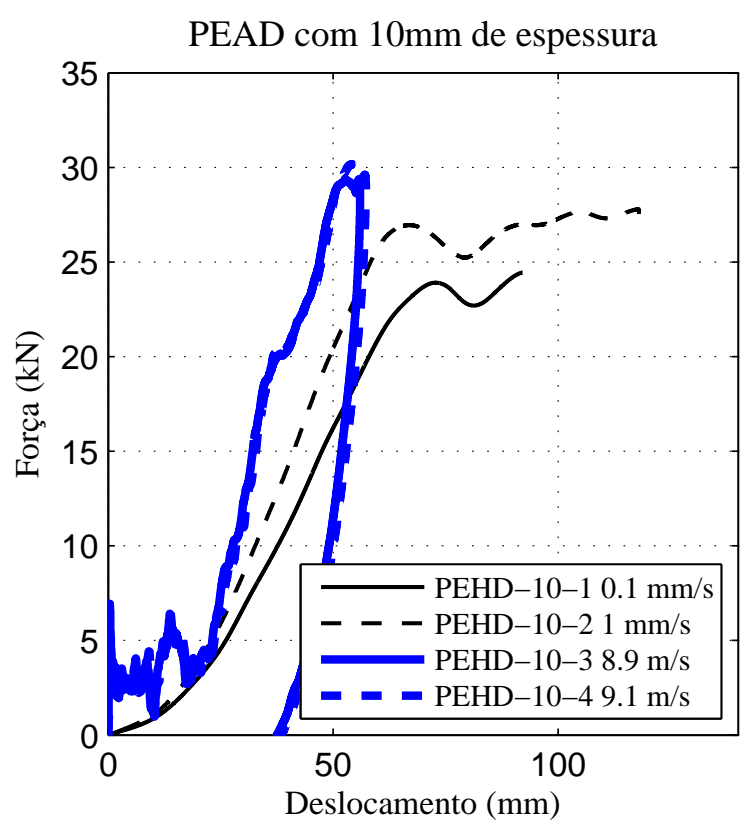

(a) PEAD

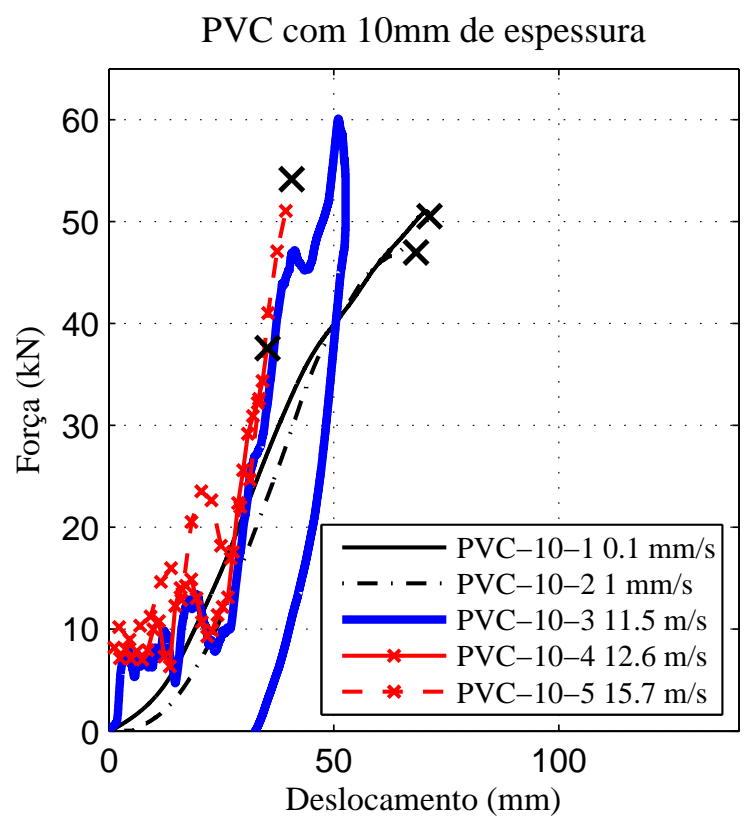

(b) PVC

Figura 7.9: Comparação dos resultados da simulação numérica do impacto nas placas com os resultados experimentais. 


\section{Capítulo 8}

\section{Discussões e Conclusões}

Foram realizados ensaios experimentais para a caracterização mecânica do material cobrindo um grande intervalo de taxas de deformação. Em baixíssimas taxas de deformação (relaxação) em tração sendo avaliada a resposta viscoelástica do material. Nas baixas taxas de deformação, testes de compressão e tração avaliaram a sensibilidade ao tipo de carregamento, a taxa de deformação, a direção de carregamento (grau de anisotropia). Em altas taxas de deformação, foi analisada a viscoelasticidade durante a medição do módulo elástico tridimensional na propagação de ondas em barras cilíndricas. Também nessas taxas de deformação, foram obtidas as propriedades mecânicas viscoplásticas utilizando-se a barra de Hopkinson.

A utilização da técnica de correlação de imagens digitais permitiu o estudo minucioso do campo de deformações na superfície dos corpos de prova utilizados, levando a verificações como a baixíssima taxa de deformação na região da estriç̧ão de corpos de prova de tração ou ao comportamento predominante de cisalhamento durante o fenômeno da relaxação. A medição das deformações transversais possibilitou o cálculo da área atual e obtenção da tensão verdadeira mesmo para regiões com localizações ou mesmo sem conservação volumétrica na plasticidade.

O estudo da propagação de ondas tridimensionais em barras cilíndricas viscoelásticas permitiu a medição da sensibilidade à taxa de deformação para carregamentos elásticos. Além disso, o novo método proposto para medição dos efeitos de dispersão geométrica, material e atenuação utilizando-se duas estações de medida em conjunto com o laser permitiu uma melhor predição na estimativa das forças e deslocamentos em qualquer seç̧ão transversal da barra a partir da medição da onda de deformações em apenas um 
ponto da mesma, melhorando a confiabilidade e a acurácia nas propriedades viscoplásticas obtidas na SHPB.

A realização dos ensaios de impacto em placas poliméricas forneceu dados do comportamento mecânico a altas taxas de deformação permitindo futuras comparações com trabalhos numéricos. Os dados foram obtidos através de dois modos: $i$ ) extensômetros fixados no impactador forneceram dados de aceleração, dos quais foi possível obter uma curva força deslocamento e $i i$ ) através da análise de fotografias obtidas em altas frequências de aquisição da parte inferior da placa, durante o impacto, enquanto um padrão em forma de franjas pretas e brancas era projetado na mesma. A partir destas imagens, foi possível obter o perfil de deslocamentos transversais ao plano inicial em que a placa se encontrava.

O estudo da mecânica do contínuo não linear para entendimento e revisão de modelos para polímeros termoplásticos permitiu o desenvolvimento de uma infraestrutura na forma de subrotinas para a implementação rápida de qualquer tipo de modelo de material baseado em relações hiper-elásticas e decomposição multiplicativa do gradiente de deformações, contribuindo não somente no conhecimento adquirido pelo autor, mas também no desenvolvimento do laboratório como grupo de pesquisa.

Ainda, a conversão das subrotinas em fortran para funções equivalentes no matlab permite calibrar e avaliar as vantagens e limitações dos modelos implementados. Aliado a possibilidade de se medir as deformações longitudinais e transversais do DIC, pode-se criar otimizações para calibrar parâmetros de modelos de material simulando sua função no programa comercial de elementos finitos, em que simplificadamente esta recebe um gradiente de deformações e retorna um tensor de tensões.

Entretanto, mesmo com os dados da resistência mecânica do material disponível em diversas taxas de deformação e da possibilidade da utilização das rotinas de otimização já implementadas no matlab, percebeu-se uma dificuldade na obtenção de um conjunto de parâmetros capaz de reproduzir tanto a viscoelasticidade a baixas taxas de deformação quanto o comportamento mecânico de relaxação.

Um fator que pode ter originado esta dificuldade é o intervalo de mais de um ano entre os ensaios experimentais de tração e compressão realizados na SIMLab e os de relaxação realizados no GMSIE, no qual os termoplásticos não foram armazenados corretamente, estando por exemplo expostos a umidade. 
Outro limitante foi a câmera utilizada na fase de carregamento dos ensaios de relaxação, no qual o modo burst foi utilizado. Não se pode afirmar que o intervalo entre fotos é constante ou mesmo a precisão destes intervalos, além da dificuldade de sincronizar o início do carregamento com o início da fotografias. Para melhores resultados, seriam necessárias câmeras com maior capacidade de fotografias com segundo e uma entrada de trigger para sincronização das imagens com os dados da célula de carga.

Outra origem das dificuldades na calibração dos parâmetros viscoelásticos é o uso de células de carga com grande fundo de escala, devido ao valor das forças quando os corpos de prova atingem grandes deformações. Estas células de carga possuem resoluções maiores e portanto não seriam as preferíveis quanto que da medição das propriedades viscoelásticas.

Apesar destas fontes de desvio do resultado ideal, nota-se uma limitação do modelo proposto no cálculo da taxa de deformação viscosa, mais precisamente no termo

$$
\left(\frac{\tau}{s^{v}+n^{v} p}\right)
$$

em que o valor da pressão hidrostática $p$ é negativo e crescente tornando a fração negativa e consequentemente a taxa de deformação viscosa, com esta se deformando na direção contraria a direção do deviatórico da tensão, aumentando a tensão, aumentando a pressão e consequentemente aumentando o valor da deformação na direção contraria a do tensor de tensões, com o ciclo se repetindo e criando uma instabilidade nos resultados.

Apesar desta limitação, não se pode afirmar que o modelo de material possui problemas em sua concepção, sendo necessários mais testes de relaxação mantendo-se a deformação máxima e variando-se o tempo de carregamento, ensaios de carregamento e descarregamento variando-se ou a deformação máxima ou a taxa de deformação, utilização de uma célula de carga mais precisa e o uso das novas câmeras adquiridas pelo GMSIE que permitem até 17 qps e sincronização com a máquina de ensaios de tração.

Conclui-se que o trabalho foi positivo no que diz respeito a um estudo completo sobre os dois tipos de termoplásticos, uma vez que inovou com

- uso da correlação de imagens digitais em ensaios de relaxação;

- novo método de obtenção do mapa de correções para o estudo da dispersão e atenuação em barras cilíndricas poliméricas; 
- proposição de um modelo de material para termoplásticos amorfos e outro para semicristalinos, com um processo de otimização dos parâmetros fornecendo gradientes de deformações obtidos da correlação de imagens digitais;

além de ter fornecido a comunidade científica novos dados minuciosos sobre a resistência mecânica destes termo-plásticos juntamente com ensaios de impacto em placas para validação de novos modelos de materiais ou estudo da limitação dos existentes. 


\section{Referências Bibliográficas}

[1] Argon, A. S. A theory for the low-temperature plastic deformation of glassy polymers. Philosophical Magazine 28, 4 (1973), 839-865. Disponível em: http: //www . tandf online.com/doi/abs/10 .1080/14786437308220987.

[2] Argon, A. S., Andrews, R. D., Godrick, J. A., And Whitney, W. Plastic deformation bands in glassy polystyrene. Journal of Applied Physics 39, 3 (1968), 1899-1906. Disponível em: http://link.aip.org/link/?JAP/39/1899/1.

[3] Arruda, E. M., And Boyce, M. C. Evolution of plastic anisotropy in amorphous polymers during finite straining. International Journal of Plasticity 9, 6 (1993), 697 - 720. Disponível em: http://www.sciencedirect.com/science/article/pii/ $074964199390034 \mathrm{~N}$.

[4] Ayoub, G., Zaïri, F., NaÏt-Abdelaziz, M., and Gloaguen, J. Modelling large deformation behaviour under loading-unloading of semicrystalline polymers: Application to a high density polyethylene. International Journal of Plasticity 26, 3 (2010), 329 - 347. Disponível em: http://www.sciencedirect.com/science/ article/pii/S0749641909000928.

[5] BACON, C. An experimental method for considering dispersion and attenuation in a viscoelastic hopkinson bar. Experimental Mechanics 38 (1998), 242-249. 10.1007/BF02410385. Disponível em: http://dx.doi.org/10.1007/BF02410385.

[6] Bancroft, D. The velocity of longitudinal waves in cylindrical bars. Physical Review, Vol. 59 (1941).

[7] Batra, R., And Chen, L. Effect of viscoplastic relations on the instability strain, shear band initiation strain, the strain corresponding to the minimum 
shear band spacing, and the band width in a thermoviscoplastic material. International Journal of Plasticity 17, 11 (2001), 1465 - 1489. Disponível em: http://www.sciencedirect.com/science/article/pii/S0749641901000043.

[8] Bauwens-Crowet, C., Bauwens, J. C., And Homès, G. Tensile yield-stress behavior of glassy polymers. Journal of Polymer Science Part A-2: Polymer Physics 7, 4 (1969), 735-742. Disponível em: http://dx.doi.org/10.1002/pol.1969. 160070411.

[9] Beijer, J., And Spoormaker, J. Modelling of creep behaviour in injectionmoulded hdpe. Polymer 41, 14 (2000), 5443 - 5449. Disponível em: http://www. sciencedirect.com/science/article/pii/S0032386199007533.

[10] Belytschko, T., Liu, W., And Moran, B. Nonlinear finite elements for continua and structures. Wiley, 2000. Disponível em: http://books.google.com/ books?id=efu2QgAACAAJ.

[11] Bergström, J., And JR., L. H. A constitutive model for predicting the large deformation thermomechanical behavior of fluoropolymers. Mechanics of Materials 37, 8 (2005), 899 - 913. Disponível em: http: //www.sciencedirect.com/science/ article/pii/S0167663604001310.

[12] Bergstrom, J. Finite element modeling of polymers. Tech. rep., Veryst Engineering, LCC, 2009.

[13] Bergstrom, J. S. Large Strain Time-dependent behavior of Elastomeric Materials. PhD thesis, Massachusetts Institute of Technology, 1993.

[14] Bois, P. A. D., Kollin, S., Koesters, M., And Frank, T. Material behavior of polymers under impact loading. International Journal os Impact Engineering, 32 (2006), pp $725-240$.

[15] Bonet, J., And Wood, R. Nonlinear continuum mechanics for finite element analysis. Cambridge University Press, 1997. Disponível em: http://books.google. com. br/books?id=0RmLdrq1f I8C. 
[16] Boyce, M., Socrate, S., And Llana, P. Constitutive model for the finite deformation stress-strain behavior of poly(ethylene terephthalate) above the glass transition. Polymer 41, 6 (2000), 2183 - 2201. Disponível em: http: //www.sciencedirect.com/science/article/pii/S0032386199004061.

[17] Boyce, M., Weber, G., And Parks, D. On the kinematics of finite strain plasticity. Journal of the Mechanics and Physics of Solids 37, 5 (1989), 647 - 665. Disponível em: http://www.sciencedirect.com/science/article/pii/ 0022509689900331.

[18] Boyce, M. C. Large Inelastic Deformation of Glassy Polymers. PhD thesis, Massachusetts Institute of Technology, 1987.

[19] Boyce, M. C., And Arruda, E. M. Constitutive models of rubber elasticity: A review. Rubber Chemistry and Technology 73, 3 (7 2000), 504-523. Disponível em: http://dx.doi.org/10.5254/1.3547602.

[20] Boyce, M. C., Parks, D. M., And Argon, A. S. Large inelastic deformation of glassy polymers. part i: rate dependent constitutive model. Mechanics of Materials 7, 1 (1988), 15 - 33. Disponível em: http://www.sciencedirect.com/science/ article/pii/0167663688900038.

[21] Brinson, H., And Brinson, L. Polymer Engineering Science and Viscoelasticity: An Introduction. Springer, 2008. Disponível em: http://books.google.com.br/ books?id=QWS4-ohiK-wC.

[22] Callister, W. Ciência e engenharia de materiais: uma introdução. Livros Técnicos e Científicos, 2002. Disponível em: http://books.google.com.br/books?id= -RvIAAAACAAJ.

[23] Chree, C. The equations of an isotropic elastic solid in polar and cylindrical coordinate, their solution and applications. Cambridge Philosophical Society Transactions, Vol. 14 (1941), pp $250-369$.

[24] Clausen, A. H., Polanco-loria, M., Moura, R. T., Alves, M., Berstad, T., Langseth, M., And Hopperstad, O. S. Polymer plates subjected to impact: 
Experimental tests and numerical simulations. 1537-1543. Disponível em: http: //dx.doi.org/10.1051/dymat/2009217.

[25] Davies, R. M. A critical study of the Hopkinson bar. Phil. Trans. Roy. Soc. London, 240 (1948), pp $375-457$.

[26] Delhaye, V. Behaviour and modelling of polymers for crash applications. PhD thesis, Norwegian University of Science and Technology, 2010.

[27] Duffy, J., Campbell, J. D., And Rawlay, R. H. On the use of a torsional split hopkinson bar to study rate effects in 1100-0 aluminium. J. Appl. Mech., Vol. 38 (1971), pp $83-91$.

[28] Dusunceli, N., And Colak, O. U. Modelling effects of degree of crystallinity on mechanical behavior of semicrystalline polymers. International Journal of Plasticity 24, 7 (2008), 1224 - 1242. Disponível em: http://www.sciencedirect.com/ science/article/pii/S0749641907001258.

[29] Elhem, And Ghorbel. A viscoplastic constitutive model for polymeric materials. International Journal of Plasticity 24, 11 (2008), 2032 - 2058. Disponível em: http: //www.sciencedirect.com/science/article/pii/S0749641908000119.

[30] Eyring, H. Viscosity, plasticity, and diffusion as examples of absolute reaction rates. The Journal of Chemical Physics 4, 4 (1936), 283-291. Disponível em: http: //link.aip.org/link/?JCP/4/283/1.

[31] Fagerholt, E., Grytten, F., Gihleengen, B., Langseth, M., And BørVIK, T. Continuous out-of-plane deformation measurements of aa5083-h116 plates subjected to low-velocity impact loading. International Journal of Mechanical Sciences 52, 5 (2010), 689 - 705. <ce:title>Special Issue in Honor of Professor Tongxi $\mathrm{Yu}</$ ce:title>. Disponível em: http://www. sciencedirect.com/science/ article/pii/S0020740309002422.

[32] Fang, Q.-Z., Wang, T., Beom, H., and Zhao, H. Rate-dependent large deformation behavior of pc/abs. Polymer 50, 1 (2009), 296 - 304. Disponível em: http://www. sciencedirect.com/science/article/pii/S0032386108009427. 
[33] Filho, A. A. Elementos Finitos - A Base da Tecnologia CAE. Editora Érica, 2006. Disponível em: http://www . erica. com.br/detalhes . asp? cod=7414.

[34] Follansbee, P. S., And Frantz, C. Wave propagation in the split hopkinson pressure bar. Journal of Engineering Materials and Technology Vol. 105 (1983), pp. $61-66$.

[35] Gent, A. N. A new constitutive relation for rubber. Rubber Chemistry and Technology 69, 1 (3 1996), 59-61. Disponível em: http://dx.doi.org/10.5254/1. 3538357.

[36] Gorham, D. A. A numerical method for the correction of dispersion in pressure bar signals. J. Phys. E. Sci. Instm. Vol. 16 (1983), pp. $477-479$.

[37] Graff, K. F. Wave Motion in Elastic Solids. Dover Publications, Inc., New York, 1975.

[38] Grytten, F., Børvik, T., Hopperstad, O., and Langseth, M. Low velocity perforation of aa5083-h116 aluminium plates. International Journal of Impact Engineering 36, 4 (2009), 597 - 610. Disponível em: http://www.sciencedirect. com/science/article/pii/S0734743X08002261.

[39] Grytten, F., Fagerholt, E., Auestad, T., Førre, B., and Børvik, T. Out-of-plane deformation measurements of an aluminium plate during quasi-static perforation using structured light and close-range photogrammetry. International Journal of Solids and Structures 44, 17 (2007), 5752 - 5773. Disponível em: http: //www.sciencedirect.com/science/article/pii/S0020768307000571.

[40] Harding, J. Testing techniques at very high rates of strain. O.U.E.L. Report, N. $1308 / 80$ (1980), pp $8-24$.

[41] Haward, R. N., And Thackray, G. The use of a mathematical model to describe isothermal stress-strain curves in glassy thermoplastics. Proceedings of the Royal Society of London. Series A. Mathematical and Physical Sciences 302, 1471 (1968), 453-472. Disponível em: http://rspa.royalsocietypublishing.org/content/ 302/1471/453. abstract. 
[42] Hopkinson, B. A method of measuring the pressure produced in the detonation of high explosives or by the impact of bullets. Proc. Roy. Soc. London, 62 (1949), pp $676-700$.

[43] Jacquot, P., AND Fournier, J. Interferometry in speckle light: theory and applications : proceedings of the international conference 25-28 September 2000, Lausanne, Switzerland. Physics and astronomy online library. Springer, 2000. Disponível em: http://books.google.com.br/books?id=sHMDXm01vn4C.

[44] Jordan, J., Foley, J., And Siviour, C. Mechanical properties of epon 826/dea epoxy. Mechanics of Time-Dependent Materials 12 (2008), 249-272. 10.1007/s11043008-9061-x. Disponível em: http://dx.doi.org/10.1007/s11043-008-9061-x.

[45] J.S.Bergstrom, And J.E.Bischoff. An advanced thermomechanical constitutive model for uhmwpe. International Journal of Structural Changes in Solids 2, 1 (Abril 2010), 31-39.

[46] Kalpakjian, S., And Schmid, S. Manufacturing engineering and technology. Prentice Hall International Editions Series. Prentice Hall, 2001. Disponível em: http: //books . google. com. br/books?id=cFaSQAAACAAJ.

[47] Khan, A. S., And Farrokh, B. Thermo-mechanical response of nylon 101 under uniaxial and multi-axial loadings: Part i, experimental results over wide ranges of temperatures and strain rates. International Journal of Plasticity 22, 8 (2006), 1506 - 1529. <ce:title>Special issue in honour of Dr. Kirk Valanis $</$ ce:title $><$ ce:subtitle $>$ Valanis Issue $</$ ce:subtitle $>$. Disponível em: http: //www.sciencedirect.com/science/article/pii/S0749641905001610.

[48] Klepaczko, J. Application of the split hopkinson pressure bar to fracture dynamics. Inst. Phys. Conf. Ser., N. 47, Capítulo 2 (1979), pp $201-214$.

[49] Klompen, E. T. J. Mechanical properties of solid polymers. PhD thesis, Universidade Técnica de Eindhoven, 2005.

[50] Kolsky, H. An investigation of the mechanical properties od materials at very high rates of load. Phil. Trans. Roy. Soc. London, 213 (1914), pp $437-456$. 
[51] Kolsky, H. Stress Waves in Solids. New York Dover Publications, 1963.

[52] Kurtz, S. M. The UHMWPE Handbook, Ultra-High Molecular Weight Polyethylene in Total Joint Replacement. Elsevier, 2004.

[53] Langseth, M., And Larsen, P. Dropped objects' plugging capacity of steel plates: An experimental investigation. International Journal of Impact Engineering 9, 3 (1990), 289 - 316. Disponível em: http://www.sciencedirect.com/science/ article/pii/0734743X9090004F.

[54] Lee, E., And McMeeking, R. Concerning elastic and plastic components of deformation. International Journal of Solids and Structures 16, 8 (1980), 715 - 721. Disponível em: http://www.sciencedirect.com/science/article/pii/ $002076838090013 X$.

[55] LEE, E. H. Elastic-plastic deformation at finite strains. Journal of Applied Mechanics 36, 1 (1969), 1-6. Disponível em: http://link.aip.org/link/?AMJ/36/1/1.

[56] Lewis, J. L., And Goldsmith, W. A biaxial split hopkinson bar for simultaneous torsion and compression. Rev. Sci. Instrum., Vol. 44, N. 7 (1973), pp $811-813$.

[57] Lindholm, U. S., And Yeakley, L. M. High strain-rate testing: Tension and compression. Experimental Mechanics, Vol. 8, N. 1 (1968), pp 1 - 9.

[58] Livermore Software Technology Corporation (LSTC). Ls-Dyna Keyword User's Manual,, versão 971 / rev 5 (beta) ed., Maio 2010.

[59] Love, A. E. H. A treatise on the mathematical theory of elasticity. Dover Publications, New York, 1944.

[60] McCrum, N. G., Buckley, C., And Bucknall, C. Principles of polymer engineering. No. v. 1 in Oxford science publications. Oxford University Press, 1997. Disponível em: http://books . google.com.br/books?id=yUCpQgAACAAJ.

[61] Menard, K. Dynamic mechanical analysis: a practical introduction. CRC Press, 2008. Disponível em: http://books .google.com.br/books?id=qdd7mYa7ZdEC. 
[62] Meng, H., And Li, Q. M. An sphb set-up with reduced time-shift and pressure bar length. International Journal of Impacto Engineering, Vol. 28 (2003), pp 677 696.

[63] Meyers, M. A. Dynamic Behavior of Materials. John Wiley and Sons, 1994.

[64] Mguil-Touchal, Morestin, S., And Brunet, M. F. Various experimental application of digital image correlation method. In Computer Method and Experimental measurement (Rhodes, 21/5 a 23/5 1997), pp. 46-58.

[65] Mohanraj, J., Barton, D., Ward, I., Dahoun, A., Hiver, J., And G'Sell, C. Plastic deformation and damage of polyoxymethylene in the large strain range at elevated temperatures. Polymer 47, 16 (2006), 5852 - 5861. Disponível em: http://www.sciencedirect.com/science/article/pii/S0032386106007178.

[66] Mooney, M. A theory of large elastic deformation. Journal of Applied Physics 11, 9 (1940), 582-592. Disponível em: http://link.aip.org/link/?JAP/11/582/1.

[67] Moran, B., Ortiz, M., And Shin, C. F. Formulation of implicit finite element methods for multiplicative finite deformation plasticity. International Journal for Numerical Methods in Engineering 29, 3 (1990), 483-514. Disponível em: http: //dx.doi.org/10.1002/nme.1620290304.

[68] Moura, R. T., Clausen, A. H., Dumoulin, S., And Alves, M. Material tests on pehd and pvc using dic. In Impact Loading of Lightweight Structures (NTNU , Tondheim, Noruega, 17-19 de Junho 2008), A. H. Clausen and M. Langseth, Eds., pp. $153-156$.

[69] Moura, R. T., Clausen, A. H., Fagerholt, E., Alves, M., And LangSETH, M. Impact on hdpe and pvc plates - experimental tests and numerical simulations. International Journal of Impact Engineering 37, 6 (2010), 580 - 598. $<$ ce:title>Impact Loading of Lightweight Structures</ce:title>. Disponível em: http://www. sciencedirect.com/science/article/pii/S0734743X09002279.

[70] Moura, R. T., Clausen, A. H., Langseth, M., and Alves, M. Dispersion and inertia effects analysis on dynamic mechanical material characterization. In 
20th International Congress of Mechnical Engineering (COBEM 2009) (Gramado, RS, Brasil, Novembro 2009).

[71] Moura, R. T., Mazzariol, L. M., Clausen, A. H., Langseth, M., and Alves, M. Axial loading of cylindrs made of nylon with nano-particles. In Proceedins of the IMPLAST 2010 Conference (Providence, Rhode Island, USA, Outubro 2010), Society for Experimental Mechanicsm, Inc., pp. 48-55.

[72] Moura, R. T., Clausen, A. H., Langseth, M., And Alves, M. Dynamic mechanical behaviour of polyethylene. 497-502. Disponível em: http://dx.doi. org/10.1051/dymat/2009071.

[73] Muller, T. High strain rate behavior of iron and nickel. Journal Mechanical Engineering Science, Vol. 14, N. 3 (1972), pp 161 - 167.

[74] Mulbiken, A. D. Low to high strain rate deformation of amorphous polymers: Experiments and modeling. Dissertação de mestrado, Massachusetts Institute of Technology, 2004.

[75] Mulliken, A. D. Machanics of Amorphous Polymers and Polymer Nanocomposites during High Rate Deformation. PhD thesis, Massachusetts Institute of Technology, 2007.

[76] Nemat-Nasser, S. Decomposition of strain measures and their rates in finite deformation elastoplasticity. International Journal of Solids and Structures 15, 2 (1979), 155 - 166. Disponível em: http://www.sciencedirect.com/science/article/ pii/0020768379900192.

[77] Nemat-Nasser, S. Introduction to high strain rate testing, vol.8, mechanical testing and evaluation ed. ASM Handbook, 2000.

[78] Nemat-Nasser, S., Isaacs, J. R., and Starrett, J. E. Hopkinson techniques for dynamic recovery experiments. Proc. R. Soc. London A, 435 (1991), pp 371 391. 
[79] Parsons, E., Boyce, M., And Parks, D. An experimental investigation of the large-strain tensile behavior of neat and rubber-toughened polycarbonate. Polymer 45, 8 (2004), 2665 - 2684. Disponível em: http://www.sciencedirect.com/ science/article/pii/S0032386104001144.

[80] Pochammer, L. On the propagation velocities of small oscilations in an unlimited isotropic circular cylinder. J. f. Math. (Crelle), Vol. 81 (1876), pp $324-326$.

[81] Prager, W. Introduction to mechanics of continua. Dover phoenix editions. Dover Publications, 2004. Disponível em: http://books.google.com/books?id= Feer6-hn9zsC.

[82] Rayleigh, J. W. S. The Theory of Sound, vol. 3. Dover Publications, New York, 1945.

[83] Ree, T., And Eyring, H. Theory of non-newtonian flow. i. solid plastic system. Journal of Applied Physics 26, 7 (1955), 793-800. Disponível em: http://link. aip.org/link/?JAP/26/793/1.

[84] Rivlin, R. S. Large elastic deformations of isotropic materials. iv. further developments of the general theory. Philosophical Transactions of the Royal Society of London. Series A, Mathematical and Physical Sciences 241, 835 (1948), pp. 379-397. Disponível em: http://www.jstor.org/stable/91391.

[85] Rusinek, A., Zaera, R., Klepaczko, J., and Cheriguene, R. Analysis of inertia and scale effects on dynamic neck formation during tension of sheet steel. Acta Materialia 53 (2005), 5387-5400.

[86] Simo, J. C. A framework for finite strain elastoplasticity based on maximum plastic dissipation and the multiplicative decomposition: Part i. continuum formulation. Computer Methods in Applied Mechanics and Engineering 66, 2 (1988), 199 - 219. Disponível em: http://www.sciencedirect.com/science/article/pii/ $004578258890076 X$.

[87] Starkova, O., And Aniskevich, A. Poisson's ratio and the incompressibility relation for various strain measures with the example of a silica-filled sbr rubber in 
uniaxial tension tests. Polymer Testing 29, 3 (2010), 310 - 318. Disponível em: http://www.sciencedirect.com/science/article/pii/S0142941809002074.

[88] Tervoort, T., Smit, R., Brekelmans, W., and Govaert, L. A constitutive equation for the elasto-viscoplastic deformation of glassy polymers. Mechanics of Time-Dependent Materials 1 (1997), 269-291. 10.1023/A:1009720708029. Disponível em: http://dx.doi.org/10.1023/A:1009720708029.

[89] Trelone, L. R. G. Stress-strain data for vulcanised rubber under various types of deformation. Trans. Faraday Soc. 40 (1944), 59-70. Disponível em: http://dx. doi.org/10.1039/TF9444000059.

[90] Vacher, P., Dumoulin, S., Morestin, F., And Mguil-Touchal, S. Bidimensional strain measurement using digital images. Proceedings of the Institution of Mechanical Engineers, Part C: Journal of Mechanical Engineering Science 213, 8 (1999), 811-817. Disponível em: http://pic.sagepub.com/content/213/8/811. abstract.

[91] van Melick, H., Govaert, L., And Meijer, H. On the origin of strain hardening in glassy polymers. Polymer 44, 8 (2003), 2493 - 2502. Disponível em: http: //www.sciencedirect.com/science/article/pii/S0032386103001125.

[92] Ward, I., And SweEney, J. An introduction to the mechanical properties of solid polymers. Wiley, 2004. Disponível em: http://books.google.com.br/books?id= CjYxgGejjHAC.

[93] Weber, G., And Boyce, M. A framework for finite strain thermoelasto-plastic deformation of solids. In ASME Winter Annual Meeting Proceedings: Volume 1 (1989), D. Hui and T. Kosik, Eds.

[94] YЕOH, O. H. Some forms of the strain energy function for rubber. Rubber Chemistry and Technology 66, 5 (11 1993), 754-771. Disponível em: http://dx.doi.org/10. $5254 / 1.3547602$.

[95] ZhaO, H. Material behavior characterisation using shpb techniques, tests and simulations. Computers and Structures, 81 (2003), pp 1301 - 1310. 
[96] Zhao, H., Gary, G., And Klepaczko, J. On the use of a viscoelastic split hopkinson pressure bar. International Journal of Impact Engineering 19, 4 (1997), 319 - 330. Disponível em: http://www.sciencedirect.com/science/article/ pii/S0734743X96000383. 
Apêndice 



\section{Apêndice A}

\section{Mecânica dos Sólidos não Linear}

\section{A.1 Definições de mecânica dos sólidos não linear e movimento de corpo rígido}

\section{A.1.1 definições}

A mecânica do contínuo considera modelos de sólidos e líquidos nos quais suas propriedades e respostas podem ser representadas por funções contínuas de variáveis espaciais, descrevendo o comportamento de maneira macroscópica. Considere um corpo no instante $t=0$, como na figura A.1 . O domínio do corpo em seu estado inicial é chamado configuração inicial e denotado por $\Omega_{0}$. Para a descrição do movimento e deformação do corpo, torna-se necessário uma configuração para a qual as equações se referem, determinada configuração de referencia. A menos que seja especificado, configuração inicial será utilizada como configuração de referência. Em muitos casos, é necessário especificar a configuração não-deformada, que ocupa o domínio $\Omega_{0}$.

O domínio do corpo na configuração atual é denotado por $\Omega$, também chamada de configuração deformada. O domínio pode ser uni, bi ou tridimensional, sendo o número de dimensões dado por $n_{S D}$.

\section{A.1.2 Coordenadas Euleriana e Lagrangiana e cinemática}

O vetor posição de um ponto do material na configuração inicial é dado por $\mathbf{X}$, sendo

$$
\mathbf{X}=X_{i} \mathbf{e}_{i} \equiv \sum_{i=1}^{n_{s d}} X_{i} \mathbf{e}_{i}
$$




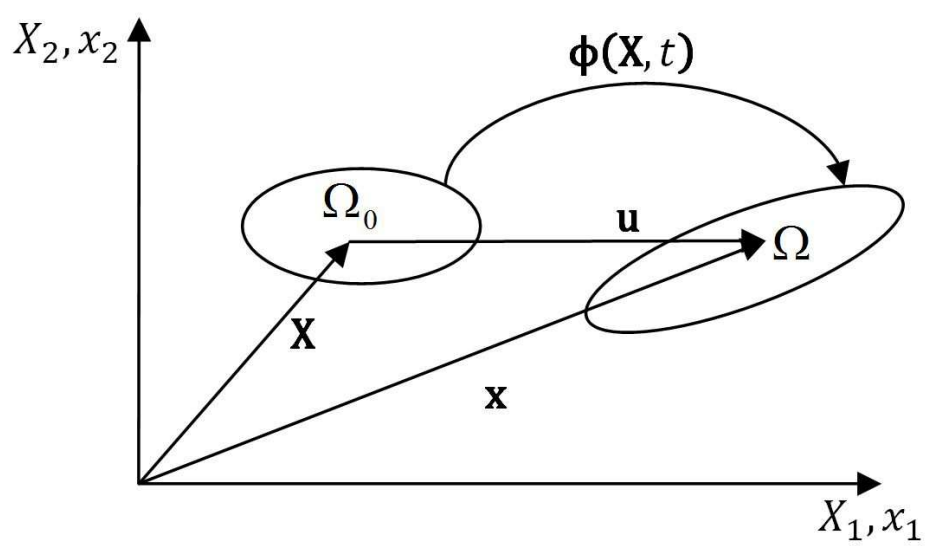

Figura A.1: Configuração de referência $\Omega_{0}$, configuração atual $\Omega$, vetor posição inicial $\mathbf{X}$, vetor posição atual $\mathbf{x}$, vetor deslocamento $\mathbf{u}$ e função mapeamento $\mathbf{\Phi}(\mathbf{X}, t)$

na qual $X_{i}$ são as componentes do vetor posição na configuração de referencia e $\mathbf{e}_{i}$ são os versores da base canônica no sistema de coordenadas cartesianas. A variável vetor $\mathbf{X}$ para um dado ponto do material não varia com o tempo, sendo então as variáveis $\mathbf{X}$ chamadas de coordenadas materiais ou de Lagrange. O vetor posição na configuração atual, $\mathbf{x}$, de um determinado ponto material $\mathbf{X}$ no instante $t$, é dado por

$$
\mathbf{x}=x_{i} \mathbf{e}_{i} \equiv \sum_{i=1}^{n_{s d}} x_{i} \mathbf{e}_{i}
$$

sendo $x_{i}$ os componentes deste na mesma base canônica, sendo chamado de coordenadas espaciais ou Eulerianas.

Podemos então descrever o movimento do corpo através do mapeamento de cada ponto material no tempo $t$ através da função $\mathbf{\Phi}(\mathbf{X}, t)$, sendo

$$
\mathbf{x}=\boldsymbol{\Phi}(\mathbf{X}, t) \text { ou } x_{i}=\Phi_{i}(\mathbf{X}, t) \text { e } \mathbf{X}=\mathbf{\Phi}(\mathbf{X}, 0) \text { ou } X_{i}=\Phi_{i}(\mathbf{X}, 0)
$$

com o mapeamento $\mathbf{\Phi}(\mathbf{X}, t)$ no instante $t$ sendo o mapeamento identidade.

\section{A.1.3 Deslocamento, velocidade e aceleração}

O deslocamento de um ponto do material, $\mathbf{u}(\mathbf{X}, t)$, é dado pela diferença entre sua posição atual e sua posição inicial, conforme figura A.1, e é descrito por

$$
\mathbf{u}(\mathbf{X}, t)=u_{i} \mathbf{e}_{i}=\mathbf{\Phi}(\mathbf{X}, t)-\mathbf{\Phi}(\mathbf{X}, 0)=\boldsymbol{\Phi}(\mathbf{X}, t)-\mathbf{X} \text { ou } u_{i}=\Phi_{i}\left(X_{j}, t\right)-X_{i}
$$


A velocidade $\mathbf{v}(\mathbf{X}, t)$ é a taxa de variação do vetor posição para um ponto do material. Esse tipo de derivada no tempo com $\mathbf{X}$ constante é conhecida como derivada material no tempo ou como derivada material ou ainda como derivada total. A velocidade pode então ser escrita como

$$
\mathbf{v}(\mathbf{X}, t)=v_{i} \mathbf{e}_{i}=\frac{\partial(\mathbf{\Phi}(\mathbf{X}, t)-\mathbf{X})}{\partial t}=\frac{\partial \Phi(\mathbf{X}, t)}{\partial t}=\frac{\partial \mathbf{u}(\mathbf{X}, t)}{\partial t}=\dot{\mathbf{u}}
$$

A aceleração $\mathbf{a}(\mathbf{X}, t)$ é a taxa de variação do vetor velocidade para um ponto do material, sendo a derivada material no tempo da velocidade e pode ser escrito por

$$
\mathbf{a}(\mathbf{X}, t)=a_{i} \mathbf{e}_{i}=\frac{\partial \mathbf{v}(\mathbf{X}, t)}{\partial t}=\frac{\partial^{2} \mathbf{u}(\mathbf{X}, t)}{\partial t^{2}}=\dot{\mathbf{v}}
$$

Mas se a velocidade estiver escrita em função das coordenadas espaciais e do tempo, sabendo que $\mathbf{v}(\mathbf{x}, t)=\mathbf{v}(\mathbf{\Phi}(\mathbf{X}, t))$, a derivada material no tempo da mesma é dada por

$$
\frac{D v_{i}(\mathbf{x}, t)}{D t}=\frac{\partial v_{i}(\mathbf{x}, t)}{\partial t}+\frac{\partial v_{i}(\mathbf{x}, t)}{\partial x_{j}} \frac{\partial \Phi_{i}(\mathbf{X}, t)}{\partial t}=\frac{\partial v_{i}}{\partial t}+\frac{\partial v_{i}}{\partial x_{j}} v_{j}
$$

ou na forma matricial

$$
\frac{D \mathbf{v}(\mathbf{x}, t)}{D t}=\frac{\partial \mathbf{v}(\mathbf{x}, t)}{\partial t}+\mathbf{v} \cdot \nabla \mathbf{v}
$$

sendo $\nabla$ o operador gradiente que define a taxa de variação de uma função em uma determinada direção, definido como

$$
\nabla=\sum_{i=1}^{n_{s d}} \frac{\partial}{\partial e_{i}} \mathbf{e}_{i} \text { e } \nabla \mathbf{f}=\sum_{i=1}^{n_{s d}} \frac{\partial f_{j}}{\partial e_{i}} \mathbf{e}_{i} \mathbf{e}_{j}
$$

De uma maneira mais simples, a derivada material no tempo de uma função escrita em coordenadas espaciais é composta sempre por duas parcelas, sendo a primeira representando o quanto esta função varia no tempo e a segunda parcela sendo a multiplicação taxa de variação da função em relação a uma coordenada e a taxa variação da posição nesta coordenada em relação ao tempo, uma vez que esta função depende do tempo e da posição e sendo que a posição depende do tempo (regra da cadeia aplicada na segunda parcela).

\section{A.1.4 Movimento de corpo rígido}

O movimento de rotação de corpo rígido tem um papel crucial na teoria de mecânica do contínuo não linear, uma vez que a magnitude da rotação em uma determinada análise 
A.1. Definições de mecânica dos sólidos não linear e movimento de corpo rígido

pode determinar se é mais adequado utilizar software de elementos finitos linear ou não linear.

O movimento de corpo rígido consiste em uma translação $\mathbf{x}_{T}(t)$ e uma rotação em torno da origem $\mathbf{R}(t)$ através de

$$
\mathbf{x}(\mathbf{X}, t)=\mathbf{R}(t) \cdot \mathbf{X}+\mathbf{x}_{T}(t) \text { ou } x_{i}(\mathbf{X}, t)=R_{i j}(t) X_{j}+x_{T i}(t)
$$

sendo que qualquer movimento de corpo rígido pode ser descrito pela equação acima.

Sabendo-se que $d \mathbf{x}_{T}=0$, podemos escrever

$$
d x_{i} d x_{i}=R_{i j} d X_{j} R_{i k} d X_{k}=d X_{j}\left(R_{j i}^{T} R_{i k}\right) d X_{k}
$$

e como não há deformações e consequentes mudanças de comprimento durante o movimento de corpo rígido, ou seja, $d \mathbf{x}=d \mathbf{X}$, podemos concluir que $\mathbf{R}(t)$ é ortogonal, ou seja,

$$
\mathbf{R}^{T} \cdot \mathbf{R}=\mathbf{I} \text { ou } \mathbf{R}^{T}=\mathbf{R}^{-1}
$$

Já a velocidade de um corpo rígido pode ser encontrada derivando no tempo, chegando a

$$
\dot{\mathbf{x}}(\mathbf{X}, t)=\dot{\mathbf{R}} \cdot \mathbf{X}+\dot{\mathbf{x}}_{T}(t) \text { ou } \dot{x}_{i}(\mathbf{X}, t)=\dot{R}_{i j}(t) X_{j}+\dot{x}_{T i}(t)
$$

Para expressar em coordenadas espaciais (descrição euleriana), pode-se isolar $\mathbf{X}$ através de

$$
\begin{aligned}
\mathbf{x}(\mathbf{X}, t)=\mathbf{R}(t) \cdot \mathbf{X}+\mathbf{x}_{T}(t) \Rightarrow \mathbf{R}^{T}(t)\left(\mathbf{x}(\mathbf{X}, t)-\mathbf{x}_{T}(t)\right) & =\mathbf{R}^{T}(t) \mathbf{R}(t) \cdot \mathbf{X} \\
\Rightarrow \mathbf{X} & =\mathbf{R}^{T}(t)\left(\mathbf{x}(\mathbf{X}, t)-\mathbf{x}_{T}(t)\right)
\end{aligned}
$$

e então obtemos

$$
\dot{\mathbf{x}}(\mathbf{X}, t)=\dot{\mathbf{R}} \cdot \mathbf{R}^{T}(t)\left(\mathbf{x}(\mathbf{X}, t)-\mathbf{x}_{T}(t)\right)+\dot{\mathbf{x}}_{T}(t)=\mathbf{\Omega}(t)\left(\mathbf{x}(\mathbf{X}, t)-\mathbf{x}_{T}(t)\right)+\dot{\mathbf{x}}_{T}(t)
$$

sendo $\Omega(t)=\dot{\mathbf{R}} \cdot \mathbf{R}^{T}(t)$ conhecido como tensor velocidade angular ou matriz velocidade angular. Esta é anti-simetrica, ou seja

$$
\frac{D}{D t}\left(\mathbf{R} \cdot \mathbf{R}^{T}\right)=\frac{D}{D t}(\mathbf{I})=0 \Rightarrow \dot{\mathbf{R}} \cdot \mathbf{R}^{T}+\mathbf{R} \cdot \dot{\mathbf{R}}^{T}=0 \Rightarrow \boldsymbol{\Omega}=-\mathbf{\Omega}^{T}
$$

Um tensor de segunda ordem anti-simétrico pode ser expressado por um vetor chamado vetor axial e o resultado da multiplicação matricial de $\boldsymbol{\Omega r}$ pode também ser obtido pelo produto vetorial com o vetor axial, $\mathbf{w} \times \mathbf{r}$, no qual

$$
\Omega_{i j} r_{j}=e_{i j k} w_{j} r_{k}
$$


no qual $e_{i j k}$ é definido por

$$
e_{i j k}= \begin{cases}1, & \text { para uma permutação ímpar de } i j k \\ -1, & \text { para uma permutação par de } i j k \\ 0, & \text { se qualquer índice é repetido }\end{cases}
$$

A relação do tensor anti-simétrico $\Omega$ e do vetor axial w, é dado por

$$
\Omega_{i k}=e_{i j k} w_{j}=-e_{i j k} w_{j} \text { ou } w_{i}=-\frac{1}{2} e_{i j k} \Omega_{i k}
$$

em outras palavras, para duas ou três dimensões, temos respectivamente

$$
\boldsymbol{\Omega}=\left[\begin{array}{cc}
0 & \Omega_{12} \\
-\Omega_{12} & 0
\end{array}\right]=\left[\begin{array}{cc}
0 & -w_{3} \\
w_{3} & 0
\end{array}\right] \text { ou } \boldsymbol{\Omega}=\left[\begin{array}{ccc}
0 & \Omega_{12} & \Omega_{13} \\
-\Omega_{12} & 0 & \Omega_{23} \\
-\Omega_{13} & -\Omega_{23} & 0
\end{array}\right]=\left[\begin{array}{ccc}
0 & -w_{3} & w_{2} \\
w_{3} & 0 & -w_{1} \\
-w_{2} & w_{1} & 0
\end{array}\right]
$$

chegando então na equação de movimento rígido mais utilizada nos livros

$$
\mathbf{v} \equiv \dot{\mathbf{x}}=\mathbf{w} \times\left(\mathbf{x}-\mathbf{x}_{T}\right)+\mathbf{v}_{T}
$$

\section{A.2 Tensores de deformação}

Ao contrario da mecânica dos sólidos linear, muitas medidas diferentes de deformação e taxa de deformação são frequentemente utilizadas na mecânica dos sólidos não linear. Alguns considerados mais importantes e utilizados serão tratados a seguir, baseados na figura A.2.

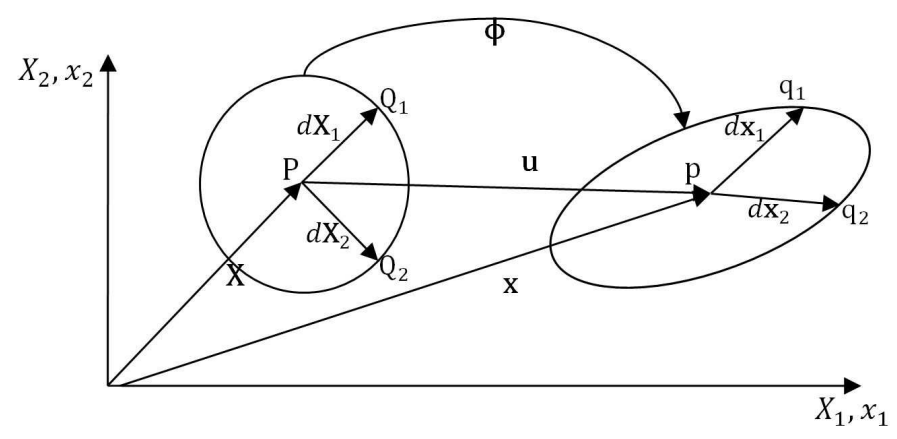

Figura A.2: Configuração de referência $\Omega_{0}$, configuração atual $\Omega$, vetor posição inicial $\mathbf{X}$, vetor posição atual $\mathbf{x}$, vetor deslocamento $\mathbf{u}$ e função mapeamento $\mathbf{\Phi}(\mathbf{X}, t)$ 


\section{A.2.1 Gradiente de deformações}

O gradiente de deformações, $\mathbf{F}$, correlaciona um segmento infinitesimal na configuração de referência, $d \mathbf{X}$, com o segmento infinitesimal correspondente na configuração atual, $d \mathbf{x}$, por meio de

$$
d \mathbf{x}=\mathbf{F} \cdot d \mathbf{X}
$$

sendo definido então por

$$
\mathbf{F}=\frac{\partial \mathbf{x}}{\partial \mathbf{X}} \equiv \frac{\partial \Phi}{\partial \mathbf{X}} \equiv\left(\nabla_{0} \boldsymbol{\Phi}\right)^{T} \text { ou } F_{i j}=\frac{\partial x_{i}}{\partial X_{j}} \equiv \frac{\partial \Phi_{i}}{\partial X_{j}}
$$

Com $\nabla_{0}$ sendo o gradiente em relação as coordenadas materiais. Sob um olhar matemático, pode-se definir o gradiente de deformações como a matriz jacobiano do movimento $\mathbf{\Phi}(\mathbf{X}, t)$.

Considerando-se um sistema cartesiano de coordenadas de três graus de liberdade $(x, y, z)$, o gradiente de deformações pode ser definido pela matriz

$$
\mathbf{F}=\left[\begin{array}{lll}
\frac{\partial x}{\partial X} & \frac{\partial x}{\partial Y} & \frac{\partial x}{\partial Z} \\
\frac{\partial y}{\partial X} & \frac{\partial y}{\partial Y} & \frac{\partial y}{\partial Z} \\
\frac{\partial z}{\partial X} & \frac{\partial z}{\partial Y} & \frac{\partial z}{\partial Z}
\end{array}\right]
$$

Considere um elemento volumétrico infinitesimal cujas arestas são paralelas ao eixo cartesiano $d \mathbf{X}_{1}=d X_{1} \mathbf{E}_{1}, d \mathbf{X}_{2}=d X_{2} \mathbf{E}_{2}$ e $d \mathbf{X}_{3}=d X_{3} \mathbf{E}_{3}$, com $\mathbf{E}_{1}, \mathbf{E}_{2}$ e $\mathbf{E}_{3}$ sendo vetores unitários ortogonais. O volume material $d V$ deste elemento pode ser obtido por

$$
d V=d \mathbf{X}_{1} \cdot\left(d \mathbf{X}_{2} \times d \mathbf{X}_{3}\right)=d X_{1} d X_{2} d X_{3}
$$

Para descobrir o volume deformado na configuração espacial, $d v$, temos

$$
\begin{aligned}
d v=d \mathbf{x}_{1} \cdot\left(d \mathbf{x}_{2} \times d \mathbf{x}_{3}\right)=\mathbf{F} d \mathbf{X}_{1} \cdot & \left(\mathbf{F} d \mathbf{X}_{2} \times \mathbf{F} d \mathbf{X}_{3}\right)= \\
= & \left(\frac{\partial \Phi}{\partial X_{1}}\right) \cdot\left(\left(\frac{\partial \Phi}{\partial X_{2}}\right) \times\left(\frac{\partial \Phi}{\partial X_{3}}\right)\right) d X_{1} d X_{2} d X_{3}
\end{aligned}
$$

O produto triplo acima é o determinante do gradiente de deformações, conhecido por Jacobiano, $J=\operatorname{det}(\mathbf{F})$. Podemos então definir que

$$
d v=J d V
$$


Como a massa de um elemento infinitesimal pode ser relacionada com o volume deste através de $d m=\rho_{0} d V=\rho d v$, a conservação de massa pode ser expressa por

$$
\rho_{0}=\rho J
$$

Considerando materiais incompressíveis ou quase incompressíveis, muitas vezes torna-se necessário separar a parte volumétrica da distorcional (ou isocórica ou deviatórica) do gradiente de deformações. Esta deve impor que o componente deviatórico, $\mathbf{F}^{\text {dev }}$, não implique em mudança de volume. Sendo que o determinante do gradiente de deformação dá a razão de volume, o determinante de $\mathbf{F}^{\text {dev }}$ deve ter valor unitário. Assim temos

$$
\mathbf{F}^{d e v}=J^{\frac{-1}{3}} \mathbf{F}
$$

e então podemos expressar o gradiente de deformações por

$$
\mathbf{F}=J^{\frac{1}{3}} \mathbf{F}^{d e v}
$$

\section{A.2.2 tensor de deformação direito de Cauchy-Green}

Como uma medida geral de deformações, será considerada a variação do produto escalar de dois vetores infinitesimais $d \mathbf{X}_{1}$ e $d \mathbf{X}_{2}$ ao se deformarem em $d \mathbf{x}_{1}$ e $d \mathbf{x}_{2}$, conforme a figura x.x. Esse variação será capaz de englobar ambos alongamento (variação no comprimento) e variação no ângulo entre os dois vetores. Sabendo-se que $d \mathbf{x}_{1}=\mathbf{F} \cdot d \mathbf{X}_{1}$ e $d \mathbf{x}_{2}=\mathbf{F} \cdot d \mathbf{X}_{2}$, pode-se encontrar o produto escalar $d \mathbf{x}_{1} \cdot d \mathbf{x}_{2}$ a partir de $d \mathbf{X}_{1}$ e $d \mathbf{X}_{2}$ através de

$$
\begin{array}{r}
d \mathbf{x}_{1} \cdot d \mathbf{x}_{2}=\left(\mathbf{F} \cdot d \mathbf{X}_{1}\right) \cdot\left(\mathbf{F} \cdot d \mathbf{X}_{2}\right)=\left(\mathbf{F} d \mathbf{X}_{1}\right)^{T}\left(\mathbf{F} d \mathbf{X}_{2}\right)=d \mathbf{X}_{1}^{T} \mathbf{F}^{T} \mathbf{F} d \mathbf{X}_{2}= \\
=d \mathbf{X}_{1} \cdot\left(\mathbf{F}^{T} \cdot \mathbf{F}\right) \cdot d \mathbf{X}_{2}=d \mathbf{X}_{1} \cdot \mathbf{C} \cdot d \mathbf{X}_{2}
\end{array}
$$

no qual $\mathbf{C}=\mathbf{F}^{T} \cdot \mathbf{F}$ é o tensor de deformações direito de Cauchy-Green. Como o tensor $\mathbf{C}$ opera nos vetores materiais $d \mathbf{X}_{1}$ e $d \mathbf{X}_{2}$, este é chamado de tensor de quantidade material.

\section{A.2.3 tensor de deformação esquerdo de Cauchy-Green}

De maneira análoga ao tensor de deformação esquerdo de Cauchy-Green, o tensor de deformações esquerdo de Cauchy-Green, ou tensor Finger, também é determinado a partir da variação do produto escalar de dois vetores infinitesimais $d \mathbf{X}_{1}$ e $d \mathbf{X}_{2}$ ao se deformarem 
em $d \mathbf{x}_{1}$ e $d \mathbf{x}_{2}$, mas nesse caso é o produto escalar $d \mathbf{X}_{1} \cdot d \mathbf{X}_{2}$ que deve ser encontrado a partir de $d \mathbf{x}_{1}$ e $d \mathbf{x}_{2}$, uma vez que

$$
\begin{aligned}
d \mathbf{X}_{1} \cdot d \mathbf{X}_{2}=\left(\mathbf{F}^{-1} \cdot d \mathbf{x}_{1}\right) \cdot\left(\mathbf{F}^{-1} \cdot d \mathbf{x}_{2}\right) & =\left(\mathbf{F}^{-1} d \mathbf{x}_{1}\right)^{T}\left(\mathbf{F}^{-1} d \mathbf{x}_{2}\right)=d \mathbf{x}_{1}^{T} \mathbf{F}^{-1 T} \mathbf{F}^{-1} d \mathbf{x}_{2}= \\
& =d \mathbf{x}_{1} \cdot\left(\mathbf{F} \cdot \mathbf{F}^{T}\right)^{-1} \cdot d \mathbf{x}_{2}=d \mathbf{x}_{1} \cdot \mathbf{B}^{-1} \cdot d \mathbf{X}_{2}
\end{aligned}
$$

no qual $\mathbf{B}=\mathbf{F} \cdot \mathbf{F}^{T}$ é o tensor de deformações esquerdo de Cauchy-Green. Como o tensor $\mathbf{B}$ opera nos vetores espaciais $d \mathbf{x}_{1}$ e $d \mathbf{x}_{2}$, este é chamado de tensor de quantidade espacial.

\section{A.2.4 Tensor de deformação de Green-Lagrange}

O tensor de deformação de Green-Lagrange fornece a variação do quadrado do comprimento do vetor material na configuração de referência $d \mathbf{X}$, através de

$$
d s^{2}-d S^{2}=2 d \mathbf{X} \cdot \mathbf{E} \cdot d \mathbf{X}
$$

com $d S^{2}=d \mathbf{X}_{1} \cdot d \mathbf{X}_{2}$ e $d s^{2}=d \mathbf{x}_{1} \cdot d \mathbf{x}_{2}$. Da definição do gradiente de deformações, tem-se que

$d \mathbf{x}_{1} \cdot d \mathbf{x}_{2}=\left(\mathbf{F} \cdot d \mathbf{X}_{1}\right) \cdot\left(\mathbf{F} \cdot d \mathbf{X}_{2}\right)=\left(\mathbf{F} d \mathbf{X}_{1}\right)^{T}\left(\mathbf{F} d \mathbf{X}_{2}\right)=d \mathbf{X}_{1}^{T} \mathbf{F}^{T} \mathbf{F} d \mathbf{X}_{2}=d \mathbf{X}_{1} \cdot\left(\mathbf{F}^{T} \cdot \mathbf{F}\right) \cdot d \mathbf{X}_{2}$

Com a dedução acima e sabendo-se que $d \mathbf{X}_{1} \cdot d \mathbf{X}_{2}=d \mathbf{X}_{1} \cdot \mathbf{I} \cdot d \mathbf{X}_{2}$, pode-se reescrever a definição do tensor de deformação de Green por

$$
d \mathbf{X}_{1} \cdot\left(\mathbf{F}^{T} \cdot \mathbf{F}\right) \cdot d \mathbf{X}_{2}-d \mathbf{X}_{1} \cdot \mathbf{I} \cdot d \mathbf{X}_{2}-2 d \mathbf{X}_{1} \cdot \mathbf{E} \cdot d \mathbf{X}_{2}=0 \Rightarrow d \mathbf{X}_{1} \cdot\left(\mathbf{F}^{T} \cdot \mathbf{F}-\mathbf{I}-2 \mathbf{E}\right) \cdot d \mathbf{X}_{2}=0
$$

E como a expressão acima deve ser verdadeira para quaisquer $d \mathbf{X}_{1}$ e $d \mathbf{X}_{2}$, temos que

$$
\mathbf{E}=\frac{1}{2}\left(\mathbf{F}^{T} \cdot \mathbf{F}-\mathbf{I}\right)=\frac{1}{2}(\mathbf{C}-\mathbf{I}) \text { ou } E_{i j}=\frac{1}{2}\left(F_{k i} F_{k j}-\delta_{i j}\right)
$$

sendo $\mathbf{C}$ o tensor de deformações direito de Cauchy-Green. Pode-se expressar $F_{k i} F_{k j}$ em função do deslocamento uma vez que $u_{i}=x_{i}-X_{i}$, obtendo

$$
\begin{aligned}
F_{k i} F_{k j} & =\frac{\partial x_{k}}{\partial X_{i}} \frac{\partial x_{k}}{\partial X_{j}} \\
& =\left(\frac{\partial u_{k}}{\partial X_{i}}+\frac{\partial X_{k}}{\partial X_{i}}\right)\left(\frac{\partial u_{k}}{\partial X_{j}}+\frac{\partial X_{k}}{\partial X_{j}}\right) \\
& =\left(\frac{\partial u_{k}}{\partial X_{i}}+\delta_{k i}\right)+\left(\frac{\partial u_{k}}{\partial X_{j}}+\delta_{k j}\right) \\
& =\left(\frac{\partial u_{i}}{\partial X_{j}}+\frac{\partial u_{j}}{\partial X_{i}}+\frac{\partial u_{k}}{\partial X_{i}} \frac{\partial u_{k}}{\partial X_{j}}+\delta_{i j}\right)
\end{aligned}
$$


E, por uma simples substituição, pode-se expressar o tensor de deformações de GreenLagrange em função do gradiente do deslocamento através de

$$
E_{i j}=\frac{1}{2}\left(\frac{\partial u_{i}}{\partial X_{j}}+\frac{\partial u_{j}}{\partial X_{i}}+\frac{\partial u_{k}}{\partial X_{i}} \frac{\partial u_{k}}{\partial X_{j}}\right) \text { ou } \mathbf{E}=\frac{1}{2}\left(\left(\nabla_{0} \mathbf{u}\right)^{T}+\nabla_{0} \mathbf{u}+\nabla_{0} \mathbf{u} \cdot\left(\nabla_{0} \mathbf{u}\right)^{T}\right)
$$

É também possível calcular também, em um caso unidimensional, o valor escalar da deformação de Green-Lagrange. Neste caso, $d \mathbf{X}_{1}=d \mathbf{X}_{2}=d \mathbf{X}, d \mathbf{x}_{1}=d \mathbf{x}_{2}=d \mathbf{x}$ e portanto ao dividirmos a definição desta deformação por $d S^{2}$, temos

$$
\frac{1}{2}\left(\frac{d s^{2}-d S^{2}}{d S^{2}}\right)=\frac{d \mathbf{X}}{d S} \cdot \mathbf{E} \cdot \frac{d \mathbf{X}}{d S}=\mathbf{N} \cdot \mathbf{E} \cdot \mathbf{N}
$$

no qual $\mathbf{N}$ é o vetor material unitário na direção de $d \mathbf{X}$.

Uma consideração importante sobre a deformação de Green-Lagrange é que esta é nula no caso de movimento de corpo rígido, uma vez que

$$
\mathbf{x}=\mathbf{R} \cdot \mathbf{X}+\mathbf{x}_{T} \Rightarrow \mathbf{F}=\mathbf{R} \Rightarrow \mathbf{E}=\frac{1}{2}\left(\mathbf{R}^{T} \cdot \mathbf{R}-\mathbf{I}\right)=\frac{1}{2}(\mathbf{I}-\mathbf{I})=0
$$

\section{A.2.5 Tensor de deformação de Eulerian-Almansi}

O tensor de deformação de Eulerian-Almansi, assim como o tensor de deformação de Green-Lagrange, também fornece a variação do quadrado do comprimento do vetor material, mas nesse caso na configuração atual $d \mathbf{x}$, através de

$$
d s^{2}-d S^{2}=2 d \mathbf{x}_{1} \cdot \mathbf{e} \cdot d \mathbf{x}_{2}
$$

E de maneira análoga a dedução do tensor de deformações de Green-Lagrange, temos

$$
\begin{array}{r}
d \mathbf{X}_{1} \cdot d \mathbf{X}_{2}=\left(\mathbf{F}^{-1} \cdot d \mathbf{x}_{1}\right) \cdot\left(\mathbf{F}^{-1} \cdot d \mathbf{x}_{2}\right)=\left(\mathbf{F}^{-1} d \mathbf{x}_{1}\right)^{T}\left(\mathbf{F}^{-1} d \mathbf{x}_{2}\right)=d \mathbf{x}_{1}^{T} \mathbf{F}^{-1 T} \mathbf{F}^{-1} d \mathbf{x}_{2}= \\
=d \mathbf{x}_{1} \cdot\left(\mathbf{F} \cdot \mathbf{F}^{T}\right)^{-1} \cdot d \mathbf{x}_{2}
\end{array}
$$

e portanto

$$
\begin{aligned}
d \mathbf{x}_{1} \cdot \mathbf{I} \cdot d \mathbf{x}_{2}-d \mathbf{x}_{1} \cdot\left(\mathbf{F} \cdot \mathbf{F}^{T}\right)^{-1} \cdot d \mathbf{x}_{2}-2 d \mathbf{x}_{1} \cdot \mathbf{e} \cdot d \mathbf{x}_{2}=0 \Rightarrow \\
\quad \Rightarrow d \mathbf{x}_{1} \cdot\left(\mathbf{I}-\left(\mathbf{F} \cdot \mathbf{F}^{T}\right)^{-1}-2 \mathbf{e}\right) \cdot d \mathbf{x}_{2}=0
\end{aligned}
$$

E como a expressão acima deve ser verdadeira para quaisquer $d \mathbf{x}_{1}$ e $d \mathbf{x}_{2}$, temos que

$$
\mathbf{e}=\frac{1}{2}\left(\mathbf{I}-\left(\mathbf{F} \cdot \mathbf{F}^{T}\right)^{-1}\right)=\frac{1}{2}\left(\mathbf{I}-\mathbf{B}^{-1}\right) \text { ou } e_{i j}=\frac{1}{2}\left(\delta_{i j}-F_{k i}^{-1} F_{k j}^{-1}\right)
$$


sendo $\mathbf{B}$ o tensor de deformações esquerdo de Cauchy-Green. Pode-se expressar $F_{k i}^{-1} F_{k j}^{-1}$ em função do deslocamento uma vez que $u_{i}=x_{i}-X_{i}$, obtendo

$$
\begin{aligned}
F_{k i}^{-1} F_{k j}^{-1} & =\frac{\partial X_{k}}{\partial x_{i}} \frac{\partial X_{k}}{\partial x_{j}} \\
& =\left(\frac{\partial x_{k}}{\partial x_{i}}-\frac{\partial u_{k}}{\partial x_{i}}\right)\left(\frac{\partial x_{k}}{\partial x_{j}}-\frac{\partial u_{k}}{\partial x_{j}}\right) \\
& =\left(\delta_{k i}-\frac{\partial u_{k}}{\partial x_{i}}\right)+\left(\delta_{k j}-\frac{\partial u_{k}}{\partial x_{j}}\right) \\
& =\left(\delta_{i j}-\frac{\partial u_{i}}{\partial x_{j}}-\frac{\partial u_{j}}{\partial x_{i}}+\frac{\partial u_{k}}{\partial x_{i}} \frac{\partial u_{k}}{\partial x_{j}}\right)
\end{aligned}
$$

E, por uma simples substituição, pode-se expressar o tensor de deformações de EulerianAlmansi em função do gradiente do deslocamento através de

$$
e_{i j}=\frac{1}{2}\left(\frac{\partial u_{i}}{\partial x_{j}}+\frac{\partial u_{j}}{\partial x_{i}}-\frac{\partial u_{k}}{\partial x_{i}} \frac{\partial u_{k}}{\partial x_{j}}\right) \text { ou } \mathbf{e}=\frac{1}{2}\left((\nabla \mathbf{u})^{T}+\nabla \mathbf{u}-\nabla \mathbf{u} \cdot(\nabla \mathbf{u})^{T}\right)
$$

sendo $\nabla$ o gradiente em relação as coordenadas espaciais. É também possível calcular também, em um caso unidimensional, o valor escalar da deformação de Eulerian-Almansi. Neste caso, $d \mathbf{X}_{1}=d \mathbf{X}_{2}=d \mathbf{X}, d \mathbf{x}_{1}=d \mathbf{x}_{2}=d \mathbf{x}$ e portanto ao dividirmos a definição desta deformação por $d s^{2}$, temos

$$
\frac{1}{2}\left(\frac{d s^{2}-d S^{2}}{d s^{2}}\right)=\frac{d \mathbf{x}}{d s} \cdot \mathbf{e} \cdot \frac{d \mathbf{x}}{d s}=\mathbf{n} \cdot \mathbf{e} \cdot \mathbf{n}
$$

no qual $\mathbf{n}$ é o vetor material unitário na direção de $d \mathbf{x}$.

\section{A.2.6 Decomposição polar}

O teorema da decomposição polar diz que qualquer tensor gradiente de deformação $\mathbf{F}$, pode ser decomposto no produto de uma matriz ortogonal $\mathbf{R}$ e um tensor simétrico $\mathbf{U}$, conhecido como tensor direito de alongamento, ou seja,

$$
\mathbf{F}=\mathbf{R} \cdot \mathbf{U} \text { ou } F_{i j}=\frac{\partial x_{i}}{\partial X_{j}}=R_{i k} U_{k j} \operatorname{com} \mathbf{R}^{T}=\mathbf{R}^{-1} \text { e } \mathbf{U}=\mathbf{U}^{T}
$$

\section{A.2.6.1 Deformações e rotações infinitesimais e seus componentes}

\section{A.2.6.1.1 Tensor de deformações infinitesimal}

Pode-se obter o tensor de deformações infinitesimal a partir da linearização do gradiente 
de deformações $\mathbf{F}$ e conseguinte linearização do tensor de deformações de Green-Lagrange $\mathbf{E}$, ambos na direção do deslocamento $\mathbf{u}$.

O tensor gradiente de deformações $\mathbf{F}$ pode ser linearizado na direção de $\mathbf{u}$ através de

$$
\begin{aligned}
D \mathbf{F}(\mathbf{x})[\mathbf{u}] & =\left.\frac{d}{d \varepsilon}\right|_{\varepsilon=0}(\mathbf{F}(\mathbf{x}+\varepsilon \mathbf{u})) \\
& =\left.\frac{d}{d \varepsilon}\right|_{\varepsilon=0}\left(\frac{\partial(\mathbf{x}+\varepsilon \mathbf{u})}{\partial \mathbf{X}}\right) \\
& =\left.\frac{d}{d \varepsilon}\right|_{\varepsilon=0}\left(\frac{\partial \mathbf{x}}{\partial \mathbf{X}}+\varepsilon \frac{\partial \mathbf{u}}{\partial \mathbf{X}}\right) \\
& =\frac{\partial \mathbf{u}}{\partial \mathbf{X}}=(\nabla \mathbf{u}) \mathbf{F}
\end{aligned}
$$

Mas, se $\mathbf{u}$ é dado em função das coordenadas materiais $\mathbf{X}$, temos

$$
D \mathbf{F}(\mathbf{x})[\mathbf{u}]=\frac{\partial \mathbf{u}(\mathbf{X})}{\partial \mathbf{X}}=\nabla_{0} \mathbf{u}
$$

O tensor de deformações de Green-Lagrange pode ser linearizado da seguinte maneira, utilizando-se a regra da cadeia,

$$
\begin{aligned}
D \mathbf{E}[\mathbf{u}] & =\frac{1}{2}\left(\mathbf{F}^{T} D \mathbf{F}[\mathbf{u}]+D \mathbf{F}^{T}[\mathbf{u}] \mathbf{F}\right) \\
& =\frac{1}{2}\left(\mathbf{F}^{T}(\nabla \mathbf{u}) \mathbf{F}+\mathbf{F}^{T}(\nabla \mathbf{u})^{T} \mathbf{F}\right) \\
& =\frac{1}{2}\left(\mathbf{F}^{T}\left((\nabla \mathbf{u})+(\nabla \mathbf{u})^{T}\right) \mathbf{F}\right)
\end{aligned}
$$

Entretanto, se a deformação é infinitesimal, não é necessário diferenciar a configuração de referência da configuração atual, ou seja,

$$
\mathbf{X}=\mathbf{X} \Rightarrow \mathbf{F}=\mathbf{I}
$$

E por fim, temos que o tensor de deformações infinitesimal é dado por

$$
\begin{aligned}
\varepsilon=\frac{1}{2}\left((\nabla \mathbf{u})+(\nabla \mathbf{u})^{T}\right)=\frac{1}{2}\left(\left(\nabla_{0} \mathbf{u}\right)+\left(\nabla_{0} \mathbf{u}\right)^{T}\right) \\
\text { ou } \varepsilon_{i j}=\frac{1}{2}\left(\frac{\partial u_{i}}{\partial x_{j}}+\frac{\partial u_{j}}{\partial x_{i}}\right)=\frac{1}{2}\left(\frac{\partial u_{i}}{\partial X_{j}}+\frac{\partial u_{j}}{\partial X_{i}}\right)
\end{aligned}
$$

Este tensor de deformações é simétrico por ser a soma de uma matriz com sua transposta. Além disso, é importante ressaltar que o tensor de deformações longitudinal não se torna nulo durante uma rotação de corpo rígido. 


\section{A.2.6.2 Tensor de rotações infinitesimal}

O tensor de rotações infinitesimal é anti-simétrico e definido por

$$
\begin{aligned}
\mathbf{w}=\frac{1}{2}\left((\nabla \mathbf{u})-(\nabla \mathbf{u})^{T}\right)=\frac{1}{2}\left(\left(\nabla_{0} \mathbf{u}\right)-\left(\nabla_{0} \mathbf{u}\right)^{T}\right) \\
\text { ou } w_{i j}=\frac{1}{2}\left(\frac{\partial u_{i}}{\partial x_{j}}-\frac{\partial u_{j}}{\partial x_{i}}\right)=\frac{1}{2}\left(\frac{\partial u_{i}}{\partial X_{j}}-\frac{\partial u_{j}}{\partial X_{i}}\right)
\end{aligned}
$$

Se temos

$$
d \mathbf{x}=d \mathbf{X}+d \mathbf{u}=\left(\mathbf{I}+\frac{\partial \mathbf{u}}{\partial \mathbf{X}}\right) \cdot d \mathbf{X}=(\mathbf{I}+\boldsymbol{\varepsilon}+\mathbf{w}) \cdot d \mathbf{X}
$$

Com $\varepsilon=0$, o segmento de linha deformado se torna $d \mathbf{x}=(\mathbf{I}+\mathbf{w}) \cdot d \mathbf{X}$. Pode-se afirmar que $\mathbf{I}+\mathbf{w}$ é aproximadamente ortogonal, uma vez que

$$
(\mathbf{I}+\mathbf{w})^{T} \cdot(\mathbf{I}+\mathbf{w})=\mathbf{I}+\mathbf{w}^{T}+\mathbf{w}+\mathbf{w}^{T} \cdot \mathbf{w} \doteq \mathbf{I}+\mathbf{w}^{T}+\mathbf{w}=\mathbf{I}
$$

sendo então que quando $\varepsilon=0$ e $\mathbf{w} \neq 0$, a deformação infinitesimal é uma rotação de corpo rígido, sendo por isso $\mathbf{w}$ chamado tensor de rotação infinitesimal.

\section{A.2.6.3 Tensor de deformações normais}

Considerando $d \mathbf{X}_{1}=d \mathbf{X}_{2}=d \mathbf{X}=\mathbf{N} d S$ e da definição do tensor de deformações de Green-Lagrange, temos que

$$
d s^{2}=d \mathbf{x} \cdot d \mathbf{x}=\mathbf{N} \cdot(\mathbf{I}+2 \mathbf{E}) \cdot \mathbf{N} d S^{2}=(1+2 \mathbf{N} \cdot \mathbf{E} \cdot \mathbf{N}) d S^{2}
$$

e conforme demonstrado anteriormente, para pequenas deformações pode-se assumir que $\varepsilon \doteq \mathbf{E}$, resultando em

$$
d s=\sqrt{(1+2 \mathbf{N} \cdot \boldsymbol{\varepsilon} \cdot \mathbf{N})} d S \doteq(1+\mathbf{N} \cdot \boldsymbol{\varepsilon} \cdot \mathbf{N}) d S
$$

podendo-se concluir que

$$
\frac{d s-d S}{d S}=\mathbf{N} \cdot \varepsilon \cdot \mathbf{N}=\varepsilon_{i j} N_{i} N_{j}
$$

também conhecido como deformação de engenharia, na direção de $\mathbf{N}$. 


\section{A.2.6.4 Tensor de deformações de cisalhamento}

Considerando dois segmentos de linha infinitesimais $d \mathbf{X}_{1}=\mathbf{N}_{1} d S_{1}$ e $d \mathbf{X}_{2}=\mathbf{N}_{2} d S_{2}$, sendo $\mathbf{N}_{1}$ e $\mathbf{N}_{2}$ perpendiculares de modo a tornar o produto escalar $\mathbf{X}_{1} \cdot \mathbf{X}_{2}=0$. Se segmentos de linha infinitesimais na configuração atual, $d \mathbf{x}_{1}=\mathbf{n}_{1} d s_{1}$ e $d \mathbf{x}_{2}=\mathbf{n}_{2} d s_{2}$, formam um ângulo $(\pi / 2)-\gamma_{12}$, sendo $\gamma_{12}$ o ângulo de cisalhamento, da definição do produto escalar $\mathbf{x}_{1} \cdot \mathbf{x}_{2}$, temos

$$
\mathbf{x}_{1} \cdot \mathbf{x}_{2}=\left|\mathbf{x}_{1}\right|\left|\mathbf{x}_{2}\right| \cos \left(\frac{\pi}{2}-\gamma_{12}\right)
$$

Analisando o lado esquerdo da definição A.60, e considerando a definição do tensor de deformações de Green-Lagrange

$$
d \mathbf{x}_{1} \cdot d \mathbf{x}_{2}=\mathbf{n}_{1} \cdot(\mathbf{I}+2 \mathbf{E}) \cdot \mathbf{n}_{2} d S_{1} d S_{2}=2 \mathbf{n}_{1} \cdot \mathbf{E} \cdot \mathbf{n}_{2} d S_{1} d S_{2}
$$

pode-se afirmar, ao assumir pequenas deformações, que

$$
d \mathbf{x}_{1} \cdot d \mathbf{x}_{2} \doteq 2 \mathbf{n}_{1} \cdot \boldsymbol{\varepsilon} \cdot \mathbf{n}_{2} d S_{1} d S_{2}=2 \varepsilon_{12} d S_{1} d S_{2}
$$

Já ao analisar o lado direito da definição A.60, sabendo que $\left|\mathbf{x}_{1}\right|=d s_{1}$ e $\left|\mathbf{x}_{2}\right|=d s_{2}$ e que da definição do tensor de deformações normal temos

$$
\frac{d s_{1}-d S_{1}}{d S_{1}}=\varepsilon_{11} \Rightarrow d s_{1}=\left(1+\varepsilon_{11}\right) d S_{1}
$$

e de maneira análoga,

$$
d s_{2}=\left(1+\varepsilon_{22}\right) d S_{2}
$$

Combinando as equações e assumindo que $\gamma_{12}$ seja pequeno o suficiente para termos $\cos \left(\pi / 2-\gamma_{12}\right)=\gamma_{12}$, temos que

$$
2 \varepsilon_{12} d S_{1} d S_{2} \doteq\left(1+\varepsilon_{11}\right) d S_{1}\left(1+\varepsilon_{22}\right) d S_{2} \gamma_{12} \Rightarrow 2 \varepsilon_{12} \doteq \gamma_{12}
$$

\section{A.2.6.5 Deformação volumétrica e deviatórica}

A deformação volumétrica para pequenas deformações, $\varepsilon_{V}$, pode ser obtida a partir da linearização do Jacobiano. Pela regra da cadeia, a derivada direcional de $J$ com respeito ao incremento do deslocamento $\mathbf{u}$, na configuração espacial, pode ser obtida pela regra da cadeia por

$$
D J[\mathbf{u}]=D \operatorname{det}(\mathbf{F})[D \mathbf{F}[\mathbf{u}]]
$$


A linearização do determinante de um tensor pode ser dada por

$$
D \operatorname{det}(\mathbf{F})[\mathbf{u}]=\operatorname{det}(\mathbf{F})\left(\mathbf{F}^{-T}: \mathbf{u}\right)=\operatorname{det}(\mathbf{F}) \operatorname{tr}\left(\mathbf{F}^{-1} \mathbf{u}\right)
$$

sendo então possível definir que

$$
D J[\mathbf{u}]=\operatorname{det}(\mathbf{F}) \operatorname{tr}\left(\mathbf{F}^{-1} D \mathbf{F}[\mathbf{u}]\right)=J \operatorname{tr}\left(\mathbf{F}^{-1} \nabla \mathbf{u F}\right)=J \operatorname{tr}\left(\mathbf{F}^{-1} \mathbf{F} \nabla \mathbf{u}\right)=J \operatorname{tr}(\nabla \mathbf{u})=J \operatorname{div}(\mathbf{u})
$$

Pode-se expressar a equação acima em função do tensor de deformações infinitesimal, $\varepsilon$, obtendo sendo então possível definir que

$$
D J[\mathbf{u}]=J \operatorname{tr}(\varepsilon)
$$

e, por fim, a derivada direcional do volume do elemento infinitesimal na direção de $\mathbf{u}$ é dada por

$$
D(d v)[\mathbf{u}]=D J[\mathbf{u}] d V=J \operatorname{tr}(\varepsilon) J^{-1} d v=J \operatorname{tr}(\varepsilon) d v
$$

A deformação volumétrica para pequenas deformações, $\varepsilon_{V}$,também pode ser encontrada diretamente a partir do tensor de deformações normais. Considere um elemento volumétrico infinitesimal cujas arestas são paralelas ao eixo cartesiano $d \mathbf{X}_{1}=d X_{1} \mathbf{E}_{1}$, $d \mathbf{X}_{2}=d X_{2} \mathbf{E}_{2}$ e $d \mathbf{X}_{3}=d X_{3} \mathbf{E}_{3}$, com $\mathbf{E}_{1}, \mathbf{E}_{2}$ e $\mathbf{E}_{3}$ sendo vetores unitários ortogonais. $\mathrm{O}$ volume material $d V$ deste elemento pode ser obtido por $d V=d X_{1} d X_{2} d X_{3}$. Se $d v=d x_{1} d x_{2} d x_{3}, d x_{2}=\left(1+\varepsilon_{22}\right) d X_{2}, d x_{1}=\left(1+\varepsilon_{11}\right) d X_{1}$ e $d x_{3}=\left(1+\varepsilon_{33}\right) d X_{3}$, pode-se definir

$$
\varepsilon_{V}=\frac{d v-d V}{d V}=\frac{\left(1+\varepsilon_{11}\right)\left(1+\varepsilon_{22}\right)\left(1+\varepsilon_{33}\right) d V-d V}{d V} \doteq \varepsilon_{11}+\varepsilon_{22}+\varepsilon_{33}=\varepsilon_{k k}=\operatorname{tr}(\varepsilon)
$$

Já a deformação deviatórica pode ser dada por

$$
\varepsilon^{\operatorname{dev}}=\varepsilon-\frac{1}{3} \operatorname{tr}(\varepsilon) \mathbf{I}
$$

\section{A.2.6.6 Deformações principais}

É sempre possível descobrir um conjunto de 3 vetores unitários mutualmente perpendiculares $\mathbf{n}_{k}$ de modo que o tensor de deformações infinitesimal com respeito a estes eixos se torna

$$
\boldsymbol{\varepsilon}=\left[\begin{array}{ccc}
\varepsilon_{1} & 0 & 0 \\
0 & \varepsilon_{2} & 0 \\
0 & 0 & \varepsilon_{3}
\end{array}\right] \text { ou } \varepsilon_{i j}=\mathbf{n}_{i} \cdot \boldsymbol{\varepsilon} \cdot \mathbf{n}_{j}=\varepsilon_{i} \delta_{i j}
$$


ou seja, não há tensão de cisalhamento. Desta forma, temos para $k=1,2,3$

$$
\boldsymbol{\varepsilon} \cdot \mathbf{n}_{k}-\varepsilon \mathbf{n}_{k}=(\boldsymbol{\varepsilon}-\varepsilon \mathbf{I}) \cdot \mathbf{n}_{k}=\mathbf{0}
$$

Como $\mathbf{n}_{k} \neq 0$, temos uma solução não trivial se e somente se

$$
\operatorname{det}(\varepsilon-\varepsilon \mathbf{I})=-\varepsilon^{3}+I_{1} \varepsilon^{2}+I_{2} \varepsilon+I_{3}=0
$$

no qual $I_{k}$ são conhecidos como Invariantes e podem ser definidos por

$$
I_{1}=\operatorname{tr}(\varepsilon) ; I_{2}=\frac{1}{2}\left(\varepsilon: \varepsilon-\operatorname{tr}(\varepsilon)^{2}\right) ; I_{3}=\operatorname{det}(\varepsilon)
$$

sendo o produto duplo é definido por $\mathbf{A}: \mathbf{B}=\operatorname{tr}\left(\mathbf{B}^{T} \mathbf{A}\right)$.

As soluções $\varepsilon_{k}$ (autovalores de $\varepsilon$ ) são conhecidas como deformações principais e e os vetores $\mathbf{n}_{k}$ (autovetores de $\varepsilon$ ) são as direções principais. Como $\varepsilon$ é simétrico, os autovalores são reais e os autovetores mutualmente perpendiculares.

\section{A.3 Tensores de taxa de deformação}

\section{A.3.1 Gradiente de velocidades}

O gradiente de velocidades, $\mathbf{L}$, define a variação do vetor velocidade ao longo de uma linha infinitesimal na configuração atual. Ou seja

$$
d \mathbf{v}=\frac{\partial \mathbf{v}}{\partial \mathbf{x}} d \mathbf{x}=\mathbf{L} d \mathbf{x} \Rightarrow \mathbf{L}=\frac{\partial \mathbf{v}}{\partial \mathbf{x}}=(\nabla \mathbf{v})^{T} \text { ou } L_{i j}=\frac{\partial v_{i}}{\partial x_{j}}
$$

entretanto, o gradiente de velocidades pode ser definido também a partir do gradiente de deformações, uma vez que

$$
\mathbf{L}=\frac{\partial \mathbf{v}}{\partial \mathbf{x}}=\frac{\partial \mathbf{v}}{\partial \mathbf{X}} \frac{\partial \mathbf{X}}{\partial \mathbf{x}}=\frac{\partial \mathbf{x}}{\partial t \partial \mathbf{X}} \frac{\partial \mathbf{X}}{\partial \mathbf{x}}=\frac{\partial}{\partial t}\left(\frac{\partial \mathbf{x}}{\partial \mathbf{X}}\right)\left(\frac{\partial \mathbf{X}}{\partial \mathbf{x}}\right)=\dot{\mathbf{F}} \mathbf{F}^{-1} \text { ou } L_{i j}=\dot{F}_{i k} F_{k j}^{-1}
$$

\section{A.3.2 Tensor de taxa de deformação e tensor spin}

O tensor de taxa de deformação ou deformação da velocidade, D, e o tensor spin, W , que neste caso representa de certa forma a velocidade angular média, podem ser encontrados a partir da decomposição do gradiente de velocidades por

$$
\begin{array}{rll}
\mathbf{L}=\frac{1}{2} \mathbf{L}+\frac{1}{2} \mathbf{L}^{T}+\frac{1}{2} \mathbf{L}-\frac{1}{2} \mathbf{L}^{T}=\mathbf{D}+\mathbf{W} & \text { ou } & L_{i j}=\frac{1}{2} L_{i j}+\frac{1}{2} L_{j i}+\frac{1}{2} L_{i j}-\frac{1}{2} L_{j i}=D_{i j}+W_{i j} \\
\mathbf{D}=\frac{1}{2}\left(\mathbf{L}+\mathbf{L}^{T}\right) & \text { ou } & D_{i j}=\frac{1}{2}\left(\frac{\partial v_{i}}{\partial x_{j}}+\frac{\partial v_{j}}{\partial x_{i}}\right) \\
\mathbf{W}=\frac{1}{2}\left(\mathbf{L}-\mathbf{L}^{T}\right) & \text { ou } & W_{i j}=\frac{1}{2}\left(\frac{\partial v_{i}}{\partial x_{j}}-\frac{\partial v_{j}}{\partial x_{i}}\right)
\end{array}
$$


O tensor taxa de deformação é definido em função da taxa de variação do quadrado do comprimento de um segmento de linha infinitesimal, uma vez que

$$
\frac{D}{D t}\left(d s^{2}\right)=\frac{D}{D t}(d \mathbf{x} \cdot d \mathbf{x})=2 d \mathbf{x} \cdot d \mathbf{v}=2 d \mathbf{x} \cdot \mathbf{L} \cdot d \mathbf{x}=2 d \mathbf{x} \cdot \mathbf{D} \cdot d \mathbf{x}+2 d \mathbf{x} \cdot \mathbf{W} \cdot d \mathbf{x}
$$

Considerando o tensor spin, $\mathbf{W}$, pode-se achar uma relação do mesmo com a taxa de variação do tensor rotação R. Para tanto começaremos reescrevendo a definição do tensor spin substituindo o gradiente de velocidades pelo seu equivalente em termos de gradiente de deformação. Assim

$$
\mathbf{W}=\frac{1}{2}\left(\mathbf{L}-\mathbf{L}^{T}\right)=\frac{1}{2}\left(\dot{\mathbf{F}} \mathbf{F}^{-1}-\mathbf{F}^{-T} \dot{\mathbf{F}}^{T}\right)
$$

substituindo o gradiente de deformações em função do tensor rotação e tensor direito de alongamento, $\mathbf{F}=\mathbf{R} \cdot \mathbf{U}$, e sua derivada temporal obtida pela regra da cadeia, $\dot{\mathbf{F}}=$ $\dot{\mathbf{R}} \cdot \mathbf{U}+\mathbf{R} \cdot \dot{\mathbf{U}}$, temos

$$
\begin{aligned}
& \mathbf{W}=\frac{1}{2}\left((\dot{\mathbf{R}} \mathbf{U}+\mathbf{R} \dot{\mathbf{U}}) \mathbf{U}^{-1} \mathbf{R}^{-1}-\mathbf{R}^{-T} \mathbf{U}^{-T}\left(\mathbf{U}^{T} \dot{\mathbf{R}}^{T}+\dot{\mathbf{U}}^{T} \mathbf{R}^{T}\right)\right) \\
& \frac{1}{2}\left(\dot{\mathbf{R}} \mathbf{U} \mathbf{U}^{-1} \mathbf{R}^{-1}+\mathbf{R} \dot{\mathbf{U}} \mathbf{U}^{-1} \mathbf{R}^{-1}-\mathbf{R}^{-T} \mathbf{U}^{-T} \mathbf{U}^{T} \dot{\mathbf{R}}^{T}-\mathbf{R}^{-T} \mathbf{U}^{-T} \dot{\mathbf{U}}^{T} \mathbf{R}^{T}\right)
\end{aligned}
$$

e rearranjando levando em conta que $\mathbf{R}^{T}=\mathbf{R}^{-1}$ e $\mathbf{U}=\mathbf{U}^{T}$, temos

$$
\mathbf{W}=\frac{1}{2}\left(\dot{\mathbf{R}} \mathbf{R}^{T}+\mathbf{R} \dot{\mathbf{U}} \mathbf{U}^{-1} \mathbf{R}^{T}-\mathbf{R} \dot{\mathbf{R}}^{T}-\mathbf{R} \mathbf{U}^{-1} \dot{\mathbf{U}} \mathbf{R}^{T}\right)
$$

mas, como $\mathbf{R R}^{T}=\mathbf{I}$, temos da derivada temporal de ambos os lados e da regra da cadeia que $\dot{\mathbf{R}} \mathbf{R}^{T}+\mathbf{R} \dot{\mathbf{R}}^{T}=\mathbf{0}$, sendo então $\dot{\mathbf{R}} \mathbf{R}^{T}=-\mathbf{R} \dot{\mathbf{R}}^{T}$. Por fim temos

$$
\mathbf{W}=\dot{\mathbf{R}} \mathbf{R}^{T}+\frac{1}{2} \mathbf{R}\left(\dot{\mathbf{U}} \mathbf{U}^{-1}-\mathbf{U}^{-1} \dot{\mathbf{U}}\right) \mathbf{R}^{T}
$$

e de maneira análoga, temos que

$$
\mathbf{D}=\frac{1}{2} \mathbf{R}\left(\dot{\mathbf{U}} \mathbf{U}^{-1}+\mathbf{U}^{-1} \dot{\mathbf{U}}\right) \mathbf{R}^{T}
$$

Fica claro então que durante um movimento de corpo rígido, $\mathbf{U}=\mathbf{U}=\mathbf{0}$ e portanto $\mathbf{D}=\mathbf{0}$ e $\mathbf{L}=\mathbf{W}=\dot{\mathbf{R}} \mathbf{R}^{T}=\mathbf{\Omega}$. 


\section{A.3.3 Tensor de taxa de deformação de Green-Lagrange}

O tensor taxa de deformação pode ser expresso em função do gradiente de deformações e sua derivada temporal por

$$
\mathbf{D}=\frac{1}{2}\left(\mathbf{L}+\mathbf{L}^{T}\right)=\frac{1}{2}\left(\dot{\mathbf{F}} \mathbf{F}^{-1}+\mathbf{F}^{-T} \dot{\mathbf{F}}^{T}\right)
$$

O tensor de taxa de deformação de Green-Lagrange, $\dot{\mathbf{E}}$, também pode ser obtido em função do gradiente de deformações e sua derivada temporal por

$$
\dot{\mathbf{E}}=\frac{D}{D t} \mathbf{E}=\frac{1}{2} \frac{D}{D t}\left(\mathbf{F}^{T} \cdot \mathbf{F}-\mathbf{I}\right)=\frac{1}{2}\left(\dot{\mathbf{F}}^{T} \mathbf{F}+\mathbf{F}^{T} \dot{\mathbf{F}}\right)
$$

e simplesmente pré-multiplicando o tensor taxa de deformações por $\mathbf{F}^{T}$ e pos-multiplicando por $\mathbf{F}$, temos a seguinte relação

$$
\mathbf{F}^{T} \mathbf{D F}=\frac{1}{2}\left(\dot{\mathbf{F}}^{T} \mathbf{F}+\mathbf{F}^{T} \dot{\mathbf{F}}\right)=\dot{\mathbf{E}}
$$

O tensor de taxa de deformação de Green-Lagrange, $\dot{\mathbf{E}}$, ainda pode ser definido em função do tensor taxa de deformação direito de de Cauchy-Green, $\dot{\mathbf{C}}$, uma vez que

$$
\dot{\mathbf{E}}=\frac{D}{D t} \mathbf{E}=\frac{1}{2} \frac{D}{D t}(\mathbf{C}-\mathbf{I})=\frac{1}{2}(\dot{\mathbf{C}})
$$

\section{A.3.4 Taxa de deformação infinitesimal}

Considere um segmento de linha infinitesimal $d \mathbf{x}=d s \mathbf{n}$, sendo $\mathbf{n}$ um vetor unitário. Podemos então escrever

$$
\frac{d \dot{s}}{d s}=\frac{D}{D t}(\ln (d s))=\mathbf{n} \cdot \mathbf{D} \cdot \mathbf{n}
$$

ou seja, a taxa de alongamento em qualquer direção é dada pela componente normal da taxa de deformação nesta direção.

O tensor taxa de deformação infinitesimal pode ser dado por

$$
\dot{\varepsilon}=\operatorname{simétrico~}\left(\frac{\partial \mathbf{v}}{\partial \mathbf{x}}\right)=\text { simétrico }\left(\frac{\partial \mathbf{v}}{\partial \mathbf{X}}\right)=\mathbf{D}
$$

e o tensor taxa de rotação infinitesimal

$$
\dot{\boldsymbol{w}}=\operatorname{anti-simétrico~}\left(\frac{\partial \mathbf{v}}{\partial \mathbf{x}}\right)=\text { anti-simétrico }\left(\frac{\partial \mathbf{v}}{\partial \mathbf{X}}\right)=\mathbf{W}
$$

Além disso, a para pequenas deformações, $\mathbf{F} \doteq \mathbf{I}$, e a relação entre $\dot{\mathbf{E}}$ e $\mathbf{D}$ se torna

$$
\dot{\mathrm{E}}=\mathbf{D}
$$




\section{A.3.5 Taxa de variação de volume}

Como visto e provado anteriormente, a variação entre o volume na configuração inicial, $d V$ e atual, $d v$, é dado em termos do jacobiano, $J$, sendo

$$
d v=J d V \text { e } J=\operatorname{det}(\mathbf{F})
$$

derivando em relação ao tempo, temos

$$
\frac{d}{d t}(d v)=\dot{J} d V=\frac{\dot{J}}{J} d v
$$

Podemos obter a linearização da derivada temporal do jacobiano utilizando-se da fórmula deduzida anteriormente

$$
D J[\mathbf{u}]=\operatorname{det}(\mathbf{F}) \operatorname{tr}\left(\mathbf{F}^{-1} D \mathbf{F}[\mathbf{u}]\right)=J \operatorname{tr}\left(\mathbf{F}^{-1} \nabla \mathbf{u F}\right)=J \operatorname{tr}\left(\mathbf{F}^{-1} \mathbf{F} \nabla \mathbf{u}\right)=J \operatorname{tr}(\nabla \mathbf{u})=J \operatorname{div}(\mathbf{u})
$$

sendo que temos então

$$
\dot{J}=D J[\mathbf{v}]=J \operatorname{div}(\mathbf{v})=J \operatorname{tr}(\mathbf{D})
$$

ou pode ser expressado em função do tensor taxa de deformação direito de Cauchy-Green, $\dot{\mathbf{C}}$, já que

$$
\begin{aligned}
\dot{J}=D J[\mathbf{v}]=J \operatorname{tr}(\mathbf{D})=J \operatorname{tr}\left(\mathbf{F}^{-T} \dot{\mathbf{E}} \mathbf{F}^{-1}\right) & =J \operatorname{tr}\left(\mathbf{F}^{-1} \mathbf{F}^{-T} \dot{\mathbf{E}}\right)=J \operatorname{tr}\left(\mathbf{C}^{-1} \dot{\mathbf{E}}\right)= \\
& =J \operatorname{tr}\left(\dot{\mathbf{E}} \mathbf{C}^{-T}\right)=J \mathbf{C}^{-1}: \dot{\mathbf{E}}=\frac{1}{2} J \mathbf{C}^{-1}: \dot{\mathbf{C}}
\end{aligned}
$$

sendo $\mathbf{A}: \mathbf{B}=\operatorname{tr}\left(\mathbf{B}^{T} \mathbf{A}\right)=\operatorname{tr}\left(\mathbf{A} \mathbf{B}^{T}\right)=\operatorname{tr}\left(\mathbf{A}^{T} \mathbf{B}\right)=\operatorname{tr}\left(\mathbf{B} \mathbf{A}^{T}\right)$ e $\mathbf{C}^{-1}=\mathbf{C}^{-T}$.

\section{A.4 Tensores de tensão}

É necessário também descrever matematicamente as forças internas e externas atuando sobre um sólido, sendo definidas de muitas maneiras. Podem ser aplicadas em um sólido de duas maneiras:

- A força pode ser aplicada sobre as extremidades de um sólido, como, por exemplo, a força aplicada por um vento ou a força de contato com outro sólido;

- O sólido pode estar sujeito a forças de corpo que atuam no interior do sólido, como a gravidade ou forças eletromagnéticas. 
Os tensores de tensão são um modo de medir estas forças e definidos de uma forma padrão como força por unidade de área. Serão definidos mais aprofundada os tensores de tensão de Cauchy, Nominal, Kirchhoff, primeiro Piola-Kirchhoff e segundo PiolaKirchhoff.

\section{A.4.1 Tensor de tensões de Cauchy (ou verdadeiro)}

Considere o elemento de área infinitesimal em $\Omega, d \Gamma$,cujo vetor unitário normal é dado por $\mathbf{n}$, a força $d \mathbf{f}$ atuando em $d \Gamma$ e o vetor tração $\mathbf{t}$ definido como força sobre unidade de área, todos representados na figura A.3.

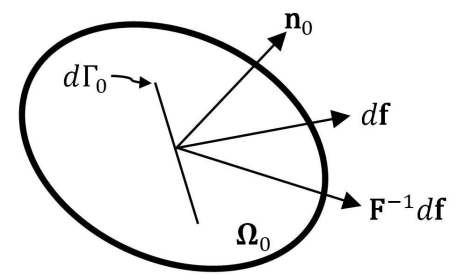

(a) Configuração inicial

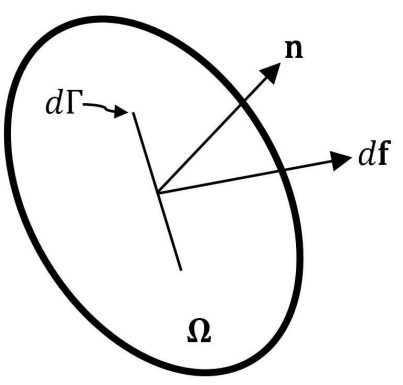

(b) Configuração atual

Figura A.3: Área infinitesimal $d \Gamma$ em $\Omega$, vetor unitário normal $\mathbf{n}$, força $d \mathbf{f}$, vetor tração $\mathrm{t}$

A lei de Cauchy ou hipótese de Cauchy diz que

$$
\mathbf{n} \cdot \boldsymbol{\sigma} d \Gamma=d \mathbf{f}=\mathbf{t} d \Gamma
$$

Como o tensor de tensões de Cauchy envolve a normal a superfície atual e a tração na superfície atual, a tensão de Cauchy normalmente é conhecida como tensão física ou verdadeira. As outras medidas de tensão se referem à superfície inicial ou não deformada. Um exemplo da importância dessa referência a configuração atual é a definição da pressão

$$
\frac{1}{3} \operatorname{tr}(\boldsymbol{\sigma})=\frac{1}{3} \sigma_{i i}=-p
$$

A terça parte do traço das outras medidas de tensão não resultam da pressão verdadeira, uma vez que se referem a área inicial. Por convenção, os componentes normais da tensão de Cauchy serão positivos em tração e a pressão então positiva em compressão. 
Além disso, devido à conservação de momento angular, o tensor de tensões de Cauchy é simétrico (as leis de conservação estão desenvolvidas no Apend. A), ou seja,

$$
\boldsymbol{\sigma}=\boldsymbol{\sigma}^{T}
$$

\section{A.4.2 Tensor de tensões nominal}

Considere agora o elemento de área infinitesimal em $\Omega_{0}, d \Gamma_{0}$, cujo vetor unitário normal é dado por $\mathbf{n}_{0}$, a força $d \mathbf{f}$ atuando em $d \Gamma_{0}$ e o vetor tração $\mathbf{t}_{0}$ definido como força sobre unidade de área inicial. O tensor de tensões nominal é dado por

$$
\mathbf{n}_{0} \cdot \mathbf{P} d \Gamma_{0}=d \mathbf{f}=\mathbf{t}_{0} d \Gamma_{0}
$$

A relação de Nanson associa o elemento de área atual $d \Gamma$ com o elemento de área da configuração inicial $d \Gamma_{0}$ por

$$
\mathbf{n} d \Gamma=J \mathbf{n}_{0} \cdot \mathbf{F}^{-1} d \Gamma_{0} \text { ou } n_{i} d \Gamma=J n_{j}^{0} \cdot F_{j i}^{-1} d \Gamma_{0}
$$

Pode-se, então, estabelecer uma relação entre a tensão nominal e a de Cauchy, sendo

$$
\mathbf{n} \cdot \boldsymbol{\sigma} d \Gamma=J \mathbf{n}_{0} \cdot \mathbf{F}^{-1} \cdot \boldsymbol{\sigma} d \Gamma_{0} \Rightarrow \mathbf{P}=J \mathbf{F}^{-1} \cdot \boldsymbol{\sigma} \text { ou } P_{i j}=J F_{i k}^{-1} \sigma_{k j}=J \frac{\partial X_{i}}{\partial x_{k}} \sigma_{k j}
$$

Vale ressaltar que o tensor de tensões nominal não é simétrico. Seu transposto é conhecido como o primeiro tensor de tensões de Piola-Kirchhoff.

\section{A.4.3 Tensor de tensões de Kirchhoff}

O tensor de tensões de Kirchhoff, $\boldsymbol{\tau}$ é definido por

$$
\tau=J \boldsymbol{\sigma}
$$

Assim, é quase idêntico ao tensor de tensões de Cauchy, mas escalonado pelo Jacobiano. Desta forma, também é conhecido como tensor ponderado de tensões de Cauchy. Para movimentos isocóricos, é igual ao tensor de tensões de Cauchy. É usado em relações constitutivas hiper-elásticas e modelos hipo-elasto-plásticos uma vez que leva à simetria do módulo tangente. 


\section{A.4.4 Segundo tensor de tensões de Piola-Kirchhoff}

O segundo tensor de tensões de Piola-Kirchhoff, $\mathbf{S}$, é definido por

$$
\mathbf{n}_{0} \cdot \mathbf{S} d \Gamma_{0}=\mathbf{F}^{-1} \cdot d \mathbf{f}=\mathbf{F}^{-1} \cdot \mathbf{t}_{0} d \Gamma_{0}
$$

Este difere do tensor de tensões nominais apenas pela força estar pré-multiplicada por $\mathbf{F}^{-1}$. Essa pré-multiplicação o torna simétrico e conjugado energético (conjugado no no que diz respeito à potência, taxa de trabalho realizado) ao tensor de taxa de deformação de Green-Lagrange. É muito utilizado em materiais path-independent como borracha e se relaciona com o tensor de tensões nominal por

$$
\left.\begin{array}{r}
d \mathbf{f}=\mathbf{F} \cdot\left(\mathbf{n}_{0} \cdot \mathbf{S} d \Gamma_{0}\right)=\mathbf{F} \cdot \mathbf{S}^{T} \cdot \mathbf{n}_{0} d \Gamma_{0} \\
d \mathbf{f}=\mathbf{n}_{0} \cdot \mathbf{P} d \Gamma_{0}=\mathbf{P}^{T} \cdot \mathbf{n}_{0} d \Gamma_{0}
\end{array}\right\} \mathbf{P}=\mathbf{S} \cdot \mathbf{F}^{T}
$$

uma vez que

$$
d f_{i}=F_{i k}\left(n_{j}^{0} S_{j k}\right) d \Gamma_{0}=F_{i k} S_{k j}^{T} n_{j}^{0} d \Gamma_{0}
$$

Já a relação com o tensor de Cauchy é dada por

$$
\boldsymbol{\sigma}=J^{-1} \mathbf{F} \cdot \mathbf{S} \cdot \mathbf{F}^{T}
$$

\section{A.4.5 Tensor de tensões para deformações infinitesimais}

Como visto anteriormente, quando consideradas deformações infinitesimais, não é necessário diferenciar a configuração de referência da configuração atual, ou seja,

$$
\mathbf{x} \doteq \mathbf{X} \Rightarrow \mathbf{F} \doteq \mathbf{I} \text { e } J=\operatorname{det}(\mathbf{F})=1
$$

Assim, todas as definições de tensores de tensão são aproximadamente as mesmas, ou seja

$$
\sigma \doteq \mathrm{P} \doteq \tau \doteq \mathrm{S}
$$

\section{A.4.6 Tensões principais e direções principais}

Sempre é possível achar um conjunto de três eixos perpendiculares definidos por vetores unitários $\mathbf{n}_{k}$, de tal maneira que o tensor de tensões de Cauchy, com respeito a estes eixos, se torna

$$
\boldsymbol{\sigma}=\left[\begin{array}{ccc}
\sigma_{1} & 0 & 0 \\
0 & \sigma_{2} & 0 \\
0 & 0 & \sigma_{3}
\end{array}\right] \text { ou } \sigma i j=\mathbf{n}_{i} \cdot \boldsymbol{\sigma} \cdot \mathbf{n}_{j}=\sigma_{i} \delta_{i j}
$$


Como os componentes de cisalhamento são nulos, ou seja, $\mathbf{n}_{i} \cdot \boldsymbol{\sigma} \cdot \mathbf{n}_{j}=0$ para qualquer $i \neq j$, pode-se escrever

$$
\boldsymbol{\sigma} \cdot \mathbf{n}_{k}-\sigma \mathbf{n}_{k}=(\boldsymbol{\sigma}-\sigma \mathbf{I}) \cdot \mathbf{n}_{k}=\mathbf{0} \text { para } k=1,2,3
$$

De modo que para termos uma solução não trivial, $\mathbf{n}_{k} \neq 0$, é necessário que

$$
\operatorname{det}(\boldsymbol{\sigma}-\sigma \mathbf{I})=-\sigma^{3}+I_{1} \sigma^{2}+I_{2} \sigma+I_{3}=0
$$

sendo então os invariantes principais do tensor de tensões de Cauchy definidos por

$$
I_{1}=\operatorname{tr}(\boldsymbol{\sigma}) ; I_{2}=\frac{1}{2}\left(\boldsymbol{\sigma}: \boldsymbol{\sigma}-\operatorname{tr}(\boldsymbol{\sigma})^{2}\right) ; I_{3}=\operatorname{det}(\boldsymbol{\sigma})
$$

ou, em função das tensões principais,

$$
I_{1}=\sigma_{1}+\sigma_{2}+\sigma_{3} ; I_{2}=-\left(\sigma_{1} \sigma_{2}+\sigma_{2} \sigma_{3}+\sigma_{1} \sigma_{3}\right) ; I_{3}=\sigma_{1} \sigma_{2} \sigma_{3}
$$

\section{A.4.7 Tensões hidrostática, deviatórica e equivalente de von Misses}

A tensão hidrostática (ou tensão média) é definida como o valor médio dos componentes de tensão normal do tensor de tensões de Cauchy. Equacionando, temos

$$
\sigma_{m}=\frac{1}{3} \operatorname{tr}(\boldsymbol{\sigma})=\frac{1}{3} \sigma_{k k}=\frac{1}{3}\left(\sigma_{11}+\sigma_{22}+\sigma_{33}\right)
$$

sendo independente do sistema de coordenadas.

O tensor de tensões deviatórico é definido por

$$
\boldsymbol{\sigma}^{\mathrm{dev}}=\boldsymbol{\sigma}-\frac{1}{3} \operatorname{tr}(\boldsymbol{\sigma}) \mathbf{I}=\boldsymbol{\sigma}-\sigma_{m} \mathbf{I}
$$

sendo que $\operatorname{tr}\left(\boldsymbol{\sigma}^{\mathrm{dev}}\right)=0$. As direções principais do tensor de tensões deviatórico são dadas por

$$
J_{1}=\operatorname{tr}\left(\boldsymbol{\sigma}^{\mathrm{dev}}\right) ; J_{2}=\frac{1}{2}\left(\boldsymbol{\sigma}^{\mathrm{dev}}: \boldsymbol{\sigma}^{\mathrm{dev}}\right) ; J_{3}=\operatorname{det}\left(\boldsymbol{\sigma}^{\mathrm{dev}}\right)
$$

sendo as direções principais do tensor de tensões de Cauchy e do tensor de tensões deviatórico são as mesmas, uma vez que

$$
\boldsymbol{\sigma}^{\mathrm{dev}} \cdot \mathbf{n}_{k}-\sigma^{\mathrm{dev}} \mathbf{n}_{k}=\left(\boldsymbol{\sigma}-\sigma_{m} \mathbf{I}\right) \cdot \mathbf{n}_{k}-\sigma^{\mathrm{dev}} \mathbf{n}_{k}=\boldsymbol{\sigma} \cdot \mathbf{n}_{k}-\left(\sigma_{m}+\sigma^{\mathrm{dev}}\right) \mathbf{n}_{k}=0
$$


sendo então os valores das tensões deviatórica principais dados por

$$
\sigma_{k}^{\mathrm{dev}}=\sigma_{k}-\sigma_{m}=\sigma_{k}-\frac{1}{3} I_{1}
$$

A tensão equivalente de von misses pode ser interpretada fisicamente como o valor representativo da energia elástica de distorção, representando um estado triaxial de tensões por um valor uniaxial de tensão e é definido por

$$
\sigma_{e q}=\sqrt{\frac{3}{2} \boldsymbol{\sigma}^{\mathrm{dev}}: \boldsymbol{\sigma}^{\mathrm{dev}}}=\sqrt{3 J_{2}}
$$

Assim como a tensão hidrostática, o valor da tensão equivalente de von Misses é independente do sistema de coordenadas.

\section{A.5 Taxas de tensão objetivas}

Uma equação constitutiva permite relacionar deformações com tensões. Esta relação pode ser direta e path-independent, conhecida como elástica, através de energia potencial de deformação armazenada e path-independent, conhecida como hiper-elástica, ou mesmo através respectivas taxas temporais de tensão e deformação, sendo então path-dependent, chamadas hipo-elásticas. Um exemplo de equação hipo-elástica é

$$
\frac{D \sigma_{i j}}{D t}=C_{i j k l}^{\sigma D} D_{k l} \text { ou } \frac{D \boldsymbol{\sigma}}{D t}=\mathbf{C}^{\sigma D}: \mathbf{D}
$$

no qual a taxa de tensão é linearmente relacionada a taxa de deformação. O exemplo a seguir tem por objetivo demonstrar que tal equação não é valida.

Considere uma viga alinhada ao eixo $x$, com uma das extremidades sobre a origem e outra sobre a parte positiva da abscissa, pré-tensionado sendo então $\sigma_{x}=\sigma_{0}$. Ao ser rotacionado sobre a origem de $90^{\circ}$, a viga estará com uma extremidade sobre o eixo y e a outra sobre a parte positiva do eixo das ordenadas, sendo $\sigma_{y}=\sigma_{0}$. Como há apenas uma rotação de corpo rígido, o tensor taxa de deformação é nulo. Da equação constitutiva, temos então que $\frac{D \sigma}{D t}$ é nulo. Fica provado então que a equação constitutiva é invalida já que $\frac{D \boldsymbol{\sigma}}{D t} \neq 0$, uma vez que $\left(\sigma_{x}, \sigma_{y}\right)$ passa de $\left(\sigma_{0}, 0\right)$ para $\left(0, \sigma_{0}\right)$.

O problema da equação constitutiva acima é que esta não leva em conta rotações de corpo rígido. Entretanto, a rotação material pode ser levada em conta utilizando um tensor taxa de tensão objetivo. Os três mais conhecidos são a taxa de Jaumann, taxa de Truesdell e a taxa de Green-Naghdi. 


\section{A.5.1 Taxa de Jaumann}

A taxa de Jaumann da tensão de Cauchy é dada por

$$
\boldsymbol{\sigma}^{\nabla J}=\frac{D \boldsymbol{\sigma}}{D t}-\mathbf{W} \cdot \boldsymbol{\sigma}-\boldsymbol{\sigma} \cdot \mathbf{W}^{T} \text { ou } \sigma_{i j}^{\nabla J}=\frac{D \sigma_{i j}}{D t}-W_{i k} \sigma_{k j}-\sigma_{i k} W_{k j}^{T}
$$

com $\mathbf{W}=\left(\frac{1}{2}\right)\left(\mathbf{L}-\mathbf{L}^{T}\right)$ sendo o tensor spin. O superscrito $\nabla$ representa uma taxa objetiva enquanto a taxa de Jaumann é representada pelo superscrito $J$. Uma equação constitutiva válida então pode ser dada por

$$
\boldsymbol{\sigma}^{\nabla J}=\mathbf{C}^{\sigma J}: \mathbf{D} \text { ou } \sigma_{i j}^{\nabla J}=C_{i j k l}^{\sigma J} D_{k l}
$$

e então a taxa material da tensão de Cauchy é dada corretamente por

$$
\frac{D \boldsymbol{\sigma}}{D t}=\boldsymbol{\sigma}^{\nabla J}+\mathbf{W} \cdot \boldsymbol{\sigma}+\boldsymbol{\sigma} \cdot \mathbf{W}^{T}=\underbrace{\mathbf{C}^{\sigma J}: \mathbf{D}}_{\text {material }}+\underbrace{\mathbf{W} \cdot \boldsymbol{\sigma}+\boldsymbol{\sigma} \cdot \mathbf{W}^{T}}_{\text {rotação }}
$$

sendo então possível afirmar que a que a derivada material da tensão de Cauchy consiste em duas partes: uma devido à resposta do material, indicada como taxa objetiva, e outra devido a variação da tensão causada pela rotação.

\section{A.5.2 Taxa de Truesdell}

A taxa de Truesdell é uma variação da taxa de Jaumann, que utiliza as partes simétricas e anti-simétricas do gradiente de velocidades, sendo dada por

$$
\begin{aligned}
\boldsymbol{\sigma}^{\nabla \mathcal{T}}=\frac{D \boldsymbol{\sigma}}{D t}+\operatorname{div}(\mathbf{v}) \boldsymbol{\sigma}- & (\mathbf{D}+\mathbf{W}) \cdot \boldsymbol{\sigma}-\boldsymbol{\sigma} \cdot(\mathbf{D}+\mathbf{W})^{T}= \\
=\frac{D \boldsymbol{\sigma}}{D t}+\operatorname{div}(\mathbf{v}) \boldsymbol{\sigma}-\mathbf{L} \cdot \boldsymbol{\sigma}-\boldsymbol{\sigma} \cdot \mathbf{L}^{T} & \quad \text { ou } \sigma_{i j}^{\nabla \mathcal{T}}=\frac{D \sigma_{i j}}{D t}+\frac{\partial v_{k}}{\partial x_{k}} \sigma_{i j}-\frac{\partial v_{i}}{\partial x_{k}} \sigma_{k j}-\sigma_{i k} \frac{\partial v_{j}}{\partial x_{k}}
\end{aligned}
$$

sendo que ambas taxas de Truesdell e Jaumann apresentam o mesmo valor na ausência de deformação, $\mathbf{D}=0$. Deve-se salientar que para representarem o mesmo material, as constantes $\mathbf{C}^{\nabla J}$ e $\mathbf{C}^{\nabla \mathcal{T}}$ devem ser calibradas independentemente, umas vez que representam a correlação do tensor taxa de deformação com os tensores taxa de Jaumann e taxa de Truesdell através de

$$
\boldsymbol{\sigma}^{\nabla J}=\mathbf{C}^{\sigma J}: \mathbf{D} \text { e } \boldsymbol{\sigma}^{\nabla \mathcal{T}}=\mathbf{C}^{\sigma \mathcal{T}}: \mathbf{D}
$$




\section{A.5.3 Taxa de Green-Naghdi}

A taxa de Green-Naghdi difere da taxa de Jaumann apenas por utilizar outra medição de rotação do material: a velocidade angular $\Omega=\dot{\mathbf{R}} \mathbf{R}^{T}$. Assim, a taxa de Green-Naghdi é expressa por

$$
\boldsymbol{\sigma}^{\nabla \mathcal{G}}=\frac{D \boldsymbol{\sigma}}{D t}-\boldsymbol{\Omega} \cdot \boldsymbol{\sigma}-\boldsymbol{\sigma} \cdot \boldsymbol{\Omega}^{T} \text { ou } \sigma_{i j}^{\nabla \mathcal{G}}=\frac{D \sigma_{i j}}{D t}-\Omega_{i k} \sigma_{k j}-\sigma_{i k} \Omega_{k j}^{T}
$$

e assim como as anteriores, podemos dizer que

$$
\boldsymbol{\sigma}^{\nabla \mathcal{G}}=\mathbf{C}^{\sigma \mathcal{G}}: \mathbf{D}
$$

\section{A.5.4 Taxa de convecção}

A derivada material no tempo do tensor de tensões de Kirchhoff, como a derivada material no tempo do tensor de tensões de Cauchy, não é objetiva. A derivada no tempo objetiva mais comum do tensor de tensões de Kirchhoff é chamada taxa de convecção e é dada por

$$
\boldsymbol{\tau}^{\nabla c}=\dot{\boldsymbol{\tau}}-\mathbf{L} \cdot \boldsymbol{\tau}-\boldsymbol{\tau} \cdot \mathbf{L}^{T}=J\left(\dot{\boldsymbol{\sigma}}-\mathbf{L} \cdot \boldsymbol{\sigma}-\boldsymbol{\sigma} \cdot \mathbf{L}^{T}+\operatorname{tr}(\mathbf{L}) \boldsymbol{\sigma}\right)=J \boldsymbol{\sigma}^{\nabla \mathcal{T}}
$$

ou seja, a taxa de convecção do tensor de tensões de Kirchhoff é equivalente a $J \boldsymbol{\sigma}^{\nabla \mathcal{T}}$, que é a taxa ponderada de Truesdell do tensor de tensões de Cauchy. 


\section{Apêndice B}

\section{Equações de Conservação}

\section{B.1 Introdução}

Muitas equações fundamentais da mecânica do contínuo advêm das leis de conservação. Estas devem ser satisfeitas por todo sistema físico. Para sistemas termo-mecânicos, as quatro leis de conservação mais relevantes são:

- conservação de massa;

- conservação de momento;

- conservação de energia;

- conservação de momento angular.

Estas leis normalmente são expressas na forma de equações diferenciais parciais, sendo aplicadas para o domínio do corpo, o que leva a relações por integral. O seguinte teorema é utilizado para extrair as equações diferenciais parciais das integrais:

- Seja $f(\mathbf{x}, t)$ uma função $C^{-1}$ e $\int_{\Omega} f(\mathbf{x}, t) d \Omega$ para qualquer subdomínio arbitrário $\Omega$ do corpo $\bar{\Omega}$ e tempo $t \in[0, t]$. Podemos então dizer que

$$
f(x, t)=0 \text { em } \Omega \text { para } t \in[0, t]
$$

\section{B.2 Teorema de Gauss}

O teorema de Gauss relaciona a integral em um domínio com a integral na fronteira desse domínio. Dessa forma, pode relacionar uma integral volumétrica com uma integral de 
superfície ou uma integral de área com uma integral de linha. Sendo $f(\mathbf{x}, t)$ uma função $C^{0}$, o teorema de Gauss é matematicamente é definido por

$$
\int_{\Omega} \frac{\partial f(\mathbf{x})}{\partial x_{i}} d \Omega=\int_{\Gamma} n_{i} f(\mathbf{x}) d \Gamma \text { ou } \int_{\Omega} \nabla f(\mathbf{x}) d \Omega=\int_{\Gamma} \mathbf{n} f(\mathbf{x}) d \Gamma
$$

mas como o teorema é verdadeiro para qualquer domínio, podemos escreve-lo em função da configuração de referência $\Omega_{0}$ por

$$
\int_{\Omega_{0}} \frac{\partial f(\mathbf{X})}{\partial X_{i}} d \Omega_{0}=\int_{\Gamma_{0}} n_{i}^{0} f(\mathbf{x}) d \Gamma_{0} \text { ou } \int_{\Omega_{0}} \nabla_{0} f(\mathbf{x}) d \Omega_{0}=\int_{\Gamma_{0}} \mathbf{n}_{0} f(\mathbf{x}) d \Gamma_{0}
$$

ou para um tensor de primeira ordem

$$
\int_{\Omega} \frac{\partial g_{i}(\mathbf{x})}{\partial x_{i}} d \Omega=\int_{\Gamma} n_{i} g_{i}(\mathbf{x}) d \Gamma \text { ou } \int_{\Omega} \boldsymbol{\nabla} \cdot \mathbf{g}(\mathbf{x}) d \Omega=\int_{\Gamma} \mathbf{n} \cdot \mathbf{g}(\mathbf{x}) d \Gamma
$$

\section{B.3 Derivada material no tempo de um integral e teorema de transporte de Reynold's}

A derivada material no tempo de uma integral é a taxa de variação de uma integral no domínio material. O domínio material se move com o material de modo que os pontos materiais na fronteira do domínio continuem na fronteira e não haja fluxo de massa através da fronteira. As várias formas de derivações materiais no tempo de integrais são chamadas de teorema de transporte de Reynold's.

A derivada material no tempo de uma integral é definida por

$$
\frac{D}{D t} \int_{\Omega} f d \Omega=\lim _{\Delta t \rightarrow 0} \frac{1}{\Delta t}\left(\int_{\Omega_{\tau+\Delta t}} f(\mathbf{x}, \tau+\Delta t) d \Omega_{\tau+\Delta t}-\int_{\Omega_{\tau}} f(\mathbf{x}, \tau) d \Omega_{\tau}\right)
$$

no qual $\Omega_{\tau}$ é o domínio espacial no tempo $\tau$ e $\Omega_{\tau+\Delta t}$ é o domínio espacial ocupado pelos mesmos pontos materiais no tempo $\tau+\Delta t$. Pode-se transportar o lado direito da equação para o domínio de referência, resultando em

$$
\frac{D}{D t} \int_{\Omega} f d \Omega=\lim _{\Delta t \rightarrow 0} \frac{1}{\Delta t}\left(\int_{\Omega_{0}} f(\mathbf{X}, \tau+\Delta t) J(\mathbf{X}, \tau+\Delta t) d \Omega_{0}-\int_{\Omega_{0}} f(\mathbf{X}, \tau) J(\mathbf{X}, \tau) d \Omega_{0}\right)
$$

Colocando-se o limite dentro da integral e da definição de derivada, obtemos

$$
\frac{D}{D t} \int_{\Omega} f d \Omega=\int_{\Omega_{0}} \frac{\partial}{\partial t}(f(\mathbf{X}, \tau) J(\mathbf{X}, \tau)) d \Omega_{0}
$$


e da regra da cadeia e da definição da derivada temporal do Jacobiano, temos

$$
\frac{D}{D t} \int_{\Omega} f d \Omega=\int_{\Omega_{0}}\left(\frac{\partial f}{\partial t} J+f J \frac{\partial v_{i}}{\partial x_{i}}\right) d \Omega_{0}
$$

e sabendo que $\int_{\Omega} f d \Omega=\int_{\Omega_{0}} f J d \Omega_{0}$, obtém-se uma das formas do teorema de transporte de Reynold's, dada por

$$
\frac{D}{D t} \int_{\Omega} f d \Omega=\int_{\Omega}\left(\frac{D f(\mathbf{x}, t)}{D t}+f \frac{\partial v_{i}}{\partial x_{i}}\right) d \Omega
$$

Uma forma alternativa do teorema de transporte de Reynold's pode ser encontrada sabendo que $\frac{D f(\mathbf{x}, t)}{D t} \equiv \frac{\partial f(\mathbf{X}, t)}{\partial t}$ e que podemos expressar a derivada em termos de coordenadas espaciais, sendo $\frac{D f(\mathbf{x}, t)}{D t}=\frac{\partial f(\mathbf{x}, t)}{\partial t}+v_{i} \frac{\partial f(\mathbf{x}, t)}{x_{i}}$, originando assim

$$
\begin{aligned}
\frac{D}{D t} \int_{\Omega} f d \Omega=\int_{\Omega}\left(\frac{\partial f}{\partial t}+v_{i} \frac{\partial f}{\partial x_{i}}+f \frac{\partial v_{i}}{\partial x_{i}}\right) d \Omega=\int_{\Omega}\left(\frac{\partial f}{\partial t}\right. & \left.+\frac{\partial\left(f v_{i}\right)}{\partial x_{i}}\right) d \Omega= \\
& =\int_{\Omega}\left(\frac{\partial f}{\partial t}+\operatorname{div}(\mathbf{v} f)\right) d \Omega
\end{aligned}
$$

ou, utilizando o teorema de Gauss,

$$
\begin{aligned}
\frac{D}{D t} \int_{\Omega} f d \Omega=\int_{\Omega} \frac{\partial f}{\partial t} d \Omega+\int_{\tau} f v_{i} n_{i} d \tau \text { ou } & \\
& \frac{D}{D t} \int_{\Omega} f d \Omega=\int_{\Omega} \frac{\partial f}{\partial t} d \Omega+\int_{\tau} f \mathbf{v} \cdot \mathbf{n} d \tau
\end{aligned}
$$

Pode-se também expressar o teorema de transporte de Reynold’s para um vetor ao invés de um escalar, sendo

$$
\frac{D}{D t} \int_{\Omega} g_{k} d \Omega=\int_{\Omega}\left(\frac{\partial g_{k}}{\partial t}+\frac{\partial\left(v_{i} g_{k}\right)}{\partial t}\right) d \Omega
$$

\section{B.4 Conservação de massa}

A massa $m(\Omega)$ de um domínio material $\Omega$ é dada por

$$
m(\Omega)=\int_{\Omega} \rho(\mathbf{X}, t) d \Omega
$$

com $\rho(\mathbf{X}, t)$ sendo a densidade. A conservação de massa requer que a massa de um domínio material seja constante, ou seja,

$$
\frac{D}{D t} m(\Omega)=\frac{D}{D t} \int_{\Omega} \rho d \Omega=0
$$


e aplicando o teorema de Reynold's,

$$
\int_{\Omega}\left(\frac{D \rho}{D t} \rho \operatorname{div}(\mathbf{v})\right) d \Omega=0
$$

e como essa igualdade deve ser verdadeira para qualquer subdomínio de $\Omega$, temos

$$
\frac{D \rho}{D t}+\rho \operatorname{div}(\mathbf{v})=0 \text { ou } \dot{\rho}+\rho \frac{\partial v_{i}}{\partial x_{i}}=0
$$

que é conhecida como a equação de conservação de massa ou equação de continuidade. Se, por exemplo, o material é incompressível, a derivada material no tempo da densidade é nula e temos

$$
\operatorname{div}(\mathbf{v})=0
$$

A conservação de massa também pode ser escrita pela definição da derivada material no tempo, originando

$$
\frac{\partial \rho}{\partial t}+\frac{\partial\left(v_{i} \rho\right)}{\partial x_{i}}=0
$$

conhecida como forma conservativa da equação de conservação de massa e largamente utilizada em mecânica dos fluidos computacional.

Em uma descrição lagrangeana, pode-se integrar $\frac{D}{D t} \int_{\Omega} \rho d \Omega=0$ no tempo para descobrir

$$
\int_{\Omega} \rho d \Omega=\int_{\Omega_{0}} \rho_{0} d \Omega_{0}=\text { cte }
$$

e transformando o lado esquerdo da equação para o domínio de referência,

$$
\int_{\Omega_{0}}\left(\rho J-\rho_{0}\right) d \Omega_{0}=0
$$

e como essa igualdade deve ser verdadeira para qualquer subdomínio de $\Omega$, temos

$$
\rho(\mathbf{X}, t) J(\mathbf{X}, t)=\rho_{0}(\mathbf{X}, t) \text { ou simplesmente } \rho J=\rho_{0}
$$

\section{B.5 Conservação de momento linear}

A equação resultante do principio de conservação de momento linear é importante para elementos finitos não-linear, sendo equivalente a segunda lei de Newton ao relacionar as forças atuantes em um corpo com sua aceleração. 
Considere um domínio arbitrário $\Omega$ com fronteira $\Gamma$ sujeito a forças de corpo $\rho \mathbf{b}$ e trações $\mathbf{t}$ na superfície, sendo $\mathbf{b}$ força por unidade de massa e $\mathbf{t}$ força por unidade de área. A força total no domínio é dada por

$$
\mathbf{f}(t)=\int_{\Omega} \rho \mathbf{b}(\mathbf{x}, t) d \Omega+\int_{\Gamma} \mathbf{t}(\mathbf{x}, t) d \Gamma
$$

e o momento linear dador por

$$
\mathbf{p}(t)=\int_{\Omega} \rho \mathbf{v}(\mathbf{x}, t) d \Omega
$$

no qual $\rho \mathbf{v}$ é o momento linear por unidade de volume.

A segunda lei de movimento para um contínuo de Newton, o princípio de conservação de momento, diz que a derivada material no tempo do momento linear é igual à força. Deste modo temos

$$
\frac{D \mathbf{p}}{D t}=\mathbf{f} \Rightarrow \frac{D}{D t} \int_{\Omega} \rho \mathbf{v}(\mathbf{x}, t) d \Omega=\int_{\Omega} \rho \mathbf{b}(\mathbf{x}, t) d \Omega+\int_{\Gamma} \mathbf{t}(\mathbf{x}, t) d \Gamma
$$

Ambos os lados da equação podem ser simplificados. Considerando primeiro o lado esquerdo da equação e usando teorema de Reynold's, temos

$$
\frac{D}{D t} \int_{\Omega} \rho \mathbf{v} d \Omega=\int_{\Omega}\left(\frac{D}{D t}(\rho \mathbf{v})+\operatorname{div}(\mathbf{v}) \rho \mathbf{v}\right) d \Omega=\int_{\Omega}\left[\rho \frac{D \mathbf{v}}{D t}+\mathbf{v}\left(\frac{D \rho}{D t}+\operatorname{div}(\mathbf{v}) \rho\right)\right] d \Omega
$$

na qual a última igualdade foi obtida pela regra da cadeia em $\frac{D}{D t}(\rho \mathbf{v})$ e rearranjando os termos. Entretanto, o termo entre parêntesis multiplicando a velocidade é a equação de continuidade provinda da conservação de massa. Assim

$$
\frac{D}{D t} \int_{\Omega} \rho \mathbf{v} d \Omega=\int_{\Omega} \rho \frac{D \mathbf{v}}{D t} d \Omega
$$

Já o termo do lado direito da equação pode ser convertido para uma integral no domínio. Primeiro, utilizando a relação de Cauchy,

$$
\int_{\Gamma} \mathbf{t} d \Gamma=\int_{\Gamma} \mathbf{n} \cdot \boldsymbol{\sigma} d \Gamma \text { ou } \int_{\Gamma} t_{i} d \Gamma=\int_{\Gamma} n_{i} \sigma_{i j} d \Gamma
$$

e utilizando o teorema de Gauss,

$$
\int_{\Gamma} \mathbf{n} \cdot \boldsymbol{\sigma} d \Gamma=\int_{\Omega} \nabla \cdot \boldsymbol{\sigma} d \Omega \text { ou } \int_{\Gamma} n_{i} \sigma_{i j} d \Gamma=\int_{\Omega} \frac{\partial \sigma_{i j}}{\partial x_{i}} d \Omega
$$


e substituindo estas simplificações, temos

$$
\int_{\Omega} \rho \frac{D \mathbf{v}}{D t} d \Omega=\int_{\Omega} \rho \mathbf{b}(\mathbf{x}, t) d \Omega+\int_{\Omega} \nabla \cdot \boldsymbol{\sigma} d \Omega \Rightarrow \int_{\Omega}\left(\rho \frac{D \mathbf{v}}{D t}-\rho \mathbf{b}-\nabla \cdot \boldsymbol{\sigma}\right) d \Omega=0
$$

e como essa igualdade deve ser verdadeira para qualquer subdomínio de $\Omega$, temos

$$
\rho \frac{D \mathbf{v}}{D t}-\rho \mathbf{b}-\nabla \cdot \boldsymbol{\sigma}=0 \Rightarrow \rho \frac{D \mathbf{v}}{D t}=\operatorname{div}(\boldsymbol{\sigma})+\rho \mathbf{b} \text { ou } \rho \frac{D v_{i}}{D t}=\frac{\partial \sigma j i}{x_{j}}+\rho b_{i}
$$

que também pode ser escrita em função de coordenadas eulerianas por

$$
\begin{aligned}
\rho(\mathbf{x}, t)\left(\frac{\partial \mathbf{v}(\mathbf{x}, t)}{\partial t}+(\mathbf{v}(\mathbf{x}, t) \cdot \operatorname{grad}) \mathbf{v}(\mathbf{x}, t)\right) \operatorname{div}(\boldsymbol{\sigma}(\mathbf{x}, t))+\rho \mathbf{b}(\mathbf{x}, t) \\
\text { ou } \rho\left(\frac{\partial v_{i}}{\partial t}+\frac{\partial v_{i}}{\partial x_{j}} v_{j}\right)=\frac{\partial \sigma_{j i}}{\partial x_{j}}+\rho v_{i}
\end{aligned}
$$

Entretanto, se realizarmos o procedimento utilizado para achar a equação de momento de maneira similar, mas usando a densidade inicial $\rho_{0}$ e integrais no domínio de referência $\Omega_{0}$, obtemos o seguinte resultado

$$
\rho_{0} \frac{\partial \mathbf{v}(\mathbf{X}, t)}{\partial t}=\nabla_{0} \cdot \mathbf{P}+\rho_{0} \mathbf{b} \text { ou } \rho_{0} \frac{\partial v_{i}(\mathbf{X}, t)}{\partial t}=\frac{\partial P_{j i}}{\partial X_{j}}+\rho_{0} b_{i}
$$

que é a forma lagrangeana da equação de momento.

Em muitos casos, as cargas são aplicadas muito lentamente e as forças de inércia são, por conseguinte, pequenas e podem ser desprezadas. Neste caso, a aceleração na equação de momento é nula e temos

$$
\nabla \cdot \boldsymbol{\sigma}+\rho \mathbf{b}=0 \text { ou } \frac{\partial \sigma_{j i}}{\partial x_{j}}+\rho b_{i}=0
$$

que é conhecida como a equação de equilíbrio. A descrição lagrangeana da mesma resulta em

$$
\nabla_{0} \cdot \mathbf{P}+\rho_{0} \mathbf{b}=0 \text { ou } \frac{\partial P_{j i}}{\partial X_{j}}+\rho_{0} b_{i}=0
$$

\section{B.6 Conservação de momento angular}

A forma integral da equação de conservação de momento angular é obtida pelo produto cruzado de cada termo com o vetor posição $\mathbf{x}$, originando

$$
\frac{D}{D t} \int_{\Omega} \mathbf{x} \times \rho \mathbf{v}(\mathbf{x}, t) d \Omega=\int_{\Omega} \mathbf{x} \times \rho \mathbf{b}(\mathbf{x}, t) d \Omega+\int_{\Gamma} \mathbf{x} \times \mathbf{t}(\mathbf{x}, t) d \Gamma
$$


e, sendo o produto cruzado $\mathbf{a} \times \mathbf{b}=e_{i j k} a_{j} b_{k}$, podemos reescrever na forma indicial com a ajuda da equação de Cauchy

$$
\int_{\Omega} \rho e_{i j k} x_{j} a_{k} d \Omega=\int_{\Omega} \rho e_{i j k} x_{j} b_{k} d \Omega+\int_{\Gamma} e_{i j k} x_{j} n_{m} \sigma_{m k} d \Gamma
$$

e com a partir do teorema de Gauss e regra da cadeia, temos

$$
\int_{\Gamma} e_{i j k} x_{j} n_{m} \sigma_{m k} d \Gamma=\int_{\Omega} e_{i j k} \frac{\partial\left(x_{j} \sigma_{m k}\right)}{\partial x_{m}} d \Omega=\int_{\Omega} e_{i j k}\left(\sigma_{j k}+x_{j} \frac{\partial \sigma_{m k}}{\partial x_{m}}\right) d \Omega
$$

uma vez que $\frac{\partial x_{j}}{\partial x_{m}}=\delta_{j m}$ e $\delta_{j m} \sigma_{m k}=\sigma_{j k}$.

Como essa igualdade deve ser verdadeira para qualquer subdomínio de $\Omega$, temos

$$
\begin{aligned}
& \rho e_{i j k} x_{j} a_{k}=\rho e_{i j k} x_{j} b_{k}+e_{i j k}\left(\sigma_{j k}+x_{j} \frac{\partial \sigma_{m k}}{\partial x_{m}}\right) \Rightarrow \\
& \Rightarrow e_{i j k}\left[\sigma_{j k}+x_{j}\left(\frac{\partial \sigma_{m k}}{\partial x_{m}}+\rho b_{k}-\rho a_{k}\right)\right]=0
\end{aligned}
$$

e como o que está entre parênteses é nulo pois equivale a equação de momento, temos que

$$
e_{i j k} \sigma_{j k}=0 \Rightarrow \sigma_{j k}=\sigma_{k j} \text { ou } \boldsymbol{\sigma}=\boldsymbol{\sigma}^{T}
$$

sendo então tensor de tensões de Cauchy simétrico, como havia sido constatado anteriormente. Desta relação, podemos obter

$$
\boldsymbol{\sigma}=\boldsymbol{\sigma}^{T} \Rightarrow J^{-1} \mathbf{F} \cdot \mathbf{P}=\left(J^{-1} \mathbf{F} \cdot \mathbf{P}\right)^{T} \Rightarrow \mathbf{F} \cdot \mathbf{P}=\mathbf{P}^{T} \cdot \mathbf{F}^{T} \text { ou } F_{i k} P_{k j}=P_{i k} F_{k j}
$$

ou ainda

$$
\left.\begin{array}{r}
\mathbf{F} \cdot \mathbf{P}=\mathbf{P}^{T} \cdot \mathbf{F}^{T} \\
\mathbf{P}=\mathbf{S} \cdot \mathbf{F}^{T}
\end{array}\right\} \Rightarrow \mathbf{F} \cdot \mathbf{S} \cdot \mathbf{F}^{T}=\mathbf{F} \cdot \mathbf{S}^{T} \cdot \mathbf{F}^{T} \Rightarrow \mathbf{S}=\mathbf{S}^{T}
$$

\section{B.7 Conservação de energia}

Em um processo termomecânico, a conservação de energia consiste em

$$
\mathcal{P}^{\text {tot }}=\mathcal{P}^{\text {ext }}+\mathcal{P}^{\text {calor }}
$$

ou seja, a taxa de variação de energia total de um corpo (energia interna mais cinética) é igual a taxa de trabalho realizado por forças externas somada as taxas de trabalho 
provindas do fluxo de calor e fontes de energia. Esta é conhecida como a primeira lei da Termodinâmica.

A taxa de variação da energia total do corpo consiste em

$$
\mathcal{P}^{\text {tot }}=\mathcal{P}^{\text {int }}+\mathcal{P}^{\text {cin }} \text { sendo } \mathcal{P}^{\text {int }}=\frac{D}{D t} \int_{\Omega} \rho w^{\text {int }} d \Omega \text { e } \mathcal{P}^{\text {cin }}=\frac{D}{D t} \int_{\Omega} \frac{1}{2} \rho \mathbf{v} \cdot \mathbf{v} d \Omega
$$

sendo $\mathcal{P}^{\text {int }}$ a taxa de variação da energia interna, $\mathcal{P}^{\text {cin }}$ a taxa de variação da energia cinética, $w^{\text {int }}$ a energia interna por unidade de massa e $\rho w^{\text {int }}$ a energia interna por unidade de volume. A disposição da energia interna depende do material. Em um material elástico, toda energia é armazenada como energia interna elástica e é completamente recuperável com o descarregamento. Já em materiais elasto-plásticos, parte da energia interna é convertida em calor e parte é dissipada em mudanças na estrutura interna do material.

A taxa de variação da energia devido ao trabalho externo é dada por

$$
\mathcal{P}^{\mathrm{ext}}=\int_{\Omega} \mathbf{v} \cdot \rho \mathbf{b} d \Omega+\int_{\Gamma} \mathbf{v} \cdot \mathbf{t} d \Gamma=\int_{\Omega} \rho v_{i} b_{i} d \Omega+\int_{\Gamma} v_{i} t_{i} d \Gamma
$$

consistindo no trabalho das forças de corpo b no domínio $\Omega$ e das forças de tração $\mathbf{t}$ na superfície $\Gamma$.

Já a potência abastecida pelas fontes de calor s e pelo fluxo de calor por área na forma de um vetor, q, é dada por

$$
\mathcal{P}^{\text {calor }}=\int_{\Omega} \rho s d \Omega-\int_{\Gamma} \mathbf{n} \cdot \mathbf{q} d \Gamma=\int_{\Omega} \rho s d \Omega-\int_{\Gamma} n_{i} q_{i} d \Gamma
$$

sendo o sinal do termo do fluxo de calor é negativa uma vez que um fluxo de calor para fora do corpo é considerado positivo.

Assim, podemos escrever a conservação de energia por

$$
\frac{D}{D t} \int_{\Omega}\left(\rho w^{i n t}+\frac{1}{2} \rho \mathbf{v} \cdot \mathbf{v}\right) d \Omega=\int_{\Omega} \mathbf{v} \cdot \rho \mathbf{b} d \Omega+\int_{\Gamma} \mathbf{v} \cdot \mathbf{t} d \Gamma+\int_{\Omega} \rho s d \Omega-\int_{\Gamma} \mathbf{n} \cdot \mathbf{q} d \Gamma
$$

Considerando o lado esquerdo da equação e aplicando o teorema de Reynold's, temos

$$
\begin{aligned}
\frac{D}{D t} \int_{\Omega}\left(\rho w^{i n t}+\frac{1}{2} \rho \mathbf{v} \cdot \mathbf{v}\right) d \Omega=\int_{\Omega}\left(\rho \frac{D w^{i n t}}{D t}+\right. & \left.\frac{1}{2} \rho \frac{D(\mathbf{v} \cdot \mathbf{v})}{D t}\right) d \Omega= \\
& =\int_{\Omega}\left(\rho \frac{D w^{i n t}}{D t}+\rho \mathbf{v} \cdot \frac{D(\mathbf{v})}{D t}\right) d \Omega
\end{aligned}
$$


e considerando agora o lado direito da equação e aplicando a lei de Cauchy, temos

$$
\int_{\Gamma} \mathbf{v} \cdot \mathbf{t} d \Gamma=\int_{\Gamma} \mathbf{n} \cdot \boldsymbol{\sigma} \cdot \mathbf{v} d \Gamma
$$

e aplicando o teorema de Gauss na equação acima e na equação que considera o fluxo de calor na superfície, temos

$$
\begin{aligned}
\int_{\Gamma} \mathbf{n} \cdot \boldsymbol{\sigma} \cdot \mathbf{v} d \Gamma=\int_{\Omega} \nabla \cdot(\boldsymbol{\sigma} \cdot \mathbf{v}) d \Omega & =\int_{\Omega} \frac{\partial\left(\sigma_{j i} v_{i}\right)}{\partial x_{j}} d \Omega=\int_{\Omega}\left(\frac{\partial\left(v_{i}\right)}{\partial x_{j}} \sigma_{j i}+v_{i} \frac{\partial\left(\sigma_{j i}\right)}{\partial x_{j}}\right) d \Omega= \\
& =\int_{\Omega}\left(L_{j i} \sigma_{j i}+v_{i} \frac{\partial\left(\sigma_{j i}\right)}{\partial x_{j}}\right) d \Omega=\int_{\Omega}\left(D_{j i} \sigma_{j i}+W_{j i} \sigma_{j i}+v_{i} \frac{\partial\left(\sigma_{j i}\right)}{\partial x_{j}}\right) d \Omega= \\
\boldsymbol{\sigma}=\boldsymbol{\sigma}^{T} \mathrm{e} \mathbf{W}=-\mathbf{W}^{T} \Rightarrow & =\int_{\Omega}\left(D_{j i} \sigma_{j i}+v_{i} \frac{\partial\left(\sigma_{j i}\right)}{\partial x_{j}}\right) d \Omega= \\
& =\int_{\Omega}(\mathbf{D}: \boldsymbol{\sigma}+(\nabla \cdot \boldsymbol{\sigma}) \cdot \mathbf{v}) d \Omega
\end{aligned}
$$

$\mathrm{e}$

$$
\int_{\Gamma} \mathbf{n} \cdot \mathbf{q} d \Gamma=\int_{\Omega} \nabla \cdot \mathbf{q} d \Omega
$$

originando

$$
\int_{\Omega}\left(\rho \frac{D w^{i n t}}{D t}+\rho \mathbf{v} \cdot \frac{D(\mathbf{v})}{D t}-\mathbf{v} \cdot \rho \mathbf{b}-\rho s-\mathbf{D}: \boldsymbol{\sigma}+(\nabla \cdot \boldsymbol{\sigma}) \cdot \mathbf{v}+\nabla \cdot \mathbf{q}\right) d \Omega=0
$$

e, rearranjando os termos,

$$
\int_{\Omega}\left(\rho \frac{D w^{i n t}}{D t}-\mathbf{D}: \boldsymbol{\sigma}+\nabla \cdot \mathbf{q}-\rho s+\mathbf{v} \cdot\left(\rho \frac{D(\mathbf{v})}{D t}-(\nabla \cdot \boldsymbol{\sigma})-\rho \mathbf{b}\right)\right) d \Omega=0
$$

cujo termo em parênteses é a equação de conservação de momento. Como essa igualdade deve ser verdadeira para qualquer subdomínio de $\Omega$, temos

$$
\rho \frac{D w^{i n t}}{D t}+\mathbf{D}: \boldsymbol{\sigma}-\nabla \cdot \mathbf{q}+\rho s
$$

que é a equação diferencial parcial de conservação de energia. Entretanto, se o fluxo de calor e as fontes de calor desaparecem, com em um processo puramente mecânico, a equação de energia se torna

$$
\rho \frac{D w^{i n t}}{D t}+\mathbf{D}: \boldsymbol{\sigma}=\boldsymbol{\sigma}: \mathbf{D}=\sigma_{i j} D_{i j}
$$

definindo a taxa de variação de energia de uma unidade de volume do corpo em termos de medidas de tensão e deformação, dado neste caso pela tensão de Cauchy e a taxa de deformação. Dizemos então que ambos são formam um par conjugado energeticamente. 
Então neste caso no qual não há fluxo de calor ou fontes de calor, a taxa da energia interna do sistema é dada por

$$
\rho \frac{D W^{i n t}}{D t}=\int_{\Omega} \rho \frac{D w^{i n t}}{D t} d \Omega=\int_{\Omega} \mathbf{D}: \boldsymbol{\sigma} d \Omega=\int_{\Omega} \sigma_{i j} D_{i j} d \Omega=\int_{\Omega} \frac{\partial v_{i}}{\partial x_{j}} \sigma_{i j} d \Omega=\mathcal{P}^{\mathrm{def}}
$$

sendo $\mathcal{P}^{\text {def }}$ a potência de deformação.

A potência de deformação pode ainda ser escrita por

$$
\mathcal{P}^{\text {def }}=\int_{\Omega} \boldsymbol{\sigma}: \mathbf{D} d \Omega=\int_{\Omega_{0}} J^{-1} \boldsymbol{\tau}: \mathbf{D} J d \Omega_{0}=\int_{\Omega_{0}} \boldsymbol{\tau}: \mathbf{D} d \Omega_{0}
$$

sendo então o tensor de tensões de Kirchhoff e a taxa de deformação pares conjungados energeticamente referentes a configuração de referência.

Pode-se encontrar a forma lagrangeana da equação de energia escrevendo as potências em função do domínio inicial $\Omega_{0}$ na configuração de referência e realizando os procedimentos equivalentes a descrição anterior. Obtém-se então

$$
\int_{\Omega_{0}}\left(\rho_{0} \frac{\partial w^{i n t}}{\partial t}-\frac{\partial \mathbf{F}^{T}}{\partial t}: \mathbf{P}+\nabla_{0} \cdot \widetilde{\mathbf{q}}-\rho_{0} s+\left(\rho_{0} \frac{\partial \mathbf{v}(\mathbf{X}, t)}{\partial t}-\left(\nabla_{0} \cdot \mathbf{P}\right)-\rho_{0} \mathbf{b}\right) \cdot \mathbf{v}\right) d \Omega_{0}=0
$$

cujo termo em parênteses é a equação de conservação de momento na forma lagrangeana. Como essa igualdade deve ser verdadeira para qualquer subdomínio de $\Omega_{0}$, temos

$$
\rho_{0} \dot{w}^{i n t}=\rho_{0} \frac{\partial w^{i n t}(\mathbf{X}, t)}{\partial t}=\dot{\mathbf{F}}^{T}: \mathbf{P}-\nabla_{0} \cdot \widetilde{\mathbf{q}}+\rho_{0} s
$$

que é a equação diferencial parcial de conservação de energia em sua forma lagrangeana. Entretanto, se o fluxo de calor e as fontes de calor desaparecem, com em um processo puramente mecânico, a equação de energia se torna

$$
\rho_{0} \dot{w}^{i n t}=\dot{\mathbf{F}}^{T}: \mathbf{P}=\mathbf{P}: \dot{\mathbf{F}}^{T}=\dot{F}_{j i} P_{i j}
$$

e podemos definir que

$$
\mathcal{P}^{\text {def }}=\int_{\Omega_{0}} \dot{\mathbf{F}}^{T}: \mathbf{P} d \Omega_{0}
$$

sendo o tensor de tensões nominal o par conjugado energético da derivada material no tempo do gradiente de deformações.

Por fim, pode-se desenvolver $\dot{\mathbf{F}}^{T}: \mathbf{P}$, sendo

$$
\dot{\mathbf{F}}^{T}: \mathbf{P}=\dot{F}_{i k} P_{k i}=\dot{F}_{i k} S_{k r} F_{r i}^{T}
$$


e por causa da simetria de $\mathbf{S}$, podemos definir

$$
\dot{F}_{i k} S_{k r} F_{r i}^{T}=F_{r i}^{T} \dot{F}_{i k} S_{k r}=\left(\mathbf{F}^{T} \cdot \dot{\mathbf{F}}\right): \mathbf{S}
$$

mas, decompondo $\mathbf{F}^{T} \cdot \dot{\mathbf{F}}$ em suas partes simétrica e anti-simétrica

$$
\left(\mathbf{F}^{T} \cdot \dot{\mathbf{F}}\right): \mathbf{S}=\left(\frac{1}{2}\left(\mathbf{F}^{T} \cdot \dot{\mathbf{F}}+\mathbf{F} \cdot \dot{\mathbf{F}}^{T}\right)+\frac{1}{2}\left(\mathbf{F}^{T} \cdot \dot{\mathbf{F}}-\mathbf{F} \cdot \dot{\mathbf{F}}^{T}\right)\right): \mathbf{S}
$$

e uma vez que a contração de um tensor simétrico e um tensor anti-simétrico é nula, temos que

$$
\left(\frac{1}{2}\left(\mathbf{F}^{T} \cdot \dot{\mathbf{F}}+\mathbf{F} \cdot \dot{\mathbf{F}}^{T}\right)+\frac{1}{2}\left(\mathbf{F}^{T} \cdot \dot{\mathbf{F}}-\mathbf{F} \cdot \dot{\mathbf{F}}^{T}\right)\right): \mathbf{S}=\frac{1}{2}\left(\mathbf{F}^{T} \cdot \dot{\mathbf{F}}+\mathbf{F} \cdot \dot{\mathbf{F}}^{T}\right): \mathbf{S}
$$

que pode ser simplificado pela definição $\dot{\mathbf{E}}=\frac{1}{2}\left(\mathbf{F}^{T} \cdot \dot{\mathbf{F}}+\mathbf{F} \cdot \dot{\mathbf{F}}^{T}\right)$, podemos concluir que

$$
\rho_{0} \dot{w}^{i n t}=\dot{\mathbf{E}}: \mathbf{S}=\mathbf{S}: \dot{\mathbf{E}}=\dot{E}_{i j} S_{i j}
$$

sendo o segundo tensor de tensões Piola-Kirchhoff o par conjugado energético da taxa de deformações de Green-Lagrange. 


\section{Apêndice C}

\section{DIC - Correlação de imagens digitais}

\section{C.0.1 introdução}

Considere uma imagem digital (ou seja, composta de pixels) de referência, com um determinado ponto $A$. Pode-se definir o padrão de correlação como a região dos pixels no entorno de $A$. Considere também uma segunda imagem digital, diferente da imagem de referência por um deslocamento e/ou deformação.

A correlação digital de imagem ou DIC (Digital Image Correlation), em sua definição mais abrangente, consiste em localizar $A$ na segunda imagem através de comparação de padrões de correlação. Em outras palavras, DIC é uma técnica utilizada para se medir campos de deslocamento em uma superfície ao correlacionar a imagens da mesma em diferentes estados.

Além da imagem digital, também são elementos que caracterizam a técnica DIC:

- marcação por meio de depósitos de materiais que não alterem as propriedades mecânicas do material analisado, de modo a ser possível calcular o deslocamento de um determinado ponto. Em análises macromecânicas, como ensaios de tração, é comum a utilização de uma pintura da superfície do corpo de prova com tinta nas cores branca e preta;

- função para cálculo do coeficiente de correlação entre as funções de nível de cinza na figura de referência, $f(x, y)$, e na figura atual, $f^{*}\left(x^{*}, y^{*}\right)$;

- função de interpolação para calcular a distribuição de nível de cinza entre pixels, permitindo melhor a acurácia para um nível de subpixel; 
- funções representativas do campo de deslocamento $u(x, y)$ e $v(x, y)$, sendo utilizadas tanto para a melhora da acurácia em um processo iterativo de mudança de forma e tamanho do padrão de correlação quanto no calculo do gradiente de deformações, possibilitando a obtenção de diversos tipos de tensores de deformação.

Apesar do escopo da tese não ser a implementação de um software de DIC, a codificação do mesmo em um nível básico é importante para a compreensão dos detalhes do método, de modo a melhor calibrar os parâmetros so software comercial 7D, utilizado para tratamento dos dados nos ensaios experimentais neste estudo. Além disso, a implementação também possibilita uma maior confiança nos dados fornecidos pelo programa e melhor aproveitamento dos mesmos. Desta forma, nas subseções seguintes será feito o rastreamento de um ponto em um ensaio de tração, obtenção do campo de deslocamentos e deformações, além da comparação com outras formas de medição de deslocamentos.

\section{C.0.2 marcação da superfície e relação espaço físico por pixel}

Conforme explicitado, o método utiliza a variação de nível de cinza em um conjunto de pixels subsequentes para calcular o deslocamento de um determinado ponto. Quando a superfície analisada não possui naturalmente um padrão possível de ser rastreado por DIC, este é aplicado artificialmente.

Devido ao grande número de aplicações possíveis da técnica, variando entre a aplicação extremas como

- um padrão retangular de ouro de $2,5 \mu \mathrm{m}$ de intervalo em uma área de $2 x 2 \mathrm{~mm}^{2}$ na análise da tensão residual de um aço contendo uma fase de martensita e outra de ferrita após o descarregamento elástico de uma deformação de 1\%, sendo as imagens obtidas por microscopia de varredura eletrônica e tendo por propriedades a resolução de 4000 por 3162 pixels e $0.1 \mu \mathrm{m} /$ pixels [43];

- estudo da iteração entre tuneis e solo no qual o solo é substituído por 150000 pequenos cilindros de $4 \mathrm{~mm}$ de diâmetros e $50 \mathrm{~mm}$ de comprimento, colocados de modo a formar, juntamente com o tunel, uma superfície de 1,5 m de largura por $1 \mathrm{~m}$ de altura, sendo fotografados por uma Kodak Mega Plus de um megapixel de resolução colocada a 15 metros do modelo. Há uma marcação feita a caneta apenas 
no túnel, uma vez q a propria reflexão na face dos cilindros é uma marcação possível de ter a técnica DIC aplicada [64].

Entretanto, na grande maioria dos casos, o padrão é randômicamente aplicado através de tintas pulverizadas sobre a superfície, sendo aplicada primeiro uma camada branca, seguida de uma aplicação com uma distância necessária para se obter apenas pontos esparsos de tinta preta. É de supra importância a realização do teste prontamente após a pintura para que a tinta se deforme com a superfície, uma vez que se esta secar, irá craquelar durante a deformação da mesma.

Não existe uma regra para a pintura da superfície, entretanto [90] criou duas leis empíricas, sendo elas:

- o tamanho médio de um ponto deve ser menor que 20 pixels;

- os níveis de cinza podem variar entre 0 e 255 , mas devem variar entre dois pixels consecutivos.

Há um compromisso entre a dimensão física do padrão, da resolução e zoom (ótico) da foto e da acurácia pretendida. Por exemplo, dada a pintura de uma superfícies com tintas spray, não há sentido em utilizar-se de técnicas óticas para aumentar a relação pixels por metros e obter mais de 50 pixels em um ponto preto no padrão randômico. Neste caso, para se obter uma maior acurácia nos resultados, seriam necessários outros métodos de aplicação do padrão em conjunto com as técnicas óticas, sendo um exemplo utilizar-se de um pó fino preto aplicado sobre a pintura branca.
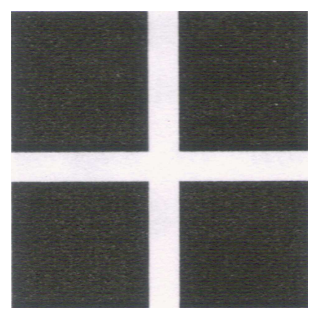

(a) Grade

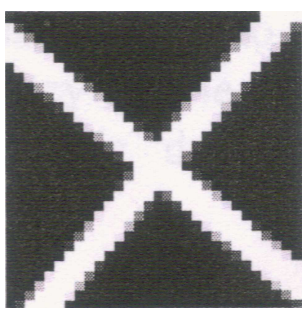

(b) Grade rotacionada

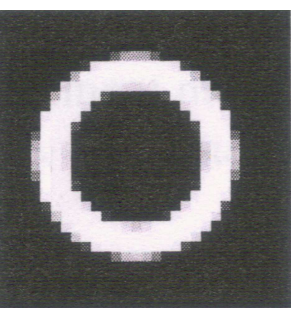

(c) Círculo

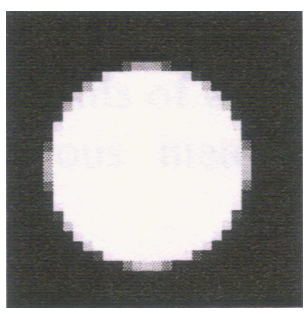

(d) Disco

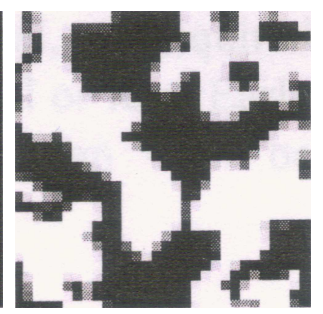

(e) Randômico

Figura C.1: Padrões de correlação gerados para análise comparativa de acurácia em deslocamento.

Em uma análise sobre a acurácia em pixels da técnica DIC, pode-se destacar o trabalho de Doumalin e Bornert [43], no qual os padrões demonstrados na fig. C.1 foram translada- 
dos em intervalos de 0.05 pixels até uma pixel de deslocamento, sendo as diferenças entre os resultados de deslocamentos estimado e imposto foram analisados estatisticamente e o resultado apresentado na tabela C.0.2, com o padrão randômico tendo o melhor resultado. Segundo os autores, este desempenho superior se deve a maior quantidade de pixels entre o branco e o preto, diminuindo a brusquidão e melhorando o resultado de correlação já que a função de interpolação entre pixels é mais próxima da realidade.

\begin{tabular}{lccccc}
\hline Padrão & Grade & Grade rotacionada & Círculo & Disco & Randômico \\
\hline Desvio padrão & 0.0545 & 0.0221 & 0.014 & 0.0196 & 0.0140 \\
\hline Erro máximo & 0.118 & 0.0346 & 0.0285 & 0.0379 & 0.0253 \\
\hline
\end{tabular}

Tabela C.1: Desvio padrão e erro máximo, retirada de [43]

\section{C.0.3 equacionamento}

De modo a apresentar os fundamentos matemáticos da técnica DIC, passando por uma resolução em pixel, resolução em subpixel e o processo iterativo no qual o tamanho e a forma do padrão de correlação mudam, o equacionamento será apresentado durante um exemplo em seu procedimento.

\section{C.0.3.1 Detalhes do teste experimental do exemplo}

O teste escolhido para servir de exemplo e ter o equacionamento apresentado durante respectiva análise é um ensaio experimental de tração realizado em PVC. A geometria em detalhes será apresentada em detalhes na seção 4.1.2, mas basicamente possui secção transversal de $12 \mathrm{~mm}$ de largura por 4 de profundidade e comprimento de aproximadamente $33 \mathrm{~mm}$. Há um pequeno entalhe na largura, de apenas um décimo de profundidade, sendo o suficiente para determinar o local do início do empescoçamento mas não influenciar o valor da tensão.

O teste foi realizado em uma máquina de ensaios universal de frame Dartec e controle Instron, sendo a garra móvel deslocada a uma velocidade de $0.033 \mathrm{~mm} / \mathrm{s}$ e consequentemente obtermos uma taxa de deformação inicial de $10^{-3} \mathrm{~s}^{-1}$. As fotos foram tiradas por uma Canon EOS-1D Mark II com 2336 por 3504 pixels de resolução em formato 'jpg' de 24 bits de profundidade. As 66 fotos foram tiradas em intervalos de 10 segundos e 
nas próximas duas seções serão analisadas as primeiras 10 fotos, sendo os gráficos relacionando sempre a primeira imagem (fig. C.2(a)), ou imagem de referência e a imagem 10 (fig. C.2(b)).
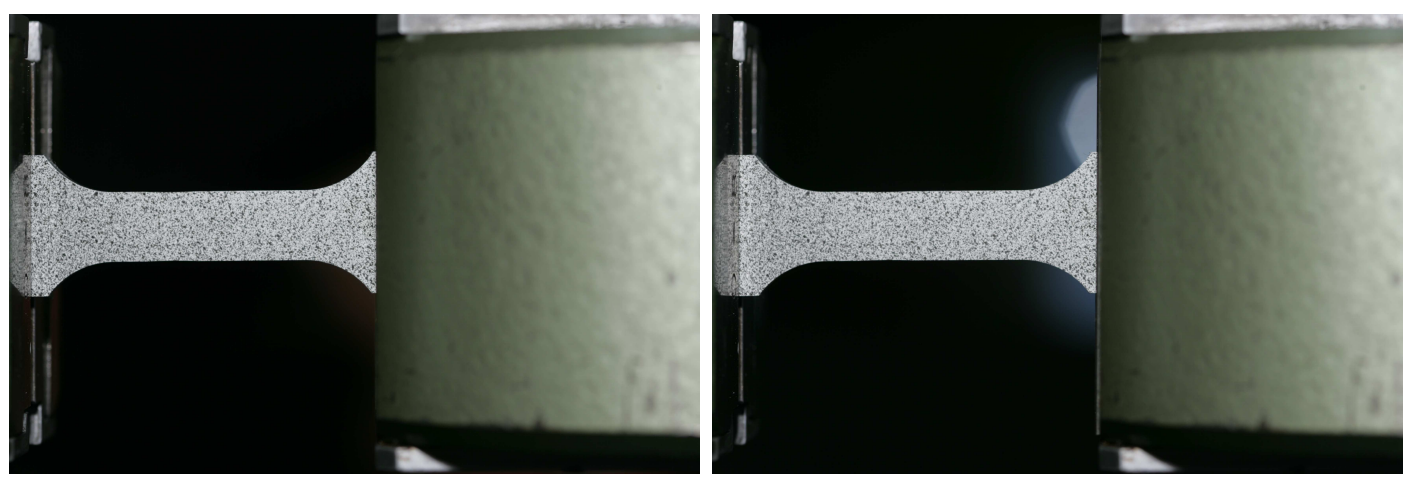

(a) figura de referência obtida antes do teste (b) Décima figura obtida no decorrer do teste, no instante $\mathrm{t}=100 \mathrm{~s}$

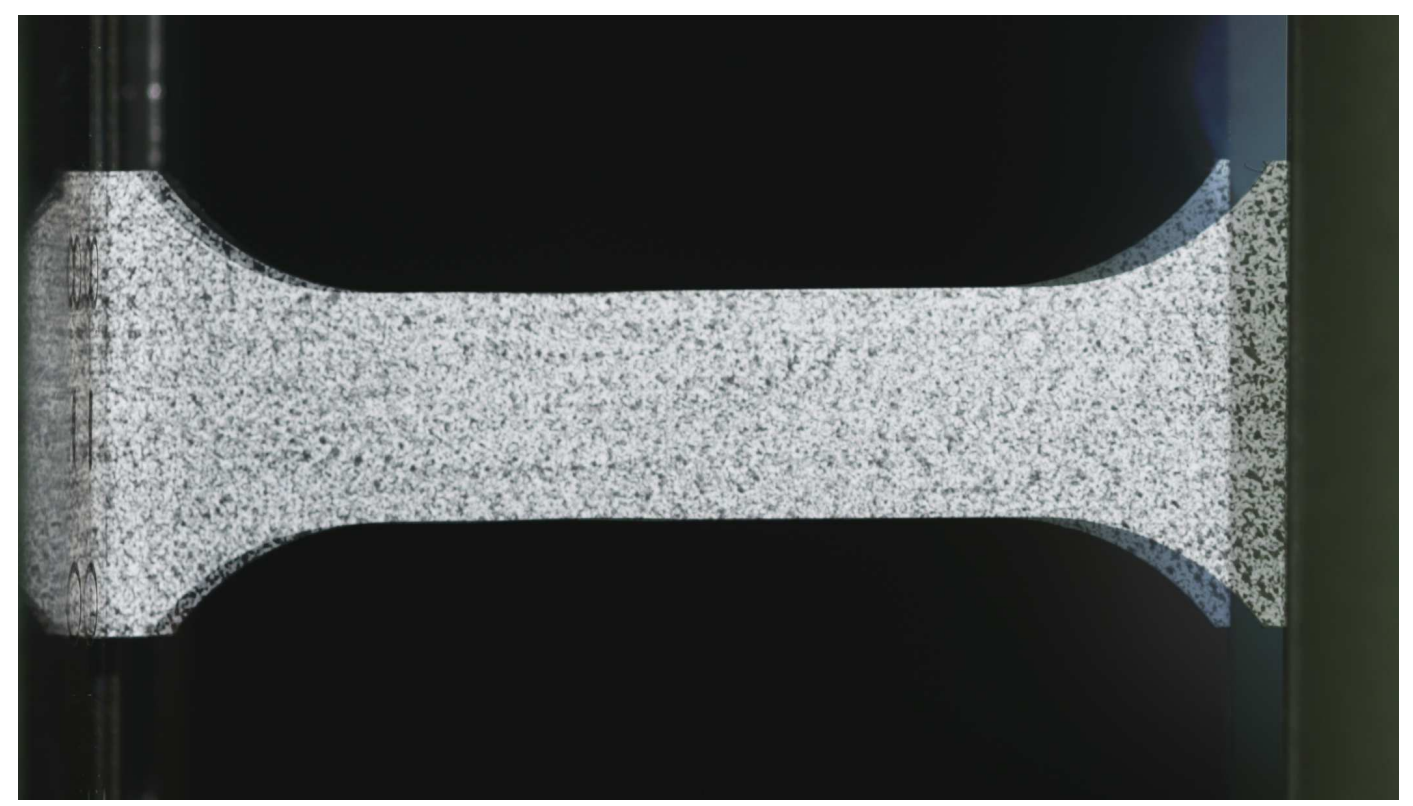

(c) sobreposição das figuras de referência em em t=100 s

Figura C.2: Padrões de correlação gerados para análise comparativa de acurácia em deslocamento.

A figura C.2(c) mostra uma sobreposição de ambas imagem de referência e imagem 10. Um detalhe interessante é a movimentação do corpo de prova em sua extremidade esquerda. Esta acontece devido ao deslocamento das cunhas que compões a garra, até que a força gerada na compressão da extremidade seja o suficiente para existir uma força de atrito suficientemente elevada e evitar o escorregamento, ou seja, quanto mais força é aplicada no sentido de deslizar o corpo de prova para fora da garra, mais forte será 
a compressão da garra e maior será a fixação desta extremidade. Apesar do sistema de garra com cunhas ser eficiente, permite um pequeno deslocamento no início do teste, invalidando por exemplo uma estimativa inicial do módulo elástico ao se usar somente os valores de deslocamento no tempo da garra na direita das figuras C.2.

Por meio da medida manual das posições em pixel da garra móvel das 11 primeiras imagens, foi traçado o gráfico da fig. C.3, e o coeficiente angular da melhor aproximação linear obtida pelo método da soma dos mínimos quadrados determinou uma velocidade de 0.9264 pixels/seg. Assim, pela simples divisão entre as velocidades em mm/s e pixels/s, pode-se obter uma relação estimada de que cada pixel corresponde a $0.0328 \mathrm{~mm}$. Ou seja, uma acurácia de um pixel equivale a aproximadamente três décimos de milímetro. Entretanto, as técnicas aqui apresentadas possuem acurácia de ao menos 1 décimo de pixel, ou seja, aproximadamente 3 milésimos de milimetro neste exemplo.

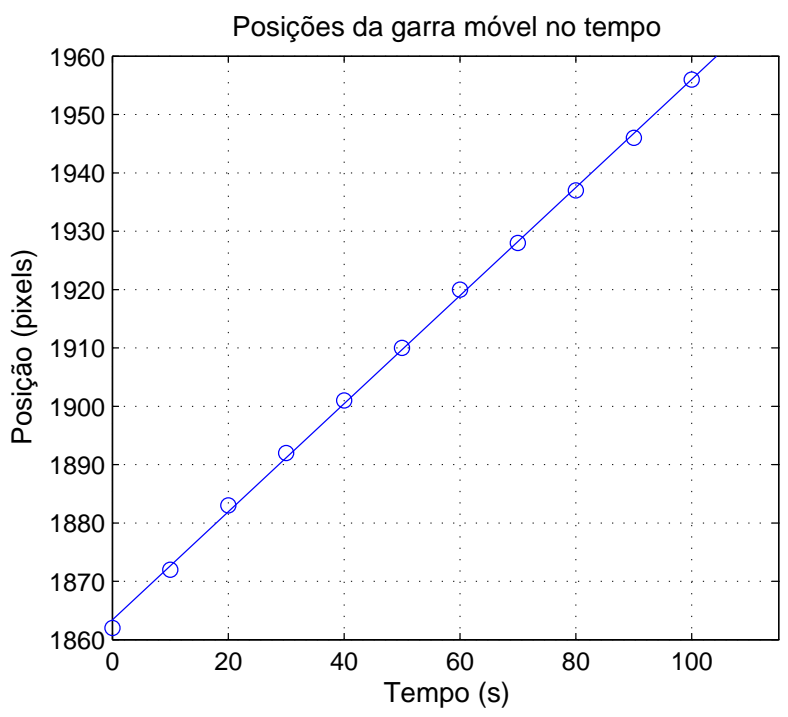

Figura C.3: Posições em pixels da garra móvel no tempo

Conforme explicitado na seção C.0.1, o método DIC consiste em calcular o coeficiente de correlação de uma determinada área, denominada padrão de correlação ao redor do ponto que se deseja descobrir a posição em outra imagem, por meio da função de nível de cinza $f(x, y)$ na imagem de referência e $f^{*}\left(x^{*}, y^{*}\right)$ na outra imagem em questão, repetindo o procedimento entre a imagem de referencia e a terceira, entre a imagem de referência e a quarta e assim por diante. Todo o tratamento dos dados obtidos nos ensaios experimentais desta tese é feito no software comercial Matlab ${ }^{\circledR}$. A função imread(figura.jpg) 
retorna uma matriz na qual cada elemento representa um pixel, de modo que para se descobrir o valor dos pixels uma linha horizontal na figura, basta examinar as diferentes colunas de uma mesma linha da matriz relativa a linha horizontal da figura. Entretanto, o valor de cada elemento é dado por um conjunto de 3 valores digitais com 8 bits de profundidade, referentes as cores vermelha $(R)$, verde $(G)$ e azul $(B)$. É invocada então a função rgb2gray, que converte para nível de cinza discreto $(I)$ (em inteiros de 8 bits) eliminando a tonalidade e a saturação através da fórmula

$$
I=0.2989 R+0.5870 G+0.1140 B
$$

e finalmente o valor é convertido para um inteiro real do tipo ponto flutuante pela função double. O resultado de nível de cinza, que pode variar entre 0 e 255, de toda a imagem de referência está apresentado na fig. C.4(a). Pode-se notar claramente o corpo de prova variando em muito seu valor de cinza devido ao padrão randômico, enquanto o nível de cinza na garra e no fundo possui valores mais constates com pequenas variações entre pixels adjacentes.

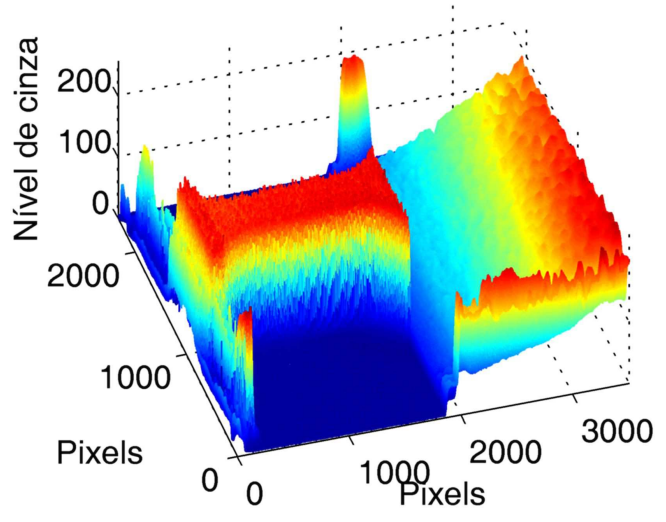

(a) Nível de cinza da imagem de referência

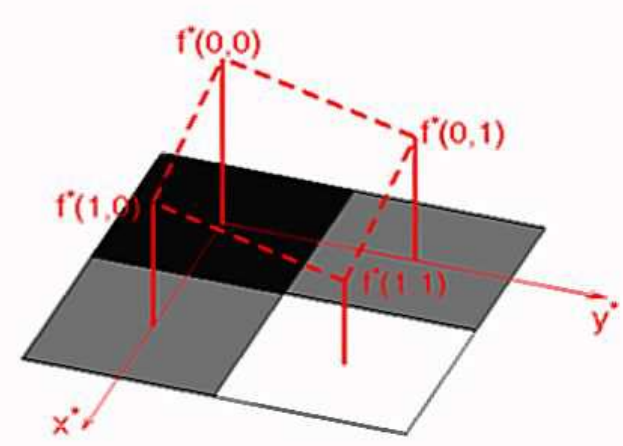

(b) Função de interpolação entre 4 pixels

Para melhorar a acurácia no cálculo, é utilizada uma função de interpolação a cada 4 pixels adjacentes, com um sistema de coordenadas naturais locais variando entre 0 e 1 , conforme a fig. C.4(b). Esta pode ser bilinear ou bicúbica, sendo que este segundo tipo facilita a localização do mínimo global na superfície de correlação ao deixa-la sem ruídos mas em compensação possui maior custo computacional. Para o carácter ilustrativo desta secção, utilizaremos a interpolação bilinear na imagem de referência descrita por

$$
f(x, y)=\alpha x+\beta y+\gamma x y+\lambda
$$


sendo possível calcular estas 4 constantes diretamente a partir dos valores dos 4 pixels por

$$
\begin{aligned}
& \alpha=f(1,0)-f(0,0) \\
& \beta=f(0,1)-f(0,0) \\
& \gamma=f(1,1)+f(0,0)-f(1,0)-f(1,0) \\
& \lambda=f(0,0)
\end{aligned}
$$

e na imagem atual temos que a função nível de cinza é dada por

$$
f^{*}\left(x^{*}, y^{*}\right)=f^{*}[x+u(x, y), y+v(x, y)]=\alpha x^{*}+\beta y^{*}+\gamma x^{*} y^{*}+\lambda
$$

com $u(x, y)$ e $v(x, y)$ compondo os campos de deslocamentos em $x$ e $y$ respectivamente. De maneira análoga, temos

$$
\begin{aligned}
& \alpha=f^{*}(1,0)-f^{*}(0,0) \\
& \beta=f^{*}(0,1)-f^{*}(0,0) \\
& \gamma=f^{*}(1,1)+f^{*}(0,0)-f^{*}(1,0)-f^{*}(1,0) \\
& \lambda=f^{*}(0,0)
\end{aligned}
$$

\section{C.0.3.2 resolução em pixels}

A figura C.4(c) mostra de maneira ampliada o corpo de prova. Apesar de sutil, é possível notar o entalhe de 1 décimo de milímetro na secção transversal posicionada em $x=800$ pixels. Já a linha horizontal que divide o corpo de prova ao meio está localizada aproximadamente em $y=1079$ pixels. Considerando o ponto $(800,1074)$ como o centro de um elemento quadrado de 50 pixels de lado, obtemos os pontos $(775,1054)$, $(825,1054)$, $(775,1104)$ e $(825,1104)$. A partir da localização destes quatro pontos na imagens subsequentes, determina-se o elemento em cada uma delas. A deformação deste elemento pode ser calculada a partir dos deslocamentos dos pontos por aproximações exatamente como no método dos elementos finitos. Na figura C.4(c) estão marcados o ponto $(775,1054)$ e o padrão de correlação em torno deste ponto, de 44 pixels de lado, demarcado pela região azul translúcida.

As figuras C.4(d) e C.4(e) mostram em detalhes a imagem do padrão de correlação ao redor do ponto $(775,1054)$ e sua superfície de nível de cinza, respectivamente. O processo de localizar este determinado ponto na outras imagens do teste consiste basicamente em:

1. Delimitar uma provável região no qual o ponto se encontrará, de modo a diminuir o custo computacional do processo como um todo; 


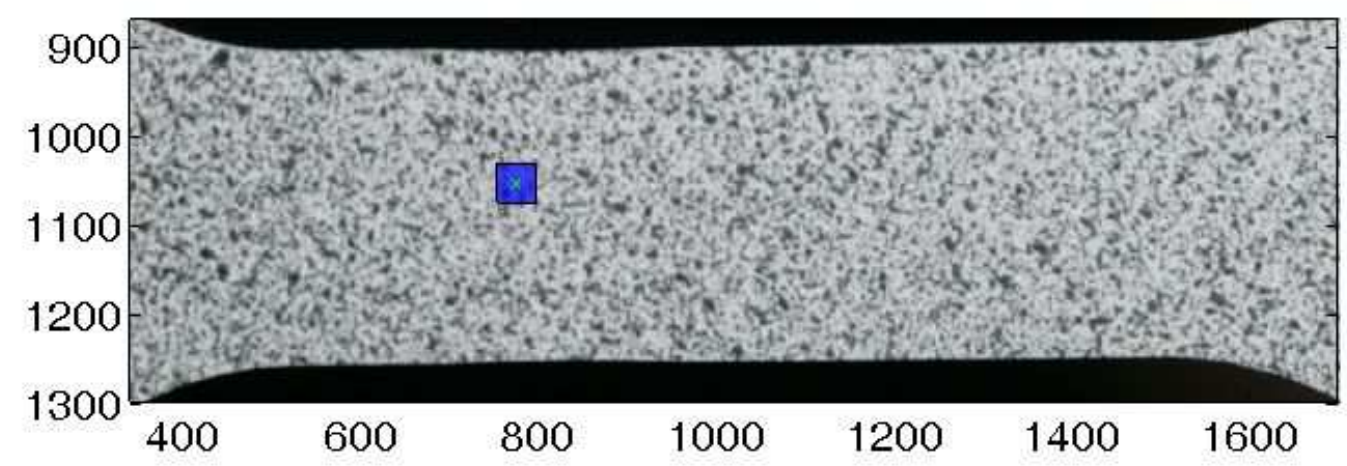

(c) corpo de prova com ponto a ser localizado e padrão de correlação em azul
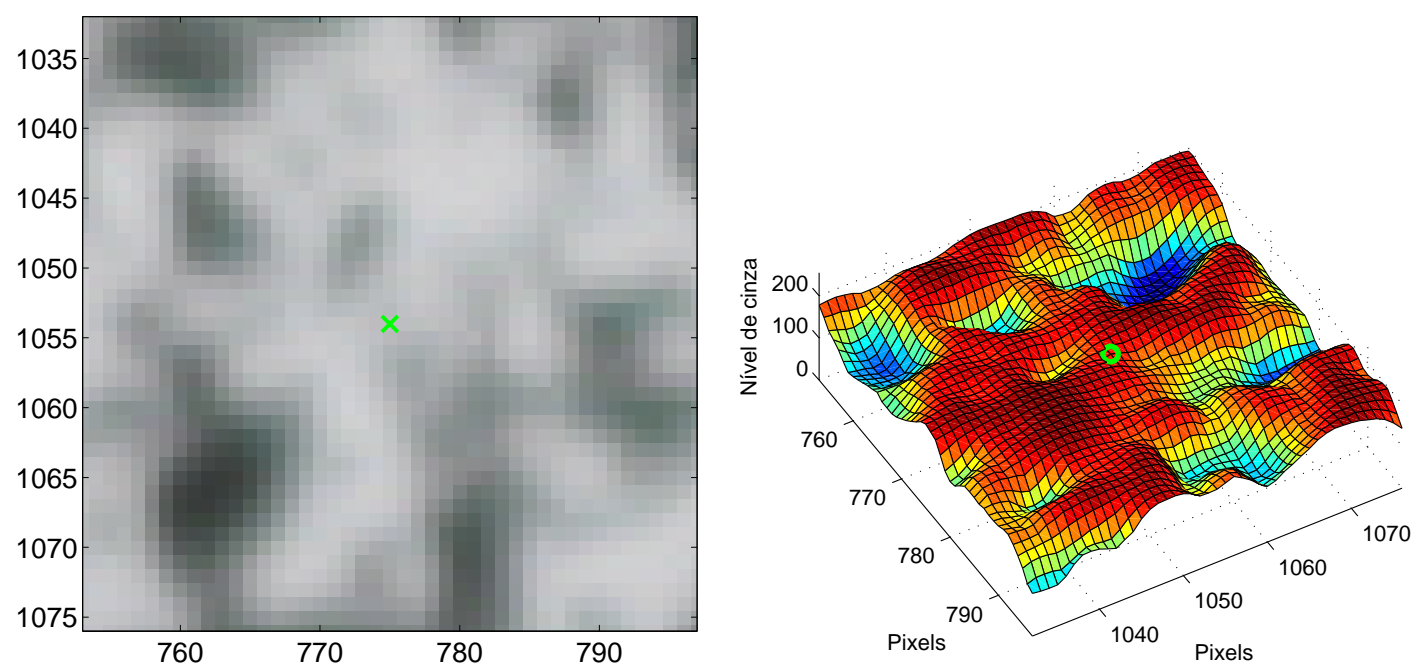

(d) zoom em padrão de correlação com ponto (e) valor do nível de cinza em padrão de correno centro lação com ponto no centro

Figura C.4: Padrões de correlação gerados para análise comparativa de acurácia em deslocamento.

2. Calcular o coeficiente de correlação entre o ponto na imagem de referência e cada pixel dentro da região previamente delimitada;

3. Determinar o mínimo global da superfície de correlação formada pelo valor de correlação de cada pixel da região delimitada.

e este ponto de mínimo é a posição na imagem do ponto $(775,1054)$ na imagem de referência.

C.0.3.2.1 Delimitando a região de cálculo A análise do movimento da garra móvel no gráfico da figura C.3, indica um deslocamento máximo para a direita de 1 pixels 
por segundo, sendo que então podemos delimitar os limites verticais da esquerda como a posição do ponto na última figura em que foi calculada a nova posição menos um delta e como o limite direito a posição do ponto na última figura mais 10 pixels de deslocamento máximo (10 segundos entre cada foto e 1 pixels por segundo de deslocamento da garra) mais um delta. No caso do limite esquerdo, o delta tem por função possibilitar o cálculo após ruptura do corpo de prova e conseguinte descarregamento elástico ou visco-elástico e no caso do limite direito, além do movimento devido ao descarregamento, o cálculo do coeficiente de correlação nos pixels neste delta facilitam a visualização do vale de mínimo global.

No caso de limites horizontais superior e inferior, uma distância entre ambos com o mesmo valor de pixels que separam os limites esquerdo e direito será suficiente, já que a relação entre deformações na direção do corpo de prova e na direção transversal tem sinais opostos e a deformação transversal é no máximo metade da na direção de movimento da garra.

Entretanto, neste caso exemplo, limites maiores foram adotados apenas para melhor visualização da superfície representativa dos coeficientes de correlação.

C.0.3.2.2 Calculando o coeficiente de correlação De acordo com [64], o coeficiente de correlação pode ser calculado de diversas maneiras, sendo as mais comuns dadas por:

$$
C_{1}=\int_{\Delta S}\left(f(x, y)-f^{*}\left(x^{*}, y^{*}\right)\right)^{2} d x d y
$$

$\mathrm{Ou}$

$$
C_{2}=1-\frac{\int_{\Delta S}\left(f(x, y) \cdot f^{*}\left(x^{*}, y^{*}\right)\right)^{2} d x d y}{\sqrt{\int_{\Delta S}(f(x, y))^{2} d x d y \int_{\Delta S}\left(f^{*}\left(x^{*}, y^{*}\right)\right)^{2} d x d y}}
$$

no qual $\Delta S$ corresponde a área do padrão de correlação.

A integral da equação na área do padrão de correlação pode ser fatorada na soma de integrais de limites $(x, y)$ indo de 0 a 1 para cada pequena área entre os centros de cada 4 pixels adjacentes, de acordo com a função de interpolação bilinear explicada em C.3 eC.5. Como são polinômios, o valor da integral é exata e pode ser determinada em função das oito constantes, quatro da imagem de referência e outras 4 da outra imagem. Este valor foi obtido utilizando as funções de integral e derivadas simbólicas do Matlab ${ }^{\circledR}$, sendo então implementadas e tendo como variáveis de entrada apenas os valores de nível 
de cinza dos 4 pixels adjacentes na imagem de referência e os 4 na imagem na qual se deseja localizar a nova posição do ponto.

C.0.3.2.3 Encontrando o mínimo na superfície de correlação Os resultados do cálculo da superfície de correlação entre a imagem de referência e a imagem 10 estão ilustrados na figura C.5.

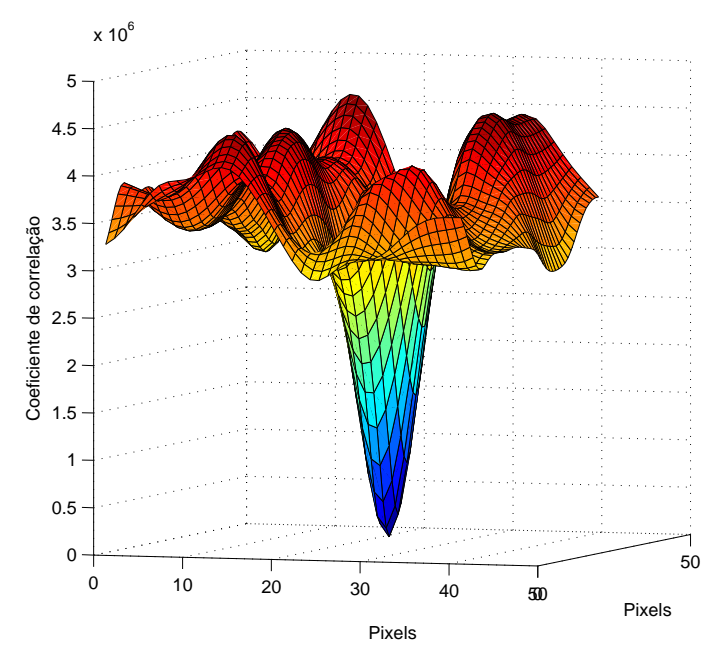

(a) Superfície de correlação entre imagem de referência e imagem 10 obtida utilizando a eq. C.6

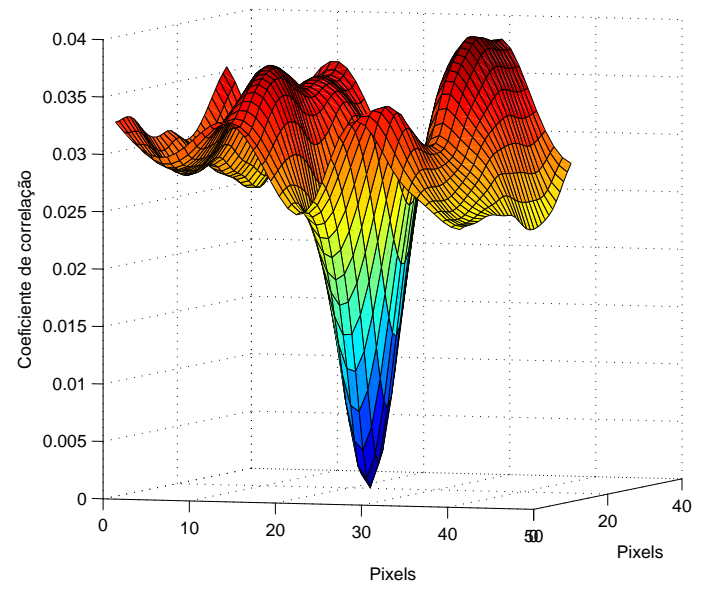

(b) Superfície de correlação entre imagem de referência e imagem 10 obtida utilizando a eq. C.7

Figura C.5: Superfícies de correlação

Ambos gráficos apresentam um mínimo global facilmente identificável e na mesma posição $(827,1052)$. Deste modo, a superfície de nível de cinza do padrão de correlação da imagem 0 e a da imagem 10, de mesmo formato e tamanho que na imagem de referência mas centrada no ponto de mínimo foram construídas com $30 \%$ de transparência e estão representadas na fig. C.6(c), além de suas imagens nas figuras C.6(a), contendo a imagem de referência, e C.6(b), contendo a imagem 10. Apesar de não serem idênticas na intensidade dos pixels, com a imagem de referência mais escura, pode-se afirmar com absoluta certeza que o ponto da imagem de referência foi localizado com precisão na imagem 10.

Apesar das figuras representarem apenas o processo ilustrativo da correlação digital entre as imagens de referência e 10, o procedimento foi aplicado entre a imagem de referência e todas as outras obtidas neste intervalo de 100 segundos e os resultados estão dispostos na tabela C.2. 

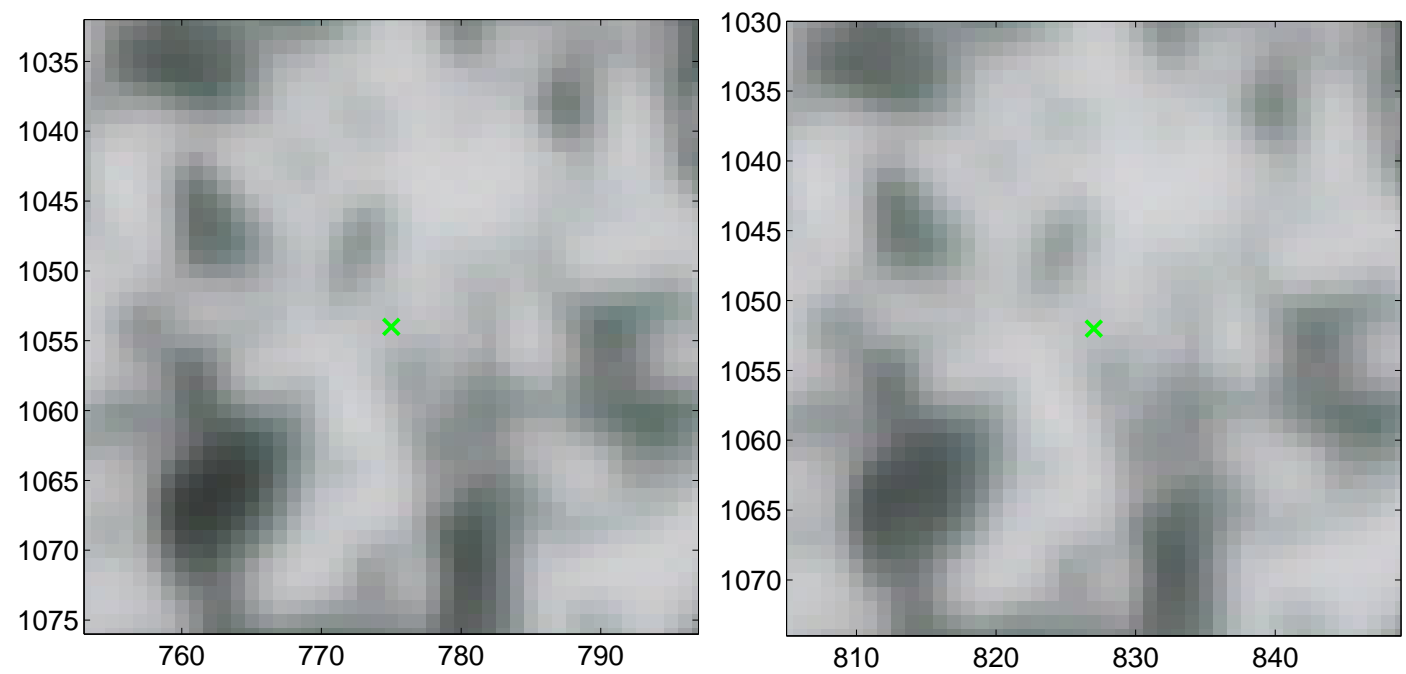

(a) zoom em padrão de correlação com ponto (b) zoom em padrão de correlação com ponto no centro na imagem de referência no centro na imagem 10

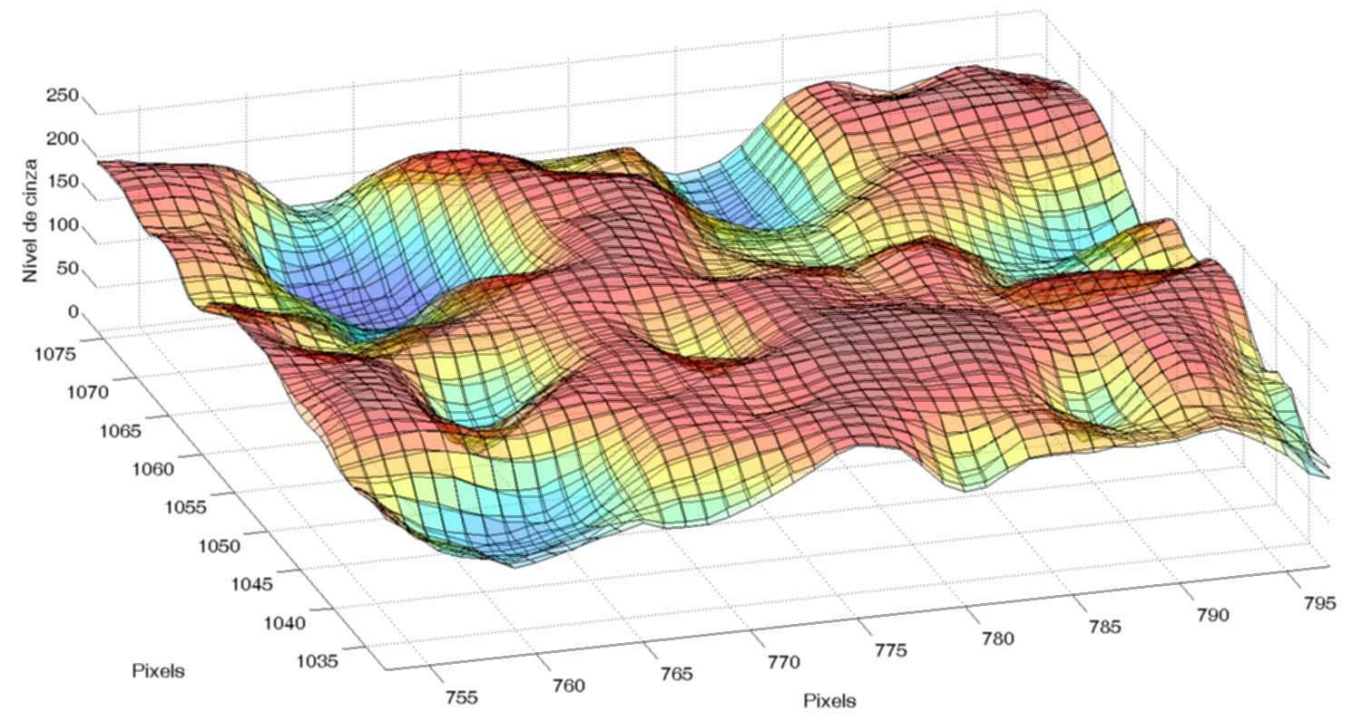

(c) níveis de cinza sobrepostos e com transparência

Figura C.6: Padrão de correlação na imagem de referência, na posição determinada durante o procedimento DIC na imagem 10 e ambas superfícies de nível de cinza sobrepostas.

\section{C.0.3.3 resolução em subpixels}

Apesar de, a partir de uma analise visual entre as figuras C.6(a) e C.6(b), ser possível considerar ter encontrado a localização do ponto demarcado na imagem de referência na imagem 10, ao se observar as superfícies de correlação da figura C.5, nota-se que o mínimo global não se encontra em nenhum dos pontos, mas em uma região entre eles. 
Apêndice C. DIC - Correlação de imagens digitais

\begin{tabular}{cccccccccccc}
\hline \multicolumn{2}{c}{ imagem 0 } & \multicolumn{2}{c}{ imagem 1 } & \multicolumn{2}{c}{ imagem 2 } & \multicolumn{2}{c}{ imagem 3 } & imagem 4 & \multicolumn{2}{r}{ imagem 5} \\
\hline $\mathrm{x}$ & $\mathrm{y}$ & $\mathrm{x}$ & $\mathrm{y}$ & $\mathrm{x}$ & $\mathrm{y}$ & $\mathrm{x}$ & $\mathrm{y}$ & $\mathrm{x}$ & $\mathrm{y}$ & $\mathrm{x}$ & $\mathrm{y}$ \\
\hline 775 & 1054 & 782 & 1053 & 791 & 1051 & 796 & 1049 & 801 & 1049 & 806 & 1049 \\
\hline
\end{tabular}

\begin{tabular}{cccccccccc}
\hline \multicolumn{2}{c}{ imagem 6} & \multicolumn{2}{c}{ imagem 7} & \multicolumn{2}{c}{ imagem 8} & \multicolumn{2}{c}{ imagem 9 } & \multicolumn{2}{c}{ imagem 10} \\
\hline $\mathrm{x}$ & $\mathrm{y}$ & $\mathrm{x}$ & $\mathrm{y}$ & $\mathrm{x}$ & $\mathrm{y}$ & $\mathrm{x}$ & $\mathrm{y}$ & $\mathrm{x}$ & $\mathrm{y}$ \\
\hline 810 & 1050 & 815 & 1051 & 819 & 1051 & 823 & 1052 & 827 & 1052 \\
\hline
\end{tabular}

Tabela C.2: Posição de um determinado ponto nas 11 primeiras fotos, fundo de escala de um pixel

Deste modo, torna-se necessário o desenvolvimento de um procedimento de resolução em subpixel.

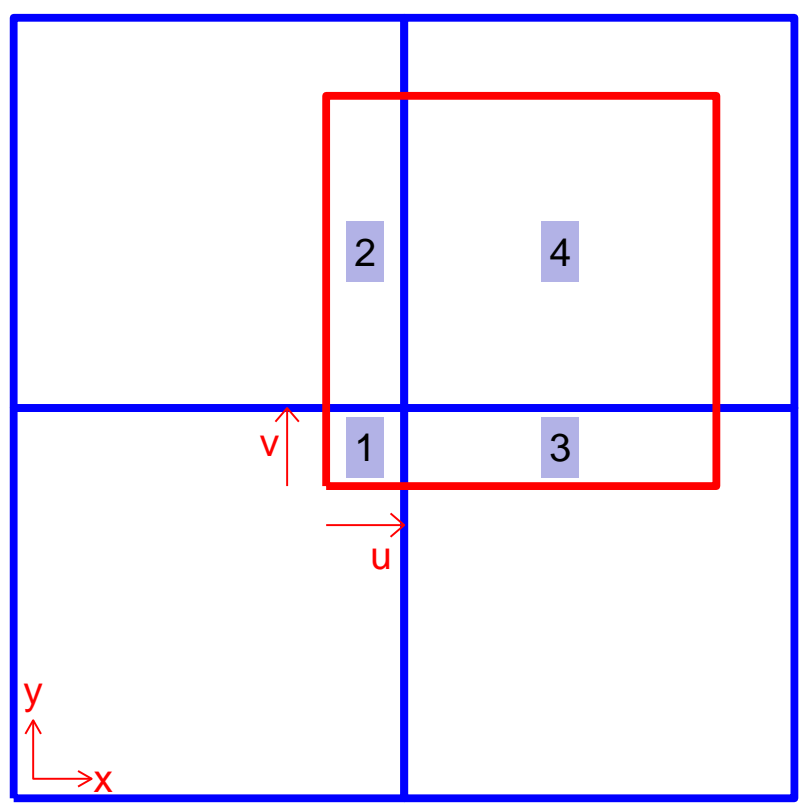

Figura C.7: Áreas definidas para realização das integrais em separado

Para tanto, considere a figura C.7. O quadrado vermelho representa a imagem de referência, sendo cada vértice o centro de um pixel. Para alcançar a resolução em subpixel, a imagem 10, em azul, é deslocada até a coincidência dos vértices e depois deslocada de um valor $u$ em $x$ e $v$ em $y$. A integral realizada em coordenadas naturais neste caso foi 
dividida em 4 parcelas, cada uma representando uma determinada região da figura, sendo

$$
\begin{aligned}
& (1) \rightarrow \int_{0}^{u} \int_{0}^{v} g\left(f(x, y), f^{*}(1+x-u, 1+y-v)\right) d y d x \\
& (2) \rightarrow \int_{0}^{u} \int_{v}^{1} g\left(f(x, y), f^{*}(1+x-u, y-v)\right) d y d x \\
& (3) \rightarrow \int_{u}^{1} \int_{0}^{v} g\left(f(x, y), f^{*}(x-u, 1+y-v)\right) d y d x \\
& (4) \rightarrow \int_{u}^{1} \int_{v}^{1} g\left(f(x, y), f^{*}(x-u, y-v)\right) d y d x
\end{aligned}
$$

com $g\left(f, f^{*}\right)$ sendo a função em C.6 ou C.7. Neste caso, somente foi implementada a correlação por subtração e novamente os valores exatos da mesma em função dos valores em nível de cinza dos 4 pixels da imagem de referência, dos 9 da imagem 10, dos valores de deslocamento em $x$ e $y$, com uma superfície aparentemente contínua, representada na fig. C.8.

Uma nova posição foi localizada então no ponto $(826,7,1052,0)$ e, de maneira análoga ao procedimento com resolução em pixels, as superfícies de nível de cinza do padrão de correlação foram plotadas com transparência na figura C.9, obtendo um resultado ainda melhor do que na figura C.6(c).

E o procedimento foi repetido entre a imagem de referência e todas as outras anteriores ao instante $t=100 \mathrm{~s}$, com os resultados disposto na tabela C.3.

\section{C.0.3.4 cálculo do campo de deslocamento e processo iterativo}

Conforme descrito na seção C.0.3.2, a técnica DIC é utilizada para calcular os deslocamentos e, consequentemente, as novas posições de um elemento quadrilátero, sendo neste exemplo de coordenadas $(775,1054),(825,1054),(775,1104)$ e $(825,1104)$ na imagem de referência e então determinar o campo de deslocamentos possibilitando o cálculo de deformações.

Com este intuito, além do cálculo descrito em detalhes para o ponto $(775,1054)$, também calculou-se as posições dos outros três nas imagens seguintes até a imagem 10, com resolução em pixels e padrão de correlação de 44 pixels de lado, obtendo-se os resultados da tabela C.4. 


\section{$\times 10^{5}$}

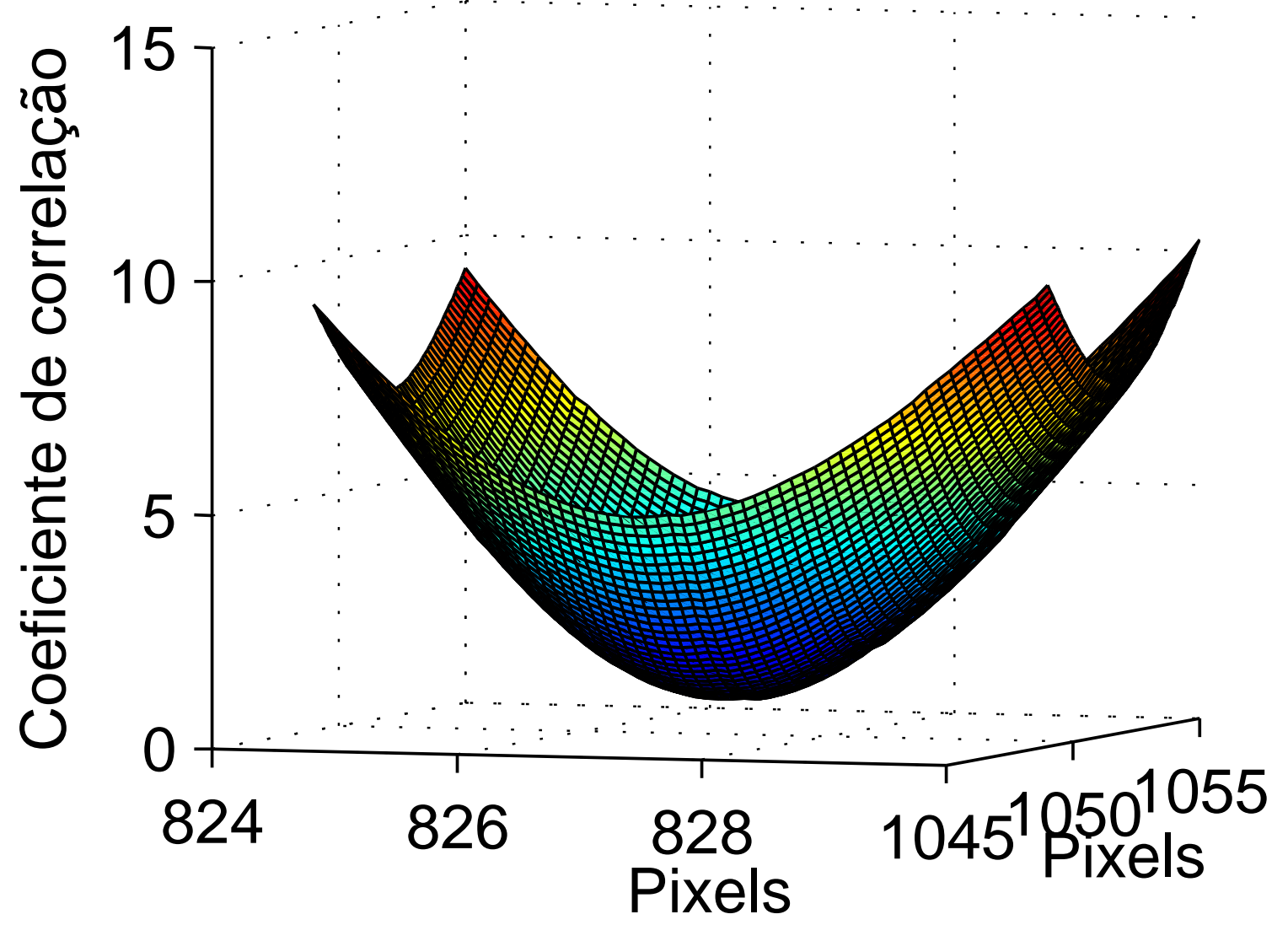

Figura C.8: Coeficiente de correlação calculado para variações de 0.1 pixels

\begin{tabular}{|c|c|c|c|c|c|c|c|c|c|c|c|}
\hline \multicolumn{2}{|c|}{ imagem 0} & \multicolumn{2}{|c|}{ imagem 1} & \multicolumn{2}{|c|}{ imagem 2} & \multicolumn{2}{|c|}{ imagem 3} & \multicolumn{2}{|c|}{ imagem 4} & \multicolumn{2}{|c|}{ imagem 5} \\
\hline $\mathrm{x}$ & $\mathrm{y}$ & $\mathrm{x}$ & $\mathrm{y}$ & $\mathrm{x}$ & $\mathrm{y}$ & $\mathrm{x}$ & $\mathrm{y}$ & $\mathrm{x}$ & $\mathrm{y}$ & $\mathrm{x}$ & $\mathrm{y}$ \\
\hline 775,0 & 1054,0 & 782,2 & 1053,0 & $790,6 \quad 1$ & 1051,3 & 796,0 & 1049,4 & $800,6 \quad 1$ & $1049,0 \quad 8$ & 805,5 & 1049,3 \\
\hline ima & agem 6 & ima & agem 7 & ima & agem 8 & ims & agem 9 & imą & agem 10 & & \\
\hline $\mathrm{x}$ & $\mathrm{y}$ & $\mathrm{x}$ & $\mathrm{y}$ & $\mathrm{x}$ & $\mathrm{y}$ & $\mathrm{x}$ & $\mathrm{y}$ & $\mathrm{x}$ & $\mathrm{y}$ & & \\
\hline 810,3 & 1050,0 & 815,0 & 1050,6 & 819,2 & 1051,3 & 3823,3 & 1051,7 & 826,7 & $7 \quad 1052,0$ & & \\
\hline
\end{tabular}

Tabela C.3: Posição de um determinado ponto nas 11 primeiras fotos, fundo de escala de um décimo de pixel 


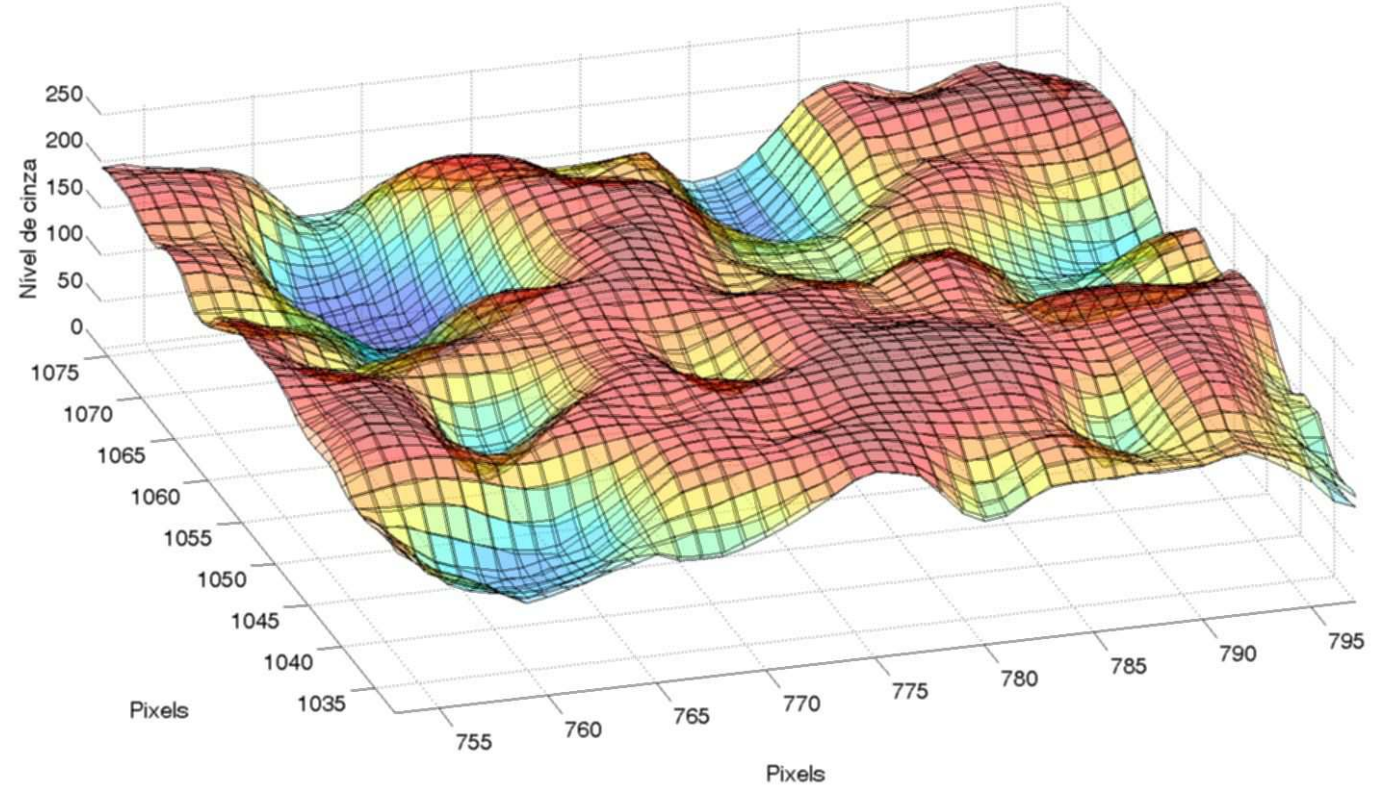

Figura C.9: níveis de cinza sobrepostos e com transparência, relativos a imagem de referência e a imagem 10 na posição de coeficiente de correlação mínimo

\begin{tabular}{ccccccccccccc}
\hline \multicolumn{2}{c}{ imagem 0 } & \multicolumn{2}{c}{ imagem 1 } & \multicolumn{2}{c}{ imagem 2 } & \multicolumn{2}{c}{ imagem 3 } & \multicolumn{2}{c}{ imagem 4 } & \multicolumn{2}{c}{ imagem 5 } \\
\hline $\mathrm{x}$ & $\mathrm{y}$ & $\mathrm{x}$ & $\mathrm{y}$ & $\mathrm{x}$ & $\mathrm{y}$ & $\mathrm{x}$ & $\mathrm{y}$ & $\mathrm{x}$ & $\mathrm{y}$ & $\mathrm{x}$ & $\mathrm{y}$ \\
\hline 775 & 1054 & 782 & 1053 & 791 & 1051 & 796 & 1049 & 801 & 1049 & 806 & 1049 \\
825 & 1054 & 832 & 1053 & 841 & 1051 & 846 & 1049 & 851 & 1049 & 856 & 1049 \\
825 & 1104 & 832 & 1103 & 841 & 1101 & 846 & 1099 & 851 & 1099 & 856 & 1099 \\
775 & 1104 & 782 & 1103 & 791 & 1101 & 796 & 1099 & 801 & 1099 & 806 & 1099 \\
\hline
\end{tabular}

\begin{tabular}{cccccccccc}
\hline \multicolumn{2}{c}{ imagem 6} & \multicolumn{2}{c}{ imagem 7} & \multicolumn{2}{c}{ imagem 8} & \multicolumn{2}{c}{ imagem 9 } & \multicolumn{2}{c}{ imagem 10 } \\
\hline $\mathrm{x}$ & $\mathrm{y}$ & $\mathrm{x}$ & $\mathrm{y}$ & $\mathrm{x}$ & $\mathrm{y}$ & $\mathrm{x}$ & $\mathrm{y}$ & $\mathrm{x}$ & $\mathrm{y}$ \\
\hline 810 & 1050 & 815 & 1051 & 819 & 1051 & 823 & 1052 & 827 & 1052 \\
861 & 1050 & 865 & 1051 & 870 & 1051 & 874 & 1052 & 878 & 1052 \\
861 & 1100 & 865 & 1100 & 870 & 1101 & 874 & 1101 & 878 & 1102 \\
810 & 1100 & 815 & 1100 & 819 & 1101 & 823 & 1101 & 827 & 1102 \\
\hline
\end{tabular}

Tabela C.4: Posição de um determinado ponto nas 11 primeiras fotos, fundo de escala de um décimo de pixel

A partir destes resultados, o procedimento descrito na seção C.0.3.3 foi adotado, vasculhando-se o coeficiente de correlação em uma área de 3 por 3 pixels, centrada nos resultados do procedimento anterior, obtendo os valores da tabela C.5. 
Apêndice C. DIC - Correlação de imagens digitais

\begin{tabular}{ccccccccccccc}
\hline \multicolumn{2}{c}{ imagem 0 } & \multicolumn{2}{c}{ imagem 1 } & \multicolumn{2}{c}{ imagem 2 } & \multicolumn{2}{c}{ imagem 3 } & \multicolumn{2}{c}{ imagem 4 } & \multicolumn{2}{c}{ imagem 5 } \\
\hline $\mathrm{x}$ & $\mathrm{y}$ & $\mathrm{x}$ & $\mathrm{y}$ & $\mathrm{x}$ & $\mathrm{y}$ & $\mathrm{x}$ & $\mathrm{y}$ & $\mathrm{x}$ & $\mathrm{y}$ & $\mathrm{x}$ & $\mathrm{y}$ \\
\hline 775,0 & 1054,0 & 782,2 & 1053,0 & 790,6 & 1051,3 & 796,0 & 1049,4 & 800,6 & 1049,0 & 805,5 & 1049,3 \\
825,0 & 1054,0 & 832,2 & 1053,0 & 840,6 & 1051,2 & 846,0 & 1049,3 & 851,0 & 1049,0 & 856,0 & 1049,2 \\
825,0 & 1104,0 & 832,2 & 1103,0 & 840,7 & 1101,2 & 846,0 & 1099,3 & 851,0 & 1098,7 & 856,0 & 1099,1 \\
775,0 & 1104,0 & 782,2 & 1103,0 & 790,6 & 1101,2 & 796,0 & 1099,4 & 800,7 & 1099,0 & 805,6 & 1099,1 \\
\hline
\end{tabular}

\begin{tabular}{cccccccccc}
\hline \multicolumn{2}{c}{ imagem 6} & \multicolumn{2}{c}{ imagem 7} & \multicolumn{2}{c}{ imagem 8} & \multicolumn{2}{c}{ imagem 9} & \multicolumn{2}{c}{ imagem 10} \\
\hline $\mathrm{x}$ & $\mathrm{y}$ & $\mathrm{x}$ & $\mathrm{y}$ & $\mathrm{x}$ & $\mathrm{y}$ & $\mathrm{x}$ & $\mathrm{y}$ & $\mathrm{x}$ & $\mathrm{y}$ \\
\hline 810,3 & 1050,0 & 815,0 & 1050,6 & 819,2 & 1051,3 & 823,3 & 1051,7 & 826,7 & 1052,0 \\
860,7 & 1050,0 & 865,4 & 1050,6 & 870,0 & 1051,3 & 874,3 & 1051,7 & 878,2 & 1052,1 \\
861,0 & 1099,7 & 865,4 & 1100,5 & 870,0 & 1101,0 & 874,3 & 1101,4 & 878,1 & 1101,6 \\
810,3 & 1099,7 & 815,0 & 1100,5 & 819,2 & 1101,1 & 823,3 & 1101,4 & 827,0 & 1101,6 \\
\hline
\end{tabular}

Tabela C.5: Posição de um determinado ponto nas 11 primeiras fotos, fundo de escala de um décimo de pixel

Determinadas as posições dos quatro vértices do elemento ao longo do tempo, é necessário estabelecer um campo de deslocamento $u(x, y)$ e $v(x, y)$ nos eixos $x$ e $y$, respectivamente, para permitir posteriormente o cálculo das deformações. Deste modo, considere a figura C.10, sendo o quadrilátero na imagem de referência dado por $A B C D A$ e em uma imagem posterior dado por $A^{*} B^{*} C^{*} D^{*} A^{*}$, centrados em $P$ e $P^{*}$ respectivamente.

A partir da aproximação bilinear do campo de deslocamentos dada por

$$
\begin{aligned}
& u(x, y)=a_{u} x+b_{u} y+c_{u} x y+d_{u} \\
& v(x, y)=a_{v} x+b_{v} y+c_{v} x y+d_{v}
\end{aligned}
$$

pode-se encontrar os valores das constantes $a_{u}, b_{u}, c_{u}, d_{u}, a_{v}, b_{v}, c_{v}$ e $d_{v}$ pelas condições de contorno obtidas das posições na imagem de referência e atual de modo a termos para um quadrilátero inicial de lado $L_{p}$ :

$$
\left.\begin{array}{l}
d u_{A}=u\left(x_{A}, y_{A}\right) \\
d u_{B}=u\left(x_{A}+L_{p}, y_{A}\right) \\
d u_{C}=u\left(x_{A}+L_{p}, y_{A}+L_{p}\right) \\
d u_{D}=u\left(x_{A}, y_{A}+L_{p}\right)
\end{array}\right\} \begin{aligned}
& d u_{A}=a_{u} x_{A}+b_{u} y_{A}+c_{u} x_{A} y_{A}+d_{u} \\
& d u_{B}=a_{u}\left(x_{A}+L_{p}\right)+b_{u} y_{A}+c_{u}\left(x_{A}+L_{p}\right) y_{A}+d_{u} \\
& d u_{C}=a_{u}\left(x_{A}+L_{p}\right)+b_{u}\left(y_{A}+L_{p}\right)+c_{u}\left(x_{A}+L_{p}\right)\left(y_{A}+L_{p}\right)+d_{u} \\
& \left.d u_{D}=a_{u} x_{A}+b_{u}\left(y_{A}+L_{p}\right)+c_{u} x_{A}+L_{p}\right)\left(y_{A}+L_{p}\right)+d_{u}
\end{aligned}
$$




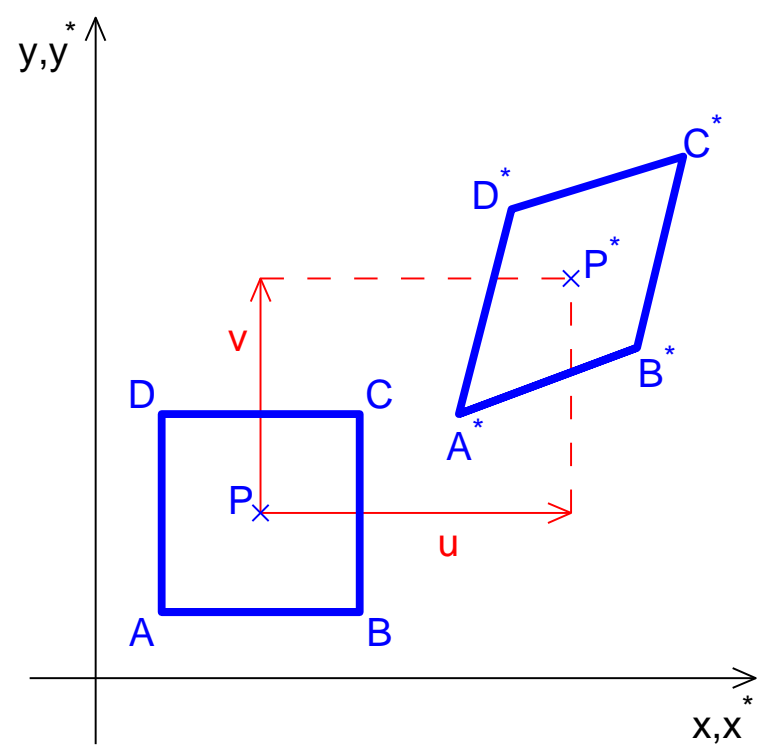

Figura C.10: Elemento quadrático na imagem de referência e distorcido em outra imagem com $t>t_{\text {ref }}$

$\mathrm{e}$

$$
\left.\begin{array}{l}
d v_{A}=v\left(x_{A}, y_{A}\right) \\
d v_{B}=v\left(x_{A}+L_{p}, y_{A}\right) \\
d v_{C}=v\left(x_{A}+L_{p}, y_{A}+L_{p}\right) \\
d v_{D}=v\left(x_{A}, y_{A}+L_{p}\right)
\end{array}\right\} \begin{aligned}
& d v_{A}=a_{v} x_{A}+b_{v} y_{A}+c_{v} x_{A} y_{A}+d_{v} \\
& d v_{B}=a_{v}\left(x_{A}+L_{p}\right)+b_{v} y_{A}+c_{v}\left(x_{A}+L_{p}\right) y_{A}+d_{v} \\
& d v_{C}=a_{v}\left(x_{A}+L_{p}\right)+b_{v}\left(y_{A}+L_{p}\right)+c_{v}\left(x_{A}+L_{p}\right)\left(y_{A}+L_{p}\right)+d_{v} \\
& \left.d v_{D}=a_{v} x_{A}+b_{v}\left(y_{A}+L_{p}\right)+c_{v} x_{A}+L_{p}\right)\left(y_{A}+L_{p}\right)+d_{v}
\end{aligned}
$$

possibilitando então escrever o campo de deslocamentos por

$$
\begin{aligned}
& u(x, y)=\left(d u_{B}-d u_{A}\right) \frac{x-x_{A}}{L_{p}}+\left(d u_{D}-d u_{A}\right) \frac{y-y_{A}}{L_{p}}+ \\
& \quad+\left(d u_{C}-d u_{B}+d u_{A}-d u_{D}\right) \frac{\left(x-x_{A}\right)\left(y-y_{A}\right)}{L_{p}^{2}}+d u_{A}
\end{aligned}
$$

$\mathrm{e}$

$$
\begin{aligned}
v(x, y)=\left(d v_{B}-d v_{A}\right) \frac{x-x_{A}}{L_{p}} & +\left(d v_{D}-d v_{A}\right) \frac{y-y_{A}}{L_{p}}+ \\
& +\left(d v_{C}-d v_{B}+d v_{A}-d v_{D}\right) \frac{\left(x-x_{A}\right)\left(y-y_{A}\right)}{L_{p}^{2}}+d v_{A}
\end{aligned}
$$

Entretanto, além de permitir o cálculo das deformações, o campo de deslocamentos é importante para aumentar a acurácia na localização do ponto na imagem atual através de um processo iterativo quando estão presentes grandes deformações. 
Apêndice C. DIC - Correlação de imagens digitais

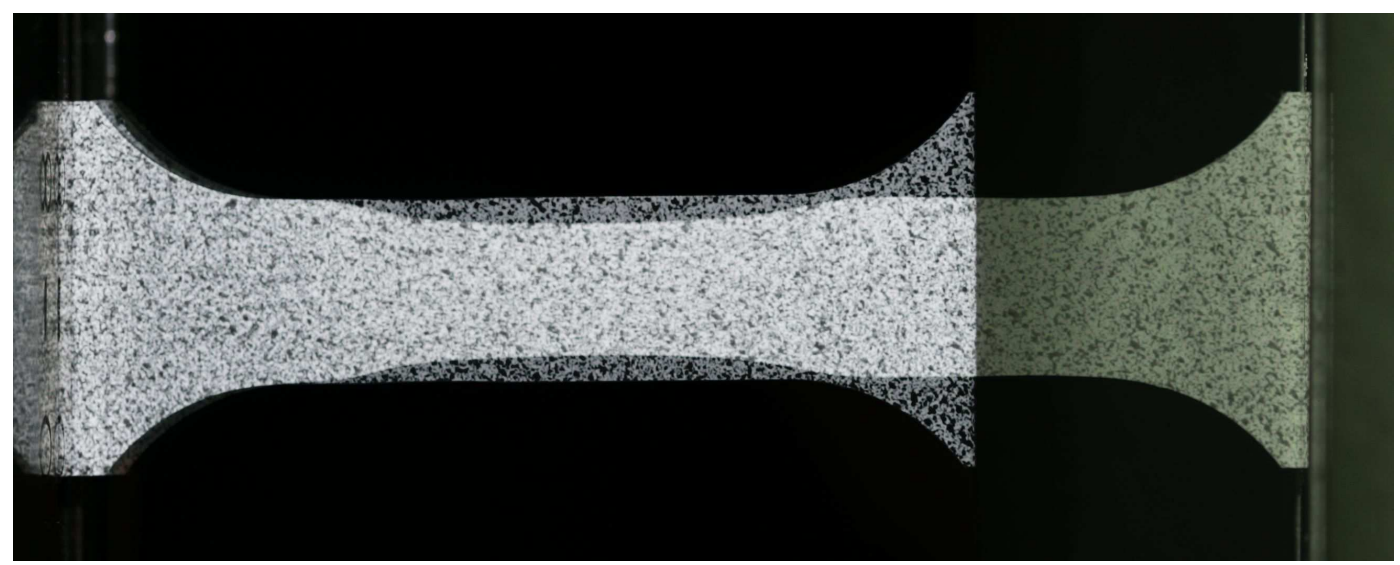

Figura C.11: Sobreposição das figuras de referência em em $t=640 \mathrm{~s}$

A figura C.11 apresenta a sobreposição entre a imagem de referência e a imagem 64, obtida poucos segundos antes da falha, sobrepostas e com transparência. O empescoçamento e as grandes deformações são visíveis, em especial, na região em que se encontrava o entalhe.

A figura C.12(a) mostra novamente o padrão de correlação na imagem de referência. Uma análise visual através de todas as imagens entre a de referência e a 64 possibilitou a determinação do padrão de correlação na imagem 64 e mostrado em detalhe na figura C.12, com a medida horizontal aumentando e a vertical diminuindo. Para facilitar a comparação com a imagem de referência, a proporção entre os eixos vertical e horizontal foi modificado e exibido na figura C.12(b) com o intuito de deixa-la aproximadamente com com as mesmas medidas da imagem de referência.

Essa mudança no padrão de correlação pode ser explicada considerando que o padrão de correlação representa uma região do corpo de prova e esta se deforma durante o ensaio experimental. Apesar de haver uma diferença entre a variação da deformação no elemento para a na região ao redor do nó deste quadrilátero, devido em especial ao processo de localização (e consequente empescoçamento) que gera uma distribuição de deformações, esta aproximação é suficiente para melhorar a acurácia na determinação do ponto na imagem atual.

De acordo com [90], este processo iterativo consiste em:

- realizar uma correlação inicial conforme descrito nas seções anteriores assumindo 


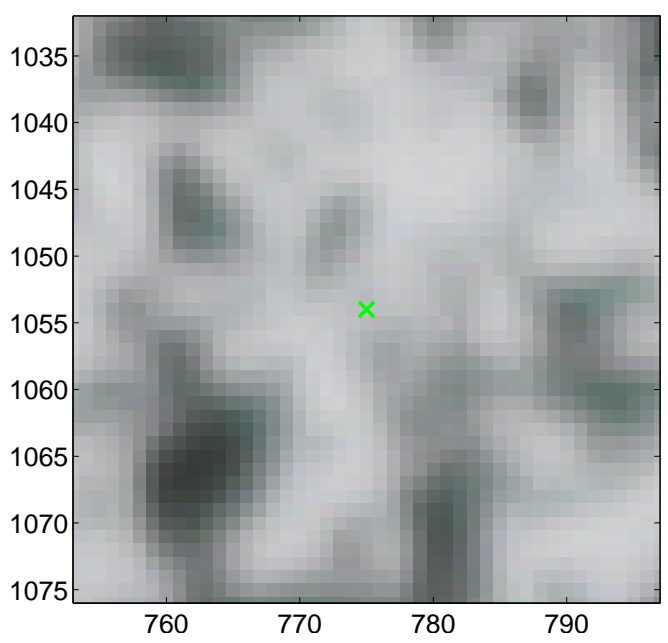

(a) figura de referência obtida antes do teste (b)

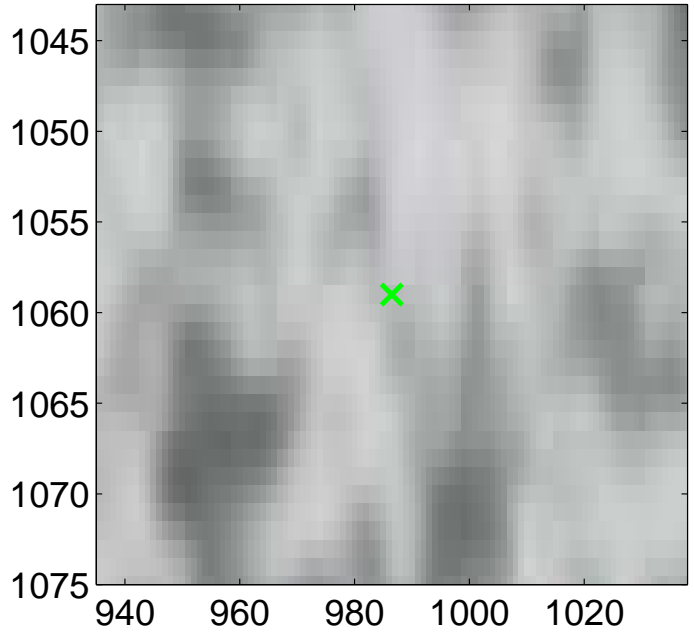

(b) Sexagésima quarta figura obtida no decorrer do teste, no instante $\mathrm{t}=640 \mathrm{~s}$, com proporção entre eixos x e y diferente de 1

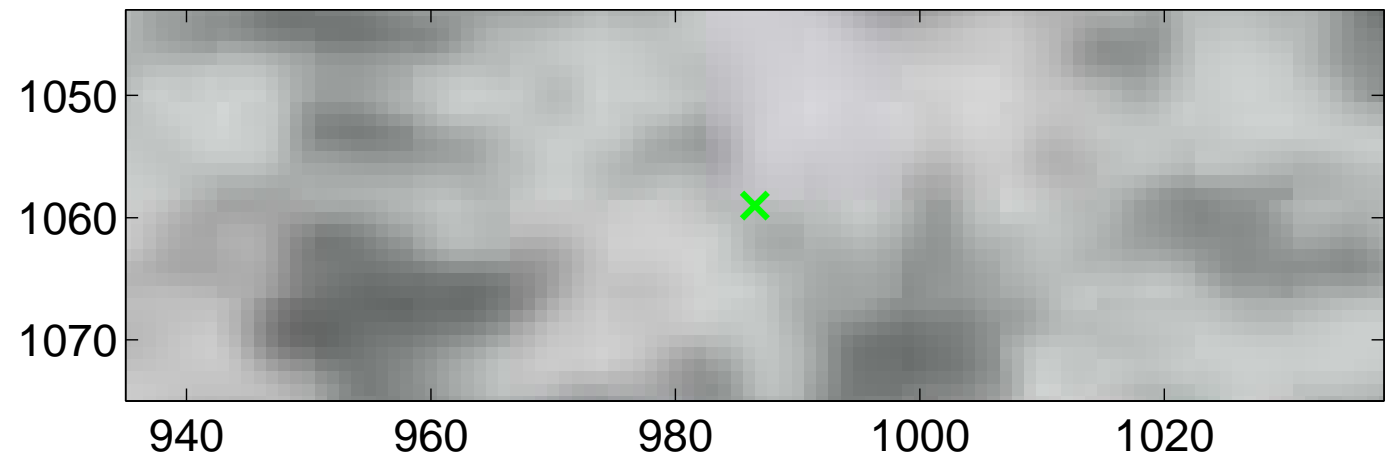

(c) Sexagésima quarta figura obtida no decorrer do teste, no instante $t=640 \mathrm{~s}$, com proporção entre eixos x e y de 1

Figura C.12: Padrões de correlação gerados para análise comparativa de acurácia em deslocamento.

um campo de deslocamento constantes dados por

$$
\begin{gathered}
u_{0}(x, y)=u_{A_{0}}(x, y)=u_{B_{0}}(x, y)=u_{C_{0}}(x, y)=u_{D_{0}}(x, y)=d u_{0} \\
v_{0}(x, y)=v_{A_{0}}(x, y)=v_{B_{0}}(x, y)=v_{C_{0}}(x, y)=v_{D_{0}}(x, y)=d v_{0}
\end{gathered}
$$

primeiro com resolução em pixel e depois refinando o procedimento com resolução em subpixel, descobrindo o ponto a localização do ponto $A_{0}$;

- mover o campo de deslocamentos para o padrão de correlação e calcular os coeficientes de correlação até encontrar a posição ótima $x_{A_{1}^{*}}$ sendo o ponto de mínimo na superfície de correlação, determinando então o ponto $A_{1}^{*}$;

- repetir o procedimento dos dois itens anteriores encontrando os pontos $B_{1}^{*}, C_{1}^{*}$ e 
$D_{1}^{*}$, obtendo o novo campo de deslocamentos dado por

$$
\begin{aligned}
u_{1}(x, y)=\left(d u_{B_{1}}\right. & \left.-d u_{A_{1}}\right) \frac{x-x_{A}}{L_{p}}+\left(d u_{D_{1}}-d u_{A_{1}}\right) \frac{y-y_{A}}{L_{p}}+ \\
& +\left(d u_{C_{1}}-d u_{B_{1}}+d u_{A_{1}}-d u_{D_{1}}\right) \frac{\left(x-x_{A}\right)\left(y-y_{A}\right)}{L_{p}^{2}}+d u_{A_{1}}
\end{aligned}
$$

e

$$
\begin{aligned}
v_{1}(x, y)=\left(d v_{B_{1}}\right. & \left.-d v_{A_{1}}\right) \frac{x-x_{A}}{L_{p}}+\left(d v_{D_{1}}-d v_{A_{1}}\right) \frac{y-y_{A}}{L_{p}}+ \\
& +\left(d v_{C_{1}}-d v_{B_{1}}+d v_{A_{1}}-d v_{D_{1}}\right) \frac{\left(x-x_{A}\right)\left(y-y_{A}\right)}{L_{p}^{2}}+d v_{A_{1}}
\end{aligned}
$$

- repetir o procedimento obtendo novos campos de deslocamento até que na n-ésima iteração tenhamos

$$
\begin{aligned}
u_{n}(x, y)=\left(d u_{B_{n}}-d u_{A_{n}}\right) \frac{x-x_{A}}{L_{p}}+\left(d u_{D_{n}}-d u_{A_{1}}\right) \frac{y-y_{A}}{L_{p}}+ \\
+\left(d u_{C_{n}}-d u_{B_{n}}+d u_{A_{n}}-d u_{D_{n}}\right) \frac{\left(x-x_{A}\right)\left(y-y_{A}\right)}{L_{p}^{2}}+d u_{A_{n}}
\end{aligned}
$$

$\mathrm{e}$

$$
\begin{aligned}
v_{n}(x, y)=\left(d v_{B_{n}}\right. & \left.-d v_{A_{n}}\right) \frac{x-x_{A}}{L_{p}}+\left(d v_{D_{n}}-d v_{A_{n}}\right) \frac{y-y_{A}}{L_{p}}+ \\
& +\left(d v_{C_{n}}-d v_{B_{n}}+d v_{A_{n}}-d v_{D_{n}}\right) \frac{\left(x-x_{A}\right)\left(y-y_{A}\right)}{L_{p}^{2}}+d v_{A_{n}}
\end{aligned}
$$

com condição de parada de iteração de

$$
\begin{aligned}
\left|d u_{\alpha_{n}}-d u_{\alpha_{n-1}}\right|<\delta_{u} & \operatorname{com} \alpha=A, B, C, D \\
\left|d v_{\alpha_{n}}-d v_{\alpha_{n-1}}\right|<\delta_{v} & \operatorname{com} \alpha=A, B, C, D
\end{aligned}
$$

$\operatorname{com} \delta_{u}$ e $\delta_{v}$ definidos anteriormente como a resolução desejada.

\section{C.0.3.5 calculo de deformações e tensões}

De acordo com [87], deformação é uma quantidade adimensional usada para descrever a mudança de forma, não sendo um quantidade física mensurável e podendo ser definida de várias maneiras. A deformação de um corpo homogêneo, isotrópico e linearmente elástico pode ser caracterizado por duas constantes físicas: o módulo elástico $E$ e o coeficiente de Poisson $\nu$. 
Considere agora um corpo de prova de tração, de comprimento inicial $l=l_{0}$, largura inicial $w=w_{0}$ e espessura inicial $t h=t h_{0}$, e que durante o ensaio experimental, o comprimento $l$ aumenta e tanto a largura $w$ quanto a espessura th diminuem (para a maioria dos materiais, nos quais $\nu>0$ ).

A medida mais simples de deformação axial é conhecida por alongamento (stretch), $\lambda_{1}$, e definida pelo coeficiente do comprimento atual pelo inicial, ou seja,

$$
\lambda_{1}=\frac{l}{l_{0}}
$$

com o subscrito 1 indicando a direção principal que coincide com a direção no qual é realizado o ensaio de tração neste tipo de experimento. As outras medidas de deformação podem ser definidas a partir dos comprimento inicial e atual ou da relação entre eles, o alongamento, sendo estas com suas respectivas datas de origem e formulações:

- Deformação de Cauchy $(1827) \varepsilon^{C}=\frac{l-l_{0}}{l_{0}}=\lambda-1$;

- Deformação de Green (1839) $\varepsilon^{G}=\frac{l^{2}-l_{0}^{2}}{2 l_{0}^{2}}=\frac{1}{2}\left(\lambda^{2}-1\right)$;

- Deformação de Almansi (1911) $\varepsilon^{A}=\frac{l^{2}-l_{0}^{2}}{2 l^{2}}=\frac{1}{2}\left(1-\lambda^{-2}\right)$;

- Deformação de Swainger (1947) $\varepsilon^{S}=\frac{l-l_{0}}{l}=1-\lambda^{-1}$;

- Deformação de Hencky (1839) $\varepsilon^{H}=\int_{l_{0}}^{l} \frac{d l}{l}=\ln \left(\frac{l}{l_{0}}\right)=\ln (\lambda)$;

com a representação gráfica destas diferentes formulações dependentes do alongamento demonstradas no gráfico da fig. C.13(a).

As deformações ainda podem ser descritas através do campo de deslocamentos, fornecidos na análise DIC. Em uma análise bidimensional e considerando deformações infinitesimais, a deformação de Green pode ser escrita por

$$
\begin{gathered}
\varepsilon_{x x}^{G}=\frac{\partial u}{\partial x}+\frac{1}{2}\left[\left(\frac{\partial u}{\partial x}\right)^{2}+\left(\frac{\partial v}{\partial x}\right)^{2}\right] \\
\varepsilon_{y y}^{G}=\frac{\partial v}{\partial y}+\frac{1}{2}\left[\left(\frac{\partial u}{\partial y}\right)^{2}+\left(\frac{\partial v}{\partial y}\right)^{2}\right] \\
\varepsilon_{x y}^{G}=\varepsilon_{y x}^{G}=\frac{1}{2}\left(\frac{\partial u}{\partial y} \frac{\partial v}{\partial x}\right)+\frac{1}{2}\left(\frac{\partial u}{\partial x} \frac{\partial u}{\partial y}+\frac{\partial v}{\partial x} \frac{\partial v}{\partial y}\right)
\end{gathered}
$$



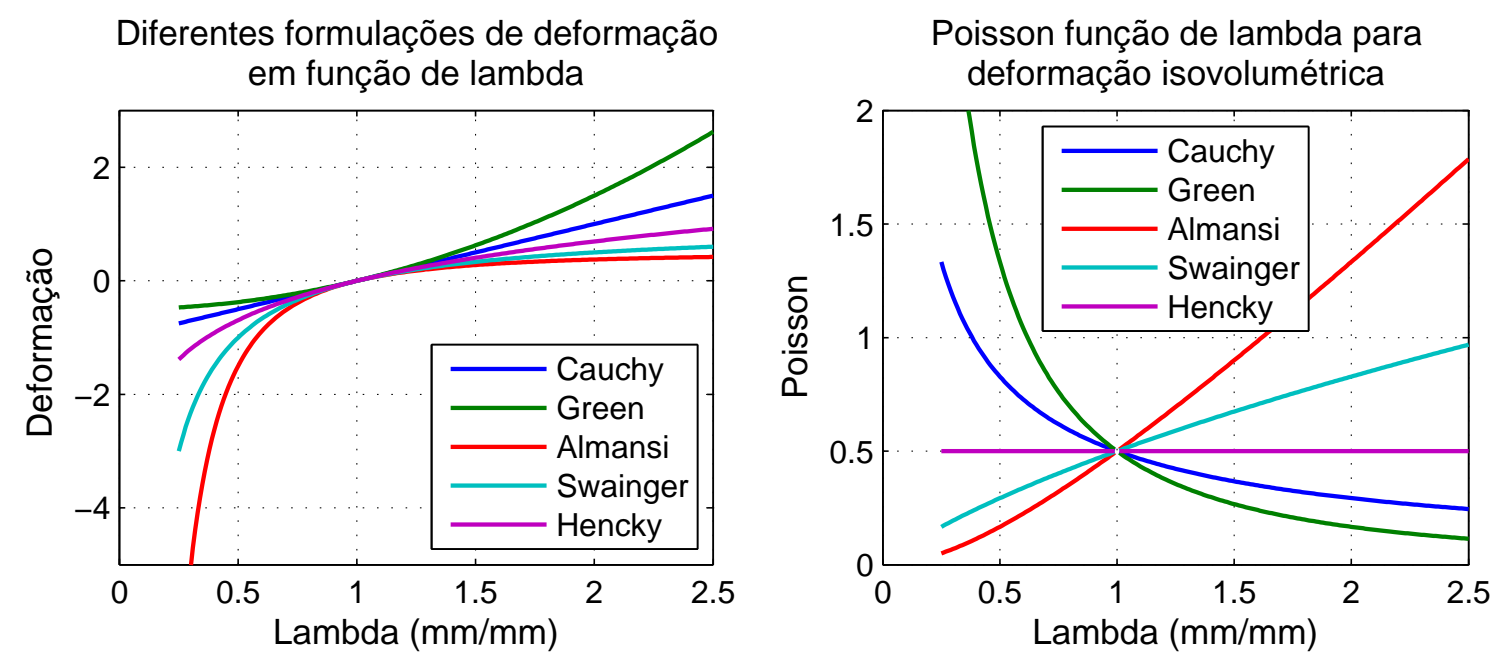

(a) Variação das diferentes definições de deforma- (b) Variação do alongamento em uma deformação ção isovolumétrica

Figura C.13: Diversas definições de deformação e coeficiente de poisson para deformação isovolumétrica, ambos em função do alongamento.

e a deformação de Almansi pode ser escrita por

$$
\begin{gathered}
\varepsilon_{x x}^{A}=\frac{\partial u}{\partial x}-\frac{1}{2}\left[\left(\frac{\partial u}{\partial x}\right)^{2}+\left(\frac{\partial v}{\partial x}\right)^{2}\right] \\
\varepsilon_{y y}^{A}=\frac{\partial v}{\partial y}-\frac{1}{2}\left[\left(\frac{\partial u}{\partial y}\right)^{2}+\left(\frac{\partial v}{\partial y}\right)^{2}\right] \\
\varepsilon_{x y}^{A}=\varepsilon_{y x}^{A}=\frac{1}{2}\left(\frac{\partial u}{\partial y} \frac{\partial v}{\partial x}\right)-\frac{1}{2}\left(\frac{\partial u}{\partial x} \frac{\partial u}{\partial y}+\frac{\partial v}{\partial x} \frac{\partial v}{\partial y}\right)
\end{gathered}
$$

Ainda de acordo com [87], cada formulação não possui grandes vantagens sobre as outras se o problema no qual emprega-las for resolvido de maneira consistente. A escolha de uma ou outra formulação,na maioria dos casos, depende da relação desta com a tensão ou com a função de energia.

Para vias de comparação entre o coeficiente de poisson para um material isotrópico em deformação isovolumétrica com as medidas locais do coeficiente de poisson obtidas com a técnica DIC, uma breve análise do assunto ser feita. O volume inicial pode ser dado pela multiplicação das três dimensões iniciais, $V_{0}=l_{0} w_{0} t h_{0}$, e similarmente o volume atual por $V=l w t h$. Sendo a deformação isovolumétrica, temos

$$
V=V_{0} \rightarrow l w t h=l_{0} w_{0} t h_{0} \rightarrow \frac{l w t h}{l_{0} w_{0} t h_{0}}=1
$$


Como o material é isotrópico, a relação entre a deformação axial e em ambas deformações transversais é igual, ou seja, $\lambda_{2}=\lambda_{3}$. Assim, de C.23, temos

$$
1=\frac{l w t h}{l_{0} w_{0} t h_{0}}=\lambda_{1} \lambda_{2} \lambda_{3}=\lambda_{1} \lambda_{2}^{2} \rightarrow \lambda_{2}=\sqrt{\frac{1}{\lambda_{1}}}
$$

Desta relação entre o alongamento axial e transversais, são calculados as deformações nas diversas formulações e calculado o coeficiente de poisson como o negativo entre a razão da deformação transversal pela axial. Os resultados estão graficamente representados na fig. C.13(b). Pode-se observar que o valor do coeficiente de poisson para um material isotrópico é constante em uma deformação isovolumétrica apenas na formulação de Hencky.

A transformação da deformação de Green em deformação de Hencky ou logarítmica pode ser dada por

$$
\left.\begin{array}{l}
\varepsilon^{G}=\frac{1}{2}\left(\lambda^{2}-1\right) \rightarrow \lambda=\sqrt{2 \varepsilon^{G}+1} \\
\varepsilon^{H}=\ln (\lambda)
\end{array}\right\} \rightarrow \varepsilon^{H}=\ln \left(\sqrt{2 \varepsilon^{G}+1}\right)
$$

No que diz respeito a tensão, assumindo um estado uniaxial de tensões enquanto o deformação axial é homogênea por todo o corpo de prova e que a aproximação por um estado uniaxial de tensões durante a localização e empescoçamento não acarretará em grandes erros, a tensão de engenharia e real uniaxiais podem ser calculadas, respectivamente, por

$$
\sigma_{e n g}=\frac{F}{A_{0}} \quad \text { e } \quad \sigma=\frac{F}{A}
$$

com $\sigma_{\text {eng }}$ sendo a tensão de engenharia, $\sigma$ a tensão real ou verdadeira, $F$ a força axial medida na célula de carga, $A_{0}$ a área inicial e $A$ a área atual. Como o programa utilizado fornece as deformações de Green, podemos escrever a área em função da deformação transversal de Green, $\varepsilon_{\text {trans }}^{G}$, e da área inicial, $A_{0}=w_{0} t h_{0}$, por

$$
\begin{aligned}
A & =w t h \\
& =w_{0} \sqrt{2 \varepsilon_{\text {trans }}^{G}+1} t h_{0} \sqrt{2 \varepsilon_{\text {trans }}^{G}+1} \\
& =w_{0} t h_{0}\left(2 \varepsilon_{\text {trans }}^{G}+1\right) \\
& =A_{0}\left(2 \varepsilon_{\text {trans }}^{G}+1\right)
\end{aligned}
$$




\section{C.0.4 exemplo em material metálico}

Descrita a técnica DIC e definidas as fórmulas para os cálculos das tensões e deformações verdadeiras, será estudado um caso exemplo de aplicação da técnica em um aço tanto para averiguar o potencial da mesma e para futura análise de comparação com outras formas de medição.

Um corpo de prova de tração de aço foi usinado a partir de uma chapa de $3 \mathrm{~mm}$ de espessura com largura de $12,5 \mathrm{~mm}$ e comprimento de $82,5 \mathrm{~mm}$. A velocidade imposta pela máquina de ensaios universais Instron 3369 foi de $0.004125 \mathrm{~mm} / \mathrm{s}$, resultando em um taxa de deformação nominal de $510^{-5} \mathrm{~s}^{-1}$. As fotos foram obtidas em intervalos de 10 segundos. Duas análises foram feitas com a técnica DIC, sendo uma utilizando todas as fotos somente na região elástica e outra utilizando uma a cada cinco fotos mas cobrindo todo o ensaio experimental.

A figura C.14 avalia a distribuição da componente de deformação verdadeira no eixo do corpo de prova.

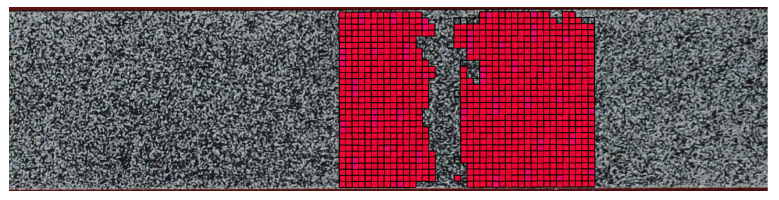

(a) $\mathrm{t}=0 \mathrm{~s}$

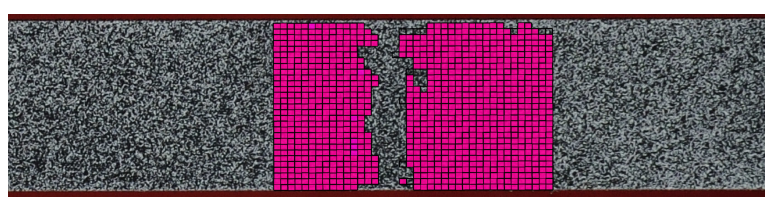

(c) $\mathrm{t}=2050 \mathrm{~s}$

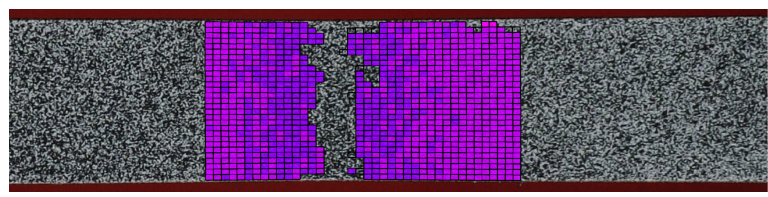

(e) $\mathrm{t}=4050 \mathrm{~s}$

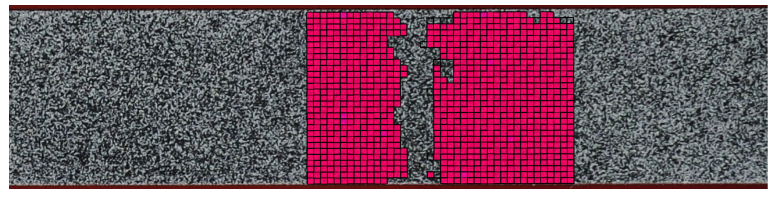

(b) $\mathrm{t}=1050 \mathrm{~s}$

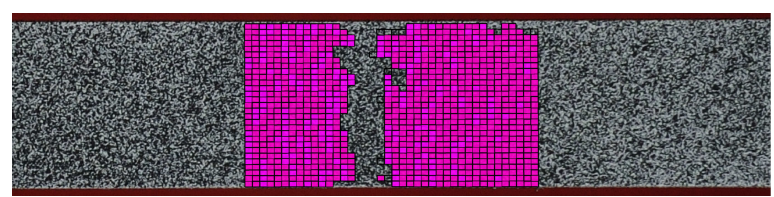

(d) $\mathrm{t}=3050 \mathrm{~s}$

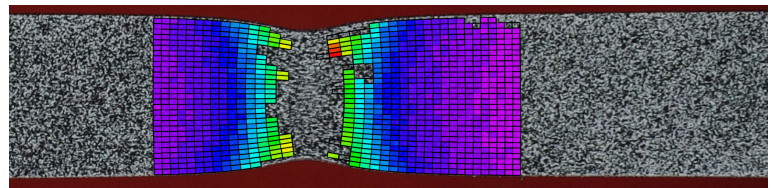

(f) $\mathrm{t}=5050 \mathrm{~s}$

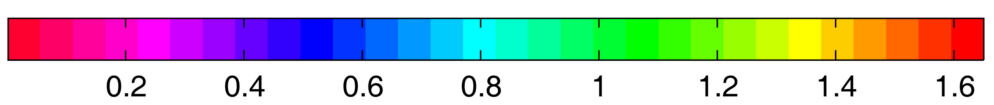

Figura C.14: DIC aço teste x sim.

Até o instante $\mathrm{t}=3050$, o campo de deformações é homogêneo, sendo o inicio da localização em aproximadamente $\mathrm{t}=4050 \mathrm{~s}$. A partir de então, a distribuição de deslocamentos deixa de ser linear, com a região próxima da secção de menor área do pescoço 
concentrando grande parte de cada acréscimo de deslocamento imposto pela máquina, mantendo assim constante ou mesmo reduzindo a deformação do restante do corpo de prova. Esse comportamento pode ser verificado na fig. C.15, na qual estão presentes as curvas de tensão-deformação real de todas as secções transversais obtidas por DIC em azul para o domínio completo do teste e em vermelho as da análise no domínio elástico do ensaio experimental.

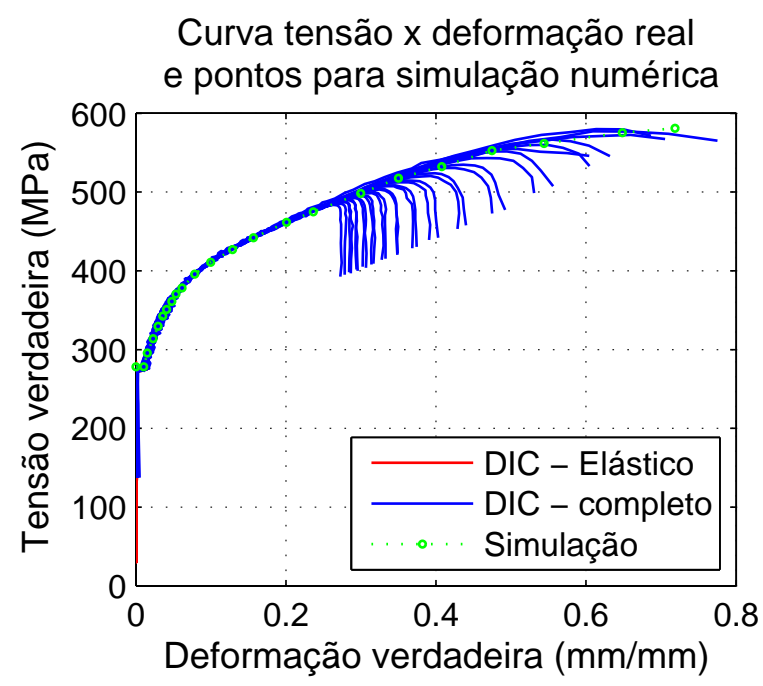

(a) simulação

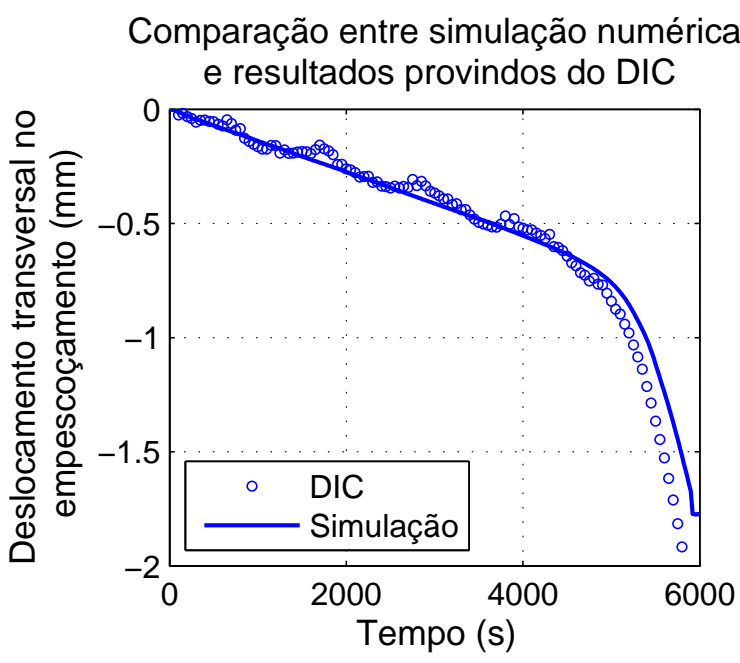

(b) comparação dos resultados

Figura C.15: DIC aço teste x sim.

Com o objetivo de testar os resultados obtidos, a curva tensão-deformação referente a secção transversal central do pescoço foi modelada em segmentos de reta, com os vértices ilustrados na figura como círculos verdes. Estes vértices serviram de dados de entrada para o modelo de material de plasticidade linear por partes (MAT_024 ou MAT_PIECEWISE_LINEAR_PLASTICITY) do programa comercial de elementos finitos Ls-Dyna. Como elemento de avaliação, foi escolhido o deslocamento transversal no tempo do elemento nó superior da secção transversal central do pescoço, com os resultados explicitados na fig. C.15(b).

Não somente a geometria do empescoçamento foi obtida na simulação numérica, como visto pela excelente grau de coincidência entre o deslocamento transversal obtidos na simulação numérica, sem o uso de nenhum tipo de modelo de dano, e experimental, pode-se notar na fig. C.16 que até mesmo as distribuições das deformações axiais são coincidentes. Estes resultados não somente validam a técnica de análise de deformações 
Apêndice C. DIC - Correlação de imagens digitais

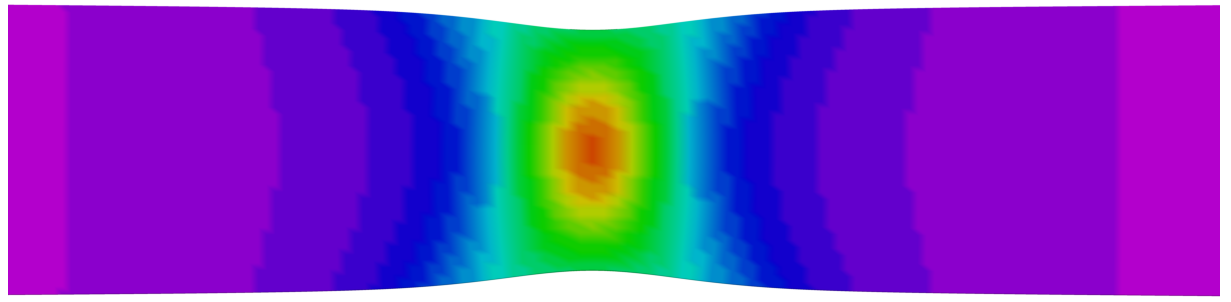

(a) simulação numérica em elementos finitos
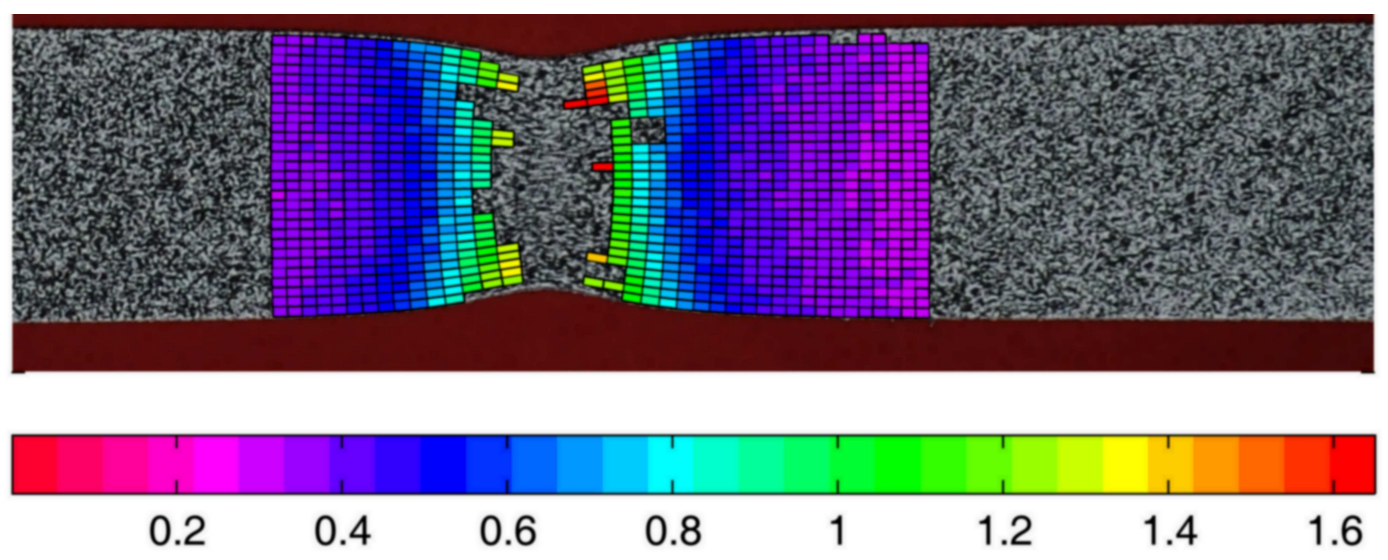

(b) resultado DIC

Figura C.16: Comparação da distribuição da deformação verdadeira axial obtidos na simulação numérica e da análise do ensaio experimental via DIC

DIC, como também mostram todo o potencial da mesma.

\section{C.0.5 comparação com outros métodos de medição}

Com o intuito de fazer uma comparação com os resultados obtidos anteriormente, outro corpo de prova idêntico de aço foi ensaiado na mesma máquina, sob os mesmos parâmetros, embora desta vez utilizou-se de 2 clip-gages, de $25 \mathrm{~mm}$ e $50 \mathrm{~mm}$ de comprimento, para a medição da deformação. A fig C.17(a) contém o gráfico da força pelo deslocamento medido no cross-head acima da célula de carga pelo encoder da máquina durante o ensaio, com o ponto em destaque sendo o valor máximo de força, ou seja, o momento em que se inicia o empescoçamento.

Já a fig. C.17(b) contem uma comparação entre os três tipos de medição supracitados. Apesar dos valores aceitavelmente próximos obtidos pelos três métodos e de um mesmo comportamento durante a maior parte do teste, há uma diferença no início que apesar de pequena, influenciará no cálculo futuro do módulo elástico. Esta diferença pode ser explicada pelo seguinte raciocínio: apesar de manualmente forçar uma cunha 


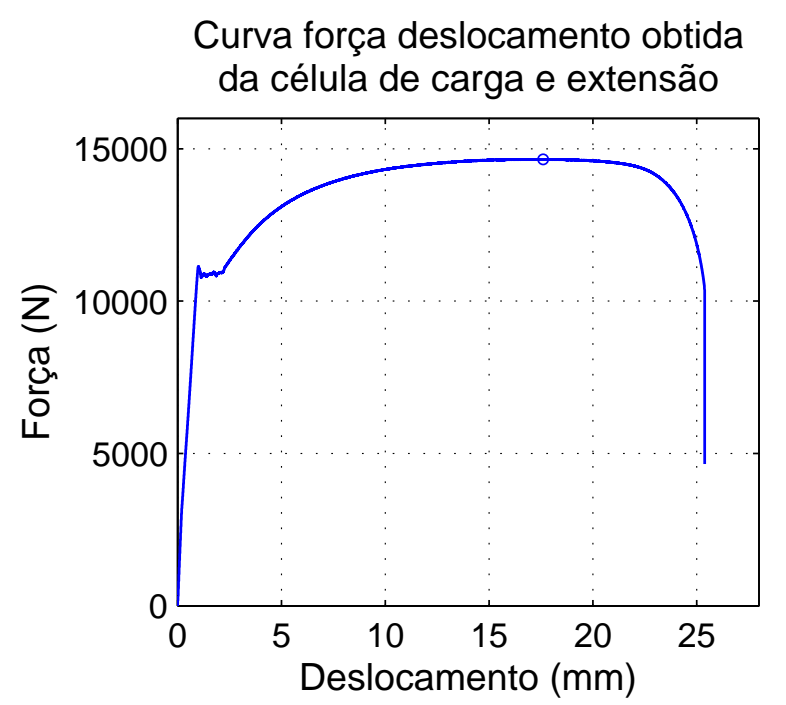

(a) curva força deslocamento do ensaio de tração (b) deformação no tempo obtida por três métodos em aço

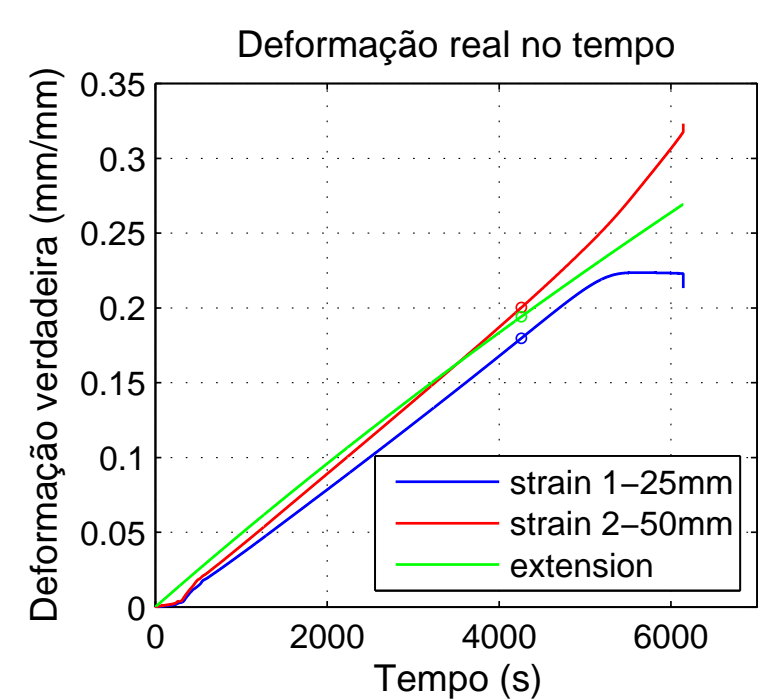

Figura C.17: DIC aço teste x sim.

contra a outra de modo a fixar o corpo de prova, ao impor deslocamentos, o efeito de cunha irá forçar ainda mais uma cunha contra a outra, havendo um movimento relativo entre as cunhas e cross-head, ou seja, parte do deslocamento imposto é absorvido pelo cunha e a outra parte será aplicada ao corpo de prova. Como os clip-gages estão afixados diretamente no corpo de prova, haverá uma não linearidade na deformação, exatamente como mostra a fig. C.17(b). Novamente, os pontos destacados evidenciam o instante de maior força no teste.

A fig. C.18 compara as curvas tensão deformação reais obtidas pelos diferentes métodos, novamente com os instantes de força máxima marcados por círculos. A partir deste momento de força máxima, começa o processo de localização que invalida os resultados obtidos pelos clip-gages, já que estes medem o deslocamento total e é assumida homogeneidade durante o cálculo da deformação real (além de isovolumetria). Enquanto a localização é pequena, os resultados estão próximos, mas conforme a localização aumenta, os resultados obtidos pelos clip-gages se distanciam dos obtidos pela técnica DIC. Também é possível notar que o empescoçamento se inicia no momento em que a segunda derivada da tensão de escoamento em função da deformação plástica acumulada é nula. Vale ressaltar que enquanto os métodos comuns foram capazes de medir com precisão até deformações de aproximadamente 0.25 , o método óptico conseguiu medir as deformações 
até o valor de 0.7 , quase o triplo.

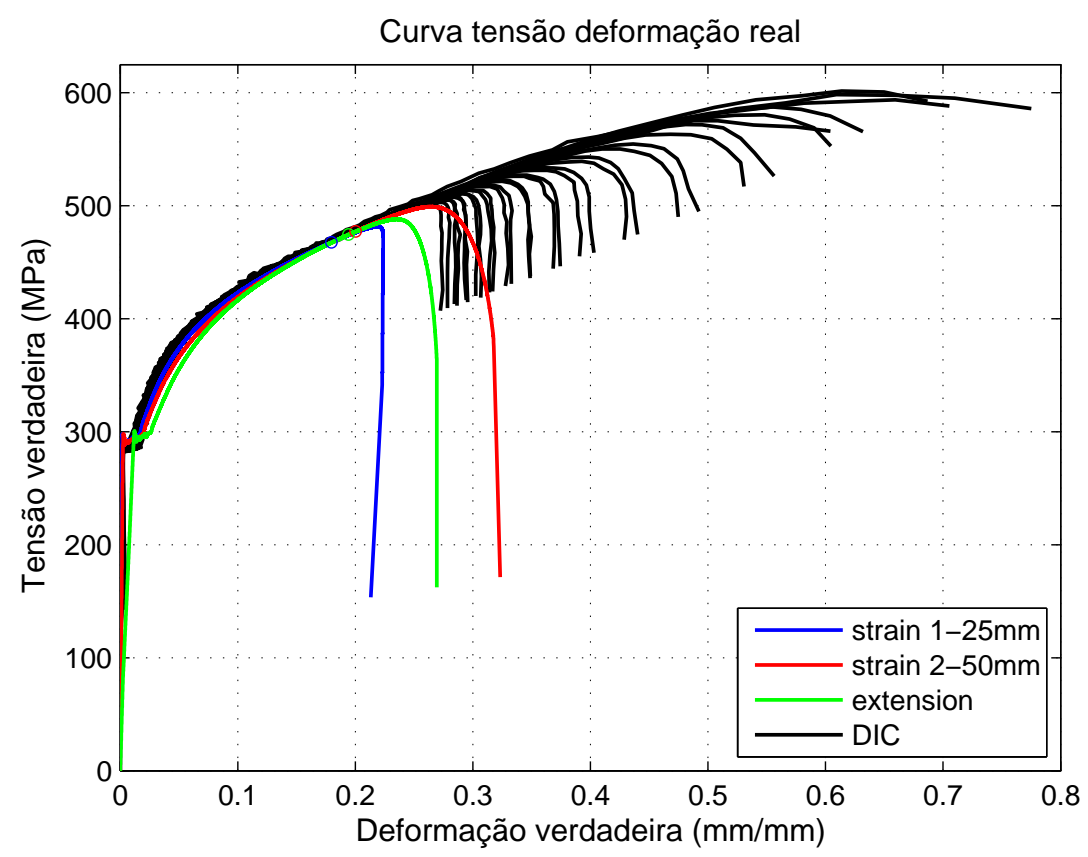

Figura C.18: Comparação entre diferentes métodos de medição de deslocamentos através das curvas tensão deformação real

Ainda sob uma perspectiva de comparação com outras técnicas de medição de deslocamentos e deformações, é válido citar o trabalho de Delhaye [26] que comparou a técnica DIC com outra técnica óptica de video traction com 7 marcas em um polímero com matriz de prolipropileno e partículas de borracha etileno-propileno. Nesta outra técnica óptica, são marcados 7 pontos na região do entalhe, conforme a fig. C.19(a). A deformação axial real no meio do elemento de volume representativo é calculada pela interpolação das quatro deformações parciais $\varepsilon_{A B}^{H}, \varepsilon_{B C}^{H}, \varepsilon_{C D}^{H}, \varepsilon_{D E}^{H}$ enquanto a transversal é calculada pela interpolação de $\varepsilon_{F C}^{H}$ e $\varepsilon_{C G}^{H}$. Os resultados finais comparativos na forma de curvas tensão deformação real encontram-se na fig. C.19(b). Os resultados estão próximos o suficiente para serem considerados iguais, entretanto enquanto a técnica DIC fornece a distribuição de deformações ao longo de grande parte do corpo de prova, a técnica de video traction fornece apenas no elemento de volume representativo. 


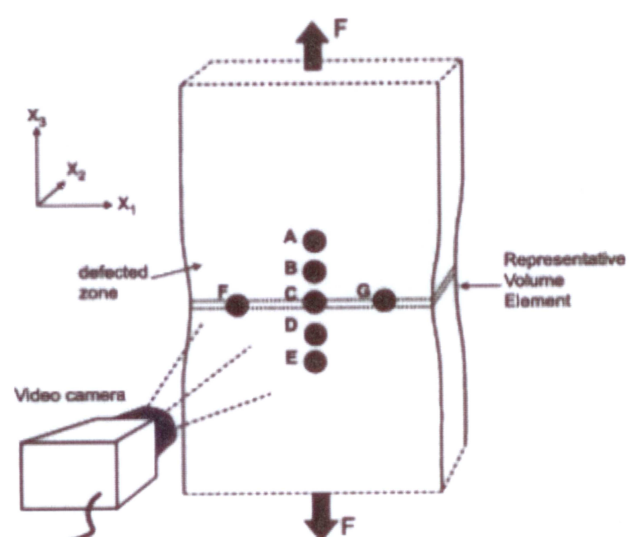

(a) esquemática da técnica de Video Traction com 7 marcas

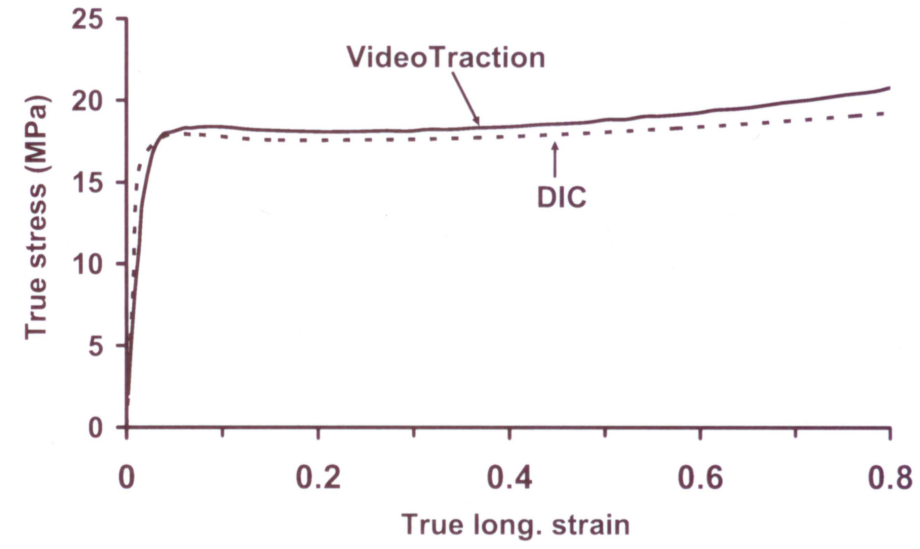

(b) comparação com resultado obtido por DIC

Figura C.19: Comparação entre a técnica DIC e Video Traction com 7 marcas. Retirado de $[26]$

\section{C.0.6 Comportamento do material e influência geométrica}

Apesar de fornecer uma comparação entre diversos métodos de medição de deslocamentos e deformações, há outros conceitos intrínsecos ao exemplo anterior ou mesmo ao conceito de realizar um ensaio de tração.

Um ensaio de tração é realizado no intuito de levantar a curva tensão deformação real do material de modo a ser possível a calibração de parâmetros de um modelo de material, como o módulo elástico, tensão de escoamento, sensibilidade a taxa de deformação. Este tipo de ensaio e sua geometria foi desenvolvida de maneira permitir um estado de tensões que pode ser simplificado por uniaxial em todos os momentos, sem perda de acurácia do resultado. Além disso, seu comportamento global deve refletir o comportamento do material em qualquer ponto do mesmo.

Considere o comportamento global de um corpo de prova de tração. Este é semelhante ao comportamento de cada secção transversal enquanto a distribuição de deformações no mesmo é homogênea, ou seja, o empescoçamento leva a localização e o comportamento global do corpo de prova deixa de refletir o comportamento do material. Em seu trabalho, Rusineck [85] simulou corpos de prova de geometrias diferentes (fig. C.20(a)) submetido a altas taxas de deformação, com o comportamento global diferenciando da curva tensão deformação real imposta como modelo de material utilizado. O comparativo entre a curva de entrada da simulação numérica e a curva resultante da análise dos dados gerados na 
simulação, para um material com $l_{0}=10 \mathrm{~mm}, w=8 \mathrm{~mm}, r=6 \mathrm{~mm}$ e $h=25 \mathrm{~mm}$, está presente na fig. C.20(b).

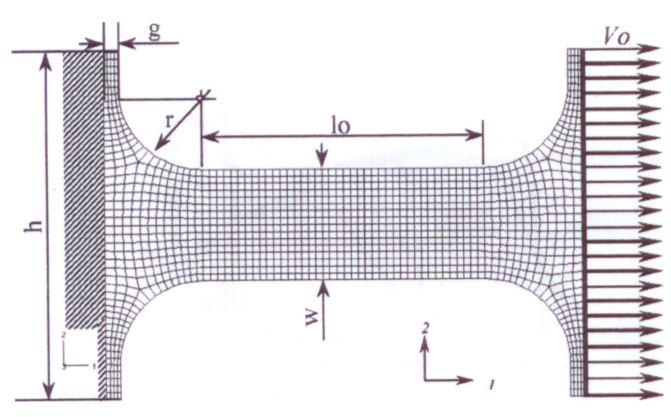

(a) detalhamento do corpo de prova

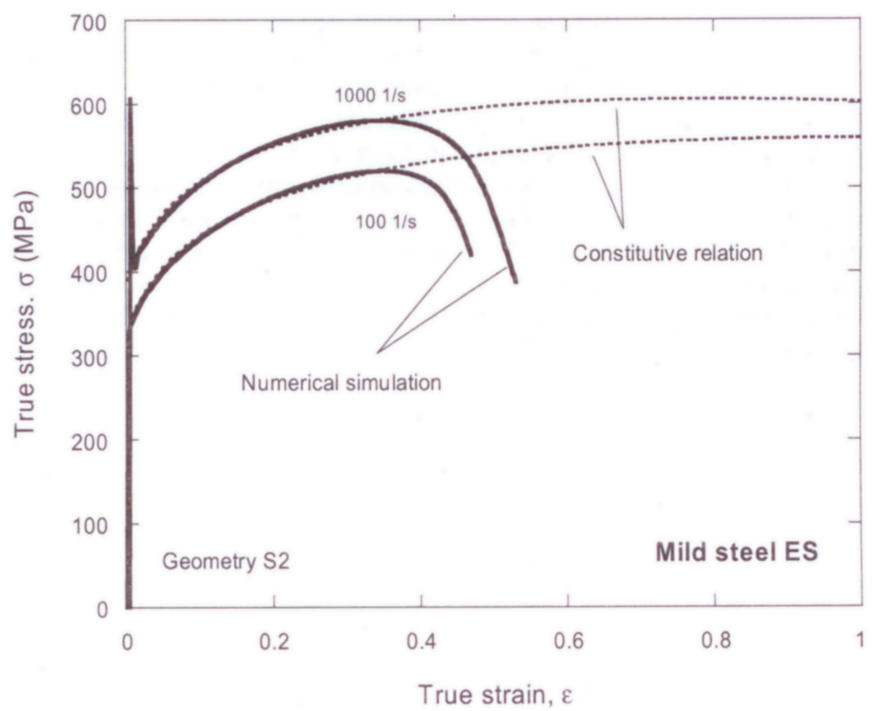

(b) resultados

Figura C.20: Comparação entre curva de referência para simulação numérica e resultado da simulação de ensaios de tração

Pode-se concluir que há então o comportamento do material e este difere do comportamento global do corpo de prova apenas quando há o início de uma influência na geometria do mesmo, ou seja, um efeito geométrico. Obviamente, quanto maior a proporção do tempo total de teste em que não há efeitos geométricos, maiores os níveis de deformação medidos por métodos comuns e mais informações do comportamento do material são fornecidas pelo ensaio de tração. A grande vantagem deste método DIC é a obtenção do comportamento do material em um nível local, independente da presença do efeito geométrico. 


\section{Apêndice D}

\section{Teoria de Ondas}

\section{D.1 Ondas elásticas em meios infinitos}

\section{D.1.1 Tipos de ondas elásticas}

Diferentes tipos de ondas podem se propagar em sólidos, dependendo de como o movimento das partículas está relacionado com a direção de propagação da onda e das condições de contorno. Uma partícula pode ser descrita como uma pequena porção de materia, mas não como um átomo, que possui uma direção de movimento diferente da direção geral de movimento por causa de restrições cristalográficas. Os tipos mais comuns de ondas elásticas são:

1. Ondas longitudinais ou irrotacionais: também conhecidas como ondas de dilatação, correspondem ao movimento para a frente e para trás ao longo da direção de propagação da onda tornando a velocidade da partícula paralela a velocidade da onda. Se a onda é de compressão, ambas as velocidades possuem o mesmo sentido. Se for de tração, os sentidos são diferentes;

2. Ondas distorcionais ou de cisalhamento: a direção do movimento das partículas é perpendicular a direção de propagação da onda. Não ha variação de densidade e todas as componentes de deformação longitudinais são nulas;

3. Ondas de Superfície ou ondas de Rayleigh: as ondas de superfície são análogas as encontradas na superfície da água. Objetos flutuantes podem ser considerados partículas e descreverem um movimento tanto para cima e para baixo quanto para a frente e para trás, descrevendo uma trajetória elíptica. Este tipo de onda está 
restrito a região prontamente próxima à superfície, já que a velocidade da partícula decresce exponencialmente com a distancia da propria superfície;

4. Onda interfacial ou de Stoneley: Quando dois materiais semi-infinitos com propriedades diferentes estão em contato, surgem ondas especiais na interface;

5. Ondas em materiais compostos por camadas ou ondas de Love: importantes em sismologia, descrevem ondas no qual a componente de deslocamento horizontal é significativamente maior que a componente vertical, sendo então diferentes das ondas de Rayleigh. As camadas podem vir a ter diferentes propriedades, originando padrões de ondas especiais;

6. Ondas de flexão: envolvem a propagação de uma flexão em um meio unidimensional, no caso de barras, ou bi-dimensional, no caso de placas e cascas.

\section{D.1.2 Equações de equilíbrio}

As tensões que atuam nos planos normais aos eixos $\mathrm{Ox}$, Oy e $\mathrm{Oz}$ são $\sigma_{x x}, \sigma_{x y}, \sigma_{x z}, \sigma_{y x}$, $\sigma_{y y}, \sigma_{y z}, \sigma_{z x}, \sigma_{z y}, \sigma_{z z}$, nas quais o primeiro índice indica a direção normal ao plano em que atuam e o segundo indica a direção em que atuam. No equilíbrio estático, a somatório de forças e a de momentos em todas as direções são nulas, conforme (D.1):

$$
\sum F=0\left\{\begin{array}{l}
\sum F_{x}=0 \\
\sum F_{y}=0 \\
\sum F_{z}=0
\end{array} \quad \text { e } \sum M=0\left\{\begin{array}{l}
\sum M_{x}=0 \\
\sum M_{y}=0 \\
\sum M_{z}=0
\end{array}\right.\right.
$$

Mas quando não estamos em equilíbrio estático, as tensões atuando em faces opostas não são iguais. Para deduzirmos as equações de equilíbrio, iremos analisar um cubo de dimensões infinitesimais, com tensões perpendiculares e tangenciais em cada face, como na figura (D.1).

A segunda lei de Newton pode ser expressa nas três direções conforme

$$
F_{x}=m a_{x} \quad F_{y}=m a_{y} \quad F_{z}=m a_{z}
$$




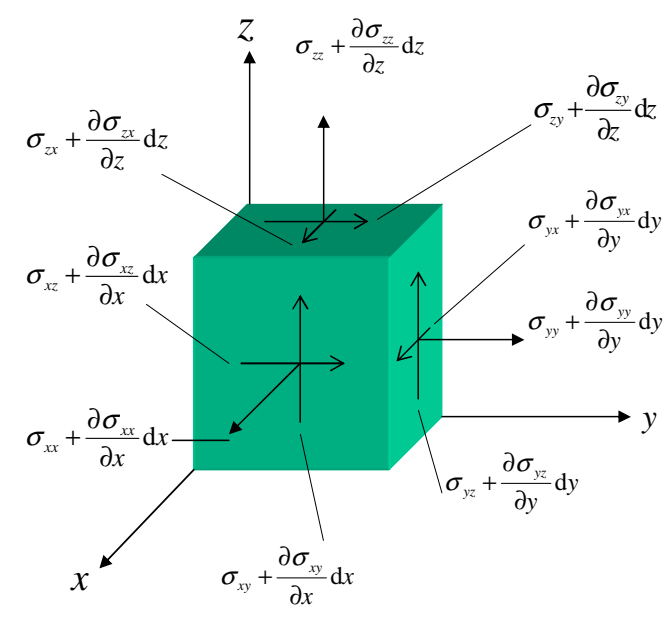

Figura D.1: Elemento infinitesimal em equilíbrio dinâmico

ou seja:

$$
\begin{aligned}
& \sum F_{x}=(\rho \mathrm{d} x \mathrm{~d} y \mathrm{~d} z) \frac{\partial^{2} u}{\partial t^{2}} \\
& \sum F_{y}=(\rho \mathrm{d} x \mathrm{~d} y \mathrm{~d} z) \frac{\partial^{2} v}{\partial t^{2}} \\
& \sum F_{z}=(\rho \mathrm{d} x \mathrm{~d} y \mathrm{~d} z) \frac{\partial^{2} w}{\partial t^{2}}
\end{aligned}
$$

Na direção Ox, temos as tensões $\sigma_{x x}, \sigma_{x x}+\frac{\partial \sigma_{x x}}{\partial x} \mathrm{~d} x, \sigma_{y x}, \sigma_{y x}+\frac{\partial \sigma_{y x}}{\partial y} \mathrm{~d} y \sigma_{z x} \mathrm{e} \sigma_{z x}+\frac{\partial \sigma_{z x}}{\partial z} \mathrm{~d} z$. Considerando o somatório de forças, teremos:

$$
\begin{array}{r}
\left(\sigma_{x x}+\frac{\partial \sigma_{x x}}{\partial x} \mathrm{~d} x-\sigma_{x x}\right) \mathrm{d} y \mathrm{~d} z+\left(\sigma_{y x}+\frac{\partial \sigma_{y x}}{\partial y} \mathrm{~d} y-\sigma_{y x}\right) \mathrm{d} z \mathrm{~d} x+ \\
\left(\sigma_{z x}+\frac{\partial \sigma_{z x}}{\partial z} \mathrm{~d} z-\sigma_{z x}\right) \mathrm{d} x \mathrm{~d} y=(\rho \mathrm{d} x \mathrm{~d} y \mathrm{~d} z) \frac{\partial^{2} u}{\partial t^{2}}
\end{array}
$$

E, dividindo ambos os lados por $\mathrm{d} x \mathrm{~d} y \mathrm{~d} z$, teremos:

$$
\frac{\partial \sigma_{x x}}{\partial x}+\frac{\partial \sigma_{y x}}{\partial y}+\frac{\partial \sigma_{z x}}{\partial z}=\rho \frac{\partial^{2} u}{\partial t^{2}}
$$

De maneira análoga, encontramos:

$$
\begin{aligned}
& \frac{\partial \sigma_{x y}}{\partial x}+\frac{\partial \sigma_{y y}}{\partial y}+\frac{\partial \sigma_{z y}}{\partial z}=\rho \frac{\partial^{2} v}{\partial t^{2}} \\
& \frac{\partial \sigma_{x z}}{\partial x}+\frac{\partial \sigma_{y z}}{\partial y}+\frac{\partial \sigma_{z z}}{\partial z}=\rho \frac{\partial^{2} w}{\partial t^{2}}
\end{aligned}
$$




\section{D.1.3 Lei de Hooke generalizada}

Para a maioria dos materiais, é demonstrado experimentalmente que a carga aplicada e a deformação são linearmente proporcionais.

Vamos calcular o equilíbrio de momentos em um cubo infinitesimal para descobrirmos relações entre as 9 tensões do mesmo.

$$
\begin{aligned}
& {\left[\left(\sigma_{z x}+\frac{\partial \sigma_{z x}}{\partial z} \mathrm{~d} z\right) \mathrm{d} y \mathrm{~d} x\right] \frac{\mathrm{d} z}{2}+\left(\sigma_{z x}\right) \mathrm{d} y \mathrm{~d} x \frac{\mathrm{d} z}{2}} \\
& -\left[\left(\sigma_{x z}+\frac{\partial \sigma_{x z}}{\partial x} \mathrm{~d} x\right) \mathrm{d} y \mathrm{~d} z\right] \frac{\mathrm{d} x}{2}-\left(\sigma_{x z}\right) \mathrm{d} y \mathrm{~d} z \frac{\mathrm{d} x}{2}=0
\end{aligned}
$$

Fazendo $\mathrm{d} z^{2}=0$ e $\mathrm{d} x^{2}=0$ e dividindo tudo por $\mathrm{d} x \mathrm{~d} y \mathrm{~d} z$

$$
\sigma_{z x}-\sigma_{x z}=0 \quad \therefore \sigma_{z x}=\sigma_{x z}
$$

Desta forma reduzimos o numero de tensões de 9 para 6 .

As deformações são definidas por:

$$
\left\{\begin{array}{l}
\varepsilon_{x x}=\frac{\partial u}{\partial x} \\
\varepsilon_{y y}=\frac{\partial v}{\partial y} \\
\varepsilon_{z z}=\frac{\partial w}{\partial z} \\
\varepsilon_{z y}=\frac{\partial v}{\partial z}+\frac{\partial w}{\partial y} \\
\varepsilon_{x z}=\frac{\partial w}{\partial x}+\frac{\partial u}{\partial z} \\
\varepsilon_{y x}=\frac{\partial u}{\partial y}+\frac{\partial v}{\partial x}
\end{array}\right.
$$

Segundo Love ([59] p.99), cada um dos 6 componente de tensão linearmente independentes pode ser escrito em função da uma combinação linear dos 6 componentes de deformação correspondentes da seguinte forma:

$$
\left\{\begin{array}{l}
\sigma_{x x}=c_{11} \varepsilon_{x x}+c_{13} \varepsilon_{y y}+c_{13} \varepsilon_{z z}+c_{14} \varepsilon_{z y}+c_{15} \varepsilon_{x z}+c_{16} \varepsilon_{y x} \\
\sigma_{y y}=c_{21} \varepsilon_{x x}+c_{23} \varepsilon_{y y}+c_{23} \varepsilon_{z z}+c_{24} \varepsilon_{z y}+c_{25} \varepsilon_{x z}+c_{26} \varepsilon_{y x} \\
\sigma_{z z}=c_{31} \varepsilon_{x x}+c_{33} \varepsilon_{y y}+c_{33} \varepsilon_{z z}+c_{34} \varepsilon_{z y}+c_{35} \varepsilon_{x z}+c_{36} \varepsilon_{y x} \\
\sigma_{z y}=c_{41} \varepsilon_{x x}+c_{43} \varepsilon_{y y}+c_{43} \varepsilon_{z z}+c_{44} \varepsilon_{z y}+c_{45} \varepsilon_{x z}+c_{46} \varepsilon_{y x} \\
\sigma_{x z}=c_{51} \varepsilon_{x x}+c_{53} \varepsilon_{y y}+c_{53} \varepsilon_{z z}+c_{54} \varepsilon_{z y}+c_{55} \varepsilon_{x z}+c_{56} \varepsilon_{y x} \\
\sigma_{y x}=c_{61} \varepsilon_{x x}+c_{63} \varepsilon_{y y}+c_{63} \varepsilon_{z z}+c_{64} \varepsilon_{z y}+c_{65} \varepsilon_{x z}+c_{66} \varepsilon_{y x}
\end{array}\right.
$$


Sendo $c_{i j}$ as constantes elásticas. Ainda segundo Love ([59] p.99), para que a energia elástica seja uma função univalente $(f(x)$ é uma função univalente numa região $D$ se $\left.\forall z_{1}, z_{2} \in D, z_{1} \neq z_{2} \Rightarrow f\left(z_{1}\right) \neq f\left(z_{2}\right)\right), c_{i j}=c_{j i}$, reduzindo o número de constantes elásticas de 36 para 21.

Se a rede cristalina do material possuir algum plano ou eixo de simetria, este numero de constantes reduz-se mais ainda. Mais especificamente para uma rede cristalina cúbica, existem apenas 3 constantes.

Em um sólido isotrópico, o valor dos coeficientes deve ser constantes para qualquer configuração de eixos escolhida, sobrando apenas então 2 constantes elásticas, definidas por $\lambda$ e $\mu$, sendo:

$$
\begin{aligned}
& c_{12}=c_{13}=c_{21}=c_{23}=c_{31}=c_{32}=\lambda, \\
& c_{44}=c_{55}=c_{66}=\mu, \\
& c_{11}=c_{22}=c_{33}=\lambda+2 \mu,
\end{aligned}
$$

com as outras 25 constantes elásticas nulas. Desta forma, podemos reescrever (D.11) como:

$$
\left\{\begin{array}{l}
\sigma_{x x}=\lambda \Delta+2 \mu \varepsilon_{x x} \\
\sigma_{y y}=\lambda \Delta+2 \mu \varepsilon_{y y} \\
\sigma_{z z}=\lambda \Delta+2 \mu \varepsilon_{z z} \\
\sigma_{z y}=\mu \varepsilon_{z y} \\
\sigma_{x z}=\mu \varepsilon_{x z} \\
\sigma_{y x}=\mu \varepsilon_{y x}
\end{array}\right.
$$

com $\Delta=\varepsilon_{x x}+\varepsilon_{y y}+\varepsilon_{z z}$ representando a variação de volume, sendo chamado de dilatação. As constantes $\lambda$ e $\mu$ são conhecidas como constantes de Lamé e somente as duas definem completamente o comportamento de um material elástico isotrópico. Por convenção, usamos 4 constantes: módulo de elasticidade $E$, coeficiente de Poisson $\nu$, módulo volumétrico (bulk modulus) $k$ e módulo de rigidez que é idêntico a constante de Lamé $\mu$.

Usando as equações de (D.12), podemos expressar $E, \nu$ e $k$ em função de $\lambda$ e $\mu$.

$E$ pode ser definido como a relação entre a tensão aplicada e deformação, considerandose um espécime cilíndrico sujeito a tensão uniforme nos planos das extremidades e com a superfície lateral livre de restrições. Considerando o eixo $x$ paralelo ao eixo do cilindro, $\sigma_{x x}$ é a tensão aplicada e as outras 5 componentes de tensão são nulas. Obtemos então:

$$
\left\{\begin{array}{l}
(\lambda+2 \mu) \varepsilon_{x x}+\lambda\left(\varepsilon_{y y}+\varepsilon_{z z}\right)=\sigma_{x x} \\
(\lambda+2 \mu) \varepsilon_{y y}+\lambda\left(\varepsilon_{z z}+\varepsilon_{x x}\right)=0 \\
(\lambda+2 \mu) \varepsilon_{z z}+\lambda\left(\varepsilon_{x x}+\varepsilon_{y y}\right)=0
\end{array}\right.
$$


Resolvendo este sistema de equações, obtemos:

$$
\varepsilon_{x x}=\frac{\lambda+\mu}{\mu(3 \lambda+2 \mu)} \sigma_{x x} \quad \varepsilon_{y y}=\varepsilon_{z z}=-\frac{\lambda}{2 \mu(3 \lambda+2 \mu)}
$$

Sabendo-se que o módulo de Elasticidade $E=\frac{\sigma_{x x}}{\varepsilon_{x x}}$, temos que:

$$
E=\frac{\mu(3 \lambda+2 \mu)}{\lambda+\mu}
$$

O coeficiente de Poisson $\nu$ é definido pela relação entre a deformação de compressão lateral e a deformação de tração axial, novamente em um cilindro com superfície lateral livre de restrições, ou seja, $-\frac{\varepsilon_{y y}}{\varepsilon_{x x}}$, resultando em:

$$
\nu=\frac{\lambda}{2(\lambda+\mu)}
$$

Por ultimo, define-se o módulo volumétrico $k$ como a relação entre a pressão aplicada e o negativo da dilatação. Desta forma:

$$
\sigma_{x x}=\sigma_{y y}=\sigma_{z z}=-P \quad \sigma_{z y}=\sigma_{x z}=\sigma_{y x}=0,
$$

então:

$$
k=\frac{P}{\Delta}=\lambda+\frac{2 \mu}{3}
$$

O módulo de cisalhamento ou rigidez $\mu$ é a relação entre a relação a tensão de cisalhamento e a deformação de cisalhamento, coincidindo com a constante de Lamé $\mu$.

\section{D.1.4 Propagação de ondas elásticas no contínuo}

$\mathrm{Na}$ introdução foram deduzidas equações de equilíbrio dinâmico de um cubo de dimensões infinitesimais. Agora que conhecemos a relação entre tensões e deformações e a relação entre deformações e deslocamentos, podemos desenvolver mais as equações (D.5),(D.6) e (D.7).

De acordo com a relação entre tensões e deformações (D.12), partimos de:

$$
\frac{\partial \sigma_{x x}}{\partial x}+\frac{\partial \sigma_{y x}}{\partial y}+\frac{\partial \sigma_{x z}}{\partial z}=\rho \frac{\partial^{2} u}{\partial t^{2}}
$$

para

$$
\frac{\partial\left(\lambda \Delta+2 \mu \varepsilon_{x x}\right)}{\partial x}+\frac{\partial\left(\mu \varepsilon_{y x}\right)}{\partial y}+\frac{\partial\left(\mu \varepsilon_{x z}\right)}{\partial z}=\rho \frac{\partial^{2} u}{\partial t^{2}}
$$


$\mathrm{Ou}$

$$
\lambda \frac{\partial \Delta}{\partial x}+2 \mu \frac{\partial \varepsilon_{x x}}{\partial x}+\mu \frac{\partial \varepsilon_{y x}}{\partial y}+\mu \frac{\partial \varepsilon_{x z}}{\partial z}=\rho \frac{\partial^{2} u}{\partial t^{2}}
$$

Substituindo-se as deformações por suas definições, como visto em (D.10), obtemos:

$$
\lambda \frac{\partial \Delta}{\partial x}+2 \mu \frac{\partial}{\partial x}\left(\frac{\partial u}{\partial x}\right)+\mu \frac{\partial}{\partial y}\left(\frac{\partial v}{\partial x}+\frac{\partial u}{\partial y}\right)+\mu \frac{\partial}{\partial z}\left(\frac{\partial u}{\partial z}+\frac{\partial w}{\partial x}\right)=\rho \frac{\partial^{2} u}{\partial t^{2}}
$$

Aplicando a propriedade distributiva:

$$
\lambda \frac{\partial \Delta}{\partial x}+2 \mu \frac{\partial^{2} u}{\partial x^{2}}+\mu \frac{\partial^{2} v}{\partial y \partial x}+\mu \frac{\partial^{2} u}{\partial y^{2}}+\mu \frac{\partial^{2} u}{\partial z^{2}}+\mu \frac{\partial^{2} w}{\partial z \partial x}=\rho \frac{\partial^{2} u}{\partial t^{2}}
$$

Agrupando de outra maneira:

$$
\lambda \frac{\partial \Delta}{\partial x}+\mu\left(\frac{\partial^{2} u}{\partial x^{2}}+\frac{\partial^{2} u}{\partial y^{2}}+\frac{\partial^{2} u}{\partial z^{2}}\right)+\mu\left(\frac{\partial^{2} u}{\partial x^{2}}+\frac{\partial^{2} v}{\partial y \partial x}+\frac{\partial^{2} w}{\partial z \partial x}\right)=\rho \frac{\partial^{2} u}{\partial t^{2}}
$$

Colocando $u$ e $\frac{\partial}{\partial x}$ em evidencia:

$$
\lambda \frac{\partial \Delta}{\partial x}+\mu\left(\frac{\partial^{2}}{\partial x^{2}}+\frac{\partial^{2}}{\partial y^{2}}+\frac{\partial^{2}}{\partial z^{2}}\right) u+\mu \frac{\partial}{\partial x}\left(\frac{\partial u}{\partial x}+\frac{\partial v}{\partial y}+\frac{\partial w}{\partial z}\right)=\rho \frac{\partial^{2} u}{\partial t^{2}}
$$

Definindo-se o operador $\nabla^{2}$ como:

$$
\nabla^{2}=\frac{\partial^{2}}{\partial x^{2}}+\frac{\partial^{2}}{\partial y^{2}}+\frac{\partial^{2}}{\partial z^{2}}
$$

e conforme as relações (D.10), chegamos a:

$$
\begin{gathered}
\lambda \frac{\partial \Delta}{\partial x}+\mu \nabla^{2} u+\mu \frac{\partial}{\partial x}\left(\varepsilon_{x x}+\varepsilon_{y y}+\varepsilon_{z z}\right)=\rho \frac{\partial^{2} u}{\partial t^{2}} \\
\lambda \frac{\partial \Delta}{\partial x}+\mu \nabla^{2} u+\mu \frac{\partial}{\partial x}(\Delta)=\rho \frac{\partial^{2} u}{\partial t^{2}}
\end{gathered}
$$

ou:

$$
(\lambda+\mu) \frac{\partial \Delta}{\partial x}+\mu \nabla^{2} u=\rho \frac{\partial^{2} u}{\partial t^{2}}
$$

Similarmente:

$$
\begin{aligned}
(\lambda+\mu) \frac{\partial \Delta}{\partial y}+\mu \nabla^{2} v & =\rho \frac{\partial^{2} v}{\partial t^{2}} \\
(\lambda+\mu) \frac{\partial \Delta}{\partial z}+\mu \nabla^{2} w & =\rho \frac{\partial^{2} w}{\partial t^{2}}
\end{aligned}
$$

As equações (D.25), (D.26) e (D.27) são as equações de movimento em um material elástico isotrópico na ausência de forças de volume e de superfície. Estas são utilizadas para deduzirmos as equações para a propagação de dois tipos de ondas elásticas: longitudinal e distorcional. 


\section{D.1.5 Velocidade de ondas longitudinais}

Derivando as equações (D.25) em $x,(D .26)$ em $y$ e (D.27) em $z$ e somando-as, obteremos:

$$
\begin{aligned}
\frac{\partial}{\partial x}[(\lambda & \left.+\mu) \frac{\partial \Delta}{\partial x}+\mu \nabla^{2} u\right]+\frac{\partial}{\partial y}\left[(\lambda+\mu) \frac{\partial \Delta}{\partial y}+\mu \nabla^{2} v\right] \\
& +\frac{\partial}{\partial z}\left[(\lambda+\mu) \frac{\partial \Delta}{\partial z}+\mu \nabla^{2} w\right]=\rho \frac{\partial}{\partial x}\left(\frac{\partial^{2} u}{\partial t^{2}}\right)+\rho \frac{\partial}{\partial y}\left(\frac{\partial^{2} v}{\partial t^{2}}\right)+\rho \frac{\partial}{\partial z}\left(\frac{\partial^{2} w}{\partial t^{2}}\right)
\end{aligned}
$$

Distribuindo,

$$
\begin{aligned}
& {\left[(\lambda+\mu) \frac{\partial^{2} \Delta}{\partial x^{2}}+\mu \frac{\partial}{\partial x} \nabla^{2} u\right]+\left[(\lambda+\mu) \frac{\partial^{2} \Delta}{\partial y^{2}}+\mu \frac{\partial}{\partial y} \nabla^{2} v\right]} \\
& +\left[(\lambda+\mu) \frac{\partial^{2} \Delta}{\partial z^{2}}+\mu \frac{\partial}{\partial z} \nabla^{2} w\right]=\rho\left(\frac{\partial^{3} u}{\partial x \partial t^{2}}\right)+\rho\left(\frac{\partial^{3} v}{\partial y \partial t^{2}}\right)+\rho\left(\frac{\partial^{3} w}{\partial z \partial t^{2}}\right)
\end{aligned}
$$

Reagrupando de maneira inteligente,

$$
\begin{aligned}
(\lambda+\mu)\left(\frac{\partial^{2}}{\partial x^{2}}+\frac{\partial^{2}}{\partial y^{2}}+\frac{\partial^{2}}{\partial z^{2}}\right) \Delta+\mu \nabla^{2}\left(\frac{\partial u}{\partial x}+\frac{\partial v}{\partial y}+\frac{\partial w}{\partial z}\right) & = \\
& =\rho \frac{\partial^{2}}{\partial t^{2}}\left(\frac{\partial u}{\partial x}+\frac{\partial v}{\partial y}+\frac{\partial w}{\partial z}\right)
\end{aligned}
$$

$\mathrm{ou}$,

$$
\begin{aligned}
&(\lambda+\mu)\left(\frac{\partial^{2}}{\partial x^{2}}+\frac{\partial^{2}}{\partial y^{2}}+\frac{\partial^{2}}{\partial z^{2}}\right) \Delta+\mu \nabla^{2}\left(\varepsilon_{x x}+\varepsilon_{y y}\right.\left.+\varepsilon_{z z}\right)= \\
&=\rho \frac{\partial^{2}}{\partial t^{2}}\left(\varepsilon_{x x}+\varepsilon_{y y}+\varepsilon_{z z}\right)
\end{aligned}
$$

Substituindo os termos entre parênteses,

$$
(\lambda+\mu) \nabla^{2} \Delta+\mu \nabla^{2} \Delta=\rho \frac{\partial^{2} \Delta}{\partial t^{2}}
$$

Por isso,

$$
(\lambda+2 \mu) \nabla^{2} \Delta=\rho \frac{\partial^{2} \Delta}{\partial t^{2}}
$$

$\mathrm{Ou}$

$$
\frac{\partial^{2} \Delta}{\partial t^{2}}=\frac{\lambda+2 \mu}{\rho} \nabla^{2} \Delta
$$

Uma análise dimensional mostra que a unidade do termo $\frac{\lambda+2 \mu}{\rho}$ é de (distancia/tempo $)^{2}$. Essa equação diferencial parcial de segunda ordem representa uma onda viajando na velocidade de

$$
V_{\text {long }}=\left(\frac{\lambda+2 \mu}{\rho}\right)^{\frac{1}{2}}
$$


A equação (D.34) é conhecida como a equação de onda longitudinal em um meio infinito e implica na propagação de uma onda de dilatação $(\Delta)$ através de um meio com velocidade $V_{\text {long }}$ (também conhecida por "bulk sound speed"). Expressando as constantes de Lamé em função do módulo de elasticidade e coeficiente de poisson, por

$$
\begin{gathered}
\mu=\frac{E}{[2(1+\nu)]} \\
\lambda=\frac{\nu E}{[(1+\nu)(1-2 \nu)]}
\end{gathered}
$$

Chegamos a:

$$
\begin{gathered}
V_{\text {long }}=\left(\frac{(1-\nu)}{(1+\nu)(1-2 \nu)} \frac{E}{\rho}\right)^{\frac{1}{2}} \\
\nu=0.3 \quad \Rightarrow \quad V_{\text {long }}=\left(\frac{1.346 E}{\rho}\right)^{\frac{1}{2}}
\end{gathered}
$$

\section{D.1.6 Velocidade de ondas de cisalhamento}

Para calcularmos a velocidade da onda de cisalhamento, devemos eliminar a dilatação $(\Delta)$ das equações (D.25), (D.26) e (D.27). Assim, derivando (D.26) em z e (D.27) em y

$$
\begin{aligned}
& (\lambda+\mu) \frac{\partial^{2} \Delta}{\partial y \partial z}+\mu \frac{\partial}{\partial z} \nabla^{2} v=\rho \frac{\partial^{3} v}{\partial t^{2} \partial z} \\
& (\lambda+\mu) \frac{\partial^{2} \Delta}{\partial z \partial y}+\mu \frac{\partial}{\partial y} \nabla^{2} w=\rho \frac{\partial^{3} w}{\partial t^{2} \partial y}
\end{aligned}
$$

Subtraindo (D.38) de (D.39),

$$
\mu \nabla^{2}\left(\frac{\partial w}{\partial y}-\frac{\partial v}{\partial z}\right)=\rho \frac{\partial^{2}}{\partial t^{2}}\left(\frac{\partial w}{\partial y}-\frac{\partial v}{\partial z}\right)
$$

Por definição, a rotação de um corpo rígido em $x, w_{x}$,é dado por

$$
w_{x}=\frac{1}{2}\left(\frac{\partial w}{\partial y}-\frac{\partial v}{\partial z}\right)
$$

e portanto,

$$
\mu \nabla^{2} w_{x}=\rho \frac{\partial^{2}}{\partial t^{2}} w_{x}
$$

sendo que o mesmo pode ser dito de $w_{y}$ e $w_{z}$.

Desta forma, podemos dizer que a rotação $w_{x}$ se propaga com velocidade

$$
V_{\text {shear }}=\left(\frac{\mu}{\rho}\right)^{\frac{1}{2}}=\left(\frac{E}{2 \rho(1+\nu)}\right)^{\frac{1}{2}}
$$




\section{D.1.7 Considerações sobre velocidades de ondas longitudinal e de cisalhamento}

Partindo da eq. (D.25), ao dizermos que a dilatação , $\Delta$ é nula, obtemos:

$$
\mu \nabla^{2} u=\rho \frac{\partial^{2} u}{\partial t^{2}}
$$

com equações similares em $y$ e $z$.

Para que tenhamos as rotações $w_{x}, w_{y}$ e $w_{z}$ todas nulas, $u, y$ e $z$ devem satisfazer as seguintes condições:

$$
u=\frac{\partial \phi}{\partial x}, \quad v=\frac{\partial \phi}{\partial y} \quad \text { e } \quad w=\frac{\partial \phi}{\partial z}
$$

sendo $\phi$ a função potencial. Além disso, sabemos que

$$
\Delta=\nabla^{2} \phi \quad \text { e } \quad \frac{\partial \Delta}{\partial x}=\nabla^{2} u
$$

Substituindo na eq. (D.25), temos:

$$
\rho \frac{\partial^{2} u}{\partial t^{2}}=(\lambda+2 \mu) \nabla^{2} u
$$

com equações similares para $v$ e $w$.

Podemos agora afirmar que uma onda elastica no interior de um meio sólido se propaga com duas velocidades diferentes. Ondas que envolvem rotação nula se propagam com velocidade $\left(\frac{\lambda+2 \mu}{\rho}\right)^{\frac{1}{2}}$, enquanto ondas envolvendo dilatação nula se propagam com velocidade $\left(\frac{\mu}{\rho}\right)^{\frac{1}{2}}$. Podemos chamar esses dois tipos de ondas de irrotacionais ou ondas de dilatação e equivolumiais ou ondas de distorção ou ainda ondas de cisalhamento, respectivamente. Conforme demonstrado por Kolski em [[51]], iremos provar que uma onda elastica, em um meio isotrópico, viaja com ua ou outra ou ainda ambas as velocidades descritas acima. Considere uma onda propagando-se paralelamente ao eixo $x$. Sendo a velocidade de propagação da onda igual a $c$ e os deslocamentos $u, v$ e $w$ funções de um único parâmetro $\psi=x-c t$, teremos:

$$
\begin{aligned}
\frac{\partial^{2} u}{\partial t^{2}} & =c^{2} \frac{\partial^{2} u}{\partial \psi^{2}}, & \frac{\partial^{2} u}{\partial x^{2}} & =\frac{\partial^{2} u}{\partial \psi^{2}} \\
\frac{\partial^{2} v}{\partial t^{2}} & =c^{2} \frac{\partial^{2} v}{\partial \psi^{2}}, & \frac{\partial^{2} v}{\partial x^{2}} & =\frac{\partial^{2} v}{\partial \psi^{2}} \\
\frac{\partial^{2} z}{\partial t^{2}} & =c^{2} \frac{\partial^{2} z}{\partial \psi^{2}} & \text { e } & \frac{\partial^{2} z}{\partial x^{2}}=\frac{\partial^{2} z}{\partial \psi^{2}}
\end{aligned}
$$


e as derivadas com respeito a $y$ e $z$ nulas. Adotando-se $u^{\prime \prime}, v^{\prime \prime}$ e $w^{\prime \prime}$ para as segundas derivadas de $u, v$ e $z$ com respeito a $\psi$ e substituímos na equação de movimento (D.25), obtemos:

$$
\rho c^{2} u^{\prime \prime}=(\lambda+2 \mu) u^{\prime \prime}
$$

similarmente das equações (D.26) e (D.27), obtemos:

$$
\begin{gathered}
\rho c^{2} v^{\prime \prime}=\mu v^{\prime \prime} \\
\rho c^{2} w^{\prime \prime}=\mu w^{\prime \prime} .
\end{gathered}
$$

As equações (D.48), (D.49) e (D.50) podem ser satisfeitas de dois modos. Um deles é termos $c^{2}=\frac{\lambda+2 \mu}{\rho}$ e $v^{\prime \prime}=w^{\prime \prime}=0 . \mathrm{O}$ outro é $c^{2}=\frac{\mu}{\rho}$ e $u^{\prime \prime}=0$. No primeiro, temos ondas longitudinais nas quais o movimento das partículas se da na direção da propagação. Na segundo modo, o movimento das partículas é perpendicular a direção de propagação da onda.

\section{D.1.8 Ondas de Rayleigh}

Em um meio isotrópico infinito, somente dois tipos de ondas podem se propagar. Entretanto, quando há uma superfície limite, existem ondas elásticas de superfície. Rayleigh foi o primeiro a estuda esse tipo de onda, muito semelhante a ondas gravitacionais em superfícies de líquidos.

Considere a propagação deu ma onda plana através de um meio elástico com um superfície limite plana. Tentaremos achar soluções para as equações (D.48), (D.49) e (D.50) que corresponda a um distúrbio confinado ,em sua maioria, a uma região próxima a superfície limite, a qual satisfaz a condição de tensões nulas. Para simplificarmos, usaremos o plano $x y$ como fronteira com o sentido positivo de $z$ adentrando no sólido, e a onda plana se movimentando na direção $x$. Como os deslocamentos serão independentes da coordenada $y$,temos:

$$
\Delta=\varepsilon_{x x}+\varepsilon_{z z} \quad \quad \quad \quad \quad \quad=\frac{\partial^{2}}{\partial x^{2}}+\frac{\partial^{2}}{\partial z^{2}}
$$

Assim, definimos duas funções potenciais:

$$
u=\frac{\partial \phi}{\partial x}+\frac{\partial \psi}{\partial z} \quad w=\frac{\partial \phi}{\partial z}-\frac{\partial \psi}{\partial x}
$$


De maneira a termos:

$$
\begin{aligned}
\Delta & =\frac{\partial u}{\partial x}+\frac{\partial w}{\partial z}=\frac{\partial}{\partial x}\left(\frac{\partial \phi}{\partial x}+\frac{\partial \psi}{\partial z}\right)+\frac{\partial}{\partial z}\left(\frac{\partial \phi}{\partial z}-\frac{\partial \psi}{\partial x}\right) \\
& =\frac{\partial^{2} \phi}{\partial x^{2}}+\frac{\partial^{2} \psi}{\partial x \partial z}+\frac{\partial^{2} \phi}{\partial z^{2}}-\frac{\partial^{2} \psi}{\partial z \partial x}=\left(\frac{\partial^{2}}{\partial x^{2}}+\frac{\partial^{2}}{\partial z^{2}}\right) \phi \\
& =\nabla^{2} \phi
\end{aligned}
$$

$\mathrm{e}$

$$
\begin{aligned}
2 w_{y} & =\frac{\partial u}{\partial z}-\frac{\partial w}{\partial x}=\frac{\partial}{\partial z}\left(\frac{\partial \phi}{\partial x}+\frac{\partial \psi}{\partial z}\right)-\frac{\partial}{\partial x}\left(\frac{\partial \phi}{\partial z}-\frac{\partial \psi}{\partial x}\right) \\
& =\frac{\partial^{2} \phi}{\partial z \partial x}+\frac{\partial^{2} \psi}{\partial z^{2}}-\frac{\partial^{2} \phi}{\partial x \partial z}+\frac{\partial^{2} \psi}{\partial x^{2}}=\left(\frac{\partial^{2}}{\partial z^{2}}+\frac{\partial^{2}}{\partial x^{2}}\right) \psi \\
& =\nabla^{2} \psi
\end{aligned}
$$

As duas ultimas equações demonstram que $\phi$ está associado com a dilatação produzida pelo distúrbio, enquanto $\psi$ está associado com a rotação. Desta forma, estas duas funções potencial permitiram a separação dos efeitos de dilatação e rotação em um meio.

Substituindo (D.52) e (D.53) em (D.48), teremos:

$$
\begin{gathered}
\rho \frac{\partial^{2}}{\partial t^{2}} u=(\lambda+\mu) \frac{\partial}{\partial x} \Delta+\mu \nabla^{2} u \\
\rho \frac{\partial^{2}}{\partial t^{2}}\left(\frac{\partial \phi}{\partial x}+\frac{\partial \psi}{\partial z}\right)=(\lambda+\mu) \frac{\partial}{\partial x} \nabla^{2} \phi+\mu \nabla^{2}\left(\frac{\partial \phi}{\partial x}+\frac{\partial \psi}{\partial z}\right) \\
\rho \frac{\partial}{\partial x}\left(\frac{\partial^{2} \phi}{\partial t^{2}}\right)+\rho \frac{\partial}{\partial z}\left(\frac{\partial^{2} \psi}{\partial t^{2}}\right)=(\lambda+\mu) \frac{\partial}{\partial x} \nabla^{2} \phi+\mu \frac{\partial}{\partial x} \nabla^{2} \phi+\mu \frac{\partial}{\partial z} \nabla^{2} \psi \\
\rho \frac{\partial}{\partial x}\left(\frac{\partial^{2} \phi}{\partial t^{2}}\right)+\rho \frac{\partial}{\partial z}\left(\frac{\partial^{2} \psi}{\partial t^{2}}\right)=(\lambda+2 \mu) \frac{\partial}{\partial x} \nabla^{2} \phi+\mu \frac{\partial}{\partial z} \nabla^{2} \psi
\end{gathered}
$$

De forma equivalente, substituindo (D.52) e (D.53) em (D.50), teremos:

$$
\begin{gathered}
\rho \frac{\partial^{2}}{\partial t^{2}} w=(\lambda+\mu) \frac{\partial}{\partial z} \Delta+\mu \nabla^{2} w \\
\rho \frac{\partial^{2}}{\partial t^{2}}\left(\frac{\partial \phi}{\partial z}-\frac{\partial \psi}{\partial x}\right)=(\lambda+\mu) \frac{\partial}{\partial z} \nabla^{2} \phi+\mu \nabla^{2}\left(\frac{\partial \phi}{\partial z}-\frac{\partial \psi}{\partial x}\right) \\
\rho \frac{\partial}{\partial z}\left(\frac{\partial^{2} \phi}{\partial t^{2}}\right)-\rho \frac{\partial}{\partial x}\left(\frac{\partial^{2} \psi}{\partial t^{2}}\right)=(\lambda+\mu) \frac{\partial}{\partial z} \nabla^{2} \phi+\mu \frac{\partial}{\partial z} \nabla^{2} \phi-\mu \frac{\partial}{\partial x} \nabla^{2} \psi \\
\rho \frac{\partial}{\partial z}\left(\frac{\partial^{2} \phi}{\partial t^{2}}\right)-\rho \frac{\partial}{\partial x}\left(\frac{\partial^{2} \psi}{\partial t^{2}}\right)=(\lambda+2 \mu) \frac{\partial}{\partial z} \nabla^{2} \phi-\mu \frac{\partial}{\partial x} \nabla^{2} \psi
\end{gathered}
$$


Derivando (D.55) com relação a $x$ e (D.56) com relação a $z$, obtemos:

$$
\begin{aligned}
& \rho \frac{\partial^{2}}{\partial x^{2}}\left(\frac{\partial^{2} \phi}{\partial t^{2}}\right)+\rho \frac{\partial^{2}}{\partial x \partial z}\left(\frac{\partial^{2} \psi}{\partial t^{2}}\right)=(\lambda+2 \mu) \frac{\partial^{2}}{\partial x^{2}} \nabla^{2} \phi+\mu \frac{\partial^{2}}{\partial x \partial z} \nabla^{2} \psi \\
& \rho \frac{\partial^{2}}{\partial z^{2}}\left(\frac{\partial^{2} \phi}{\partial t^{2}}\right)-\rho \frac{\partial^{2}}{\partial z \partial x}\left(\frac{\partial^{2} \psi}{\partial t^{2}}\right)=(\lambda+2 \mu) \frac{\partial^{2}}{\partial z^{2}} \nabla^{2} \phi-\mu \frac{\partial^{2}}{\partial z \partial x} \nabla^{2} \psi
\end{aligned}
$$

Somando (D.57) e (D.58), encontramos:

$$
\rho \nabla^{2}\left(\frac{\partial^{2} \phi}{\partial t^{2}}\right)=(\lambda+2 \mu) \nabla^{2}\left(\nabla^{2} \phi\right)
$$

Agora derivando (D.55) com relação a z e (D.56) com relação a $x$, obtemos:

$$
\begin{aligned}
& \rho \frac{\partial^{2}}{\partial z \partial x}\left(\frac{\partial^{2} \phi}{\partial t^{2}}\right)+\rho \frac{\partial^{2}}{\partial z^{2}}\left(\frac{\partial^{2} \psi}{\partial t^{2}}\right)=(\lambda+2 \mu) \frac{\partial^{2}}{\partial z \partial x} \nabla^{2} \phi+\mu \frac{\partial^{2}}{\partial z^{2}} \nabla^{2} \psi \\
& \rho \frac{\partial^{2}}{\partial x \partial z}\left(\frac{\partial^{2} \phi}{\partial t^{2}}\right)-\rho \frac{\partial^{2}}{\partial x^{2}}\left(\frac{\partial^{2} \psi}{\partial t^{2}}\right)=(\lambda+2 \mu) \frac{\partial^{2}}{\partial x \partial z} \nabla^{2} \phi-\mu \frac{\partial^{2}}{\partial x^{2}} \nabla^{2} \psi
\end{aligned}
$$

Subtraindo (D.61) de (D.60), encontramos:

$$
\rho \nabla^{2}\left(\frac{\partial^{2} \psi}{\partial t^{2}}\right)=\mu \nabla^{2}\left(\nabla^{2} \psi\right)
$$

Desta forma, as equações (D.59) e (D.62) podem ser satisfeitas por:

$$
\begin{gathered}
\frac{\partial^{2} \phi}{\partial t^{2}}=\left[\frac{\lambda+2 \mu}{\rho}\right] \nabla^{2} \phi=c_{\text {long }}^{2} \nabla^{2} \phi \\
\frac{\partial^{2} \psi}{\partial t^{2}}=\left[\frac{\mu}{\rho}\right] \nabla^{2} \psi=c_{\text {shear }}^{2} \nabla^{2} \phi
\end{gathered}
$$

Sejam $p$ a velocidade angular da onda, $\Lambda$ o comprimento da onda, $d$ a frequência da onda, sabemos que:

$$
p=2 \pi d \quad c=\Lambda d \Rightarrow f=\frac{2 \pi}{\Lambda}=\frac{p}{c}
$$

Se considerar a onda percorrendo o sentido positivo de $\mathrm{x}$, podemos experimentar para soluções de (D.63) e (D.64):

$$
\begin{aligned}
& \phi=F(z) e^{[i(p t-f x)]} \\
& \psi=G(z) e^{[i(p t-f x)]}
\end{aligned}
$$

com $F$ e $G$ sendo funções que indicam como a amplitude da onda varia com a variação de $z$. Substituindo (D.66) em (D.63), ficamos com:

$$
-\frac{p^{2}}{c_{\text {long }}^{2}} F(z)=-f^{2} F(z)+F^{\prime \prime}(z)
$$


$\operatorname{com} F^{\prime \prime}(z)=\frac{\mathrm{d}^{2}}{\mathrm{~d} z^{2}}$. Podemos escreve-la ainda como:

$$
F^{\prime \prime}(z)-\left(f^{2}-h^{2}\right) F(z)=0
$$

$\operatorname{com} h=\frac{p}{c_{\text {long }}}$ e solução

$$
F(z)=A e^{-q z}+A^{\prime} e^{q z}
$$

com

$$
q^{2}=f^{2}-h^{2}
$$

O segundo termo da eq. (D.70) corresponde a um distúrbio que tem sua amplitude crescente com a direção positiva de $z$, desta forma $A^{\prime}=0$.

Do mesmo modo, ao substituirmos a expressão de $\psi$ da eq. (D.67) em (D.64), obtemos:

$$
-\kappa^{2} G(z)=-f^{2} G(z)+G^{\prime \prime}(z), \quad \text { com } \quad \kappa=\frac{p}{c_{\text {shear }}}
$$

e solução relevante

$$
G(z)=B e^{-s z}
$$

$\mathrm{com}$

$$
s^{2}=f^{2}-\kappa^{2}
$$

Então, as eq. (D.66) e (D.67) se tornam:

$$
\begin{aligned}
& \phi=A e^{[-q z+i(p t-f x)]} \\
& \psi=B e^{[-s z+i(p t-f x)]}
\end{aligned}
$$

Vamos escrever agora as equações das condições de contorno em função de $\phi$ e $\psi$. As componentes de tensão $\sigma_{x x}, \sigma_{z y}$ e $\sigma_{z x}$ devem ser nulas em $z=0$.Portanto:

$$
\begin{aligned}
\sigma_{z z} & =\lambda \Delta+2 \mu \frac{\partial w}{\partial z}=\lambda \nabla^{2} \phi+2 \mu \frac{\partial}{\partial z}\left(\frac{\partial \phi}{\partial z}-\frac{\partial \psi}{\partial x}\right) \\
& =\lambda \frac{\partial^{2} \phi}{\partial x^{2}}+\lambda \frac{\partial^{2} \phi}{\partial z^{2}}+2 \mu \frac{\partial^{2} \phi}{\partial z^{2}}-2 \mu \frac{\partial^{2} \psi}{\partial z \partial x} \\
& =(\lambda+2 \mu) \frac{\partial^{2} \phi}{\partial x^{2}}+\lambda \frac{\partial^{2} \phi}{\partial z^{2}}-2 \mu \frac{\partial^{2} \psi}{\partial z \partial x}
\end{aligned}
$$

Substituindo (D.75) e (D.76) em (D.77), 


$$
\sigma_{z z}=(\lambda+2 \mu)\left(A q^{2} e^{[-q z+i(p t-f x)]}\right)+\lambda\left(A i^{2} f^{2} e^{[-q z+i(p t-f x)]}\right)-2 \mu\left(B s i f e^{[-s z+i(p t-f x)]}\right)
$$

Sabendo-se que para $z=0$ temos $\sigma_{z z}=0$

$$
\begin{gathered}
(\lambda+2 \mu)\left(A q^{2} e^{[-q 0+i(p t-f x)]}\right)+\lambda\left(A i^{2} f^{2} e^{[-q 0+i(p t-f x)]}\right)-2 \mu\left(B \operatorname{sif} e^{[-s 0+i(p t-f x)]}\right)=0 \\
A\left[(\lambda+2 \mu) q^{2}-\lambda f^{2}\right]-B(2 \mu s i f)=0
\end{gathered}
$$

Similarmente para $\sigma_{z x}$

$$
\begin{aligned}
\sigma_{z x} & =\mu\left(\frac{\partial u}{\partial z}+\frac{\partial w}{\partial x}\right)=\mu\left[\frac{\partial}{\partial z}\left(\frac{\partial \phi}{\partial x}+\frac{\partial \psi}{\partial z}\right)+\frac{\partial}{\partial x}\left(\frac{\partial \phi}{\partial z}-\frac{\partial \psi}{\partial x}\right)\right] \\
& =\mu\left[\frac{\partial^{2} \phi}{\partial z \partial x}+\frac{\partial^{2} \psi}{\partial z^{2}}+\frac{\partial^{2} \phi}{\partial z \partial x}-\frac{\partial^{2} \psi}{\partial x^{2}}\right] \\
& =\mu\left[2 \frac{\partial^{2} \phi}{\partial z \partial x}+\frac{\partial^{2} \psi}{\partial z^{2}}-\frac{\partial^{2} \psi}{\partial x^{2}}\right]
\end{aligned}
$$

Substituindo (D.75) e (D.76) em (D.80),

$$
\sigma_{z x}=\mu\left[2\left(A q i f e^{[-q z+i(p t-f x)]}\right)-B i^{2} f^{2} e^{[-s z+i(p t-f x)]}+B s^{2} e^{[-s z+i(p t-f x)]}\right]
$$

Sabendo-se que para $z=0 \operatorname{temos} \sigma_{z x}=0$

$$
\begin{gathered}
=\mu\left[2\left(\text { Aqif } e^{[-q 0+i(p t-f x)]}\right)-B i^{2} f^{2} e^{[-s 0+i(p t-f x)]}+B s^{2} e^{[-s 0+i(p t-f x)]}\right] 0 \\
A(2 q i f)+B\left(f^{2}+s^{2}\right)=0
\end{gathered}
$$

Isolando $\frac{A}{B}$ nas eq. (D.79) e (D.82) e igualando-os

$$
\begin{array}{r}
\frac{2 \mu s i f}{(\lambda+2 \mu) q^{2}-\lambda f^{2}}=-\frac{s^{2}+f^{2}}{2 i q f} \\
4 \mu s q f^{2}=\left[(\lambda+2 \mu) q^{2}-\lambda f^{2}\right]\left(s^{2}+f^{2}\right)
\end{array}
$$

elevando ambos os lados ao quadrado e substituindo $s$ e $q$ de (D.71) e (D.74) respectivamente,

$$
\begin{aligned}
& 16 \mu^{2}\left(f^{2}-\kappa^{2}\right)\left(f^{2}-h^{2}\right) f^{4}=\left[(\lambda+2 \mu)\left(f^{2}-h^{2}\right)-\lambda f^{2}\right]^{2}\left(f^{2}-\kappa^{2}+f^{2}\right)^{2} \\
& 16 \mu^{2}\left(f^{2}-\kappa^{2}\right)\left(f^{2}-h^{2}\right) f^{4}=\left[-(\lambda+2 \mu) h^{2}+2 \mu f^{2}\right]^{2}\left(2 f^{2}-\kappa^{2}\right)^{2}
\end{aligned}
$$


Dividindo ambos os lados da equação por $\mu^{2} f^{8}$

$$
16\left(1-\frac{\kappa^{2}}{f^{2}}\right)\left(1-\frac{h^{2}}{f^{2}}\right)=\left[2-\left(\frac{\lambda+2 \mu}{\mu}\right) \frac{h^{2}}{f^{2}}\right]^{2}\left(2-\frac{\kappa^{2}}{f^{2}}\right)^{2}
$$

Como definido anteriormente,

$$
h=\frac{p}{c_{\text {long }}} \quad \text { e } \kappa=\frac{p}{c_{\text {shear }}}
$$

de modo que $\frac{h^{2}}{\kappa^{2}}=\frac{\mu}{(\lambda+2 \mu)}$ que pode ser expressa puramente através do módulo de Poisson $\nu$, ou seja:

$$
\frac{\mu}{\lambda+2 \mu}=\frac{1-2 \nu}{2-2 \nu}=\alpha_{1}^{2}
$$

então $h=\alpha_{1} \kappa$.

Substituindo $h$ e $\frac{\mu}{\lambda+2 \mu}$ em (D.85)

$$
16\left(1-\frac{\kappa^{2}}{f^{2}}\right)\left(1-\alpha_{1}^{2} \frac{\kappa^{2}}{f^{2}}\right)=\left(2-\frac{\kappa^{2}}{f^{2}}\right)^{4}
$$

que por fim pode ser simplificada ainda mais chamando $\frac{\kappa}{f}$ de $\kappa_{1}$, encontrando a seguinte equação cúbica em $\kappa^{2}$

$$
\kappa_{1}^{6}-8 \kappa_{1}^{4}+\left(24-16 \alpha_{1}^{2}\right) \kappa_{1}^{2}+\left(16 \alpha_{1}^{2}-16\right)=0
$$

Uma solução aproximada foi descrita por Meyers [63] da seguinte maneira:

$$
V_{\text {Rayleigh }}=\frac{0.862+1.14 \nu}{1+\nu} V_{\text {shear }}
$$

\section{D.2 Ondas elásticas em meios finitos}

As equações de propagação de ondas de tensão em qualquer corpo solido podem ser encontradas aplicando-se as condições de contorno apropriadas as equações (D.48), (D.49) e (D.50).Entretando, quando há muitas superfícies livres, o problema se torna complexo e, em muitos casos, não possui solução exata.

\section{D.2.1 Ondas longitudinais em barras cilíndricas finas}

Como todo problema físico, existe uma equação diferencial governante, que rege a interação comportamental das variáveis presentes no problema. Na equação governante da 
barra cilíndrica, deve-se relacionar como o deslocamento $u$ se comporta com relação a posição $x$ e do instante de tempo $t$.

Para a dedução a seguir, estão feitas as seguintes suposições:

1. Barra prismática;

2. Homogeneidade do material;

3. Uma secções planas e paralelas permanecem planas e paralelas;

4. Tensão uniaxial;

Embora por suposição a tensão seja uniaxial, nada foi dito no sentido de que a deformação seja uniaxial. Por causa do efeito de Poisson, expansões e contrações radiais são resultados da tensão axial. Essa inércia lateral será re-estudada adiante, pois é a causa do efeito conhecido como dispersão.

Considere a figura (D.2):

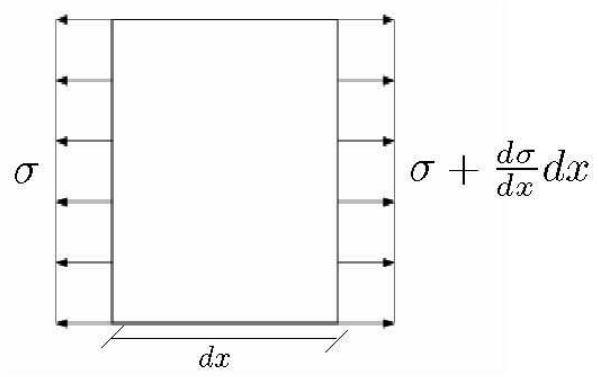

Figura D.2: Elemento diferencial da barra cilíndrica

Sendo $x$ a coordenada da seç̧ão transversal, $u(x, t)$ o deslocamento longitudinal da secção. Presumindo que a barra cilíndrica esteja sobre uma variação dinâmica de tensão, $\sigma(x, t)$, para que as secções adjacentes estejam sob tensões diferentes, é possível escrever:

$$
-\sigma A+\left(\sigma+\frac{\partial \sigma}{\partial x}\right) A=\rho A \mathrm{~d} x \frac{\partial^{2} u}{\partial t^{2}}
$$

na qual $A$ é a área da secção transversal.

A equação (D.90) pode ser reduzida a:

$$
\frac{\partial \sigma}{\partial x}=\rho \frac{\partial^{2} u}{\partial t^{2}}
$$


Como ainda não foram introduzidas características de materiais, a equação governante serve para problemas elásticos e não elásticos. Presumindo que o material é elástico e obedece a lei de Hooke, temos:

$$
\sigma=E \varepsilon
$$

com $E$ e $\varepsilon$ representando o módulo de elasticidade e a deformação axial respectivamente. Entretanto é sabido que:

$$
\varepsilon=\frac{\partial u}{\partial x}
$$

Substituindo (D.93) e (D.92) em (D.91), obtém-se:

$$
E \frac{\partial^{2} u}{\partial x^{2}}=\rho \frac{\partial^{2} u}{\partial t^{2}}
$$

$\mathrm{Ou}$

$$
\frac{\partial^{2} u}{\partial x^{2}}=\frac{1}{V_{0}} \frac{\partial^{2} u}{\partial t^{2}} \quad, \operatorname{com} V_{0}=\sqrt{\frac{E}{\rho}}
$$

\section{D.2.2 Características da propagação de ondas}

A solução da equação diferencial (D.95) é da forma:

$$
u(x, t)=f\left(V_{0} t-x\right)+F\left(V_{0} t+x\right)
$$

Com a função $f$ correspondente a onda se propagando na direção positiva do eixo $x$, enquanto a função $F$ corresponde a onda se propagando na direção negativa de $x$. $V_{0}$ é a velocidade de propagação longitudinal da onda na barra cilíndrica sem considerar a dispersão. A velocidade $V_{0}$ é frequentemente designada de velocidade de barra, para nos ser confundida com outras velocidades de propagação.

A tabela (D.1)(retirada de [37]) de mostra alguns dos valores de $V_{0}$.

Vamos considerar as consequências da equação (D.96), a qual pode ser aplicada a propagação de ondas elásticas cujo comprimento de onda é muito maior que o diâmetro da barra. Por simplificação, iremos penas considerar a propagação no sentido negativo de $x$, de forma a termos:

$$
u=f\left(V_{0} t+x\right)
$$

Derivando ambos os lados em função de $x$

$$
\frac{\partial u}{\partial x}=f^{\prime}\left(V_{0} t+x\right)
$$




\begin{tabular}{cc}
\hline Material & $\begin{array}{c}\text { Velocidade de barra } \\
\left(m \backslash s 10^{-3}\right)\end{array}$ \\
\hline Aço & 5.06 \\
\hline Alumínio & 5.23 \\
\hline Bronze & 3.43 \\
\hline Cádmio & 2.39 \\
\hline Cobre & 3.58 \\
\hline Ferro & 5.18 \\
\hline Magnésio & 4.9 \\
\hline Níquel & 4.75 \\
\hline Ouro & 2.03 \\
\hline Prata & 2.64 \\
\hline Tungstênio & 4.29 \\
\hline Zinco & 3.81 \\
\hline
\end{tabular}

Tabela D.1: Velocidade de barra para alguns materiais

com $f^{\prime}$ indicando a diferenciação com respeito ao argumento $\left(V_{0}+x\right)$.

De maneira similar, derivando ambos os lados de (D.97) com respeito a $t$ :

$$
\frac{\partial u}{\partial t}=V_{0} f^{\prime}\left(V_{0} t+x\right)
$$

De (D.98) e (D.99), temos:

$$
\frac{\partial u}{\partial t}=V_{0} \frac{\partial u}{\partial x}
$$

Sabendo-se que $\frac{\partial u}{\partial t}$ é igual a $\frac{\sigma_{x x}}{E}$, obteremos

$$
\sigma_{x x}=\left(\frac{E}{V_{0}}\right) \frac{\partial u}{\partial t}=\left(\frac{E}{\sqrt{\frac{E}{\rho}}}\right) \frac{\partial u}{\partial t}=(\sqrt{E \rho}) \frac{\partial u}{\partial t}=\left(\rho V_{0}\right) \frac{\partial u}{\partial t}
$$

A eq. (D.101) mostra que há uma relação linear entre a tensão em qualquer ponto e a velocidade da partícula, sendo proporcionais através do termo $\rho V_{0}$, chamado de impedância característica. Esta pode ter com unidade 'ohms acústicos', devida a semelhança com a Lei de Ohm.

Se a velocidade de propagação da onda $V_{0}$ for independente das componentes de frequência presentes na onda de tensão, as componentes da Transformada de Fourier do 
da onda de tensão terão comprimentos de onda muito superiores ao diâmetro da barra e então a onda de tensão se propagará sem dispersão.

Quando este pulso atinge a extremidade livre da barra, ele será refletido. Para descobrirmos como este pulso será refletido, basta aplicarmos as condições de contorno de tensão normal nula na extremidade da barra. Se considerarmos o deslocamento devido ao pulso incidente como

$$
u_{1}=F\left(V_{0} t+x\right)
$$

e o deslocamento devido ao pulso refletido como

$$
u_{2}=f\left(V_{0} t-x\right)
$$

e as tensões geradas por ambos os pulso

$$
E \frac{\partial u_{1}}{\partial x} \quad E \frac{\partial u_{2}}{\partial x}
$$

Desta forma, como tensão final teremos:

$$
E\left(\frac{\partial u_{1}}{\partial x}+\frac{\partial u_{2}}{\partial x}\right)=E\left[F^{\prime}\left(V_{0} t+x\right)-f^{\prime}\left(V_{0} t-x\right)\right]
$$

E com a condição de tensão normal nula em $x=0$, teremos como condição

$$
F^{\prime}\left(V_{0} t\right)-f^{\prime}\left(V_{0} t\right)=0
$$

Sabemos que o formato do pulso de pressão refletido é o mesmo do pulso incidente, mas com sinal oposto. Assim, um pulso de compressão será refletido como um pulso similar de tração. Desta forma, o deslocamento em qualquer ponto da barra, dado por $u_{1}+u_{2}$, será $2 F\left(V_{0} t\right)$ na extremidade livre da mesma, já que $x=0$ nesta posição. Como o deslocamento, as velocidades das partículas nesta extremidade também serão o dobro da velocidade nos outros pontos da barra.

Já quando um pulso é refletido em uma extremidade fixa da barra, temos por condição de contorno impor deslocamento nulo. Neste caso, de (D.102) e (D.103)

$$
u_{1}+u_{2}=F\left(V_{0} t+x\right)+f\left(V_{0}-x\right)
$$

e portanto em $x=0$

$$
F\left(V_{0} t\right)=-f\left(V_{0}\right)
$$


ou seja, o deslocamento causado pelo pulso de pressão incidente é de mesma amplitude e sinal oposto ao causado pelo pulso refletido.As tensões causadas por ambos os pulsos, $E \frac{\partial u_{1}}{\partial x}$ e $E \frac{\partial u_{2}}{\partial x}$, são iguais. Desta forma, um pulso de pressão é refletido sem modificações em uma extremidade fixa, uma vez que as direções do deslocamentos e as direções de propagação são ambas invertidas. Pode-se afirmar, então, que a tensão nesta extremidade fixa é o dobro da gerada pelo pulso de pressão em outro ponto da barra.

Como ilustração da teoria de reflexão em barras brevemente explica, analisaremos o movimento de uma barra $A C$ livre suspensa. Há uma pressão $P$ atuando na extremidade $C$ em um pequeno intervalo de tempo $\mathrm{d} t$. Se a massa da barra for $M$ e a velocidade do centro de massa for $V$, por conservação da quantidade de movimento, temos que $M V=P \mathrm{~d} t$. No instante em que a força é removida, um comprimento $V_{0} \mathrm{~d} t$ da barra estará em compressão enquanto o restante estará em repouso e indeformado. O pulso de tensão irá permanecer com o mesmo comprimento e percorrerá a barra com velocidade $V_{0}$. Da eq. (D.101), pode-se verificar que a velocidade da partícula é $\frac{P}{A \rho V_{0}}$. Assim, para que o momento seja constante e igual a $P \mathrm{~d} t$, a massa viajando a esta velocidade é de $\rho A V_{0} \mathrm{~d} t$. Quando o pulso atinge a face $A$, é refletido como um pulso de tração que também viaja com velocidade $V_{0}$. Este por sua vez é refletido na extremidade $C$ e o ciclo se repete. O pulso ira percorrer uma barra de comprimento $L$ em um tempo $\frac{L}{V_{0}}$ e a fig. (D.3) ilustra o movimento da mesma para $\mathrm{d} t<2 \frac{L}{V_{0}}$, após a retirada da força. As curvas $A$ e $B$ indicam a posição no tempo das extremidades. A curva $C$ indica a posição no tempo do ponto médio que é deslocado duas vezes a cada $\frac{L}{V_{0}}$, já que o pulso passa duas vezes por este ponto até se refletir novamente em uma das duas extremidades. A curva $D$ descreve a posição do centro de gravidade da barra, que é uma parábola durante o tempo de aplicação da força d $t$ e uma reta depois.

A velocidade do centro de massa é sempre positiva pois tanto o movimento do pulso de compressão para a frente ou o do pulso de tração para trás implicam no movimento do centro de gravidade para a frente. Pode-se notar que para cada ciclo de $2 \frac{L}{V_{0}}$, as posições do ponto médio e do centro de gravidade coincidem quatro vezes. Duas dessas ocasiões são quando o pulso está passando pelo ponto médio da barra. As outras duas são quando apenas metade do pulso se refletiu em uma das extremidades. Na prática, o pulso ira crescer continuamente conforme se propaga na barra. Isso ocorre devido a 


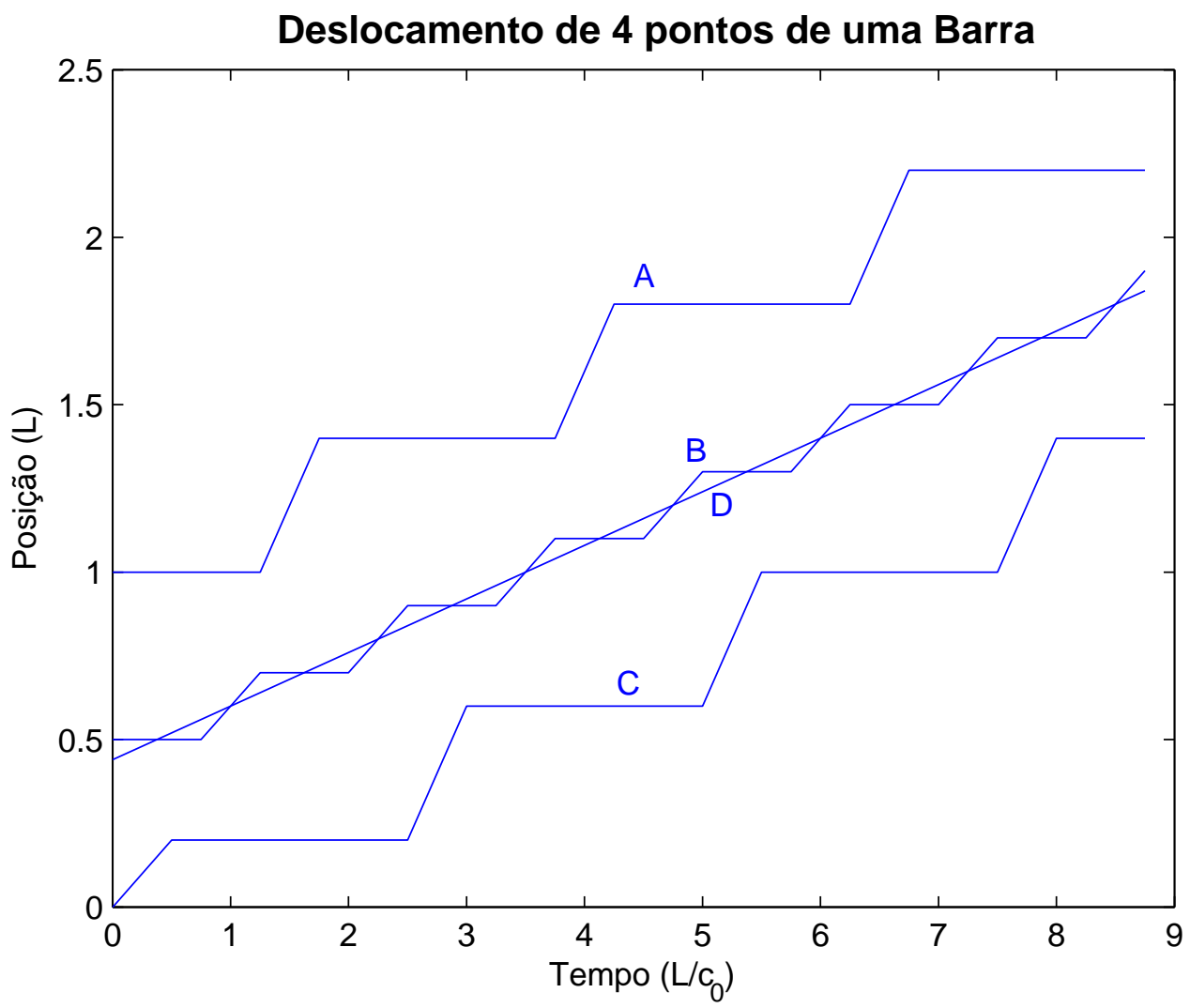

Figura D.3: Posição no tempo demonstrando o movimento descontínuo produzido por repetidas reflexões de um pulso de pressões longitudinais. Movimento de $(A)$ na face da frente da barra, $(B)$ no ponto médio, $(C)$ na face de trás, $(D)$ no centro de gravidade. As deformações foram exageradas no sentido de facilitar a compreensão do fenômeno

dispersão produzida pela inércia e movimento lateral na barra e também pelo atrito interno. Segundo Kolsky [51] os patamares iriam consequentemente se tornar arredondados e eventualmente a largura do pulso aumentaria o suficiente para tornar maior que o comprimento da barra. O problema então pode ser melhor considerado como um movimento de velocidade constante da barra inteira com, ao mesmo tempo,oscilações longitudinais em torno do centro de gravidade. As oscilações sofreriam um decaimento logarítmico, tornando o problema apenas de movimento de corpo rígido com o passar do tempo.

\section{D.3 Forma vetorial das equações de onda}

As equações de movimento podem ser expressas em forma vetorial. Uma das vantagens desse tipo de representação é que,neste formato, independem do sistema de coordenadas. 
D.3. Forma vetorial das equações de onda

Assim, expressa-las em qualquer sistema de coordenadas se torna simples.

Se o deslocamento for denotado por um vetor $\mathbf{s}$, as componentes dele por $(u, v, w)$ em um sistema de coordenadas cartesianas $(x, y, z)$, a dilatação $\Delta$ de magnitude $\left[\frac{\partial u}{\partial x}+\frac{\partial v}{\partial y}+\frac{\partial w}{\partial z}\right]$ é igual ao divergente de s, escrito div s. A rotação é um vetor, escrito em notação vetorial como $\frac{1}{2}$ curl $\mathbf{s}$, de componentes, em coordenadas cartesianas, $w_{x}, w_{y}$ e $w_{z}$. Se $\mathbf{i}, \mathbf{j}$ e $\mathbf{k}$ forem os versores ao longo de $x, y$ e $z$ respectivamente, temos:

$$
\operatorname{curl} \mathbf{s}=\left(\frac{\partial w}{\partial y}-\frac{\partial v}{\partial z}\right) \mathbf{i}+\left(\frac{\partial u}{\partial z}-\frac{\partial w}{\partial x}\right) \mathbf{j}+\left(\frac{\partial v}{\partial x}-\frac{\partial u}{\partial y}\right) \mathbf{k}
$$

Outra função que deve ser definida é a gradiente. Este é um vetor de componentes proporcionais a taxa de variação das derivadas de uma quantidade escalar. Se $V$ é uma quantidade escalar e é função de $x, y$ e $z$,temos

$$
\operatorname{grad} V=\frac{\partial V}{\partial x} \mathbf{i}+\frac{\partial V}{\partial y} \mathbf{j}+\frac{\partial V}{\partial z} \mathbf{k}
$$

Podemos então aplicar o operado de Laplace $\nabla^{2}$ em um vetor sde forma a obtermos

$$
\nabla^{2} \mathbf{s}=\nabla^{2} u \mathbf{i}+\nabla^{2} v \mathbf{j}+\nabla^{2} w \mathbf{k}
$$

$\operatorname{com} \nabla^{2} u=\left(\frac{\partial^{2} u}{\partial x^{2}}+\frac{\partial^{2} v}{\partial y^{2}}+\frac{\partial^{2} w}{\partial z^{2}}\right)$ de modo a podermos escrever

$$
\nabla^{2} \mathbf{s}=\operatorname{grad} \operatorname{div} \mathbf{s}-\operatorname{curl} \operatorname{curl} \mathbf{s}
$$

Finalmente podemos escrever as equações de movimento (D.25), (D.26) e (D.27) como uma única equação vetorial

$$
\rho \frac{\partial^{2} \mathbf{s}}{\partial t^{2}}=(\lambda+\mu) \operatorname{grad} \operatorname{div} \mathbf{s}+\mu \nabla^{2} \mathbf{s}
$$

Substituindo $\nabla^{2}$ s como descrito em (D.112),

$$
\rho \frac{\partial^{2} \mathbf{s}}{\partial t^{2}}=(\lambda+2 \mu) \operatorname{grad} \operatorname{div} \mathbf{s}-\mu \operatorname{curl} \operatorname{curl} \mathbf{s}
$$

Se escrevermos a equação (D.114) em termos da quantidade escalar $\Delta(=\operatorname{div} \mathbf{s})$ e da quantidade vetorial $\omega\left(=\frac{1}{2} \operatorname{curl} \mathbf{s}\right)$, teremos

$$
\rho \frac{\partial^{2} \mathbf{s}}{\partial t^{2}}=(\lambda+2 \mu) \operatorname{grad} \Delta-2 \mu \operatorname{curl} \omega
$$




\section{D.4 Mudando para sistemas de coordenadas curvos}

Embora as coordenadas cartesianas são convenientes para muitos problemas, não raramente é conveniente transformar as equações para um outro sistemas de coordenadas mais conveniente. Um exemplo disto seria aplicar as condições de contorno de superfície livre em uma barra cilíndrica nas equações de movimento.

Em geral, se $\left(q_{1}, q_{2}, q_{3}\right)$ são as coordenadas de um ponto em um sistema de coordenadas e $(x, y, z)$ são coordenadas cartesianas, $x, y$ e $z$ serão funções de $q_{1}, q_{2}$ e $q_{3}$, de modo a $x=x\left(q_{1}, q_{2}, q_{3}\right), y=y\left(q_{1}, q_{2}, q_{3}\right)$ e $z=z\left(q_{1}, q_{2}, q_{3}\right)$ e

$$
\mathrm{d} x=\frac{\partial x}{\partial q_{1}} \mathrm{~d} q_{1}+\frac{\partial x}{\partial q_{2}} \mathrm{~d} q_{2}+\frac{\partial x}{\partial q_{3}} \mathrm{~d} q_{3}
$$

Para um elemento de comprimento $\mathrm{d} l$, teremos:

$$
\begin{gathered}
\mathrm{d} l=\mathrm{d} x^{2}+\mathrm{d} y^{2}+\mathrm{d} z^{2} \\
\mathrm{~d} x^{2}=\frac{\partial^{2} x}{\partial q_{1}^{2}} \mathrm{~d} q_{1}^{2}+\frac{\partial^{2} x}{\partial q_{2}^{2}} \mathrm{~d} q_{2}^{2}+\frac{\partial^{2} x}{\partial q_{3}^{2}} \mathrm{~d} q_{3}^{2}+2 \frac{\partial^{2} x}{\partial q_{1} \partial q_{2}} \mathrm{~d} q_{1} \mathrm{~d} q_{2}+2 \frac{\partial^{2} x}{\partial q_{2} \partial q_{3}} \mathrm{~d} q_{2} \mathrm{~d} q_{3}+2 \frac{\partial^{2} x}{\partial q_{3} \partial q_{1}} \mathrm{~d} q_{3} \mathrm{~d} q_{1} \\
\mathrm{~d} y^{2}=\frac{\partial^{2} y}{\partial q_{1}^{2}} \mathrm{~d} q_{1}^{2}+\frac{\partial^{2} y}{\partial q_{2}^{2}} \mathrm{~d} q_{2}^{2}+\frac{\partial^{2} y}{\partial q_{3}^{2}} \mathrm{~d} q_{3}^{2}+2 \frac{\partial^{2} y}{\partial q_{1} \partial q_{2}} \mathrm{~d} q_{1} \mathrm{~d} q_{2}+2 \frac{\partial^{2} y}{\partial q_{2} \partial q_{3}} \mathrm{~d} q_{2} \mathrm{~d} q_{3}+2 \frac{\partial^{2} y}{\partial q_{3} \partial q_{1}} \mathrm{~d} q_{3} \mathrm{~d} q_{1} \\
\mathrm{~d} z^{2}=\frac{\partial^{2} z}{\partial q_{1}^{2}} \mathrm{~d} q_{1}^{2}+\frac{\partial^{2} z}{\partial q_{2}^{2}} \mathrm{~d} q_{2}^{2}+\frac{\partial^{2} z}{\partial q_{3}^{2}} \mathrm{~d} q_{3}^{2}+2 \frac{\partial^{2} z}{\partial q_{1} \partial q_{2}} \mathrm{~d} q_{1} \mathrm{~d} q_{2}+2 \frac{\partial^{2} z}{\partial q_{2} \partial q_{3}} \mathrm{~d} q_{2} \mathrm{~d} q_{3}+2 \frac{\partial^{2} z}{\partial q_{3} \partial q_{1}} \mathrm{~d} q_{3} \mathrm{~d} q_{1}
\end{gathered}
$$

Resultando em

$$
\mathrm{d} l^{2}=g_{11} \mathrm{~d} q_{1}^{2}+g_{22} \mathrm{~d} q_{2}^{2}+g_{33} \mathrm{~d} q_{3}^{2}+2 g_{23} \mathrm{~d} q_{2} \mathrm{~d} q_{3}+2 g_{31} \mathrm{~d} q_{3} \mathrm{~d} q_{1}+2 g_{12} \mathrm{~d} q_{1} \mathrm{~d} q_{2}
$$

$\operatorname{com} g_{i j}=g_{j i}=\frac{\partial^{2} x}{\partial q_{i} \partial q_{j}}+\frac{\partial^{2} y}{\partial q_{i} \partial q_{j}}+\frac{\partial^{2} z}{\partial q_{i} \partial q_{j}}$

Considerando o comprimento $\mathrm{d} l_{1}$ que corresponde a variação de $q_{1}$ a $q_{1}+\mathrm{d} q_{1}$ com $q_{2}$ e $q_{3}$ constantes, teremos $\mathrm{d} l_{1}=\sqrt{g_{11}} \mathrm{~d} q_{1}$. De maneira análoga, $\mathrm{d} l_{2}=\sqrt{g_{22}} \mathrm{~d} q_{2}$ e $\mathrm{d} l_{3}=\sqrt{g_{33}} \mathrm{~d} q_{3}$. Adotaremos $h_{1}, h_{2}$ e $h_{3}$ para $\sqrt{g_{11}}, \sqrt{g_{22}}$ e $\sqrt{g_{33}}$, respectivamente. Se as superfícies $q_{1}=$ constante, $q_{2}=$ constante e $q_{3}=$ constante sempre se intersectam formando ângulos retos, podemos considerar um elemento de volume $\mathrm{d} V$ como:

$$
\mathrm{d} V=h_{1} h_{2} h_{3} \mathrm{~d} q_{1} \mathrm{~d} q_{2} \mathrm{~d} q_{3}
$$


Considerando um vetor função $\mathbf{F}$ que tenhas componentes $\mathbf{F}_{1}, \mathbf{F}_{2}$ e $\mathbf{F}_{3}$ nas direções dos eixos de um sistema de coordenadas curvilíneas ortogonais e sejam a, b e c os versores nestes eixos de modo a:

$$
\mathbf{F}=F_{1} \mathbf{a}+F_{2} \mathbf{b}+F_{2} \mathbf{c}
$$

As funções desse vetor podem ser expressas em função dos termos $h_{1}, h_{2}$ e $h_{3}$. O divergente então pode ser escrito por

$$
\operatorname{div} \mathbf{F}=\frac{1}{h_{1} h_{2} h_{3}}\left[\frac{\partial}{\partial q_{1}}\left(h_{2} h_{3} F_{1}\right)+\frac{\partial}{\partial q_{2}}\left(h_{1} h_{3} F_{2}\right)+\frac{\partial}{\partial q_{3}}\left(h_{1} h_{2} F_{3}\right)\right]
$$

Também temos:

$$
\begin{aligned}
\operatorname{curl} \mathbf{F} & =\frac{\mathbf{a}}{h_{2} h_{3}}\left[\frac{\partial}{\partial q_{2}}\left(h_{3} F_{3}\right)-\frac{\partial}{\partial q_{3}}\left(h_{2} F_{2}\right)\right] \\
& +\frac{\mathbf{b}}{h_{3} h_{1}}\left[\frac{\partial}{\partial q_{3}}\left(h_{1} F_{1}\right)-\frac{\partial}{\partial q_{1}}\left(h_{3} F_{3}\right)\right] \\
& +\frac{\mathbf{c}}{h_{1} h_{2}}\left[\frac{\partial}{\partial q_{1}}\left(h_{2} F_{2}\right)-\frac{\partial}{\partial q_{2}}\left(h_{1} F_{1}\right)\right]
\end{aligned}
$$

E por último,

$$
\operatorname{grad} V=\frac{\mathbf{a}}{h_{1}} \frac{\partial V}{\partial q_{1}}+\frac{\mathbf{b}}{h_{2}} \frac{\partial V}{\partial q_{2}}+\frac{\mathbf{c}}{h_{3}} \frac{\partial V}{\partial q_{3}}
$$

Para transformarmos (D.124), (D.125) e (D.126) em um determinado sistema de coordenadas, devemos encontrar $h_{1}, h_{2}$ e $h_{3}$ correspondentes. Usaremos um sistema de coordenadas cilíndricas com $r, \theta$ e $z$, sendo $\mathrm{d} l_{1}=\mathrm{d} r, \mathrm{~d} l_{2}=r \mathrm{~d} \theta$ e $\mathrm{d} l_{3}=\mathrm{d} z$, resultando em $h_{1}=1, h_{2}=r$ e $h_{3}=1$.

\section{D.5 Equações de movimento em coordenadas cilín- dricas}

Se usarmos as coordenadas cilíndricas, com $r, \theta$ e $z$ e deslocamentos correspondentes $u_{r}$, $u_{\theta}$ e $u_{z}$, temos como equações de movimento:

$$
\begin{gathered}
\rho \frac{\partial^{2} u_{r}}{\partial t^{2}}=(\lambda+2 \mu) \frac{\partial \Delta}{\partial r}-\frac{2 \mu}{r} \frac{\partial w_{z}}{\partial \theta}+2 \mu \frac{\partial w_{\theta}}{\partial z} \\
\rho \frac{\partial^{2} u_{\theta}}{\partial t^{2}}=(\lambda+2 \mu) \frac{1}{r} \frac{\partial \Delta}{\partial \theta}-2 \mu \frac{\partial w_{r}}{\partial z}+2 \mu \frac{\partial w_{z}}{\partial r} \\
\rho \frac{\partial^{2} u_{z}}{\partial t^{2}}=(\lambda+2 \mu) \frac{\partial \Delta}{\partial z}-\frac{2 \mu}{r} \frac{\partial}{\partial r}\left(r w_{\theta}\right)+\frac{2 \mu}{r} \frac{\partial w_{r}}{\partial \theta}
\end{gathered}
$$


com a dilatação nestas coordenadas sendo

$$
\Delta=\frac{1}{r} \frac{\partial\left(r u_{r}\right)}{\partial r}+\frac{1}{r} \frac{\partial u_{\theta}}{\partial \theta}+\frac{\partial u_{z}}{\partial z}
$$

e as componentes de rotação $w_{r}, w_{\theta}$ e $w_{z}$, nas direções do vetor raio $r$, perpendicular ao plano $r z$ e paralelo ao eixo $z$, definidas por

$$
\left\{\begin{array}{l}
2 w_{r}=\frac{1}{r} \frac{\partial u_{z}}{\partial \theta}-\frac{\partial u_{\theta}}{\partial z} \\
2 w_{\theta}=\frac{\partial u_{r}}{\partial z}-\frac{\partial u_{z}}{\partial r} \\
2 w_{z}=\frac{1}{r}\left[\frac{\partial\left(r u_{\theta}\right)}{\partial r}-\frac{\partial u_{r}}{\partial \theta}\right]
\end{array}\right.
$$

Multiplicando a primeira equação por $r$ e derivando em função de $r$, derivando a segunda equação em função de $\theta$ e, na terceira equação, passando $r$ multiplicando o lado direito e derivando-a em função de $z$, obtemos:

$$
\left\{\begin{array}{l}
2 \frac{\partial\left(r w_{r}\right)}{\partial r}=\frac{\partial^{2} u_{z}}{\partial r \partial \theta}-\frac{\partial^{2}\left(r u_{\theta}\right)}{\partial r \partial z} \\
2 \frac{\partial w_{\theta}}{\partial \theta}=\frac{\partial^{2} u_{r}}{\partial \theta \partial z}-\frac{\partial^{2} u_{z}}{\partial \theta \partial r} \\
2 \frac{\partial\left(r w_{z}\right)}{\partial z}=\frac{\partial^{2}\left(r u_{\theta}\right)}{\partial z \partial r}-\frac{\partial^{2} u_{r}}{\partial z \partial \theta}
\end{array}\right.
$$

e somando as 3 equações e multiplicando por $\frac{1}{2 r}$

$$
\frac{1}{r} \frac{\partial\left(r w_{r}\right)}{\partial r}+\frac{1}{r} \frac{\partial w_{\theta}}{\partial \theta}+\frac{\partial\left(w_{z}\right)}{\partial z}=0
$$

\section{D.6 Equações de Pocchammer-Chree para barras ci- líndricas}

Como mencionado anteriormente, é possível resolver qualquer problema de vibração ou propagação de ondas de tensão em um meio elástico inserindo as condições de contorno corretas nas equações de movimento (D.25), (D.26) e (D.27). Entretanto, por causa da grande complexidade das equações diferenciais em que se tornaram as equações de movimento após inserção das condições de contorno, ainda não foi possível achar a solução exata para cilindros de comprimento finito em vibração axial. Soluções muito próximas 
da solução exata forma descobertas, desde que o comprimento do cilindro seja muito superior ao diâmetro do mesmo. Pocchammer, em [80] foi o primeiro a investigar este problema em termos de equações elásticas. Chree, de maneira independente, alcançou os mesmos resultados em [23]. Love estudou e analisou as idéias de Pocchammer em [59].

É extremamente complicado inserir as condições de contorno nas equações de movimento escritas em coordenadas cartesianas (D.25), (D.26) e (D.27), sendo reescreve-las em coordenadas cilíndricas. Esse procedimento foi previamente explicado, no qual usamos as variáveis $r, \theta$ e $z$ e deslocamentos correspondentes $u_{r}, u_{\theta}$ e $u_{z}$.

No caso do cilindro, temos como condições de contorno tensões radias nulas. Desta forma, $\sigma_{r r}, \sigma_{\theta r}$ e $\sigma_{z r}$ são nulos. Estas três tensões podem ser descritas por:

$$
\left\{\begin{array}{l}
\sigma_{r r}=\lambda \Delta+2 \mu \frac{\partial u_{r}}{\partial r} \\
\sigma_{\theta r}=\mu\left[\frac{1}{r} \frac{\partial u_{r}}{\partial \theta}+r \frac{\partial}{\partial r}\left(\frac{u_{\theta}}{r}\right)\right] \\
\sigma_{z r}=\mu\left[\frac{\partial u_{r}}{\partial z}+\frac{\partial u_{z}}{\partial r}\right]
\end{array}\right.
$$

Se considerarmos a propagação de um pulso de infinitas ondas senoidais ao longo do cilindro sólido de forma a termos o deslocamento em cada ponto como uma função harmônica em $z$ e $t$, teremos:

$$
\left\{\begin{array}{l}
u_{r}=U e^{[i(\gamma z+p t)]} \\
u_{\theta}=V e^{[i(\gamma z+p t)]} \\
u_{z}=W e^{[i(\gamma z+p t)]}
\end{array}\right.
$$

com $U, V$ e $W$ sendo funções de $R$ e $\theta$, sendo a frequência da onda $\frac{p}{2 \pi}$ e o comprimento de onda $\frac{2 \pi}{\gamma}$. A velocidade da onda é, então, $\frac{p}{\gamma}$. Substituindo (D.135) nas equações (D.127), (D.128) e (D.129) e inserindo as condições de contorno das três componentes de tensão descritas em (D.134), podemos obter a velocidade de fase para uma dada frequência.

\section{D.6.1 Equações de Pocchammer-Chree para ondas longitudi- nais em cilindros}

Assumindo o deslocamento $u_{\theta}$ nulo, pois a movimentação é simétrica ao redor do eixo do cilíndro, tornamos $U$ e $W$ independentes de $\theta$. Também podemos dizer que, de (D.131), 
$w_{r}$ e $w_{z}$ também são nulas. Então, (D.127), (D.128) se tornam:

$$
\begin{gathered}
-\rho p^{2} u_{r}=(\lambda+2 \mu) \frac{\partial \Delta}{\partial r}+i 2 \mu \gamma w_{\theta} \\
-\rho p^{2} u_{z}=i(\lambda+2 \mu) \gamma \Delta-\frac{2 \mu}{r} \frac{\partial}{\partial r}\left(r w_{\theta}\right)
\end{gathered}
$$

já que de (D.135) temos que $\frac{\partial u_{r}}{\partial t}=i p u_{r}, \frac{\partial u_{r}}{\partial z}=i \gamma u_{r}$ e similares para $\frac{\partial u_{r}}{\partial t}$ e $\frac{\partial u_{r}}{\partial z}$.

Temos por objetivo achar equações que dependam somente de $\Delta$ ou $w_{\theta}$.

Multiplicando (D.136) por $r$

$$
-\rho p^{2} r u_{r}=(\lambda+2 \mu) r \frac{\partial \Delta}{\partial r}+i 2 \mu \gamma r w_{\theta}
$$

Derivando em $r$

$$
-\rho p^{2} \frac{\partial\left(r u_{r}\right)}{\partial r}=(\lambda+2 \mu) \frac{\partial}{\partial r}\left(r \frac{\partial \Delta}{\partial r}\right)+i 2 \mu \gamma \frac{\partial\left(r w_{\theta}\right)}{\partial r}
$$

mas, pela regra da cadeia,

$$
\frac{\partial}{\partial r}\left(r \frac{\partial \Delta}{\partial r}\right)=\frac{\partial \Delta}{\partial r}+r \frac{\partial^{2} \Delta}{\partial r^{2}}
$$

obtendo então,

$$
-\rho p^{2} \frac{\partial\left(r u_{r}\right)}{\partial r}=(\lambda+2 \mu)\left(r \frac{\partial^{2} \Delta}{\partial r^{2}}+\frac{\partial \Delta}{\partial r}\right)+i 2 \mu \gamma \frac{\partial\left(r w_{\theta}\right)}{\partial r}
$$

e dividindo por $r$

$$
-\rho p^{2} \frac{1}{r} \frac{\partial\left(r u_{r}\right)}{\partial r}=(\lambda+2 \mu)\left(\frac{\partial^{2} \Delta}{\partial r^{2}}+\frac{1}{r} \frac{\partial \Delta}{\partial r}\right)+i \frac{2 \mu \gamma}{r} \frac{\partial\left(r w_{\theta}\right)}{\partial r}
$$

Sabendo-se que, de (D.135), $\frac{\partial u_{z}}{\partial z}=i \gamma u_{z}$ e portanto $u_{z}=\frac{\left(\frac{\partial u_{z}}{\partial z}\right)}{i \gamma}$, temos de (D.137),

$$
-\rho p^{2} \frac{\partial u_{z}}{\partial z}=-(\lambda+2 \mu) \gamma^{2} \Delta-i \frac{2 \mu \gamma}{r} \frac{\partial}{\partial r}\left(r w_{\theta}\right)
$$

Somando-se (D.142) e (D.143),

$$
-\rho p^{2}\left(\frac{1}{r} \frac{\partial\left(r u_{r}\right)}{\partial r}+\frac{\partial u_{z}}{\partial z}\right)=(\lambda+2 \mu)\left(\frac{\partial^{2} \Delta}{\partial r^{2}}+\frac{1}{r} \frac{\partial \Delta}{\partial r}\right)+(\lambda+2 \mu) \gamma^{2} \Delta
$$

Substituindo-se por $\Delta$ o valor dos termos entre parênteses do lado esquerdo da igualdade de acordo com (D.130), chegamos a:

$$
-\rho p^{2} \Delta=(\lambda+2 \mu)\left(\frac{\partial^{2} \Delta}{\partial r^{2}}+\frac{1}{r} \frac{\partial \Delta}{\partial r}-\gamma^{2} \Delta\right)
$$


e por fim

$$
\frac{\partial^{2} \Delta}{\partial r^{2}}+\frac{1}{r} \frac{\partial \Delta}{\partial r}+h^{\prime} \Delta=0 \quad \text { com } \quad h^{\prime}=\frac{\rho p^{2}}{\lambda+2 \mu}-\gamma^{2}
$$

Agora só resta descobrirmos uma equação que dependa apenas de $w_{\theta}$. Com essa intenção, conhecendo a relação $u_{r}=\frac{\partial u_{r}}{\partial z} \frac{1}{\gamma i}$, podemos reescrever (D.136) como

$$
-\rho p^{2} \frac{\partial u_{r}}{\partial z} \frac{1}{\gamma i}=(\lambda+2 \mu) \frac{\partial \Delta}{\partial r}+i 2 \mu \gamma w_{\theta}
$$

$\mathrm{Ou}$

$$
\rho p^{2} \frac{\partial u_{r}}{\partial z}=-i(\lambda+2 \mu) \gamma \frac{\partial \Delta}{\partial r}+2 \mu \gamma^{2} w_{\theta}
$$

Derivando (D.137) com relação a $r$,

$$
-\rho p^{2} \frac{\partial u_{z}}{r}=i(\lambda+2 \mu) \gamma \frac{\partial \Delta}{r}-\frac{\partial}{\partial r}\left(\frac{2 \mu}{r} \frac{\partial}{\partial r}\left(r w_{\theta}\right)\right)
$$

Pela regra da cadeia

$$
\begin{gathered}
\frac{\partial}{\partial r}\left(r w_{\theta}\right)=1 w_{\theta}+r \frac{\partial w_{\theta}}{\partial r} \Rightarrow \frac{2 \mu}{r} \frac{\partial}{\partial r}\left(r w_{\theta}\right)=\frac{2 \mu w_{\theta}}{r}+2 \mu \frac{\partial w_{\theta}}{\partial r} \\
\frac{\partial}{\partial r}\left(\frac{2 \mu}{r} \frac{\partial}{\partial r}\left(r w_{\theta}\right)\right)=\frac{\partial}{\partial r}\left(\frac{2 \mu w_{\theta}}{r}+2 \mu \frac{\partial w_{\theta}}{\partial r}\right)=-\frac{2 \mu w_{\theta}}{r^{2}}+\frac{2 \mu}{r} \frac{\partial w_{\theta}}{\partial r}+2 \mu \frac{\partial^{2} w_{\theta}}{\partial r^{2}}
\end{gathered}
$$

Substituindo em (D.149),

$$
-\rho p^{2} \frac{\partial u_{z}}{r}=i(\lambda+2 \mu) \gamma \frac{\partial \Delta}{r}-\left(-\frac{2 \mu w_{\theta}}{r^{2}}+\frac{2 \mu}{r} \frac{\partial w_{\theta}}{\partial r}+2 \mu \frac{\partial^{2} w_{\theta}}{\partial r^{2}}\right)
$$

Somando com (D.148),

$$
\rho p^{2}\left(\frac{\partial u_{z}}{r}-\frac{\partial u_{z}}{r}\right)=\frac{2 \mu w_{\theta}}{r^{2}}+2 \mu \gamma^{2} w_{\theta}-\frac{2 \mu}{r} \frac{\partial w_{\theta}}{\partial r}-2 \mu \frac{\partial^{2} w_{\theta}}{\partial r^{2}}
$$

Chegando finalmente em:

$$
\frac{\partial^{2} w_{\theta}}{\partial r^{2}}+\frac{1}{r} \frac{\partial w_{\theta}}{\partial r}-\frac{w_{\theta}}{r^{2}}+\kappa^{\prime} w_{\theta}=0 \quad \text { com } \quad k a p p a^{\prime}=\frac{\rho p^{2}}{\mu}-\gamma^{2}
$$

Se trocarmos a variável em (D.146) de $r$ para $h^{\prime} r$ e em (D.153) de $r$ para $\kappa^{\prime} r$, obteremos as seguintes equações:

$$
\begin{gathered}
\frac{\partial^{2} \Delta}{\partial\left(h^{\prime} r\right)^{2}}+\frac{1}{\left(h^{\prime} r\right)} \frac{\partial \Delta}{\partial\left(h^{\prime} r\right)}+\Delta=0 \\
\frac{\partial^{2} w_{\theta}}{\partial\left(\kappa^{\prime} r\right)^{2}}+\frac{1}{\left(\kappa^{\prime} r\right)} \frac{\partial w_{\theta}}{\partial\left(\kappa^{\prime} r\right)}-\frac{w_{\theta}}{\left(\kappa^{\prime} r\right)^{2}}+w_{\theta}=0
\end{gathered}
$$


A equação de Bessel possui o seguinte formato

$$
\frac{\mathrm{d}^{2} b}{\mathrm{~d} m^{2}}+\frac{1}{m} \frac{\mathrm{d} b}{\mathrm{~d} e}+\left(1-\frac{d^{2}}{m^{2}}\right) b=0
$$

e tem solução $J_{d}(m)$.

Desta forma, podemos dizer que

$$
\Delta=G J_{0}\left(h^{\prime} r\right)
$$

$\mathrm{e}$

$$
w_{\theta}=H J_{1}\left(\kappa^{\prime} r\right)
$$

com $G$ e $H$ funções de $z$ e $t$, mas independentes de $r$.

Desenvolvendo (D.130), descobrimos que

$$
\begin{gathered}
\Delta=\frac{1}{r} \frac{\partial}{\partial r}\left(r u_{r}\right)+\frac{1}{r} \frac{\partial}{\partial \theta} u_{\theta}+\frac{\partial}{\partial z} u_{z} \\
\Delta=\frac{1}{r}\left(u_{r}+r \frac{\partial}{\partial r} u_{r}\right)+\frac{\partial}{\partial z} u_{z} \\
\Delta=\frac{u_{r}}{r}+\frac{\partial}{\partial r} u_{r}+\frac{\partial}{\partial z} u_{z}
\end{gathered}
$$

Substituindo $u_{r}$ e $u_{\theta}$ de (D.135), temos

$$
\Delta=\frac{U e^{i[\gamma z+p t]}}{r}+\frac{\partial}{\partial r} U e^{i[\gamma z+p t]}+W i \gamma e^{i[\gamma z+p t]}
$$

chegando a

$$
\Delta=\left(\frac{\partial U}{\partial r}+\frac{U}{r}+i \gamma W\right) e^{[i(\gamma z+p t)]}
$$

Agora desenvolvendo (D.131) e substituindo $u_{r}$ e $u_{\theta}$ de (D.135), descobrimos que

$$
2 w_{\theta}=\frac{\partial}{\partial z}\left(u_{r}\right)-\frac{\partial}{\partial r}\left(u_{z}\right)=\left(i \gamma U-\frac{\partial W}{\partial r}\right) e^{[i(\gamma z+p t)]}
$$

Para satisfazer (D.157), (D.158), (D.163) e (D.164), $U$ e $W$ devem ter os seguintes formatos:

$$
\begin{gathered}
U=A \frac{\partial}{\partial r} J_{0}\left(h^{\prime} r\right)+C \gamma J_{1}\left(\kappa^{\prime} r\right) \\
W=A i \gamma J_{0}\left(h^{\prime} r\right)+\frac{C i}{r} \frac{\partial}{\partial r}\left[r J_{1}\left(\kappa^{\prime} r\right)\right]
\end{gathered}
$$

com $A$ e $C$ sendo constantes. 
Para checar a validade das forma proposta de $U$ e $W$ de (D.165) e (D.166), vamos igualar a definição de $\Delta$ de (D.157) com a de (D.163), obtendo:

Substituindo (D.165) e (D.166) em (D.135) e depois inserindo (D.135) nas equações de Condição de Contorno de $\sigma_{r r}$ e $\sigma_{r z}$ dadas por (D.134), obtemos:

$$
\left\{\begin{array}{l}
A\left[2 \mu \frac{\partial^{2}}{\partial a^{2}} J_{0}\left(h^{\prime} a\right)-\frac{\lambda}{\lambda+2 \mu} p^{2} \rho J_{0}\left(h^{\prime} a\right)\right]+2 C \mu \gamma \frac{\partial}{\partial a} J_{1}\left(\kappa^{\prime} a\right)=0 \\
2 A \gamma \frac{\partial}{\partial a} J_{0}\left(h^{\prime} a\right)+C\left(2 \gamma^{2}-\frac{p^{2} \rho}{\mu}\right) J_{1}\left(\kappa^{\prime} a\right)
\end{array}\right.
$$

(com $\frac{\partial}{\partial a}$ significando $\left.\left[\frac{\partial}{\partial r}\right]_{r=a}\right)$. Ao isolarmos $\frac{A}{C}$ de cada uma das equações de (D.167) e igualarmos ambos, obtemos a Equação de Frequências ou Equação de PocchammerChree, dependente apenas da frequência e comprimento da onda, raio do cilindro $a$, constantes elásticas $\mu$ e $\lambda$ e da densidade $\rho$. Essa solução não são exatas para cilindros de comprimento finito, já que não utilizamos a condição de contorno de tensão nula na extremidade da barra. Entretanto, se o comprimento do cilindro for muito maior que o raio $a$, a tensão residual se torna muito pequena e desprezível.

Podemos expandir $J_{0}\left(h^{\prime} a\right)$ e $J_{1}\left(\kappa^{\prime} a\right)$ como séries de potência do seguinte modo:

$$
\begin{gathered}
J_{0}\left(h^{\prime} a\right)=1-\frac{1}{4}\left(h^{\prime} a\right)^{2}+\frac{1}{64}\left(h^{\prime} a\right)^{4}-\ldots \\
J_{1}\left(\kappa^{\prime} a\right)=\frac{1}{2}\left(\kappa^{\prime} a\right)-\frac{1}{16}\left(\kappa^{\prime} a\right)^{3}+\ldots
\end{gathered}
$$

Se o raio do cilindro for suficientemente pequeno para termos tanto $h^{\prime} a$ quanto $\kappa^{\prime} a$ menores que a unidade, podemos aproximar a Equação de Frequência desprezando as potências maiores que um de $h^{\prime} a$ e $\kappa^{\prime} a$, usando

$$
\begin{aligned}
& J_{0}\left(h^{\prime} a\right)=1 \\
& \frac{\partial J_{0}\left(h^{\prime} a\right)}{\partial a}=-\frac{1}{2} h^{\prime 2} a \\
& \frac{\partial^{2} J_{0}\left(h^{\prime} a\right)}{\partial a^{2}}=-\frac{1}{2} h^{\prime 2} \\
& J_{1}\left(\kappa^{\prime} a\right)=\frac{\kappa^{\prime 2} a}{2} \\
& \frac{\partial J_{1}\left(\kappa^{\prime} a\right)}{\partial a}=\frac{\kappa^{\prime 2}}{2}
\end{aligned}
$$

Substituindo todas na Equação de Frequências, teremos

$$
\left(2 \gamma^{2}-p \rho^{2}\right) \kappa^{\prime} a\left(h^{\prime 2}+\frac{\lambda p^{2} \rho}{\mu(\lambda+2 \mu)}\right)=2 \gamma^{2} \kappa^{\prime} a
$$


Desprezando a solução $\kappa^{\prime}=0$, que corresponde a velocidade $\left(\frac{\mu}{\rho}\right)^{\frac{1}{2}}$, substituindo $h^{\prime}$ de (D.146)

$$
\frac{p^{2}}{\gamma^{2}}=\frac{\mu(3 \lambda+2 \mu)}{(\lambda+\mu) \rho}
$$

Mas, expressando em função do modulo de Elasticidade da equação (D.15), temos:

$$
\frac{p^{2}}{\gamma^{2}}=\frac{E}{\rho}
$$

Levando em conta as potências quadráticas de $a$ da expansão em série da função de Bessel, alcançamos

$$
\left.\frac{p}{\gamma}=\left(\frac{E}{\rho}\right)^{\frac{1}{2}}\left(1-\frac{1}{4} \nu^{2} \gamma^{2} a^{2}\right)\right)
$$

com $\nu$ sendo o coeficiente de Poisson.

Rayleigh, em [82], através de considerações energéticas associadas ao movimento lateral da barra, chegou nesta mesma equação, só que adimensionalizada, sendo ela:

$$
\frac{V_{p}}{V_{0}}=1-\nu^{2} \pi^{2}\left(\frac{a}{\Lambda}\right)^{2}
$$

na qual $c_{p}=\frac{p}{\gamma}$ é a velocidade de fase, $V_{0}=\left(\frac{E}{\rho}\right)^{\frac{1}{2}}$ é a velocidade de onda em um cilindro desconsiderando a distorção e $\Lambda=\frac{2 \pi}{\gamma}$ o comprimento de onda. A equação mostra que a velocidade de fase decresce com a diminuição do comprimento de onda de maneira a se tornar nula em um comprimento de onda de $\nu \pi a$. Desta forma, esta equação é cada vez mais confíavel quanto maior o comprimento de onda com relação ao raio do cilindro.

Um conceito importante é o de Velocidade de Grupo, $c_{g}$, que é a velocidade na qual a energia é transmitida. Ela é definida, segundo Kolsky [51] como a velocidade na qual cada pacote de ondas é propagado,com os comprimentos de onda das ondas que compõe o pacote estando próximas de $\Lambda$. Desta forma, a relação entre

$$
V_{g}=V_{p}-\Lambda \frac{\mathrm{d} c}{\mathrm{~d} \Lambda}
$$

Aplicando o conceito de velocidade de grupo, da aproximação de Rayleigh, obtemos

$$
\frac{V_{g}}{V_{0}}=1-\nu^{2} \pi^{2}\left(\frac{a}{\Lambda}\right)^{2}
$$




\section{D.7 Comparação entre velocidades dos tipos de onda}

Um modo simples de compreender as diferenças entre as velocidades dos diversos tipos de ondas encontrados ate agora seria examiná-los em um gráfico. Deste modo, o gráfico (D.4) foi construído demonstrando diversas velocidades de onda e suas variações de acordo com o comprimento de onda.

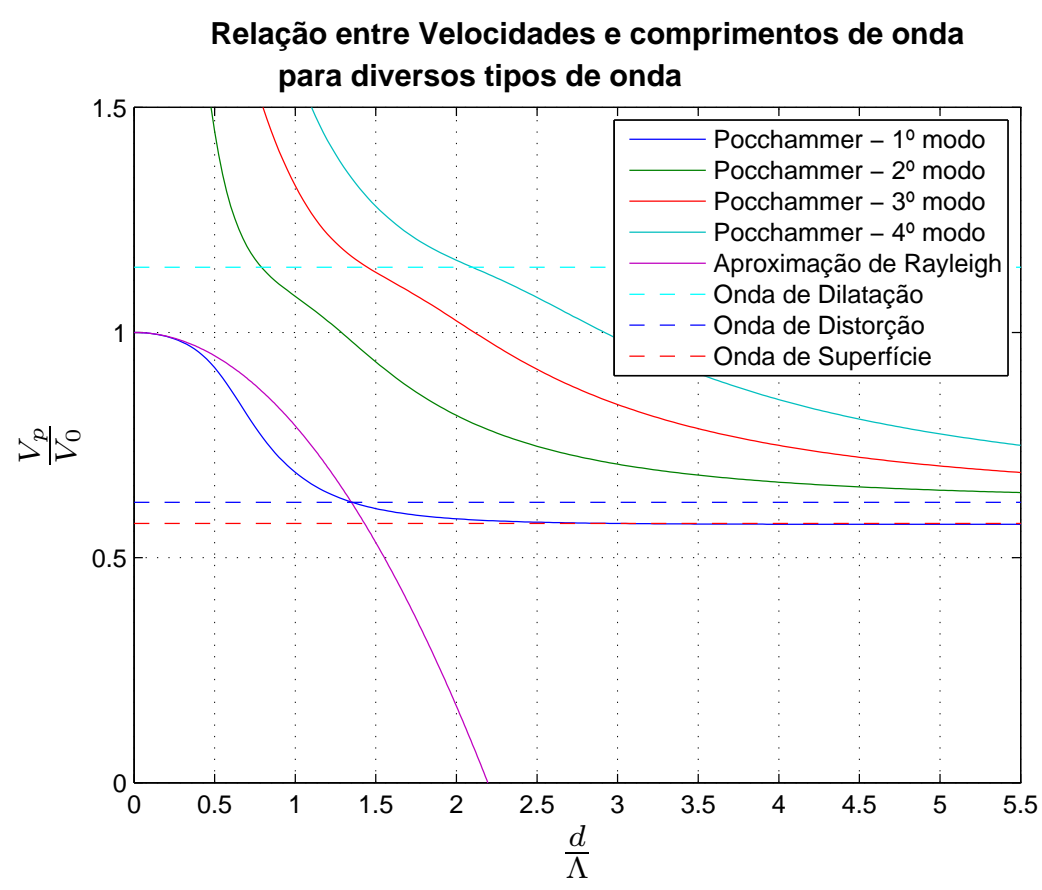

Figura D.4: Velocidades de diversos tipos de onda

Pode-se notar que até $\frac{d}{\Lambda}<0.25$, ou melhor, para comprimentos de onda pelo menos 4 vezes maiores que o diâmetro da barra, a aproximação de Rayleigh é muito boa. Para comprimentos de onda menores, é melhor utilizar soluções numéricas da equação de frequências para descobrir a velocidade de fase de um determinado comprimento de onda. 


\section{Apêndice E}

\section{Programas em Fortran e Matlab}

\section{E.1 Programas em Fortran}

\section{E.1.1 dyn21rtm_operacoes.F}

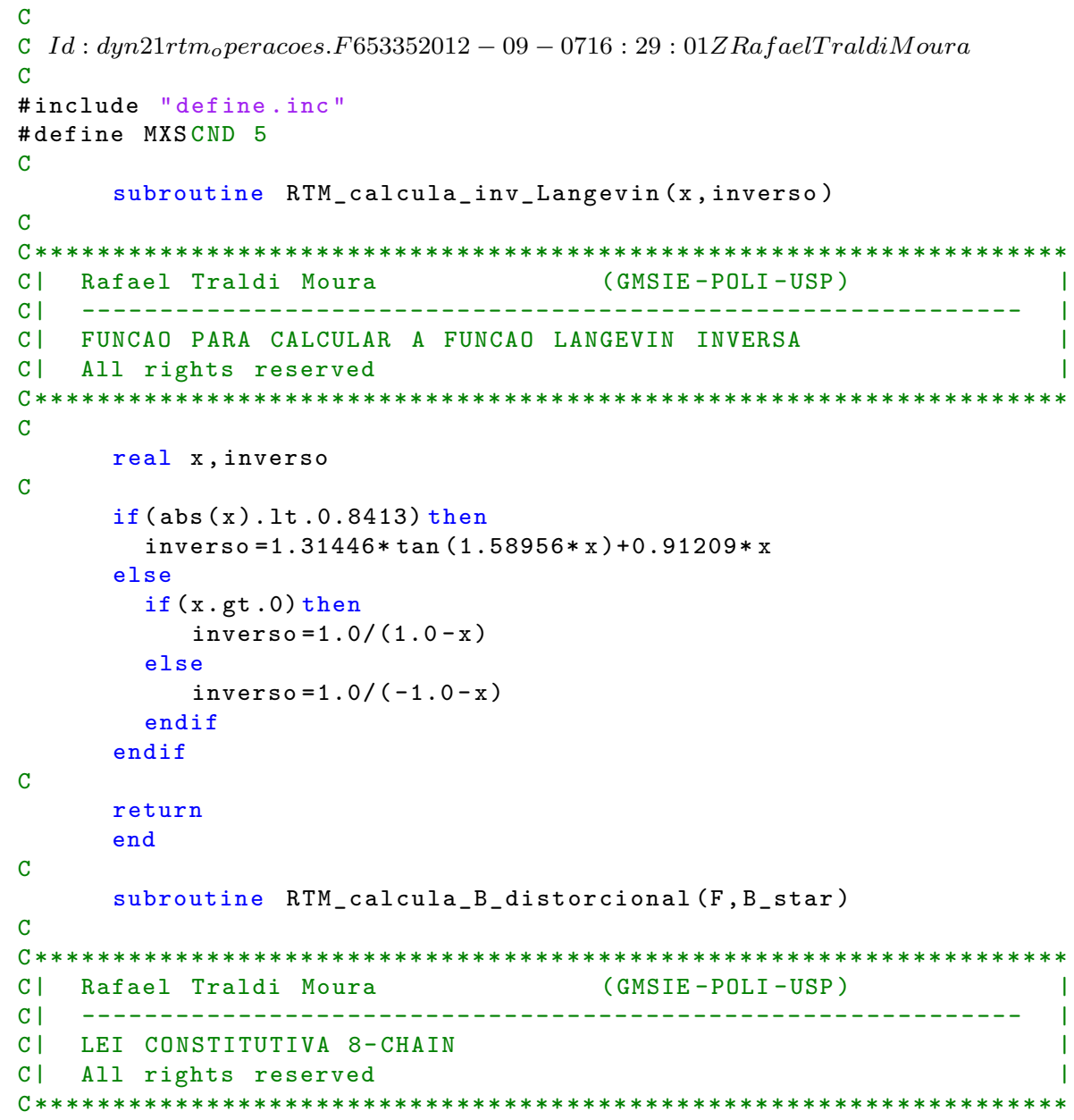




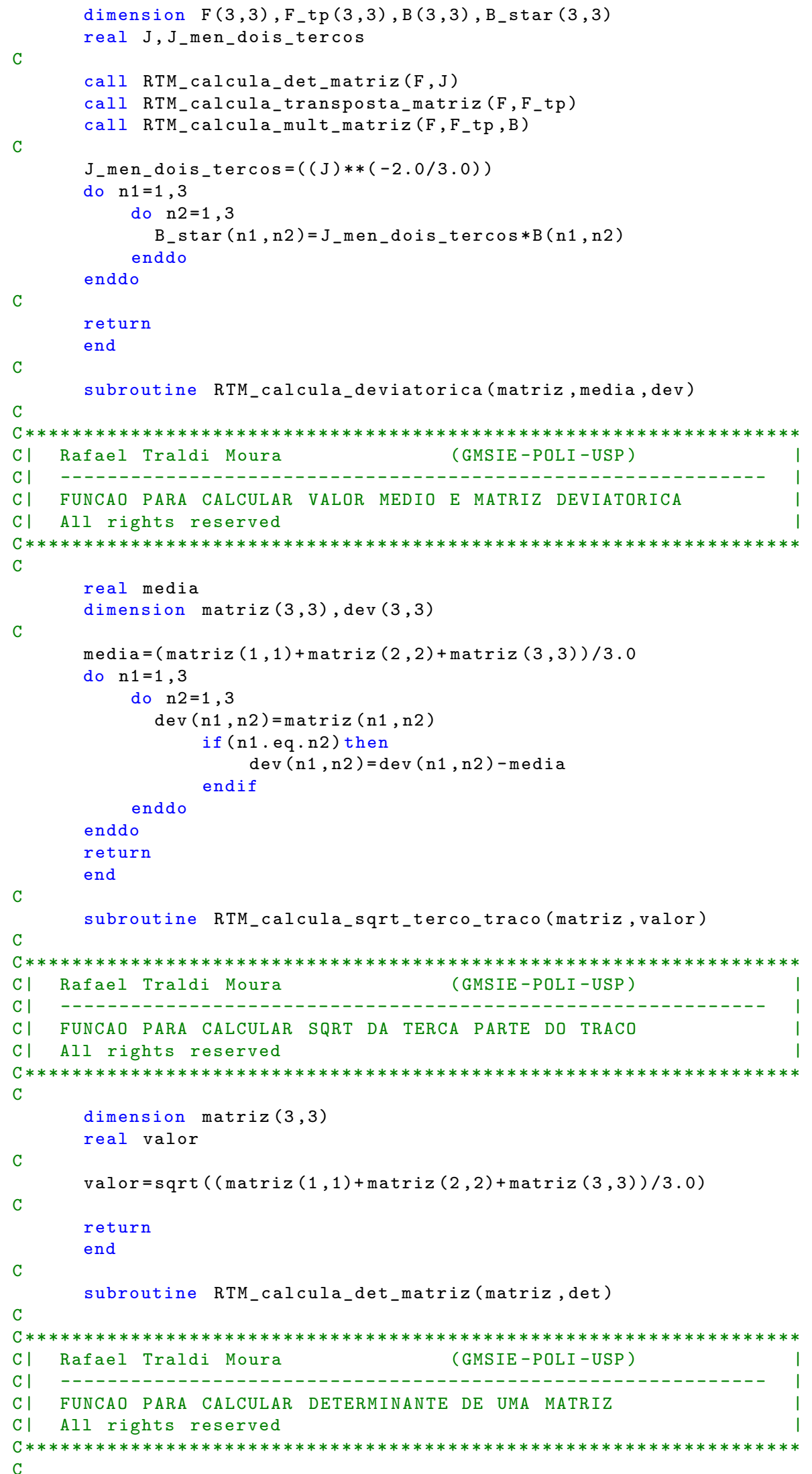




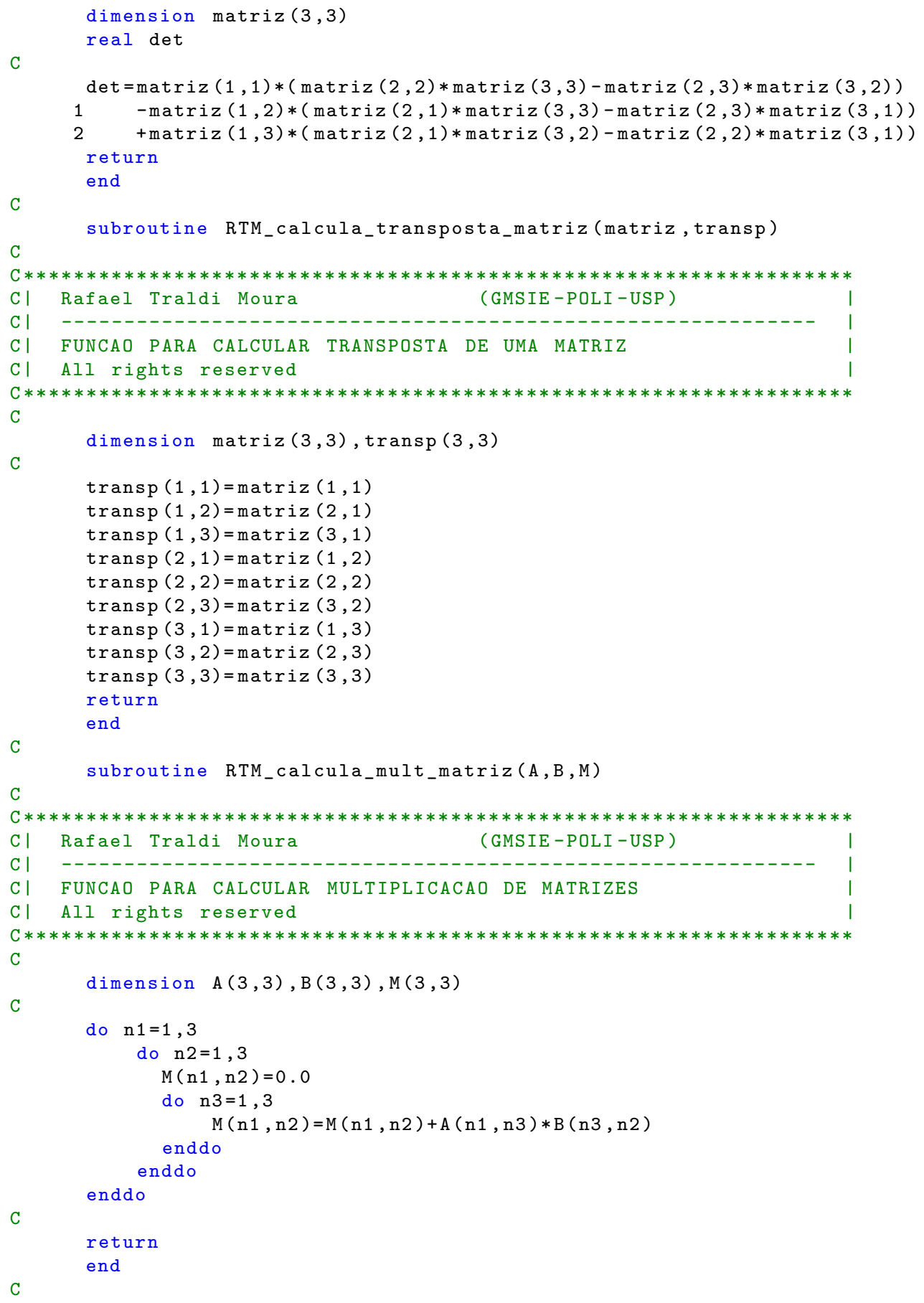

\section{E.2 Programas em Matlab}

\section{E.2.1 operações}

function [ inverso ] = RTM_calcula_inv_Langevin ( $\mathrm{x}$ )

if $(\operatorname{abs}(x)<0.8413)$ 


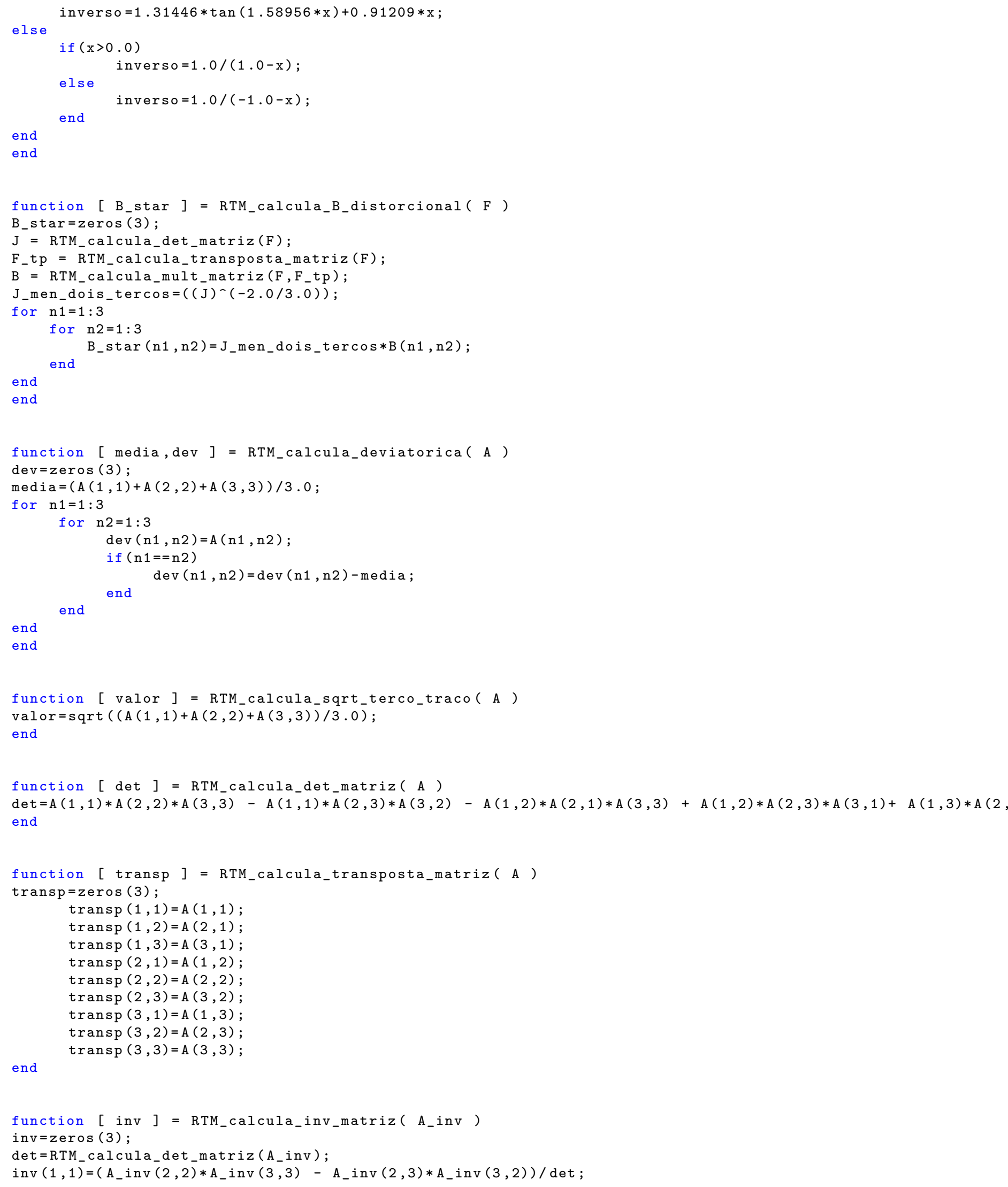




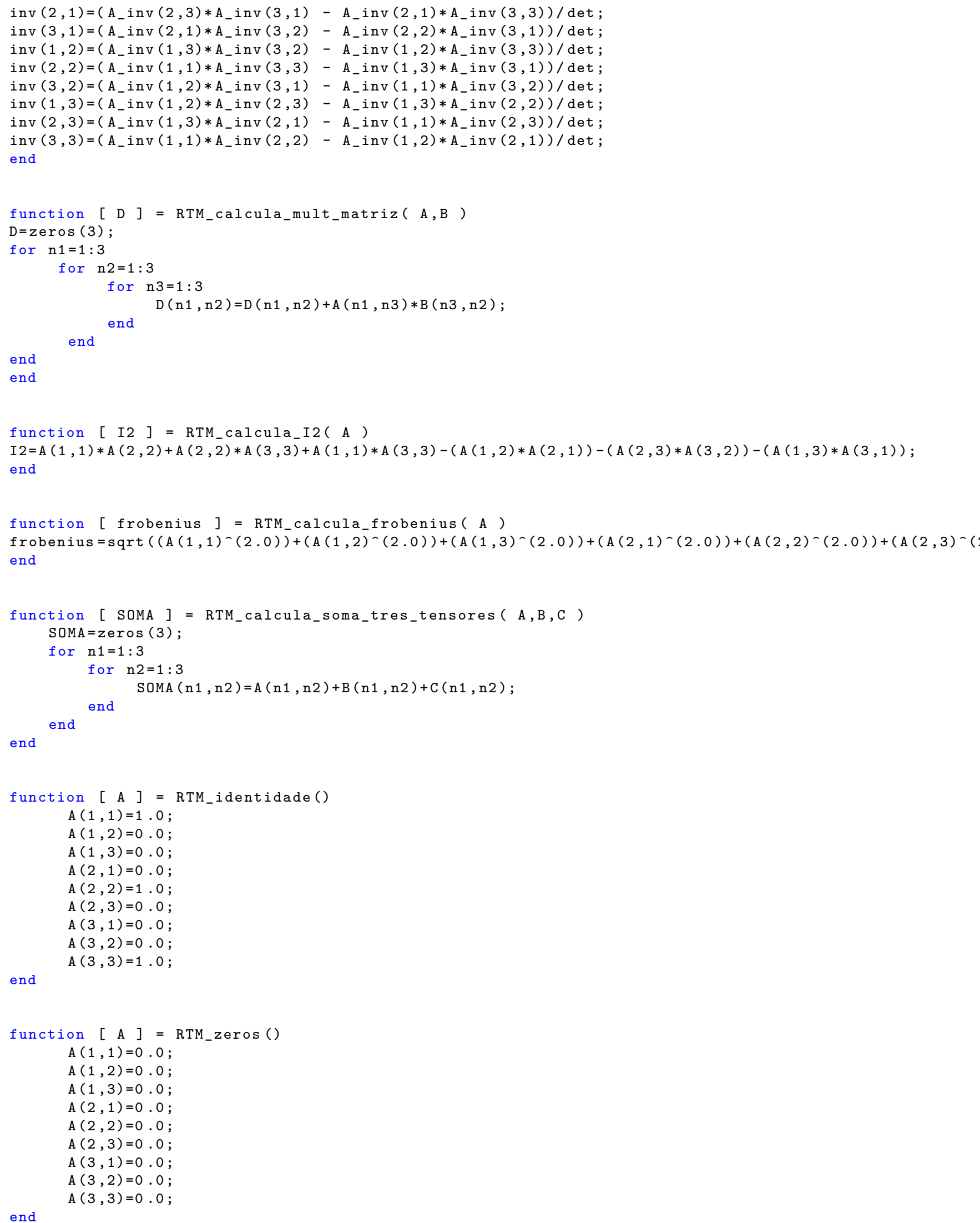




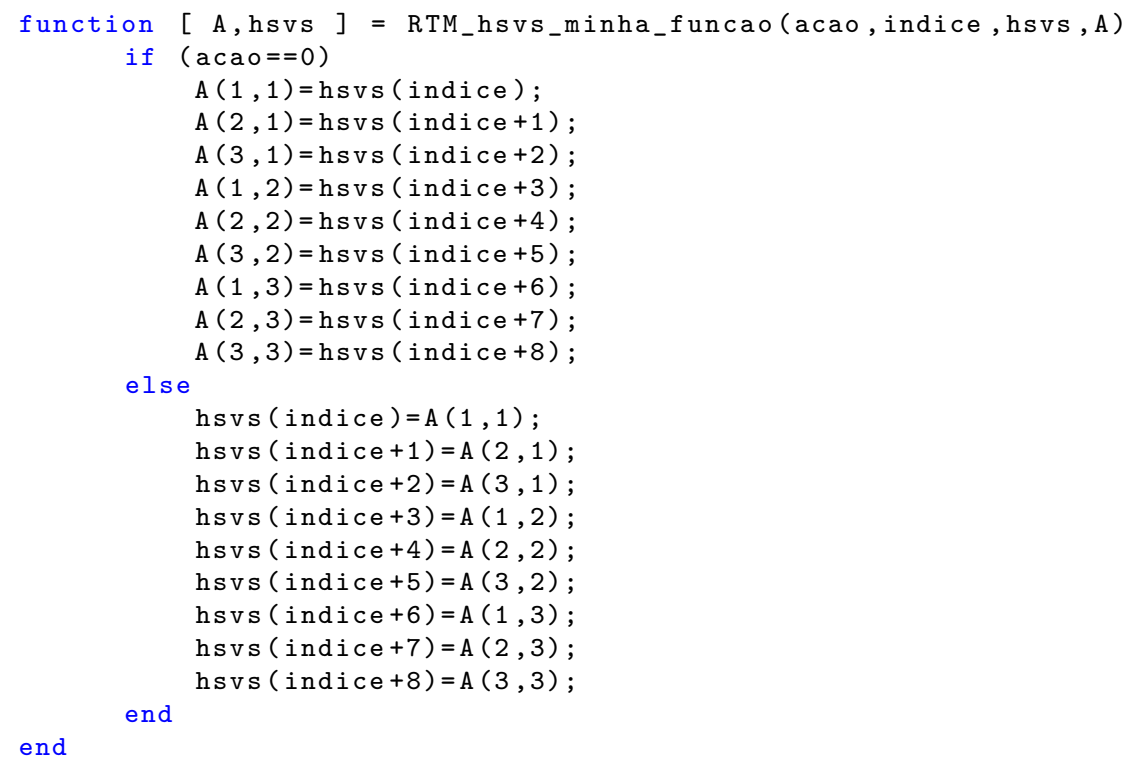

\section{E.2.2 Relações hiperelásticas, leis de escoamento plástico e vis- coso e as de evolução}

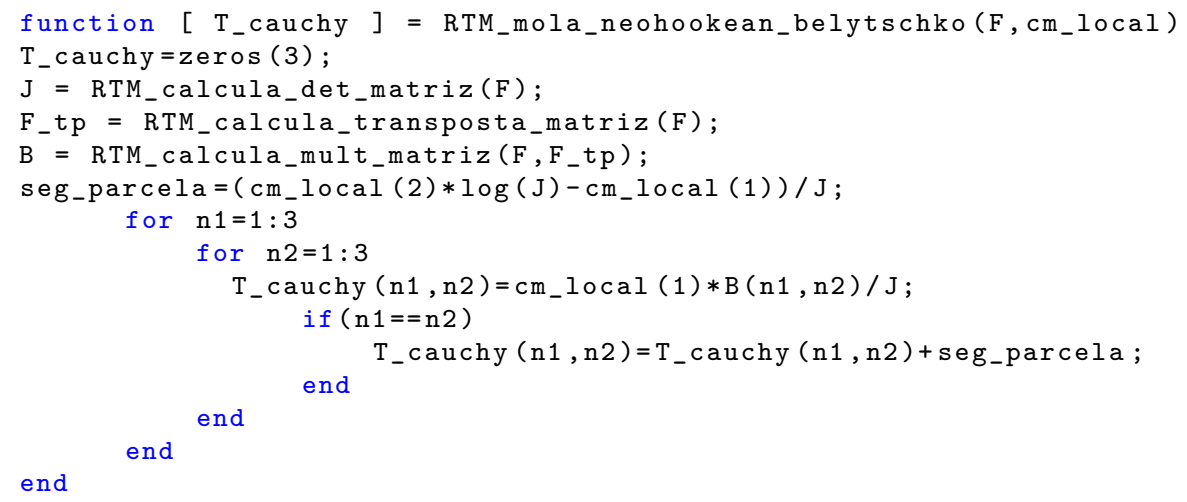




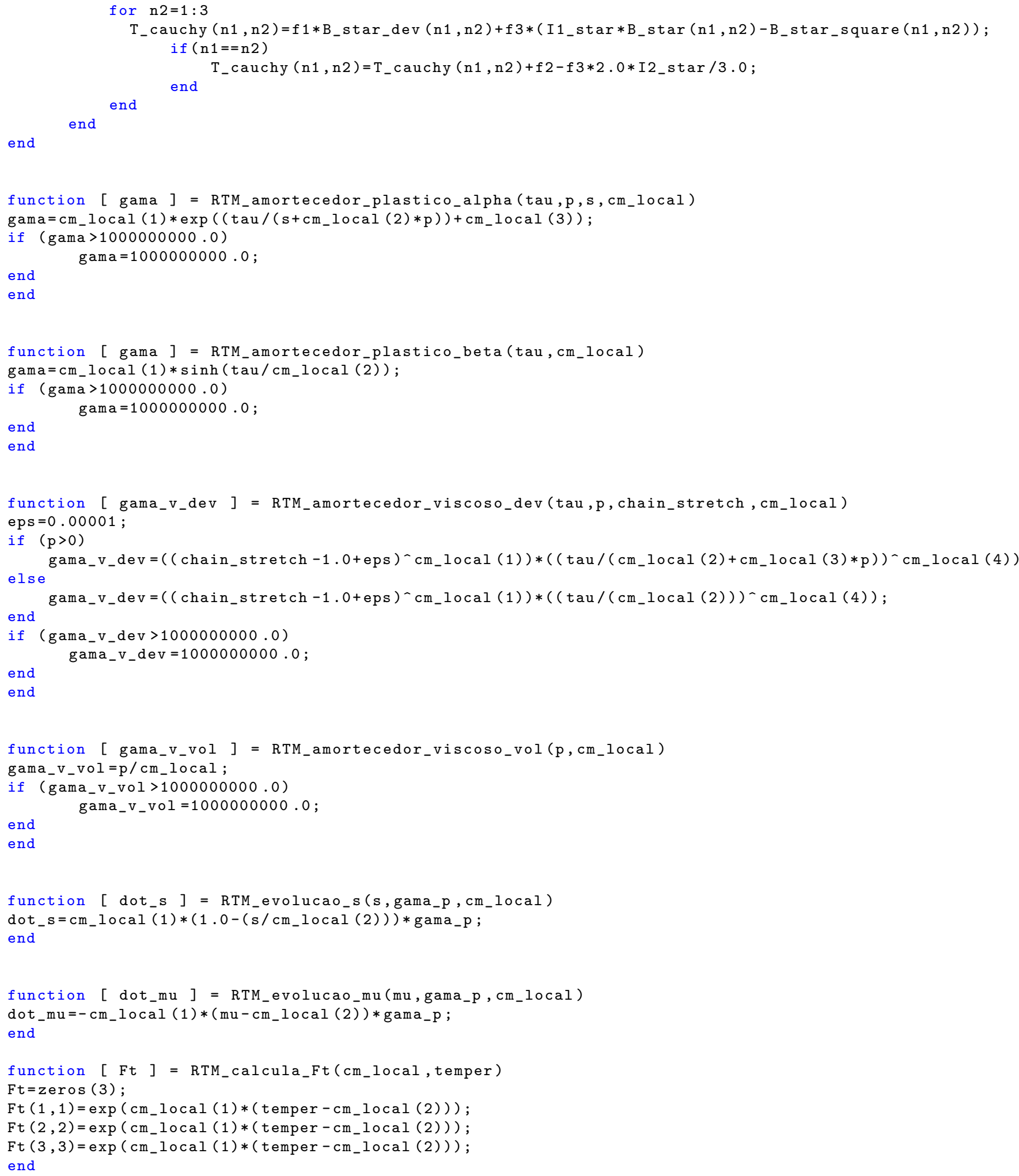

\section{E.2.3 Fase $\alpha$}




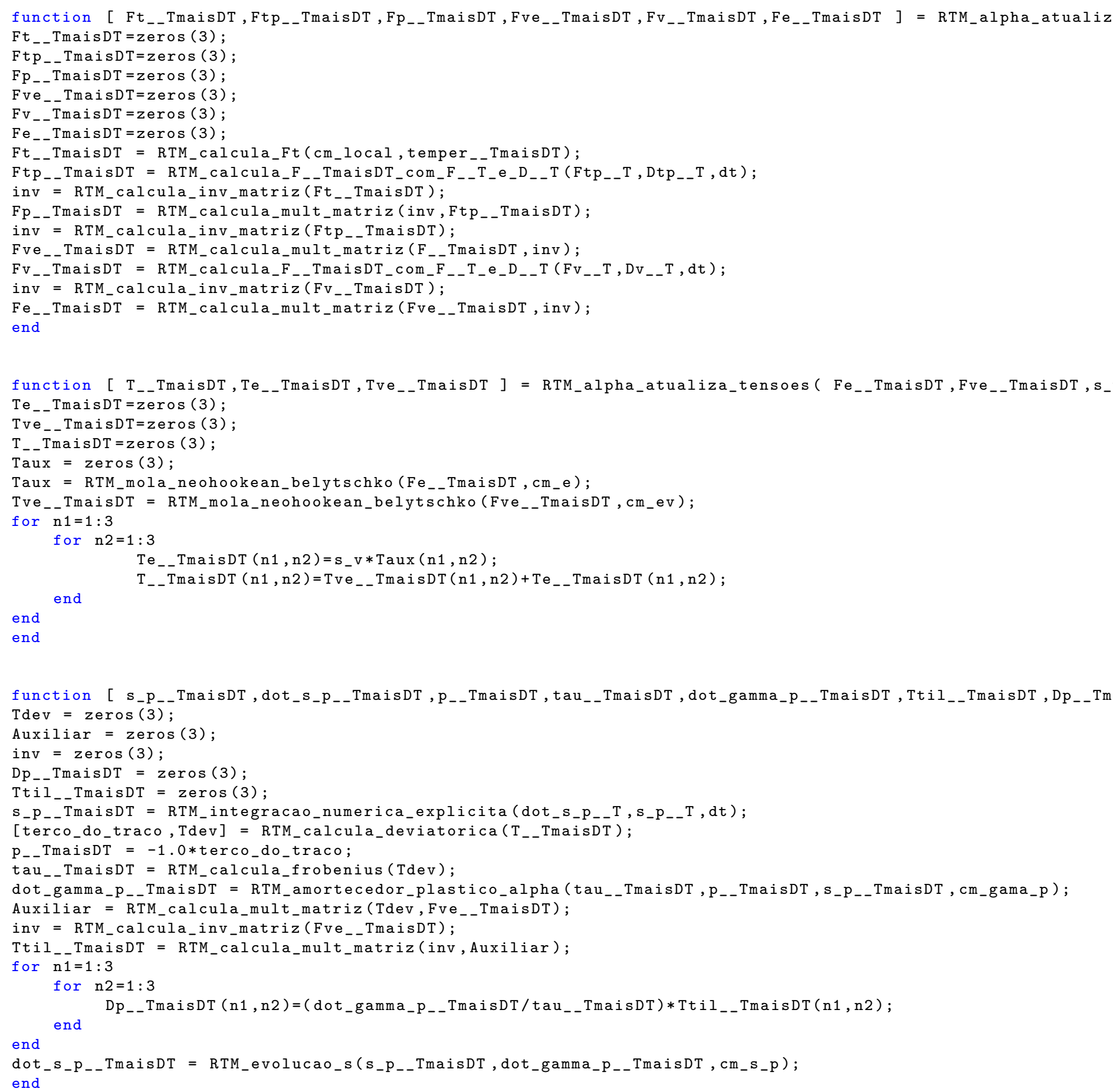




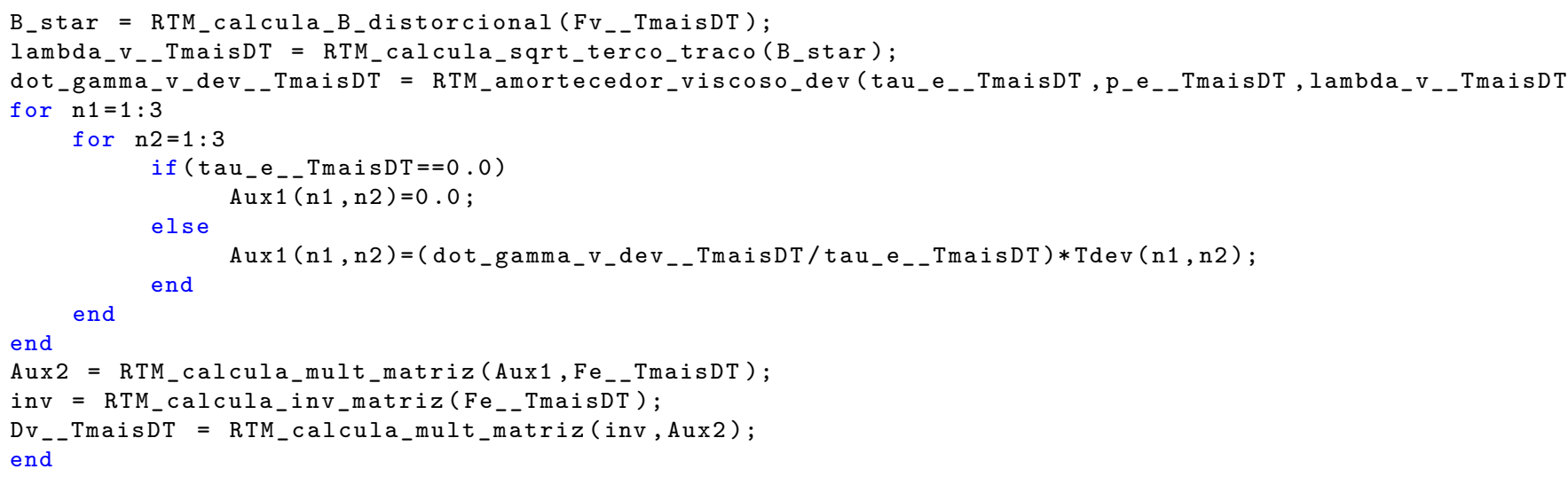

\section{E.2.4 Fase $\beta$}

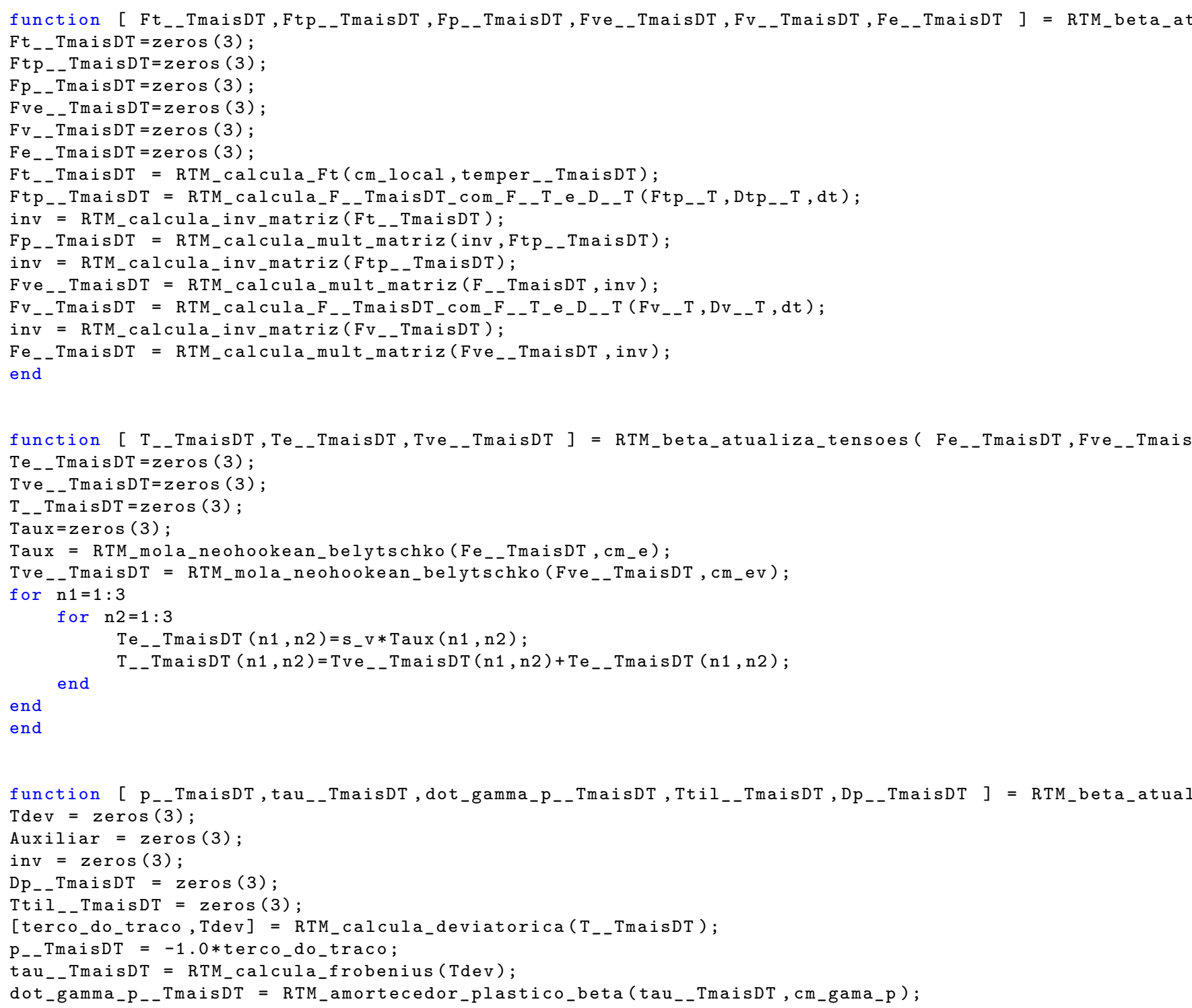




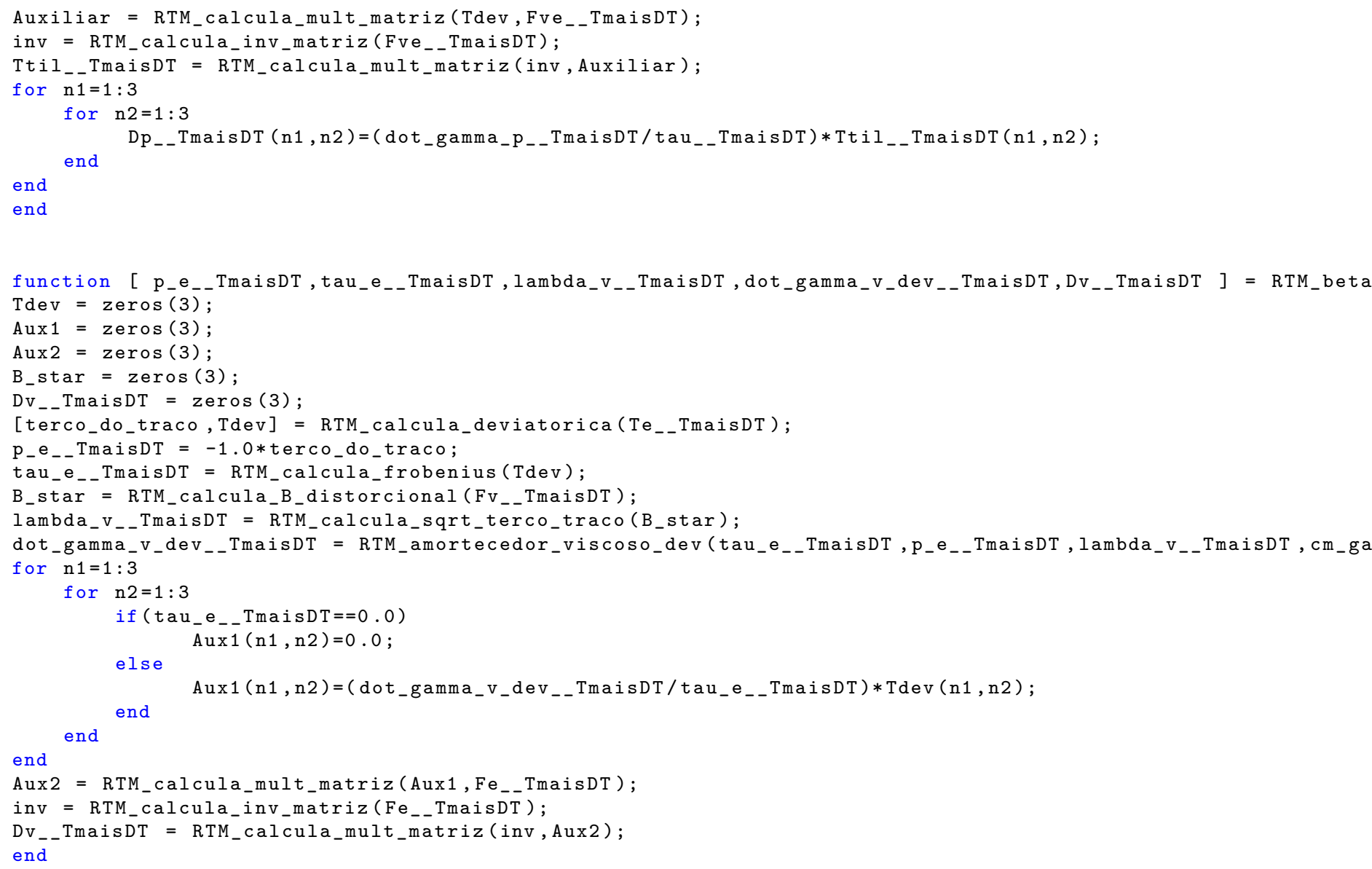

\section{E.2.5 Fase semi-cristalina}

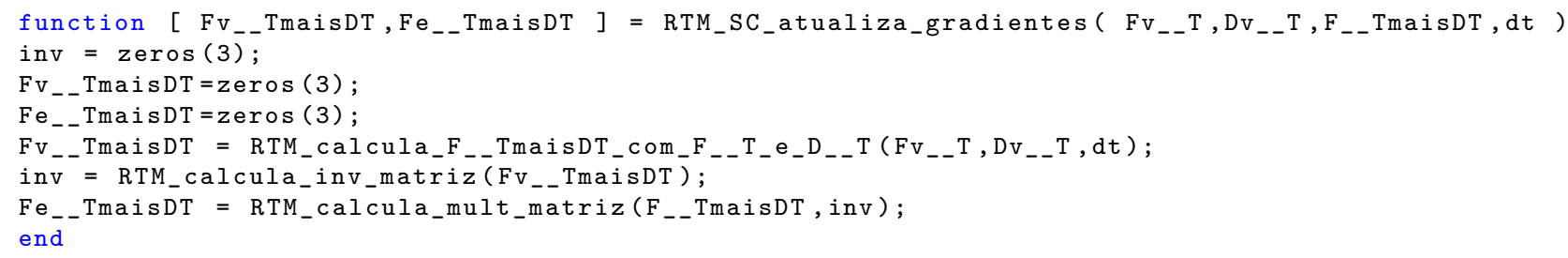




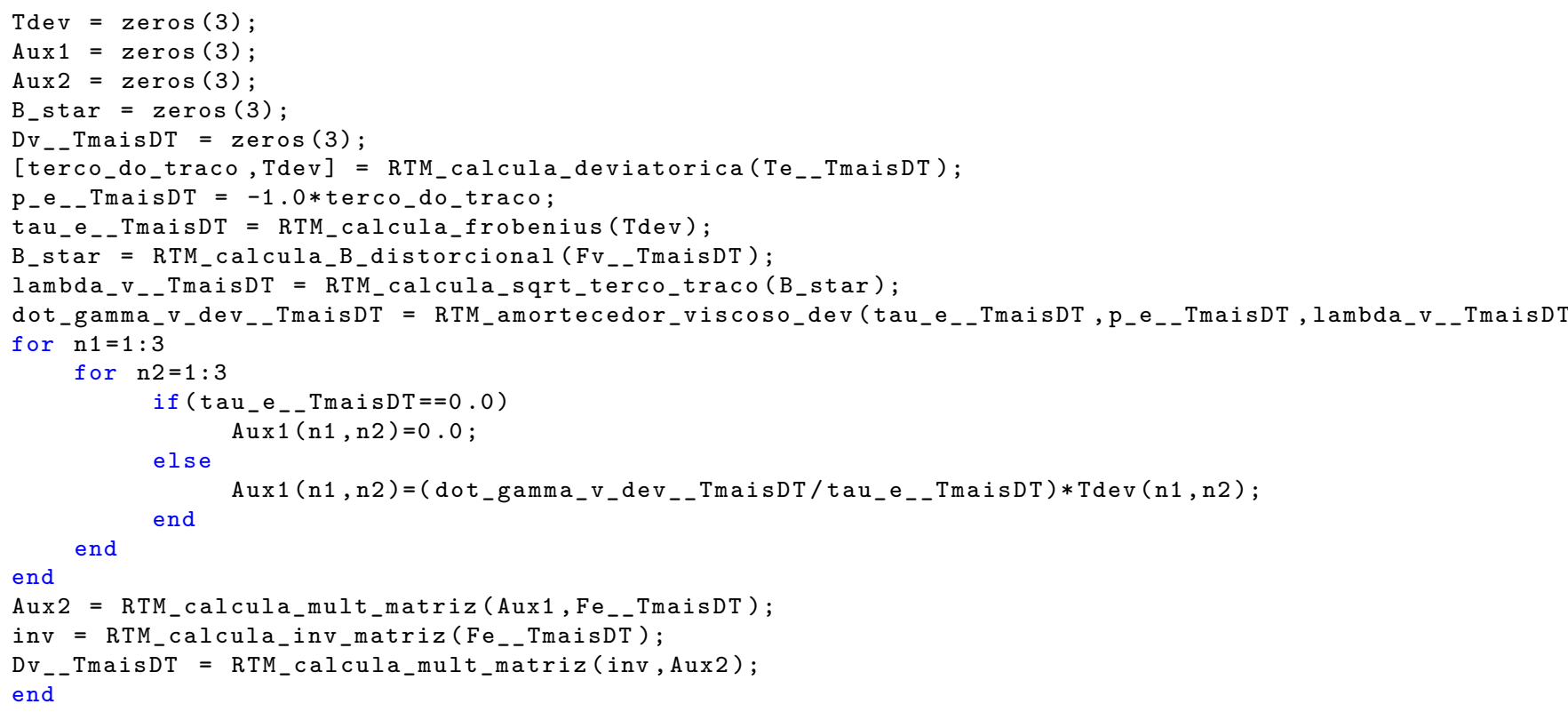

\section{E.2.6 Resistência entrópica}

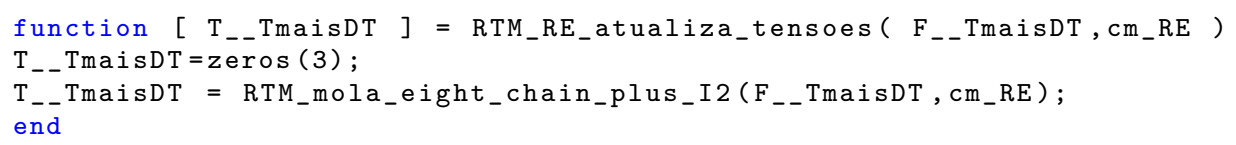

\section{E.2.7 Atualizando taxa de temperatura e taxa de deformação termoplástico}

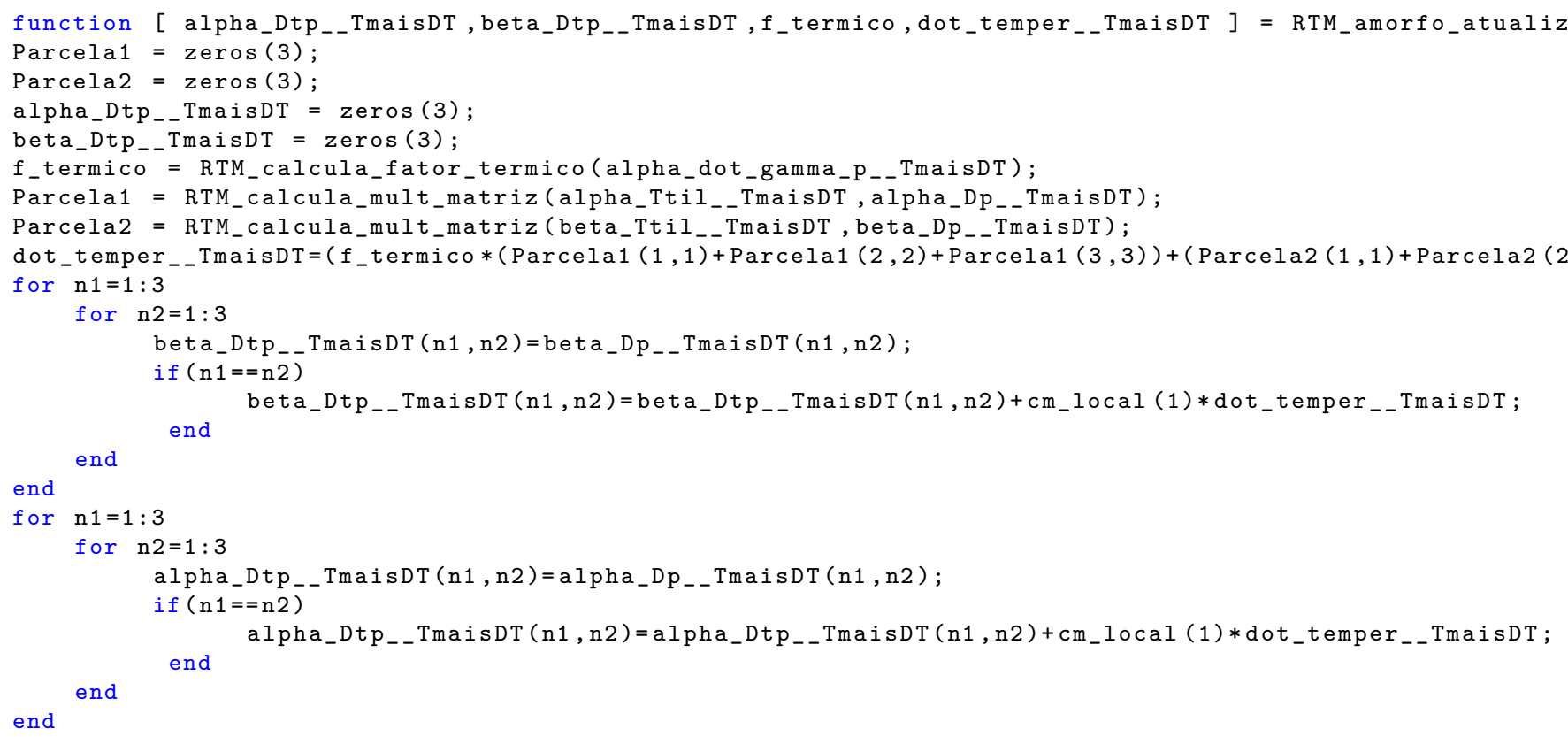


end

function [ alpha_Dtp_-TmaisDT, f_termico, dot_temper_- TmaisDT ] = RTM_SC_atualiza_dot_temper_e_Dtp( alpha_Dp Parcela1 = zeros $(3)$;

alpha_Dtp_- TmaisDT $=\operatorname{zeros}(3)$;

$f_{-}$termico = RTM_calcula_fator_termico(alpha_dot_gamma_p__TmaisDT);

Parcela1 = RTM_calcula_mult_matriz(alpha_Ttil__TmaisDT, alpha_Dp_-TmaisDT);

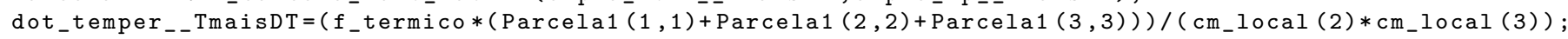

for $n 1=1: 3$

for $n 2=1: 3$

alpha_Dtp__TmaisDT $(\mathrm{n} 1, \mathrm{n} 2)=$ alpha_Dp__TmaisDT (n1, n2);

if $(\mathrm{n} 1==\mathrm{n} 2)$ end

alpha_Dtp_- TmaisDT (n1, n2) =alpha_Dtp__TmaisDT (n1, n2) + cm_local (1)*dot_temper_- TmaisDT;

end

end

end

\section{E.2.8 Variáveis históricas}

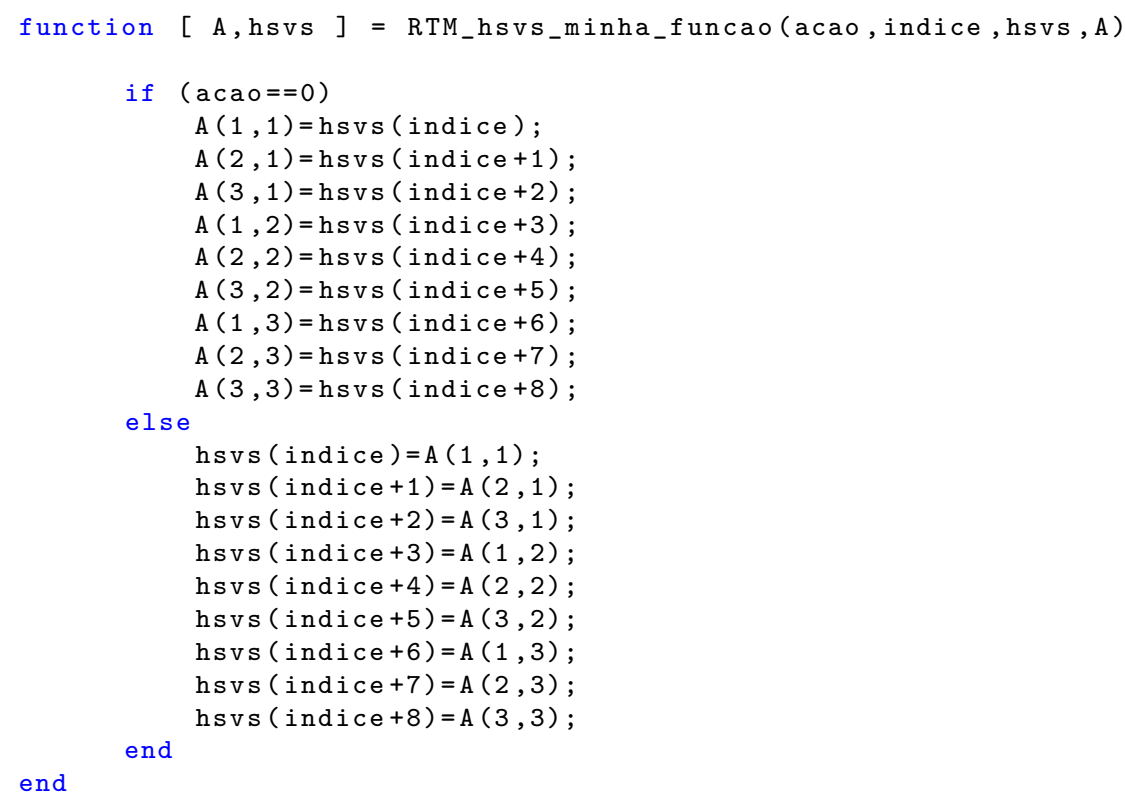

end

\section{E.2.9 Modelos de material}

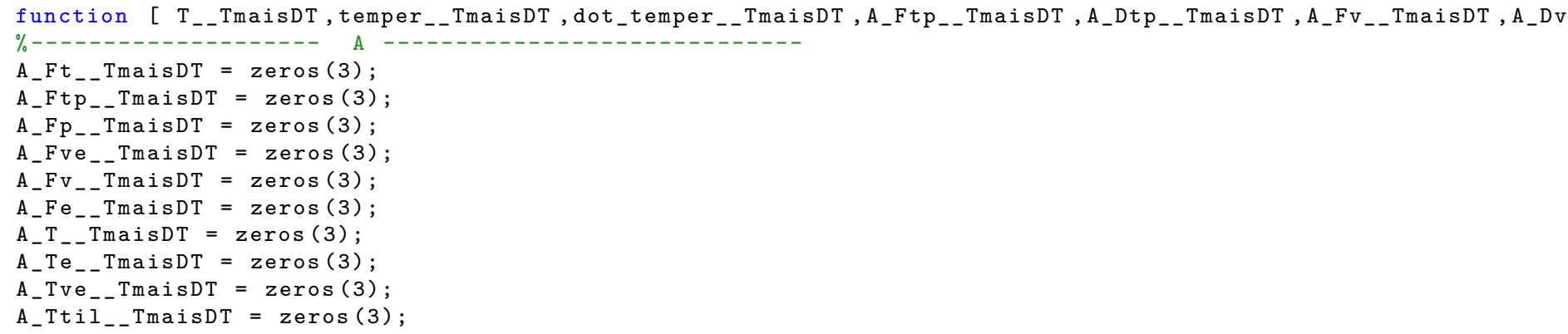




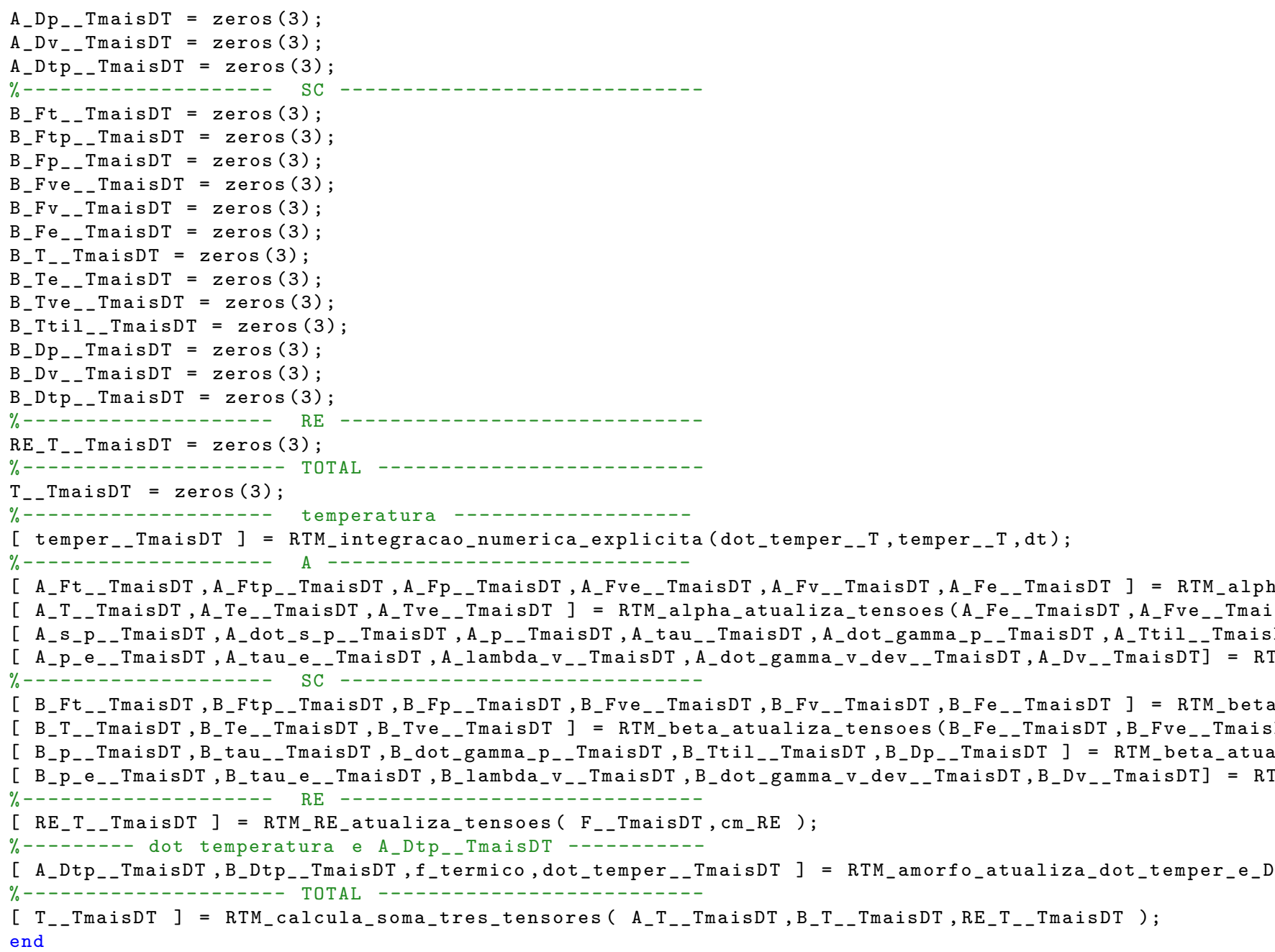




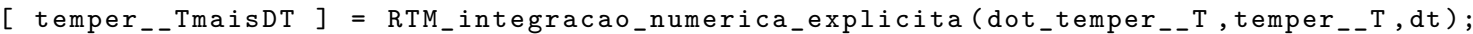

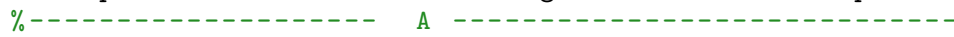

[ A_Ft__TmaisDT, A_Ftp__TmaisDT, A_Fp__TmaisDT, A_Fve__TmaisDT, A_Fv__TmaisDT, A_Fe_-TmaisDT ] = RTM_alpha_atua [ A_T__TmaisDT, A_Te__TmaisDT, A_Tve__TmaisDT ] = RTM_alpha_atualiza_tensoes (A_Fe_-TmaisDT, A_Fve__TmaisDT, A_ [ A_s_p_- TmaisDT, A_dot_s_p_- TmaisDT, A_p__TmaisDT, A_tau_-TmaisDT, A_dot_gamma_p__TmaisDT, A_Ttil__TmaisDT, A_D [ A_p_e _- TmaisDT, A_tau_e _- TmaisDT, A_lambda_v _- TmaisDT, A_dot_gamma_v_dev__TmaisDT, A_Dv A $_{-}$TmaisDT] = RTM_alph $\%--------------, \quad S C----------------------$

[ SC_Fv_- TmaisDT, SC_Fe_- TmaisDT ] = RTM_SC_atualiza_gradientes ( SC_Fv_- T, SC_Dv_- T, F S $_{-}$TmaisDT, dt );

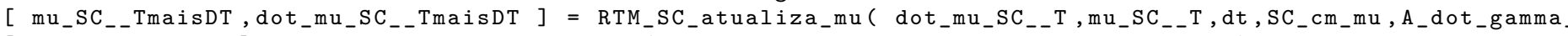

[ SC_T_- TmaisDT ] = RTM_SC_atualiza_tensoes ( SC_Fe__TmaisDT,mu_SC__TmaisDT, SC_cm_e );

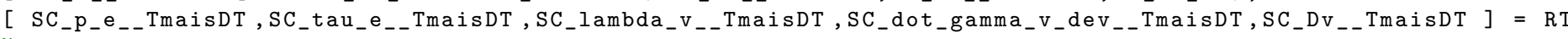

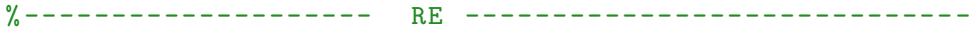

[ RE_T_-TmaisDT ] = RTM_RE_atualiza_tensoes ( F_- TmaisDT, cm_RE );

$\%------$ dot temperatura e A_Dtp_-TmaisDT $------_{---}$

[ A_Dtp_-TmaisDT,f_termico, dot_temper_-TmaisDT ] = RTM_SC_atualiza_dot_temper_e_Dtp( A_Dp_-TmaisDT, A_Ttil $\%$

$\left[\mathrm{T}_{--}\right.$TmaisDT $]=$RTM_calcula_soma_tres_tensores ( A_T_- TmaisDT, SC_T_- TmaisDT, RE_T _- TmaisDT ); end

\section{E.2.10 UMATS}

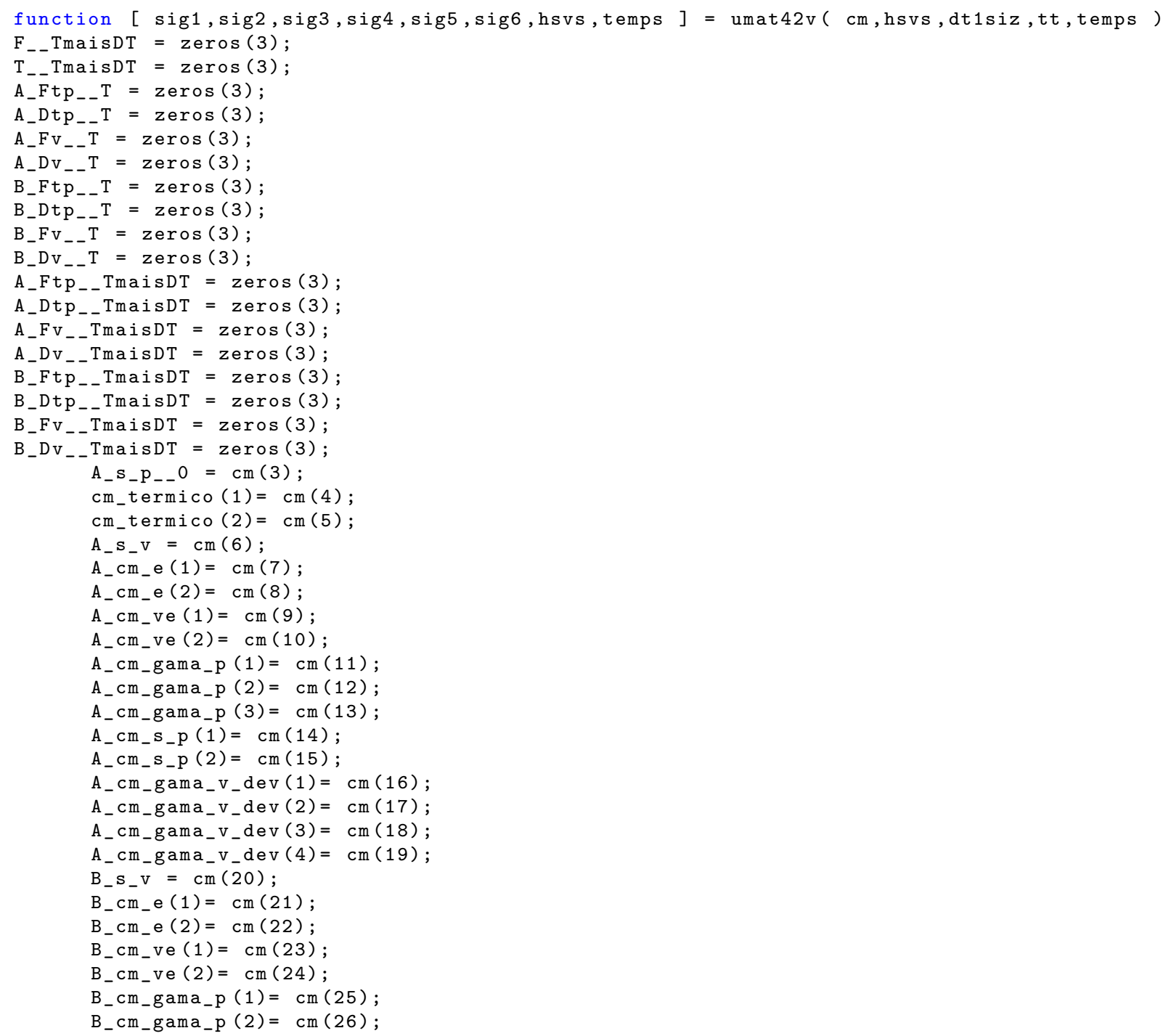




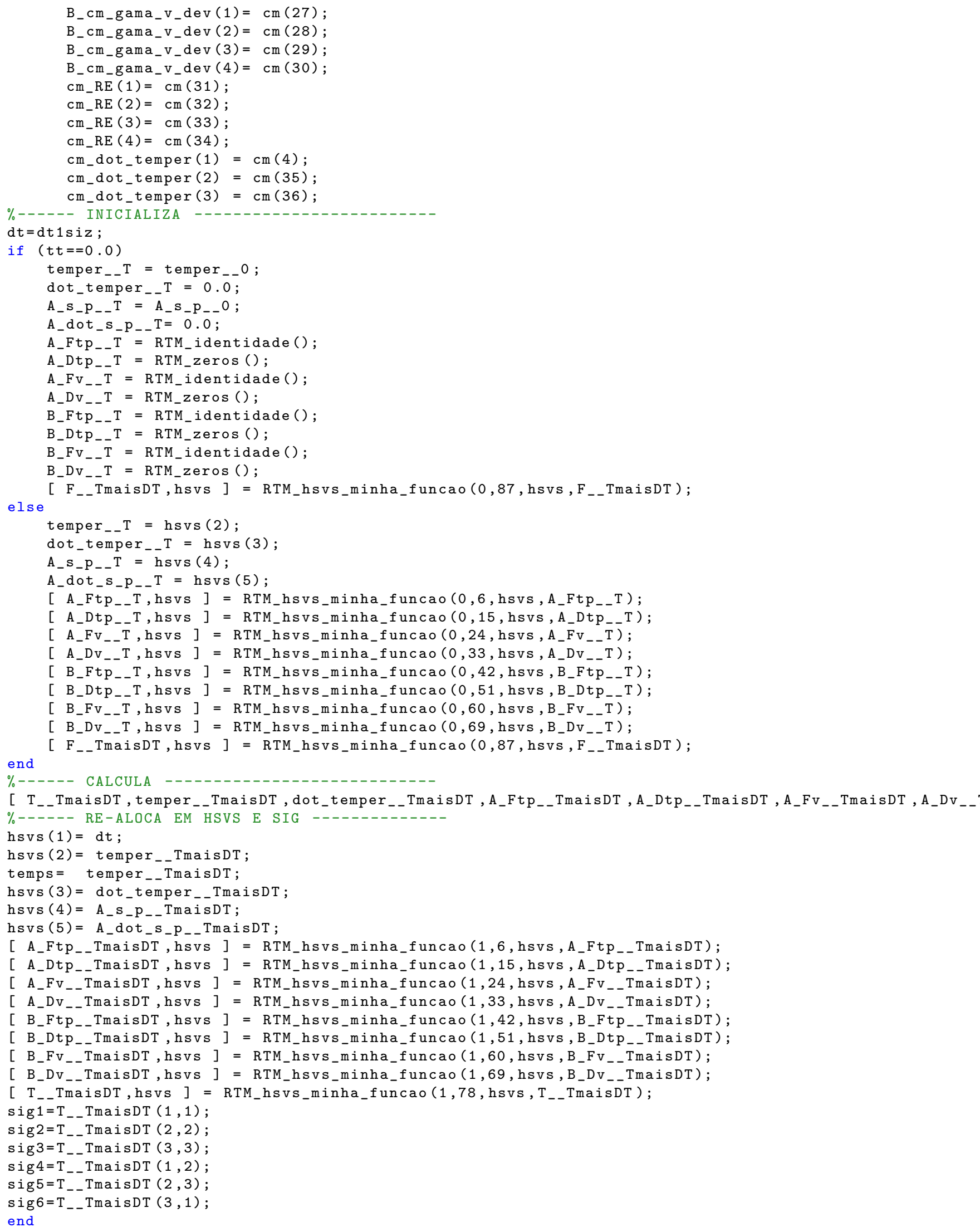




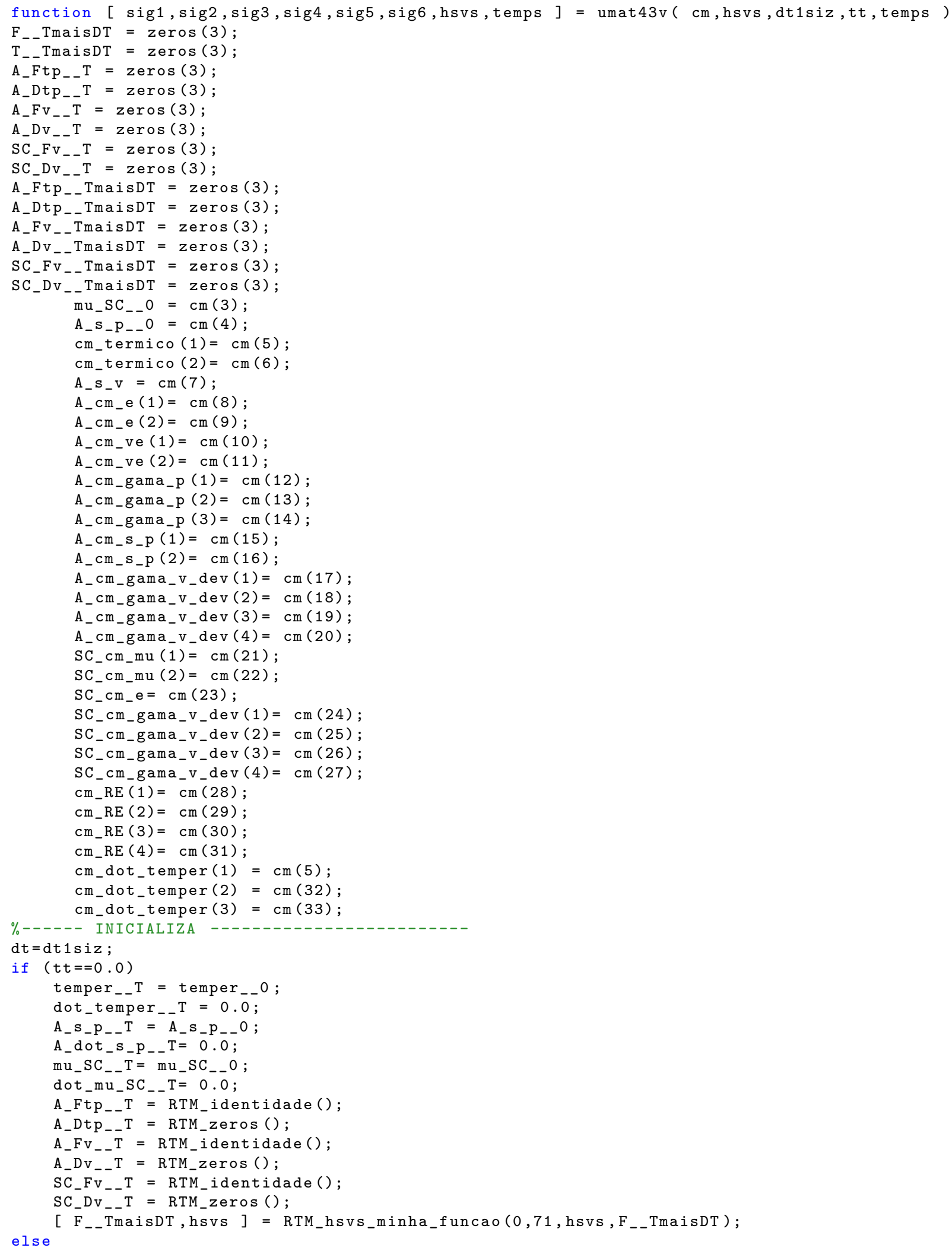




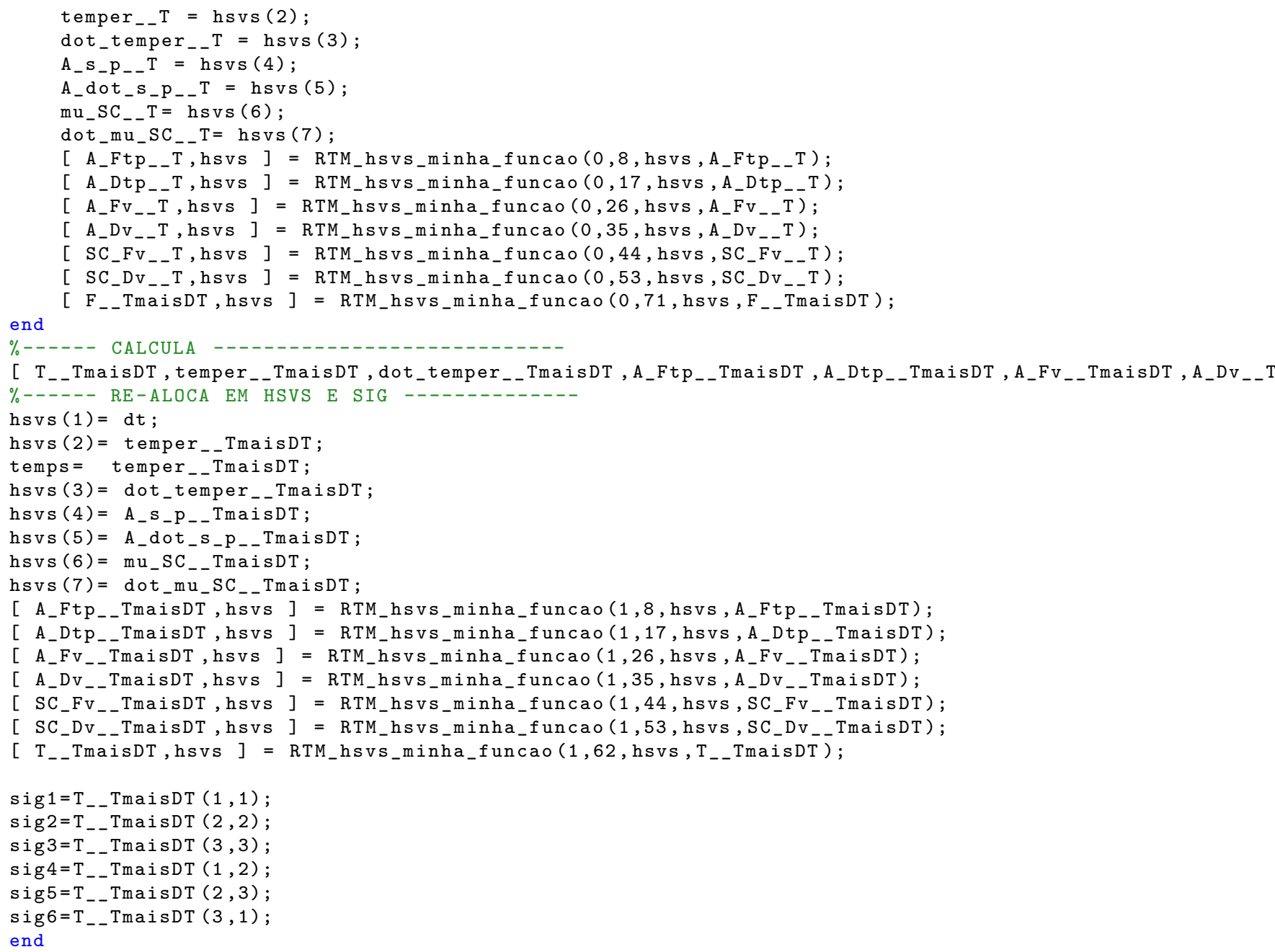

